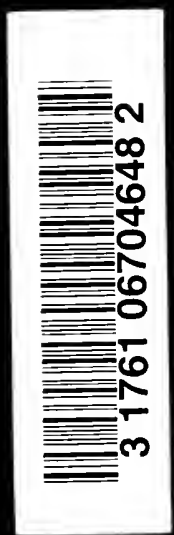





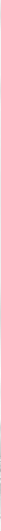

$\therefore$
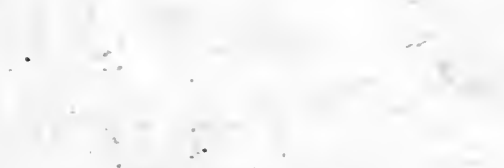

$x^{2}=$ $-$ 

Digitized by the Internet Archive in 2007 with funding from Microsoft Corporation 
Plate I.

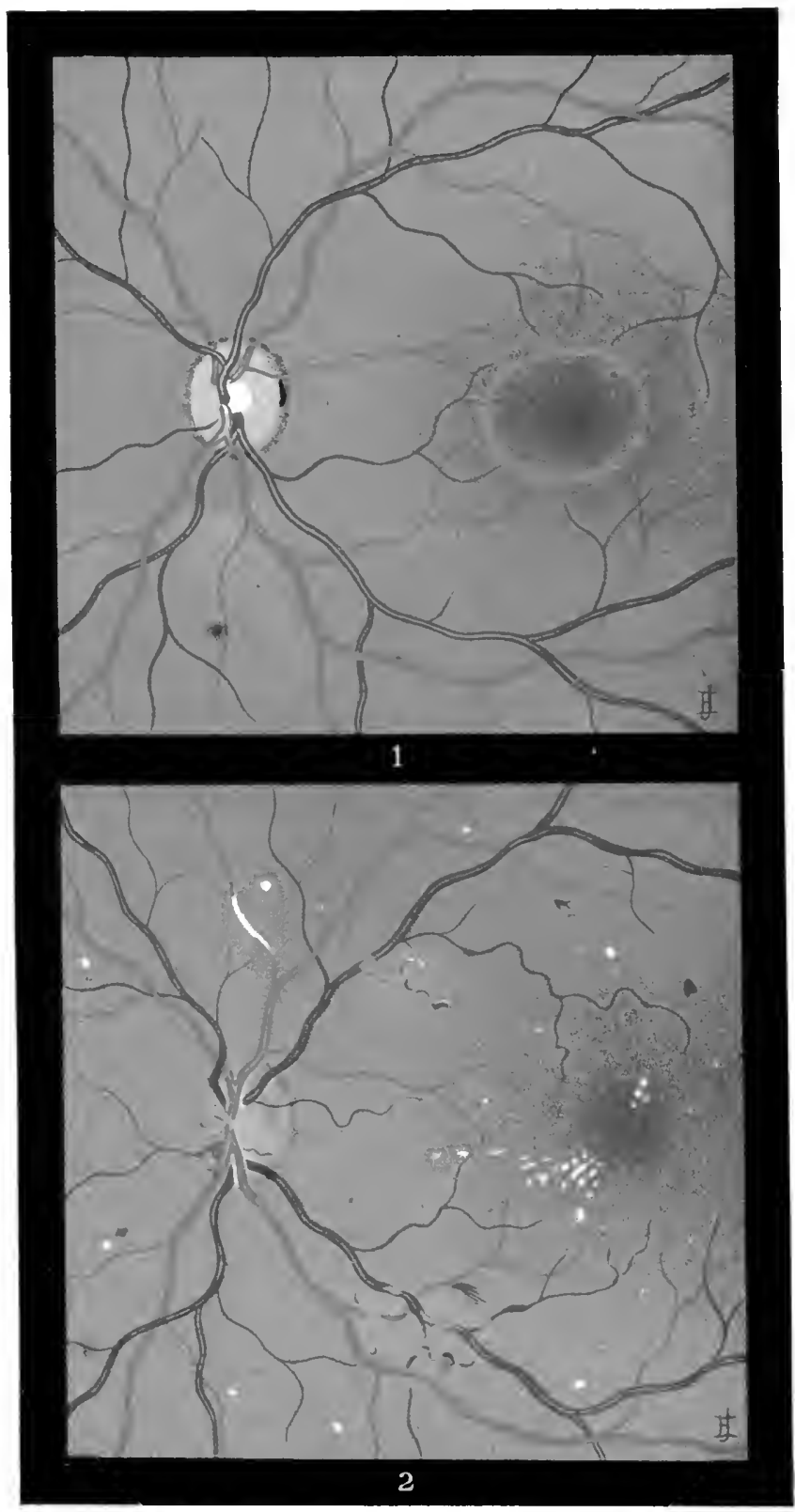




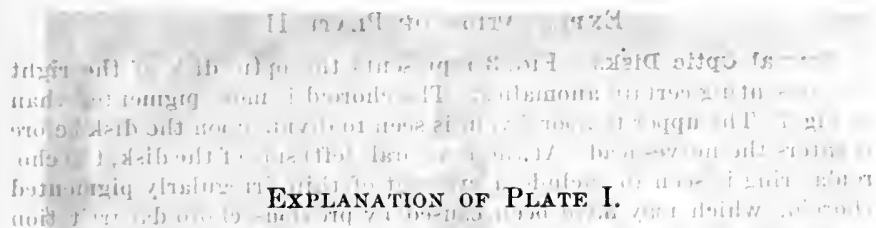

The Normal Fundus.-Frg. 1 represents the normal fundus of the left oye as seen in the erect image. The oval is the optic disk or optic-nerve entrance, pink in color, and with a white center, normally depressed. The retinal vessels emerge throngh it, the arteries lighter and yellower, the veins darker and more crimson in color. A round the disk the brown, irregular margin represents the choroidal ring.

$\Lambda$ Toward the right of the figure the darker red portion indicates the appearance of the macula., The oval lighter ring represents the retinal reflex that surrounds the maeula., It is ouly seen by a certain illumination, most frequently through the undilated pupil. The larger main brauches of the retinal vessels pass above and below the macula, giving off smaller branches that run in toward it, but not to its center. Each of the larger vessels shows a light streak along' its middle. This is commonly most marked on the arteries. The color of the normal fundus may vary greatly from that shown.

-1/The 'part of the fund us here represented (about' $10 \mathrm{~mm}$. on a side) is much more than can be seen with the ophthalmoscope at any one time. Even with the pupil fully dilated, one eannot usually see more ance than the disk and a zone around it about as wide as the disk itself. The actual appearance is better represented by covering the page with a picee of black paper in which is cut a circular opening 3 or 4 centimeters in diameter. The appearance presented by astigmatism may be, seen by looking at this, figure through a strong convex cylindrical lens.

Albuminuric Retinitis.-FIg. 2 represents a case of moderate albuminuric retinitis of the left eye. The optic disk is a dirty red, and its central depression is quite obliterated. Changes in the walls of one of the arteries passing upward have rendered them entirely opaque and white for a space. Isolated white spots, due to fatty' degeneration, are scattered throughout the retina, and at the macula they are arranged in a few radiating lines. Near the upper temporal vein, and also near the lower, are patehes of lighter color, due to exudate into the retina. These partly hide the vessels passing through them. At the upper margin of the lower patch is a small "Hame-shaped" hemorrhage. Other small spots of dark red, representing retinal hemorrhage, are scattered throughout the fundus. The larger retinal veins are rather dark and wavy, and some of the smaller veins are decidedly tortuous and irregularly, dilated.
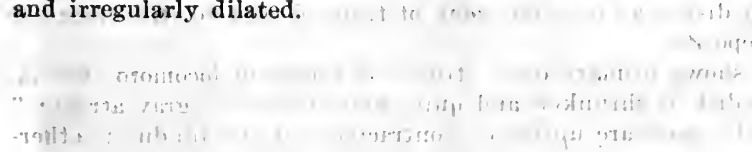


\section{Explanation of Piate II.}

Normal Optic Disks.-Fig. 3 represents the optic disk of the right eye presenting certain anomalies. The ehoroid is more pigmented than in Fig. 1. The upper temporal vein is seen to diride upon the disk before it enters the nerve-head. At the temporal (left) side of the disk, the choroidal ring is seen to include a crescent of thin, irregularly pigmented choroid, which may liave been caused by previous ehoroidal irritatiou or congestion. In this creseent is seen a choroidal vessel, and from it starts a cilioretinal artery, which passes a, little way on the disk, then turus upon itself to be distributed toward the macula. Af and

Fia. 4 illustrates a left optie disk surrounded by a "scleral ring," the opening in the choroid being larger than the optie-nerve entrance. It also shows a broad deep" "physiological cup." The darker spots in the floor of the enp are the openings or meshes in the lamina cribrosa. A small artery and a small vein eross the floor of the cup and climb its temporal side." The lower margin of the cup orerhangs, so that some of the retinal vessels are first seen at its edge.

FIG. 5 represents a somewhat rare anomaly of the disk, a portion of it looking almost like the general fundus. In some cases there is no indication of the true outline of the eoncealed portion of the disk, which looks as though covered by choroid.

Abnormal Optic Disks.-FIg. 6 illustrates the cupping of the optic disk in glaueoma. The depression extends to the extreme margin of the disk, whieh is surrounded by a white ring, the "halo atrophy" of glaucoma. The sides of the eup overhang all around, except outward (to the right) and a little downward, where one small artery may be scen to climb out of the excaration. The floor of the cup is quite gray, and the meshes of the lamina are large and very noticeable.

Fig. 7 represents the optie disk of the right eye at the beginning of an optie neuritis. The disk is red and slightly swollen, and its small vessels are numerous. The veins are rather full and wayy. 'Such ani appearanee might be caused by eye-strain, but in this case was due to brain tumor.

FIG. 8 shows the appearance of the same optic disk, several weeks later, than Fig. 7. The ontlines of the disk are entirely hidden by a swelling extending 5,D. into the vitreous. The reins are,dark and swollen; the arteries, are narrowed. Both are very tortuous at the disk, but the arteries in other parts of the fundus were straight, while the veins were tortuous thronghout. A small "flame-shaped" hemorrhage is shown at the temporal (left) margin of the swelling. The vision in this cye was still almost normal when this sketch was made, but declined very rapidly a month later.

FIG. 9 represents a case of "consecutive optic atrophy." The disk is a dead-white or paper-white- "white atrophy," It is devoid of "small vessels. The retinal vessels are contraeted and quite irregular in caliber, aud white lines along their margins show thiekening of the vessel-walls. Around the disk is an irregular zone of thinned ehoroid with irregular pigment-deposits.

FIG. 10 shows primary optie atrophy in a case of locomotor ataxia. The whole disk is shrunken and quite grạ in color- "gray atrophy." The retinal ressels are uniformly contracted, but the fundus is otherwise normal. 
Plate II.

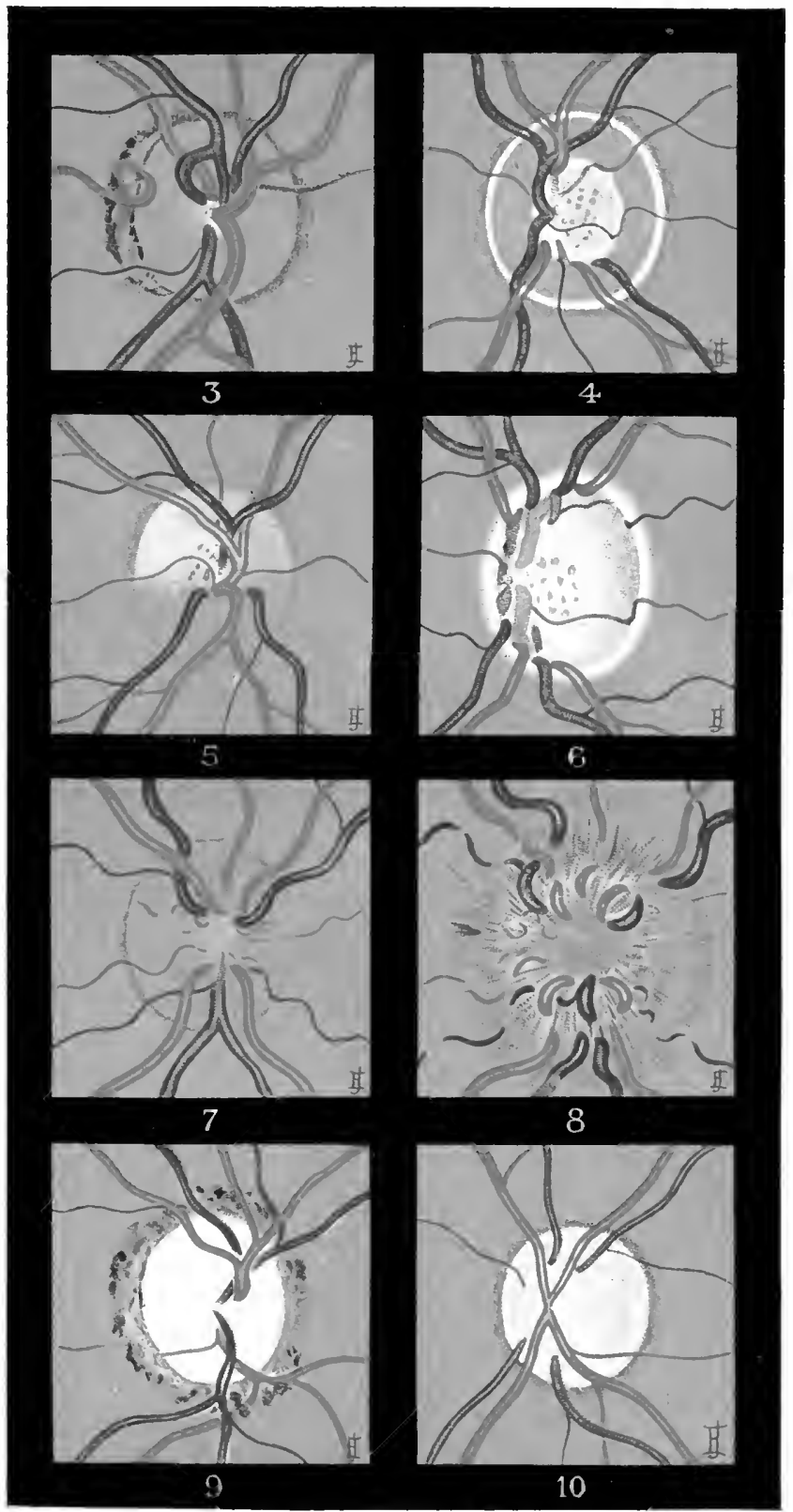





\section{A MANUAL}

OF THE

\section{DIAGNOSIS AND TREATMENT}

OF THE

\section{DISEASES OF THE EYE}

BY

EDWARD JACKSON, A. M., M. D.

Professor of Ophthalmology in the University of Colorado; Emeritus Professor of Diseases of the Eye in the Philadelphia Polyclinic; Formerly

Chairman of Section on Ophthalmology of the American Medical Association; Ex-President of the American Academy of Medicine, and of the American Academy of Ophthalmology and Oto-Laryngology, and Member of the American Ophthalmological Society

\section{Iecond Edition, Tborougbly Revised}

With 182 Illustrations and 2 Colored Plates PHILADELPHIA AND LONDON

\section{W. B. SAUNDERS COMPANY}




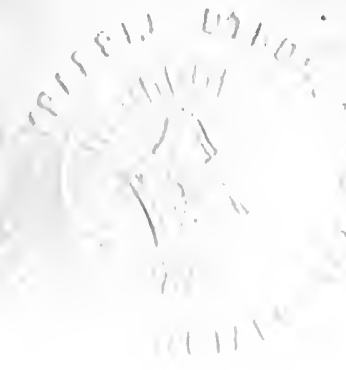

- Copyright, rgo7,

BY W. B. SAUNDERS COMPANY

ELECTROTYPED BY WESTCOTT \& THOMSON, PHILADA,
PRESS OF W. B. SAUNDERS COMPANY 


\section{PREFACE TO THE SECOND EDITION.}

Is this new edition the original purpose and plan of the work have been closely adlhered to, and the size of the book has been but slightly increased. Yet many changes have been necessary in the way of descriptions of newly recognized conditions, and additional consideration of diseases or methods of treatment of which brief mention formerly seemed sufficient. In a few instances the teaching with regard to certain conditions has been essentially modified, or to some extent reversed. But an especial effort has been made to avoid being carried away by those temporary enthusiasms which become so noticeable in medical literature from time to time, only to disappear completely a little latter. It is felt that the permanent value of the MANUAL will be thus increased, even though it seems to show a lack of response to the "very latest" ideas.

The most important changes have been with regard to some of the newer methods of diagnosis as, Testing the Light Sense; Mapping Central Scotoma; Taking the Prominenee of the Eye-ball and the "Fogging Method"; the Account of the Mechanism of Accommodation and Pseudo-accommodation; Special Use of Lenses in the Ophthalmoscopic Examination; Changes in Refraction with Age; Amblyopia with Squint; the Treatment of Comitant Strabismus; Diseases and Congenital Defects of the Ocular Muscles; Petrifying Conjunctivitis ; Special Conditions that Influence Keratitis and its Treatment; Family Degeneration of the Cornca; Uveitis in its General Relations; Theories of Sympathetic Ophthalmia; General Considerations regarding Diseases of the 
Retina; Maenlar Atrophy of the Retina; Obstruction of the Retinal Vessels; Developmental Alexia (Congenital Word Blindness); Persistent Hyaloid Artery; Anomalies of the Lids; Blastomycosis; Removal of Speeial Foreign Bodies in the Eye; the X-ray; the Newer Local Anesthetics and Preparations of the Suprarenal Body ; Dionin ; Operations for Ptosis ; Pterygium, Extirpation of the Lacrinal Sac, Extended Tenotomy, Magnet Extraction; Myasthenia Gravis, and in general the applications of the newer additions to the Materia Medica.

The best publications by which to become acquainted with ophthalmic literature have largely changed since the first edition of this book. This has made necessary a complete re-writing of the bibliography of the subject, and for general reference it is more convenient to bring the whole bibliography together. This has been done on pages 585-594. It is hoped that this work will still merit favor, as one especially adapted for the systematic reading of the student and the special reference book of the general practitioner.

Denver, Colorado,

January, 1907. 


\section{PREFACE.}

THIs book is intended to meet the needs of the general practitioner of medicine and the begimner in ophthalmology. It is designed to aid in the actual work of dealing with disease, and therefore gives the place of first importance to the recognition and management of the conditions likely to be presented early in practice, rather than to the rarer diseases and more difficult operations that may come later.

For practitioners in other departments of medicine and surgery the most important phase of ophthalmology is that of the relations of ocular symptoms and lesions to general diseases. While Chapter XX is specifically devoted to these relations, the references it contains will, it is hoped, put the reader in tonch with the important related facts to be found in all the preceding chapters.

For the matter here presented the writer acknowledges lis large indebtedness to a host of patient workers in ophthalmic seience and art, although the scope of this book forbids any attempt to properly apportion their credit.

The bibliography at the end of each chapter is not intended to be complete. It is merely an attenipt to open a path for the student into the broader literature of ophthalmology. The references composing it have been selected, not on aceount of their historical or general scientific importance, but because they were deemed most widlely accessible, and best opened up the general literature of the subject.

The student who desires to search the whole domain of recent ophthalmic literature ean find the titles, for the 
years of its publication, in the Index Medicus ; and brief abstracts in the "Systematic Reports on the Progress of Ophthalmology" in the Archives of Oplithalmology. Most important communications are reproduced in abstract in the Ophthalmic Review and the Annals of Ophthalmology. The most complete review of the world's literature is published in German, in Nagel's Jahresbericht ueber die Leistungen und Fortschritte im Gebiete der Ophthalmologie. For the relations of eye diseases to general diseases, Schmidt-Rimpler's Erkrankungen des Auges im Zusammenhang mit Andern Krankheiten is the most complete treatise, and furnishes the best bibliographies.

The following general treatises and papers of especial value, but not belonging to any particular chapter, may here be referred to:

American Text-book of Diseases of the Eye, Ear, Nose, and Throat, edited by G. E. de Schweinitz and B. A. Randall (referred to in chapter bibliographies as "American Text-book").

System of Diseases of the Eye, edited by W. F. Norris and C. A. Oliver (referred to in bibliographies as "System of Diseases of Eye").

Text-book of Ophthalmology, by E. Fuchs, translated by A. Duane.

Diseases of the Eye, by Geo. A. Berry.

The Origin of Inflammation, by Th. Leber. Abstracted by Priestley Smith, "Ophthalmic Review," Nov., 1891, to Feb., 1892.

The Pathological Examination of the Eyeball. C. D. Marshall, " Roval London Ophthalmic Hospital Reports," vol. xiv. Part II.

Method of Mounting Ophthalmic Spccimens. Priestley Smith, "Ophthalmic Review," Jan., 1897.

Denver, Colorado, 


\section{- CONTENTS.}

CHAPTER I.

Examination of the Patient ; Case Records; Abbrevia= tions ...................... . . 17

The Study of tire Case, 17-Case History, 17-Inspection of the Eyes, 17-Family History, 18-Special Examination, 18-Approximate or Provisional Diagnosis, 19-Case Records, 20Sketches and Diagrans, 21-Field of Vision, 23-Abbreviations, 23.

CHAPTER II.

\section{Acuteness of Vision; Field of Vision ; Subjective Phe=} nomena ; Color Blindness . . . . . . . . . . . . . .

Acuteness of Vision, 25-Test-objects, 26-Five minute angle, 27-Cards of Test-letters, 28-Illumination, 29-Fingers, 29Other Tests, 29-Light Sense, 30-IMPaIRMIENT of Vision, 30Pin-hole Disk, 31--Loss of Sight in One Eye, 32-The FifiLD of Vision, 33-'The Perimeter, 34-Taking the Field of Vision with the Hand, 36-Hemianopsia, 36-Sector-like Defects of the Field of Vision, 38-Scotona, 39-Narrowing of the Field of Vision, 41 -Inconstant Impairment of Vision, 41-Temporary Hemianopsil, 42-Inconstant Narrowing of the Field of Vision, 42-Musce V'olitantes, 42-Shadows of Rietinal Vessels, 53-Circulation of Blood in Retinal Vessels, 43-Subjecrive Visual Sensations, 44Flashes of Light, 45-Visual Sensations of Ophthahmic Migraine, 45-Distortion of a Point of Light, 45--Rings of Light, 46-MLultiple Images, Diplopia, 46-Color Vision, 47-Color Fields, 47Color Blindness, 48-PAIN, 51-Smarting and Burning, the Feeling of a Foreign Body, 51-Stinging, 52-Aching, 52-Neuralgic Pain, 52-Fulness or Discomfort of the Eyes, 53-Aching Outside the Eyes, 53-Headache, 53-Loss of Sensibility to Touch, 54Absence of Pain, 54.

CHAPTER III.

\section{External Examination of the Eye ; Oblique Illumination ;} The Pupil

Examination of the Lids, 54-Prominence of the Eyeball, 5i; -The Lashes, 55-Movements of the Lids, 56-Motility of the 
Eyeballs, 57-Eversion of the Lids, 57-Hrperemis, 60-Lidnargins, 60-Hyperemia of the Conjunctiva, 60-Pericorneal Redness, 61 -Deep Hyperemia of the Selera, $6: 2$-Fnlargement of the Selemal Veins, 63-Mixed Forms of Hyperemia, 63-SwrLd -Swelling of the Lids, 64 -Exophthalmos, 65-Swelling of the Conjumetiva, 65-Cosjuxctival Discinarge, 66-Mieroscopie Exanimation, 67-Oblrque or Focal Illumisation, 68-The Magnifier, 68-Opacities of the Cornea, 70-Reflections from the Surface of the Cornea, 70-Inspection of the Iris, 71-Tine Pupin, 71Size of the Pupil, 72-Pupillary Reactions, 72-Reactions to Ljght, 73-Genemal Reactions of the Pupil, 75-Transillumination, 77.

\section{CHAPTER IV.}

Ophthalmoscopic Diagnosis . .

The Opithalioscope, 78-Methods of Using the Ophthalmoscope, 80-Opacities in the Media, 81-Examination of Tur Eye-ground, 84-The Optic Disk, 8£-The Retinal Vessels, 86-Color of the Fundus, 87-The Details of the Choroid, 87Region of the Macula, 88-Retinal Reflections, 89-NorMaI Appearaxces and Anomalies of The Retina, 90-Haziness in the Retiua, 90-Hemorrliage, 90-Fatty Degeneration, 91Medullated Nerve-fibers, 91-Changes in the Retinal Vessels, 92Changes in the Optic Disk, 93-Redness, 93-Opacity of the Nerve-head, 94-Swelling of the Disk, 95-Pallor of the Optic Disk, 96-Cupping of the Disk, 97-Anomalies of the Optic Nerve, 98-Prgmextation, 99-Pigmentation of Optic Nerve, 99-Pigment-deposits in the General Fundus, 99-Pignentdeposits in the Retina, 99-Choroidal Pigment-changes, 100-Pigment-blotches at the Maeula, 101-Choromal Exudate AND Choromal Atrophy, 101-The Myopic Crescent, 102-Other Local Lesions, 102.

\section{CHAPTER V.}

\section{Refraction; Prisms and Lenses, and their Strength and} Numbering. . . . . . . . . . . .

Refraction of Light, 104-Dioptric Media, -105-Index of Refraction, 105-Prisus, 110-Numbering of Prisns, 111LExses, 112-Varieties of Lenses, 114-Strength of Lenses, 115Numbering of Lenses, 116-The Trial Set, 119-Fogging, 121.

\section{CHAPTER VI.}

\section{Refraction of the Eye; Mydriatics and Myotics; the $\mathbf{R e}=$} fraction Ophthalmoscope; Skiascopy........

Assorting of Light, 121-Refraction of the Eye, 123-Aceommodation, 124-Mydriatics ok Cycloplegics and Myotics, 127-Mydriatics, 127-Myoties, 129-OPTICAL THEORY of 'THE 
Ophthalmoscope, 130-Direct Method for the MeasureMENT of ReFraction, 131-Emmetropia, 131-Hyperopia, 131 - Myopia, 133-SkiAscopy, 134-Myopia, 134-Details of the Test, 135-Hyperopia, 139-Emmetropia, 139-A ppearance of the Liglit in the Pupil, 140-Practical Applications of the Test, 141 -Indirect Method of Ophthalmoscopic Examination, 142 -Special Methods, 143.

\section{CHAPTER VII.}

\section{Errors of Refraction, Cylindrical Lenses, Presbyopia, and the Wearing of Glasses . . . . . . . . . . . . . 144}

Presiyopia, 144-Symptoms, 144-Diagnosis, 145--'Treatment, 145-Prognosis, 147-HYPeropia, 147-Causes, 149-Varieties, 149-Symptoms, 150-Diagnosis, 152-Treatment, 153-Prognosis, 154-MYoPiA, 155-Causes and Course, 156-Varieties, 158Symptoms, 158-Diagnosis, 162-Treatment, 163-Prognosis, 166 -Astigmatism AND Cylindrical Lenses, 167-Cylindrical Lens, 167-Regular Astigmatism, 169-Causes and Seat, 172Varietes, 172-Symptoms, 173-Diagnosis, 174-'The Ophthalnımeter, 178-Skiascopy, 180-Test-lenses, 183-Treatment, 184Prognosis, 186-Aberration, 186-Irregular Astigmatism, 187-ANisometropia, 188-The Mounting and Wearing of Glasses, 189--Effects of Oblique Ienses, 190-Periscopic Lenses, 190-Changes with Age, 191.

\section{CHAPTER VIII.}

Disorders of the Ocular Movements

Ocular Movements, 192-The Metren-Angle, 193-ProjecTION AND Diplopia, 194-Amblyopia with Squint, 198-Causes of Squint, 198-Diagnosis of Squint, 199-The Cover-test, 199Power of Moving Eyes in Different Directions, 200-Measuring of Amount of Squint, 201-Varieties of Squint, 203-PARALYTIC Squint, 204-Canses, 204-Varieties, 204-Symptoms, 205-Diagnosis, 206-Palsies of Particular Muscles, 208-Treatment, 212Prognosis, 214-Concomitant SQuint, 215-Canses, 215-Varieties, 216-Convergent Squint, 217-Divergent Squint, 218-Vertical Squint, 219-Diagnosis, 219-Treatment, 221-Prognosis, 224 -Latent Squint, 225-Varieties, 225-Causes, 227-Symptons, 227-Diagnosis, 227-Maddox Double Prism, 229-Systematic Exercise, 233-Operations, 233-Prognosis, 234-SPastic SQUINT, 234-Nystagmus, 234-Nodding Spasm, 235-Retraction of Eyeball, 235-Diseases of the Ocular Muscles, 236.

\section{CHAPTER IX.}

Diseases of the Conjunctiva. . . . . . . . . . . . . 237

Hyperemia, 237-Acute Catarrhal Conjunctivitis, 237-Exanthematous Conjunctivitis, 241-Ácute Coutagions Conjunctivitis, 241-Diplobacillus Conjunctivitidis, 242-Ophthalmia Nodosa, 243 -Brief Recurring Episcleritis, 243-Purulent Conjunctivis, 243- 
Croupous Conjunctivitis, 250-Diphtheria of the Conjunctiva, 250 -Chronic Membranous Conjunetivitis, 253-Chronic Catarrlal Conjunctivitis, 253-Parinaud's Conjunctivitis, 255-Vernal Conjunctivitis, 255-Follicular Conjunctivitis, 256-Trachoma, 256Petrifying Conjunctivitis, 261-Phlyetenular Conjunctivitis, 261Pterygium, 265-Pinguecula, 267-P'emphigus, 267-Xerosis, 268 -Tuberenlosis and Lupus of the Conjunctiva, 268-Syphilis of the Conjunctiva, 268-Amyloid Degeneration, 269-Symblepharou, 269-Elema, 270-Emphysema, 270-Ecchymosis, 270-T'umor: 271-Concretions, 271-Burns, 272-Discoloration, 273-Diseases of the Caruncle, 273 .

\section{CHAPTER X.}

Diseases of the Cornea and Sclera

General Conditions Regarding the Cornea, 273-CoRsEaL ULCErs, 276-Simple Ulcer of the Cornea, 276-Suppurating Ulcer, 278-Special Forms of Corneal Ulcer, 286-Plylyctenular Keratitis, 288-Abscess of the Cornea, Hypopyon, and Onyx, 290-NoxUlcERATIVE KerAtitis, 292-Interstitial Keratitis, 292-Punetate Keratitis, 297-Striate Keratitis, 298-Pannus, 298-CorxEAI. Opacities, 300-Causes and Varieties, 300-Symptoms, 303Treatment, 303-Protrusions of the Cornea, 305-Anterior Staplyyloma, 305-Keratectasia, 309-Conical Cornea, 309-Ker:1toglobus, 310-Tumors, 311-Burns of the Cornea, 311-DisEAsis OF THF ScLERA, 311-Scleritis, 311-Staphyloma of the Selera, 313-Buphthalmos, 313-Injuries, 313.

\section{CHAPTER XI.}

\section{Diseases of the Iris, Ciliary Body, and Choroid ; Sympa= thetic Ophthalmia}

Uveits, 314-Iritis AND Crclitis, 314-Iritis, 314-Crelitis, 324-Sequels of Iritis AND Crclitis, 326-Myopia, 326-Posterior Synechire, 326-Ocelusion of the Pupil, 327-Exclusion of the Pupil, 327-Total Posterior Synechix, 328-Atrophy and De-

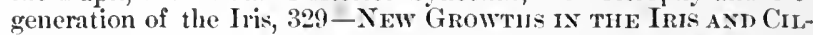
IARY BODY, 330-Gumma of the Iris and Ciliary Boly, 330Tuberenlosis of the Iris, 330-Sarcoma of the Iris or Ciliary Pody, 331-Carcinoma, 331-Benign Tumors, 331-Motor Disorners of tile Iris and Ciliary Muscle, 332-Myosis, 332-Cveloplegia, 332-Spasm of the Ciliary Muscle, 333-Sympatuetro OpItIAImi, 333-Sympathetic Inflammation, 334-Sympathetic Trritation, 340-Disesses of THE Choroto, 341-Purulent Choroiditis, 341-Plastic Inflammation and Atroply of the Choroid, 344-Choroidal Hemorrhage, 349-Detachment of the Choroid, 349-Colloid Masses, 349-Ossification of the Choroid, 349Slupinking of the Eyeball, 350-Tumons of TuF Cuoword, 350Sarcoma, 350-Carcinoma and Adenoma, 353-Axomalies of 
THE IRIS AND CHoroin, 353-Anomalies of the Iris, 353-Anomalies of the Pupil, 353-Coloboma of the Choroid, 355-Albinism, 355-Minor Anomalies of Pigmentation, 356.

\section{CHAPTER XII.}

\section{Diseases of the Retina}

General Considerations, 357-Symptoms of Retinal Disease, 357RFtrvitrs, 362-Simple Retinitis, 362-Purulent Retinitis, 362Leukemic Retinitis or Neuroretinitis, 363-Hemorrhagic Retinitis, 364-Albuminuric Retinitis, 365-Gouty Retinitis, 368-Diabetic Retinitis, 368-Syphilitic Retinitis and Chorioretinitis, 369-Punctate Retinitis, 370-Striate Retinitis, 370-Proliferating Retinitis, 371-Circinate Retinitis, 371-Retinitis from Excessive Light, 371 -Pigmentary Degeneration, 372-Amaurotic Family Idiocy, 374Angioid Streaks in the Retina, 374--Retinal Maculir Atrophy, 374 -Spasm of the Retinal Arteries, 374-Obstruction of the Retinal Vessels, 374-Thrombosis of the Retinal Artery, 376-Thrombosis of the Retinal Veins, 377-Detachnent of the Retina, 377-Subretinal Cysticercus, 380-Gliona of the Retina, 380-Anomalies of the Retina, 381 .

\section{CHAPTER XIII.}

\section{Diseases of the Optic Nerve, Visual Tract and Centers; Amblyopias. . . . . . . . . . . . . 383}

Hyperemia of the Optic Nerve-head, 383-Anemia of the Optic Disk, 384-INFrammations of the Optric Nerve, 384-Neuroretinitis, 384-Optic Neuritis, 385-Retrobulbar Optic Neuritis, 391-A trophy of the Orric Nerve, 391-Optic Nerve Atrophy, 391-Other Organic Changes in the Optic Nerve, 396Hyaline Bodies in the Nerve-head, 396-Tumors of the Optic Nerve, 396-Coloboma of the Optic Nerve, 397-Toxic AmbLYopIAs, 397-Tobacco Amblyopia, 397-Alcohol Amblyopia, 399Iodoform Amblyopia, 400-Bisulphid of Carbon Amblyopia, 400 -Nitrobenzol Amblyopia, 400-Quinin Amblyopia, 401-Salicylic Acid, 402-Acetanilid, 402-Jamaica Ginger, 402-Filix Mas, 402 -Congenital, Hysterical, and Simulated Amblyopias, 402 -Congenital Amblyopia, 403-Amblyopia from Imperfect Focussing, 403-Congenital Color Blindness, 403-Hysterical Amblyopia and Simulated Amblyopia, 403-Developmental Alexia, 406.

\section{CHAPTER XIV.}

\section{Diseases of the Anterior Chamber, Crystalline Lens and} Vitreous Humor . . . . . . . . . . . . . . 407

The Anterior Chamber, 407-Depth, 407-Alterations of the Aqueous Humor, 407-Hyphemia, 408-Infection, Obstruction, Cysts, 408-Diseases of the Crystalline Lens, 408-Cataract, 408-Alterations of the Lens by Age, 408-Senile Cataract, 409Juvenile or Soft Cataract, 418-Partial ('ataract, 419-Anterior 
Polar Cataract, 419--Posterior Polar Cataract. 420-Iamellar Cataract, 420-Fusiform and Central Cataract, 421-Secondary Cataract, 421-Dislocation of the Lens, 424-Coloboma of the Lens, 425-Lenticonus, 426-A phakia, 426-Diseases or Tuk Vitreous, 426-Vitreous Opacities, 426-Fluid Vitreous, 428Hyalitis, 429-Hemorrhage into the Vitreous, 429-Jloml-vessels in the Vitreols, 430-Detachment of the Vitreous, 430-Parasites in the Vitreous, 430-Persistent Hyaloid Artery, 431.

\section{CHAPTER XV.}

Disorders of Tension of the Eyeball

Normal Intra-ocular Currents and Pressure, 432-'Testing of Intra-ocular 'Pension, 434-GLAucoMA, 434-Primary Glaucoma, 435-Glaucoma with Exacerbations, 435-Simple Glaucoma, 443Secondary Glaucoma, 444.

\section{CHAPTER XVI.}

\section{Diseases of the Lids, Lacrimal Apparatus, Orbit, and}

Orbital Walls . . . . . . . . . . . . . . . . 448

A Nomalies of tife LiDs, 448-IxFlaymation of the LiDs, 448-Blepharitis, 448-Blastomycosis, 448-Marginal Blepharitis, 449-Stye, 450-Abscess, 450-Tamitis, 450-Duskases of TuE Skin of TuE Lids, 451-Eczema, 451-Fissures of the Extemal Canthus, 451-Toxic Dermatitis, 451-Erysipelas, 452-Herpes Zoster, 452-Molluseum, 452-Warts and Horn-like Growtls, 453 - Xanthelasma, 453-Milium, 453-Spontaneous Gangrene, 45:3Syphilis, 453-Diseases of THE LAsHes aND Erforows, 454Pediculosis, 454-Trichiasis ; Distichiasis, 454-Distor'tıons, DIsPLACEMENTs, AXD ADIIEsions of TIIE LiDs, 455-Entropion, 455 -Ectropion, 456-Lagophthalmus, 456-Blepharospasm, 457-Ptosis, 457-Epicanthus, 458--Blepharophimosis, 458-Anchyloblepharon, 458-Sweldivas axi Turors of THe EYelids, 459Edema, 459-Emplivsema, 459-Chalazion, 459-Lipoma, 460Fibroma, 460-Nemoma, 460-Cysticercus, 460-Angioma, 460Sarcoma, 461-Lupus, 461-Epithelioma, 461-Burns, 462-D!sEasfs of the Lacrimal Passages, 462-Epiphora, 462-Closnre of the Punctum, 463--Displacement of the Punctum, 464-Obstruction of the Camaliculus, 464-Obstruction of the Nasal Duct, 4ti5 - Iacrimal Abscess, 467-Diseasis of tha Lacrimal Glaxn, 467-Inflammation, 467-Ilypertrophy, 468-Dislocation, 468Cyst, 468-Tumors, 468-DisEAsts OF THF (ORHIT ANU OHBTAI. W ALIs, 468 -Orbital Cellulitis, 468-Inflammition of the Oculoorbital Fascia, 470-Periostitis, Can'ies, and Necrosis, 470-Enophthalmos, 471-Exophthamic Goiter, 472-Pulsating Exoplathalmos, 472-Angiomata, 474-Dermoid Cysts of the Orbit, 474Other Cysts, 475-Orbital Tumors, 475-Imperfect Development, 476 -Dishases of TuE AnJorsixg Cavitues, 476 -Maxillary Antrum, 476-Frontal Sinus, 477-Ethmoiral Sinus, 478-Sphenoidal Sinus, 478. 
Con'usions, 479-Bruise of the Eyelids, 479-Fracture of the Bones of the Orbit, 479-Dislocation of the Eyeball, 480-Rupture of the Eyeball, 480-Contusion of the Eyeball, 481-Rupture of the Iris, 481-Paralysis of the Iris Sphincter, 481-Traumatic Cycloplegia, 481-Hemorrhage into the Vitreous, 482-Injuries of the Lens, 482-Traumatic Edema of the Retina, 483-Injuries of the Choroid, 483-Wounds Without Lopg Fment of Foreign Bontes, 485-Wounds of the Lids, 485-Penetrating Wounds of the Orbit, 486-Wounds of the Conjunctiva, 487-Wounds of the Cornea, 487-Wounds of the Sclera, 488-Wounds of the Ciliary Body, 488-Wounds Involving the Iris, 488-Wounds of the Lens, 489-Wounds Involving the Vitreous, 491-ForeIgN BoDIEs IN The Eye And Orbit, 491-Lids and Orbit, 492-Foreign Bodies in the Conjunctivi, 492-Foreign Bodies in the Cornea, $493-$ Foreign Bodies in the Sclera, 495-Anterior Chamber and Iris, 495 -Lens, 496-Vitreous, Retina, and Choroid, 496.

\section{CHAPTER XVIII.}

Remedies and their Applications .

Rontgen RaYs, 500-REst, 500-Massage, 501-A pPlications of Heat and Cold, 502-The Making of Applications to the Conjunctiva, 504-Antiseptic and Cleansing Solutions, 507-Conjunctival Applications, 509-Dusting PowDERs, 511-Caustics, Astringents, and Irritants, 511--OintMents, 513-Anesthetics, 514-Mydriatics, 516-CyclopleGias, 517-Mrotics, 519-Miscellaneous Solutions, 520Drugs Usfid for their Sistemic Influence, 520.

\section{CHAPTER XIX.}

\section{Common Ophthalmic Operations .}

General Considerations, 523-Preparation of Patient, 523 -Preparation of Surgeon, 524-Preparation of the Instruments, 524-Position and Illumination, 525-Retraction of the Lids and Fixation of the Eyeball, 525-Sponging, 527-Dressings, 527Hemostasis, 529-A bstriction of Blood, 529-Operations UPON THE LIDs, 529-Removal of Displaced Lashes, 529-Entropion and Disticliasis, 531 -Canthotomy, 532-Canthoplasty, 532Division of the Upper Lid, 533-Union of the Lids, 533-Ectropion Operations, 534-Plastic Operations on the Lids, 525-Epithelial Grafts, 535-Ptosis Operations, 536-Chalazion, 537Operations on the Conjunctiva, 537-Pterygium, 537-Symblepharon, 538-Epithelial Grafts, 538-Trachoma Operations, 539-Peritomy, 539-Oprrations on tite Lacrimat. Passages, 540-Syringing, 540-Slitting the Canaliculus, 540-Proling the Nasal Duct, 541-Lacrimal Stricture, 542-Extirpation of Lacri- 
mal Sac, 542-Operations on the Eye-muscies, 543-Tenotomy, 543-Advancement, 544-Opkrations on the Cornea, 545 -Remoral of Foreign lodies, 545-Curetting of the Cornea, 546-Paracentesis, 546-Incision of Corneal Ulcer, 546-Actual Cautery, 547-Galvano-cautery, 547-Tattooing the Cornea, 548Excision of Anterior Staphyloma, 548-OPERATIONS ON THE Sclera, 549-Anterior Sclerotomy, 549-Posterior Sclerotomy, 549-OPERATIOXS ON THE IRIS, 549-I ridectomy, 549-Iridotomy, 552-Corelysis, 552-I ridencleisis, 553-OPERATIONS ON THE LENS AND ITS CAPSUle, 553-Simple Extraction, 553-Extraction with Iridectomy, 557-Linear Extraction, 557-Suction-operation, 557 - Extraction within the Capsule, 557-Scoop-extraction, 557Wenzel's extraction, 557-Discission, 558-Capsulotomy, 559Removal of Lens for High Myopia, 560-OPERATIONS on THE Eyebai,L, 560-Magnet-extraction, 560-Enucleation of the Eye, 561 - Evisceration, 564-Implantation of an Artificial Vitreous, 565 Paraffin Splieres, 56.5-Osteoplastic Resection of Orbital Wall, 566.

\section{CHAPTER XX.}

\section{Ocular Symptoms and Lesions Connected with General}

Disease. . . . . . . . . . . . 566

Diseases of the Nervous Srstem, 567-Symptoms often FxPlained by Ocular Examinatioxs, 568-Diseases of the Circulatory System axd Kinneys, 572-Diathetic Diseases, 574 -Chronic Infectious Disfases, 575 -Acute Infectious Diseases, 577-CoNDitions of The Sexual Organs, 581-Diseases of tire Nose, 582-Poisons, 583.

Bibliography . . . . . . . . . . . . . 58. 
DISEASES OF THE EYE. 



\section{CHA P T E R I.}

\section{EXAMINATION OF THE PATIENT; CASE RECORDS; ABBREVIATIONS.}

\section{THE STUDY OF THE CASE.}

THe study of a case should begin with an attentive hearing of the case history, noting especially the symptoms to which chief importance is attached or from which relief is sought. This takes time, but it is time well spent. It is the more important because in most ophthalmic eases the diagnosis rests ehiefly on what the surgeon diseovers by special methods of examination; and on that aceount the patient's view of his ease is liable to be neglected altogether. An attentive hearing strengthens the patient's confidence. Even the time occupied by a garrulous patient in utterly insignificant details need not be wasted.

The patient being seated facing the surgeon, in a good light, the eareful inspection of the cyes and face can go on with the case history. The attitude of the head may indicate weakness in certain ocular muscles; a constant frown may suggest eye-strain; unconscions movements to avoid the light tell of photophobia. The ocular movements are to be noted, and the appearance and positions of the lids and the lashes. The brightness of the corneal surface, the presence or absence of hyperemia of the globe, the evidence of conjunctival discharge, the existence and extent of scars on the eyeball, lids, laerimal apparatus, or related parts, should elaim attention. The color and reaction of the iris, and the form, size, and color of the pupil give evidence regarding intra-ocular conditions.

The case history is to be extended in all important 
direetions by questions, especially as to lieadache, nervous symptoms, and previous attacks of eye disease or general illness. The patient's age is so often an iniportant element in the ease that it should always be ascertained. Family history is chiefly of value as to the occurrence of blindness and the age at which it occurred; althongh in conmection with optic neuritis, or ocular affections due to general disease, it may be important in other direetions. Consanguinity of parents is sometimes important; and race and previons place of residence may throw light on some cases. With women the facts as to menstruation and child-bearing should be bronght ont.

The personal or fimily history of syphilis is so often of primary importance that it should always be in the surgeon's mind. 'The direct question as to previons syphilis is mostly worthless as to family history, and often yields nothing as to the history of the patient. It may be sometimes omitted. But the careful inquiry for evidence of syphilitic lesions should never be neglected.

The special examination of a ease should generally begin with tests of the acuteness of vision, with the testtype at four or six meters. If the vision is good enongh to make near vision of small objects possible, the near point of distinct vision should be ascertained. The balance of the ocular muscles may be tested with the Maddox rod. Next, the anterior segment of the eye should be carefully inspected by the oblique illumination, first with the mnaided eye and then through a magnifying lens, noting the transparency of the cornea and erystalline lens, the smoothness of the corneal surface, the depth of the anterior chamber, and the appearance of the pupil and the iris.

The most important step in the routine examination, to be applied to all eases in which it is possible, is the ophthalmoscopic examination. 'This should include the inspection from a distance to ascertain the transparency of the media and the general color of the fundus reflex, the measurement, more or less eareful, of the refraction of the retina or other points to which attention is directed, 
and finally the eareful inspection of the details of different parts of the eye-ground.

Such a routine examination will furnish the material for an approximate or provisional diagnosis, and indicate the direction for further investigation. For instance, if there is reason to suspect lacrimal disease, the puncta and region of the lacrimal passages must be minutely studied. Pressure is to be made over the lacrimal sae to try if there be any accumulation within it. If there are indications of conjunetival disease, the lid will be everted and the conjunctiva examined. In either of these cases the discharge may be studied microscopically and bacteriologically, and the nose should be carefully examined for causative or related lesions.

If there has arisen reason to suspect disorders affecting the ocular tension, this should be tried, after the ophthalmoseopic examination, by the method detailed in Chapter $\mathrm{XV}$. The tension should be tested in all obscure cases. If ametropia be an important factor in the case, the ophthalmoscopie examination should be supplemented by skiascopy, the ophthalmometer may be used, and the refraction should be tested with trial-lenses, and if needful, a mydriatic employed.

If the earlier examination has pointed to disease of the optic nerve or central nervous system, or to lesions of the retina, the field of vision is to be taken, first for form and then for certain colors, green, red, and blue; and the condition of the reflexes and other evidences of the state of the general nervous system are to be investigated.

Should the routine examination, especially that of the fundus, reveal evidence of general-disease, such as Bright's disease, diabetes, severe anemia, syphilis, tuberculosis, etc., the special examination must include the search for other evidences regarding such eonditions. Certain examinations as to the general conditions, as the testing of the urine for albumin and sugar, should be made as a matter of rontine before undertaking important operations, such as extraction of cataract. Justice to the patient requires a constant lookout for general manifesta- 
tions of constitutional diseases that may have affected the eye, as syphilis, rheumatism, gout, or tuberculosis.

It may be stated as a general principle that disease of a tissue represented in the eye, especially if chronic, should raise the inquiry as to the condition of similar tissues in the other organs. Disease of the skin of the lids should lead to the inquiry as to skin disease in other parts of the body. Conjunctivitis should make the surgeon consider the condition of other mucous membranes. Disease of the retinal vessels strongly suggests vascular disease elsewhere throughout the body, as optic-nerve disease suggests disease in other parts of the nervous system.

Case Records. - The keeping of accurate case histories soon teaches the unreliability of one's recollections of symptoms. In ophthalmic practice the need for case records is the greater because of the wide variations that occur in different normal eyes. An appearance that must be regarded as of no serious import in the optic disk of one patient might be significant of grave organic disease when observed in the eye of another. It is often of great importance to know if a certain lesion be recent or of long standing; and some lesions, such as an opacity in the cornea, lens, or vitreous, or an atrophy or disturbed pigmentation of the choroid, may exist unchanged for many years, presenting such an appearance that it is impossible to judge from it the age, and therefore the significance, of the lesion. To know of the previons existence or non-existence of such eonditions, and to know the previous vision and muscular balanee of the eyes, is often essential to a correct prognosis or a full understanding of the case.

What to record is a serious question for young surgeons; later a species of selection occurs, each learning for himself to select the facts to be especially noted. It wastes time and tends to befog important points with irrelevant detail to attempt to make each case record encyclopedic, but there are certain things which it is wise to note in every ease. 
The record should show the name, sex, and age of the patient; and race and nativity may have considerable seientifie value. The patient's address is important in a business way and for the identification of the ease. The oecupation should be reported, so as to show the actual charaeter of the daily work ; thus, "house work, sews three hours a day;" "teacher, French and German, written exereises." Every note made should be dated.

The vision of each eye should be noted, with any circumstance especially affecting it, as the use of a correeting lens and its strength, the name of the mydriatic employed, its strength, and the time since its instillation. If at sueceeding visits vision is found unchanged, no note regarding it is required. But whenever a ehange in the acuteness of vision oceurs, it should be reeorded.

The notes should inelude the elearness or lack of elearness in the dioptric media, and the general condition of the eye-ground. All deeided anomalies and sears due to former injury or disease should be noted, so that at a subsequent date any marked departure from the normal, not mentioned in the reeord, may be presumed to have oceurred sinee the ease was last examined. Such a presumption may, however, prove misleading, unless great care is taken in the examination of every ease, and the complete record is made at the time.

The record will include such points of personal and family history as are deemed important. Generally it is useless to reeord a negative, unless the negative is itself of great signifieanee, as the absence of albumin from the urine in a ease of apparent albuminuric retinitis. Besides the ehief elinieal features of the case, and all treatment instituted, it is often well to record also the prognosis or the definite opinion given. It is very embarrassing to have a former opinion quoted, often incorreetly, against one's self, with no recollection of the real facts to correet misapprehensions.

Sketches and diagrams of anomalons or morbid appearances are an extremely valuable part of ease records. They abbreviate by replacing verbal deseriptions, 
and often give a more complete and exact reeord than any verbal description can. To facilitate their use, case books have been prepared with outline diagrams of the lids, the anterior segment of the eye, and the fundus; also stamps by which such outlines can be reproduced. These are sometimes helpful, but not essential. For recording fundus lesions a plane ground of the fundus color, which can be rubbed or scraped away to white, and will readily take black and other colors, is most helpful. The. essential thing is practice and familiarity with the making of such sketches. A large part of the skill is in the secing of the thing to be sketched; and no one can be regarded as well trained in ophthalmology who cannot make such sketches as will be valuable additions to his case records.

In working in black and white, the lead-pencil is more manageable than pen and ink; but additional effects can be secured by using both. For making water-color or oil sketches, some little acquaintance with the laying and combination of colors is required, but not more knowledge of color values than is needed to appreciate the various appearances presented by the findus of the eye.

By judicious selection of points to be noted, by use of abbreviations, including those to be mentioned below, and the employment of sketches, when needed, a very good ease history may be recorded in the space commonly occupied by two or three hundred words of manuscript. Such histories may be written in an ordinary hlank-book, one or two eases to a page; and, if well indexed, this is quite satisfactory for the ordinary purposes of private practice.

For the comparative study of similar cases, for the division of clinical work among several workers, and for hospital records, a card record is superior. This may be kept on specially prepared blanks in a special form of ease, or on ordinary Manila cards kept in a box. The card record has the advantages that it can be written with the typewriter and that the individual eard may be small, while for cases with prolonged histories any number of 
cards may be used. Arrangement in alphabetical order renders the ordinary index unneeessary ; but indexes may be added, giving references and eross-references to all desired classes of cases.

The careful study of a case presenting any marked defeet of the field of vision will usually include the mapping of the ficld. The map or diagram is preserved by fastening it to the other part of the ease record, or in a "field book," with a reference to the record. A very useful record of the field of vision can, however, be made in this way:

$\begin{array}{lll}60 & 55 & 80 \\ 60 & \mathrm{R} . & 95 \\ 65 & 75 & 90\end{array}$

Normal field for form for the right eye. The letter in the eenter tells which eye, and the figures the number of degrees the field extends in the different directions.

Abbreviations allow the condensation of a case so that it will oceupy less space, and may be more quickly looked over. Those given below are in general use or have proven of special service to the writer. Some of them are used throughout this book. Such abbreviations are puzzling when different authors use similar abbreviations to indicate entirely different meanings. Snellen used $\mathrm{D}$. to indicate the distance at which a letter of any given size would subtend the angle of five minutes; while D. has come to be universally understood as meaning diopters. Nettleship used O. D. for optic disk, although it is very generally used to mean oculus dexter, the right eye.

\section{Abbreviations :}

A. or Acc.,
As.,
Ax., .
B.
C. or Cyl.,
Cm.,
Cr.
D.
E.
H.

Accommodation.

Astigmatism, or astigmatic.

Axis of cylindrical lens.

Base of prism.

Cylinder, or cylindrical lens.

Centimeter.

Centrads.

Diopter, or diopters.

Emmetropia, or emmetropic.

Hyperopia, or hyperopic. 
Hl. or H. L.

Hm. or H. M.

M.

M. a.

mm.,

Pp.,

Pr.,

R. or R. E. or

L. or L. E. or

S. or Sph.,

T.

V.

Obl.,

Oph.,

Skia.,

Mom.,

$$
\frac{1}{=}
$$

Hyperopia latent.

Hyperopia manifest.

Myopia, or myopic.

Meter angles.

Millimeters.

Punctum proximum, near point of distinct vision.

Presbyopia.

O. D., The right eye.

O. S., The left eye.

Spherical lens.

Intraocular tension; $+\top$, increased tension; $-T$, diminished tension. (See Chap. XV.)

Vision, or acuteness of vision.

Results of examination by oblique illumination.

Results of oplithalmoscopic examination.

Results of skiascopic examination.

Results of examination with ophthalmometer.

Plus, or convex.

Minus, or concave.

Combined with.

Degrees.

In making records of the balance, or lack of balance of the ocular muscles-records that must be made many times and compared, to be of much service-the following are found useful :

Orth.,

$\stackrel{\sim}{<}$ or Ex.

$>$ or Eso.,

$\|$ Rt. Hyperph.

$\wedge$ Lt. Hyperph.
Orthophoria, or proper balance in all directions.

Proper lateral balance.

Exophoria, less than normal convergence, tendency to divergence.

Esophoria, more than normal tendency to convergence.

Vertical balance.

Right hyperphoria, tendency of the right eye to turn above the left.

Left hyperphoria, or tendency of the left eye to turn above the right. 
CHA PTER II.

ACUTENESS OF VISION ; FIELD OF VISION ; SUBJECTIVE PHENOMENA; COLOR-BLINDNESS.

\section{ACUTENESS OF VISION.}

Normat vision requires focussing of light upon the retina, and the transmission of the nervous impulses cansed by the focussed light, through the optic nerve and traet, to the normally related centers in the brain. Disturbance of any part of this series of aetions eanses impairment of the vision. The character of the impaiment often indicates the seat of the disturbance.

Acuteness of vision is tested, as the acuteness of touch, by the ability to recognize the separateness of impressions.

If two points of light make upon the retina impressions sufficiently removed from one another, they appear as separate points; but if the impressions be brought closer and closer together, there comes a limit in the power to distinguish between them, the two fuse into one, and the eye sees but a single point of light.

The distanee the impressions must be separated in order to appear separate might be measured upon the retina. In Fig. 1, this would be the distance between $a$ and $b$, the point on whieh inipressions are made by rays from $A$ and $B$.

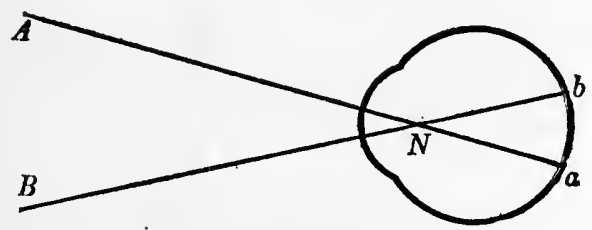

FIG, 1.-The visual angle.

It is better to indicate their separation by an angle formed by these rays, $A a$ and $B b$. These rays cross at a certain point, called the nodal point of the eye $(N)$, 
and at that point make an angle $A N B$, and its equal the angle $a N b$ (Fig. 1).

By testing many persons, it lias been found that the angle between the direction of the two rays that will give separate impressions in a normal eye is abont one minute, one-sixticth of a degrec. In some healtlyy eyes it is slightly greater than this. In others with especially good sight, the angle is notably less, but most eyes fairly conform to the standard of a one-minute angle as the normal acuteness of vision.

To ascertain the acuteness of vision of an cye, we test its visual angle. This might be done by taking two points at a certain distance and bringing them closer together until they appeared as one, and noting the smallest angle at which they could be seen as separated. For convenience, it is better to have a series of points separated by varying distances, and find out which of these can be distinguished at a certain known distance from the eve.

Test Objects.-The simplest test object is a group of black dots on a white eard. The person tested is required to tell the number of dyts in cach group. A series of such groups, graduated so as to be distinguished at different distanees, makes a test for visual acuteness which is applicable to the illiterate and to persons of all nationalities (Fig. 2).

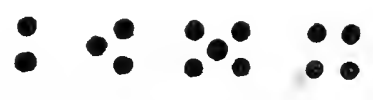

Fir. 2.-Dots large enourh to be counted at five meters.

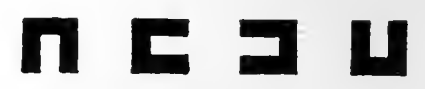

FIG. 3-Ineomplete square test for full vision at six meters.

Another test, which has the same range of application, is that proposed by the writer, in which the figure of an incomplete square is used and the deficient side turned either up or down or to the right or left, als shown here (Fig. 3).

The patient is required to designate which side is 
incomplete, and thus to show at what distance the separate arms are distinct from one another. With normal acuteness of vision, the space between the arms subtends an angle of one minute, the whole figure subtending an angle of three minutes.

The most generally popular and valuable tests, however, are carefully arranged series of test letters. Snellen, who first put test types on a scientific basis, arranged series of letters, each of which should have five spaces in height and five spaces in width, that must be seen in order that the letter shonld be distinctly recognized. As each part of the letter must make its distinct impression on the retina, the size chosen was such that the whole letter.should subtend an angle of five minutes, at the distance at which it was to be seen by an eye with normal acuteness of vision. This is illustrated by the block letters E and B of Fig. 4, which shonld be recognized at a distance of ten meters.
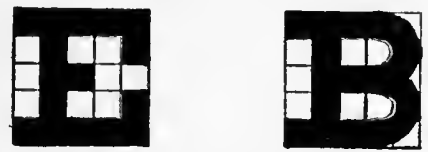

Fig. 4.-Snellen letters which subtend an angle of five minutes when plaeed at ten meters.

To recognize fully each portion of such a letter requires about the five-minnte angle that Snellen fixed upon. There are, however, many letters in the alphabet, as $\mathrm{O}, \mathrm{L}, \mathrm{T}$, and others, which ean be recognized withont seeing distinetly five separate parts of height or breadth. Hence, for many persons with normal vision, most of the letters of the Snellen seale are too large; and patients frequently reeognize at twenty feet letters intended to be seen at ten or fifteen feet. On many test cards, B and S are the only letters requiring full normal vision for their recognition at the given listance.

'This has led to the employment of smaller letters, such 
as would subtend an angle of four or four and one-half minutes at the required distance. But with any test card different letters of uniform size will be seen at different distances or with different degrees of distinctness. This makes the apparent acuteness of the vision depend somewhat upon the particular card employed.

The great practical advance made by Snellen was in numbering his test type by the distance at which they could be read by a normal cye. He thus enabled the surgeon to make definite records of the acuteness of vision suited for comparison. "Such records are made by expressing the acuteness of vision by a fraction, of which the denominator is the distance at which the letters should be visible, and the numerator is the greatest distance at which they can be read. Thus, if letters which should be visible at forty feet ean only just be read at twenty feet, the acuterfess of vision is expressed by the fraction $\frac{20}{40}$. This distance may be expressed in terms of any unit, as feet, meters, or inehes. If the six-meter type be read at four meters, the vision will be recorded as $\frac{4}{6}$, or if the thirty-inch type is just made out at eighteen inches, the record will be $\frac{18}{30}$ ths. Sncllen used Roman numerals for the denominators, intending thus always to indieate the number of feet at which the type should be read. Thus $\frac{20}{x x}$ indieated vision normal at twenty feet.

The cards of test letters as commonly printed have each line marked with the number of feet or meters, or both, at which it should be visible to the normal eye.

Any test eard intended for use at a certain distance shonld have at least one row of letters upon it smaller than can be read by eyes with normal acuteness of vision at that distance, to provide for eases in which the vision is above the standard.

Test letters are used by placing the patient at the clistance corresponding to a line of letters upon the test card, commonly four or six meters (fifteen to twenty feet). He is then requested to read all the letters he can at this standiud distance. When it is impossible to read even 
the largest letter on the test eard at the standard distance, the vision is to be tested by bringing the card nearer until the largest letter is made out. The distance at which this is done will then be the numerator for the fraction, the distance at which the letter should be read being the denominator.

In all use of test letters, great care should be taken to secure a good and uniform illumination. Any deficieney or variability in the brightness of the illumination will vitiate the results of such tests. The card can be exposed to the light from an area of unobstructed sky. This will be sufficient during the brighter portions of fair days. But to secnre constant illumination, it is better to employ artificial light, which should be as bright as that of a good Argand burner, placed within twelve inches of the card.

Counting Fingers.-When it is impossible to read even the largest letters at a distance of a foot, the aeuteness of vision is to be tested by holding up the fingers against a dark background and requiring the patient to count them. The ability to do this is recorded as "counts fingers" at a distance of so many inches. The ability to count fingers at a certain distance, requires slightly less power of vision than the reading of the sixty meters or two hundred feet letters at the same distance.

Other Tests.-When fingers cannot be counted, even a very few inches from the eyes the power of vision is to be tested by moving the hand in different directions and requiring the patient to indicate in what direction it is moved. The ability to do this will be recorded as "ability to see noving oljjects."

When objects cannot be seen, the eye should be tested in a darkened room as to its ability to recognize the direction of a lamp-flame, "light-projection," and when a lamp-flame is turned up or down, or bronght closer or earried farther away from the eye, the power of "quantitative perception of light." Where these are lacking, the test is to be made of concentrating a bright light upon the eye, and then turning it away, and leaving the eye in complete darkness, and 
requiring the patient to say when the light is thrown on the eyes and when it is removed. This tests the power of simple "light-perception." In applying the test for light-pereeption in one eye, care must be taken to have the other thoroughly covered with some opaque object; simply elosing the lids does not answer, beeanse lightperception is quite possible through the closed lids of a sound eye. 'The power of vision is to be tested for each eye separately. (See page 32.)

The accurate determination of the power of vision frequently requires special eare, not to be misled by statements of the patient. In the reading of test letters, the patient will frequently stop as soon as the recognition of the letters requires effort, and say that he can sce no more. Yet, by taking a little more time, and coaxing the patient to guess at one letter after another, lie can be made to read a line or two farther down. Mistakes indicate the approach to the limit of visual acuteness. . Patients often believe they ean see considerable light, although quite blind. They must be required to tell the number of fingers held up, the direction the hand is moved before the face, or when the light is made brighter or dimmer.

Light Sense.-The amount of light necessary to render visible the test area in a dark chamber is called the light minimum. The smallest difference of illumination perceptible when two unequally lighted areas are compared is the light difference. These are tested by a special apparatus, a photometer, which consists essentially of a dark chamber in which test areas are illuminated through an adjustable aperture by a standard candle, or equivalent source of light. Test letters seen under diminished illumination, or against various gray backgrounds, also test the light sense.

\section{IMPAIRMENT OF VISION.}

Vision better than $\frac{6}{6}$ or ${ }_{x x}^{20}$ of the. Snellen scale, as $\frac{6}{4}$ or $\frac{20}{15}$, may generally be regarded as normal. Vision that falls below this should be regarded as impaired, and the cause of impairment should be sought for. 
In seeking the cause of impairment of vision, we must first inquire, Is vision impaired for all distances, and at all times? Impairment of vision for objects at one distance, when objects at another distance can be seen perfectly, can only depend upon imperfect adjustment of the eyes for the distance at which the vision is impaired. This imperfect adjustment may be due to abnormality of the muscles that turn the eyes, but generally it is due to imperfect focussing.

If a patient can only read the thirty-meter type at four meters, but can read the quarter-meter type at one-fourth of a meter, the focussing for four meters is imperfect, the impairment of vision is due to myopia. If, on the other hand, distant objects are always seen more elearly, but there come times when the patient is unable to read fine print or do fine sewing at the ordinary working distance, this fact alone demonstrates that the power of accommodation, the power of focussing the eyes for near work, is insufficient for the continuous demand made upon it. If impairment of vision exists for all distances, but greater at one distance than another, the difference is due to imperfect foenssing.

If the impairment of vision be equal for all distances, it may still be due to imperfect focussing. This can be determined by using the pin-hole disk of the trial set, or, making a pin-hole in cardboard, and holding it before the eye. Looking through such a minute opening, the vision is always improved if its defect is due to imperfect focussing, which can thus be differentiated from impaired vision due to any other cause.

When the impairment of vision affects objects equally at all distanees, but is inconstant, it usually depends on some serious derangement of the nervous apparatus of vision, the optic nerves, tracts, or centers. When the impairment is constant, and looking through the pin-hole does not improve it, it probably depends upon organic changes, which may be either within the eyeball, where they will be visible; or in the deeper structures where, perhaps, no other direet evidence of their existence may be obtained. 
Loss of Sight in One Eye.-In testing the power of vision, each eye is to be tested separately, care being taken to effectually cover the other eye without making any pressure upon it. Pressure on the eyeball diminishes the power of sight for the time; and having subjected one eye to pressure while testing the other, we should not get its full acuteness of vision upon testing it. It is better to hold something in front of the eye to be excluded, than to permit the patient to hold it closed while he looks with the other. The act of holding one eye closed while the other is open, often requires excessive pressure of the lids of the closed eye.

Impairment of vision affecting only one cye arises from disease in front of the optic chiasm, in the optic nerve or

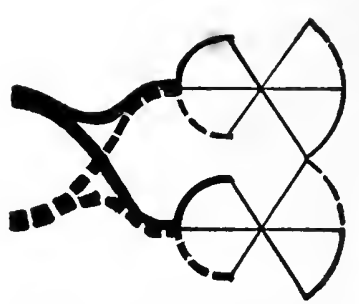

FIG. 5.-Relation of the optic tracts to the fields of vision. Semidecussation at the chiasm. the eye itself. Fig. 5 illustrates the course of the nerve fibers and the connections of the nerve centers concerned in the act of vision. The fibers coming from the retina of one eye pass back through the optic nerve until they reach the chiasm, and there separate into two sets that do not again come together. Those from the temporal half of the retina are associated with fibers from the nasal half of the retina of the other eye; and those from the nasal lialf of the retina are associated with fibers from the temporal half of the retina of the other eye. Hence, any lesion interrupting them back of the chiasm will produce impaiment of the vision in both eyes, and not interference of one alone. Gowers, however, believes that in each half of the cerebral cortex there is a higher center concerned only with the eye of the opposite side, and that disturbance of this center causes a crossed blindness of one eye. Cases of that kind rarely, if ever, reach the ophthalmologist. 


\section{THE FIELD OF VISION.}

The form of the normal field of vision is shown in Fig. 6. R. is a diagram of the field for the right cye as commonly represented. The eross at the center marks the direetion in which the eye is looking, the point

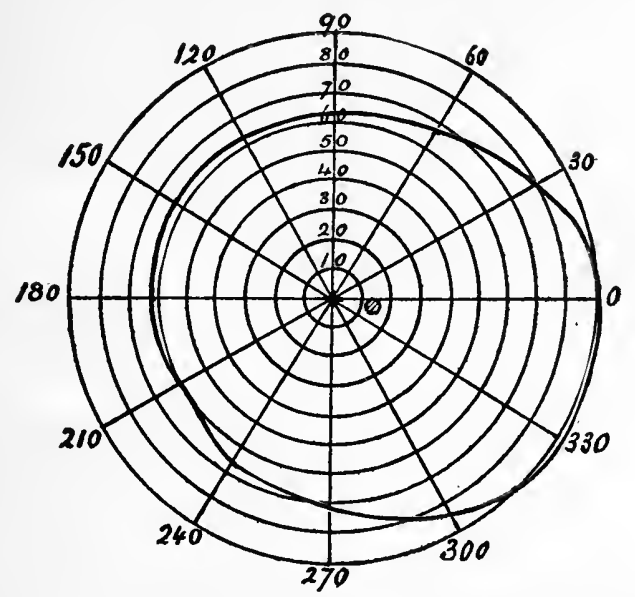

Fig. 6.-Chart of field of vision of right eye. The center of the circles represents the fixation point, and the small shaded area to the right of it the physiological blind spot.

upon which it is fixed. The small circle near it indicates the physiological blind spot, corresponding to the entrance of the optic nerve. The concentric circles indicate each ten degrees of departure from the visual axis.

'To the temporal side, and a little downward, the ficld extends beyond ninety degrees from the visual axis. In other direetions it is somewhat limited by the brow, nose, and cheek, making the normal field unsymmetrical for each eye alone, but symmetrical as to the median line, when the fields of both eyes are viewed together. The two fields overlapping have a certain portion, common to both, in which alone binocular vision is possible. This is shown in Fig. 7, where the two fields are super- 
imposed, the cross representing the direction of fixation for both eyes.

The Perimeter.-The ficld of vision may be aceurately mapped out by use of a perimeter, shown in Fig. 8. "This consists essentially of an are that can be revolved about an axis passing through its center, broad enongh and blackened to furnish a background for the test object. 'The patient's eye is placed at the center of this are, the ehin rest and cheek rest being designed to keep it fixed in this position. The visual axis is turned

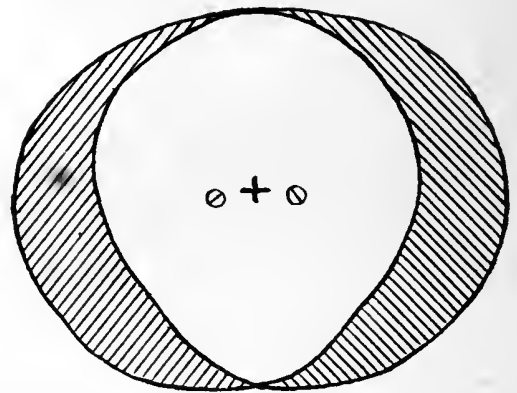

Fig. 7.-Fields of vision for the two eyes superimposed. White area the field of binocular vision. The cross marks the point of fixation, and the circles on either side the physiological blind spots of the respeetive fields.

in the direetion of the axis of the instrument $B$ by fixing the gaze on a point in that direction.

To use the perimeter the are is set in a certain direction, ancl a test object is noved along the are, and the limit determined at which it becomes invisible. The position of the are is then changed and the trial is repeated. This is done until a suffieient number of points have been determined to indicate the ontline of the field. The test object mostly employed is a white square one eentimeter on the side. If another is used it should be especially noted.

A better method for accurately deternining hemianopsia, is to fix the test object upon the are a certain number of degrees from its axis; then to revolve the are 
the test object describing a circle, and the patient noting where on this circle it appears and disappears.

The blackboard is msed to take the field of vision by having the patient fix a mark in the center, and moving a piece of chalk to and from this mark. A line joining the parts at which the chalk appears or disappears gives the

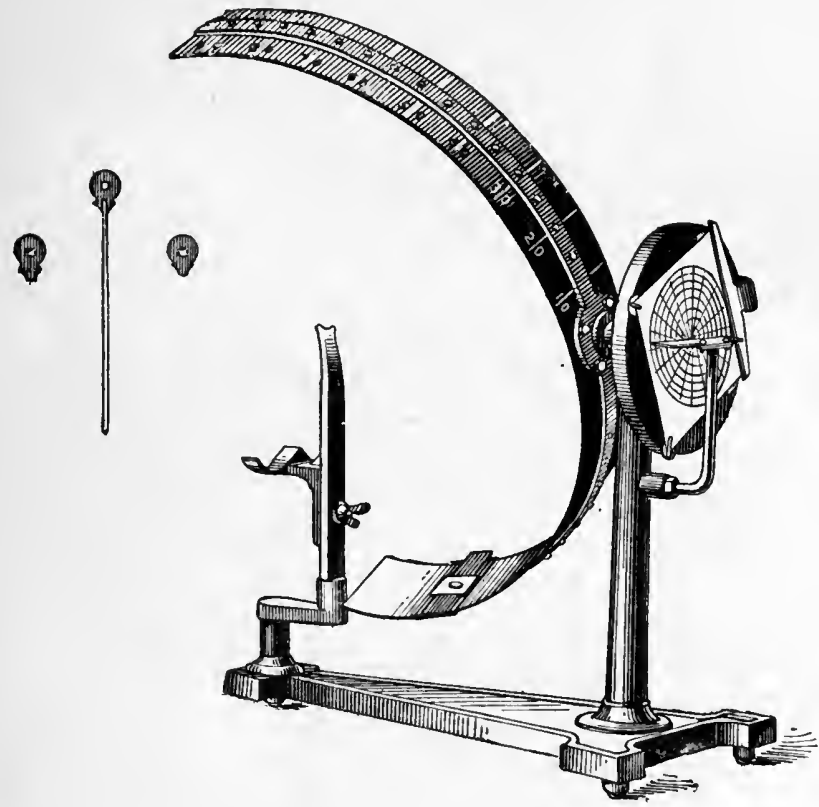

FIG. 8.-Registering perimeter.

outline of the field. The blackboard method is chiefly serviceable for central portions of the visual field. A modification of it, Bjerrum's method, is used for the aceurate study of slight defects in this region. Instead of the blackboard a 2-meter square of jet black eloth is placed 2 meters from the eye. Before this the test objeets, whieh 
are usually 1 or $2 \mathrm{~mm}$., lut may vary to $20 \mathrm{~mm}$. square, are moved by a black rod.

Taking the field of vision with the hand will usually be found most convenient and sufficiently accurate in practical work. To do this, the patient is seated facing the surgeon, so that the light shall fall equally on both. If the right eye is to be tested, the patient closes his left, and the surgeon his right eye, and each looks directly at the open eye of the other. While the eyes are thus directed, the surgeon carries his hand to one part of the periphery of the field of vision. He brings the hand towards the visual axis in a plane half way between himself and the patient mil the fingers are just perceptible to himself. Then moving the fingers or holding them still, he requires the patient to say which he is doing. This is repeated at all parts of the boundary of the field of vision. If the field be normal, the patient answers correctly whenever the position of the fingers is clear to the surgeon. If the field be limited in some one direction, the patient in that direction will require the hand to be brought closer to the visual axis to reeognize these movements.

In making this test, the surgeon superimposes the visual field of one of his eyes upon the visual field of the eye he is testing. A corresponding allowance must, of course, be made for difference in height of nose, or prominence of brow, or cheek; and, at best, the test is only to be regarded as an approximate one. But it is one that is easily made anywhere, and it will reveal the presence of any such condition as hemianopsia.

Hemianopsia, or half blindness, is the condition where objects are seen with distinctness in one-half of the field of vision, while in the other half there is partial or eomplete blindness. In hemianopsia, the blind half of the visual field is commonly separated from the seeing half by a vertical line. When the right half of the field is blind (the left half of the retina), it is called right hemianopsia; when the left lialf is blind (the righit 
half of the retina), it is caller left hemianopsia. If the right half of the field for each eye is blind (temporal field for right eye, nasal field for left eye), it is called right homonymous hemianopsia. Where the left half of each field is blind (nasal field of right eye, and temporal field of left eye), it is left homonymous hemianopsia.

Fig. 9 represents the field of vision in a case of right homonymous hemianopsia.

Homonymous hemianopsia depends always on some
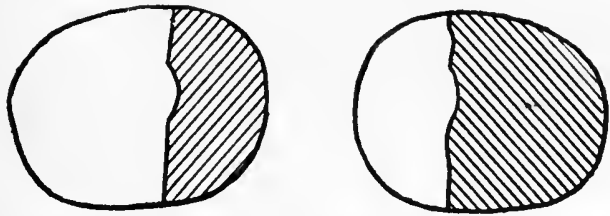

Fig. 9.-Field of vision in right homonymous hemianopsia, from apoplectic lesion involving left occipital lobe.

lesion back of the optic chiasm. Reference to Fig. 5 will show that it is back of the chiasm that the nerve fibers eoncerned with these portions of the visual fields come together. Right hemianopsia indicates a lesion back of the chiasm in the left optic tract, or in the eerebrum. Left hemianopsia indieates a lesion of the right tract, or cerebrum.

Occasionally, bitemporal hemianopsia oceurs. In this, the temporal half of each field (corresponding to the nasal half of each retina) is blind, indieating that the fibers which eross at the chiasm are injured, while the other fibers have escaped. 'This locates the lesion definitely at the optic chiasm. The other forms described are: Binasal hemianopsia, which might be due to symmetrical pressure on both tracts just opposite the chiasm, the erossing fibers escaping; and altitudinal hemianopsia, the loss of the upper or lower half of the field of vision. The last, if not due to detachment of the retina, or other lesion within the eye, may generally 
be regarded as a symptom of hysteria, or as one of the hysterical symptoms, which oceur in comnection with organic disease of the brain, but it might be due to a disease of a limited portion of the visual eenters.

In homonymous hemianopsia, the line dividing the blind from the secing portions of the ficld of vision is not always vertical. Its apparent inclination to the right or left may be due to an incorrect position of the head and eyes while taking the field. But in most eases it deviates towards the blind side near the fixation point, passing some five degrees or more from it and leaving the center of the ficld of vision unaffected. This seems to indicate that the part of the retina corresponding to this center of the field of vision, is supplied with fibers conneeting it witli both sides of the brain.

Hemianopsia may involve color-perception alone, so that one-half of the field of vision is simply color-blind, hemichromatopsia; or it may amount only to a loss of ability to recognize form as clearly in one-half of the field of vision as in the other. These varieties are called relative hemianopsia.

Hemianopsia from organic disease is usually permanent, and is absolute, light-perception being lost in the affected part of the field. But transient relative hemianopsia is not rare. In hemianopsia, the reaction of the pupil to light thrown upon the blind portions of the retina should always be tested. Its significance is given with the reactions of the pupils (Chapter III).

Sector-like defects of the field of vision are essentially like hemianopsia, except that less of the field is lost. 'They are broad at the margin of the field with an angle towards the center, but generally leaving central vision unaffected. When one-quarter of the field is lost, it is called a quadrant defect. Such a defeet may be relative or absolute. It may be due to disease or pressure acting only on certain portions of the optic tract, or radiating fibers; or may arise from discase of part of the visual cortex. 
Fig. 10 represents the appearance of the field in such a case.

Such a defeet should be sought for when sudden obseure interference with vision is complained of. The patient does not usually understand the nature of his
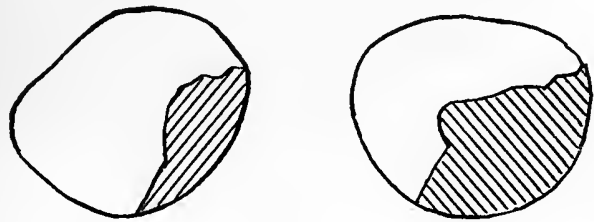

FIG. 10.-Sector defect of the field of vision from gunshot wound involving the left occipital lobe.

trouble; and, unless the visual field is tested, the existence of such defeet will eseape observation.

Scotoma.-A seotoma is an area of partial or complete blindness lying within the field of vision. The patient may notice it as a clond obscuring vision in a certain direction, positive scotoma due to disease of the retina; or merely as a space in which objects are not seen, negative scotoma due to conditions of the optic nerve, tract, or centers. The physiological blind spot is an example of the latter varicty.

A scotoma may be either relative or absolute-that is, vision in the part of the retina corresponding to it may be impaired, or entirely lost. Seotomas may affect any part of the field of vision. Generally they oceur in a single eye, or, when present in both, depend on separate lesions, even when symmetrically placed. They commonly depend on lesions in the eyes themselves, or of the optic nerve in front of the chiasm. True scotoma, due to a lesion of the retina or optie nerve, is fixed in position. It is to be distinguished from false scotoma, and the obseuration of vision that may arise from an opacity, a small blood-clot, or comnective-tissue formation, floating in the vitreous. A false seotoma changes its position with reference to the axis of vision, upon 
movement of the eye. It is positive seotoma that is liable to be confused with the shadow thrown by an opacity in the vitreous.

A form of special importance is central scotoma due to disease of the choroid and retina in the region of the macula, to toxie amblyopia, or to a special form of retrobulbar neuritis. Central scotoma presents special difficulties in the determination of its boundaries, because the impaiment of vision involving the fixation point prevents the patient from keeping his eye continually turned in a certain direction throughout the test. It is best mapped ont by having the eye direeted at first to a series of eoneentric cireles upon the black-board or a sheet of paper. The large circles must be seen outside of the

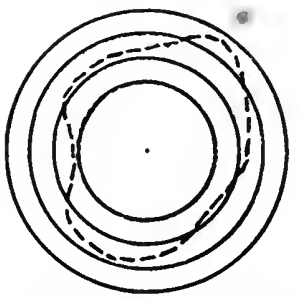

FI(i. 11.-Diagram of central sentoma from tobacco amblyopia, the actual size of the absolute scotoma at one meter. region of the scotoma, enabling the patient to keep the eye comparatively fixed. It is to be noted at what points the inner circles are obseured. These points being connected by lines give a map of the scotoma. This map may be revised by having the patient fix his eye upon it, and notice whether as it is moved from him the outline drawn disappears within the seotoma all at once. By repeated revisions, an accurate diagram of the scotoma is thus obtained. Figure 11 represents such a diagram.

Instead of coneentric rings we may use a group of dots. The patient sees these by a flash of light, and tells how many are seen and their position (Hess). Binocular fixation may be used where but one eye is affected. The patient fixes with the sound eye through some form of stereoseope, the defeetive eye being directed by a diagram similar to that presented to the sound eye (Haitz).

Central color scotome is detected by holding test wools of several colors behind a sheet of paper with an opening of 1 to $10 \mathrm{~mm}$. which the patient fixes. The patient is required to name the color's successively shown behind 
the opening. If the patient be allowed to look away from the opening, so that the impression is made upon some portion of the retina other than that affected (the macula), the color might be correctly named, although at the fixation point the color blindness were complete.

Ring scotoma is a form in which the center of the field of vision and the periphery remain normal, or less impaired than a ring-like area surromding the center of the field. It may possibly be due to a lesion affecting a special portion of the optic nerves or tracts, but generally it is caused by disease in the corresponding portions of the choroid and retina. Most frequently, seotomas are single, or arranged without symmetry; they may be permanent or quite transient. The latter will be referred to in connection with transient impairment of vision.

Narrowing of the field of vision is the most significant symptom of atrophy of the optic nerve and certain allied affections. It is ascertained by testing the field of vision with the hand or with a perimeter. Symmetrical narrowing points to primary atrophy of the optic nerve or to the effects of certain poisons. [See Quinin Blindness, Chapter XIII.] It is apt to affect the field of vision for colors before there is any notable change in the field for form. Irregular narrowing of the field, which may also affeet the field for colors more than the field for form, is indicative of secondary optic atrophy, or injury to the tracts as by glaucoma, optic neuritis, ete.

Inconstant impairment of vision after the eyes have for some time been used for close work, oceurring particularly in the latter part of the day, or when the eyes are used by artificial light in the evening, is caused by the sudden relaxation of the accommodation, after the ciliary muscle has been exerted until it is tired and will work no longer. It is apt to oceur in persons coming to the age when they require glasses for near work, or in young persons who have high hyperopia. It may oceur in such persons for a short time after eating a meal. 
Sudden brief blurring of the sight of one eye may be caused by pressure on the eyeball.

What is often spoken of as a blurring of the sight of one eye, is temporary hemianopsia, a blurring of one half of the field of vision, or a sector-like defect. It may be accompanied with the appearance of irregular figures and rays of light. This symptom is due to some disturbance of the visual tracts or visual centers. It commonly lasts for a few minutes, and, as it disappears, is followed by a severe headache, which may be confined to one part, or may spread all over the head. Frequently the whole of the field of vision is involved in such an obscuration. The attacks occur at irregular intervals, sometimes quite frequently, for years.

Temporary scotomas may be caused by the exhaustion of the retina from gazing so that a bright light will fall continuously on some one part of it. Such a scotoma is noticed after looking at the sun, or an electric light. It usually occupies the center of the field of vision, interfering with the perception of the object looked at; but it may appear in some other part of the field. When the object gazed at has decided color, the scotoma may have the complementary color. In certain conditions of the retina these scotomas may be made to change color by changes in the general illumination of the retina, or by pressure on the eyeball.

Inconstant narrowing of the field of vision, particularly diminution of the field while being tested, is indicative of hysteria or neurasthenia.

Muscæ volitantes (named from their apparent similarity to flying flies) are shadows cast upon the retina ly specks in the vitreous humor. Such shadows are thiefly noticed by myopic eyes. But something of the kind may be broight out in any eye by entoptic observa. tion; that is, by looking through a small pin-hole held one-half inch before the eye with a uniformly illuminated background, or by looking through a microscope with the field illuminated but unoceupied by any distinguishable object. Such shadows move with the specks causing them, 
when the eyes move; but do not preserve a constant relation to the visual axis or the point looked at. When the eye ceases to move they do not at once come to rest, but gradually settle up or down across the field of vision, until they reach the position of rest. The smaller and more delicate of these shadows have generally the shape of dots which may be arranged in strings, or of threads. The larger ones may assume any shape. The patient often becomes familiar with the shape of each and can promptly recognize it. The depth of such specks may be measured by using two pin-holes about half the width of the pupil apart. With these two overlapping luminous circles are seen, and in the overlapping portion the shadows are seen double. The distance between the double images is to the distance between the centers of the two circles, as is the distance of the speck in front of the retina, to the distance of the pupil in front of the retina, about $18 \mathrm{~mm}$.

The shadows of the retinal vessels may be rendered visible in the dark room by sitting in the position for oblique illumination of the eye, turning the eye strongly toward the nose, concentrating the light on the sclera with a convex lens, and then moving the lens slightly up and down, or back and forth. This shows the shadows of the larger trunks of the retinal vessels, except those that pass to the nasal side, the so-called figure of Purkinje.

The figure of the finer vessels which ramify in the region of the macula may be brought out by looking at a uniformly illuminated background through a pin-hole held close to the eye and moved rather rapidly in a small circle before the pupil. The movement must be kept up for a minute or so, and then a figure like that of Fig. 12 slowly makes its appearance.

The circulation of the blood in the retinal vessels may be seen by looking at a uniform light clond, or at the sky, through a rather dark-blue glass. Looking steadily' two or three minutes, small light oval bodies will appear, moving rapidly toward the center of the field, 
bnt before reaching it turning and whirling away again. These are colpuscles moving in the capillaries, sometimes retarded and elongated in narrow portions, then regaining their form and grliding rapidly onward. They are seen to follow definite paths, but the walls of the vessels through which they pass are invisible. For certain intelligent

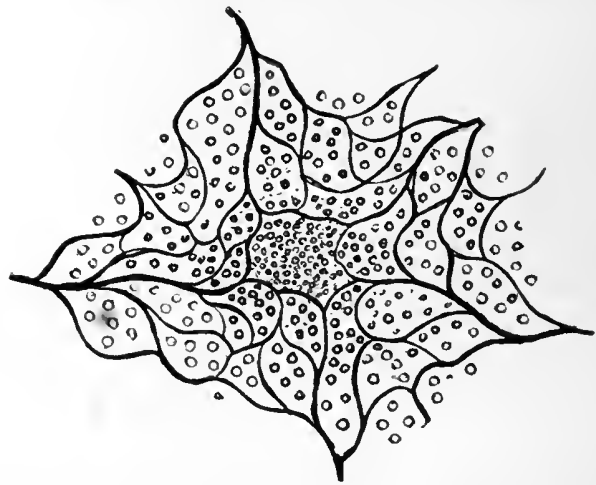

Fig. 12.-Arrangement of minute vessels at center of macula.

patients, it is possible to use the entoptic method, figures of the retinal vessels, and the retinal cireulation to study minute intracular lesions. Minute specks of the vitreous opacity may be studied entoptically, althongh not perceptible in any other way. Somewhat larger opacities after being located in this way may be recognized with the ophthalmoscope.

\section{SUBJECTIVE VISUAL SENSATIONS.}

The removal of an eye or the eomplete blindness of both eyes is not followed by a continual sense of darkness; and, in the absence of the normal stimulus to the visual centers, vision memories may be so vivid that it is diffieult to convince the patient that he does not still see. In some cases the sensations, partieularly of flashes of light, beeome quite annoying. They may indieate 
mechanical, circulatory, or reflex excitation of the visual centers, possibly proceeding from the stump of the optic nerve or some portion of the visual tract, but generally from other sources.

Flashes of Light.-These may arise from excitation of any part of the visual tract. The most common cause acting within the eye and giving rise to them is the irritation or involvement of the retina, in connection with acute choroidal inflammation. Where this is strictly localized, flashes may appear confined to a single part of the field of vision. Where the attendant hyperemia is more general, the sensations will be more widely distributed. They are most evident in complete darkness with the eyes closed, and, sometimes can be provoked at will by pressure of the lids on the globe. Their liability to be affected by pressure upon the eyeball is the means of distinguishing flashes of light due to ocular disease from those due to irritation of the nerve tracts or centers.

The abnormal visual sensations of ophthalmic migraine are found by most patients difficult to describe, yet the account given of them cannot be mistaken for anything else. They are sometimes compared to the quivering of the air over a heated surface; sometimes to the glimner of light in the water; at others to a stream or flood of water, proceeding from a particular part of the field of vision. Most frequently they are compared to fire-works; and a figure with re-entering angles like a fortification is very often alluded to. In a few cases they take definite recognizable forms, as that of a ball of fire, or even a human face or outline figure. Generally the appearances vary at different stages of the attack, passing away as a cloud of luminons mist, which may be the only appearance noticed. The feeling is, not that the part of the field of vision is blind, but that the real objects in it cannot be perceived through these subjective visual appearances.

Distortion of a Point of Light.-The conventional figure of a star, a central point surrounded by divergent rays, is based upon the fact that a point of light presents 
such an appearance to a great majority of eyes. This arises fronı stigmatism; mostly from irregular stigmatism. An eye free from this defeet sees a point of light simply as a brilliant dot.

The exact figure presented differs for each eye, as is demonstrated by comparing closely the position and the length of the rays of the right and left eyes used separately. It may also be made to vary by ehanges in accommodation. Any change in such a figure indicates a change in the stigmatism. This may be dependent upon changes in the cornea, as by corneal ulcer or abrasion, or in the erystalline lens, as before eataract.

Rings of light exhibiting different colors of the rainbow abont a point of light, as a lamp-flame, are usually a symptom of glancoma. They may, however, arise apart from glaueomathrough alterations in the cornea.

Multiple Images; Diplopia.-Monocular Diplopia.-When a single object gives rise to two or more impressions, we must, by closing one eye, ascertain whether this symptom exists when only one eye is used. If the diplopia be monocular, it eommonly depends on a defect of the refraeting surfaces, or media. It may indicate a dislocation of the lens, so that part of the light entering the eye passes through the edge of the crystalline lens, while another part passes alongside of it. Similar monocular diplopia is produced by looking through the edge of a spectacle lens or prism. Or it may arise from great inequalities in the lens itself, and fiom ehanges preceding cataract, or from the prisnatic action of facets in the cornea; from either of these latter causes the images notieed will be irregular and imperfect and will generally be of unequal distinetness.

Irregularities of the dioptric apparatus sufficient to cause multiple images can always be detected by careful objective examination. Where no such irregularities exist to accomt for monocnlar diplopia, it must be regarded as due to abnormality of the visual centers. In this form the images are commonly perfectly definite and regular, although not always of equal intensity. This 
variety of diplopia is probably in most cases only pretended. It may occur in hysteria, or as one of the hysteroid symptoms of organic disease of the brain. Its reality is very difficult to determine.

Binocular Diplopia.-Double vision, the one image belonging to one eye, and the other to the other eye, always indicates that the eyes are not both turned in the same direction, but that they squint. The subject is therefore considered mainly in connection with paralyses of the ocular museles and squint. (See Chapter VIII.)

But while such diplopia cannot exist withont squint, the squint may be present without diplopia. Althongh the eyes may be turned in different directions, one may not perceive any image of the object looked at, or the image may be so feeble as to be disregarded. In some cases the second imagre may be noticed at times and at other times be absent; and this may mean either that the squint is temporarily absent, or that the second image is for the time unnoticed. The diplopia is apt to be persistent and annoying where squint has occurred during adult life, if vision remains good in the squinting eye.

\section{COLOR VISION.}

None of the theories of color perecption, explained in works on physiology, is fully established. They are of much theoretie interest, but have not sufficient bearing on ordinary elinieal ophthalmology to justify repetition here.

Color perception is a more delicate function of the nervous apparatus of vision than the perception of form, and is more easily impaired or destroyed by disease.

Color perecption is most vivid at the ecnter of the macula, from which point the retina beeomes less sensitive, most rapidly for green, almost as rapidly for red, and more slowly for blue.

In general shape, the color fields resemble the field for form. With the usual one-centimeter square of color for a test object, the fields are about as shown in 
Fig. 13. Narrowing of the field is to be ascertained with colored tests, as impairéd field for form is studied with a white test object. Hemichromatopsia and color scotoma lave been referred to on pages 38 and 40 .

The appearance of objects as to color is largely a matter of contratst. Colored vision is a curions phenomenon, probably due to contrast. Blue vision, kyanopsia, is usually seen after the extrietion of senile eataract. The

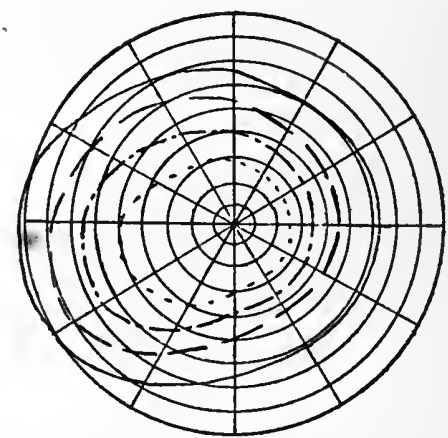

Fig. 13.-Fields of vision for eolors of the right eye. The dotted line shows field for green, the alternate dots and lines that for red, and the broken line for blue. The solid line is the field for form.

eataract has long given an amber or brown tinge to all the light entering the eye through it; and when it is removed the light seems to have the eomplementary color, blue. If the other eye is still the seat of cataraet, and therefore continues to receive the amber light, the contrast may keep the blue color noticeable for seremal weeks. But if the other eye receives uncolored light, the blue quickly fades away.

Red vision, or erythropsia, is notieed sometimes after cataract extraction or after exhausting discase, but more frequently after prolonged exposure of the eyes to brilliant illumination, as in high mountain regions and upon the Polar snow-fields.

Color Blindness.-Narrowing of the color fieldis may extend to their complete extinguishment. This is 
seen in comnection with severe diseases of the retina, optic nerves, or visual centers, and constitutes a variety of color blindness.

More frequently color blindness is a congenital defect which becomes apparent when the attempt is made to discriminate certain colors. In the grcat mass of cases the colors imperfectly perceived are red and green, this form of defect being known as red-green blindness. Cases occur in which the complementary colors, orange and blue, or yellow and purple, are not recognized, but these varieties of color blindness are very rare.

Something of the effect of color blindness may be produced by viewing objects through colored glasses. The objects still seem to have color, but not their proper colors, and the change is most noticeable with regard to the color of the glass used or its complementary color.

Congenital color blindness cannot be cured or overcome by any course of training. Its recognition is of importance in connection with certain occupations. Inability to recognize red or green may be extremely dangerous in a pilot or railway engineer. But on the other hand, persons who have imperfect perception of color learn to distinguish objects by their shading, and often excel in work devoid of color but requiring the exact appreciation of shading, as in engraving, or judging of black goods.

For practical purposes, the defect is to be recognized by the Holmgren test with colored wools. . For this the person to be tested is given certain skeins of colored wools called test-skeins, and required to select from a pile of miscellaneous colors, the skeins which most nearly match the test. The skeins from which the selcetion is to be made include some of the same color as the test, but of lighter or darker shades. These are called "mateh skeins." With them are mixed skeins of what are known as "confusion colors," colors which appear to the normal eyc entircly different from that of the test skein, yet are nost likely to be selected by the color blind as resembling it. 'The first test is one of very light green, 
to be matelied with skeins of the same hue; and such skeins the normal-sighted will select without hesitation. The color blind will, however, place with this a sage green, red, very light brown, or gray. With these may also be placed some of the mateh skeins. Or the person tested, while not actually placing the confusion colors with the test, may pick them up and consider them as elosely resembling it. Some of the confusion skeins, as the sage green, indicate an imperfect pereeption of color short of complete color blindness.

The first test is to detect the existence of color blindness of any kind. A second test shows whether it is red blindness, or green blindness. This test skein is of light pink, and should be matched by darker skeins of rose pink. But the red blind will incline to place with it dark blue or purple, while the green blind will choose the confusion colors, dark gray or green. A third test skcin, used in confirmation of the results obtained with the others, is a bright red. In red blindness it will be confused with dark greens or browns. In green blindhess it will be confused with lighter greens or browns.

Complete color blindness is rare, but incomplete eolor blindness is quite common. Among males about 4 or 5 per cent. fail to match accurately the test skeins, but among females only one-half of 1 per cent. make similar mistakes.

For positions in which colored signals have to be used and obeyed, nothing less than perfect eolor perception is admissible, because even those whose color perception is but slightly below the normal, will err in quick decisions as to signals seen throngh fog, snow, or smoke, or when in rapid motion.

Other methods to test the power to reeognize colors are : the placing of colored squares or eolored letters upon a black background and determining the distance at which the eolors ean be recognized. Or, in imitation of the signals in orlinary use, a lamp-flame at a considerable distance from the eye may be covered successively by glass of different eolors. Or letters of red and green may 
be placed on a gray background, where by a color-blind eye either the red or the green will not be noticed.

These latter tests are of practical value principally in detecting small central color scotoma, and for confirming the results of the tests with colored wools; or in demonstrating, to those not familiar with color blindness, the justice of decisions based on the wool tests.

\section{PAIN.}

Pain, although a symptom to which attention is pretty certain to be called by the patient, is one about which it is often difficult to get a clear and accurate impression. As to its severity the manifestations of suffering on the part of the patient are but an imperfect guide. One patient makes little complaint of pain that has entirely prevented sleep, while another manifests great excitement over pain of very moderate severity. Then too, the same morbid process, running in other respects the same course, will in one case cause severc pain and in another very little. So that the sympton cannot be regarded as indicating the severity of the disease causing it, as compared with similar attacks in other persons. Even in a given case it is liable to vary without close relation to the progress of the disease, although generally its marked abatement may be taken as a positive sign of improvement.

Different persons describing pain of the same kind differ greatly in the terms they employ, and a considerable acquaintance with such descriptions is necessary to their proper appreciation. In any case it is well to try to get the patient to describe his pain in more than one phrase.

Smarting and Burning; The Feeling of a Foreign Body.-Pain described as of this kind, may be usually regarded as dne to conjunctivitis. Sonctimes the patient will only characterize it as the fecling of "something in the eyc." It is liable to vary greatly in severity. It is aggravated by dust, exposure to air, light, or heat, or by the use or movement of the eyes. 
If due to an acute conjunctivitis it will be accompanied with noticeable hyperemia of the conjunctiva. But if it arises from chronie inflammation the conjunctiva may appear paler than normal.

Such pain, usually slight but sometimes severe, may follow the use of cocain even in the normal eye, being noticed from one to four hours after the use of the drug. It may also be produced by the use of atropin or one of the other mydriaties, in patients who have an idiosyncracy toward these drugs. A common exciting cause is eyestrain, partienlarly beginning presbyopia in persons who are trying to continue to work without glasses. In such eases, there is usually hyperemia at the time the pain is felt, but this may not be noticed, and only the pain complained of. Such pain may also be due to a foreign body in the cornea or conjunctival sac, or to the misplacement of an eye-lash.

Stinging is a term which may be used to describe the same sensation as is frequently called smarting or burning, and will then have the same significance. Or, it may be used to indicate a totally different form of pain, a sudden lancinating pain due to cramp of the ciliary muscle, or neuralgie in character.

Aching may be a sort of extreme spontaneous soreness, as in inflanmatory discase with swelling and tension of sensitive parts; or it may be a nerve pain of the same character as headache, sometimes described as "a headache in the eyes." The inflammatory ache may be spoken of as burning, especially where there is conjunctival or corneal disease present. Its significanee is mainly as evidence of severe tension of the parts from inflammatory exudate. It may be severe in corncal disease, but is more apt to be severe in iritis or eyclitis or glancoma. Aching of the eyes, independent of inflanmation, most frequently arises from eve-strain; but sometimes through choroidal congestion, and sometimes throngh eramp or tire of the ciliary muscle.

Neuralgic Pain.-This may be described as shooting, aching, or burning, and may be a manifestation of 
either functional or organie nerve discase. In cases of ophthalmic zoster, or other serious disease of the ophthalmic branch of the fifth nerve, it is liable to be extremely severe and persistent; and, in such cases it requires care to discriminate between pain having such an origin, and that which might be attributed to the inflammatory conditions usually present in such cases.

Fulness or Discomfort of the Eyes.-Many cases of eye-strain present more or less constantly this symptom or sensation, only occasionally rising into an actual headache.

Aching Outside of the Eye.-It is frequently stated by the patient that the eyes are free from pain, but that there is aching or pain back of them. This frequently means that the pain is really in the eyeball; and not upon its surface or in the lids; that it has a different location from that produced from something getting into the eye.

But, in some cases it seems fair to refer such pain to the region of the orbital museles or their attachments. Any severe pain affecting the eyeball is likely to be referred to adjoining parts. Thus in glaucoma or iritis, the pain may be complained of as situated mainly in the brow or chcek. In such cases, however, the history generally shows that it started in the eye and then spread to the adjoining parts.

Headache. - It ought to be universally recognized that eye-strain is the common cause of headache. Aside from headaches produced by fever, toxemia, and organic disease of the brain and its membranes, eye-strain is almost invariably a factor in the produetion of headache. The headache of eye-strain is not of any special character. It may be constant or intermittent; slight or severe, felt only on the use of the eyes, or felt after their use, continuous, or reeurring irregularly, or at certain intervals. It is aggravated by many other eauses, such as hunger, exhaustion, exposure to heat or eold, or indigestion ; or it may seem entirely independent of other influenees. In the majority of eases eyc-strain is not the only factor in the 
production of headache. But it may be the only factor of practical importance because it alone can be removed, and its removal will give relicf. Such headaches are generally felt in the frontal, temporal, or occipital regions. Rarely are they most severe in the vertex.

Loss of sensibility to touch results from disease of the centers, trunk, or peripheral branches of the fifth nerve. It is often not noticed by the patient. It is discovered by comparing the sensibility of one eye with that of the other, as by tonching one cornea and then the other with a pledget of absorbent cotton rolled up to a point. The extent of the reflex produced by the touch of the cotton on the cornea is to be noted, as well as the distinctness of sensation. Decided diminution in the sensibility of the cornea is found in connection with malarial neuralgia (brow agne), in herpes, where it may coexist with intense pain, and in glaneoma.

Absence of pain is notable in some discases where it might be expeeted to be present. Thus, severe inflammation of the optie nerve and retina, or plastic inflammation of the ehoroid, may run its course without giving rise to any pain whatever. Iritis is usually extremely painful, but some eases are quite free from pain, until the disease has existed for many days or weeks, and has eaused the firm adhesion of the iris to the lens over a large part of the surface of contact. Cataract is quite painless, and complaints of pain about the eyes should always suggest in old persons the possibility of glancoma. (See Chap. X V.)

\section{CHAPTER III.}

EXTERNAL EXAMINATION OF THE EYE; OBLIQUE ILLUMINATION; THE PUPIL.

TuE examination of the ere should begin by eareful inspection of the lids and neighboring parts in a good light 
-at first without tonching the eyes or in any way interfering with them. This inspection may begin with the lids closed, afterward continuing with them open, and should include careful comparison of the two sides of the face. The lids may present some congenital deficiency - coloboma of the lids-which may leave part of the eyeball continuously exposed. If the lids be of normal formation, inability to close them entirely will be due to loss of power in the orbicularis muscle. This is liable to arise from disease of the facial nerve. The portion distributed to the orbicularis is frequently involved with disease of the oculomotor nerve without the involvement of other portions of the seventh or facial nerve.

Prominence of the Eyebal1.-Pushing forward of the eyeball eauses separation of the lids, and sinking of the eyeball in the orbit narrows the space between the lids. Opening the eye widely causes an appearance of protrusion, while narrowing of the palpebral fissure produces apparent sinking of the eyeball in the orbit. 'The actual prominence of each eye should be carefully noted. The prominence of the center of the cornea is measured with the exophthalmometer. This is placed against the outer margins of the two orbits, and gives the number of $\mathrm{mm}$. that the cornea advances in front of the line joining these two points. The simplest form of the instrument, the proptometer, consists of a flat scale hollowed out for the prominence of the nose and eye. At either end are millimeter divisions running the long way of the proptometer. The seale is pressed against the outer angles of the orbits. Then sighting along the parallel lines of the side of the eye examined, it is noted where on the scale the most prominent point of the eornea seems to fall. The protrusion of the cornea in front of the line joining the outer angles of the orbit varies from 8 to $20 \mathrm{~mm}$. under normal conditions.

The Lashes. - The position and regularity of the lashes should be noted. A marked deformity of the individual cilia, inequality of length, and displacement 
generally indicate long-continued inflammation of the margin of the lids. Considerable displacement of the row of lashes inward-trichiasis-or similar displacement of the whole lid-margin, so that the lashes turn in against the eyeball-entropion-commonly indicates chronie disease of the conjunctiva. Displacement of the lid-margins outwarl-eetropion-may arise from eicatricial contraction of the skin of the lid, or from relaxation of the orbieularis muscle.

Oceasionally the eilia are found to support nits or ova of the pediculus pubis.

Movements of the Lids.-The lids may exhibit involuntary movement, from slight fibrillar twitehing in the middle or temporal portions of the lower lid to a general spasm (blepharospasm), which may prevent their being opened for a considerable period of time. It is to be noted whether the patient ean open the lids to the normal extent, and equally on the two sides. If not, ptosis is present, and it should be observed whether the tendeney of the lid to droop ean be overeome by increased museular exertion, and whether it depends on binding down of the lid, or apparent loss of museular power. If the inability to raise the lids appears complete, the surgeon should notice whether the attempt to raise them eauses any retraction of the upper lid, just beneath the brow. Any retraction at this point indieates some power in the elevator of the lid. If, however, the movement of the lid depends entirely upon the museles of the brow and forehead, special effort to raise it will be attended rather by the obliteration of any groove in this situation. Where it is suspeeted that paralysis of the elevator is pretended, this groove shonld be watched while the patient is direeted to look upward.

Abnormal retraction of the lids and failure of the upper lid to follow the movements of the eyeball when it is turned down are signs of exophthalmie goitre. It should be remembored that the instillation of eocain causes an increased retraction of the lids, and physo- 
stigmin (eserin) causes fibrillary twitehing of the lower licl.

When the lids have been opened, the position of the lacrimal puneta should be ascertained, and whether the tears are properly carried away, or accumulate at the lid-margin.

Motility of the Eyeballs.-This will frequently need to be studied by the special tests deseribed in Chapter VIII, but it should also be considered in the routine examination. The patient is first asked to look in different directions and the movements of the eves watched. Then he may be requested to look stearlily at the end of a peneil, helil a half-meter in front of the eyes and moved into different parts of the field of vision, while the surgeon observes whether both eyes properly follow it in all directions. Especially should it be noticed whether the eyes steadily fix upon it near the limits of the visual field, or whether they here begin to oscillate-an indieation of weakness of the muscles brought into use.

The pencil should then be held directly in front of the face a little lower than the eyes and gradually brought nearer, until it is so close that they can no longer be turned in enough to enable both to fix upon it. This determines the power of convergence. At the near point of convergence one of the eyes remains fixed upon the object and the other turns ontward. With nornal convergence this oceurs only when the fixation-point is bronght within four inehes of the eye. The inability to execute these movements points to weakness of the muscle or museles upon which such movements depend.

Eversion of the lids is required for their complete examination. The lower lid is turned out by placing a finger "pon the skin near its free margin, and drawing the lid-margin down with a slight pressure of the fingertip, the eye being at the same time rolled strongly "pward. A little movement of the finger-tip, changing the direetion of the traction, serves to expose in succession all parts of the lower sae of the conjunctiva. 
Eversion of the upper lid is really a folding of the lid upon itself. The method of doing it may be understood from Fig. 14. The lid must first be drawn out from beneath the brow, far enough to give room for the folding. On this account the eye must be turned strongly down, the patient looking at the floor throughout the whole manipulation, because thus the elevator of the upper lid is relaxed. The lashes and lid-margin are lightly seized between the thumb and forefinger and the lid drawn gently out and down, as shown in Fig. 14. With the other hand, the end of a probe, lead-pencil, or

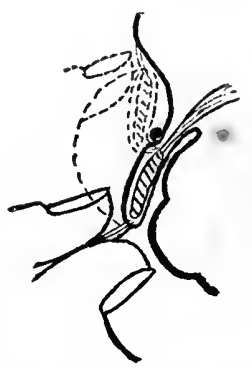

Fig. 14.- Eversion of the upper lid. The dotted are shows where the lid-margin is carried up, and the dotted lines above show the position in which the lid is held everted.

stiffuess of the normal cartilage will keep the lid from unfolding and slipping back.

The critical point in this little manipulation is when the tension made by thumb and finger is relaxed, and the folding attempted. If at this time the patient looks up, or if the probe is placed on the eartilage (instead of at its upper margin), so that pressure of the probe prevents the sweeping over and tuming out of the cartilage, the eversion becomes impossible. If the lid is thickened and the cartilage rounded, as by chronic inflammation, it becomes diffienlt to evert the upper lid, and sometimes impossible to keep it everted. With a normal lid and the full co- 
operation of the patient in looking steadily down, the eversion is easy and painless. The beginner should place the probe about parallel with the upper margin of the cartilage, where it can remain until the eversion is fully accomplished. The expert will often dispense with the probe altogether, using the tip of a finger instead.

Inspection of the everted lids reveals the state of the conjunctival vessels, the smoothness or roughness of the surface, the existence and character of exuclate, the presence of a foreign body, or the localized grayish discoloration of chalazion. Roughening of the, surface by minute points that do not appear to differ from the general substance of the conjumetiva, a roughening that is comparatively uniform like that of sand-paper, is often called "granulated lids." It is entirely different from true granular conjunctivitis or trachoma, in which the protruding masses are larger, and set in an abnormally red, thickened conjunctiva, like small grains of partly cooked sago or tapioca. Sears may also be found on the lids, but a normal lack of vessels near the center as compared with the redder ends of the lid, caused by the pressure of eversion, should not be misunderstood.

Eversion of the upper lid usually does not expose the whole upper sae of the conjunetiva. To examine the retrotarsal fold it may be necessary to turn the eye strongly down, hold the lid away from the globe without eversion, and look up into the sac from below. For this purpose some form of lid elevator is neeessary, such as is

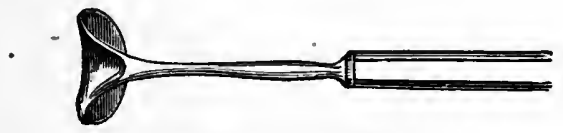

FIG. 15.-Lid elevator.

shown in Fig. 15: 'The edge of this instrument is gently insinuated between the lids, and the upper lid retracted with it, and held away from the eyeball. Its use is sometimes necessary for the inspection of the eyeball itself, as in young ehildren who resist the examination, or when as 
after injury or in purulent conjunctivitis the swelling of the lid prevents its nomal opening or eversion.

The study of the intra-oeular tension is described in Chapter X V.

\section{HYPEREMIA.}

Hyperemia about the eyes may involve one or more of three distinct vascular regions. The first of these is the lid-margins. Redness, usually with swelling, of the lid-margins is symptomatic of inflammation in the hairfollicles or glands of these portions of the lids, and usually arises in connection with chronic congestion or inflammation of the conjunctiva. Where such hyperemia is persistent or frequently occurs, some persistent canse should be sought. This may be a tendency to catarrh, affecting the conjunctiva in conmon with other mucous membranes, as with the so-called strumous diathesis. More commonly it is a persistent congestion due to eyc-strain.

Hyperemia of the conjunctiva may exist without any considerable discharge. There is increase in the size and apparent number of vessels, and general redness of the membrane. The conjunctival vessels come forward from the bottom of the conjunctival eul-de-sac above and below the eyeball. Here the largest trunks become visible, dividing as they pass forward, some to be distributed to the bulbar, and some to the palpebral conjunctiva and subconjunctival tissue, subdividing and growing smaller as they approach the cornea and free margins of the lids. The tissue to which this system of vessels is distributed is thickest at the cul-de-sac, and thins out forward, especially on the globe. Hyperemia of this system of vessels therefore shows the greatest inerease of redness in the retrotarsal region, the redness fading out into the normal color, as we go forward toward the cornea or toward the free margin of the lid. The increased redness is most apparent back from the cornea in the region of the cul-de-sac. This sort of ocular hyperemia is represented in Fig. 16. It is frequently noticed in aente general disease. It may be present with fever from any cause, and 
attends certain diseases such as measles. It may be provoked by exposure to an atmospherie irritant, such as dust, smoke; irritant gases, etc. It may mark the first effects of a specifie irritant, such as the virus of gonorrhea. It may be reflex, as from irritation in the nose, or may be produced by a foreign body imbedded in the cornea and scratching the lid.

Localized Conjunctival Hyperemia.-Prolonged exposure to the light and the heat of the sun, especially reflected from surfaces of white sand or water, or to the light and licat of a hot fire is liable to produce hyperemia, sometimes with swelling of the part of the conjunctiva

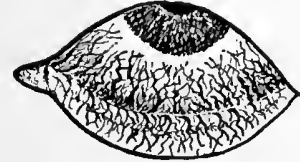

Fig. 16.-Conjunctival hyperemia.

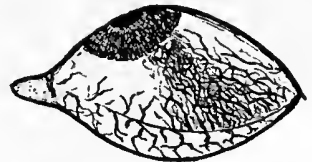

FIG. 17.-Hyperemia of phlyctenular conjunctivitis.

direetly exposed-that is, the conjunetiva of the globe in a triangular area to the outer and inner sides of the cornca.

Hyperemia affecting some particular portion of the conjunctiva of the globe and the adjoining inner surfaces of the lid is usually due to traunatism, or the contact of some chemical irritant or hot substance. Portions of the lower eul-de-sae are most liable to be thus affected.

Hyperemia characterized by the enlargement of the vessels rumning from one part of the cul-de-sae forward upon the globe, usually to the corneal margin and sometimes extending upon the cornea, is significant of plylyctenular disease. This form is represented in Fig. 17.

Pericorneal Redness.-In contrast with conjunctival hyperemia, which is most pronounced at the periphery of the sclera, and fades out as the cornea is approached, is the redness due to the enlargement of the minute vessels which encircle the cornea in the scleral 
margin, and furnish to the non-vaseular cornea a large part of its nutrient supply. These vessels are supplied mainly by the deep arteries and empty mainly into the deep veins of the eyeball, althongh they anastomose freely with the peripheral loops of the conjunctival vessels. They have intimate connections with the vessels of the iris and the ciliary body. Normally they are quite invisible; but when dilated they canse a distinct pink or rosy zone, more or less completely encircling the cornea and from 3 to $5 \mathrm{~mm}$. in width (Fig. 18).

Such hyperemia is indieative of inflammation of the cornea, iris, or eiliary body, or all of these. When severe,

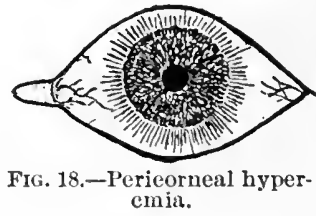

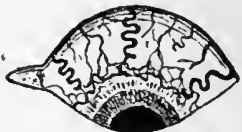

FIG. 19.-Eularged veins in chronic glaucoma.

it involves the whole eirele of ressels, but may be most noticeable in some one direction.

It is a valuable symptom pointing to a foreign body in the cornea, when such foreign body has been lodged there for sonie days. In corneal uleer the pericomeal redness has a similar relation to the seat of the lesion. In iritis an ineomplete zone of pericorneal redness indieates a portion of the iris in which the inflammation has been more violent and subsides more slowly, such an incomplete zone being usually seen during the decline of the disease.

Deep Hyperemia of the Sclera.-This may consist in a general enlargement of the vessels that rm eomparatively straight toward the cornea, and whieh lie deep in the tissue; in eontrast to the eonjunctival vessels, which are more tortnons, and move freely with the conjunctiva when this is rubbed about with the lid. The involrement of the seleral vessels indieates inflammation or eongestion of the interior of the eyeball.

Another form of scleral hyperemia is that in which the 
smaller vessels over one or more isolated patehes of selera are involved along with the straight large trunks of that region, giving a patch having a pink or deeper purplish red color. This appearance indieates a local inflammation of the selera.

Enlargement of the Sclera1 Veins.-Enlargement of the seleral veins (Fig. 19) is still another form of hyperemia. The prineipal trunks of these vessels emerge from the seleral, 4 to 10 millimeters back from the corneal margin, and pass backward over the globe. One or more of them ean usually be detected in the normal eye. In the condition now referred to they become greatly enlarged, prominent, and connected one with another by a a network of large vessels surrounding the cornea, a little distance back from it. This kind of venous eongestion is indieative of ehronic inerease of intra-ocular tensionglaueoma.

Mixed Forms of Hyperemia.-The typical varieties of hyperemia above deseribed are often seen, but in many cases two or more of them are blended together. Thus, a foreign body in the cornea, by seratehing the palpebral conjunetiva and by reflex influence, will pioduee an active hyperemia of the eonjunetiva, while its presence in the cornea for a few hours will also give rise to hyperemia of the pericorneal zone. Severe iritis, particularly in its early stages, is likely to be aceompanied with conjunetival hyperemia. Glaneoma in its inflammatory forms includes an inflammation of the iris and a marked pericorneal zone of enlarged eapillary vessels. In general, any severe inflammation will probably cause some extension of hyperemia beyond the traet of vessels whose involvement would be typieal of the disease.

\section{SWELLING.}

Swelling, being due to the increase in the size of the vessels or the escape of exuclate from them, is neessarily elosely allied to hyperemia, but either may exist without the presence of the other being noticed. 
Swelling of the Lids. - It will be remembered that the cellular tissue of the lids furnishes one of the common localities for serous exudation in chronic renal disease, or in acute general edema from any cause. The extent of the swelling in such cases varies with the effect of gravitation, according to variations in the position of the patient, being greatest after lying down. Great swelling of the lids may result from emphysema, due commonly to wounds of the nose. The infiltration by air is recognized by the softness and crackling of the tissne under pressure, and increase of swelling by blowing the nose.

In other cases general swelling of the lids is inflammatory ; and the focus of the inflammation causing it may be either in the lids or in the neighboring structures. A very small focus of inflammation may lead to great general swelling of the lids through interference with venons currents caused by pressure or thrombosis.

General swelling of the lids may also arise from interference with the orbital cireulation by pressure, from a focus of inflammation or a new growtli deep in the orbit. A gain, great and sudden swelling of the lids vithout other obvious reason should lead to the suspicion of grave intraocular disease. The loose tissue allows the lid to swell rapidly without much pain. As the swelling subsides the skin beeomes wrinkled.

A somewhat chronic, firm swelling of the lids has been designated solid edema, or lymphoid infiltration. It aceompanies certain ob:cure general conditions, as Hodgkin's discase, in which connection it may be of diagnostic importance.

Localized swelling of the lids may indicate a focus of inflammation such as a small ahscess, but a distinet tumor is more frequently chalazion. Occasionally, small eystic tumors form in connection with the glands of the skin in this region. Dermoid eysts occurring in the region of the orbit-one of their favorite positions-may oecasion swelling of the lids. Swelling of the lids may also be dine to deeply seated growths, such as grummia of the periostem of the orbit, osteoma, fibroma, or sarcoma 
of the orbit, or to empyema of the frontal or ethmoidal sinuses. Swelling of the nasal extremity of the lower lid and of the side of the nose and adjoining parts is frequently caused by obstruction of the lacrimal duct. 'The dilatation of the sac alone may cause a noticeable tumor, or inflammation around the sac may be added to the dilatation.

Prominence of the Eyeball ; Exophthalmos.Apparent prominence of the eyeball may be due simply to the wide opening or retraction of the lids, or such retraction may exaggerate a real prominence, as in exophthalmic goiter. Elongation of the eyeball in high degrees of myopia makes it appear prominent. The nature of the trouble here becomes more evident when the patient turns the eye strongly toward the nose. Actual forward displacement of the eyeball may result from paralysis of one or more of the ocular muscles. Complete paralysis of the oculomotor nerve always produces some such displacement. It may be due, also, to actual swelling of the orbital tissue, either from inflammation (orbital cellulitis), from hemorrhage, from new growth, or from venous stasis (see Chapter XVI).

Swelling of the Conjunctiva.-Swelling of the conjunctiva, affeeting the palpebral portion, shows itself by the thickening of the lids. Swelling of the ocular conjunctiva, if moderate in amount, is seen chiefly back from the cornea; but if more extensive it involves the membrane up to the corneal margin, and may cause it to rise around the cornea like a wall, or even quite overhang the corneal margin. This is the condition known as chemosis. It is apt to arise in violent conjunctival inflammation, such as severe purulent conjunctivitis, and from severe injury or very acute inflammation within the eyeball. The swelling of chemosis is produced by a serous exudation, and the thickened conjunctiva is comparatively transparent. Another form of thickening, as abrupt as chemosis, but much less in height, flattened rather than rounded, and often exhibiting a peculiar appearance of radiating pleats, attended with little or no 
swelling in other parts of the conjunctiva, is characteristic of vernal conjunctivis. A somewhat similar appearance without hyperemia is not rarely seen in the colored race, as an anomaly.

Great swelling of the ocular conjunctiva, with cellinfiltration, occurs in trachoma and diphtheritic conjunctivitis, or may mark a late stage of purulent conjunctivitis.

\section{CONJUNCTIVAL DISCHARGE.}

From the healthy conjunctiva, the slight secretion and loosened epithelium are washed away by the tears; and very considerable increase over the normal secretion, if attended with a proportionate increase of the tears, may be removed in the same manner without attracting attention, or showing any, sign upon casual examination. When this is the case, the pathological discharge may only become evident when, after the lids have been closed during sleep, the evaporation of tears leaves a deposit of such discharge upon the lid-margins, or causes them to stick together in the morning. Such adhesion of the lids will often reveal the occurrence of a discharge when no other evidence of it can be detected.

Conjunctival discharge, if moderate in amount, consists largely of an increase of the normal constituentsmucus and epithelium-but as it increases in amount it includes an increasingly large proportion of pus-cells. No sharp line can be drawn between mucous or catarrhal and purulent discharges, one rumning gradually into the other. In specific purulent inflammation the discharge may be extremely profuse. In a few cases the exudate becomes croupous or diphtheritic in character. A deposit upon the surface which, when removed, occasions bleeding, but which can be removed without great force, is termed croupous. The diphtheritic deposit is more intimately incorporated with the tissue, and cannot be separated from it. Where diphtheritic deposit occurs, the escaping discharge, instead of being purulent, is commonly scrous or flocculent. It must be borne in mind 
that recent investigations show that a diphtheritic deposit may occur in the conjunctiva quite apart from the specific disease-diphtheria-and that true diphtheria may involve or even destroy the eye without any characteristic diphtheritic deposit.

Microscopic Examination.-In general, the microscopic or bacteriologic examination of a conjunctival discharge furnishes more definite information regarding the true character of the case than the macroscopic appearances.

The discharge is taken from the conjunctiva with a loop of platinum wire sterilized by passing through an alcohol flame, and placed on a clean cover-glass. Another cover-glass is placed over this, and the two firmly pressed together to diffuse the discharge in a uniform film over them. Each glass is now grasped in a spring elip that will prevent any mistake as to which side the film is upon, and allowed to dry. A few drops of the stain are then placed on the film for the required number of minutes, and it is afterward washed with distilled water, and decolorized if desired. It is then thoroughly dried and mounted with a drop of Canada balsam.

The most useful stains are: Strong alcoholic solution of methylene-blue, 30 ; one per cent. solution of caustic potash, 100. This stains most bacteria in ten to fifteen minutes.

Anilin oil, 1 ; distilled water, 100 ; gentian-violet to saturation. Add alcohol (3 parts), and filter. This also stains most bacteria satisfactorily.

For the Gram method, after staining for ten to fifteen minutes with the above gentian-violet, place the film for one or two minutes in-

Iodin, 1; potassium iodid, 2; distilled water, 300 .

Then wash it, and place in alcohol until the color is nearly gone; dry and mount.

The most conclusive study of the bacteria of the conjunctiva is made by inoculating with the matter on the loop, tubes of agar, agar-serum, and blood-scrum, and studying macroscopically and microscopically the cultures thus obtained. 


\section{OBLIQUE OR FOCAL ILLUMINATION.}

The patient is placed facing the surgeon and in such a position that the light shall shine across his face, preferably from the side of the eye to be examined. The examination is commonly made in a dark room, using strong artificial light concentrated upon the eye by a strong lens, focal illumination. The relative positions of the lampflame, $L$, the lens, and the patient's eye, $E$, are shown in Fig. 20. 'The lens should be held so as not to focus perfectly the light upon the eye, for a uniform diffused illumination is

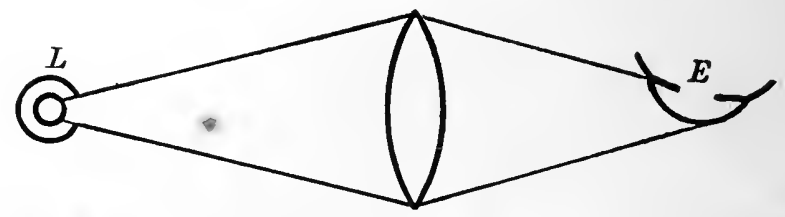

FIG. 20.-Manner in which the peneil of rays should be focussed on the eye for oblique illumination.

better than one which varies in intensity in different parts of the lighted area, as completely focussed light usually does. Where oblique illumination is resorted to with goor daylight, as by placing the patient with his side to a large window, but little is gained by the use of the condensing lens. Using the lens it is possible by varying its position to throw light first on the surface of the cornea, leaving the iris and pupil in comparative shadow, then to throw the light upon the iris, leaving the comea in shadow. This is a great aid in determining the location of a particular point, when there is considerable opacity of the cornea.

Many of the appearances studied by focal illumination require for their full appreciation the use of a magnifier. This may be an ordinary convex lens of ahont $20 \mathrm{D}$. (two inches focal distance); or a stronger lens, often called a "corneal loupe," may be employed. The lens is held at slightly less than its focal distance from the eye to be examined, the surgeon placing one 
of his eyes in line with it at a eonvenient distance. The compound microseope has also been adapted to the examination of the eye by oblique illumination, by giving it a very large objective, and mounting it with the proper facilities for adjustment. With such magnificrs only monocular vision is possible.

To gain the important advantages of binocular vision, a binocular magnifier must be employed. This consists essentially of two convex lenses joined at an angle, the right eye looking through one, the left through the other. With the lenses are combined prisms which lessen the required effort of convergence. 'The form most readily

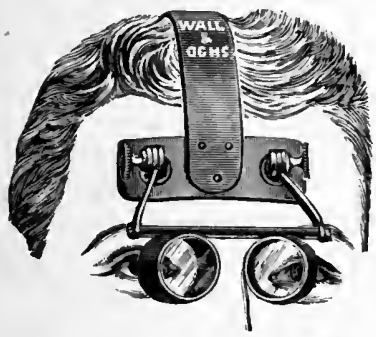

Fig. 21.-Binocular magnifier supported by a spring steel headband, for examination of the eye, and the performance of eertain operations.

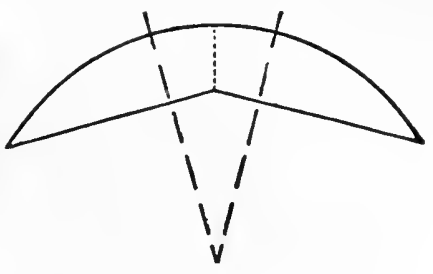

Fig. 22--Jaekson's binocular magnifying lens. The broken lines show the direetions of the two lines of sight meeting in the point looked at.

used is shown in Fig. 21. A form more easily earried in the pocket and quite as useful when one has acquired the mastery of it is shown in Fig. 22.

With either form, the magnifier must be held with the line joining the centers of the lenses parallel to the line joining the centers of the surgeon's pupils. It is well to start with the magnifier quite close to the patient's eye, and after binoeular vision has been seeured, to withdraw the lenses almost to their focal distance from the eye, to get the benefit of their full magnifying power.

Focal illumination is employed to diseover foreign bodies in the cornea or anterior chamber, or upon the 
iris; to study opaeities or ulcerations of the cornea, and to determine almormalities of the iris.

Most opacities of the cornea thus illuminated give rise to a gray appearance. An are of gray near the upper and the lower margins of the comea, but with some clearer cornea between it and the sclerotic, is the so-called arcus senilis. As age advanees, the ares extend until they form a complete ring. This appearance is not confined to the very old, but may occur even in very early childhood. It is more apt to occur early, in the negro race. It has no definite or special significance, either as an evidence of the state of the general nutrition or of the cye itself.

Opacities in the cornea vary in proportion to the depth of tissue affected, and the extent of its departure from normal. When wlight and superficial, an opacity is called a nebula. If of limited extent and nore decided, so that it ean be detected by ordinary inspection, but yet does not entirely hide the iris behind it, it is a macula. If still denser, so that the structure and color of the iris camnot be scen through it, from its whitish-gray color it is called a leucoma. Opacities of the cornea containing points of black or brown discoloration generally mark the site of a former perforating ulcer, in the healing of which the iris has become entangled in the cicatrix, and remains adherent to it, constituting an adherent leucoma.

The reflections from the surface of the cornea should be carefully observed, the position of the eye with reference to the light being varied, so as to get the reflection of the source of the light from all parts of the eornea successively. Any irregularity in the surface, as from a foreign body or a corneal ulcer, will become evident in the irregularity of the reflection. Very minute foreign bodies or abrasions may be covered by the corncal mucus, so as to give rise to no irregularity in the reflection until the cornea has been gently wiped with absorbent cotton (sce Chapter XVII), when even the most minute irregularities become manifest. Distortions of the corneal surface, as by cicatricial changes following previous inflam- 
mation, cause, not the sharp break in the reflcetion produced by recent injury, but a distortion of the shape of the reflex. The cornea being normally flattened toward its periphery the reflections are always larger there than near the center. Distortions of the corneal reflex are best studied with the Placido disk, which consists of alternate circles of black and white. It is held before the eye to be examined, the patient being placed with his back to the light and the observer's eye at the opening at the center of the disk.

The symptoms presented in the anterior chamber are discussed in Chapter XIV.

Inspection of the Iris.-Oblique illumination best reveals any inequalities of thickness or irregularity of structure in the iris, although differences of color, especially those indicating hyperemia, are best seen by direct examination in elear daylight. Thickening may be due to parenehymatous inflammation, in which case the iris will be devoid of reflex and altered in color, from blue or gray toward greenish by the excess of blood in it, and the swelling general; or there may be sharply localized swelling of deeidedly different color from the surrounding iris, which indicates a new growth, as gumma, or tuberele usually accompanied with iritis, or sarcoma which grows at first slowly and without evidenees of inflammation. Cysts of the iris are usually still slower in development, and of rounded outline.

\section{THE PUPIL.}

By oblique illumination, the pupil may be made to contract when the light is thrown more direetly into it ; or dilate as it is thrown in more obliquely. Slight departure of its form from a perfect eirele and slight inequalities in the size of the two pupils are common. Decided irregularity of the shape of the pipil is usually abnormal. Most frequently it is due to adhesions of the iris, either to the cornea, anterior synechia, or to the capsule of the lens, posterior synechia. 'Anterior' synechia generally occurs in connection with adherent lencoma, and the pupil is often 
partly hidden by the opacity of the cornea when looked at from in front. But ly throwing the light quite obliquely into the eye, and placing the eye of the observer near the direction from which the light comes, the pulling forward of the adherent portion of the iris can be diseovered. Posterior synechia becomes most evident when the pupil is dilated, either by the use of a mydriatic or by examining the eye in the dark room.

The size of the pupil is not usually so important as its reaction. It should be measured both in a strong light and in as feeble illumination as will allow of an aceurate measurement. The measurement may be made with an ordinary millimeter seale held as close as possible

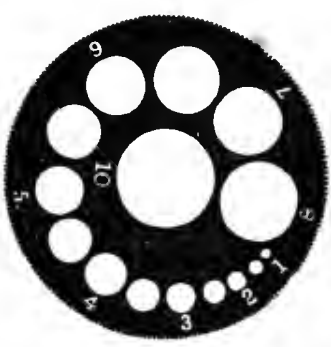

Fig. 23.-Simple pupillometer. to the patient's eye, the surgeon's eye being some distance away. This under-estimates the diameter of the pupil in proportion as the scale is nearer the surgeon's eye than is the pupil measured. Another method is to have a series of black circles on a eard, or of eirenlar openings in a metal disk, varying in size from 1 to 10 mm., with $\frac{1}{2} \mathrm{~mm}$. intervals, as shown in Fig. 23. This is to be beld alongside the patient's eye, and the circle or opening found which most nearly corresponds to the size of the pupil.

Pupillary Reactions. - The pupil is most mobile in early ehildhood, being at that time commonly large in moderate illumination, dilated widely in the dark, yet strongly contracted on exposure to bright light. With inereasing age it becomes more rigid and mostly smaller. If the pupils are small, their reaetion can best be studied in a feeble light, as by oblique illumination in the dark room. If large, as after the use of a mydriatic, the reactions may be more distinet in a stronger light. Absolute measurement of the extent of the reaction has by itself but limited significanee. Inequalities of reaction and 
alteration in the essential character of the reaction are more important.

Reactions to Light.-Normally, contraction of the pupil is brought about by increase of the light entering the eye, or by throwing the light upon a more sensitive part of the retina, such as the macula. It may be tested by alternately shading and uncovering the eyes in daylight; but if not shown in this way, the test is made in the dark room, by concentrating the light from the lampflame upon the pupil, with the ophthalmoscope mirror held at its focal distance in front of the eye. Turning the mirror so that the light will fall on some other part of the face, the pupil is permitted to dilate; then the pencil of light being suddenly thrown upon the eye, the appreciable time required for the reaction allows the observer to note the size of the pupil as it was in comparative darkness, before the sudden contraction due to the effect of the light. Under these conditions the slightest reaction to light can be detected. The turning of the light on and off the eye is to be repeated, until the surgeon is fully satisfied as to its effect. The first contraction to light is often followed by a perceptible dilatation, this by a new contraction, and so on, each dilatation and contraction growing less until the pupil becomes stationary. Exaggeration of this is hippus.

Failure of the pupil to contract may be due to the use of a mydriatic, to adhesions or rigidity of the iris, to loss of function in the retina or optic nerve-tracts, or to interference with the motor tract from the pupillary centers to the iris. By mydriatics, iritic adhesions, or motor paralyses, all movements of the pupil are interfered with. If, however, other movements are normal, the cause of any impairment of the light reaction must lie in the visual sensory tract, or in the fibers connecting this with the centers for pupillary contraction. The course of the sensory tract is shown in Fig. 24; from the retina, through the nucleus of the corpora quadrigemina, to the visual center in the occipital lobe. If the sensory tract be involved, vision will be impaired as much as or 
more than the pupillary reaction. Hence, if vision be good and the pupil fails to react only to light, the fanlt is known to lie in the fibers connecting the optic tract (sensory), with the centers (motor) for pupillary contraction.

A pupil showing absence of the reaction to light, where vision and other pupillary movements remain good, is

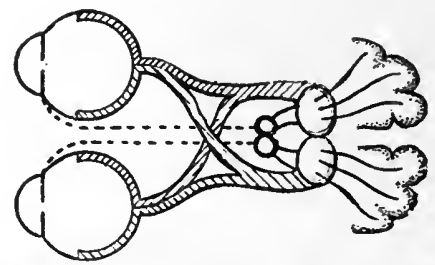

FIG. 24,-Tracts concerned in the pupillary reflex, the efferent or motor tract being represented by the dotted lines.

known as the Argyll-Robertson pupil. It is an important early symptom of locomotor ataxia or multiple selerosis.

It should be borne in mind that each pupil reaets - freely to light thrown in the other eye-consensual renction-and that even ehanges of light upon the elosed lids of the other eye may eause a noticeable reaction. Where loss of reaction to light is due to involvement of fibers connecting the sensory and motor tracts, the pupil commonly remains contracted in the darkened room. This has been taken to indieate that the condition was one of excessive innervation of the sphineter of the iris, a view supported by the oceasional dilatation of the pupil and the restoration of the light reflex in late eases of selerosis, after complicating lesions like apoplexy. Interference with the sensory tract eauses complete blindness before it destroys the pupillary reaction to light. When loss of light-reaction does oecur, it is important evidenee corroborative of a patient's statement that an eye has become quite blind.

The light-reaction is lost only when the interruption of the sensory tract is in front of the corpora quadrigemina where the fibers which eomneet it with the motor 
tract are given off. Blindness due to a lesion back of this point may be absolute without interference with the pupillary reaction. 'This fact is of importance in localizing a lesion causing hemianopsia. A single lesion of the sensory tract back of the optic ehiasm causes hemianopsia. If the lesion lie between the chiasm and the corpora quadrigemina, it also destroys the reflex of the pupil to light thrown upon the blind half of the retina, althongh the reflex remains perfect to light thrown on the seeing half of the retina. This is the so-called Wernickè reaction of the pupil or hemiopic pupillary inaction. If the lesion causing the hemianopsia be back of the corpora quadrigemina, it will not interfere with the reaction of the pupil to light thrown upon any part of the retina. Hence, hemiopic loss of the pupillary reflex points to lesion of the optic tract, between the chiasm and the corpora quadrigemina, or within the latter. The search for this reaction must be carefully made in a dark room, with light carefully excluded from the seeing halves of the retinas.

Slowness of the reaction of the pupil to light, or inequality of the turo pupils, or of the same pupil at different times, is an indication of chronie degenerative changes in the central nervous system. Complete loss of the lightreaction may be caused by any lesion of the optic nerve or eye that eauses complete blindness. Vision, however, may be very greatly impaired with but little loss of the pupillary light reflex; and even when blindness seems complete, and by ordinary tests the pupil seems not to react to light, complete darkness may eanse slow dilatation, and exposure to strong sumlight a slow contraction.

General Reactions of the Pupil.-Normally the pupil dilates under nervous excitement, fear, surprise, during hunger, in anemia, or from other causes of nervous instability. It contracts with the effort to focus the eyes for near objects, and with the convergence or turning in of the visual axes. It also contracts strongly during sleep.

The test of contraction with convergence and accom- 
modation-associated contraction-is to be made by getting the patient to look first at a distant object, and then at the point of a pencil or similar object held close to the eye in a line with the distant object, to avoid any change of illumination. Looking alternately from one to the other, the changes in the size of the normal pupil are readily observed. Failure of the pupil to contract with convergence, or great sluggishness of contraction, indicates some fault in the motor apparatus. Dilatation of the pupil and sluggish reaction with convergence occur in glaucoma, and large pupils in elderly persons should always bring this discase to mind.

If not due to glancoma or injury in the eye, or the use of a mydriatic, moderate dilatation of the pupil, with failure to contract to any stimulus, indicates lesion of the oculomotor nerve or its nuclens in the pons. Generally if the dilatation of the pupil be accompanied by the loss of power in the external muscles supplied by the third nerve, the lesion is located somewhere in the nerve-trunk. If the dilatation or partial dilatation of the pupil and failure to contract under stimulus be accompanied only with loss of accommodation, they constitute the condition known as ophthalmoplegia interna, and depend upon some lesion involving the nucleus from which the nerve proceeds.

Persistent eontraction of the pupil is due to narcotic poisoning (opium) or to cerebral irritation, as from inflammatory disease of the brain and its membranes, or from the congestion which attends cerebral apoplexy or the early stages of the acute fevers. It may, however, occur from a lesion involving the inhibitory fibers of the cervical spinal eord. But tle most common cause of contracted pupil-always to be thought of and sought for-is the adhesion of the iris to the lens capsule-posterior synechia. Such adhesion, if extensive, causes absolute immobility of the pupil, generally in a state of great contraction.

Persistent dilatution of the pupil, aside from blindness, glaucoma, and the use of mydriaties, is liable to be caused 
by irritation of the upper portion of the spinal cord, as in the early stages of organic disease.

The color of the pupil by oblique illumination is not usually elear black, but the anterior surface and the substance of the lens reflect some light, giving it a slightly gray tinge. This becomes more deeided as the patient grows older, and after middle life is always very noticeable and liable to be mistaken for cataract. It is rendered most evident by allowing the light to fall upon the eye very obliquely, and viewing the pupil obliquely over the bridge of the nose from the opposite side.

In this way there may be observed, sometimes even in children, a group of radiating lines situated in the anterior surface of the lens, which is, however, quite physiological and not to be mistaken for commeneing opacity.

By dilating the pupil and bringing the source of illumination rather more in front of the eye, the whole thickness of the lens can be inspected and opacities - revealed in any part of it, or in the anterior portion of the vitreous humor. The results obtained by focal illumination, however, should not be relied on, in any doubtful ease, without confirmation by examination with the ophthalmoscope.

Transillumination.-Illumination of the interior of the eye through the sclera is of value for revealing the presence and extent of tumors or foreign bodies lying close behind the iris or ciliary region, or to reveal atrophie thinning of these parts. An eleetric lamp is enclosed in an opaque cover from which projects a glass rod, also covered by an opaque eoating, exeept at the end which is bronght in contact with the selera. The light shining through the rod enters the eyeball through the normal selera and ehoroid, eausing a red glow in the pupil. But when the rod is placed over a tumor, or opaque foreign body, this glow diminishes or disappears entirely. 


\section{CHAP'TER IV. \\ OPHTHALMOSCOPIC DIAGNOSIS.}

THE OPHTHALMOSCOPE.

The ophthalmoscope enables the surgeon to inspect the interior of the eyeball through the cornea and the crystalline lens, which mag-

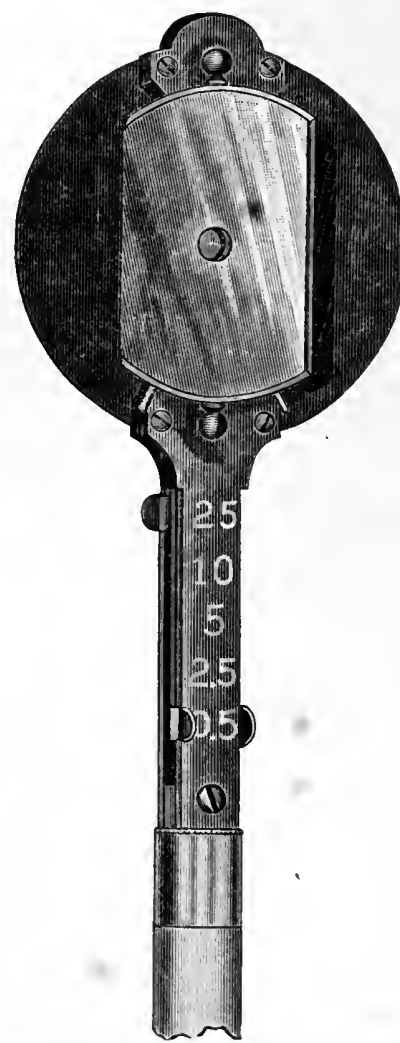

FIG. 25.-Author's ophthalmoscope. nify the details of the fundus 10 to 20 diameters, according to the refraction of the eye. It consists essentially of a mirror for throwing the light into the eye, with a central perforation through which the surgeon can look in the direction that the light is thrown, and a series of lenses to focus the light from the structures examined.

The form of ophthalmoscope preferred by the author is illustrated in Fig. 25. The mirror is swung upon a pirot, placed at each end, so that it can be tilter to an angle of 25 to 30 degrees with the back plate that shades the surgeon's eye from the light. The aperture in the mirror is about 2 millimeters in diameter. The lenses are arranged in two slides just behind the mirror. They are moved by the tip of the forefinger acting on milled projections from the lower ends of the slides. This 
allows the use of all lenses and combinations of lenses of which the instrument is eapable without removing it from the eye. By taking ont a screw from the lower end of the stem, the slides of lenses are readily removed for cleaning. The lens series furnished by the instrument includes either convex, $1,2,3,4,5,6,8,11$, and $15 \mathrm{D}$.; and concave, $1,2,3,4,5,6,7,8,9,10,15$, and $30 \mathrm{D}$.; or convex, $0.5,2,1.5,2,2.5,3,3.5,4,7.5$, and $10 \mathrm{D}$.; and concave, $1,1.5,2,2.5,3,4,5,6,7,8,9,10$, and 25 D. Either series is sufficiently complete for all practical purposes; but the former is preferable, the $0.5 \mathrm{D}$. intervals being of no value except to the expert who is constantly measuring refiaction with the ophthalnoscope.

There are many other good forms of oplithalmoscope, most of them having the lenses arranged in one or more disks. That of Loring is one of the best, except that the large sight-hole in the mirror fits it rather to measure refraction than to examine the fundus of the eye. The most common fault is in the direction of elaborating the instrument into a machine that could do things that one never wants to do with an ophthalmoscope.

In general, a good ophthalmoscope should have a thin tilted mirror with a small sight-hole, free from reflections. Reflections are to be tested by trying the instrument in the thoroughly darkened room. Any inıperfection of the kind causes a luminous laze in front of the surgeon's eye, which interferes with the seeing of the conditions in the patient's eye. The lenses must be furnished with a spring catch that will cause each lens to stop at its proper position before the sight-hole. All lenses shonld be available without removing the instrument from the eye and without bringing the surgeon's hand too much before the patient's face. It should be simple, and should include no unnecessary lenses, cumbersome "improvements," or useless parts.

Why any special apparatus is necessary to inspect the interior of the eye, and the exact function of the lenses will be explained in the section on "the measurement of refraction" with the ophthalmoscope, Chapter V. Two 
essentially different methods of using the ophthalmoscope, the direct and the indireet, are employed. 'The latter,

- formerly much used, is now only resorted to in speeial eases. If not otherwise stated, it will be mnderstood that the direet method is here referred to. 'The optical details of both will be described in Chapter V.

Methods of Using the Ophthalmoscope.-The ease with which an ophthalmoscopic examination can be made depends upon the size of the pupil. If this be not dilated by a mydriatic, it is necessary to make the examination in a darkened room. The patient is placed with his back to the light, which should be readily movable from side to side. The surgeon then places himself exactly alongside of the patient, but facing in the opposite direction, sitting on the right side to examine the patient's right eye and on the left side to examine the left eye. The lamp-flame, $L(F i g .26)$ is then drawn far

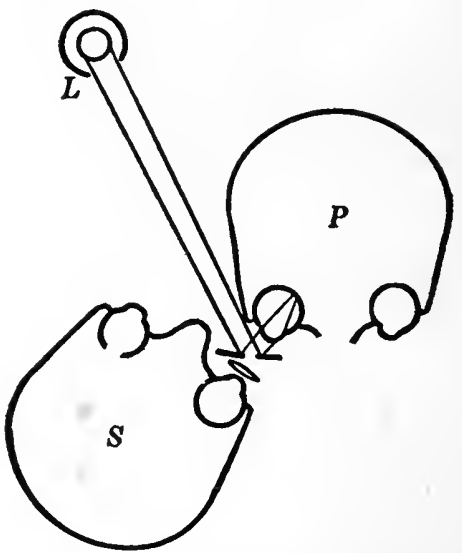

FIG. 26.-FIorizontal section showing relative position of surgeon $(S)$, patient $(P)$, and lamp-fiame $(L)$ during ophthalmoscopic examination.

enough to the side of the eye to be examined for the light from it, just escaping the temple of the patient, to fall on the outer lishes. If it be nore behind the patient's head, 
$P$, it will be cut off from the mirror when this is brought close to the patient's eyc. If it be more to the side of the patient, it may be cut off from the mirror by the surgeon's nose, and will require an exeeedingly oblique position of the mirror in orler to refleet it into the patient's eye. The patient is to keep his head directed forward, inelined toward the side of the surgeon, and to turn the eyes a little to that side. The ophthalmoseope is to be held in the right hand and to the surgeon's right eye to examine the patient's right eye, and the left land and eye are used for the patient's left eye. The mirror is tilted to face toward the light; and, as a preliminary, the ophthalmoseope is held about 12 inches from the eye to be examined, in such a way as to throw the light upon it.

The corneal reflex, a small bright image of the source of light, appears on the part of the cornea perpendicular to the direetion in which the surgeon looks; and beside the corneal reflex, the pupil, previously black, beeomes ocenpied with a red glow-the fundus reflex-which varies in hue according to the brightness of the illumination and the color of the fundus of the eye under examination, being brighter in light and duller in dark eyes.

\section{OPACITIES IN THE MEDIA.}

Having obtained the fundus reflex, the surgeon is to observe whether it is interrupted by any black dots or masses. Such black spots indicate opacity somewhere between the choroid and the observer's cye. They may be produced by a bubble of air on the eornea, by a foreign body in the cornea, by specks of exudation on the anterior capsule of the lens, by isolated opacities of the lens, or by opacities of the vitreous. If an opacity is diseovered, the presence of other opacities should be determined by the surgeon moving his head to different points of views, or the patient looking in different directions. Such movements will also produce an apparent change in the position of the opaeities seen, and thus indieate their position. 
The apparent position of an opacity is always referred to the margin of the pupil. Opacities situated in the plane of the pupil preserve their relation to it from whatever direction they are seen. Those situated in front of the pupil appear to move across it in the direction opposite to that of the movement of the surgeon's eye or in the same direction as the patient's eye is turned. Those situated behind the pupil appear to move across it in the direction in which the surgeon's eye is moved, or in the direction opposite to that of the movement of the patient's eyc. The reason of this is shown in Fig. 27 in which $I I$ represents the plane of the iris, $A$ an opacity in front of the pupil, as a foreign body in the cornea, $B$ an opacity in the pupil as an anterior polar eataract, and $C$ an

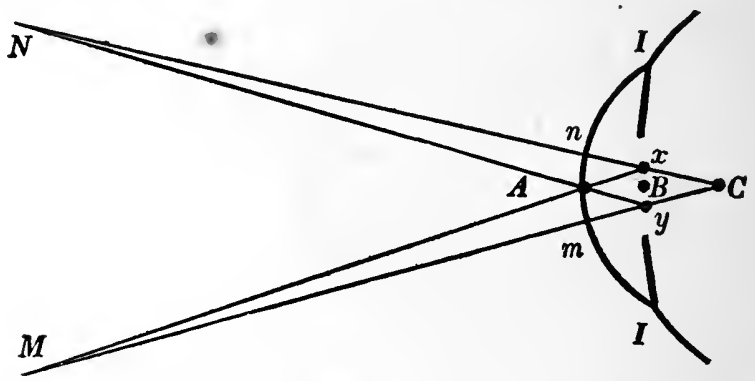

FIG. 27.-Apparent position of opacities, in front of, at, or behind the pupil.

opacity behind the pupil, such as a posterior polar cataract. When the eye is looked at from the direction $M$, the opacity at $A$ appears to be situated at $x$ near the upper margin of the pupil, and the opacity at $C$ appears at $y$, near the lower margin of the pupil. As the surgeon's eye moves from $M$ to $N$, the opacity at $A$ appears to go in the opposite direction, while that at $C$ appears to move with it, so that on reaching $N, A$ appears to be at $y$ and $C$ at $x$; but from all directions, $B$ maintains its position at the center of the pupil. The nearer the opacity is to the plane of the pupil, the slower its movement; and the farther alway it is from the plane of the 
pupil, the more rapid its apparent movement. In this way the depth of the opacity within the eyeball may be roughly estimated.

An aid in this estimate is the apparent movement of the opacity as compared with that of the corneal reflex.

In all positions, the reflex comes from the direction of the center of curvature for the cornea. For the direction $M$ it will be seen at $m$. For the direction $N$ it will be seen at $n$. If then, the opacity at $C$ be situated exactly at the center of curvature of the cornea, its apparent movement across the pupil will exactly keep pace with the apparent movement of the light-reflex of the cornea. If the opacity be situated deeper in the eye than the center of curvature of the cornea, it will move more rapidly across the pupil, and get ahead of the corneal reflex. If it be situated in front of the center of curvature of the cornea, it will move more slowly across the pupil, and lag behind the corneal reflex. Thus one can determine whether a foreign body is in front of or behind the center of curvature of the cornea. The position of the center of curvature of the cornea can be accurately determined with the ophthalmometer (see Chap. VII).

The position of opacities deep in the vitreous humor may be determined by measurement of their refraction with the ophthalmoscope. Opacities in the cornea and lens are commonly fixed; in the aqueous humor they float frecly, and in the vitreous they move with a freedom dependent on its fluidity or loss of normal consistency.

Opacities arise in the cornea from foreign bodies, injuries, inflammation, and deposits on the posterior surface in connection with iritis. Those of the vitreous indicate inflammation of the choroid or ciliary process, as do also those of the lens, in some cases.

Crystals of cholesterin may be encountered in the cornea, aqueous, lens, vitreous, or retina. They may appear as flakes of opacity, or when the light strikes them at a certain angle show brilliant iridescence. They are not incompatible with normal vision, although more commonly seen in the eyes that have undergone degenerative changes. 


\section{EXAMINATION OF THE EYE=GROUND.}

The Optic Disk.-Having searched the dioptric media for opacities, the oplithalmoscopic examination is directed to the region of the optic disk. The optic nerve enters 10 or 12 degrees to the nasal side of the posterior pole of the eyeball. 'To examine it the patient should turn his eyes slightly toward the surgeon, who, keeping still 10 degrees or 12 degrees to the temporal side of the visual axis, is able to look in the direction of the optic disk without getting in front of the patient's face. To find the direction of the disk the surgeon watches the fundus reflex, and moves his eye until the red glare from the pupil becomes noticeably brighter and of a lighter color, indicating that the optic disk has been bronght in line with it. Keeping as near as possible in this direction, the surgeon brings his own eye with the ophthalmoscope as elose as possible to that of the patient, as shown in Fig. 26. During this movement care must be taken to keep the mirror so turned that it will steadily refleet light into the patient's pupil-a thing difficult at first, although easily done after long practice.

It is not sufficient for some part of the light from the mirror to fall upon the patient's pupil. The light must enter the paticnt's eye from the part of the mirror inmediately around the sight-hole. The form of tiltingmirror illustrated in Fig. 25, the one commonly used on American ophthalmoseopes, is nuch larger than is of value for the direct ophthalmoscopie examination, in which only a circle about $15 \mathrm{~mm}$. in diameter immediately around the sight-hole ean be utilized. Light may fall on the eye from other parts of the mirror without giving the surgeon any fundus reflex whatever.

With the mirror properly directed and the surgeon's eye as elose as possible to that of the patient-generally within one or two inches - there will appear in the pupil an area of light color, surrounded by the darker red of the fundus reflex. By relaxing the aceommodation or pushing up the proper lens, the margin of this area with the other 
details of the fundus will become clear. It is then found that the area is circular or somewhat oval, generally with the long axis vertical, and presents somewhat the appearance shown in Fig. 28 and in Fins. 1, 3, 4, and 5 of the colored plates I and II.

Its color is usually rather pink or cream, yet in contrast with the darker red around, it looks almost white. In some eyes it is quite gray, or even brown pigment is deposited in its connective-tissue stroma. Striking

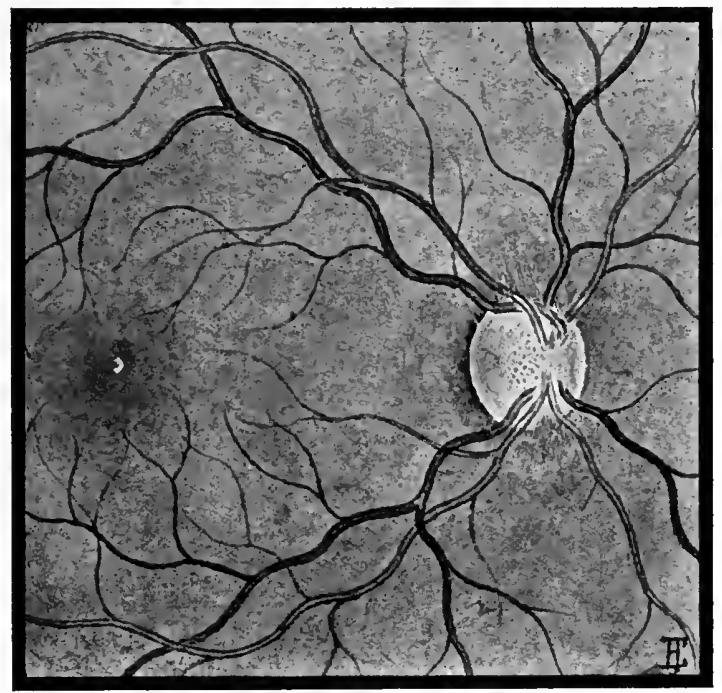

Fig. 28. - The normal fundus. The darker vessels are veins, the lighter arteries. The dark speeks on the oval optic disk are sjaces in the lamina cribrosa. The light creseentie spot represents the reflex from the fovea.

anomalies are oecasionally eneountered. The common variations of color, however, depend on the vascularity of the nerve-head. It is generally darker on the nasal side and paler at the center of the disk and toward the temporal margin. At the border of the disk may be seen points, or a complete ring of brown or black, the "choroidal ring" (see l'late's I and II). Within this may often be 
noticed a crescent to the temporal side (Plate II, 3), or a complete ring of white surrounding the disk (Plate II, 4), the part of the selera exposed by a comparatively large opening in the choroid.

Upon the disk appear as red lines, the retinal vessels, the veins darker and more crimson in color, the arteries lighter and more scarlet. The larger vessels show a white glistening line along their centers-the light streak. The smaller arteries and veins are more alike, so that whether a certain vessel is an artery or a vein can only be ascertained by noticing the larger vessel with which it is connected. Frequently the normal veins may be seen to pulsate where they turn to pass back into the optic nerve, but pulsation of the arteries is abnormal. The largest branches pass upward and downward, then bend toward the temporal side. Occasionally a vessel of medium size does not arise from the general system of vessels upon the disk, but appears independently near the temporal margin, passes a little on to the disk, and then turns back and is distributed to the retina toward the macula. Such are called cilioretinal vessels (Plate $\cdot \mathrm{II}, 1$ ).

In the lighter area at the center of the disk may often be seen a dark stippling, a network of white with dark interspaces (Sce Plate II, 4 and 6, and Fig. 28). This network is the lamina cribrosa, the continuation of the selerotic across the space through which the optic nerve enters the eye, the white network being the connective-tissue bundles, and the dark interspaces the openings through which the nerve-fibers pass.

The center of the optic disk is commonly marked by a depression-the physiologieal cup-which varies greatly in depth and forn in normal eyes. Its presence and depth are most clearly demonstrated by measuring the refiaction of different portions of the disk-surface. Generally it is somewhat conical in shape. Compare Plate I, 1, Plate II, 3 and 4, and Figs. 28, 29, 33, and 34 .

Usually the nasal side is more abrupt than the temporal. The eentral artery and the central vein, or their primary branches, first make their appearance at the bot- 
tom of this eup, then pass up its sides or even into the nerve-tissue around it, and emerge on the level of the disk. Usually the diameter of the "physiological cup" approaches half that of the optie disk; but it may be larger or smaller than this, or the eup may be entirely absent without indicating disease.

The normal color of the fundus, or eye-ground, varies greatly. The retina, which is almost transparent, is only seen when the tissue behind it is of comparatively dark color. The pigment-layer of the retina presents all variations from complete transparency to almost complete opacity, according to the amount of pigment deposited in the cells. When transparent the eolor of the fundus is the color of the structures behind it; when opaque, nothing back of this layer is visible. The fundus is comparatively dark in the dark races, brown, or mahogany, rather than red. With sueh a background, the retina will be noticed as a gray veil, thickest above and below the optic disk, where it is somewhat striated, the striæ running in the direction of the bundles of nerve-fibers, first upward and downward, and then curving around above and below the region of the maeula. The retinal veil becomes thinner as we go forward toward the periphery of the retina, until it is no longer visible.

When less pigment is deposited in the retinal pigmentlayer, more of a red glow is transmitted from the choroid behind it, and with the inerease of light eoming through it, the retina itself becomes less visible, and details of the choroid may be seen. In most eyes, immediately around the disk and in the maeula, the retinal layer holds so mueh pigment that none of the choroidal details are visible, but toward the periphery of the fundus they may be studied in nearly all eyes.

The details of the choroid consist first of the largest choroidal vessels, which appear with interspaces, either darker or lighter, according to the amomnt of pigment deposited in the stroma of the choroid (see Fig. 118). The vessels are comparatively broad, and form an irregular network of rounded loops in contrast to the retinal vessels, 
which are narrow and run a comparatively direct course without inoseulation, and bifurcate at irregular intervals, the branches becoming progressively smaller toward the periphery of the retina.

In most eyes the retinal vessels are the more distinetly seen; but in eyes devoid of pigment choroidal vessels may appear equally distinet, so that only their size and form of distribution reveal to which system they belong.

With diminution of pigment the fundus becomes lighter. In some albino eyes the general background is a pink or vellowish white; against this background appear many large and small vessels, among which it becomes difficult to trace those belonging to the retina. This general backgromind is the sclera, revealed by the transpareney of the coats in front of it, when these are devoid of pigment.

The region of the macula is bronght under inspection by having the patient look at the sight-hole in the mirror. This brings the corneal reflex a good deal in front of the pupil, and the greater sensitiveness of the retina at this point eauses the pupil to contract, so that without the use of a mydriatie it is sometimes impossible to make a thorough examination of this region. Whatever the general pigmentation of the eye, it is greatest in the region of the macula, where the vessels of the ehoroid are rarely traceable.

The greater thiekness of the retina in this region with this darker background causes it to be more frequently visible luere than in other parts of the eye, exeept above and below the optie disk. The distribution of retinal vessels in this region is peeuliar; the prineipal trunks run above and below the macula, only as a rare anomaly erossing it. These trunks give off branches which run directly towarl the maenla from all silles, and become invisible by division. In the maeula the only detail to be recognized is the gramular appearance due to the irregular distribution of pigment in the retinal pigmentlayer. 'This granular appearance exists throughout the eye, being most noticeable in eyes of moderate or dark 
pigmentation, but it is best developed in this region of the macula.

At the center of the macula is commonly found a crescent of shining reflex, marking the border of the fovea centralis (see Fig. 28). It varies in size and shape with the varying dimensions of that depression in the retina, the crescent being a reflection from a portion of the margin of the depression. By slightly changing the angle at which the light enters the eye, by change of the direction of the mirror, the part from which the reflection is obtained varies; sometimes the complete ring of reflex may be seen.

Retinal Reflections.-Gleams of light, shifting or vanishing as the position or direction of the mirror is slightly changed, nay be perceived in various parts of the retina. In an eye with a dark retina and choroid these often resemble the reflections from the surface of silk, and are spoken of as the "watered silk" or "shotted silk" appearance of the retina. Sometimes they follow the course of the largest retinal vessels, but often they cross them irregularly. They are best studied with a mirror having a very short focus, and with a lens focussed for rays coming from a little in front of the retina. With the ordinary oplithalmoscope mirror they are more noticeable through the undilated pupil than after the use of a mydriatic.

One of the most regular of these reflections is an oval, or sometimes circle, around the macula (see Plate I, 1). Through the undilated pupil usually only small portions of this can be seen at onee, and after the use of a mydriatic it often cannot be discovered, except with a special mirror. Increased visibility of these reflections has been regarded as an evidence of irritation or edema of the retina, but it must be considered a rather indefinite and uncertain sign of such conditions.

A distinct reflex concentric with the optic disk and a little to its nasal side, the "Weiss reflex," indicates swelling of the disk, and has been considered an evidence of progressive inyopia. It is represented in Fig. 34. 


\section{ABNORMAL APPEARANCES AND ANOMALIES OF THE RETINA.}

Haziness in the retina interferes with the perception of the structures that lie baek of it, as the stippling of the pigment-layer, or the network of ehoroidal vessels, and also the parts of the retinal vessels that are decply buried in the retina. Where the vessels come elose to, or lie upon, the anterior surface of the retina, however, they will be clearly seen, being often more distinct than normal, because the gray of the hazy retina gives a stronger contrast to the red of the vessel than does the normal fundus.

Haziness in the retina renders more marked or extends beyond the normal limits the appearanee of the retina as a gray veil. In proportion as it is present, the red hue of the fundus is masked by the gray or the greenish or bluish eolor that it canses. It may be either general or localized. In the former ease it is most pronounced in those regions where the retina is thiekest. In general, it indieates edematous swelling of the retina.

Haziness of the retina is seen in some eases of eycstrain. It is also likely to be present after bruise of the eyeball, causing a general disturbance of the coats. It is an early sign of albuminurie retinitis, one of the distinetive signs of neuroretinitis, and is very marked in the retinitis of leukemia. It is very pronouneed and general in embolism or thrombosis of the central retinal vessels, sometimes giving the fundus of the eyc a gray or white appearanee that shades off toward the periphery, and in the macula is interrupted by a very dark red spot at the fovea. (Compare Plate I, 2, and Figs. 116, 117, and 119.)

Hemorthage sometimes oceurs on the surface of the - retina, immediately adjoining the hyaloid membrane separating it from the vitreous. Sueh a hemorrhage may be seen covering the region of the maeula or in other parts of the eye, haring a sharply defined, rounded border. Such subhyaloid hemoirhages are to be distingnished from those oceurring into the substance of the retina. 
These latter generally lie in the nerve-fiber layer, and the blood composing them is distributed somewhat in the direction taken by the nerve-fibers. 'They have what is called a "flame-shaped" outline, the narrower end toward the optic disk and the broader extremity from it, with feathered edges, especially at its peripheral margin (see Plate I, 2, II, 8, and Figs. 116 and 117).

Such hemorrhages conceal the retinal vessels that pass across them.

Fatty degeneration, either of the retina or of exudate into it, eauses a patch of white, often quite brilliant. Such white patches are especially characteristic of the retinitis that attends ehronic vaseular and renal disease-albuminuric retinitis (Plate I, 2, and Fig. 117). In this affection there are at the macula points or large patches of white, arranged in lines radiating from the center of the maeula, sometimes in only one direction, sometimes in all directions. The typical appearance is seen before the spots run together in large irregular patches, when the appearance is less characteristic. In the later stages, too, the patches are less likely to be pure white, but have a brownish discoloration. Sometimes the white patehes of fatty degeneration are confined to the walls of one or more vessels, eausing the vessel for a certain distance to appear as a white line (Plate I, 1). Such an appearance indicates advanced degeneration of the vessel-walls, generally attended with similar changes in other vessels of the body. White patehes in the retina have to be distinguished from white patehes back of the retina, due to exposure of the selera through atrophy of intervening structures.

Medullated Nerve-fibers. - In the optic nerve each axis-cylinder has its opaque medullary sheath, but in the retina the sheath is laeking. At or behind the lamina cribrosa the sheath commonly begins. If it begins just in front of the lamina the nerve-head is rendered opaque and the lamina invisible. Sometimes a portion of the nerve-fibers have medullary sheaths while in the retina. When a very few fibers are thus furnished, there results a 
striate appearanee of the retina, frequently seen above or below the optie disk. When a large number of the fibers are so eovered, the result is a large white patch resembling in color the patches of fatty degeneration in the retina, but, unlike them, situated at the upper or lower margin of the disk and extending in the direction in which the nerve-fibers run (see Fig. 125).

In most eases of the kind the fibers do not keep the sheath continuously, but lose it at the edge of the optic disk, so that the white pateh does not hide the disk itself but is confined to the neighboring retina. Its distal margin is never abrupt, some of the fibers losing their sheaths, while others still retain them, giving a gradual transition from the white pateh to the normal red of the fundus-the so-ealled "feathered edge." It is this edge and the distribution of the white pateh that distinguish medullated nerve-fibers from the sharply bounded, white patehes of retinal degeneration. In both cases the retinal vessels may run across the surface at some points, and at others may be quite lost from view in the white opaque tissue.

Changes in the Retinal Vesse1s.-Hyperemia of the retina is not exhibited by an increase in the general red of the fundus so mueh as by the enlargement of the individual retinal vessels. By enlargement a greater number become visible; the principal branches are noticeably broadened as compared with the size of the optic disk; and the ressels, enlarged not only laterally but also in the direction of their length, become more tortuous. Their tortuosity is shown, both by their more visibly wavy course and by the fact that certain portions of each vessel stand out in front of the retina, while other parts are correspondingly sunk beneath the surface. In the presence of haziness of the retina this makes a decided contrast in the elearness with which the different parts of a vessel are seen. This symptom must be carefully distinguished from one of the ophthalmoscopic appearances of astigmatism. (Compare the appearances represented in 
Plate I, 2, and ${ }^{\circ}$ in Plate II, 8 with the appearances of these plates seen through a strong cylindrical lens.)

Enlargement of the retinal vessels is commonly uniform unless the vessel-walls are themselves diseased, when they are liable to irregular dilatations. In elderly persons irregularities in the caliber of the retinal vessels are not rare. It cannot be asserted that these vessels are entirely healthy, although sometimes they seem to return to and remain in a normal condition. Contraction of the retinal vessels is mostly seen in connection with optic atrophy. It indieates that the atrophy has been due to disease involving the retina. It is commonly general and uniform, except when arising from disease of the vessel-walls, or shortly after a complete or almost complete interruption of the retinal circulation, as by embolism. The arteries and veins may be equally dilated or contracted, or one set of vessels may be more altered than the other. Pressure at the nerve-head, as in glaucoma or optic neuritis, tends to distend the veins and diminish the arteries (see Figs. 30 and 32). The color of the retinal vessels may be altered by changes in the constitution of the contained blood. In diabetes it is sometimes impossible to distinguish between the arteries and veins. In anemia they become paler, especially the veins. At death the blood-column is seen to become finely granular before its movement ceases.

\section{ChANGES IN THE OPTIC DISK.}

Redness.-Most of the eyes examined ophthalmoscopically present disks that are abnormally red. Redness of the disk is liable to attend all kinds of eye-strain and all ocular inflammation. Within the normal limits, however, the redness of the disk varies greatly, and its apparent redness depends also on the contrast of the color of the fundus aromd it. When the fundus is dark, the disk appears relatively white by contrast, and when the surrounding fundus is light, the disk appears more nearly of the same color. 
Only by the extensive use of the ophthalmoseope, including examinations of normal eyes, ean the observer establish an approximate standard for the normal color of the disk. Inereased redness, if slight, does not hide the nsual gradations of colors presented by the normal disk. The temporal side and central depression remain less red than other parts; but, if the hyperemia be very great, these differences of eolor are usually less pronounced. Redness of the disk includes a uniform alteration of hue from dilatation of invisible vessels, and the increase in size and number of visible vessels. At its maximum the disk may have the color of the surrounding fundtis. The increased redness may be limited to the disk in cases of optic neuritis. In cases of eye-strain, however, it is assoeiated with hyperemia of the retina and choroid, more closcly and directly with the latter, because the ressels which supply the head of the optic nerve are not bramehes of the central retinal vessels, but branehes of the ressels that furnish the blood-supply of the cloroid.

The hyperemia of the disk arising from eye-strain is essentially similar to the hyperemia present in the early statge of scrious organic disease of the optie nerve, in connection with brain-tumor or meningitis. In later stages of optic neuritis from brain-discase the hyperenia is quite different. The general pink flush that exists in health and is emplosized in early hyperemia is wanting; and the alteration of color depends on an increase in number, with irregular dilatation of the smaller visible vessels. Hyperemia of this eharaeter marks the transition from inflammation of the optie nerve to atroplyy.

Opacity of the Nerve-head.-The normal variations in the visibility of the lamina prevent it from serving als a test for the exudation in the nerve-head in a large proportion of eases. If from previous examination it is known that the lamina was normally visible, as in Fig. 29, the obscunation of it will be one of the first signs of opacity of the nomally transparent tissue in the nervehead. Later may come obscuration of the large vessels, the disk-margin, and the ehoroidal ring. 
The upper and lower margins of the disk are usually partially obscured by the nerve-fibers, the bulk of which pass off in these directions. Such obscuration is by striations, while that due to swelling of the tissue is by a general haziness.

The degree to which the different structures are obscured will depend on the amount of exudation into the nerve-head. In some cases it amounts to complete hiding of the nerve-outline beneath a reddish-gray swelling, which can only be certainly recognized as the site of the
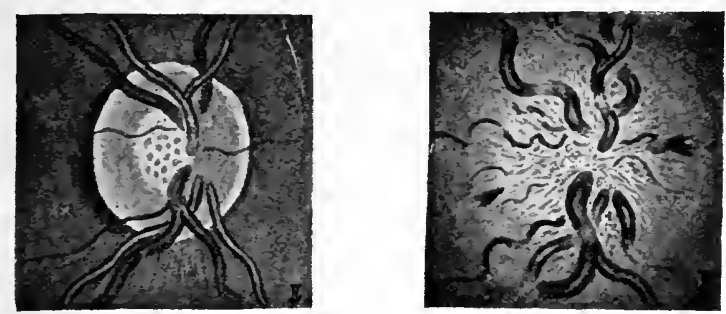

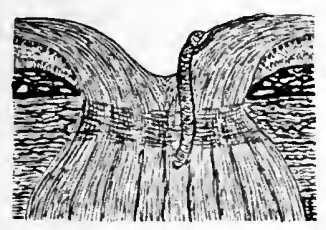

FIG. 29.

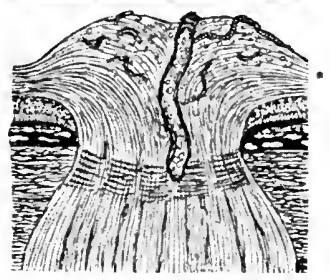

FIG. 30.

FIG. 29.-The normal optic disk, shown in section below, in contrast with F1G. 30, which shows the ophthalmoscopic appearances and section of the optic nerve-head in optic neuritis.

optic disk by the divergence of the retinal vessels from it (see Fig. 30). Such a condition is reached very rarely in the neuritis, due to eye-strain. It indicates rather that the changes in the nerve-head are due, either to general disease, such as Bright's disease or pernicious anemia, or to organic cerebral disease. In a very few cases some such appearance may be presented as an anomaly.

Swelling of the Disk.-Great opacity and hypere- 
mia only occur with swelling. The swelling is shown by the altered contour of the vessels, and particularly by the difference of their refraction at the center of the disk, from that of the neighboring fundus. This is to be estimated with the ophthalmoscope by the method given in Chapter VI. First, the refraction is to be measured of the most prominent, most hyperopic, or least myopic details of the nerve-head. Then the refraction of the adjoining portion of the fundus which appears most nearly normal is to be ascertained. The difference between the two gives the height of the swelling.

It is to be borne in mind that in normal eyes there are variations in refraction in different parts of the optic disk, aside from the physiological cup. One may find a difference of one diopter or more between the temporal and the nasal sides of the normal disk, the latter being usually the more hyperopic. In some eyes, too, the nerve-head normally projects in front of the surrounding fundus.

Redness, opacity, and swelling are signs of inflammation of the optic nerve-head, whether from eye-strain, brain discase, or other causes.

Pallor of the Optic Disk. - The variations of the color of the optic disk in health make it always difficult to say when it is abnormally pale. The strictly normal disk is paler than the great majority of those examined. Paleness of the disk indicates optic atrophy, and sometimes other signs of atrophy must be sought to decide if the disk is abnormally pale. 'The slightest pallor of the disk is a diminution of the pink blush, from narrowing of invisible vessels. With greater change the number of small visible vessels will be found reduced. In severe eases, all of the small vessels become invisible, and only the larger branches of the central retinal vessels can be seen.

These retinal vessels may either remain of normal size, as in primary optic atrophy or atrophy from disease of the optic tracts, as illustrated in Fig. 31 ; they may be somewhat enlarged, as in the carliest stages of postneuritic atrophy; or they may be diminished, as usually in the 
later stages of postneuritic atrophy, and in optic atrophy due to diseases of the disk, retina, or ehoroid, or of the vessels themselves (sec Plate II, 9).

The color of the optic disk does not depend solely upon its blood-supply. In some cases of optic atrophy the disk is dead white, in others more distinctly gray, bluish, or even decidedly greenish, as seen by a yellow light. 'These variations depend on the original color of the disk, and on the amount and character of the exudation into the nerve-head, during the process that has preceded the atrophy (see Plate II, 9 and 10).

Cupping of the Disk.-Variations in the normal level of the disk-surface and in the size and shape of the physiological cup (Fig. 29) make it always difficult to determine the beginning of pathological cupping of the disk. The most constant distinction between the normal
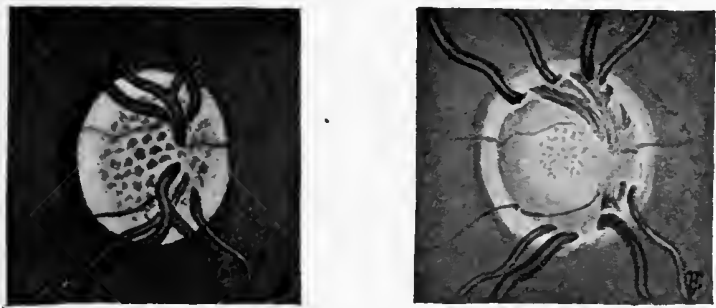

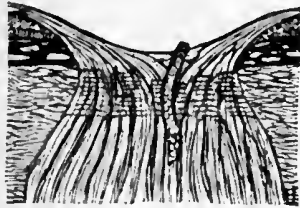

Fig. 31.

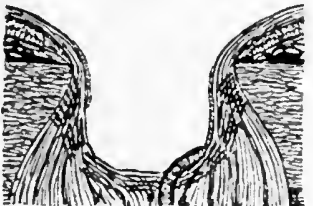

FIG. 32.

FIG. 31 shows disk in optic atrophy with broader shallow depression than in Fig. 29, and in contrast with FIG. 32, which shows the ophthalmoscopic appearances and section of the glaucomatous excavation.

and the pathological cup is that the latter extends to the disk-margin, while the former does not. But in cases of early glaucoma or atrophy, the cupping may not yet have 
reached quite to the margin, and in rare cases the cup extends to the disk-margin, althongh vision and the visual field are normal.

A broad shallow depression with sloping sides, sancershaped (see Fig. 31), is to be regarded as due to parenehymatons or interstitial changes in the nerve-head. A cup with abrupt edges, sometimes overhanging, as illustrated in Fig. 32, is to be regarded as due to intra-ocular pressure; generally to abnormally high intra-ocular tensionglancoma.

The existence and the extent of the cup of optic atrophy are aseertained by the measurement of refraction at its center and margins. The glaucoma cup presents a more striking appearance. The retinal vessels appear at the bottom of it, pass on to the sides of the cup, often entircly out of sight, and climbing over the margin of the cup, reappear in a new position quite disconneeted, apparently, from the one they occupied at the bottom of the cup. They therefore seem to have a new, hook-like beginning at the disk-margin, the hook being the curve of the vessel out of the eup to the general surface of the fundus. These looks, presenting a greater depth of blood to be looked through, appear darker than the other parts of the vessels. The normal optic nerve as it enters the sclerotic becomes smaller, each nerve-fiber losing its medullary sheath. On this account when the eup extends quite to the nervemargin, it is larger below the surface of the choroid than at that point. It is what is called "kettle-shaped," so that its margins overhang. The optie nerve enters the eye from the nasal side and faces the center of the eyeball, not the pupil. Hence, without any overhanging the nasal side of the cup wonld be invisible, while the temporal side would still be seen.

'The depth of the pathological eup is of little value for prognosis. It depends largely "pon the extent of the physiologieal eup previonsly present, and in glaucoma more on the duration of the process than on the malignaney of the case.

Anomalies of the Optic Nerve.-Sometines the 
site of the optic disk is occupied by a cavity which may be broader and deeper than the largest glaucoma cup, along the side of which the normal amount of nerve-tissue may make its way to the retina, securing full vision and a good field; or nerve-tissue nuay be largely or entirely absent, and the sight correspondingly defective. This condition is known as coloboma of the optic nerve. The visible eavity sometimes extends a considerable distance back of the sclera and may vary greatly in size. It may be associated with coloboma of the choroid or exist alone.

\section{PIGMENTATION.}

Pigmentation of the optic nerve is not rare. The pigment appcars as one or more black blotehes, like an irregular ink-spot on the disk. In rarer cases a pigmentation, apparently continuous with that of the normal choroid and pigment coat of the retina, seems to cover a portion of the disk (see Plate II, 5).

Pigment-deposits in the General Fundus.These are dark brown or black in color, and of irregular shapes. They must be distinguished from opacities in the media. 'This is done easily enough when the eye is steady, and they are clearly focussed, but it is sometimes difficult when only glimpses of a dark object are caught during ocular movements. They are located either in the retina or choroid.

Pigment-deposits in the Retina.-In the retina they sometimes overlie the branches of the retinal vessels or enelose the vessel like a sheath. Sometimes the vessel around or along which the pigment-patch is developed is too small to be visible, or disappears in the course of later degenerative changes, the pigment-spot retaining the branched shape of the vessel. Other spots have the form of a central lens-shaped body with radiating branches, somewhat the shape of a "bone-corpuscle." These are the typical forms of retinal pigment-deposits. They are illustrated in Fig. 118.

A striking form of retinal pigment prescuts a large 
area or areas of black or very dark pigment, giving, at first glance, the impression of very serious disease, but it shows no disturbanee of the choroidal tissue, and is compatible with full vision. Another anomaly consists of dots of dark brown or black occurring singly or in groups upon a background of normal fundus.

Choroidal Pigment-changes.-In the ehoroid the patehes of pigment are rounded or irregular in shape, and associated with more or less choroidal atrophy. Their most common seat is in the region immediately around the disk. Normally, outside of the disk-margin is generally found a ring of pigmentation darker than that of the general fundus, ealled choroidal ring (see Plates I and II and Fig. 31). This varies in width from a mere line to one-third or one-half that of the disk. It is sometimes uniform throughout, but more frequently broader in one direction than in others. In the majority of eyes the pigmentation of the ring is quite irregular. At some points the pigment is heaped up in black masses; at others it is partly or entirely removed with more or less complete atrophy of the choroid. While such irregu-

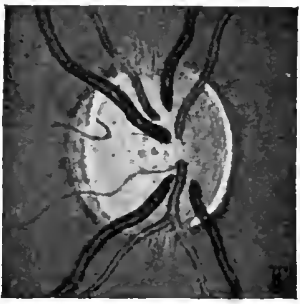

FIG, 33.

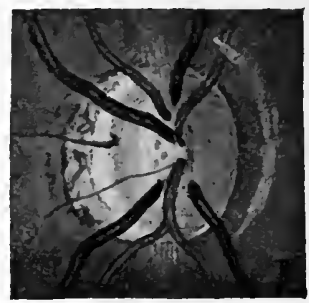

Fig. 34.

F1G. 33.-Myopic crescent, early stage; atrophy of choroid incomplete.

F1G. 34.- Myopic crescent more advanced. The atrophy of the original cres. cent is now complete, and a larger crescent of incomplete atrophy has formed, and a crescent of pigment-disturbance beyond that. The disk has also become more oblique, and therefore, apparently narrower. On the right is seen the curved reflex of Weiss.

larities may be normal, they denote in a large proportion of eases, as in that represented in Fig. 33, past eye-strain, with hyperemia of the part suceeded by atrophy. 'The extension of the atrophy and the pushing before it of 
irregular pigmentation, usually to the temporal side of the disk, give the atrophic ereseent of myopia (see Figs. 33 and 34). Sometimes the area of this erescent is entirely white or yellowish white, exeept where the retinal vessels eross it; in other eases it shows irregular pigment-patches.

Pigment-blotches at the macula result from inflammation of the choroid, or perhaps hemorrhages. Multiple patches of pigment-deposit with choroidal atrophy, whether few or many, indicate disseminated choroiditis (see Fig. 110). Where numerous, they are frequently confluent, forming large areas. The pigmentdeposit marks a late stage of choroiditis. During the early stages there is no increase of pigment; and when the deposit becomes entirely stationary, it is probable that the morbid process has run its course, and that no further change will occur.

Spots with rounded or oval outline, either discrete or confluent, may be indicative of syphilis, but cannot be regarded as pathognomonic. Sometimes choroidal changes accompany the bone-corpuscle pigment-patehes characteristic of retinitis pigmentosa ; this association usually indieates a form of disease due to aequired syphilis.

\section{CHOROIDAL EXUDATE AND CHOROIDAL ATROPHY.}

A light spot in the fundus is known to be due to lesions lying back of the retina, when the retinal vessels pass across it without being rendered less distinct, or when choroidal vessels are seen in it. Yellowish or orangecolored spots, generally slightly swollen, sometimes surrounded by a darker red than is normal to the fundus, indicate localized exudation into the choroid. Very acute choroidal exudation is usually attended with considerable haziness of the retina and vitreous in front of it; where the choroidal condition is not thus veiled, it is probably somewhat chronic.

From the yellowish indefinite discoloration of the choroidal exudation there is, with the progress of the 
ease, the gradual passing over into the whiter, but still somewhat yellow, pateh of atrophy. As the transition occurs, the swelling disappears, and usually along the margin of the spot pigment-deposits beeome evident.

Primary atrophy, or atrophy withont swelling of the ehoroid, leads fir'st to a diminution of the fundus red; then the larger ehoroidal vessels become visible. Later, these too mulergo eontraction, and may also entirely disappear. There remains then only the white area of selera, more or less diseolored by pigment, over which may pass the retinal or some of the largest choroidal vessels. As eompared with the color of the normal disk, complete ehoroirlal atrophy is decirledly whiter ; but it never presents the gleaming white appearanee of medullated nervefibers, or fatty degeneration of the retina in albuminuric retinitis.

The "Myopic" Crescent.-The commonest seat of choroidal atrophy is to the temporal side of the disk, where it may be seen in many cases of severe eye-strain, being most largely developed in eases of progressive myopia. Such an atrophy starts first as a yellow erescent lying on the temporal side of the disk, which broadens either by gradual extension, or by the suceessive appearance of similar erescents of atrophy to the tenporal side. If these proceed far enough, there results a somewhat triangular area of yellowish white, with its base at the disk and its apex toward the maeula, ealled a conus (see Fig. 63). With its extension in this direction the atrophy is apt also to eneirele the disk, and gradually extend in other directions.

Other Local Lesions.-Less frequently choroidal exudate or atrophy is found in other parts of the fundus, being most serious in the region of the macula, which should be carefully searehed for them. Snch areas may also be found confined to the periphery of the fundus.

One or more erescentic areas, approximately concentric with the optic disk, but quite removed from it, generally in the direction of the macnla, sometimes even beyond it, are characteristic of so-called mpture of the choroid (see 
Fig. 148). They are usually attended with marked alterations of other parts of the fundus. Oecasionally there oeeur sharply defined, rounded areas, or a similar white area stretches from some point below the disk or even from above the disk forward to the lower periphery of the fundus. This is coloboma of the choroid (see Fig.

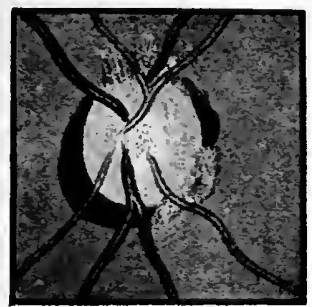

$34 a$.

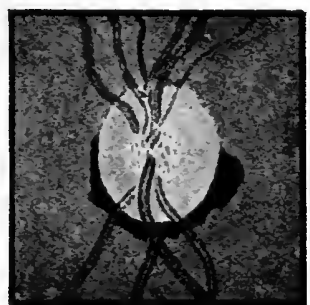

$34 b$.

FIGs, $34 a$ and $34 b$.-Anomalous deposits of pigment in the choroidal ring.

115). Anomalies of the choroid, sueh as are shown in Figs. $34 a$ and $34 b$, and which are due simply to an unusual formation of pigment, and not to any pathological ehange, are generally to be known by absence of atrophy in eonneetion with the pigment deposit. (Compare with Figs. 33 and 34.)

\section{CHAPTER V .}

REFRACTION; PRISMS AND LENSES, AND THEIR STRENGTH AND NUMBERING.

UPOx the free surface of the body light falls from eaeh point of every visible object, and were the sensitive retina so placed as to reeeive this light, each point of the retina would be impressed by light from every luminous point before it. Eaeh point of the retina would then receive an impression similar to that made upon every other point, giving only a general pereeption of light. 
For eomplete vision each luminous point must make its distinct impression on a single point of the retina, and through it upon a single nerve-cell or group of nervecells in the brain. 'To accomplish this, the light falling on the retina must be assorted or focussed. To support the retina so that it shall properly receive assorted light is the function of the eyeball. The assorting is effeeted in the human eye by refraction, and the whole function of the eyeball being to support and protect the retina so that it may reeeive properly refracted rays, the refraetion of the eye is of primary importanee in its physiology and pathology.

\section{REFRACTION OF LIGHT.}

Light consists of successive waves passing from each luminous point in all direetions, like the waves which arise when a stone is dropped in still water.

The direction of wave-movement is always perpendicular to the wave-crest or wave-front.

Waves of light travel faster in some substances than in others. Upon these two faets depend all the phenomena of refiaction.

In Fig. 35 the eireles represent wave-fronts of light from a luminous point, $A$. The radiating lines perpendicular to the wave-fronts represent the directions in

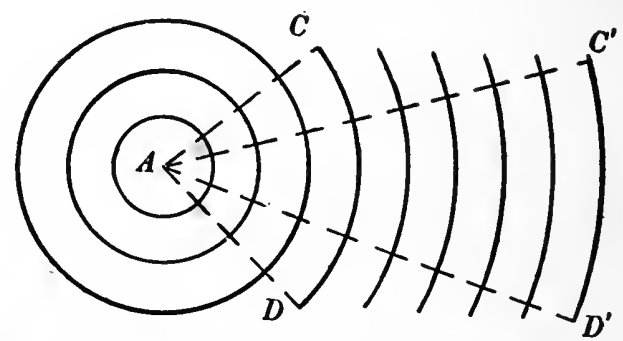

FIG. 35.-Waves of light passing off from a luminous poinl, and rays along which the light passes.

whieh the different parts of these wave-fronts are moving. They are ealled "rays" of light. Close to the point from 
which the light emanates, the rays included in a given space as $C D$ will be very divergent. At a greater distance the rays included in this same space $C^{\prime} D^{\prime}$ will $\cdot$ be less divergent. As the waves pass on, the included part of a wave-front becomes more and more nearly straight, and at an infinite distance the rays included in a certain space would be parallel, and the parts of the wave-fronts not circular but straight. Here we have only to consider the rays and parts of the wave-fronts that enter the eye through the pupil, usually from 3 to $6 \mathrm{~mm}$. in diameter. It is customary to speak of rays that come from 20 feet and only diverge the width of the pupil as parallel rays. This is not strictly correct; but it is convenient, and unless otherwise stated, they will be so considered here.

Transparent substances are called dioptric media. Of the dioptric media we have to consider, light moves most rapidly through air. If we take the time it requires for light to travel a given distance in air as 1, the times required to travel the same distance in other transparent substances are indicated as follows :

Water, the cornea, aqueous or vitreous humors, . . . 1.33

The crystalline lens,. . . . . . . . . . . . . 1.45

Crown glass, used for spectacles, . . . . . . . . 1.53 to 1.54

Rock crystal, "pebble,". . . . . . . . . . . 1.56

Flint glass, . . . . . . . . . . . . 1.57 to 1.70

Diamond, . . . . . . . . . . . . 2.25 to 2.60

Such a number indicating the relative length of time required for light to travel a unit of distance in a given substance is its index of refraction.

When light passes from a substance having one index of refraction into a substance having another index of refraction, its rate of movement undergoes a change corresponding to the difference between the two. On account of slower movement the successive waves will be closer together in the medium having the higher index, and on account of faster movement they will be farther apart in the medium having the lower index of refraction. What occurs when the wave-fronts correspond to the surface 
separating the media and the rays fall perpendicular to that surfice, is shown in Fig. 36 .

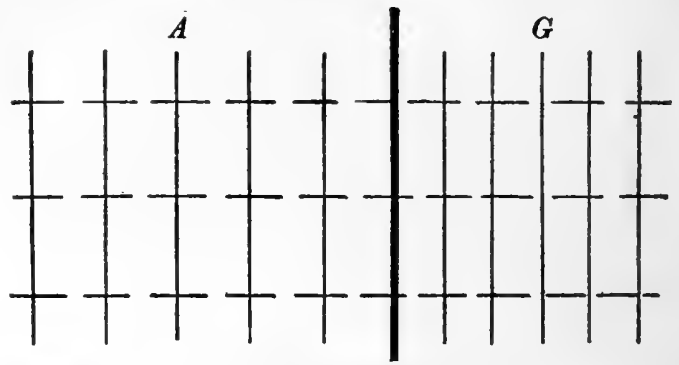

Fig. 36.-Waves of light passing from air into glass, retarded, but their direetion not altered.

Within the substance $G$ (glass) having the higher index, the wave-fronts are eloser together, but have the same direction, and the rays perpendieular to them lave the same direction, as in the substance $A$ (air). This is true whether the waves be passing from $A$ to $G$ or from $G$ to $A$.

When the waye-fionts and rays strike obliquely the

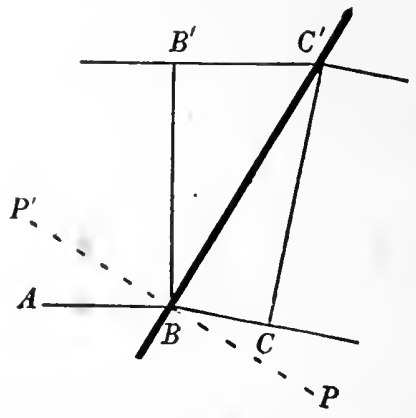

Fig. 37.-Refraction of light when the waves pass olliquely from the air into glass, illustrating the "law of the sines."

surface separating the dioptric media, the effeet is different, as illustrated in Fig. 37. 
When a wave-front travelling through air reaches the position $B B^{\prime}$, a portion at $B$ passes into the second medium, which we will take as glass, and its movement is immediately retarded, so that while $B^{\prime}$ travels to $C^{\prime \prime}, B$ only travels to $C$, a distance the reciprocal of the index of refraction of the glass, $\frac{1}{1.53}$. The effect of this is that when the wave has reached $C C^{\prime}$, its direction has essentially changed; since light moves along lines perpendicular to the wave-fronts, its movement will now be in rays perpendieular to $C C^{\prime}$, making a decided angle with the rays perpendicular to $B B^{\prime}$. By passing obliquely from one dioptric medium into the other, the direction of the rays of light has been changed.

The same thing occurs if the light passes from the glass into the air, the wave-front going from $C C^{\prime}$ to $B B^{\prime}$. In either case the direetion of the ray is equally bent at the surface separating the two media. But, in passing toward the medium having the higher index, ealled the more refracting, the ray is bent toward a perpendieular $P P^{\prime}$ of the bounding surface; and in passing toward the medium with a lower index of refraction, called the less refracting medium, the ray is bent from the perpendicular. The amount of this bending depends on the difference of the indexes of refraction and on the obliquity of the wavefront to the bounding surface. The more the wave is retarded by the glass or the farther the wave at $B$ has to travel in the glass while the part at $B^{\prime}$ is still in air, the greater will be the change of direction.

If $P P^{\prime}$ be drawn perpendicular to the bounding surfaee at $B$, the angle $A B P^{\prime}$ between the perpendieular and $A B$, the direction of the ineident ray, is called the angle of incidence; and $C B P$, the angle between the same perpendicular and the direction of the ray after it has been refracted, is called the angle of refraction. The relation of one of these angles to the other is illustrated in the triangles $B B^{\prime} C$ and $B C C^{\prime}$, the angle $B^{\prime} B C^{\prime}$ being equal to the angle of incidence, $A B P^{\prime}$ (because their sides are mutually perpendicular), and the angle $B C^{\prime} C$ being equal 
to the angle of refraction $P B C$ (because their sides are mutually perpendicular). But these two triangles $B B^{\prime} C^{\prime \prime}$ and $B C^{\prime} C$ are right-angled triangles with a common side $B C^{\prime}$, which may be taken as radius or 1 , for both triangles. By the common relation of the sides of a riglit-angled triangle to the sine of the opposite angle we have

$B C^{\prime}: 1:: B^{\prime} C^{\prime}: \sin B^{\prime} B C^{\prime}$, the angle of ineidence. $B C^{\prime \prime}: 1:: B C: \sin B C^{\prime} C$, the angle of refraction. or $B^{\prime} C^{\prime}: \sin B^{\prime} B C^{\prime}:: B C: \sin B C^{\prime} C$. $\sin B^{\prime} B C^{\prime}: \sin B C^{\prime} C:: B^{\prime} C^{\prime \prime}: B C$.

That is, the sine of the angle of refraction is to the sine of the angle of incidence, as the index of refraction of the substance from which the light passes is to the index of refraction of the substance to which the light passes. This is called the law of the sines; and, as is shown above, depends simply on the fact that light moves perpendicular to its wave-fronts.

When light passes through a plate of glass with parallel sides, if it enter the glass in such a way that the rays are perpendienlar to the surfaee, their direetion will not be changed either on entering or leaving the glass. The whole wave-front entering the glass at the same time is equally retarded, and keeps its original direetion, merely moving through the glass more slowly; and on reaching the other surfaee it all passes out at once, and has its movement equally aecelerated in all parts (see Fig. 36). If a ray of light fall obliquely upon the surface of the glass, it will be refracted toward the perpendieular on entering the glass, but equally from the perpendicular on leaving it if the two surfaces of the glass are parallel; so that the direction of the ray after leaving the glass is parallel to its direetion before entering it. This is shown in Fig. 38 , the ray $A B$ being refracted toward the perpendienlar on entering the glass at $B$, and being refracted from the perpendicular on leaving the glass at $C$, so that the direetion of $C D$ will be parallel to $A B$.

When, however, light passes through a piece of glass, 
the sides of which are not parallel, but inclined toward one another, the portion of each light-wave that has to pass through the thicker part of the glass is more retarded

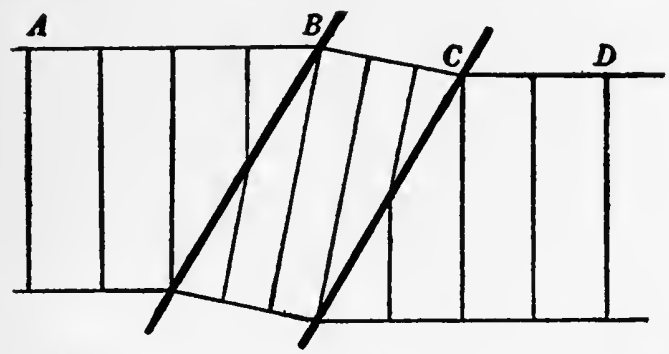

Fig. 38.-Refraction of light by a plate of glass with parallel sides. Direction of waves and rays altered on entering the glass, and restored on passing out.

than the portions of the wave which pass through the thinner portions of the glass; and, on this account the direction of the wave-fronts, and the direction of the rays

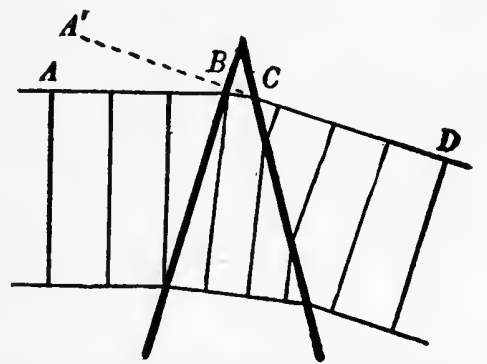

FIG. 39.-Refraction of light by a prism. Direction of waves and raye altered on entering the prism, and still further altered on leaving it.

perpendicular to it, are permanently changed. This change is illustrated in Fig. 39, in which the wave-fronts are changed from their original direction on entering the glass, and swung around still further on leaving it, $C D$ having an essentially different direction from $A B$. In all cases the part of the wave-front which goes through the thicker portion of the glass is more retarded, so that the ray is bent toward that part of the glass. 


\section{PRISMS.}

A piece of glass bounded by plane surfaces which are inclined toward each other is called a prism. The line in which these plane surfices intersect is the edge or apex of the prism. The thickest portion is the base of the prism. The angle between the two intersecting surfaces is ealled the refracting angle of the prism.

From what has been demonstrated it is evident that if light passes through a prism it will be turned toward the base, and after leaving the prism will proceed as thongh from $A^{\prime}$ (Fig. 39), more in the direction of the apex. The refracting pouer of the prism (its ability to turn rays of light from their original direction) depends first on the index of refraction of the glass of which the prism is composed as compared with that of the air around the prism. This determines the retardation of the wave while in the prism. Second, it depends on the shape of the prism, which determines how much longer one part of a lightwave is subjected to the retarding influence of the glass than another part.

The higher the index of refraction of the prism and the larger its refracting angle, the "stronger" the prism. The effeet of the prism also depends on its obliquity to the light. If the light enters or leaves the prism very obliquely, it acts as a.stronger prism. This can be demonstrated thus: Take a weak prism from the trial case, hold it so as to be nearly perpendicular to the line of sight, and note the displacement it seems to cause in a line, like a window-sash. Then rotate the $\cdot p r i s m$ about its base or apex, and note how the displacement increases as the surfaces become oblique. The effect of a prism also varies with the color of the light that it refracts. A prism of a given strength refracts the blue and the violet rays more than the red. The difference of effect of the same prism on light of different colors, canses the dispersion of white light into the prismatic colors or spectrim. This power of dispersion differs with different substances, but not in proportion to the index of refraction. 
Dispersion is much less through the erown glass, ordinarily used for spectacles, than it is for the heavier, softer "flint" glass, employed in some other optical instruments.

Numbering of Prisms.-Formerly prisms were numbered by the refraeting angle-that is, a prism having surfaces which met at an angle of 10 degrees was called a No. 10 prism. 'This wats its number whatever the kind of glass from which it was made, so that prisms having the same number would vary according to the index of refraction of the glass of which they were conposed. In 1887 the writer suggested that they should be numbered aceorling to the effect they prodnce on the light passing through them, aceording to their angle of deviation.

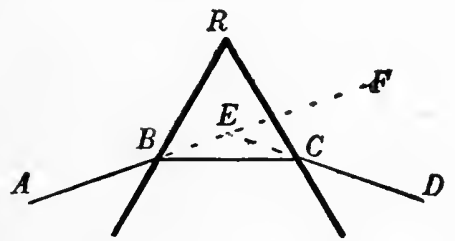

Fig. 40.- The course of a ray $(A B C D$ ) refracted by a prism.

In Fig. 40 the ray $A B$ passing through the prism is turned, so that instead of continuing in the direction of $F$ it proceeds toward $D$. The angle $D E F$ is the angle of deviation. For "erown" glass this is somewhat more than half the refracting angle $B R C$, so that if the prism were numbered by degrees of deviation, a given number wonld indicate a prism of almost donble strength of the old system. It is, however, proposed instead of numbering the prism by degrees of deviation it produces, to number it by the centrads (Dennett) or prism diopters (Prentice) of deviation that it produces. A centrad being a deviation, the are of which is $\frac{1}{100}$. of the rallius, and the prism diopter a deviation, the tangent of which is $\frac{1}{100}$ of the radius.

For the strength of prisms ordinarily used, these will 
be practically the same thing; and numbered by either centrads or prism diopters, the numbering corresponds very closely to that of the old system, because the prism with one degree of refracting angle causes very nearly one centrad, or one prism diopter of deviation.

The exact relations of the two systems are shown in the following table:

\section{TABle I.-Numbering of Prisms.}

\begin{tabular}{ccc|ccc}
\multicolumn{2}{c}{ Deviatioss. } & \multicolumn{3}{|c}{ Deviations. } \\
Centrads. & Prism Diopters. & $\begin{array}{c}\text { Refracting } \\
\text { Angle. }\end{array}$ & $\overbrace{\text { Centrads. }}^{\text {Prism Diopters. }} \begin{array}{c}\text { Refracting } \\
\text { Angle. }\end{array}$ \\
1 & 1. & 1.06 & 9 & 9.02 & 9.39 \\
2 & 2. & 2.12 & 10 & 10.03 & 10.39 \\
3 & 3. & 3.18 & 11 & 11.03 & 11.37 \\
4 & 4. & 4.23 & 12 & 12.04 & 12.34 \\
5 & 5. & 5.28 & 13 & 13.06 & 13.29 \\
6 & 6.01 & 6.32 & 15 & 15.11 & 15.16 \\
7 & 7.01 & 7.35 & 20 & 20.26 & 19.45 \\
8 & 8.02 & 8.38 & 50 & 54.62 & 36.03
\end{tabular}

The 30 centrad prism is just thirty times as strong as the 1 centrad prism. It will be noticed that no such relation exists between the strength and the numbers of the prisms by the old system.

The practical uses of ophthalmic prisms will be discussed in connection with spectacles (Chapter VII) and anomalies of the ocular muscles (Chapter VIII).

\section{LENSES.}

A lens is a portion of a dioptric medium bounded by one or more curved surfaces. In passing through plane surfaces, plane light-waves retain their original form, and the rays keep their original relation to one another. In passing through curved surfaces, however, the light-waves become curved, or their curves become altered, so that the relation of the rays perpendicular to them is also altered.

This is illustrated in Fig. 41. The portion of each light-wave that strikes the lens first is retarded, the por- 
tions remaining in the air get ahead of it, changing the shape of the wave-front. Again, the part of the wavefront getting out first gets ahead of the part still in the glass, and the form of the wave is still farther changed.

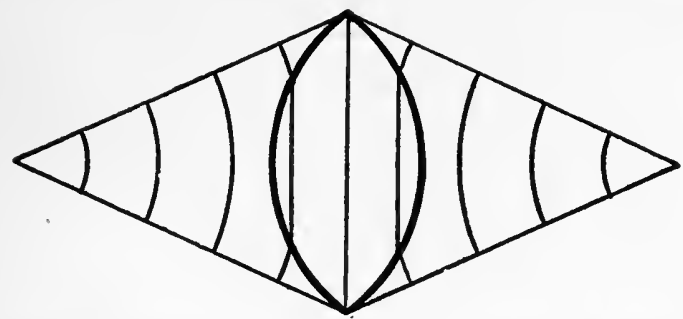

Fig. 41.-Effect of convex lens on waves of light passing through it.

In a lens, like the one represented in Fig. 41, thiekest at the center, called a convex lens, the effect is to turn all parts of the wave toward the center, and so to converge it to a single point or focus.

With the opposite kind of lens, represented in Fig. 42, ealled a concave lens, thimnest at the center and

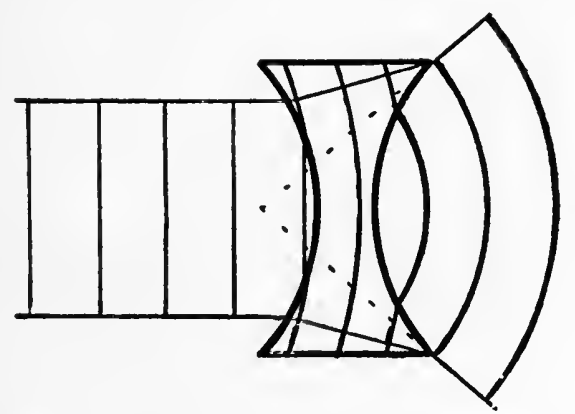

Fig. 42.-Effect of concave lens on waves of light passing through it.

thickest at the margins, the waves are most retarded at the margins, present convex surfices after passing through the lens, and tend to spread out as though they had 
started from a certain point, or focus in front of the leus.

It is olovious that, in the first case, all the rays of light tend, after passing through the lens, to eome together at the focus, which is called a real focus. In the second case, after passing through the lens they all diverge as though they had started from the focus, which is ealled a virtual focus.

Another way to understand a lens is to regard it as made up of a double series of prisms, very weak at the center of the lens and increasing in strength as we go toward the margin (sce Fig. 43). Near the center the rays will be refracted as by a weak prism, and the rays more removed from the center will be refracted as by stronger and stronger prisms.

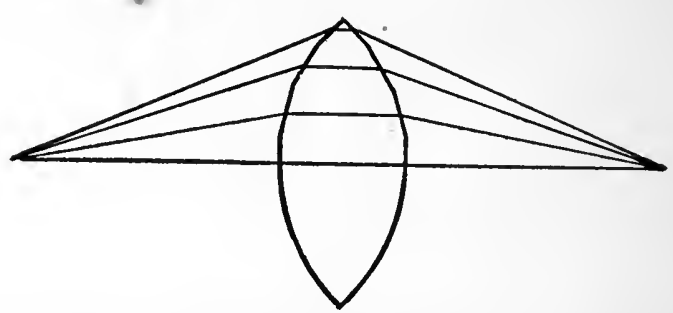

FIG. 43.-Refraction by a lens, resembling refraetion by a series of prisms which grow stronger the farther removed from the optical eenter.

At one point of every eomplete lens the two surfaces are parallel. Rays passing through this point, as through a plite of glass with parallel sicles, eontinue their course unrefracted. This point is ealled the optical center of the lens. In a convex lens it is the thickest part of the lens; in a concave lons it is the thinnest part.

Varieties of Lenses.-Convex and concave lenses are made of the different forms represented in Fig. 44. 1 is ealled a plano-convex, one side being plane. 2 is a double convex, both sides being convex. It is called biconvex when both sides are equally convex. 3 is a comcavo-concex, one side coneave, the other more convex. 4 is 
plano-concave, 5 is a double concave or bi-concave, 6 is convexo-coneave; 3 and 6 are also ealled meniscus or periscopic lenses. All that are thickest at the center have the

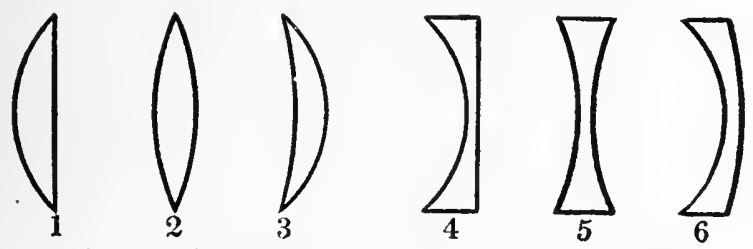

FIg. 44.-Different forms of convex and concave lenses.

effect of convex lenses, and all that are thinnest at the center have the effect of concave lenses.

Strength of Lenses.-A lens of a certain strength causes a certain amount of change in the direction of rays passing through it. If these rays are parallel when they fall upon it, they are converged to a certain focus $F$ by a convex lens (Fig. 45), or diverged from a certain focus by a concave lens (Fig. 46).

If rays diverge from the focus (Fig. 45) of a convex lens, they will be rendered parallel by it. If rays were converging (Fig. 46) toward the focus of a concave

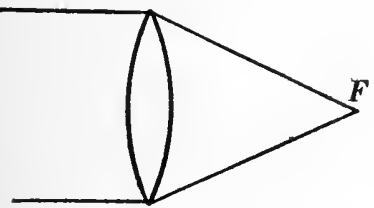

FiG. 45.-Focussing of parallel rays by a convex lens.

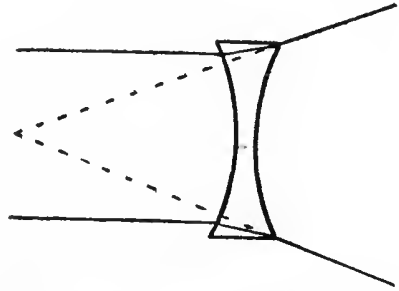

Fig.46.-Concave lens dispersing rays as though from its virtial focus.

lens they would be rendered parallel by it. The change in the direction of the rays is the same whichever way they pass through the lens.

If instead of falling upon the lens parallel, they reach 
it somewhat divergent, the convex lens will converge them to a focus farther away from it than its foeus for parallel rays, or the concave lens diverge them from a foens nearer the lens than the focus for the parallel rays. If they fall on the lens convergent, the convex lens will eonverge them to a nearer foeus, and the concave lens will diverge them from a focus farther away. Thus, for every point from or toward which the rays pass before striking the lens there will be a corresponding focus to or from which they will go after leaving it. In this way every lens has an infinite number of foci, corresponding to the different distances from which rays may come.

In order to compare the strengths of different lenses it is necessary to take their focal distance for rays of the same sort. For this purpose the focal distance of the lens for parallel rays is taken, the focus for these rays being called the principal focus and its distance from the lens the principal focal distance.

If not otherwise indicated, when the focus of a lens is spoken of, it will be understood that the principal focus is referred to, and that its focal distance means principal focal distance.

By the strength of a lens is meant its power of turning rays from their original course. If this be great, the lens is spoken of as stiong; if it be slight, the lens is weak. A strong lens will bring rays quickly to a focus; a weaker lens has its foeus at a greater distance. The distance of the focus from the lens is the inverse or reeiprocal of the strength of the lens. Representing the distance of the foeus from the lens by $F$ and the strength of the lens by $S$,

$$
\mathrm{F}=\frac{1}{\mathrm{~S}} \text { and } \mathrm{S}=\frac{1}{\mathrm{~F}}
$$

Numbering of Lenses.-The Inch System.-The first lenses used for ophthalmic purposes were numbered aceording to the radius of eurvature of the tool on which they were ground, both surfaces having the same curvature. With the glass commonly employed in them it happened that for such a lens, the number indieating the 
radius of curvature in inches also indieated approximately the number of inches of the principal focal distance. The radius of eurvature was a hittle greater than the focal distance. But nost of the early trial-sets were made in Paris and Berlin, and numbered according to Paris and Berlin inches, which are slightly longer than the English inch. Therefore, in English-speaking countries, the number of longer French or Prussian inches in the longer radius of curvature almost exactly corresponded to the number of shorter English inches in the shorter focal distance. The numbers, therefore, were soon generally regarded as indicating the focal distance of the lens.

In such a system of numbering the strength of the lens was necessarily expressed by a fraction-one divided by the focal distance of the lens. Thus, the 18-inch lens had a strength of $\frac{1}{18}$. In combining lenses in practical work, it becomes necessary to add and subtract the strengths of the lenses combined. Such calculations must be made repeatedly for every eye that is tested, and the difficulty of adding and subtracting vulgar fractions made it a matter of serious importance. Minor objections to the old system of numbering were the variations of inches in different countries, and the irregular intervals in the series.

To avoid these objections the dioptric or metric system of numbering lenses was adopted. In it each lens is numbered by its strength, in whole numbers or in decimal fractions, which ean be added or subtracted like whole numbers. The unit is a diopter-the focussing power required to bring parallel rays to a focus at a distance of 1 meter. A lens that has this focussing power is called a 1 diopter lens. A lens having twice this strength is called the 2. D. lens, and has a focal distance of onc-half meter. One three times as strong is a 3 . D. lens, and has a focal distance of one-third meter. One having only a quarter of the unit of strength is a $0.25 \mathrm{D}$. lens, and has a focal distance of 4 meters; and so on throughout the series.

The greater convenience and uniformity of the dioptric 
or metric system have caused its general adoption. It is, however, well to be familiar with the old or inch system of numbering, since in certain cases we lave to add to, or subtract from, the focal distance of a lens. In these cases the old or inch system is much the more convenient, because in it the focal distances are expressed in whole numbers.

The equivalents for the metric lenses in ordinary use are given in the following table. The first column gives the metric number, the second gives the exact equivalent focal distance in inches, and the third column gives the nearest equivalent commonly furnished in trial sets, or spectacle lenses numbered according to the old system.

\section{Table II.-Numbering of Lenses.}

Strength,

Diopters.

$0.12(0.125)$

0.25

0.37

0.50

0.62

0.75

0.87

1.

1.12

1.25

1.37

1.50

1.75

2.

2.25

2.50

2.75

3.

3.25

3.50

3.75

4.

4.50

5.

5.50

6.

7 .

8.

9.
Focal Distance, Inches.

315.

157.5

105.

78.7

63.

52.5

45.

39.37079

35.

31.5

28.6

26.2

22.5

19.7

17.5

15.7

14.3

13.1

12.1

11.2

10.5

9.8

8.7

7.9

7.2

6.5

5.6

4.9

4.4
Number in

Old Series.

144

100

72

60

48

40

36

30

24

20

18

16

14

12

11

10

9

8

7

6

$5 \frac{1}{2}$

5

$4 \frac{1}{2}$ 


$\begin{array}{ccc}\begin{array}{c}\text { Strength, } \\ \text { Diopters. }\end{array} & \begin{array}{c}\text { Foeal Distance, } \\ \text { Inehes. }\end{array} & \begin{array}{c}\text { Number in } \\ \text { Old Series. }\end{array} \\ 10 . & 3.9 & 4 \\ 11 . & 3.6 & 3.1 \\ 12 . & 3.3 & 3 \\ 13 . & 3 . & 2.3 \\ 14 . & 2.8 & 2.1 \\ 15 . & 2.6 & \\ 16 . & 2.4 & 2 ! \\ 17 . & 2.3 & \\ 18 . & 2.2 & 2 \\ 19 . & 2.1 & \\ 20 . & 2 . & \end{array}$

The Trial Set.-The lenses mentioned in the above table are the spherical lenses, convex and concave, which wonld be furnished in pairs in a complete trial set. In addition the set shonld contain cylindrical lenses having the same numbers up to 6. or 8. D., prisms of 1 to 20 centrads, a stenopaic slit, a pinhole disk, metal and ground glass disks, and two or more trial frames to support the glasses before the eyes. Some of the weaker lenses may be omitted, making the smallest interval $0.25 \mathrm{D}$. instead of $0.12 \mathrm{D}$., without much impairing the practical usefulness of the set, even a very much smaller set will answer the purpose. Thus by combining two or more lenses, one can get all necessary powers from these few- -0.25 , $0.50,0.75,1 ., 2 ., 3 ., 4 ., 5 ., 10$. and 15. D. A larger assortment is simply more convenient.

Use of Trial Lenses.-The lenses are used by placing them before the patient's eye, to find by trial the lens or combination of lenses with which he sees best. This might be thought to require no special skill, and yet accurate results with the trial lenses are not obtained - without care, system, experience, and good judgment.

If the testing is too long continued, the patient's attention is exhausted, and his answers become inaccurate and unreliable. On this account it is always best to know pretty nearly what his refraction is before starting with the test lenses. Here is the great value of other methods of measuring refraction. Then if the patient does tire with the lenses, he should be allowed to go, and come 
again to have the test completed at another hour or on another day.

To secure reliable answers the change made in the lens should always be so great that the patient can eertainly notice an effect from it. Only when the vision is normal, and the patient is a pretty good observer, can a $0.25 \mathrm{D}$. of change be certainly recognized. Until vision has been bronght up, to about the normal, the changes in the lenses should be $0.50 \mathrm{D}$., or greater if the vision is very poor.

The change from one lens to another should be as nearly instantaneous as possible. This is aceomplished by holding in the hand both the lenses that are to be compared, and moving first one before the eye and then the other in immediate succession; or by placing one lens in the trial frame and then holding before it a weak supplementary lens which, when added to the lens in the trial franie, will make the desired change of strength. The supplementary lens is held before the eye and then removed, and this may be repeated several times, so that by repeated trials the patient can make sure which is the better.

Often it is best to take two supplementary lenses in the hand, one a weak convex, the other a weak concave, and by trying first one and then the other, to ascertain if it makes the vision better, to increase or to diminish the strength of the lens before the eye. Thus, in a case in whieh $a+2$. D. lens seemed to be required, this should be placed in the trial frame and $\mathrm{a}+0.50 \mathrm{D}$. and $\mathrm{a}-$ $0.50 \mathrm{D}$. taken as supplementary lenses; and held alternately before the lens in the trial frame. The patient, being asked which makes vision better, may say that the $-0.50 \mathrm{D}$. makes it worse, but that he is uncertain if the $+0.50 \mathrm{D}$. really improves it. This would indieate that +1.50 was worse than +2 ., but that it was doubtful if +2.50 were better than +2 . Hence, +2.25 would probably prove the best correction. Here the doubling of a change by reversal is utilized. When the change from 2 . to 2.50 did not make a very positive improvement, the comparison of the 2.50 with 1.50 gave unmistakable evidence in favor of the former. 
Fogging.-To bring out as much hyperopia as possible without a eycloplegic, the test at the first visit having indicated certain lenses, at subsequent visits the previously determined correetion, to whieh has been added convex spherical $0.5 \mathrm{D}$. or $1 \mathrm{D}$., is placed before each eye. This causes indistinctness of distant vision or " fogging." The two eyes are then compared by alternately covering first one and then the other; and if one shows decidedly more blurring than its fellow, the convex spherical before it is reduced until vision in the two eyes is about equal. Then the sphericals are reduced before both eyes until the best vision is obtained. (For the use of cylindrical lenses, see page 183.)

\section{CHAPTER VI.}

REFRACTION OF THE EYE; MYDRIATICS AND

MYOTICS; THE REFRACTION OPHTHALMOSCOPE; SKIASCOPY.

Assorting of Light.-If we take a eonvex lens, as in Fig. 47, and suppose light to fall upon it from different points, as $A$ and $B$, from each of these points, one ray will pass through the optical center, entering the lens and emerging from it at points where its two surfaces are

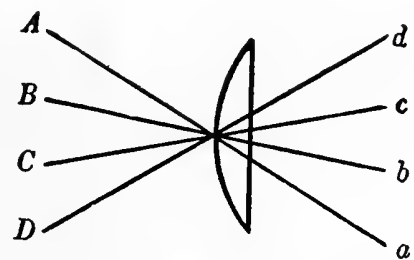

FIG. 47.-Rays that pass through a lens without being refraeted.

parallel. These rays will not be refracted, but pass on in their original direction. All the other rays that fall upon 
the lens will be bent from their original course toward the rays passing through the optical center. All the rays from $A$ being bent toward $a$, and all the rays from $B$ being bent toward some point $b$. The same thing is true of any number of points, the rays from $C$ being collected at $c$, and those from $D$ at $d$. In this way all the light falling on the lens is assorted, the light from each point in front of the lens being colleeted at a single point behind it.

In the eye the convex surface of the cornea acts on the light which enters it as a eonvex lens. Behind it is the crystalline lens, acting as another convex lens. The average normal cornea eonverges to a point $31 \mathrm{~mm}$. behind it, laving a focussing power of $32 \mathrm{D}$. The crystalline lens may be regarded as $6 \mathrm{~mm}$. behind the cornea, where the rays are converging toward a point $25 \mathrm{~mm}$. awaythat is, they are convergent to $40 \mathrm{D}$. The lens has a converging affect of $20 \mathrm{D}$., which, added to the $40 \mathrm{D}$., makes $60 \mathrm{D}$.; and after passing through the lens the rays converge to a point $1000 \div 60=16.667 \mathrm{~mm}$. behind it, or . $22.667 \mathrm{~mm}$. behind the eornea, the point to which they would converge if the cornea had a refracting power of $44 \mathrm{D}$. This is the dioptric eye.

The eye may be regarded as though the cornea and the erystalline lens were replaced by a single stronger convex lens situated at the cornea. Most of the optical problems of the eye can be worked ont more readily, and for all practical purposes with equal exactness, with some such reduced eye. The reduced eye of Donders has a cornea with a radius of $5 \mathrm{~mm}$., and the retina $20 \mathrm{~mm}$. behind it.

In the eye the assorting of the rays is accomplished by its foeussing power. This is represented in Fig. 48. The rays coming in a certain direction, as from the point $A$, are focusses on a certain point $a$ within the eye. The rays entering the cye from the point $B$ are focussed at the point $b$. It will be noted that the rays are gradually concentrated, until a certain distance back from the cornea, those coming from a single point ontside of the eye are brought to a single point within it. The assorting of the rays is perfect only at this point. If the rays pass 
beyond $a b$ they again spread ont and intermingle. It is only at the one distance that the focussing is perfect, and at this distance back of the cornea the retina must be

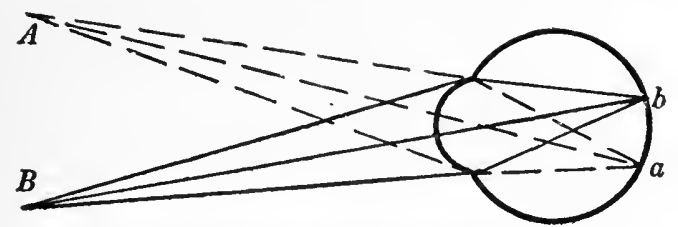

FIG. 48.-The focussing or assorting of light by the eye.

placed, if it is to receive perfectly focussed light, which alone permits clear vision.

Refraction of the Eye.-We have seen, however, that with any convex lens, the lays coming from points at different distances in front of the lens will be focussed at different distances behind it. It is, therefore, customary to speak of the refraction of the eye, as we do of the refraction of a lens, with regard to its influence on parallel rays.

An eye that is so proportioned that parallel rays will be focussed on the retina as at $E$ (that has the prineipal focus of its dioptric media on its retina) is said to be emmetropic. Its state of refraction is emmetropia. If the retina be situated in front of the principal focus of

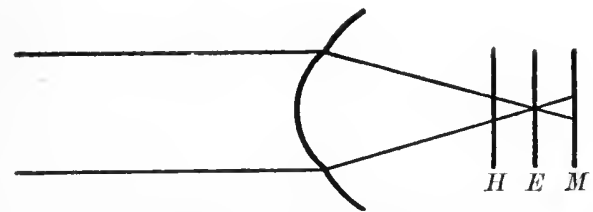

FIG. 49.-Position of retina in hyperopia, emmetropia, and myopia.

the dioptric media, as at $H$ (parallel rays tending toward a focus back of the retina), its refraction is hyperopia, and the eye is hyperopic or hypermetropic. If the retina is situated back of the focus of the dioptric media, as at $M$ (parallel rays being foeussed in front of it), the refrac- 
tion of the eye is myopia, and the eye is myopic. Emmetropia must be regarded as the standard of refraction for the eye. All departures from this standard are included under the general term ametropia. Such departures from the standard of ocular refraction are spoken of as errors or anomalies of refraction.

Accommodation.--To get distinct focussing of rays having different degrees of divergence the eye has the power of varying its lens-strength-the power of accommodation.

The refraction of the eye means its optical condition with reference to parallel rays when it is entirely at rest. This optical condition is independent of any musenlar exertion, and remains the same immediately after death, or when all power of accommodation is removed, as by the use of a mydriatic. In this condition its refraction is

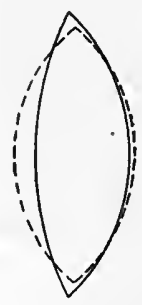

FIG. 50.-Change in lens during aecommodation: Solid unes showing outline with $A$, relaxed; broken line outline of lens during aceommodation.

at its weakest. The power of accommodation is the power to increase the refractive effeet of the eye, by increasing the enrvature of the crystalline lens. This increase of eurvature is blought about by the natural clasticity of the crystalline lens, which causes it to assume a more convex form, when it is released from the tension of the anterior and posterior layers of its eapsule, between which it is usually somewhat compressed and flattenerl.

The increased convexity of the lens occurs chiefly near its anterior and posterior poles. The change of shape 
consists not in the lens becoming more globular, but in the development of an anterior and a posterior lenticonus. (See Fig. 50.) Accommodation is rendered more effective by the accompanying contracted pupil, which admits light only through the more convex center of the lens.

In any case it is certain that accommodation depends on two factors-the active contraction of the ciliary muscle, and the flexibility and elasticity of the lens. In early childhood the lens is most flexible and elastic. Year by year it becomes less flexible, and loses its elasticity; until, at about sixty or seventy years of age, it becomes so rigid that it can undergo no change of shape under the influence of the ciliary muscle. The loss of elasticity causes loss of power of accommodation, which goes on until at the age mentioned that power is usually

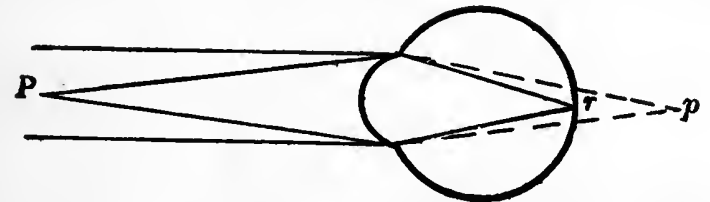

FIG. 51.-Effect of accommodation in focussing rays from a near point.

completely lost. Later the ciliary muscle undergoes atrophy.

Pseudo-accommodation.-Occasionally after the removal of the crystalline lens the patient is able to see well through the same lens at different distances. This may be due to the smallness of the pupil ; to differences in refraction in different parts of the pupil; to looking obliquely through the lens, or by varying the distance of the lens from the eye.

Effect of Accommodation.-This may be better understood by study of Fig. 51, representing an emmetropic eye. The parallel rays coming from distant objects are focussed on the retina; but rays coming from a near point $P$ won!d, with the eye at rest, focus back of the retina at $p$. By increasing the convexity of the lens to just the proper extent, the focus of the dioptric system of 
the eye is shortened, so that for these diverging rays it falls upon the retina at $r$.

The extent of ehange in the shape of the lens varies with the contraction of the ciliary muscle, and can by it be adjusted to rays of various degrees of divergenee. The variation of refractive power of which a given eye is capable begins on the one side at the refraction of the eye when entirely at rest, and extends on the other side to that produced by the maximum contraction of which the ciliary muscle in that partieular eye is capable. When this maximum power is exerted, rays of a certain degree of divergenee ean be focussed on the retina. The point from which come the rays that can just be foeussed is called the near point (punctum proximum) of distinct vision. Paralysis of $A$. is considered, p. 333.

The difference in refractive power between the dioptric system of the eye with the ciliary muscle entirely at rest and that of the eye with the eiliary muscle most strongly contracted is called the amplitude of accommodation. It is equal to the effect of a convex lens of a certain strength, and is usually expressed as we express lens-strength, in diopters. Thus, in an eye which when at rest focusses parallel rays upon the retina, and which has a near point of $\frac{1}{8}$ of a meter, from which the rays reach the eye so divergent that it would take an 8 . D. lens to make them parallel, the power of aecommodation is said to be $8 . \mathrm{D}$.

The following table gives the average power of accommodation in diopters, at different ages, with the distance of the near point in inches, from an emmetropic eye having such power of accommodation.

TABLE III.-Accommodation.

$\begin{array}{llll}\text { A., } & \text { Pp. } & \text { A. } & \text { Pp. }\end{array}$

Age. Diopters. Inches. Age. Diopters. Inches.

$10 \ldots \ldots 12.2 \quad 3.340 \ldots \ldots .5 .5 \quad 7.1$

$\begin{array}{llllll}15 & \ldots .7 & 45 & \ldots & \ldots & \end{array}$

$20 \ldots \ldots 10 . \quad 4.50 \ldots \ldots 2.9 \quad 13.5$

$25 \ldots \ldots 9 . \quad 4.455 \ldots \ldots \ldots 1.5 \quad 26.5$

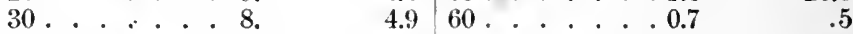

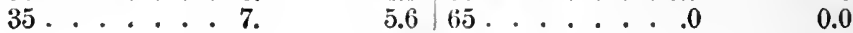




\section{MYDRIATICS OR CYCLOPLEGICS, AND MYOTICS.}

Drugs like atropin, which are known as mydriatics, on account of the dilatation of the pupil they produce, have also the more important action of producing cycloplegia, or paralysis of the ciliary muscle. 'These drugs are as follows: Atropin is commonly used for its cycloplegic effect in a solution of 1 to 120,4 grains to the fluid ounce. A single drop of this solution in the normal eye will usually produce complete mydriasis and cycloplegia; but if it is entrusted to the patient or a member of his family for application, it should be instilled three times a day. The effect of stch an application begins in fifteen minutes, and reaches its maximum in two or three hours, continues for two or three days with very little alteration, and gradually passes off in two weeks.

Daturin, hyoscyamin, duboisin, and scopolamin are used in solutions half or less than half the strength of that of atropin. Their effect is similar, but begins in eight or ten minutes, reaches a maximum in one or two hours, and passes off in a week or ten days. Scopolamin is sometimes used in one-tenth of 1 per cent. solution, instilled two or three times; and in this-way proves an efficient cycloplegic, rather more brief in its action than when used in stronger solution.

Homatropin is used in 2 or 3 per cent. solution, 10 or 15 grains to the fluid ounce, and even in that strength must be used four or five times at intervals of five minutes, to produce full cycloplegia. It begins to act in fifteen minutes, reaches its maximum influence in one hour, and passes off in abont two days.

All of these drugs are liable in the doses mentioned to cause constitutional symptoms, but homatropin causes them very rarely and less severely than any of the others. On this account, and because of the brevity of its action, it is to be preferred to other eycloplegics for diagnostic purposes.

The use of one of these drugs is necessary, whenever it is desired to make a complete study and aceurate meas- 
urement of the refraction, in a patient under fifty years of age. Withont them the refiaction ean be gnessed at, often correctly. Many patients have all their hyperopia manifest, even in early life; and in most eyes prolonged and carcful study, by all the objective and subjective methods, will reveal approximately the astigmatism. But without a eycloplegie, one cannot be ecrtain of his ground, he will gencrally be less accurate in his refraction work, and in occasional cases he will make the most serious blunders. Since patients usually come to a doctor for glasses because they want certainty, as opposed to the gnessing of the optician, and since no serious inconvenience is entailed, and the strained eyes are benefited by the use of homatropin or one of the slower cycloplegies, they should generally be used in studying the refraction of the eye up to the age of fifty. Let it be remembered that accommodation fails first from increasing rigidity of the lens, and not from weakness of the ciliary muscle. Hence about as strong a cycloplegic is required to paralyze the accommodation at forty as in ehildhood.

When symptoms of mydriatic intoxication do ariseusually unsteadiness of gait, or in children a pleased delirium - the instillation of the drug should be stopped, morphin administered in small doses, and water given freely to favor elimination. Although a small dose of one of these drugs may cause symptoms that will alarm those about the patient, the dangerous dose is much larger than the quantity commonly used as a cycloplegic.

After the age when accommodation ceases to interfere with the measurement of refraction, it is sometimes necessary to use a mydriatic simply to enlarge the pupil, as the extreme contraction of the pupil sometimes found in elderly people prevents the satisfactory cxamination of the fundus or the accurate measurement of the refraction. To overcome such eontraction of the pupil a solution of cocain 2 to 4 per cent., or the homatropin and cocain solution may be used. 'These will require from thirty to fifty minutes to dilate the pupil. They do not prevent its contraction in strong light, a voiding much of the dazzling 
caused by the other mydriatics, yet in a dark room or in a moderate light they dilate the pupil more widely than do the "stronger" mydriatics, and the effect passes off in about twelve hours.

Euphthalmin, a true mydriatic more feeble and brief in its action than homatropin, is a valuable dilator of the pupil for diagnostic purposes, but has no practical value as a cycloplegic. It is used in a 2 to 5 per cent. solution of the hydrochlorate, or a solution of 1 per cent. each of euphthalmin and cocain hydrochlorates.

The myotics are drugs which produce myosis-contraction of the pupil-and also cause increased contraction of the ciliary muscle. In these respects they are direct antagonists of the mydriatics; but in other ways, as in their influence on the nutrition of the cornea, they have an effect quite similar to that of atropin.

Eserin, or Physostigmin.-A single drop of a solution of the sulphate 1 to $2000, \frac{1}{4}$ grain to the fluid ounce, in the normal eye will produce a marked contraction of the pupil, and increase the power of accommodation, and in sensitive eyes causes painful spasm of the sphincter of the pupil and of the ciliary muscle, with dimness of vision. Shortly after its instillation there is generally a twitching of the lids, which lasts ten or fifteen minutes. In fifteen minutes the effect on the pupil is noticeable. The effect reaches the maximum in onc or two hours, and passes off entirely in thirty-six to forty-eight lours. In old people, in whom the ciliary muscle is atrophied and the pupil sluggish, eserin is less likely to produce a painful spasm, and can be used more freely.

Pilocarpin is commonly employed as a hydrochlorate. It is twenty to twenty-five times weaker than eserin, and not liable to cause painful spasm in the iris or ciliary muscle. A drop of a solution 1 to 500 (gr. to $\mathrm{f} z \mathrm{j}$ ) produces contraction of the pupil and increase of accommodation, beginning in twenty to thirty minutes, reaching a maximum in one or two hours, and passing off in eight to twelve hours. 
For details regarding the practical use of mydriatics and myotics see Chapter XVIII.

\section{OPTICAL THEORY OF THE OPHTHALMOSCOPE.}

Since the cye is able to focus the rays from a point outside of it to a single point on its retina, and since the dioptric media exert the same influence on the light emerging from the eye as upon the light entering it, the rays from any particular point of the retina that pass out through the pupil will all be turned toward a certain point outside of the eye. Hence, on looking into an eye, only those rays can reach the observer which come from a certain part of the retina. In Fig. 48 (p. 123), looking into the eye from $A$, only rays will be received that come from $a$. But the retina at $a$ receives rays only from the direction of $A$. Hence, when an observer's cyc is placed at $A$ and shuts off, as it necessarily does, a considerable amount of light from entering the observed eye in this direction, the part of the retina at $a$ is in shadow. Although the retina at $b$ may be brightly illuminated, all the light from $b$ passes to $B$, and so of all points of the interior of the eye. The pupil of the observed eye, therefore, appears black. In looking into the eye under ordinary conditions, although other parts of the retina may be brilliantly lighted up, the part of the retina that the observer sees is always in shadow.

To overcome this, and light up the part of the retina looked at, the ophthalmoscope was devised. It enables one to examine the interior of the cye by throwing light from the mirror on the part of the retina looked at.

The mirror conmonly used is concave. It converges the light reflected from it, throwing a larger amount of light into the pupil than would a plane mirror. This light, bcing convergent, is generally focussed in front of the retina, and forms on the retina a circle of diffused light, fivorable for revealing changes in the tissues examined. In eyes that are highly hyperopic the rays may be focussed on the retina, in which case a small com- 
paratively distinct image of the lamp-flame is seen, instead of the larger uniformly illuminated circle. The mirrors employed on most American ophthalmoscopes have a focussing distance of 6 or 8 inches, a sort of compromise between that which would be best for the direct, and that which would be best for the indirect method of examination. For the direct examination a mirror of about 4 inches focal distance is most satisfactory. For the indirect method one of 10 to 15 inches focal distance is better.

If the ophthalmoscope is furnished with two mirrors, the one for the direct examination should be small-15 $\mathrm{mm}$. in diameter-and should tilt. For the indirect method of examination, the mirror need not tilt and may be much larger, since whatever its size, light can be concentrated from all parts of it upon the pupil. The mirror in ordinary use, shown in Fig. 25, is called the "rectangular tilting mirror." The size of the sight-hole influences the ease with which the instrument can be used to inspect the fundus of the eye, and the accuracy with which it will measure refraction. If the sight-hole be small, it is comparatively easy to obtain a clear view of the fundus, but the determination of the refraction will be comparatively inexact. If the sight-hole be large, the instrument will be more valuable to measure refraction, but less perfectly suited to show the condition of the fundus through an undilated pupil.

\section{THE DIRECT METHOD FOR THE MEASUREMENT OF REFRACTION.}

Emmetropia.-If the surgeon's eye be placed as close as possible to the pupil of the patient's eye, it will reccive rays as they pass from the latter-paralle], divergent, or convergent. If the surgeon's eye be emmetropic and his accommodation relaxed, parallel rays will be accurately focussed on his retina, as illustrated in Fig. 52, and a clear view of the retina and choroid will be obtained.

Hyperopia.-If the patient's eye be hyperopic and 
entirely at rest, the rays from his retina will diverge on leaving the cornea; and, to render them parallel will

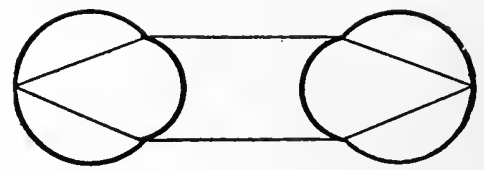

FIG. 52.-Course of the rays in emmetropia.

require sneh a convex lens as would canse parallel rays to be focussed on the patient's retina. If this lens be placed as represented by the solid lines in Fig. 53, it will

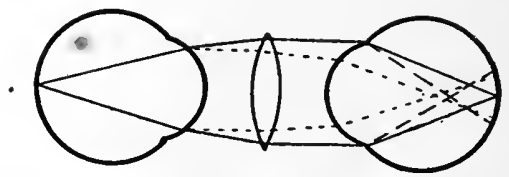

FIG. 53.-Course of the rays in hyperopia, patient's eye on the left. Dotted lines show effect of accommodation in patient's eye; broken lines show effect of accommodation in the surgeon's eye.

render the divergent rays parallel; they will be focussed on the surgeon's retina, and the details of the fundus will be elearly seen.

If the patient exerts any power of aceommodation, the rays emerge from his cornea less divergent, parallel, or even eonvergent. In sueh a ease the convex lens, otherwise required, foensses the rays in front of the surgeon's retina, and a blurred image results. Such a course of the rays is illustrated by the dotted lines in Fig. 53. Again, if the surgeon whose eye is emmetropic exerts his own accomnodation, he will no longer aceurately focus parallel rays, and will receive from them only a blurred image. Such a course of the rays is shown by the broken lines.

If accommodation is used during such an examination, a weaker convex lens, or none at all, or even a coneave 
lens will be required, and this is true whether the accommodation be in the patient's eye or in the surgeon's.

In myopia, as shown in Fig. 54, the rays from the patient's retina emerge convergent; and without a lens they would be foeussed in front of the surgeon's retina,

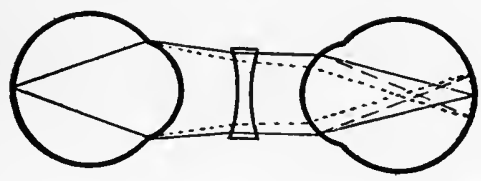

Fig. 54.-Course of the rays in myopia. Dotted lines show A. in patient's eye; broken lines show $A$, in surgeon's eye.

giving only a blurred image. By placing before the eye a concave lens just strong enough to correct the myopia, these rays are rendered parallel, and the surgeon is able to focus them on his retina. The use of any accommodation in this case, either in the patient's or in the surgeon's eye, will again bring the rays to a focus in front of the retina, illustrated as in the ease of hyperopia by dotted and broken lines, and will render neeessary the employment of a coneave lens stronger than is required to correet the myopia-one strong enough to correet the myopia and nentralize the aceommodation too.

Hence, the surgeon's eye being emmetropic, if no accommodation be used, the lens that will give the clearest view of the patient's fundus is the one that will correct the ametropia.

If any accommodation be used, the strongest convex lens, or the weakest concave lens, giving a clear view of the fundus, will be the nearest right.

If the surgeon's eye be ametropic, he must use an additional lens to correct his ametropia, or must add or subtract such correction to find the ametropia in the patient's eye.

The measurement of refraction ean be made with the ophthalmoseope, with approximate aceuracy, only after long practice. The chicf obstacle to aceuracy is the exer- 
tion of an unknown amount of accommodation. This may be combated in the surgeon's eye by practice. Accommodation in the patient's eye may be overcome by the use of a cycloplegic. It may often be relaxed by making the ophthalmoscopic examination in a large, thoroughly darkened room, with the patient's gaze fixed on a perfectly blank wall at the farther end. But the measurement of refraction by the ophthalmoscope can never be relied on for the accurate prescription of lenses. It is chiefly of valne for an approximate diagnosis, or to determine the extent of swelling in the fundus, or the location of an opacity in the vitreons.

The actual shortening or lengthening of the eye, corresponding to different degrees of hyperopia and myopia, is shown by the following table:

Table IV.-Changes in the Visual Axis for Each $D$. of Ametropia.

\begin{tabular}{|c|c|c|c|c|c|c|c|c|}
\hline Diopters. & & & $\begin{array}{l}\text { HI., } \\
\text { Shorten- } \\
\text { ing. }\end{array}$ & $\begin{array}{l}\text { M., } \\
\text { Lengthen- } \\
\text { ing. }\end{array}$ & Diopters. & & $\begin{array}{l}\text { H., } \\
\text { Shorten- } \\
\text { ing. }\end{array}$ & $\begin{array}{l}\text { M. } \\
\text { Lengthen- } \\
\text { ing. }\end{array}$ \\
\hline 1 & & 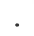 & . .31 & .32 & 11 & - & . 3.02 & 4.26 \\
\hline 2 & . . & $\cdot$ & . .62 & .66 & 12 & . & . . 3.25 & 4.73 \\
\hline 3 & . . & . & . .92 & 1.01 & 13 & . & 3.47 & 5.23 \\
\hline 4 . & & . & . 1.21 & 1.37 & 14 & - & 3.69 & 5.74 \\
\hline 5. & . . & - & .1 .50 & 1.74 & 15 & . & 3.91 & 6.28 \\
\hline 6 . & & & .1 .76 & 2.13 & 16 & . & 4.11 & 6.83 \\
\hline 7. & & & . 2.03 & 2.52 & 17 & . & . .4 .32 & 7.41 \\
\hline & - & & . 2.28 & 2.93 & 18 & . & 4.52 & 8.03 \\
\hline 9 & • & & . 2.53 & 3.35 & 19 & • & 4.71 & 8.65 \\
\hline 10 . & $\cdot$ & . & 2.78 & 3.80 & 20 & & . .4 .90 & 9.31 \\
\hline
\end{tabular}

\section{SKIASCOPY.}

Myopia.-As already mentioned, rays from the retina of the myopic eye pass into the air convergent. If not interrupted in their comse they continue to converge until they are focussed at that point in front of the eye, for which it is optically adjusted. 'This is true of rays coming from each point of the retina, so that at that distanee there is formed an image of the fundus. This image is inverted, as is illustrated in Fig. 55. The rays from the 
lower part of the retina come to a focus above, and form the upper part of the image, and the rays from the upper part of the retina are focussed below to form the lower part of the image. If the surgeon places his eye closer than this image to the eye of the patient, as at $\dot{A}$ in Fig.

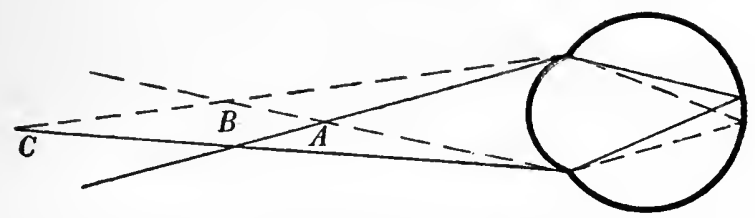

Fig. 55.-Focussing of rays coming from the retina in skiascopy; and the point of reversal.

55, he will observe the fundus of the patient's eye in an erect image, as he does in the direct method of ophthalmoscopic examination. 'This image may require a concave lens to render it clear ; but whether elear or dim, it is necessarily erect. If the surgeon's eye be placed farther from the patient's than $B$, as at $C$ he will no longer view the erect image, but will perecive the inverted image formed in the air at $B$. This inverted image may require the use of a convex lens to focus it elearly upon the surgeon's retina; but whether elearly focussed or not, it is always an inverted image.

We have, therefore, at the point $B$, for which the myopic eye is optically adjusted, reversal of the image seen; this point we therefore name the point of reversal. Its position is to be determined by noticing where the ereet changes into the inverted image, or vice versa. Having ascertained its position, the measurement of its distance from the patient's cye gives the focal distance of the lens required to correct his myopia.

Details of the Test.-Skiascopy (the shadow-test or retinoscopy) is a method of determining the position of this point of reversal, by noting the apparent direction of the movement of light and shadow across the pupil. The movement of light and shadow in the pupil 
is produced by changing the inclination of a perforated mirror which reflects light into the eye.

The best light is furnished by acetylene gas, next comes that of the incandescent mantle (W' elsbach), or a good candle; but a gas or kerosene-flame will answer. 'The mirror employed may be either plane or concave.

With the plane mirror the source of light is to he brought as close to the mirror as possible, and shaded from the patient's face, as shown in Fig. 56, an opening

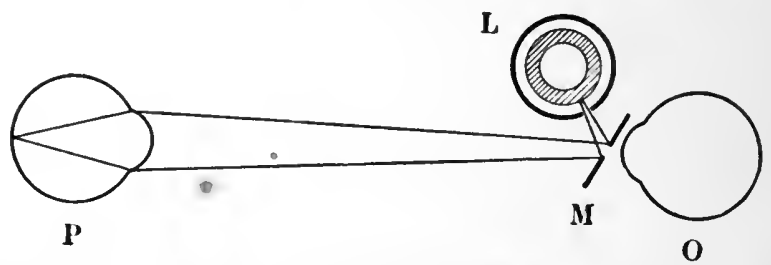

FIG. 56.-Position of light $(L)$, mirror $(M N)$, and eyes of surgeon $(O)$ and patient ( $I^{\prime}$ ) for shiascopy with the plane mirror.

$5 \mathrm{~mm}$. in diameter being left in the shade opposite the brightest part of the flame. The mirror should lave a central opening 2 to $2.5 \mathrm{~mm}$. in diameter.

The effect of changing the inclination of the mirror is represented in Fig. 57, in which light from the lamp-flame

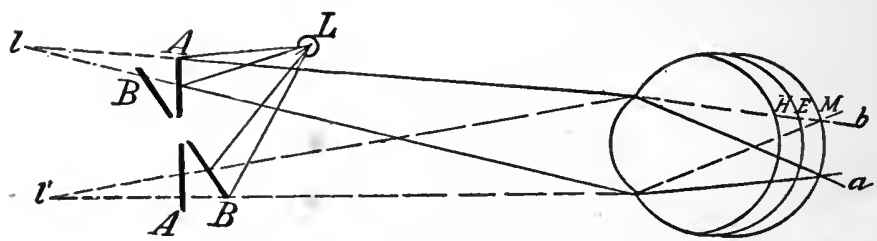

Fig. 57.-Skiascony with the plane mirror.

$L$ is reflected into the eye from the mirror first held at $A A$ and then moved to $B B$. With the mirror at $A A$, the light conters the eye as though it came from $l$, and falls on the retina towald $a$. With the mirror at $B B$, the light enters the eye as though it came from $l^{\prime}$, and it 
falls in the direction of $b$. As the mirror is moved from $A A$ to $B B$, the light moves on the retina from $a$ to $b$. At the same time the part of the light from the mirror which falls on the face about the eye, moves upwardthat is, the light on the retina moves, "with" the light on the face-c with" the mirror.

This happens whether the retina be situated at $H, E$, or $M$; whether the eye be hyperopic, emmetropic, or myopic. With the plane mirror the real movement of the light upon the retina is always " with" the movement on the face. If the retina be seen in the erect image, the apparent movement of the light in the pupil will be "with" the light on the face. If the retina be seen with the inverted image, the apparent movement of the light in the pupil will be the opposite of the real movement. Farther from the patient's eye than the point of reversal, the light in the pupil, therefore, appears to move "against" the light on the face.

With a concave mirror the movement of the light and shade will be just the opposite of the above. Why this is so is illustrated in Fig. 58. $L$, the lamp-flame, is placed

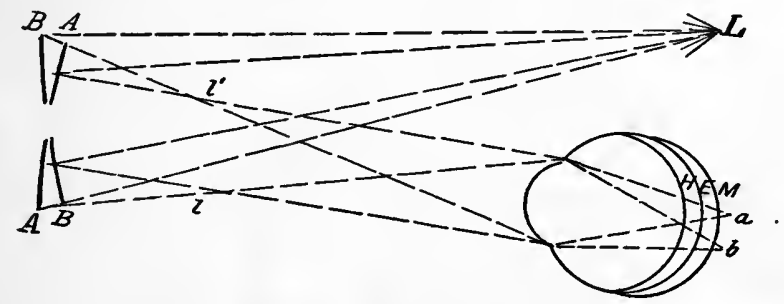

FIG. 58. - Skiascopy with the concave mirror.

behind the patient, the rays from it being foenssed by the concave mirror at $l$ when the mirror is at $A A$, and at $l^{\prime}$ when the mirror is at $B B$. From $l$ they enter the eye toward $a$ on the upper part of the retina. From $l^{\prime}$ they fall on the lower part of the retina toward $b$. When the mirror is at $A A$, the light is thrown down on the 
face, but falls on the upper part of the retina. When the mirror is at $B B$ the area of the light is higher on the face, but lower upon the retina. Hence, with the concave mirror the light on the retina really moves "against" the mirror- "against" the light on the face.

The apparent movement of the light being watehed in the pupil, when the ereet image is seen will be in the real direetion, and when seen in the inverted image, in the opposite direction. Hence, in any case of myopia, testing with the plane mirror will show the light moving " with" the light on the face when viewed eloser than the point of reversal, and moving against the light on the face when viewed from beyond the point of reversal. If tested with a concave mirror, it will show the light in the pupil moving "against" the light on the face from within the point of reversal, and "with" the light on the face beyond the point of reversal.

Distance.-In praetice one should vary his distance so as to try the movements both from within the point of reversal and from beyond it, until the approximate position of that point is determined with eertainty. When the plane mirror is used, the distance of the surgeon from the patient can be varied greatly, without interfering much with the aceuracy of the test. With a concave mirror, however, but very slight variations of distance between the patient and the surgeon are admissible. It is necessary to keep the surceon's eye a fixed distance from the patient's, and cause the distance of the point of reversal to vary, by placing before the patient's eye lenses that will correct more or less of the myopia. The distance for the usual coneave ophthalmoseopie mirror should be rather less than 1 meter. The lens that brings the point of reversal to 1 meter is one that eorrects all the myopia but 1. D., which must be added to the strength of the lens to get the total myopia.

When the plane mirror is employed and the distance varied, that distance must be measured, or, at least, approximately estimated, and the myopia corresponding to it added to that represented by the eorrecting lens em- 
ployed. The aceurate determination of the point of reversal requires it to be brought about $\frac{1}{2}$ to 1 meter before the eye.

Hyperopia.-In hyperopia the rays from the retina emerge from the eye divergent. There ean be no inverted image, no point of reversal, until a convex lens strong enough to more than correct it, is plaeed before the eye. The light in the pupil will move "with" the light on the face with a plane mirror, and "against" the light on the face with a coneave mirror at all distances. To measure the hyperopia the rays which leave the patient's eye divergent must be rendered eonvergent by a convex lens, as $L$ in Fig. 59. The position $B$ of the point of reversal

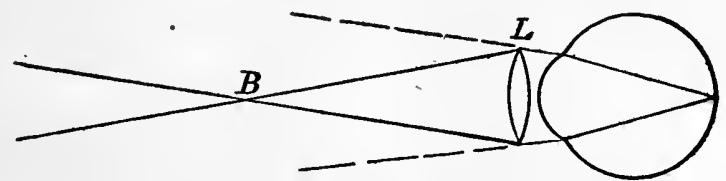

Fig. 59.-Rays emerging from a hyperopic eye rendered convergent to give a point of reversal.

for this myopic combination of the eye and lens is then determined, and thus the amount of myopia that the lens eauses.

The lens $L$ may be regarded as doing two things. Part of its effect is to make the divergent rays parallel, correcting the hyperopia; the remainder of its strength makes the parallel rays convergent, causing an artificial myopia. The amount of the lens-strength eausing eonvergenee of the rays, deducted from the whole strength of the lens used, gives the strength required to correct the hyperopia. Thus with +3 . D. lens, causing 1 . D. of artificial myopia, 3. D. -1 . D. $=2$. D., the amount of lens-strength required to eorreet the hyperopia in the eye.

Emmetropia. - When the eye, tested as for liyperopia, shows an amount of myopia produced just equal to the strength of the convex lens used, it is evident that the 
hyperopia of the eye was 0 -that is, that the eye was emmetropic to start with.

Appearance of the Light in the Pupil.-When the surgeon's eye is near the point of reversal, it sces the patient's retina enormously magnified and the movement of the light and shadow in the pupil appears correspondingly rapid. When the surgeon's eye is far removed from the point of reversal, when there is much uncorrected myopia or hyperopia, the apparent movement of the light and shadow in the pupil is slow. Just at the point of reversal, or at a great distance from it, the illumination is found comparatively feeble, and the boundary between light and
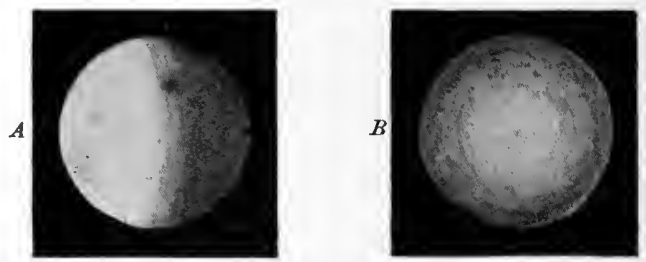

Fig. 60.-Appearance of light in the pupil: $A$, about 1. D. from the point of reversal, and $B$, about 5 . D. from the point of reversal.

shadow indefinite. At about 1. or 2. D. from the point of reversal, the brightest illumination and most distinet movement of the light and shadow in the pupil are observed. When these points are borne in mind, the rapidity in movement and, to some extent, the brilliancy of illumination become approximate indications of the amount of ametropia to be corrected.

Of the appearance of the pupillary light-area in regular astigmatism, aberration, and irregular astigmatism, more will be said in connection with these forms of ametropia.

Practical Applications of the Test.-The room should be darkened and the lamp-flame shaded by an opaque chimney, the circular opening for the emission of light being turned toward the surgeon's eye. For the plane mirror the source of light is to be kept as close to the surgeon's eye as possible (see Fig. 56), and must be 
movable. With the concave mirror the light should be placed behind the patient, about 2 meters from the surgeon; and the opening in the shade may be 25 to $30 \mathrm{~mm}$. in diameter, or the shade can be omitted. This gives the concave mirror an advantage when the test must be applied away from office facilities.

The mirror, being turned so as to refleet the light into the patient's eye, is rotated slightly from side to side. If with the plane mirror the light moves "against" the light on the face, there is a point of reversal between the surgeon's eye and the patient's eye. Its position is to be determined by coming closer to the patient, or by placing a concave lens that will bring this point of reversal to the distance of the surgeon's eye.

If the movement with the plane mirror is "with" the light on the face, there is no point of reversal in front of the surgeon's eye, but one must be brought there with a convex lens. If the convex lens that brings the point of reversal to a certain position be weaker than the amount of myopia corresponding to that distance, the case is one of low myopia. If the amount of myopia exactly equals the lens-strength, the eye is emmetropic. If the myopia produced by the convex lens be less than the strength of the lens, the eye is hyperopic. The point of reversal is to be ascertained by repeated trials both from within and from beyond it. Generally its location will be most accurately determined by fixing it at the greatest distance at which movement "with" the light on the face is seen with the plane mirror, or the shortest distance at which it is noticeable with the concave mirror.

To secure accuracy, it is well to make the final determination with the point of reversal as far from the eye as the movement of light and shade can be certainly reeognized. If the pupil has the same refraction in all parts, this distance may be 1 meter. If the movement has to be watehed in a comparatively small portion of the pupil, the refraction and movement there being different from the refraction and movement in other portions, it is necessary to make the test from a shorter distance. 


\section{THE INDIRECT METHOD OF OPHTHALMOSCOPIC EXAMINATION.}

When the eye is viewed with the ophthalmoscope from a distance greater than that of the point of reversal, the image obtained is always an inverted image. In the shadow-test that image is not aceurately focussed, so that the relations of its different portions are not recognized, as in the ordinary ophthalmoscopic examination. If, however, the myopia be of high degree, so that the inverted image is formed close to the eye, it may be viewed from some little distance, where it can be focussed and seen distinctly, so that not only the different portions are recognized, but any marked anomaly or evidence of disease can be studied.

If the eye be not myopic, by placing 2 to 3 inches before it a very strong convex lens $(12$. to 20 . D.) called the object-lens, an inverted image of the fundus can be formed. The surgeon's eye must be placed beyond this, far enough to foeus it. By placing the object-lens at or near its foeal distance in front of the eye, the pupil is so magnified that it appears to oecupy the greater part of the object-lens, enabling the surgeon to see a considerable part of the fundus at once. With a 2-inch object-lens, the lens would be 2 inches in front of the eye, and the image formed about 2 inches in front of it. Then the surgeon must place his eye far enough away to focus this image, say 12 inches from it, making it 16 inches from the eye under observation. This distance may be shortened somewhat by placing back of the ophthalmoscopic mirror a convex lens of from 3. to 5. D, to aid the surgeon's power of accommodation.

In the indireet method a larger part of the fundus may be seen at once, so that it is easier to make seareh for gross ophthalmoscopic changes. On the other hand, the image of the fundus thus obtained is less magnified than that studied by the direct method, so that slight lesions are less readily recognized. The method is, therefore, of use for a general survey of the fundus. 


\section{SPECIAL METHODS.}

Lenses Before the Eye.-The ophthalmoscope is usually furnished with a mirror that gives the best retinal illumination when the eye is approximately emmetropic. On this account, in very high lyperopia or myopia, the most satisfactory ophthalmoscopic examination can usually be made by placing in front of the patient's eye a lens which approximately corrects his ametropia, instead of depending on the lenses back of the ophthalmoscopic mirror, which have no influence on the pencil of rays entering the eye to illuminate the retina.

In examining an opacity, tumor, or detached retina, close behind the crystalline lens, place a strong convex lens, 20 to $30 \mathrm{D}$., in front of the eye, and make the ophthalmoscopic examination throngh this.

Use of Direct Sunlight.-In blind eyes with hazy media, or to see back of a detached retina, ophthalmoscopy by direct sunlight is of great value. The sun must shine directly upon the ophthalmoscopic mirror, but its rays must not be concentrated upon the surface of the eye or face, nor upon the retina. This is guarded against by using a plane mirror, or by care as to the distance from the concave mirror to the eye. Direct sunlight should be thrown on the eye but a short time, and the attempt repeated after a few minutes' rest. Such light has greater penetrating power than ordinary ilhminants, revealing details otherwise hidden by hazy, vitreous, or detached retina.

\section{Influence of Light on the Color of the Fundus.} -The color of the fundus, described page 87, is that seen with the ordinary gas or lamp flame. By changing the color of the source of light, the colors of the eye-ground may be completely altered. With direct sunlight, or diffuse daylight, the fundus of the eye appears paler and more yellow. With the Welsbach mantel it is paler, and the whites more bluish or greenish. With the mercury vapor lamp the general color of the fundus is green, the optic disk greenish, and the retinal vessels a deep purple. 


\section{CHAPTER VII.}

ERRORS OF REFRACTION, CYLINDRICAL LENSES, PRESBYOPIA, AND THE WEARING OF GLASSES.

\section{PRESBYOPIA.}

Even with the emmetropic eye, increasing rigidity of the crystalline lens diminishes the power of focussing on the retina the divergent rays that come from near objects. On this accomnt the near point of distinct vision recedes from the eye. Reading and similar near work become difficult, and later impossible. When this loss of accommodation reaches such a degree as to interfere with the patient's ordinary occupation, the condition is called presbyopia or old sight.

Presbyopia begins before the accommodation is so far lost as to absolutely prevent the seeing of near objects. The ciliary muscle, like other muscles, is eapable, for brief periods, of stronger contraction than can be kept up continuously. An eye cannot keep up for continuous reading the effort it can make during a brief test to ascertain the near point. Usually the amount of accommodation which can be sustained for continuous work is about two-thirds of the total accommodation of which the eye is capable. Hence when two-thirds of the total accommodation is less than the amount required for near work, presbyopia begins, and the aid of a convex lens is required.

The symptoms of presbyopia may be either the actual indistinctuess of near objects, or evidence of strain after using the eye for near-seeing. The patient finds himself unable to read fine print especially at night, or he has to hold the print too far away. Sometimes, although on beginning near work the sight is clear, it suddenly becomes dim after a time, the print seeming to run together or blur. Then, if the eyes are closed for an instant, the power of near-sceing is regained, and continues for some 
time, when it again fails suddenly. These blurrings, which are due to sudden involuntary relaxation of the ciliary muscle, tend to become more frequent the longer the effort is continued. They may also occur from strain of accommodation in connection with hyperopia in young persons. More frequently before there is any actual inability to see clearly for near work, there come evidences of strain from its performance. After reading or sewing, particularly in the evening, the eyes smart or burn, or the following morning they look red; or there occur repeated attacks of conjumctivitis.

The symptoms of presbyopia usually begin between the ages of forty or fifty years. They begin earlier in hyperopic eyes which are compelled to use part of their accommodation for the correction of their hyperopia. In myopic eyes less accommodation is required for near vision, and presbyopia begins later. If the degree of myopia is such that ordinary near-seeing can be done withont any use of the accommodation, presbyopia never occurs.

Diagnosis.-Between forty and fifty years of age, symptoms of eye-strain or difficulty of near-seeing gradually develop and increase. Distant vision is good without glasses, and rendered worse by them; near vision is improved or made easier by convex lenses.

Treatment.-The treatment for presbyopia is either abstinence from near work or doing it only with such aid from convex lenses that not more than the proper proportion of the accommodation need be used. Ordinarily two-thirds can be used, but some patients can continuously use three-fourths of their accommodation. Others, especially younger people, cannot safely employ more than one-half.

The accommodation is measured by finding the shortest distance at which the finest type can be clearly seen. A near vision test-card being held at 15 or 20 inches from the eye, the patient is asked to read the finest type he can see. If he reads the 20 -inch (half-meter) type, the card is pushed gradually toward him until he can no longer see it clearly. Its distance from the eye is then meas- 
ured, this being the focal distance of the lens, having a focussing power equivalent to the accommodation. (See table of lenses and focal distances, page 118.) To get the full amount of accommodation, the patient must sometimes be coaxed to make a special effort.

Having ascertained the amplitude of accommodation, two-thirds of that amount must be subtracted from the focnssing power required for near work. The differenee will be the refractive power of the lens needed to correct the presbyopia.

For example, if an emmetropic eye can read the 20inch type clearly at 13 inches, or ean just make out the 13-inch type at that distance, it proves clear focussing at 13 inches, the focal distance of a 3. D. lens. The patient then has 3 . D. accommodation. Two-thirds of this, or 2. D., is what we may expect him to use safely for continuons near work. Now if he has to read and write at a distance of 12 inehes, where $3.25 \mathrm{D}$. of focussing power will be required, he nust make up the difference between $3.25 \mathrm{D}$. and 2 . $\mathrm{D}$. or $1.25 \mathrm{D}$. by convex lenses of that strength, when doing near work.

The following table, based on the decline of accommodation, as shown in the table on page 126 , indicates for different ages the near-point in inches, anplitude of accommodation in diopters, two-thirds of that amplitude or accommodation available for near work, and the difference between the available accommodation and the focussing power, 3. D., required to eorrect the presbyopia for that working distance.

Tabie V.-Accommodution and Lenses for Presbyopia.

\begin{tabular}{|c|c|c|c|c|}
\hline Age. & Near-Point. & Total Accom. & Available A. & Lens Required. \\
\hline 40 & - 7 in. & $5.5 \mathrm{D}$. & 3.67 & 0. \\
\hline 45 & . $.10 \mathrm{in.}$ & 4. D. & 2.67 & 0.50 \\
\hline 50 & $.16 \mathrm{in.}$ & $2.5 \mathrm{D}$. & 1.67 & 1.50 \\
\hline 55 & - . $31 \mathrm{in.}$ & 1.25 & 0.83 & 2.25 \\
\hline 60 & . $.78 \mathrm{in.}$ & 0.5 & .33 & 2.75 \\
\hline 65 & .00 & 0. & 0. & 3. \\
\hline
\end{tabular}

Such a table should never be used for prescribing glasses, for it only represents an average, from which the particu- 
lar ease may differ greatly. Neither should glasses be prescribed in any way from the age of the patient, for besides individual variation in the loss of accommodation, hyperopia and myopia influence the glass required, and must always be considered. Nor can the glasses required for presbyopia be guessed at from the blurring of the patient's vision, since this depends as much on the size of the pupil as upon the perfection of the focussing. In every case the total accommodation should be ascertained by the determination of the refraction of the eye and its near-point of distinet vision. If the patient has some working distance other than one-third of a meter-13 inches - the available accommodation must be dedueted from the focussing power required for that distance, to find the lens required. Presbyopia complieated by hyperopia or myopia is discussed in connection with their treatment.

Prognosis.-Presbyopia continues to inerease until all power of accommodation is lost, at the age of fifty-five or sixty. Until this time the lenses given to correct it should be changed every two or three years. After that age no change of lènses may be required for several years.

\section{HYPEROPIA.}

Hyperopia (hypermetropia or far-sight) is the most common error of refraction, being present in about 70 per cent. of all eyes. To the savage it is far less dangerous than myopia, which lessens his power to secure food and guard against enemies. But with civilization and the general employment of the eyes for near work, hyperopia becomes a serious defect.

The hyperopic eye refracts parallel rays toward a point behind the retina; the retina is in front of the principal focus of the dioptric media. The hyperopic eye is relatively too short, either because its refracting surface is not sufficiently curved, hyperopia of curvature; or beeause its anteroposterior axis is actually shorter than that of the average eyeball, axial hyperopia. In the majority 
of cases the latter is the condition present; and in high hyperopia the eyeball may be noticeably small in all its dimensions, so that it does not properly fill the orbit.

The course of the rays in the hyperopic eye is shown in Fig. 61 ; parallel rays passing in the course of the

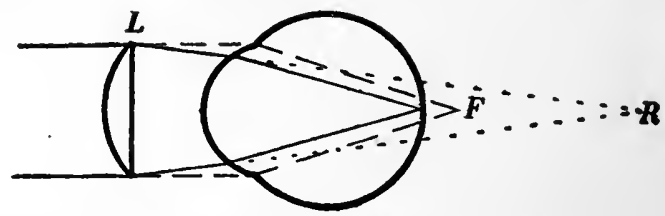

FIG. 61.-Course of rays in the hyperopic eye, with and without the correcting lens.

broken lines would be focussed at $F$, back of the retina. To cause the rays to be focussed on the retina they must be given a certain amount of convergence before they reach the eye; they must be turned in the direction of the dotted lines toward $R . \quad R$ is called the far-point of the hyperopic eye. It is a kind of "virtual" far-point, situated behind the eye. It is the principal focus of the lens $L$ that will correct the hyperopia. When rays are converged towarl it, the refractive power of the eye is sufficient to focus them on the retina, as shown by the solid lines.

Rays emerging from a point of the retina of the hyperopic eye traverse the same path in the opposite direction. As they pass out of the cornea they are not rendered parallel, but still diverge as though they came from the "far-point" of the eye $R$; and they require a convex lens $L$, with its principal focus at $R$, to make them parallel. If the lens be placed at the eye, its foeal distance will be the distance of the far-point back of the eye; but if the lens be placed in front of the eye, its focal distanee must be proportionately inereased. Thus, if the far-point be 4 inches back of the cornea, the focal distance of a correcting lens placed at the cornea must be 4 inches (10. D. lens); but if the lens be placed $\frac{1}{2}$ inch in front of the cornea, its foeal distance must be $4 \frac{1}{2}$ inches $(9 . \mathrm{D}$. 
lens). Either of these lenses at its proper distance from the eye will render clear distant objeets as test-letters; or it will render parallel the rays that pass from the patient's retina to the surgeon's eye through the ophthalmoscope. Hyperopia may also be usually correeted by the proper amount of accommodation, having the effect of a convex lens.

Causes.-Hyperopia is due to a congenital departure from the proportions of the emmetropic eye, or it may arise from the removal of the crystalline lens, or cicatrical flattening of the cornea.

Varieties. - The theoretieal varieties, hyperopia of curvature and axial hyperopia, have been mentioned. The chief clinical varieties depend on the relations of the hyperopia to the accommodation. When the accommodation is entirely relaxed, as under the influence of a cycloplegie, all the hyperopia is revealed. This is the total hyperopia. When the hyperopia is so great that the maximum exertion of the accommodation leaves part of it uncorreeted, this part is called the absolute hyperopia. When, as frequently happens, the habit of correeting hyperopia by accommodation is so strong that it is impossible for the patient to look at even a distant object without using some accommodation, although he may have a convex lens before the eye that renders acconmodation unnecessary, the part of the hyperopia he cannot help correcting is ealled the latent hyperopia. All the liyperopia that is not latent is the manifest hyperopia. That part of hyperopia between the latent and the absolute, the part that can be correeted by the aceommodation or left uncorrected at pleasure, is the facultative hyperopia. 'The relations of these different varieties to each other and to the voluntary and involuntary accommodation are shown in the following diagram :

Total Accommodation.

\begin{tabular}{|r|c|c|} 
Involuntary A. & Voluntary A. & \\
\hline Latent H. & Facultative H. & Absolute H. \\
& Manifest H. \\
Total Hy peropia.
\end{tabular}


On trying convex lenses before an eye which presents all these varieties of hyperopia, commencing with a weak lens, vision is improved as the lens is made stronger until all the absolute $\mathrm{H}$. is corrected; when with the aid of all the accommodation the full vision may be obtained. Inercasing the strength of the lens yet further, the full vision is still obtained, bnt with less effort of acconmodation until all of the facultative $\mathrm{H}$. is corrected, no voluntary accommodation being needed. But on still inereasing the strength of the lens distant vision gets worse, since the accommodation cannot be further relaxed; and a part of the latent $\mathrm{H}$. is doubly corrected, making the eye to that extent near-sighted.

In early life none is absolute unless the total hyperopia is of very high degree. After fifty or fifty-five it all becomes absolute. Before fifty, hyperopia is partly latent in about one-third of all cases, when both eyes are tested together. When each eye is tested separately, a much higher proportion fail to manifest all their $H$. H. is more apt to become latent when the eves have been strained or irritated; and the proportion that is latent may vary greatly from day to day, or even in a few minutes.

Symptoms.- In early childhood, hy peropia causes convergent squint, which arises in the larger number of cases before six years of age. Squint may be associated with any degree of H.; but it is a high degree of H., 2. to 6 . D., though not the highest degree, that most frequently causes squint. Squint due to $H$. is very often variable in degree or intermittent.

Hyperopia becomes a cause of eye-strain. When the eyes begin to be much used for reading, looking at pictures, etc., there arises chronic hyperemia of the conjunetiva and lid-margins. Later, as puberty is approached, headache becomes an important symptom. From that time up to middle life, hyperopia, with or withont astigmatism, contimues to be the most frequent and most important cause for headache. Later, H. gives rise to the symptoms of presbyopia, coming on some year's earlier than it otherwise would. 
Headaches caused by hyperopia are not peculiar to that condition; but are similar to headaches from loss of slecp, exhaustion, anemia, etc. The pain is most frequently quite dull and confined to, or most severe in, the frontal region. It may be constant (usually with exacerbations of greater severity), may be felt only at such times as the eyes have been much used for near work, or it may take the form of distinct attacks of migraine. In some cases the periods of its occurrence are periods of specially hard use of the eyes; in others they are the nenstrual periods, or any time of nerve-exhaustion. In some eases the headaches cease as soon as the $\mathrm{H}$. is corrected, or the eyes are placed under the influence of a cycloplegic; in others they disappear quite gradually, or only after improvement of the general health.

Imperfect distant vision from hyperopia alone is uncommon in early life, and is only met with when the $H$. is very high. Cases of this kind are frequently mistaken for cases of myopia. The child inclines to hold things very close because of his imperfect vision, and by holding the object very near he gets a large retinal image. Then his strong convergence is accompanied with a strong contraction of the pupil, which renders his retinal images less indistinet. When the power of accommodation has been lost, even the lowest degrees of $H$. will render vision imperfect. When the eyes are used much for near work, even early in life, moderate degrees of $H$. are liable to cause sudden failure of accommodation, particularly toward the latter part of the day. This has been mentioned as a symptom of presbyopia.

The severity of the symptoms of hyperopia gives little indication of the degree of the defect. One person with high H. may go until nearly forty with no scrious inconvenience; while another, with much less, is compelled to wear glasses constantly from childhood. Symptoms are likely to arise first when the eyes have been subjected to some special strain of near work, as during term exam- 
inations at sehool; or they may appear after an attack of acute illness, like influenza or typhoid fever.

Diagnosis.-Distant vision is often very good, if the aceommodation be sufficient. If vision be imperfect, it will be improved on looking throngh the pinhole disk. Near vision is relatively the worse. The near-point of distinct vision is not so close as it should be at the patient's age. Vision is not impaired by eonvex lenses unless they are too strong. With the ophthalmoscope the fundus is clearly seen withont a lens, or with a convex lens. By skiascopy an ereet image (movement "with" light on the face with plane mirror) is obtained through a convex lens, beyond the focal distance of the lens. The amount of $H$. is to be measured as deseribed on page 139 .

With test lenses, if the power of aceommodation has been removed by age or the use of a mydriatic, each eye should be tested alone. The convex lens giving the best distant vision will be the one which focusses on the retina rays from the test-objeet. If the test-objeet is 4 meters away, the rays from it are $0.25 \mathrm{D}$. divergent, and truly parallel rays would be focussed on the retina by a lens $0.25 \mathrm{D}$. weaker. This $0.25 \mathrm{D}$. must therefore be subtracted fiom the lens chosen at 4 meters to find the true correction of the hyperopia. With the test-type at 6 meters the theoretieal deduction would be one-sixth of a diopter.

When the accommodation is active, the hyperopia is best measured by testing both eyes together. Begin by placing before them convex leuses strong enough to somewhat blur distant vision. Then gradually weaken these, by holding snecessively stronger concave lenses before them, or by replacing by weaker convex lenses. Care must be taken not to allow the patient to look at the test-type withont glasses, and thus bring the accommodation into active use. When good vision has thus been obtained, eover one eye and then the other; if the vision of one eye is still imperfect, make the eonvex lens before it still weaker, until vision is as good as that of the other eye, or is not further improved by the weaken- 
ing of the glass. This method presupposes that each eye is capable of good vision, and is free from astigmatism, or has it already corrected.

Treatment.-Hyperopia of itself requires no treatment. Most eyes that do the moderate work required of them, without damage or inconvenience to their possessors, have hyperopia of low degree; but whenever symptoms liable to arise from $H$. oceur, the probability of their being due to it is to be considered, and the standard therapeutic resources will not have been employed without use of proper correcting glasses. For headache and congestion or inflammation of the eves or lids, the correcting lenses should be worn constantly. Where no inconvenience is experienced exeept in direct connection with use of the eyes for near work, the glasses may be worn for near work only. In exceptional cases where the hyperopia is high, and the symptoms it eauses are insignificant and only connected with near work, a partial correction may be worn at such times.

Sometines the full eorrection of the hyperopia, in young persons who have some of that hyperopia latent, causes at first blurring of distant objects. If the glasses have been correctly chosen, this blurring will pass away after a time, the $\mathrm{H}$. becoming all manifest. Sometimes this requires several weeks, in other cases it requires but a few hours. It indicates an improper activity of the ciliary muscle, which passes away with the wearing of glasses, or more quickly by the use of a eycloplegic. Until it is overcome, the eye cannot be regarded as quite well, and the full benefit of the glasses will not be experienced. The patient should be previously warned that this may oeeur when the glasses are first worn, or whenever the eyes are particularly tired or irritated; and that it is an indication, not for removal of the glasses, but rather for the steady wearing of them, with lessening of the near work required of the eyes.

It is generally easier for the eyes to become accustomed to the full correction than to a partial correction that includes some of the latent $H$.; and those eases that have 
the most trouble in becoming accustomed to the full correction often experience the greatest benefit from it. If it is known that the patient, even after an explanation of the difficulty, will not wear correcting lenses long enough or stearlily enough to get the benefit of them, a partial correction of the hyperopia may be prescribed, with the warning that the glasses will soon need to be changed and that full relief may not be secured until the full correction is worn. The full correction of hyperopia will not be satisfactory unless the glasses at the same time accurately correct any astigmatism present and any difference of refraction between the two eyes.

When the hyperopic eye becomes also presbyopic, the glasses that correct the hyperopia and serve for far seeing will not be suffieient for near work, for which another pair of lenses must be worn. 'The glasses for near work may be determined by placing on the patient the lenses correcting his $H$., and with them determining the near point, and from it the eorrection for presbyopia, to be added to the correction for $\mathrm{H}$. for continuous near work. Or one may determine the "near point" directly, without glasses, and from it and the known hyperopia calculate the glasses that will enable the patient to work at the required distance without using more than two-thirds of his accommodation.

Prognosis. - At birth almost all eyes are hyperopic, and during early childhood some become less hyperopic, and some even myopic. But from the age of fifteen years the general tendeny is for $\mathrm{H}$. to increase, probably by the slow growth of the crystalline lens, which continues until ohl age. As the lens increases in all dimensions, its focus lengthens. In early adult life the increase of $H$. is usually very slight; but it is often more rapid after middle age. In extreme old age hyperopia may diminish through changes in the crystalline lens. No definite opinion can be given as to how often glasses correcting hyperopia require to be changed. Usually it is not for several years, sometimes many years, but oceasionally within a year or two. 'The hyperopia following the extraction of the crystalline lens 
generally increases markedly for several months after the operation.

\section{MYOPIA.}

Myopia (brachymetropia, short sight or near sight) is extremely rare among savages. But it is quite common among civilized people, arising as the result of disease caused or favored by the overuse and strain of the eyes for near seeing. It is most frequent among students and others who lead sedentary lives and do mueh close eyework, such as tailors, dressmakers, etc.; while among outdoor laborers, farmers, and sailors, it is comparatively rare.

The myopic eye focusses parallel rays in front of its retina, the retina is behind the principal focus of the dioptric surfaces. It is relatively too long, either because the refracting surfaces are too nuch eurved-myopia of curvature; or beeause the antero-posterior axis of the eyeball is really longer than it should be-axial myopia. Usually the myopia is axial, having been eaused by the yielding of the sclero-corneal coat to the intra-ocular pressure. When the myopia is very high in degree, the enlargement of the eyeball causes it to fill the orbit and protrude, making the eye prominent. The course of rays in the myopic eye is illustrated in Fig. 62. Parallel rays,

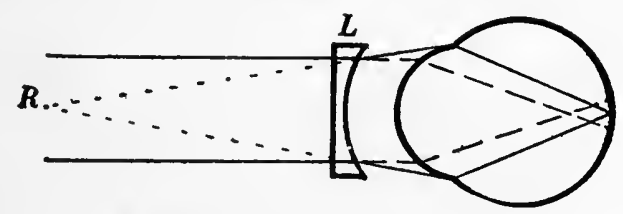

Fig. 62.-Course of rays entering the myopic eye, with and without correcting lens.

entering in the direction of the broken lines, are bronght to a foeus within the vitreous; and when they reach the retina they have become divergent again, so that distinct distant vision is impossible. Rays with a certain amount of divergence, coming from $R_{\text {f }}$ the point for which the 
eye is optically adjusted-the far-point of the eye-are accurately focussed on the retina. To focus parallel rays on the retina it is necessary to place before the eye a concave lens that will cause them to diverge, as though they came from the far-point $R$. Rays emerging from a point in the retina of the myopic eye, traversing the same path in the opposite direction, leave the comea turned toward the far-point $R$. They require a concave lens having its principal focus at $R$ to make them parallel.

Myopia is "corrected" by a concave lens having its principal focus at the far-point of the myopic eye. 'The distance of the far-point from the eye will be the focal distance of the lens, which, when placed at the eye, will correct the myopia. But if the lens be placed in front of the eye, nearer the far-point, its focal distance will have to be to that extent shorter. Suppose the far-point to be 3 inches in front of the eye. If the lens be placed at the eye, a 3 -inch (13. D.) lens will correct the nyopia. But if placed a half-inch in front of the eye, the correcting lens will be only $2 \frac{1}{2}$ inches from the far-point, and a $2 \frac{1}{2}$ inch (15. D.) lens will be required to correct the myopia.

The myopic eye is mable to correct its defect by accommodation. When the accommodation is exerted, the focus of the parallel rays is brought still farther in front of the retina, and rays to be focussed on the retina must reach the eye still more divergent. It ean see distinctly closer than the emmetropic eye of the same age, and thus has some of the advantage, as well as the disadvantages, of an eye with a magnifying glass before it.

Causes and Course.-Myopia is due chiefly to the straining of the eyes for ncar work. There secm to be two important factors in its prodnction-namely, softening of the scleral coat by congestion, and pressure of the muscles around the eyes in fixing near objects. These co-operate with the normal intra-ocular tension to produce stretching of the sclero-corncal coat, at the region of greatest softening and least resistance, usually about the posterior pole of the eye, or the entrance of the optic 
nerve. An important eause of eye-strain and myopia is astigmatism. Sometimes the initial softening of the selera occurs as a result of aeute general disease, as after one of the eruptive fevers; and vascular tension has been credited with an important influence in causing it.

The proeess of distention, beginning in hyperopic eyes, leads first to diminished hyperopia, and later to myopia. In its earlier stages it is often arrested by diminished strain of the eyes on account of pain, or other symptoms of irritation that arise. If the distention and the thinning of the selera have not progressed too far, the normal increasing rigidity of the selera tends to arrest it in early adnlt life. Often when one eye is praetieally useless, and convergence to secure binocular vision is given up, the increase of myopia ceases. But generally the more the selera is thinned the more rapidly does it continue to yield to intra-oeular pressure, until extreme myopia terminates in blindness, by vitreous opaeities, atrophy of the choroid, or detachment of the retina.

As myopia increases, a vicious circle is established. The patient, disabled for distant seeing, uses his eyes more and more for near work. At the same time near work becomes harder and more dangerous, because of the ehange in shape of the eyeball. The normal eye is a sphere, turning in a spherical socket, equally well in all directions. In high myopia the eyeball always becomes more or less ovoid, lying in the space included by the cone of muscles that arise from the apex of the orbit and pass forward to be attached to its anterior segment. 'This ovoid eyeball fits in its socket only in one direetion. If turned from this direction it must push aside the tissue composing its socket, or be compressed by it. The ovoid soeket having the direction of the muscular cone, and the visual axis being nearly in the direction of the long axis of the eyeball, there is almost always a tendency for highly nyopic eyes to diverge. Because of this tendency to divergence, and the neeessity of excessive convergence for binocular vision at the only distance at which clear vision is possible, the myopie eye is subjeeted to excessive 
effort of convergence, with increased pressure on the sides of the globe, tending to distend it still further anteroposteriorly. This injurious influence continues active until the need for excessive convergence is removed by the wearing of glasses, or until binocular vision ceases, either by the practical blindness of one eye or by its actual divergence-divergent squint.

Varieties.-Besides axial myopia and myopia of curvature (sec p. 155), theoretically there might be added myopia due to changes in the index of refraction of one or more of the dioptric media. The temporary myopia referred to as a sequel of iritis (Chapter XI) has been ascribed to this eause; and the myopia which comes on in old agc, often as a forerunner of cataract, is due to increase in the refraction of the lens nucleus. Progressive myopia is a term that would apply to all cases of M. at some stage. But it is usually intended to imply that the case continues progressive while under observation. Malignant myopin is applied to a small group of cases which, in spite of treatment and avoidance of near work, continue to go steadily from bad to worse until all useful vision is lost. The same term is sometimes applied to any case that has gone so far that there remains but little sight, and little to expect from treatment, although such a condition may have been produced only by reckless disregard of all hygienic measures.

It is also convenient to elassify myopia according to its degree as follows: Low M., not over 2. D., some accommodation being required for most kinds of near work. Moderate M., from 2. D. to 4. D., near work being possible without accommodation and without cxcessive convergence. High M., from 4. to 10 . D., binocular vision being still possible but with excessive convergence. Very high M., over 10. D., binocular vision bèing usually impossible without concave lenses.

Symptoms.-Myopia always causes impairment of distant vision. In a few cases this impaiment has not been noticed until the eyes come to be tested ; but generally it is the first thing to attract attention, and is usually 
quite striking. It depends on the degree of the myopia and size of the pupil, which is often rather large in myopic eyes, and on retinal lesions that accompany the myopia. In any ease the near vision is comparatively good, and the near-point eloser to the eye than normal.

With high myopia the impairment of vision prevents the patient from recognizing and imitating, or responding to the facial expression of others. Hence, the face of the myope often looks dull, unresponsive, or expressionless. When trying to see distant objeets elearly, the myope almost closes the lids, to narrow the eireles of diffusion on the retina. This habitual "nipping" of the lids also affects the facial expression, and gave rise to the term myopia. Imperfect distant vision gives a distaste for outdoor sports that require good sight, excludes from certain oceupations, and turns the patient to sedentary pursuits requiring distinet vision at short distanees only. These symptoms disappear when correeting glasses are worn continuously.

The difficulty of turning the ovoid myopie eye in its socket causes the patient partly to substitute movements of the head and body for those of the eyes. This causes a peeuliar carriage of the head when walking, and a characteristic attitude and movement of the head in reading. Instead of holding the head and book still, and following each line by a movement of the eyes, the whole head is turned somewhat, from side to side, the book being at the same time moved in the opposite direction. These movements are greatly exaggerated when the patient reads without glasses, because of the greater angle suibtended by the line when held very elose to the eye. If the book or other object looked at is too heavy to raise to the eyes, the head is bent down toward it, interfering with the return of venous blood in the neek, and favoring congestion of the head and eyes. The connection of divergent squint with myopia is farther considered in Chapter VIII.

The diffieulty of excenting ocular movements may canse frequent and severe aching in the eyes, besides the head- 
aches which may occur in connection with myopia, as with hyperopia or astigmatism, through eye-strain. It should be noted that with myopia, althongh near vision without accommodation is theoretically possible, it is not usually accomplished in practice. The difference in the degree of M. between the eyes, and the strong effort of convergence required, nearly always provoke some effort of accommodation, and a slight inaccuracy in the distance of the near work may compel as much accommodation as the emmetropic eye is usually required to exert. Thus, a myope having M. of 10. D., holding his book 1 inch nearer his eyes than necessary, would need to use $3 . \mathrm{D}$. of accommodation-the same as an enmetrope reading at 13 inches.

The occurrence of muscr volitantes with myopia has already been alluded to (p. 42). Moving clouds before the sight may indicate the presence of vitreous opacities of any size. They usually appear rather suddenly after some especial strain of the eye. With the ophthalmoscope the opacities may be identified, and their progress watched. If large they rarely disappear entirely, although they become less annoying. The tendency is for the vitreous slowly to become more disorganized and fluid, the opacities becoming more freely movable, even though the degree of myopia be not increasing.

Cataract occurs ultimately in a large proportion of highly myopic eyes. It is apt to be of slow development and dark in color-the so-called choroidal cataract. Posterior polar cataract is sometimes seen in myopic eyes for many years before there is any general opacity of the lens.

Choroidal changes almost invariably mark the progress of myopia. They begin usually with haziness or a fluffy' appearance, which is often confined to the temporal side of the optic disk, but may be more general. Then there appears thinning of the choroid with irregular deposit of the pigment and atrophy of the choroidal stroma, so that the sclera shows through in the form of a crescent at the temporal side of the disk. Such a myopic crescent is 
shown in Figs. 33 and 34 at different stages in its development. Exactly similar appearances brought about in the same way may be seen in hyperopic cyes. But as the eye passes over into myopia, the ehoroidal changes generally continne. A crescentic portion of the choroid adjoining the atrophic ereseent becomes disturbed, infiltrated, and atrophied, and by this process the myopic crescent extends. Fig. 34 shows the extension of choroidal changes beyond the original crescent.

The distention of the eyeball continuing, the atrophic area extends, so that it assumes rather a triangular form with the base toward the disk and the apex toward the

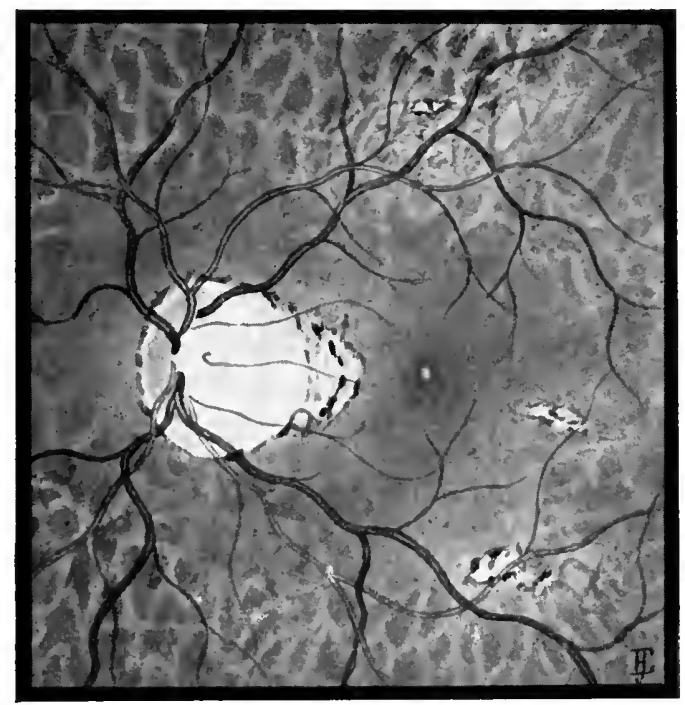

Fig. 63.-Fundus of highly myopic eye with "dragged" disk, large "conus," general atrophy of retinal pigment, revealing the choroidal vessels, and patches of choroidal atrophy, one of which is commencing in the macula.

macula. Such an area is called a comes. At the same time areas of thimned and disturbed choroid beeome noticeable in other parts of the fundus, especially near the 
macula, and tend to undergo atrophy. These appearances of advanced choroidal cliange are illustrated by Fig. 63.

The degeneration of the choroid is nsually attended with vitreous opacities. In a few eases the crescent of atrophy is situated not at the temporal, hut at the upper, lower, or even nasal margin of the disk. As it grows larger it tends to encircle the disk.

A decided atrophy at the temporal side of the disk usually accompanies the marked bulging of the selera that sometimes oceurs at this point, called posterior staphyloma. In this case the disk, being tilted so as to face rather laterally into the eye and not forward toward the pupil, appears foreshortened, narrow from side to side, and therefore more of an ellipse, with the long axis vertieal. The stretching also causes the vessels to run straight across the region of atrophy, as shown in Fig. 63; giving the appearance known as the "dragged disk."

The retina in the irritative stages of myopia may be swollen and hazy with increased reflexes. The "Weiss reflex" (p. 100) at the temporal side of the disk has some signifieance as a sign of swelling. Later, in some parts the retina may atrophy with the underlying choroid, althongh generally it does not. In very high myopia the retina is liable to detachment, probably from retraction of parts of the disorganized and partly cicatricial vitreous.

Diagnosis. - Imperfect vision from any eause, inducing the patient to hold print or small objects close to the eyes, is liable to be called near-sightedness: But in myopia near vision is always relatively better than distant. A hyperope may be able to read print at 5 inches that he cannot read at 20 inches, but type four times as large will be read more easily at 20 inehes. But the myope able to read 10 -inch type at 5 inches will not be able to read 40-inch type at 20 inches.

We have then in myopia impaired distant vision, which is improved by the pinhole disk. Near vision is relatively good, and the near-point closer to the eye than for the emmetropic eye at the same age. With the ophthalmoscope the fundus eannot be seen elearly in the erect 
image, without the use of a concave lens; but on drawing back from the eye one may, in very high myopia, see clearly an inverted image of the fundus. By skiascopy (p. 134) a point of reversal is found between the surgeon and the patient's eye, or closer to the patient's eye than the principal focus of a convex lens placed in front of it.

Concave lenses render clearer the distant vision. Under a cycloplegic the lens which gives the best distant vision corrects the myopia. When the eyes are not free from accommodation, the weakest concave lens that will give the patient his best vision is to be sought, by trying first lenses that are too weak, and as their strength is increased, noting the one with which vision ceases to improve. An approximate estimate of the nyopia may be made by neasuring the greatest distanee at which the finest type is visible. This will be approximately the distance of the far-point from the eye, the focal distance of the lens correcting the myopia.

Treatment.-The first remedy for myopia is the wearing of correcting lenses. These are necessary to remove the most important influcnees that tend to increase the myopia, and to give the patient the best vision of which his eyes are capable. In gencral, they should correct all the myopia and should be worn constantly. The exceptions to this will be noted presently. Such lenses allow the patient's eye to work under conditions most nearly similar to those of emmetropia. They induce him to relax his accommodation entirely when looking at distant objects-a thing he may not do when it will not bring clear vision-and to use the normal accommodation for neal-seeing. They discourage excessive convergence, since with it must occur strain of accommodation. They enable the patient to enter upon occupations and amusements requiring distant vision, and to escape from those which tend most strongly to increase his myopia.

Glasses worn only a part of the time, or which only partly correct the myopia, do not give these benefits. Lenses partly correcting myopia may be extremely dangerous. For rays passing through it obliquely a lens acts 
as a stronger lens, and produces a greater refractive effect than for rays passing in the direction of its primary axis, perpendieular to its surfices. The myope with a partial correction finds this out, finds he can see better or farther by looking obliquely through his glasses, and does so. But, besides increased strength, obliquity gives a totally rlifferent and very undesirable effect. It causes a spherical lens to act as a sphero-cylindrical lens or a sphero-cylindrieal to act like one having a cylinder of different strength or differently placed. This exposes the patient to the dangers of eye-strain from astignatism, and an astigmatism that varies with the direction in which the patient looks.

The exceptions to the constant wearing of the full correction are: In presbyopia, glasses which allow for the failure of the accommodation must be given for near work. They are determined by subtracting from the correcting lenses worn for far-seeing, the strength required for correcting the presbyopia which is found, either by taking the near-point with the correcting glasses on, or by taking the near-point without glasses, and from it and the far-point calculating what will be necessary to enable the patient to do his near work withont using more than twothirds of his aceommodation.

A few persons who have not reached the age of presbyopia suffer from continued nse of even less than half their accommodation. Such persons, if emmetropic, use convex lenses for near work, and if myopic, shonld have glasses weaker than their correcting lenses, to use for near work only. The persons who are better off for a permanent arrangement of this kind are but few. A larger number will be helped by wearing weaker coneave lenses for near work, and their correcting lenses for listance, temporarily, while becoming fully aceustomed to the latter.

Patients who have given up or are just giving up binocular vision should not always be given eorrecting lenses. In some cases such lenses may restore binocular vision,.. with alvantage to the patient. In other cases they. will lead to persistence in the attempt to use both 
eyes together, and thus to further increase of an already high myopia, which would otherwise be cheeked by giving up binocular vision and the accompanying effort of convergence.

Persons who see very imperfectly through their correcting lenses may be distinctly worse off with them, because of the diminished size of the retinal images. The retinal image of the myopic eye is larger than that of the emmetropic eye, because the retina is farther from the nodal point, but when a concave lens is placed before the eye the nodal point is shifted back toward the retina. With the correeting lens at the anterior focus of the cye, about $\frac{1}{2}$ inch in front of the cornca, the retinal images are the same size as those of the emmetropic eye. But this may be such a reduction in their size as to cause great annoyance to the myope accustomed to the larger images. Such a patient may go without glasses, or with a partial correction, since he will feel no temptation to increase the effect of the lens by looking through it obliquely.

Operative Treatment. - Persons with very high myopia experience much annoyance from the strength of their correcting lenses, their weight, the prismatic effect if they get slightly out of place, the difficulty in becoming accustomed to them, and the diminished size of the retinal images. When the myopia amounts to 15 . D. or over, and correcting lenses are not worn with satisfaction, or perhaps when the myopia has reached 13 . D. before the age of puberty, and is still rapidly increasing, in spite of correcting lenses and abstinence from near work, it is proper to practise removal of the clear crystalline lens. This is accomplished in children by needling alone, and in adults by needling the lens to cause a traumatic cataract, and, before it eauses undue swelling of the lens and irritation of the eye, extracting it like any other soft cataract.

The removal of the crystalline lens gives much larger retinal images than the wearing of a correcting lens, sometimes more than 50 per cent. larger, and if everything goes well, it may be expereted to improve the acute- 
ness of vision to that extent. It deprives the eye of the power of accommodation; but to the eye that is very highly myopic and cannot wear a correcting lens, accommodation is useless. 'The removal of the clear lens is attended with about the same risks as eataract extraction, and in some eases confers almost equal benefit. It does not, however, remove the danger of detachment of the retina, and sometimes does not prevent a further increase of the myopia. It should not be done unless it has been demonstrated with lenses that correction of the myopia ean greatly improve vision, and that such lenses cannot be comfortably worn. 'The amount of myopia corrected by the removal of the erystalline lens varies from 15 . D. to 30 . D. The higher the myopia, the greater the effect that can be expected from the operation. Generally the eye after operation will require correcting lenses for distant vision and others for near work.

Besides its optical treatment, myopia, if at all progressive, demands rest from near work, or its eareful regulation. Rest will sometimes need to be made absolute by the continued use of a cycloplegic. Regulation includes eare of the conditions under which eyc-work is done, especially avoidance of excessive convergence, and limiting the amount within the endurance of the eyes. After - acute discase care must be taken to avoid eye-work until the strength has been fully restored; and any condition unfavorable to the health and nutrition of the coats of the eye should receive attention.

Prognosis.-Under the treatment outlined nearly all eases of myopia will cease to be progressive. But even if the eye does not become more myopic, if it be already highly so in early life, there is danger of degenerative changes in the ocular tissues as the patient grows old. If the myopia be morlerate or low, there is a probability that it will slightly decrease as the patient grows older, throngh continued growth of the crystalline lens. With correcting lenses even high degrees of $M$. may become quite stationary. The writer has seen a ease in which 20. D. lenses fitted at the age of nineteen still fully cor- 
rected the myopia thirty years later, although the patient, a elergyman, had used the eyes to excess in reading and study.

\section{ASTIGMATISM AND CYLINDRICAL LENSES.}

In speaking of lenses and the eye, it has been thus far supposed that their dioptric surfaces eurved equally in all directions, and that the light coming from one point was perfeetly focussed to another point. 'To an eye with such surfaces a point of light, such as a star or distant electric light, appears as a simple point. Most persons, however, see such a point of light either as a line, or as a number of lines of light radiating from a center, the conventional figure of a star $*$. This is due to inequalities in the curves of the dioptric surfaces of the eye, which prevent light from a point outside the eye from being focussed perfectly to a point on the retina. Hence this defect is called astigmatism or astigmia. Astigmatism is divided into regular astigmatism and irregular. When the word astigmatism is used withont qualification, regular astigmatism is meant. It is regular astigmatism that we are now to consider.

A cylindrical lens, or a "cylinder," represents the simplest case of such asymmetry of a dioptric surface. It is bounded on one side by a portion of the surface of a cylinder. Such lenses and the way they refract light are represented in Fig. 64, which represents the convex cylindrical lens, and Fig. 65, which represents the concave. In

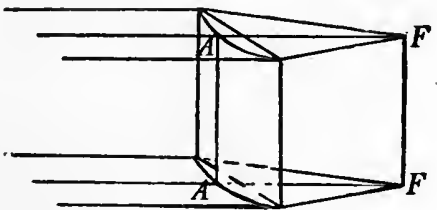

Fig. 64.-Refraction by a eonvex cylindrical lens, bringing parallel rays to a focal line.

one direction the lens-surface has a curve like that which a spherical surface has in all directions, but at right 
angles to this curve the surface is perfectly straight. A straight line $A A$ rumning at the thickest part of a convex, or the thinnest part of a concave lens, is called the axis of the lens.

In the direction of its axis a cylindrical lens has no more effect on the light passing through it than a plate

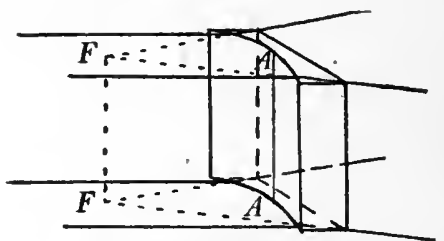

FIG. 65.--Refraction by a concave eylindrieal lens, dispersing rays as though from a foeal line.

of glass with parallel sides. In the direction of its curve a eylindrical lens focusses light like a spherical lens of the same strength. If we eonsider the action of the lens on the light passing through it in a plane perpendicular to the axis, we see that the light will continue in this plane, being turned neither up nor down, and that the ray passing through $A$ will not be refracted at all, but that all the rays passing on the right or left will be turned in to meet this central ray at $F$. The same thing happens in all planes perpendicular to the axis, so that all the light passing through the lens is focussed in the points of the line $F F$, which may be called the focus of the cylindrical lens.

Since a cylindrical lens refracts light only in one plane, in prescribing or speaking of such a lens it is necessary to indicate the direction of its axis on a graduated circle such as is placed on the front of trial frames. On the scale commonly used in this comtry the graduation starts with zero at the right of the horizontal diameter when the circle is looked at from in front, goes upwarl to $90^{\circ}$, which is vertical, and over to $180^{\circ}$ at the left of the horizontal diameter. Or the graduation, starting at the left 
of the horizontal diameter, goes downward and then to the right.

The regular astigmatism of the eye is due chiefly to the shape of the eornea, and it often is convenient to speak as if it were wholly due to the cornea. The cornea curves in all direetions, but astignatism is eaused by its eurving more in one direction than in another. The direction in which it curves most and the direction in which it eurves least are (for regular astigmatism) at right angles to each other. They are called the principal meridians of corneal curvature or the prineipal meridians of astigmatism. The meridian of greatest curvature is commonly vertical or nearly so, the meridian of least curvature horizontal or nearly so. When this is the ease, it is said to be astigmatism according to the rule; when the relative curvatures are reversed, it is astigmatism against the rule.

The refraction of light by an astigmatic eye ean be best understood by combining a spherieal +10 . D. with

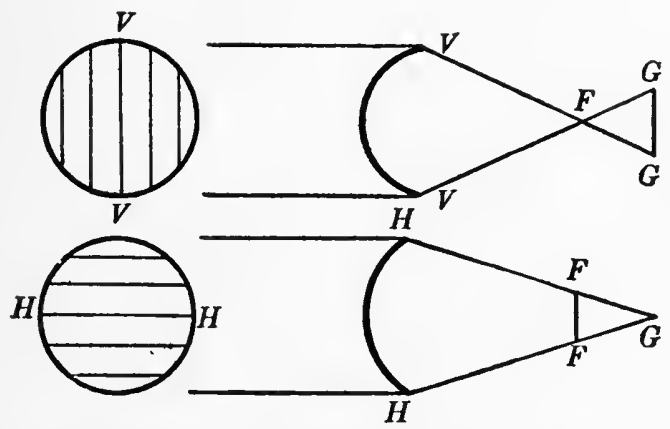

FIG. 66.-Refraction of light in principal meridians of an astigmatic eye, the upper part representing the vertical, and the lower part the horizontal meridian.

a cylindrical $+4 . \mathrm{D}$. lens from the trial case (or by using a spherocylindrieal lens, one surface spherieal, the other surface eylindrieal, of this strength), and studying how it focusses light from a distant point in a dark room. A 
card held so as to intercept the pencil of refracted rays, first at one and then at another distance from the lens, shows the different forms the pencil assumes; and shutting off part of the surface of the lens with eolored glass shows what part of the pencil the rays coming through that part of the lens oecupy.

The foenssing of light by the astigmatic eye is also illustrated by Fig. 66 in which $V V$ represents the meridian of greatest, and $H H$ the meridian of least curvature. Vertically, in the direction of $V V$, all the rays above and below are turned down and up so mueh that they are brought to the level of the ecntral ray at $F$. But horizontally, in the direction of $H H$, they are not turned in so much by the weaker eurve, and do not come into line with the eentral ray until they reach $G$. The rays are converged in both'direetions, but unequally, so that at $F$, being all gathered to the same level but still spread out laterally, they form a horizontal focal line $F F$. Then they begin to spread out up and down, although stiil gathering together from the sirles, until at $G$ they are colleeted in the vertical focal line $G G$. Beyond $G$ they spread out in all directions. $F F$ is called the anterior focal line, and $G G$ the posterior focal line. The distance between the focal lines is the focal interval of Sturm.

The greater the difference between the curvatures of $V V$ and $H H$, the greater will be the focal interval, the longer the focal lines, and the higher the degree of astigmatism. The degree of astigmatism is expressed by the difference in the refractive power of the eye in the two principal meridians. It is corrected by the eylindrical lens, which brings the two foeal lines together, making them a single point. It may be a convex eylinder, placed so that its eurve will help the weaker eurve of the cornoa, which will bring the posterior focal line forward to the anterior; or it may be a concave cylinder placed so that its eurve will partly nentralize the stronger eurve of the cornea, and thus earry the anterior back to the posterior focal line. It will be noticed that the horizontal focal line has its position fixed by the vertical eurve of the 
cornea, and that the vertical focal line has its position fixed by the horizontal curve of the cornea. To help the horizontal enrve of the cornea the eurve of the lens must be horizontal and its axis vertical, and to neutralize the vertical curve the curve of the lens must be vertical and its axis horizontal. The enrve of the lens being applied to a certain curve of the eye, the axis of the lens at right angles to that curve has the direction of the foeal line which the lens affects.

Appearance of Lines.-Astigmatism affects the seeing of lines in this way. One of the focal lines is the nearest to a foens that rays are brought by the astigmatic eyethe anterior focal line being a little the shorter of the two. - When one of these focal lines is brought on the retina, as it usually can be by the accommodation, lines looked at whieh rum in the same direction as the focal line will be seen clearly, but all other lines will be blurred. Each point of a line makes the impression of a foeal line on the retina. If these impressions overlap, they reinforee each other, and make the strong distinet impression of a single line. But if these impressions, instead of overlapping each other, overlap the impressions made by other points at the sides of the lines, they are weakened so as to eause a blur.

This is illustrated in Fig. 67 , in which $A$ shows parallel

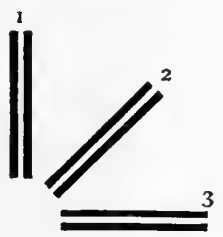

A

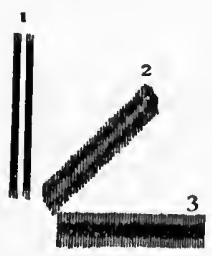

$\boldsymbol{B}$

FIG, 67.-Appearanee of lines running in different directions: $A$, as seen by the normal eye; $B$, as seen by the astigmatie eye.

lines as they appear to the cye free from astigmatism, each point of the line making its impression on a single point of the retina, and not overlapping in any direction. 
$B$ represents the appearance these lines present to an astigmatic eye with the vertical focal line falling on the retina, each point making the impression of a vertical line. For the vertical lines the inpressions overlapping one another make the lines sharp except at the ends, which are blurred. But for the horizontal line the vertical overlapping runs them together, making a broad blurred band with distinct ends.

Causes and Seat.-Astigmatism is commonly due to a congenital anomalous development of the cornea. Sometimes the asrmmetry of the corneal curvature develops during childihood or in adult life. It may be produced by extensive corncal wounds, as that made for cataractextraction, in which case the cornea is flattened in the meridian perpendicular to the corneal incision. It may be produced by cicatricial changes following corneal ulcers, or by the bulging of the conical cornea. In most cyes the difference between the corneal astigmatism as measured by the ophthahmometer, and the total or net astigmatism of the eye as measured by skiascopy or the test lenses, shows that the crystalline lens also takes part in the causation of astigmatism. Usually the lens-astigmatism partly neutralizes that of the cornea, the net astignatism of the eyc being less than that of the cornea alone, yet in some eyes the lens-astigmatism greatly predominates. Lens-astigmatism may be due to asymmetry of the lens-surfaces, or to their being placed obliquely with regard to the rays entering the pupil.

Varieties.-Astigmatism is always ametropia of curvature, its direction and amount being entirely independent of the position of the retina. Still its recognized elinical varieties are based on the varions positions of the retina with reference to its focal lines. Thesc are five in number. They are illustrated in Fig. 68, in which $F$ represents the anterior and $G$ the posterior focal line. The retina may be in front of both focal lines as at (1) the eye hyperopic in both principal meridians; this is called componnd hyperopic astigmatism. The retina may pass throngh the anterior focal line (2), the cye being 
hyperopic for the meridian of least eurvature and emmetropie for the other; this is simple hyperopic astigmatism. The retina may lie between the foeal lines (3), the eye being still hyperopie for the meridian of least eurvature, but myopic for the meridian of greatest eurvature-mixed.

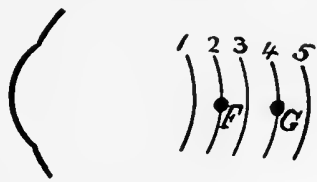

Fig. 68,-Different positions of the retina with reference to the foeal lines: 1 , compound hyperopic; 2 , simple hyperopic; 3 , mixed astigmatism; 4 , simple myopic; 5 , compound myopic.

astigmatism. The retina may pass through the posterior focal line (4), the eye being myopic for the meridian of greatest curvature and emmetropic for the meridian of least curvature-simple myopic astigmatism. 'The retina may lie beyond the posterior focal line (5), making the eye myopic for both meridians-compound myopic astigmatism.

By elongation of the eyeball, such as produces myopia, the same eye may pass from compound hyperopic to compound myopic astigmatism through all the intermediate varieties, without material change in the direction or curvature of the principal meridians, and withont change in the amount of the astigmatism.

Symptoms.-Astigmatism of high degree always diminishes aenteness of vision, both distant and near. The extent to which it does this depends on the degree of the astigmatism, the size of the pupil, and the ability of the patient to picee together and interpret partial retinal images; for the astigmatic eye can often by a certain amount of accommodation bring one focal line on the retina, so that certain lines are seen elearly, and then by another amount of accommodation it ean bring the other focal line on the retina, and see other lines clearly. The mental ability to combine and ntilize the partial impres- 
sions so obtained will greatly influence the patient's response to the ordinary tests of visual acuteness.

Normal acuteness of vision by the usual standard may be possessed by eyes so astigmatic as to cause serious eye-strain. It is by eyc-strain that low degrees of astigmatism manifest their existenee. The symptoms depend on the requirements marle of the eyes in the way of elose work, and the endurance of the nervous system and oeular tissues, as determined by the state of the general health.

The liability to headache, its charaeter, and amenability to other treatment are much the same with astigmatism as with other forms of ametropia. Astigmatism causes the same congestion, or chronic or reeurring inflammation of the eonjunetiva and lid-margins. It is a very important eause of the ehoroidal ehanges that aceompany and probably aid in eausing myopia. Many cases pass, as Risley says, from hyperopia to myopia "through the turnstile of astigmatism." The symptoms of astigmatism may vary with the amount of effort required of the eyes, or they may be more apparently conneeted with variations in the general health.

Diagnosis.-Impairment of vision is always present with astigmatism of high degree, but it is less than for the same degree of hyperopia or myopia. It affects distant and near vision about equally. 'The patient usmally reeognizes some letters better than others, misealling some letters in one line, and reading others correctly that are two or three lines smaller. The near-point is about where it would be for emmetropia at the patient's age, unless there is also hyperopia or myopia to affeet it. With the special test-cards of radiating lines, the lines running in some one direction (uswally the direction of the posterior focal line if aecommodation is good) are seen more clearly than others; but sometimes a patient will deny that the lines are elearer in any one direction, or will give contradietory answers.

On looking at a point of light the astigmatie eye may see it as a line of light, the lens indicating the direction 
of one of the principal meridians. This is made the basis of certain tests for astigmatism, but if the pupil is dilated, the line significant of regular astigmatism is in many eyes masked by the radiating lines due to irregular astigmatism. Hotz's astigmometer and Thomson's ametrometer are based on this distortion of a point of light as seen with an astigmatic eye.

In the trial case will be found a metal disk with a narrow slit in it, the stenopaic slit. If this be placed before an astigmatic eye and turned in various directions, it is found that a.certain direction gives the best vision, and that at right angles to this the vision is worst. The former direction is that of the least ametropic eurve; the latter direction is that of the most ametropie eurve. The slit being placed in one of these directions, the spherieal lens whieh most improves the vision is the lens which corrects that principal meridian. When both

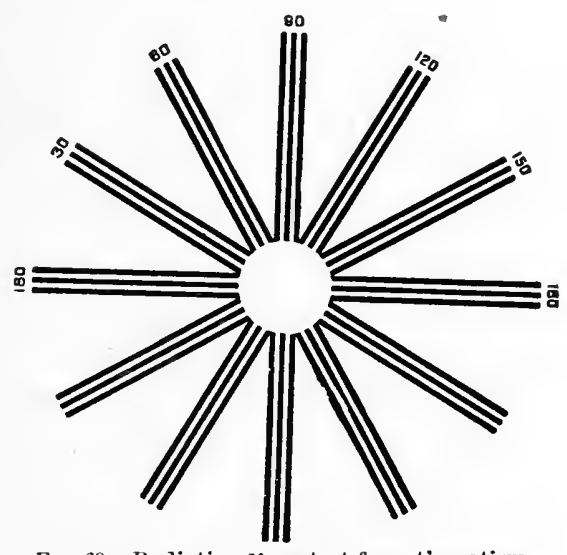

FIG. 69.-Radiating lines test for astigmatism.

meridians have thus been tested, the difference between the two is the amount of astigmatism.

Difference in the distinctness of lines running in different direetions may be detected by looking at such a 
figure as is shown in Fig. 69 . If difference of elearness in the radiating lines is noticed, three parallel lines, small enongh to be just clistinguishable at the distance at which they are placed, may be turned in different directions, and that direction noted in which they appear clearest. By trial the spherical lens is then found which renders the lines most distinet in that direction. It is the measure of the ametropia in the meridian at right angles to the lines. The lines are then turned 90 degrees, and the lens found which renders them most clear in that direction. The differenee between the two lenses measures the astigmatism.

If either of the above tests are applied to an eye which has power of accommodation, the strongest eonvex or weakest concave lens which fulfils the neeessary conditions is the ouge to be aimed at. 'Thus, the strongest convex or weakest concave lens that leaves the line of light will fix its direetion most definitely with the Hotz or Thomson instruments. The strongest convex or weakest concave lens that gives the best vision with the stenopaie slit, or renders the parallel lines most distinet, is the one which most nearly indicates the ametropia in the corresponding meridian.

The above subjective tests are of value for discovering and approximately measuring astigmatism. The objective methods of approximately estimating astigmatism are, by the refraction ophthalmoscope, by measuring the corneal astigmatism with the ophthalmometer, and by skiascopy.

The value of the ophthalmoscope in the diagnosis of astigmatism depends on the fact that a peneil of rays emerging through an astigmatic eornea is rendered astigmatic, so that it forms on the retina of the surgeon, not a point but a focal line. Such focal lines enable the surgeon to see elearly those lines in the patient's retina which run parallel to them, while all others are blurred. Thus, if al rertical focal line falls on the surgeon's retina, he sees clearly the parts of the patient's retinal vessels which rmu vertirally, or the vertieal sides of the patient's optic disk; but all other parts of the retinal vessels, and all 
other parts of the outline of the optie disk appear blurred, the parts that run horizontally being most blurred. The peculiar appearance of the fundus in a highly astigmatic eye is best reproduced by looking through $a+6$. D. cylindrical lens at a picture of the normal fundus (Plate I.) held at a distance of 10 or 12 inches.

The direction in which the lines appear most clear is the direction of one of the principal meridians of astigmatism. It is most accurately determined with the strongest

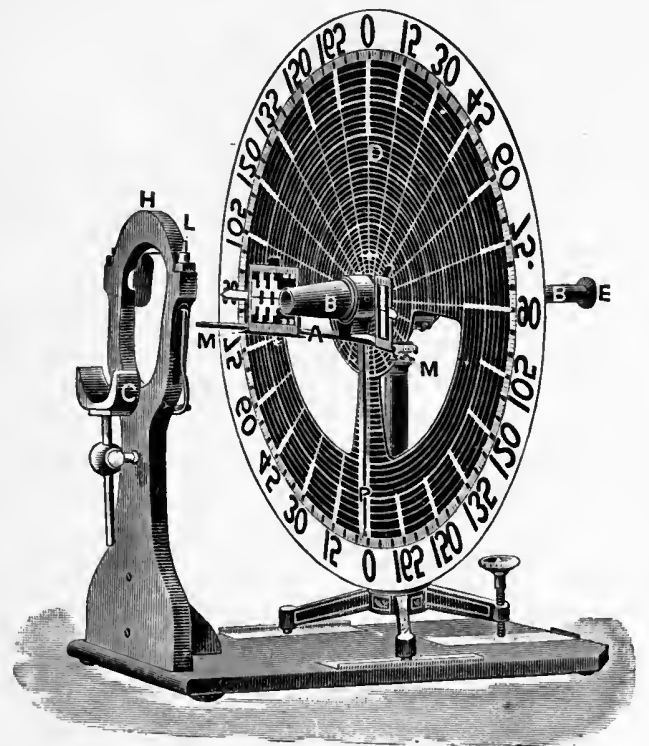

FIG. 70.-Javal-Schiötz ophthalmometer.

convex or weakest concave lens that leaves the vesscls clear in any one direction; that lens also measures the ametropia in that meridian. The other prineipal meridian is at right angles to the first, and the strongest convex or weakest concave lens that renders the vessels clear in that direction measures its ametropia. The difference between the two gives the astigmatism. 
The ophthalmometer measures the curvature of the cornea by the size of the reflection it gives of a known object. 'The instrument of Javal and Schiötz has had most general elinical use. It is illustrated in Fig. 70 and is now alone alluded to. In it the test-object is the distance between the two "mires" $M M$ which are movable on the arm $A$, which revolves in front of the large disk I). This object is placed a fixed distance from the patient's eye, the distance at which the telescope $B E$, through which the surgeon looks, focusses the reflection from the patient's comea, so that both it and the crosshairs fixed in the body of the telescope are seen clearly. 'The size of the reflection is fixed by the strength of a "doubling prism" behind the object-glass of the telescope, a reflection of the proper size being secured when the two adjoining images, of the mires, as seen through the telescope, appear to tonch. They are made to touch by moving one of the mires; and when they tonch, the position of an index on the mire indicates on the arm the radius of eurvature of the cornea in millimeters, and the refraction of the eye in that meridian in diopters.

To use the instrument the disk and mires must be strongly illuminated. The patient, with his brow applied to the head-rest $H$ and his ehin on $C$, looks with the eye to be measured into the telescope, the other eye being covered. The surgeon, looking through the telescope from $E$, directs it so that the arljoining

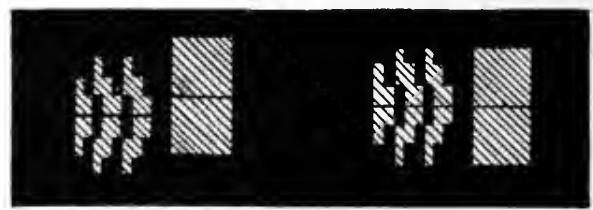

A

$B$

Fig. 71.-Mires of the ophthalmometer: $A$, with the arm not eorresponding to either prineipal meridian of the cornea; $B$, turned to one of the principal meridians.

images of the two mires come to the center of the field. If the black lines aeross the two mires do not 
appear continuous as in Fig. $71 A$, the arm is not parallel to either of the prineipal meridians of the eornea. It must first be made parallel to one of these meridians and the lines continnous, as at $B$, by revolving the body of the telescope. When the arm corresponds to one of the principal meridians, the movable mire must be shifted till its reflection just touches that of the fixed mire, as at $C$ in Fig. 72. The arm is then rotated to the other principal meridian. If the mires overlap as at $D$, Fig. 72,

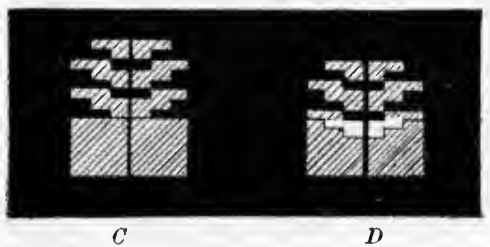

FIG. 72.-Mires of the ophthalmometer: $C$, in the meridian of least refraction, just touehing; $D$, in the meridian of greatest refraction, overlapping for $1.7 \overline{\mathrm{D}} \mathrm{D}$. of astigmatism.

the number of steps of overlapping shows the number of diopters of astignatism. If the mires separate, as at $B$ in Fig. 71, the movable mire must be shifted until it touches the other, and the arm then rotated back to the first principal meridian, when the overlapping will indicate the astigmatism. The overlapping occurs in the meridian of greatest eurvature, the vertical meridian in astigmatism with the rule.

Reid's oplithalmometer is a practical instrument, and being but little larger than an ophthalmoscope is readily earried and used anywhere. In it the test-object is a circular opening in the side of the telescope, the size of which is varied by an iris diaphragm. The reflection of this object from an astigmatic cornea is an ellipse, and the sizes of the opening necessary to render the doubled images of the ellipse just tangent, first in the direction of the long axis, and then in the direction of the short axis, indicate the anetropia in the prineipal meridians. The difference between the two meridians gives the astigma- 
tism. The short axis of the ellipse corresponds to the meridian of greater curvature of the cornea.

In a great many eyes the corneal astigmatism is about $0.5 \mathrm{D}$. greater than the total or net astigmatism of the eye. This amount deducted from the corneal astigmatism when with the rule, or added to it when it is against the rule, may be taken as the indication of the ophthalmometer. But it must always be remembered that the difference between the corneal and the net astigmatism may be very much greater, and that they may have their principal meridians in totally different directions.

Skiascopy is by far the best objective method for measuring astigmatism. The rays emerging from the astigmatic eye when made to converge (by a convex lens when the eye is not myopic) come together, not at a single point but at two points of reversal, one for each principal meridian. At each of these points of reversal the light in the pupil assumes more or less the appearance of a band, rumning in the direction of the principal meridian to which the point of reversal belongs. This band-like appearance is illustrated in Fig. 73. It is brought out

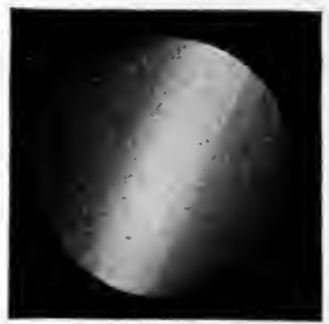

Fig. 73.-Band-like appearance in direction of principal meridian of greatest curvature at $70^{\circ}$.

most distinctly when the source of light is a small circular opening in the metal shade over the lamp-flame, this source being so placed that the light enters the patient's eye as if from the point of reversal of the other principal meridian.

The movement and appearance of light in the pupil 
from different distances (with the plane mirror) are as follows: When eloser to the patient's eye than the point of reversal the surgeon sees the light moving "with" the light on the face in all directions. As he draws back, approaching that point of reversal which is the nearer to the patient, the light is seen to move more swiftly in the direction of the meridian to which that point of reversal belongs, and to assume the appearance of a band ruming in that direction. At the nearer point of reversal it cannot be distinguished which way the light moves in the direction of the band, but at right angles to its length the band is readily made to move "witl" the light on the face. Withdrawing still farther from the patient, the movement in the direction of the band is again distinguished, but it is now "against" the light on the face. The movement still continues "with" the light on the face in the other meridian. The band now rapidly becomes indistinet, and half-way between the two points of reversal not a trace of it remains. Here the appearance of light in the pupil is preciscly the same as in an eye free from astigmatism, except that the light moves "with" the light on the face in one meridian and "against" it in the other. Still farther from the patient's eye the band begins to be seen in the direction of the other principal meridian, and the movement of light in that meridian, still "with" the light on the face, becomes more rapid. At the point of reversal for the meridian of least curvature, the band is seen rumning in the direction of that meridian. 'The movement in the direction of this band is now indistinguishable, and the movement in the other meridian is "against" that of the light on the face. Withdrawing beyond this farther point of reversal the movement is found to be "against" the light on the face in all directions, rapid at first in the direction of the last band, but soon growing slower in all directions.

To illustrate the use of skiascopy, let us suppose an eye requiring a correction of +1 . spl. $\bigodot+1$. eyl. ax. $90^{\circ}$, to be examined with the plane mirror. The surgeon sits two or three feet in front of the patient with the mirror 
to his eye, and the light as close as possible to the mirror. Reflecting the light on the patient's eye the light in the pupil is found to move "with" the light on the face in all direetions; and because the light in the pupil moves rather slowly, it is known that considerable lens-strength will be needed to bring a point of reversal to the surgeon's eye.

A + 3. D. sph. is placed before the eye. With this the movement is "against" the light on the face up and down, but still "with" it from side to side. This shows astigmatism. The surgeon then leans toward the patient and at 0.5 meter ( 20 inches) from the patient's eye the vertical movement "against" is replaced by a vertical band, in the direction of which the movement is indistinguishable. This band moves from side to side "with" the mirror. This, then, is the nearer point of reversal. To fix most accurately its direction, while keeping the observing eye at 20 inches from the patient's, the light is pushed away from the mirror until, when it is 20 inches from the mirror, the band becomes most distinet, the light now being reflected from the mirror as if it came from a point 40 inches away-the farther point of reversal. Under these cireumstances the band from 1. D. of astigmatism may be quite as distinet as that shown in Fig. 73 .

Having thus determined one principal meridian, the other (being always at right angles to it) is also known. The point of reversal is then carefully determined by bringing the light as close as possible to the mirror, and getting the movement in the vertical meridian alternately "with" and "against," noting where it changes from one to the other. Its distance from the eye is then measured, 20 inches, corresponding to 2. D. of myopia. As the 3. D. lens canses 2. D. of M., there must have been $3--2=1$. D. of hyperopia in this meridian. The other point of reversal is then determined in the same way. In this case it is fonnd to be at 40 inches or one meter from the eye; indicating that the lens used causes $1 . D$. of myopia in this meridian, and that without the lens there is $3-1=2$. D. of hyperopia in the meridian of least 
curvature. The difference between the two meridians, or 1. D., is the amount of astigmatism.

To confirm the results obtained by skiascopy it is always best to place before the eye the cylinder that is expected to correct the astigmatism, and repeat the test to see if it really does so. Thus, in the above case, placing $a+1$. D. cyl. ax. $90^{\circ}$ before the eye, the point of reversal will be found at 20 inches for all meridians; on placing $a-1$. D. cyl. ax. $180^{\circ}$ before the eye, the point of reversal will be found at 40 inches for all meridians.

When the astigmatism is low $(0.5 \mathrm{D}$. or less), it may be impossible to bring out a band of light in the pupil. But it can be noticed that the movement becomes indistinguishable, or reverses sooner in one direction than in others; and this proves the existence, and indicates the meridians of the astignatism.

The test-lenses have been called the court of last appeal in the diagnosis of errors of refraction. But in this connection it should be remembered that the real value of the decision of a court of last appeal rests on its opportunity to review all the arguments and decisions that have gone before. The accuracy of the result obtained with the test-lenses depends largely on the knowledge of the refraction previonsly acquired by skiascopy and other methods. If one cannot nse skiaseopy and has no ophthalmometer, the stenopaic slit or the parallel lines with spherical lenses can give very valuable assistance in the diagnosis of astigmatism.

The trial with the test-lenses should begin by placing in the trial-frames, before the eye, the corrceting lenses, as these have been determined by other methods. When the patient has read the test-letters as far as he can with these, they are to be morlified by holding in front of them supplementary lenses. First +0.50 and -0.50 spherical, may be alternated unless the vision is still quite poor, when +1 . and -1 . D. should be used. If either of these improves vision, a corresponding change is to be made in the lens in the trial-frame; and the trial with supple- 
mentary lenses repeated until any ehange in the spherical makes vision worse.

Then the direction of the eylinder may be tested by turning it first to the right then to the left, and asking the patient to say "stop," as soon as the change begins to make vision worse. The points on each side, at which vision is rendered pereeptibly worse, must be carefully noted in repeated trials, and a point half-way between them is the proper direction for the axis of the eylinder.

To test the strength of the cylinder the astigmatic lens should be used. 'This is a crossed cylinder, or an equivalent sphero-eylindrical lens, convex in one moridian and equally concave in the meridian at right angles to that. The most useful combination is $-0.25 \mathrm{sph} . \bigcirc+0.50$ cyl., but a lens of double that strength and one of half that strength are also useful. The astigmatic lens is used as a supplementary lens, the axis of the cylinder being first held in the same direction as the axis of the eylinder in the trial-frame, and then turned perpendienlar to it. In one position it adds to the effeet of the cylinder in the trial-frame; in the other it diminishes that effect. The patient is asked which way is the better, or whether one way is any better than the other. If it makes no difference which way the astigmatic lens is turned, the cylinder already in the trial-frame is of the right strength. If the astigmatic lens does make it better in one direction than the other, the cylinder in the trial-frame is to be changed aceording to that indieation.

After this the strength of the spherical is again to be - tested, in connection with the new eylinder, and the direction of its axis must be re-tested ; this process must continue until any ehange in the lenses makes vision worse. The testing should be interrupted to let the patient rest whenever he becomes tired, otherwise his answers become unreliable. When there is any diserepancy between the results of skiascopy and the test-lenses, it may be well to repeat skiascopy, and, after the eye has recovered from mydriasis, to try it with the lenses again.

Treatment.-Astigmatism, when it requires treat- 
ment, demands the constant use of correeting lenses. Low degrees do not materially impair the acuteness of vision, and if the eyes are not used much, and no sign of eyestrain arises, nothing need be done for it. When, however, glasses have to be worn for hyperopia or myopia, if any astigmatism is present, even $0.25 \mathrm{D}$., it is usually better to correct it.

Since any ease of astigmatism can be corrected by either a convex eylinder with its curve in the direction of the less curved meridian, or a concave eylinder with its eurve to the more curved meridian, there is always a chance to choose between two combinations. It has been customary to correct hyperopie astigmatism with a convex, and myopie astigmatism with a concave eylinder, thus:

$$
+1 \text {. sph. }=+1 \text {. cyl. ax. } 90^{\circ} \text {. }
$$

But

$$
+2 \text { sph. } \odot-1 \text {. cyl. ax. } 180^{\circ}
$$

is equally effective. It will be noticed that the first requires the use of a weaker spherieal than the second; but the second, having one concave and one convex side, if mounted with the former toward the eye, gives the advantage of a periscopic lens.

Any case of astigmatism can be corrected by erossed eylinders, as thus for the above case :

$$
\text { +1. cyl. ax. } 180^{\circ} \mathrm{O}+\text { 2. cyl. ax. } 90^{\circ} \text {. }
$$

But such lenses eannot be ground with perfect aceuracy, and are far more expensive, while they offer no advantage over the periscopic formula.

In general, the full correcting cylinder is ordered, in conjunction with the needed spherical for any use. But when a strong lens is looked through obliquely, its strength is so increased that the full correcting lens might be too strong. It is therefore better to deduct 0.25 or $0.50 \mathrm{D}$. from very strong cylinders that will have to be looked through obliquely. It should be borne in mind also that when a strong spherical is looked through obliquely it has the effect of a sphero-cylinder (see p. 191). 
Prognosis. - As a rule, astigmatism changes but little throughout life. In some cases, however, it changes very markedly. It is especially liable to change in rapidly growing children, and at about the age of fifty; and generally in eyes that are rapidly becoming less hyperopic or more myopie. After cataract extraction, or other corneal injury, the resulting astignatism reaches its height in a few days after the complete closure of the corneal wound, and then slowly subsides, the permanent condition not being reached sometimes for several months.

\section{ABERRATION.}

The cornea is always more eurved at its center and flattened toward its periphery. The crystalline lens is flatter at the center and more convex at its periphery. These usually balance each other near the center of the pupil, causing an area, the visual zone, the refraction of which usually compares well with that of artificial optical instruments. But at the periphery of the dilated pupil, either the flattening or the increased curvature predominates, causing aberration.

If the increased curvature predominates, so that the eye is more myopic or less hyperopic at the edge of the pupil than at the center, it is called positive aberration. This resembles the aberration of a spherical lens. It is the more common form. If the flattening predominates at the edge of the pupil, making it less myopic or more hyperopic than at the eenter, it is called negative aberration. The difference between the refraction of the center of the pupil and that of the margin often amounts to 1. D. or over.

Aberration interferes with the measurement of ametropia. It is, next to accommodation, the most serious obstacle to accurate measurements with the refraction ophthalmoscope, and makes it necessary in skiascopy to eome near the patient, to get the movement of light and shade in the visual zone at the eenter of the pupil, which may be directly opposite to the movement at the 
edge of the pupil. 'These two areas of light that it causes. in the pupil are shown in Fig. 74.

In exceptional cases it causes the patient to select under a mydriatic a lens which will not suit him when

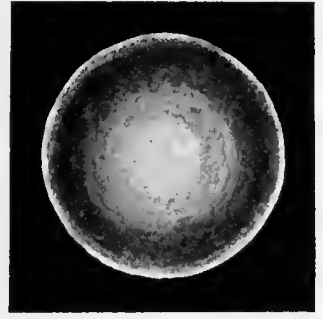

$A$

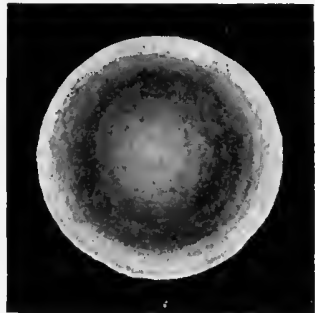

$\boldsymbol{B}$

FIG. 74.-Appearance of the pupil in aberration: $A$, from near the point of reversal for the extra-visual zone near the margin of the pupil; $B$, from near the point of reversal of the visual zone at the center of the pupil.

the pupil has contracted. With negative aberration he may choose under a mydriatic a convex lens too strong to allow of clear distant vision when the mydriatic has passed off. The aberration should be examined by skiascopy in each case of refractive error. The cases of greatest aberration (negative) are those of conical cornea, in which the apex of the cone may be 20 . or $30 . \mathrm{D}$. myopie, while the periphery of the pupil is even hyperopic. Aberration, usually negative, also appears as the result of the lens-changes preceding cataract.

\section{IRREGULAR ASTIGMA'TISM.}

Irregular astignatism exists in all eyes. Usually it is confined to the periphery of the dilated pupil ; but often a low degree of it may be detected, by skiascopy, at the center of the pupil. The term includes interference with refraction caused by all irregularities of the cornea or erystalline lens. Typical forms are caused by the alterations in the cornea that follow keratitis, and by the changes in the crystalline lens that precede senile cataract. It eauses impairment of vision, and interferes with the 
various tests for ametropia. It may also cause monocular polyopia, multiple images of objects, especially of the moon or sources of artificial light, by reason of different parts of the cornea or lens forming each its separate image on the retina. The parts of the pupil which form the particular images ean be ascertained by noticing the effeet of eovering particular portions of the pupil. What has been called normal irregular astigmatism by Donders is partly aberration. It causes, when the pupil is dilated by darkness, the rays which most eyes see, extending from a point of light, as a star or distant are light.

Irregular astigmatism cannot be corrected by any lens. Narrowing of the pupil diminishes its effect. Spectacles with an opaque disk having a small opening, or a narrow slit in it, ealled stenopaic spectacles, sometimes improve vision. But they can rarely be worn, because they limit the field of vision so much. Often there is with high irregular astigmatism some small part of the cornea presenting regular astigmatism, hyperopia, or myopia, the correction of which will give the patient greatly improved vision. Such areas should be carefully sought for and corrected.

\section{ANISOMETROPIA.}

Anisometropia, or inequality in the refraction of the two eyes, exists in slight degree in a very large proportion of cases. The term is usually applied only to cases presenting great differences between the two eyes, or when one eye is hypcropic, and the other myopic, for which state antimetropia is also used. If the difference of refraction is small-1. D. or less-each eye is given its eorrecting lens. This plan ean often be followed until the difference amounts to 2. or 2.5 D., although in these cases it is sometimes better to weaken slightly the stronger of the two lenses. When the difference is greater than $2.5 \mathrm{D}$., each eye may be given its correcting lens in some eases; but sometimes it is best to give the correcting lens for the better eye, and one of about the same strength for the other. 


\section{THE MOUNTING AND WEARING OF GLASSES.}

Lenses, to be of service, must be properly mounted and worn. Spectacle frames are superior to eye-glasses (pince-nez) for strong eylinders; the former generally can be more accurately adjusted, and keep their place better. Eye-glasses, however, because of their appearance, will sometimes be worn when spectacles would not. They are more convenient for slipping on and off, if this must frequently be done, as with glasses used for presbyopia.

In any frame the lenses must be mounted so as to take their proper position before the eyes. They must have the proper distance between their centers (usially the pupillary distance); and must stay permanently at the proper height, not slip down because the nose-piece is too high. They must be the proper distance before the eyes, usually just far enough away to escape being touched by the lashes; and they must have such an inclination that when in use the eyes will look as nearly perpendicular to the surfaces of the glass as possible-that is, for distance the glass should face directly forward; for near-seeing they should face somewhat downward.

Effects of Oblique Lenses. - With strong lenses it is very important to have the line of sight nearly perpendicular to the lens surfaces. When looked through obliquely, the effect is that of a stronger lens to which has been added a cylinder with its axis parallel to the line about which the lens is rotated to make it oblique. Thus, a $10 \mathrm{D}$. convex lens, rendered oblique by rotating it around its horizontal axis, is changed according to the amount of obliquity, to aet as follows:

10 degrees as a $+10.10+0.37$ cy. axis $180^{\circ}$,
20 " $"$ " $+10.40+1.38$ cy. axis $180^{\circ}$,
30 " $"$ " $+10.93+3.65$ cy. axis $180^{\circ}$,
40 "

Patients sometimes look obliquely through the edge of their glasses to get the effect of a stronger lens than has been furnished them, or a cylindrical effect that their lenses do not give. This expedient is not a good one, beeanse when the obliquity is sufficient to give a decided effect a slight 
change of obliquity gives a marked change in that effect. To prevent the undesirable effects of looking obliquely throngh a lens, the periscopic form is to be adopted. (See p. 115 and p. 185.) The ideal combinations for such periscopic lenses are indicated in the following table:

\begin{tabular}{|c|c|c|c|c|c|}
\hline \multicolumn{6}{|c|}{ SURFACES FOR PERISCOPIC LEXSE } \\
\hline $\begin{array}{l}\text { Lens } \\
\text { strength. }\end{array}$ & $\begin{array}{l}\text { Anterior } \\
\text { surface. }\end{array}$ & $\begin{array}{l}\text { Posterior } \\
\text { surface. }\end{array}$ & $\begin{array}{l}\text { Anterior } \\
\text { surface. }\end{array}$ & $\begin{array}{r}\text { Poster } \\
\text { surfa }\end{array}$ & \\
\hline $1 . \mathrm{D}$ & $+6 . \mathrm{D}$. & -- 5. D. & $+5.5 . \mathrm{D}$. & -6.5 & D. \\
\hline 2.D. & + 8. D. & $-6 . \mathrm{D}$. & +5 & -7. & D. \\
\hline $3 . \mathrm{D}$. & $+10 . \mathrm{D}$. & $-7 . \mathrm{D}$. & $+4.5 . \mathrm{D}$. & -7.5 & D. \\
\hline $4 . \mathrm{D}$. & $+12 . \mathrm{D}$. & - 8. D. & +4. D. & -8. & D. \\
\hline 5. D. & + 13. D. & - 8. D. & $+3.5 . \mathrm{D}$. & -8.5 & D. \\
\hline 10.0. & $+21 . \mathrm{D}$. & $-11 . \mathrm{D}$. & Plane & -10 & D. \\
\hline 15.0. & +27.0 & $-12 . \mathrm{D}$. & Plane & -15. & D. \\
\hline
\end{tabular}

Changes with Age.-Beside the gradual increase of presbyopia that usually occurs between 45 and 60 years of age, changes in refraction occur, apart from injury or clisease of the eyes, making oceasional ehanges in the correcting glasses advisable. In early ehildhood the hyperopia, always present at birth, tends to diminish. Myopia shows the greatest tendency to increase between 10 and 20 years of age, but high degrees of it may continue to increase throughout life. In most persons hyperopia increases during adult life, and myopia of low degree often shows a tendency to diminish. Astigmia may change in every respeet, and in a large proportion of persons there is a tendency to a shifting of its meridians, so that in old age the meridian of greatest eurvature is apt to be horizontal or nearly so, astigmia against the rule, while in childhood astignia according to the rule is much more common. (See page 169).

The Period of Adaptation.-Seeing through a pair of new lenses demands a new co-ordination of the nervous and museular actions concerned in vision, which, like any other new exereise, requires time to master. Until the new actions have become customary and antomatic, the best help will not he obtained from the glasses. The hyperope may have trouble in relaxing his accommoda- 
tion so as to let the glass do the work. The myope may at first find it an effort to keep up the accommodation needed for near-seeing. Lenses of mnequal strength, for correcting unsymmetrical astigmatism, cause apparent distortion of objects (binocular metamorphopsia) and confusion of perspective, that may not wholly disappear for many months.

If the new lenses correct a considerable degree of refractive error, previously uncorrected, the patient should be informed that they will not be entirely comfortable at first. The necessary period of adaptation will be somewhat proportioned to the patient's age, varying from a day or two in children, to two or three months or even longer in old people. If the patient be not informed of these difficulties at the time of getting his glasses, he will think that there has been some mistake about them, and may meet subsequent explanations with incredulity.

\section{CHAPTER VIII.}

\section{DISORDERS OF THE OCULAR MOVEMENTS.}

Movements of the eyeball are required to place the most sensitive part of the retina where it will receive the image of the object especially looked at; to keep the eye turned in the desired direetion, during movements of the head and body that would otherwise displace it; and to keep the two eyes directed toward the same point, to secure images which by fusion will give binocular vision. There may be inability to execute these movements, or they may be accomplished, but by undue effort.

If an eye is so directed that the image of the point on which attention is fixed falls upon the fovea, the eye is said to fix that point. Normally, both eyes "fix" the same point. If, however, one of them does not fix the point looked at, but has its visual line direeted elsewhere, 
it is said to deviate. Such an eye is called a deviating eye, the other is called a fixing eye. The point "fixed" is called the point of fixation, the angle between the deviating position of the visual line and its normal direction through the point of fixation is the angle or degree of squint. An eye which deviates is said to squint. The deviation eonstitutes the abnormal condition of squint or strabismus.

Ocular Movements.-The normal extent of the oeular movements varies with the general muscular power, and with the form and prominence of the eyeballs and their relations to the orbit. The eyes can generally be turned from forty-five degrees to fifty-five degrees to either the right or the left, a total excursion horizontally of ninety degrees to one hundred degrees, and they are capable of a total vertieal movement of seventy-five degrees to one hundred degrees. These movements earry the eye outward until the outer margin of the cornea is behind the external eanthus, inward until the inner corneal margin touehes the plica and caruncle, and up or down to where the margin of the cornea passes considerably behind the widely opened lids. As the limits of movement in any direction are reached, the effort becomes fatiguing or painful, and the eye tends to oseillate, exhibiting a kind of normal nystagmus.

Although the eyes are commonly so directed that their visual lines meet in the point looked at, and their movements are so co-ordinated as to preserve this relation constantly, it is a relation that ean be ehanged within certain limits. Thus, the visual lines commonly lie in the same plane, passed through the fovea of each eye and the point fixed. But one eye may be made to turn up or down more than the other. It will do so to prevent double vision, if a prism be placed before one eye with its base down or up. The power of doing this is ealled the power of sursumduction or sursumvergence. It varies normally from one to two degrees-that is, double vision does not oceur unless the prism used thus is as strong as 2 to 4 centrads. The eyes are said to overcome weaker 
prisms by their power of sursumduction. If prisms be placed before one or both eyes with their bases toward the nose, the eyes looking at a distant object turn out and their visual lines diverge, to "overcome" the prisms and avoid double vision. This is called abduction or prism-divergence. Its normal extent is about 5 to 10 centrads. When prisms are placed before the eyes with their bases toward the temple the eyes turn in to "overcome" them. This is the adduction or prism-convergence. Its normal limits are from 12 to 20 centrads. The normal relation of abduction to adduction power is 1 to 2 or 1 to 3 . The adduction power may be increased by practice; and by using accommodation and rendering the distant object indistinct, the eyes can be converged very much more. But this is not what is usually meant by the power of adduction. By a maximum effort the visual lines may be caused to converge to the extent of 100 to 150 centrads (60 degrees to 85 degrees), so that they will meet at a point even less than 3 inches from the eyes. This power of converging the eyes is ealled the power of convergence. It can be measured by the nearest point at which an object can be seen single, the neas-point of convergence; or by the power to "overeome" prisms with their bases toward the temple, if the patient has learned to exert his full power in this way.

\section{THE METER=ANGLE.}

When the eyes look at a point directly in front of them, and one meter away from each eye-that is, when both visual lines meet one meter from ach eyein the perpendicular to the line joining the centers of rotation of the two eyes at its middle, the angle which each visual line will make with this perpendicular is called a meter-angle. Thus, in Fig. 75: Suppose $R$ and $L$ to represent the centers of rotation of the two eyes, and $P M$ the perpendicular to the midclle point of the line joining $R$ and $L$. When the distance $R M$ or $L M$ is 1 meter, the angle $R M P$ or the angle 
$L M P$ is one meter-angle. If the distance from the eye to the point fixed, as $R M^{\prime}$, is $\frac{1}{2}$ meter, the angle $R M^{\prime} P$ equals two meter-angles. If the distance of the point fixed is $\frac{1}{3}$ of a meter, the angle equals three meter-angles, and so for other distances. The number of meter-angles of convergence las the same relation to the distance of the point fixed as the strength of a lens in diopters has to

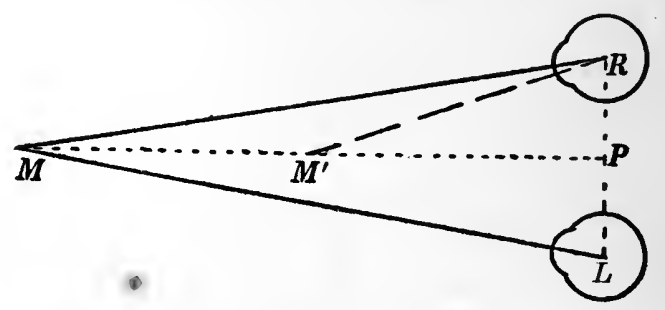

Fig. 75.-The meter-angle.

the focal distance of the lens. The value of the meterangle in centrads or degrees varies with the distance between the centers of the two eycs. Thus, if the distance between the centers of rotation (regarded in practice as equal to the distance between the centers of the pupils) be $50 \mathrm{~mm}$., the meter-angle equals 2.5 centrads or 1.43 degrees; for $60 \mathrm{~mm}$. it is 3 centrads or 1.72 degrees, and for $70 \mathrm{~mm}$. it is 3.5 centrads or 2.005 degrees.

\section{PROJECTION AND DIPLOPIA.}

The image of an object is formed on the retina at the point where a straight line from the objeet, through the nodal point of the eye, pierces the retina. Conversely, when an image is formed on the retina, the object from which light eomes to form it is referred or "projected" in the direetion of the straight line from that point of the retina, through the nodal point of the eye. These "projections" of the impressions made on the retina by external objects become by experience intimately assoeiated with impressions made through other senses, and with them serve to loeate the oljects. 
When the two eyes are fixed on the same point, its image falls on both foveas. These are corresponding points. For any other point of the retina, the line of projection from which makes a certain angle with the visual line of that eye, there is a point in the other retina from which the line of projection has the same relation to the visual line of that eye. Such points are also corresponding points. When the two eyes are fixed on a certain point, impressions of the point fixed, and of certain other points, fall on "corresponding points" of the two retinas. These points, whose images fall on corresponding points of the retinas, constitute a surface called the horopter. Only points lying on the horopter can make their impressions on exactly corresponding points of the two retinas. All points lying nearer to the eyes than the horopter, or lying beyond it, make their impressions on parts of the retina that do not exactly correspond. Impressions of an object made in the two eyes on corresponding points of the retina give rise to a single perception of the object.

If the points of the two retinas almost correspond, there still results a single impression; but the stereoscopic effect by which we judge the relative distance of objects is added. If the points on which the impressions are made in the two eyes differ too widely in their relation to the visual line, instead of the stereoscopic effect there results a confused pcrception. If the points differ a little more widely yet, two separate perceptions of the object arise, and are referred in different directions, as though belonging to different objects. This perceiving of the objects separately by the two eyes constitutes binocular diplopia, or double vision.

Such diplopia is readily produced by placing a fingertip on the middle of the lower lid, just within the margin of the orbit, and pressing slightly backward. Keeping both eyes steadily open, and fixed on some prominent object, a false image will be seen to separate from the true one, as the pressure of tissues back into the orbit causes the eye to rotate downward. The student should 
try this experiment to get a better understanding of certain points in regard to squint and diplopia.

The departure from exact correspondence between the points on which the impressions are made in the two eyes, necessary to cause diplopia, varies for different parts of the retina. At the fovea, where normally the impressions are always made at exactly corresponding points, the slightest lack of correspondence causes confusion, and is extremely annoying. On the periphery of the retina, where there is generally a lack of exact correspondence in the impressions, they may fall on widely different points, yet diplopia may not be pereeived or will not be annoying. Separation of peripheral impressions constantly occurs, and habitually passes unnoticed. But it can be perceived and studied thus: Hold two pencils in a line with the nose, one 6 inches in front of the face, the other 12 inehes in front of it. On fixing the eyes on the nearer pencil, the more distant one will appear double, its image falling not on corresponding parts of the two retimas, but on the nasal side of the fovea in both. On fixing the eyes on the more distant pencil, the nearer one will likewise appear double, its images falling on the temporal portions of both retinas, instead of corresponding points, which would be the temporal side of one retina and the nasal side of the other. In this experiment, as in all physiological use of the eyes, the images at the foreas exactly correspond, hence the diplopia is not annoying, but may be even difficult to discover. When the fixation-point is also involved in the lack of correspondence between the two retinal impressions, the diplopia is obvious and annoying. It cannot generally be ignored.

When a seeing eye, which previously has fixed normally with its fellow, begins to deviate, diplopia results, and the variety of the diplopia varies with the direction of the deviation. "The eye which still fixes properly receives the image of the object looked at upon its fovea; and projects it in its true direction-the true image. The deviating eye receives the impression on some other part 
of the retina and projects it in some other direction, as a second object of the same kind-the false image. 'The relation of these to one another ean best be illustrated thus: Suppose Fig. 76 to represent a ease of eonvergent squint in which $R$ is the fixing and $L$ the deviating eye. In $R$, the image of $O$, the point looked at, falls at the fovea. But in $L$ the image of $O$ falls elsewhere at $f$.

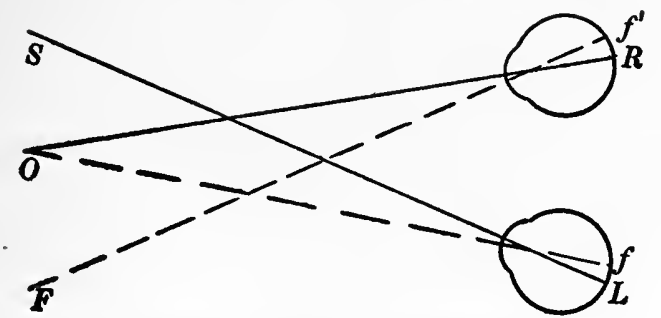

Fig. 76.-The projection of the false image in squint.

Hence, the projection of the false image seen by $L$ will not correspond to the projection of the true image seen by $R$, but will be in the direction of $F$, the line $f^{\prime} \dot{F}$ making with the visual line $R O$ the same angle as $f O$ makes with the visual line $L S$.

It should be noted that if the deviating eye be turned up, the impression of the object fixed is made on the upper part of the retina, and the false image is projeeted below the true image. If the deviating cye be turned to the right, the impression is made on the right half of its retina, and the false image is projeeted to the left of the true image. In general, the false image is projeeted in a direction from the true image, the opposite of that in which the eye deviates.

When the image seen by the right eye appears to the right, and that belonging to the left eye to the left, the diplopia is ealled homonymous. When the image belonging to the right eye is seen to the left, and that belonging to the left eye appears more to the right, it is crossed diplopia. Homonymous diplopia oecurs when the eyes are crossed, and crossed diplopia when the eyes diverge. 
Diplopia is more annoying in proportion to the previous perfeetion of binoenlar vision, the suddenness of its ocenrrenee, the age of the patient, and the nearness of the false image to the true image. Where the power of binocular vision has never dereloped, as in patients affected with squint from infancy, diplopia is never noticed, and it may be impossible to provoke it. When the vision of one eye is very imperfeet, diplopia causes little annoyance. With high degrees of squint, too, diplopia is not troublesome, because the filse image fills so far from the fovea. In squint of long standing, especially if developed in childhood, the annoyance of diplopia is avoided by habitually disregarding the impression made on the deviating eye, much as one acenstomed to the use of the ophthalmoseope, mieroscope, or other monoeular optical instrument, learns to disregard the visual impressions made on his unused eye, and to work with both eyes open. Any ehange in the position of the false image on the retina is likely to make it more noticeable. This may be taken advantage of in attempting to provoke diplopia. It must also be remembered that where binocular fusion is impossible, diplopia may be rendered very annoying by bringing the image to the maeula.

\section{AMBLYOPIA WITH SQUINT.}

In the majority of eases vision is poorer in the deviating than in the fixing eye. This may be due to an error of refraction, to noticeable defects within the eyebail, or to congenital amblyopia. But often it is largely a consequence of the squint-amblyopia ex anopsia. Visual acuteness, and especially the power to recognize letters, is developed by use, which the deviating eye does not get. In some cases vision in the squinting eye actually deteriorates after squint is established. This is aseribed to habitual "suppression" of the image to prevent diplopia.

Causes of Squint.-Congenital inability to turn the eyes in certain directions is rare, but eases ocenr. It will be referred to under Paralytic Squint. Ineomplete power of binocular eo-ordination is much more eommon. This 
might be expected from the extremely complex character of the adjustments required and the comparatively recent evolution of the power of binocular vision. The general causes of acquired squint are paralysis of one or nore of the ocular muscles; and imperfect vision in one eye, either from opacity of the media, distortion of its dioptric surfaces, or disease of the choroid, retina, or optic nerve, rendering it unable to participate in binocular vision. Hyperopia, myopia, and other special causes will be considered with the particular forms of squint which they occasion.

Diagnosis of Squint.-The evidence of squint is often revealed by the most casual inspection of the eyes. Still the most obvious appearance of squint may be misleading. We judge the direction of the eyes by the direction of the cornea; and when the visual line pierces the cornea at the usual point a little to the nasal side of the center, we can thus judge correctly. When, however, the visual line pierees the cornea at a distance from its center, the cornea will appear to be turned in one direction, while the visual line is really directed somewhere else. The eye will appear to squint, when really both eyes have their visual lines direeted to the point fixed; or it will appear to be properly directed when really squinting. The appearance of squint must therefore be confirmed by carcfil tests.

The Cover-test.- If both eyes possess useful vision, the covering of the squinting eye compels the patient to "fix" with what was previously the deviating eye. This he may do by turning the head, in a case of paralytic squint, or by simply turning the eyes in a case of comitant squint. The eyc which had previously deviated turns, so as to fix the point at which the patient is trying to look; and the eye that had fixed turns elsewheredeviates. Thus, by covering the fixing eye, the deviation or squint is transferred from one eye to the other. By shifting the cover from one cye to the other the squint is transferred back and forth. The cover, which may be the hand or a piece of cardboard, held in front of the eye, should be far enough in front to allow the surgeon to 
wateh the movement that occurs behind it; but it must be so held as certainly to interrupt the patient's view with the covered eye.

The direction from which the eyes move when the cover is shifted indicates the direction of the squint. Thus, if on meovering the right eyc, it moves to the right to fix the object, it must have been deviating to the left-convergent squint; if it moves upward, it was deviating downward-vertical squint; if it moves to the left, it was deviating to the right-divergent squint.

Power of Moving Eyes in Different Directions.Having ascertained that squint is actually present, we must next determine is it comitant (concomitant) squint or paralytic squint. 'This may be done by watching the behavior of the eyes when they attempt to fix an object held successively in different directions. The patient may be directed to fix continuously the end of a finger or a lead peneil, which the surgeon holds first in one part of the field and then in another. If the squint be comitant, it remains substantially the same, whatever the direction in which the eyes are turned. If, however, the squint be due to the weakness or paralysis of some particular muscle or muscles, the eyes move and fix normally together, so long as the affected muscle or muscles are not called upon. But when the contraction of the affected muscle is necessary for the movement required of one of the eyes, that eyc will lag behind its fellow, will no longer fix the oljeet, but will deviate; and the stronger the contraction required of the paralyzed muscle the greater the deviation. The direction of the movement which the squinting eye fails to execute shows which muscle is affected. Thus, if the right eye fails to turn 11pward with the left, the right superior rectus is at fault; if it fails to turn to the right, the right external rectus does not properly perform its function; if it lags on looking down, the inferior rectus; on turning the eye to the left, the internal rectus is responsible for the deviation.

The test of movements in the different directions should include a trial of the power of convergence by 
holding the point looked at in the median plane and bringing it steadily toward the nose until the patient ean no longer fix it with both eyes, but is compelled to allow one of them to deviate. The nearest point that can be fixed by both eyes at once is the near-point of convergence.

Measuring the Amount of Squint.-Having aseertained the presence of squint and its variety, the next step is to measure its degree. The old plan of measuring the deviation of the eye upon a rule held before it, or laid along the edge of the lower lid has been discarded for more aecurate methods. One of these is by the perimeter. The are of the perimeter being turned in the direction in which the eye deviates, the squinting cye is placed at the center of the are, just as for the taking of its visual field. The fixing eye is then turned toward some distant point, as some point aeross the room, exactly in the line of the axis of the instrument. The deviating eye would, if properly direeted, look toward the same point in the axis of the instrument. The surgeon, noting where this eye is direeted, reads from the graduation of the are the number of degrees of deviation. To determine exaetly the direetion in which the eye is turned, the surgeon's eye is moved along the are of the perimeter, with a eandle-flame just in front of it, and when the refleetion of the flame from the patient's cornea appears to be in the center of the pupil, the desired direetion of the deviating eye has been found. For the candle-flame may be substituted an ophthalmoscopie mirror reflecting a flame placed elsewhere.

To measure the degree of squint by the tangent of the angle of deviation, the surgeon places lis cye 1 meter from the patient, in the dark room, and with the ophthalmoscopic mirror throws the light on the patient's deviating eye and watehes its corncal reflex. The patient fixes the surgeon's finger held 1 meter away and moved in the direction opposite to that in which the eye deviates, until the corneal reflection of the light appears in front of the center of the pupil. When this is the 
case, the patient's "deviating eye" is direeted toward the surgeon' s eye and the ophthalmoscopie mirror, while his "fixing eye" is directed toward the surgeon's finger. The distance from the surgeon's eye to the finger is the tangent to the angle of deviation. It may be neasured on a tapemeasure or meter-stick, on which may be laid off a seale of tangents. Approximately, each centimeter means an angular deviation of 1 centrad, or the deviation of a 1 degree prism.

The tests as above deseribed do not give exactly the deviation of the visual line, but the deviation of a line drawn through the center of eurvature of the eornea and the eenter of the pupil. Any notable departure of this line from the visual line nay be observed by eovering the patient's fixing eye and having him fix the sight-hole in the ophthalmoseopie mirror with the eye that ordinarily deviates, and noting the apparent position in the pupil of the corneal reflex. If this be at the center of the pupil, the two lines in question eoineide; if it be not at the center of the pupil, its position is to be noted; and the reflex must be broight to this same position in measuring the degree of squint.

The Diplopia Test.-If the patient can recognize binocular diplopia, it gives the most aceurate means of measuring the degree of squint. It ean be most favorably tested by having the patient gaze at a small flame 4 meters distant in a dimly lighted room. If there is diffienlty in observing the false image, on aecount of the extreme deviation or imperfeet vision of the squinting eye, the fixing eye may be covered with dark glass to diminish the vividness of its image; or with the hand for a little time, to allow the patient to notice the image belonging to the deviating eye, before letting the other image appear.

When the two images have been eertainly reeognized, the eovering of one eye causes its image to disappear, indieating which image belongs to it. Or the better eye may be covered with a colored glass to lessen the brightness of its image and distinguish it by color. 
To measure the degree of squint by the diplopia test, prisms are placed before one or both eyes in such a way as to bring the two images together. 'The strength of the prisms required to do this is a measure of the degree of the squint.

In general, the prism must be placed with the apex in the direction in which the eye deviates. For instance, in a case of convergent squint, the image belonging to the right eye would be to the right, and that of the left eye to the left. To bring them together, a prism must be placed before the right eye with the apex to the left, or before the left eye with the apex to the right. Other methods of detecting and measuring squint are more appropriately described under Heterophoria or Latent Squint.

Varieties of Squint.-Strabismus, due to the paralysis or paresis of one or more of the muscles that turn the eye in the orbit, occurs only when the weakened muscle is called on to perform its function. There is actual limitation of movement in a certain direction. This is paralytic squint. In contrast to this are the cases in which deviation depends upon a wrong co-ordination of the movements of the two eyes, by which they habitually converge too much or too little, so that the visual lines intersect nearer or farther than the object fixed. Or the two visual lines do not lie in the same plane, one going higher than the other. These abnormal relations of the visual lines are maintained, whatever the direction of the object looked at. Squint of this kind is called comitant or concomitant squint.

Paralytic squint may amount only to a weakness in a certain muscle or muscles, making necessary an increased effort, or a eompensatory action on the part of the other muscles, to execute certain movements. This constitutes an insufficiency of the muscle or muscles in question. Comitant squint may amount only to a tendency of the visual lines to deviate, a tendency habitually overcome by an effort, in the interest of binocular vision. Such a tendency is rendered evident when on covering one eye, or otherwise 
preventing binocular vision, the visual lines deviate. 'This tendency of the visual lines to deviate is ealled heterophoria. Heterophoria has been used as synonymous with insufficiency of the ocular muscles, and it is convenient to consider both classes of cases together under the heading Latent Squint. The term "insufficiency," however, will be here applied to the cases in which the latent squint appears only when the attempt is made to use a certain muscle or muscles, or to execute certain movements like convergence ; and "heterophoria" will be applied to those cases in which the tendency to deviation appears during all sorts of ocular movements.

\section{PARALYTIC SQUINT.}

It is characteristic of a squint purely paralytic that, when the eyes are in certain positions, no squint is present. As the effort is made to turn them in a certain direction. one eye commonly executes normal movements, while the other does not move at all, or moves to less than the normal extent. By the extent of the failure in normal movement, it "deviates" from a normal position.

Causes of paralytic squint may affeet either the muscles themselves, the nerve-trunks, or the nerve-centers. Those affecting the muscles themselves are chiefly wounds, or the cicatrices eaused by wounds, suppuration, or new growths involving the muscle. Lesions of the nervetrunks are most frequent. They occur by swelling of adjoining structures or hemorrhage, or are eaused by syphilis, rheumatism, renal and vaseular disease, influenza, and other acute diseases. Degenerations due to exposure, alcoholism, or other toxie influences, may affect either the nerve-trunks or the nuelei from which they arise. Paralytic squint may be congenital. (See page 235.)

Varieties.-Each of the six ocular museles may be paralyzed alone, giving rise to its peenliar form of diplopia; or the palsies of two or more museles may be combined in various ways. The paralysis of the muscles supplied by a certain nerve-trunk is a common association. "Thus, 
we have paralysis of the oculomotor nerve, involving the superior, internal, and inferior recti, and the inferior oblique with the elevator of the lid, the ciliary muscle, and the sphincter of the iris.

Recurrent oculomotor paralysis is a special form which oecurs in early life. 'The attack begins with extreme headache, chiefly of one side of the head, nausea, and vomiting, and edema and swelling of the orbital tissues and lids of the affected side. After a few days the pain and swelling subside, the muscles regain their power, and the patient continues well for a perior varying from a few days to many months, then a similar attack occurs. After a number of such attacks the ocular muscles fail to regain their power, and there remains eomplete and permanent oculomotor paralysis with recurrent attacks of pain. The causes of this form of oculomotor paralysis are not known. Paralysis of the fourth cranial nerve affects only the superior oblique muscle; and of the sixth nerve, the external rectus.

Sometimes the paralysis affects only certain associated movements. Thus, the vertieal movements may be greatly limited, although lateral movements are good ; convergence may be lost, although either internal rectus aets normally when the eyes are both turned to the right or left; or lateral movements may be wanting, although the internal reeti can still eonverge the eyes. Palsies of this kind arise from lesions of the nerve-centers presiding over the movements in question. They may be sometimes distinguished from peripheral palsies by the difficulty or impossibility of fully fusing the double images when these are brought together by prisms. Paralysis of all the external museles of the eye, without involvement of the iris or ciliary muscle, is called ophthalmoplegia externa.

Symptoms.-Paralysis of one or more oeular museles may arise suddenly, the patient awaking in the morning to find the affected muscles absolutely powerless. More commonly the symptoms gradually increase from day to day for several days, or even for some weeks. In the 
latter case the patient is conscious of gradually increasing diffieulty in using the eyes, which passes into noticeable doubling of the images at some times, although at other times there is no such difficulty. The patient may or may not recognize that the donbling oceurs only when he looks in a certain direction; and can be avoided by turning the hẹad instead of the eyes to look in that direction, or by elosing one eye.

Even after diplopia is established, the feelings of confusion, strain, giddiness, and nausea continue. For in one part of the field there remains normal single vision, and between that part and the region of diplopia lies a zone, where double vision is avoided only by increased effort or the closing of one eye. Closure of the eye or turning of the head to prevent diplopia becomes habitual. The ocular symptoms may be accompanied by headache, neuralgic pain from involvement of the sensory nerves, or impairment of vision. Paralysis of more than one musele gencrally causes protrusion of the eyeball.

At first the deviation and diplopia may be confined to half of the field of fixation or less. After a time the antagonist of the paralyzed musele, finding it no longer meets with the accustomed resistance, undergoes what is called a secondary contraction, so that the eye, instead of remaining properly directed when at rest, is permanently turned from the paralyzed muscle. This is best illustrated in the turning ont of the eye in paralysis of the oculomotor nerve, which involves all the adduetors of the eyeball. Secondary contraction may not occur with congenital palsies.

Secondary deviation oceurs in the sound eye, when it is covered and the affected eye attempts to fix. The weakened muscles of the affected eye are able to fix it only by an effort in excess of the normal; and this excessive effort, extending to the related muscles of the sound eye, causes in it an excessive deviation. The secondary deviation, being greater than the primary, is sometimes an important diagnostic sign of paralytic squint.

Diagnosis. - The presence of paralytic squint is 
proved by limitation of the movements of an eye, or by diplopia confined to one part of the field of vision, and increasing the farther the eyes are turned in that direction. In determining the variety of the squint, and the particular muscle affected, the first point is to ascertain which eye does not move normally. In severe cases this is readily ascertained by watching the motions of the eyes, as they turn to follow an object moved in different directions. If the deviation is slight, this will be more difficult. If vision is equally acute in both eyes, the patient will incline to use the unaffected eye, fixing with it and allowing the other to deviate. If, however, vision is decidedly better in the affected eye, it may be used for fixation, and the sound one will appear to deviate.

Which eye fixes is determined by letting the patient look at some point in the field of deviation, and then intermittently covering one eye. No movement occurs if the deviating eye is covered; but when the fixing eyc is covered, the deviating eye moves to fix. Often the patient's impression is correct as to which is the false image and which the true one, but not always.

The second point in the diagnosis is to ascertain which image belongs to the right eye and which to the left. This may be done by covering one eye and asking which image disappears; but sometimes the patient is mistaken in his answer, because if the fixing eye is covered, the deviating eye may move so quickly to fix the object looked at, that the corresponding change of its image is unnoticed. The false image having moved to take the place of the true image, it is supposed that the false image has disappeared while the true one has remained. By placing before one eye a piece of red or blue glass, the patient, noticing which image is colored red or blue, can always decide which image belongs to that eye.

The third point is to find what movernents of the eyes cause the widest deviation of the affected eye, the widest separation of the true and false images. This is done by moving the object looked at into various parts of the field 
of vision, or having the patient turn his head in various ways while looking at a fixed object like a lamp-flame.

The fourth point is to ascertain whether the double images remain parallel or incline toward each other at the top or bottom in various parts of the field; and if they are inelined, what the inelination is, and in what part of the field it is the greatest. This is done by having a long object, such as a white ophthalmoscope handle with a dark background. 'This objeet should be placed vertieally, and the patient asked if the false image remains vertieal, parallel to the true image in all parts of the field; or, if inelined, whether they are eloser together at the top or bottom. The one image remaining vertical may show which eye it is that deviates.

Finally, the patient must observe whether the two images are on the same level, or whether one of them is higher than the other; and which is higher, and in what part of the field the differenee of level is greatest.

The recti museles attached in front of the eenter of rotation turn the cornea towards their insertions, as the superior up. The obliques attaehed behind the center of rotation turn the cornea from them, as the superior downward. The eye lags in the direetion the paralyzed muscle should turn it, and the resulting false image is projected too far in that direction. The greatest separation of the images oeeurs with the attempt to turn the eyes in the direetion the paralyzed musele should earry them.

Paralysis of the external rectus limits movement of the eye toward the affeeted side. If the right eye be involved, it eannot be turned to the riglit; if the left eye, it eannot be turned to the left. It causes a convergent squint which increases as the eyes are turned toward the affeeted side. The diplopia is homonymous, the images separating as the eves turn toward the affeeted side. The images are the same height and parallel, or slightly tilted when looking down or up.

Paralysis of the superior rectus limits movement upward, the deviation and distanee between the images inereasing in that direction. The false image is the 
higher, and toward the sound side (crossed diplopia) the images are nearly parallel when the eyes are turned toward the affected side; but the false inage is tilted, its top from the true image, when the eyes are converged or turned toward the sound side.

Paralysis of the Internal Rectus.-The eye tends to deviate outward (divergent squint), the deviation increasing as the eyes are converged or turned toward the sound side. The diplopia is crossed, the images separating as the eyes are turned toward the sound side. The images are about on a level and parallel, unless the eyes are turned strongly up or down, when some tilting occurs.

Paralysis of the inferior rectus limits the movement of the affected eye downward, and the distance between the images increases on looking down. The false image is the lower, and is toward the sound side (crossed diplopia). The images are parallel when the affected eye is turned somewhat out (looks toward the affected side); but the false image is tilted, top toward the true image, when the affected eye is turned in (looks toward the sound side).

Paralysis of the superior oblique limits movement downward and outward, and the images separate most widely in this direction. The false image is toward the affected side (homonymous diplopia), and is most tilted when the eyes are turned toward the affected side. When the eyes are turned toward the sound side, the images are about parallel, and the false image decidedly the lower.

Inferior oblique paralysis causes limitation of the movements upward and ontward, and the images separate most widely in those directions. The false image is toward the affected side (homonymons diplopia) and higher. It is most tilted on looking toward the affected side, the top from the true image, and is about parallel and most elevated on looking toward the sound side.

In Figs. 77 to 82 , inclusive, the black bars mark the part of the field in which there is single vision; the bars with the lines running up to the right indicate the image belonging to the right eye; and those with lines running up and to the left, the image belonging to the left eye. 
The bars which are darkly shaded represent the true image, and those which are lightly shaded the false image.

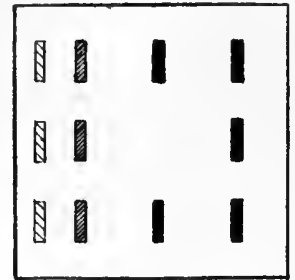

Left.

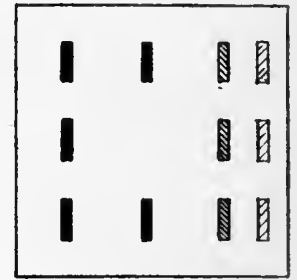

Right.

Fig. 7\%,-Paralysis of external rectus.

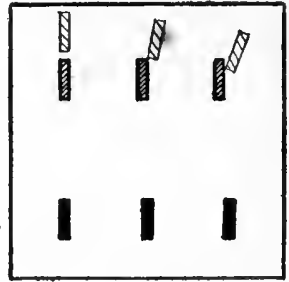

Left.

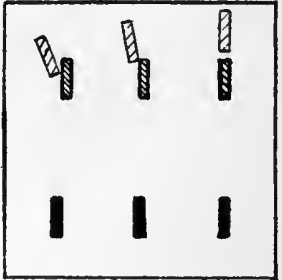

Right.

FIG. 78.-Paralysis of superior rectus.

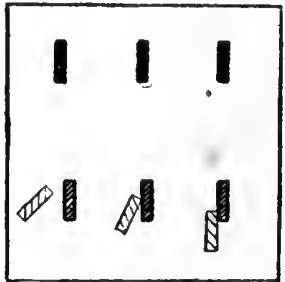

Left.

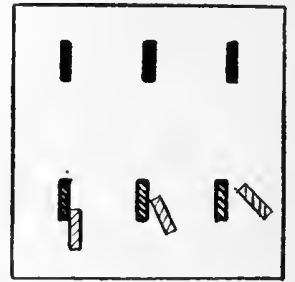

Right.

FIG. 79.-Paralysis of superior oblique.

Differential Diagnosis.-Homonymous diplopia - convergent squint-occurs in paralyses of the ocular muscles, which are thus differentiated: 


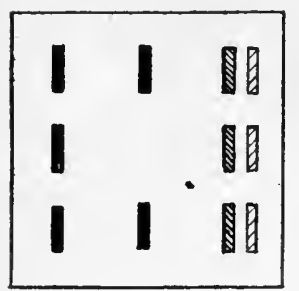

Left.

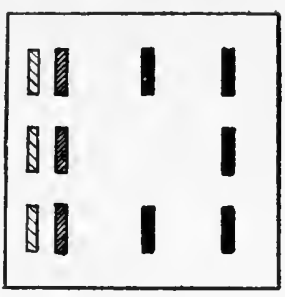

Right.

F1G. 80.-Paralysis of internal rectus.

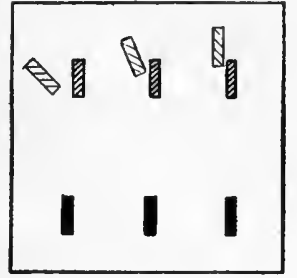

Left.

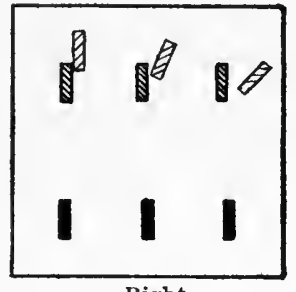

Right.

FiG. 81.-Paralysis of inferior oblique.

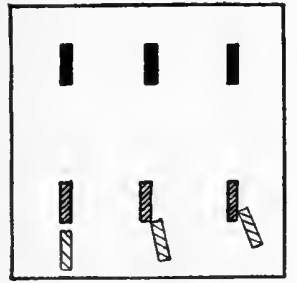

Left.

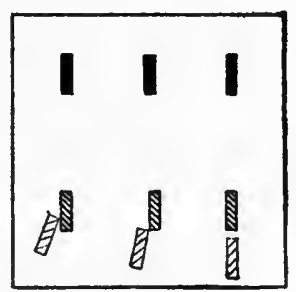

Right.

FIG. 82.-Paralysis of inferior rectus.

External Rectus.-Images the same height and parallel. They separate most widely on looking toward the affected side.

Superior Oblique.-Images separate on looking down, the false image tilted on looking toward the affected side, displaced downward on looking toward the sound side.

Inferior Oblique.-Images separate on looking up, the 
false image tilted on looking toward the affected side, displaced upward on looking toward the sound side.

Crossed diplopia-divergent squint-attends three palsies :

Internal Rectus.-Images of the same height and parallel. They separate most on looking toward the sound side.

Superior Rectus.-Images separate on looking up, parallel toward the affected side; tilted with the tops apart on looking toward the somnd side, the false image higher.

Inferior Rectus.-Images separate most on looking down, are parallel when looking toward the affected side; and tilted, tops together, in looking toward the sound side, false image lower.

Treatment.-In the early stages this will depend upon the eause. "A palsy from traumatism will require rest. If the history points toward syphilis, potassium iodid or the mixed iodids, in doses rapidly ascending to the maximum, will be indieated. These should be continued for at least two months, unless reeovery is eomplete before that. Even if there be no history of syphilis, but the etiology is obseure, the same treatment is admissible. If there is rheumatism, or a history of " cold," sodium salicylate may be given in full doses for two or three days, or sometimes longer; then the iodids may be resorted to, and eontinued for several weeks. At the very outset, eases of this kind may be favorably influenced by a hot bath, or a pilocarpin sweat.

When the paralysis is due to diphtheria, or ehronic poisoning, or arises in eonneetion with degenerative disease of the central nervous system, the treatment shonld from the start include general tonies and strychnin in aseending doses, until deeided improvement oeeurs, or the maximum physiologieal dose has been reached and kept up for several weeks. In cases of this kind, ehange of residenee, oeeupation, or manner of living may be important. These measures may be beneficial in the later stages of paralysis from all eauses.

When the paralysis has continued two or three weeks, 
electricity may be tried, the positive pole being placed as closely as possible over the affected muscle, and the negative behind the ear or on the back of the neck. When the paralysis has continued many weeks, and seems stationary, muscle-stretching may be resorted to. Under cocain the insertion of the tendon of the muscle is seized with fixation-forceps, and the eye slowly and forcibly rotated to and fro so as alternately to stretch and relax the paralyzed muscle. The rotation both ways is repeated ten or twelve times a minute for two or three minutes, at each sitting; and the sittings repeated every two or three days. The manipulation must not be so violent as to cause serious subsequent soreness, yet the paralyzed muscle and its antagonist should be decidedly stretehed.

When the case has become chronic, and the extent of the squint fixed (or in cases of moderate paresis from an earlier period), prisms may afford relief. 'The base of the prism before the affected eye should be turned toward the weakened muscle, and the prism before the sound eye correspondingly placed. Prisms thus placed render possible binocular single vision, while the eye deviates toward the apex. Prisms thus worn must be watehed, and the strength varied according to the changes in the deviation. Prisms may also be used turned the opposite way (with the apex toward the weakened muscle), to compel its more powerful exertion, and thus to develop its strength. For this purpose they are to be used only a few minutes at a time, one or more times a day.

A better method of giving the weakened muscle gymnastic exereise and training is to have the patient fix both eyes upon a small object held in the portion of the field of vision where there is no diplopia, and then slowly moving the object over into the field of diplopia, keep it single as long as possible. As soon as diplopia occurs in spite of a strong effort, the effort is to be suspended, and the eyes are to be allowed to rest for a mimute or so. Then the exercise may be repeated. Each effort should occupy ten or fifteen seconds, and it may be repeated several times at a sitting, with several sittings a day. In 
the earlier trials care should be taken not to overstrain the weakened muscle.

To eseape the vertigo and annoying diplopia, while these continue, the deviating eye may be covered by a ground gluss, or by a piece of tissue paper, pasted on the back of the patient's ordinary speetacles. Sometimes it is better to shut off in this way only the part of the field of vision in which diplopia or confusion of sight oceurs, leaving the eye free for binocular vision in the other parts of the field.

When paralytic squint has become partly comitant, the operative treatment of the latter may be applicable; and even if the squint be still chiefly paralytie, the patient ean in a few cases be given deeided help by an advancement of the affected muscle, or a tenotomy of its antagonist, or both. This will be the case when by operation it will be possible to remove the field of diplopia from directly in front, or from the direetion in which the patient wishes to use his eyes habitually, to some other part of the field of vision. Sometimes an operation may be done for cosmetic reasons.

Prognosis.-Paralytic squint, seen early and appropriately treated, is cured in a large proportion of eases. If due to syphilis or rheumatism, at least partial recovery may be expected. Diphtheritic paralysis of the ocular muscles does not show the same strong tendency to complete recovery shown by other diphtheritic palsies, although its prognosis is favorable. Nuelear palsies, coming early in degenerative disease of the central nervous system, are especially variable in the degree of disability they eanse; they sometimes go on to practically complete recovery, although the general disease continues to advanee. Partial reeovery from paralysis of the external reetus, or superior oblique, leares the patient without noticeable deformity, and often still able to use the eyes freely without diplopia or serions ineonvenience. But permanent partial paralysis of the oeulomotor nerve is mostly aceompanied with marked divergenee of the eyeball, and limitation of its movements, drooping of the 
lid, diplopia on raising the lid, and inability to use the affected cye. In recurrent oculomotor paralysis the recoveries from suceessive attacks become more and more incomplete, until complete disability of the affected muscles becomes permanent. The diplopia of paralytic squint continues, and gives annoyance so long as the deviation lasts.

\section{COMITANT SQUINT.}

The same deviation occurring in all parts of the visual field, is the characteristic of comitant squint. It may not be the same at different times, it may part of the time be entirely absent, but when present it is not contined to, or greater in, one part of the visual field than another.

Since both eyes do not iurn toward the same point, it is evident that only one can "fix," and the other one must "deviate." Habitually the patient inclines to use his better eye, if there is even a slight difference between them, and the eye with the poorer vision is allowed to deviate. But it must not be thonght on that account that the squint belongs in any peculiar way to that eye, rather than to the other. True comitant squint is a false coordination of the two eyes; it is a disorder of their relation. Either cye alone is absolutely normal, one just as normal in its movements as the other; you must have two eyes to have a squint.

Causes.-Typical paralytic and comitant squint have thus far been considered, but many cases occur of mixed type. When secondary contraction of its antagonist has occurred, recovery of power in a paralyzed muscle gives rise to a comitant squint. With full recovery of power, secondary contraction may be overcome and the squint disappear; but in the presence of other conditions that tend to eause squint, in spite of the full recovery of the paralyzed muscle or muscles, the squint continnes. This is probably the mode of origin of a considerable proportion of cases of comitant squint.

Binocular rision, and the accurate co-ordination of the movements of the two eyes are functions almost or quite 
peculiar to man. They are mutually dependent. While binocular vision is impossible without the accurate coordination of the movement of the two eyes, such accurate co-ordination is usually impossible except under the guidance of binocular vision. The two develop together, usually during the first weeks or months after birth, but sometimes they are not perfected until the child is several years old. During the period of their incomplete development they are most easily prevented or overthrown. Hence, most cases of comitant squint arise in early childhood.

Removal of the guidance of binocular vision is likely to impair the binocular co-ordination of movement at any age. Hence, complete blindness of either eye is likely to cause squint. Great impairment of vision from corneal injury or disease, which canses distortion or blurring of the retinal images by the admission of diffuse light, is likely to eause squint. On the other hand, very imperfect vision with normal retinal images may furnish the necessary guidance to binocular adjustment. Congenital defects of the retina at the fixation-point, or of the optic tracts or centers causing central seotoma, are likely to cause squint; but injury of these parts by disease, after binocular movements are well established, will not cause it.

It is probable that in a few cases anomalies in the attachments or strength of the ocular muscles tend to canse squint. But the enormons adaptability these muscles show when the eyeball is displaeed by tumor, or after their mutilation by ill-advised operations for heterophoria, makes it improbable that such mechanical influences as are exerted by a eertain general shape of orbit, or width between the orbits, play any important part in causing squint. The very intimate association of errors of refraction with eertain kinds of squint is dealt with in connection with these special varieties.

Varieties.-Constant squint, as its name implies, is always present, but it may from time to time vary greatly in degree. If the squint be part of the time entirely absent, it is called intermittent or periodic squint, but it 
presents no strictly regular periodicity. Accommodative is a form of intermittent squint that appears only when the accommodation is strongly exerted. When one eye habitually fixes and the other habitually deviates, the squint is called monolateral or monocular. If both eyes see equally well and with the same effort, sometimes one will fix, and sometimes the other. This is called alternating squint. Even when there is a slight difference between the eyes, the squint may be at first alternating. It may also alternate when the refraction of one eye adapts it to distant vision, while that of the other fits it only for nearseeing.

Squint occurring as a form or part of a convulsive seizure may be called convulsive squint. Closely allied to it is squint oceurring as a manifestation of hysteria, hysterical squint (see Spastic Squint).

Convergent squint is the commonest variety. The visual axes are at all times converged. On looking at distant objects they converge least; on looking at near objects they converge more strongly. At all times the convergence is excessive, the visual lines intersecting nearer to the eye than the point fixed. In the popular mind this variety has long been associated with the efforts of young elildren to look at objects lield too elose to the eyes. It is usually established before the age of six years.

Donders pointed out that it had a connection with hyperopia. Hyperopia requires excessive exertion of accommodation. Accommodation is closely associated with convergence, therefore hyperopia tends to produce excessive convergence. But every pair of convex or concave lenses worn affects the amount of accommodation exerted, yet usually the permanent influence they exert on the convergence of the eyes is insignificant, so that the necessary influence of hyperopia in causing convergent squint is for many cases slight. Then, since 70 per cent. of all persons are hyperopic, mere coincidence would account for the hyperopia in that proportion of the eases of convergent squint.

But there is a frequency of association between con- 
vergent squint and hyperopia of high degree, 3. to 6. D., that coincidence does not explail. These cases of squint are usually intermittent, or if constant are quite variable in degree. The spuint increases greatly when the eyes are used for areurate seeing, especially for near vision. Other causes of squint, as imperfect vision, or a previous ocular paralysis, are mostly absent from these cases, and correction of the hyperopia cures the squint. Such cases of squint seem clcarly due to an overflow of nervous impulse, which affects the convergence firom the excessive effort of accommodation.

Divergent squint is a condition of relatively deficient convergence. On looking at a distant object the visual lines may diverge, on looking at a near object they may become parallel or even convergent, but they never converge enough to meet at the object looked at. Aside from blindness and previous oculomotor paralysis, divergent squint usually arises in comnection with myopia; and since myopia is usually acquired, it comes on later in life than convergent squint.

The myopic eye, having to aceommodate but relatively little, loses whatever stimulus accommodation may give to aid convergence. Far more important factors, however, in the calusation of divergent squint are found in the excessive amount of convergence required by myopic eyes, and the excessive difficulties of eonvergence on accomt of the elongation of the cyeball already referred to (p. 159). These conditions also constitute the most scrious obstacles to the correction of this form of squint.

Divergent squint usually begins by simply allowing the worse aye to diverge relatively, when very near objects are looked at, while at other times its direction is normal. At first the squint is intermittent, merely a tailure to converge strongly, when strong convergence is required to fix the object. But when once this habit is established, the deviation is liable to become more frequent and greater, until the squint oceurs at all distances, and becomes constant. Alternating divergent squint is 
rare, since in high myopia one eye usually has decidedly better vision than the other.

Vertical squint is the deviation of one eye upwarl or downward, so that its visual line no longer lies in the visual plane-the plane passed through the center's of rotation of the two eyes, and the point on which the gaze is fixed. It oceurs separately, either from traumatism or as a sequel to a paralytic squint, but it occurs far more frequently in connection with convergent or divergent squint. Indeed, marked lateral deviation is usmally accompanied by some departure of the visual line of the deviating eye from the visual plane. Such deviation is more frequently upward than downward.

Symptoms.-Comitant squint generally first attracts attention by the appearance of the leviating eye. The deviation is usually greater at some times tlum others. In some cases it is most noticeable when the patient is tired, in others when excited or angry. The patient may think it intermittent, when in reality it is only variable. The patient is not likely to underrate the importance of a visible squint; but parents and friends, who have become accustomed to the deformity, often fail to realize the suffering and disadvantage of sueh deformity to a young person.

Diplopia is rarely complained of, and in some cases it camnot be produced. It is most likely to eause annoyance in squint developed in adult life. Comitant squint is not likely to canse symptoms of eye-strain, except in those cases in which the squint is intermittent, and gives rise to such serious diplopia that the patient' by a special effort prevents the squint or renders it latent a part of the time, to avoid the diplopia. Of the impaired judgment as to distances, lessened field of vision, or other disabilities cansed by the lack of binocular vision, the patient is not usually eonscions. 'The connection of amblyopia with squint has been suffieiently diseussed (p. 198).

Diagnosis.-To determine whether squint is real or apparent, the test of alternately covering the eyes (see p. 
199) is to be used. This will also, by the extent of the secondary deviation, indicate whether the squint is paralytie, or partly of that charaeter. If the squint is monolateral, the fixing eye will immediately return to fixation as soon as it is uneovered, and the deviation return to the other eye. If the squint be alternating, either eye, when made to fix, will continue to fix when both eyes have been uneorered. The amount of squint should be measured (see p. 201) repeatedly, at different times and under different eiremstances.

If the deviating eye has useful vision, a careful attempt should be made to seenre binocular diplopia. The fixing eye being covered, the deviating eye is made to fix a lamp-flame in the darkened room. Then the fixing eye is allowed to look through colored glass, so dark as to lower its aenteness of vision even below that of the deviating eye. Repeated trials may be required lofore the false image is reeognized, but practice renders the reeognition easier and more certain. Sometimes a strong prism, so placed as to bring the false image nearer to the maeula, aids greatly in its reeognition. The fusion tubes of Priestley Smith furnish a useful means of reeognizing diplopia, and training the patient to overcome it. They eonsist of two short eylinders, each with a convex lens in one end, and a eap with a hole in it at the other. The tubes are freely movable with reference to each other. If both holes are seen at once, we have evidence of diplopia, and by turning the tubes so as to fuse the images of the two openings, we ean aseertain the direetions taken by the visual axes.

When binoeular diplopia has been seeured, an effort should be made to bring the true and filse images together with prisms. These are to be turned with their edges in the direction in which the eye deviates. If the images when brought together with prisms ean be fused, giving linocular vision, eomplete eure by operation may be possible. If, however, the inages when brought together refuse to become one, falling short of each other with one prism, and then jumping past each other when the strength 
of the prism is slightly increased, and if this persists at repeated trials, cure cannot be expected, and accurate correction of the deviation may cause annoying diplopia. The complete diagnosis of any case of squint must include the careful measurement of the refraction and accommodation of the eyes in young children by skiascopy.

Treatment.-This should begin as soon as the squint is recognized, and include the constant wearing of accurate correcting lenses, systematic use of the worse eye, fusion training, and in some cases operation.

Use of the Deviating Eye.-If cycloplegia confined to the better eye be not sufficient to induce the patient to use the other, we keep the former excluded from vision by some kind of bandage, or by cotton placed behind its eorrecting lens. This exclusion should at first continue but a few minutes, but be repeated several times a day. Later, the periods may be lengthened until this eye is used continuously; or the patient fixes with it, when his better eye, under a cycloplegie, is uncovered. If this cannot be attained, hope of binocular vision must be given up, and cosmetic improvement alone expected.

Fusion Training.- When the eyes have become accustomed to the glasses, and the patient has learned to fix with the previonsly deviating eye, exercises to develop the fusion faculty should be undertaken. For young children the fusion tubes described above, and the Amblyoscope of Worth, are most important. The latter is a reflecting stereoscope in which the images to be fused are placed at the distal ends of two angled-tubes into which the patient looks, and are seen by light passing through thom. The illumination is adjustable, either by especial apparatus, or by turning one tube toward the window or lamp, and the other toward comparative shadow. The stronger illumination is given the image presented to the poorer or previously deviating eye. When the light is properly adjusted the two images become equally noticcable. The angle between the tubes is then varied until the two images are superimposed.

The monoscope, suggested by the writer, consists of two 
mirrors placed before one eye, with smoked glasses to reduce the illumination and equalize the images. One mirror is movable so that it can be placed parallel to the other, or for squint at such angle as to throw on the fovea of the one eye an inage of the object fixed by the other eye. It requires no special pictures, but can be used in looking at ordinary objects. Fusion training is chiefly valuable during carly childhood. If the deviation be not too great, and some progress has been made in binocular fusion, for older persons the ordinary hand stereoscope, with special pictures and diagrams, is of value.

The first step in fusion training is to bring about conscionsness of the images received through both eyes. The next step is to secure fusion, a single perception of the parts common to both inages. A third step is to maintain this fusion when the angle between the tubes is varied. With the power to do this comes ability to recognize depth or relief in the binocular image. All exercises for fusion should be given in very short sittings. They are useful only so long as they conmand the close attention and active effort of the patient.

For convergent squint the wearing of correcting lenses may begin at the age of two years. While the eyes are under a cycloplegic the child will adopt the glasses at once. Fusion training may begin equally early. Where it is impossible for a time to adopt other treatment, both eyes, or in monolateral squint, the better eye, may be kept continuously under the influence of atropine. Careful attention should be given to the patient's general health, especially where convergent squint has seemed to follow acute disease in ehildhood, or divergent squint is associated with bad hygienic conditions.

Operations.- IV hen squint persists after trial of the ahove measures, operative treatment must be considered. The habit of excessive convergence may be the chicf obstacle to development of the fusion faculty. If a young child with fixed convergent squint is fonnd by the fusion tubes to possess capacity for binocular vision, and when a few weeks wearing of correcting lenses and other treat- 
ment leaves the squint constant and but little diminished, an operation should be done to give the non-operative treatment a better chance for proving effective. Operations so done to facilitate fusion training should reduce the degree of deviation rather than aim completely to correct it, and should be followed immediately by fusion training.

In older patients, where the period for the development of the fusion faculty is quite passed, if the ametropia be of moderate or high degree, it is best to contiune the wearing of the correcting lenses at leašt six months before attempting to correct the deviation by operation. If the deviation be moderate it is well to defer operation until after puberty. In adults who have constant squint of long standing, without ametropia that would otherwise require correction, operation for its cosmetic effect may be undertaken as soon as the case has been properly studied. Intermittent squint should not be treated by operation; unless when the squint appears to be absent it is found to be merely latent or suppressed.

The operations for squint are tenotomy of a muscle which seems to turn the eye too strongly in its direction; tenotomy extencled to the muscles that assist in producing or maintaining extreme rotations of the eye; advancement of the muscle which does not exert sufficient influence on the movements of the eyeball ; lateral displacement of a tendon insertion, to modify the character of its action, or some combination of two or more of these operations.

Very different effects are yielded by the same operation in different cases of squint, but ordinarily we expect a simple tenotomy to correct 15 or 20 centrads of deviation inward, or less outward. A small deviation may be corrected by advancement alone; a greater deviation requires extended tenotomy, or tenotomy with advancement of the opposing muscle. Advancement is less likely to be followed by excessive effect than tenotomy; and where the immediate effect is excessive, a looser stitch may be placed and the original stitch removed. Extended tenotomy is applicable only to rather high degrees of convergent strabismus. It is best to plan the operation so that 
it will slightly (3 to 5 degrees) under-correet a convergent squint; or over-correet a divergent squint.

After a squint operation, if binoeular vision is to be hoped for, fusion training should be promptly tried, and the operated eye left open so that it ean participate in vision while still unable to deviate as it has been accustomed to do. In older patients, after operation, in addition to the methods of fusion training previously mentioned, and especially the stereoscope, controlled reading may be resorted to. A reading bar or ruler is held in front of the page so as to hide part of each line from either eye; hiding one part from the right, and a different part from the left. The patient on attempting to read finds it neeessary to use both eyes; and henee, easier if he keeps both eyes direeted toward a single point-binocular fixation.

Prisms and decentered lenses, which have a prismatic effect, are of little value for divergent or eonvergent strabismus, because they eannot be habitually worn strong enongh to mateh the deviation of the eyes. For vertieal strabismus which is often less in amount, they may be more serviceable. They do not "eorreet" the strabismus, but "allow" it, enabling the patient to gain binoeular vision while still squinting. They ean be used sometimes with advantage to assist the eyes in their early efforts at fusion. Or, they may be useful temporarily in supplementing or eorrecting the effects of an operation. Their ehief value, however, is in the treatment of latent squint, or heterophoria, in which connection their use is explained in detail.

Prognosis.-Squint noticed in early childhood sometimes disappears without treatment. But this is no reason to defer treatment. The large majority of squints do not so disappear; and waiting for spontaneous recovery, we lose the only time when complete reeovery can be brought about by treatment. Of eases treated during the first month, more than half are eapable of complete eure without operation. When the squint has lasted a year, or in convergent squint, when the patient has passed the age of four years, eomplete cure is less likely; and after six years it is rarely possible. The cosmetic correction of 
squint, so that the deviation may be reduced to less than 10 centrads and be very little noticed, can generally be effected by a proper operation. But the result will only be permanently satisfactory in properly chosen cases of fixed squint. It should be remembered that even among adult patients, especially those suffering from divergent squint, are some, who having developed binocular vision before the squint commenced, are capable of recovering it.

\section{LATENT SQUINT.}

When a patient with habitual binocular vision, upon having one eye covered, allows it to deviate, he is said to have a latent squint. The assumption is that the position taken when binocular vision is prevented is a position of rest or of lessened effort; that binocular vision is only maintained by a special exertion, which the perfectly balanced eyes do not have to make. This is clearly the case in paralytic squint in a zone between the portion of the field where movements are strictly normal, and the portion where diplopia occurs in spite of any effort; or in a case of insufficiency of convergence, before the effort becomes too great to be sustained, and relative divergence occurs.

Varieties.-Formerly all cases of latent squint were called "insufficiencies of the oenlar muscles." At that time only those here classed as insufficiencies were generally recognized. Heterophoria has recently been used as a synonymous term; but its proposer, Dr. Stevens, considered chiefly the conditions here classed as heterophoria, largely ignoring the true insufficiencies, except in so far as provided for in the awkward classification "heterophoria in accommodation." An insufficiency of an ocular muscle is a latent paralytic squint. Heterophoria is latent concomitant squint. The distinction between the two classes of cases should be recognized in diagnosis and treatment. Muscular Imbalance is another term used to indicate the conditions under discussion.

Insufficiency may involve either of the six extra-ocular muscles, giving rise to the same deviations, as do paraly- 
ses of these muscles; these deviations do not ocenr until binocular vision is prevented as in the tests for latent squint. For example, insufficiency of the right external rectus will cause latent squint only when the eyes are turned to the right, which will increase the farther they are turned in that direction. This squint will be convergent; the diplopia it causes, homonymous. If symptoms arise from such a latent squint, they will be comnected with the turning of the eyes to the right. Such a condition might be termed a paresis of the external rectus muscle; but for practical reasons, the term paresis should be reserved for cases of incomplete paralysis in which the squint is not wholly latent, diplopia occurring in a portion of the field. The other insufficiencies recognized in practice are insufficiencies of certain muscle-groups, as of the museles supplied hy the oculomotor nerve; and insufficiencies of certain movements, as insufficiency of vertical movements or insufficiency of eonvergence.

The last variety is of most prictieal importance. A tendency to relative divergence of 4 or 5 centrads at the ordinary distance for near work, about one-third of a meter, must be regarded as normal. Closer than this the tendeney to relative divergenec increases until for each pair of eyes a certain point, the near-point of convergence, is reached. But quite frecpuently the relative divergence at the working distance is found greater than normal. Especially in presbyopes and myopes this is the case. A majority of the latter show mirked latent divergence. Heterophoria, a tending of the two visual lines toward different points, is a departure from Oithophoria, the tending of the visual lines toward the same point. Its varieties are: Esophoria, latent eonvergent squint, a tending of the visual lines to intersect nearer than the point fixed: Exophoria, latent divergent squint, a tending of the visual lines either to diverge or to meet beyond the point fixed; and Hyperphoria, latent vertical squint, a tending of one visual line above the other. The term Cataphoria, the tending of one visual line below the other is unnecessary, since all cases of latent vertical squint are 
either right hyperphoria, tending of the right visual line above the left, or left hyperphoria, a tending of the left visual line above the right. Mixed deviations are also recognized as hyper-esophoria, where one eye tends to deviate upward and inward.

Causes.-The causes of latent squint include some of the causes of actual squint, opposed by a well-developed power of binocular co-ordination and fusion. Take away the impulse to binoeular fusion, and the squint ceases to be latent.

Symptoms. - Headache and eye-ache are the most constant symptoms of latent squint, while vertigo or a sense of strain, or a feeling of mental confusion may be present in severe cases. The headache has been regarded as more likely to be occipital than the headache due to anomalies of refraction; but there is no very marked differenee in this respect. All the manifestations of asthenopia or eye-strain may occur in connection with latent squint; but eongestion and inflammatory changes either in the eye or related parts are less common. The connection of such grave nervous disorders as epilepsy and chorea with heterophoria is very doubtful, except as heterophoria arises from the disturbance of the ocular muscles by these diseases. In a few eases, actual squint and diplopia may be discovered at times or in parts of the visual field, in patients in whom such deviation of the eyes had never been noticed.

Diagnosis. - The presence of latent squint is revealed only by special tests. On corering one eye, that eye deviates; on uncovering, both eyes fix normally. The movement of deviation is often quite gradual, oceupying some little time after the eye has been covered, and on this account it is difficult to perceive. But the movement of readjustment, or " recovery," is instantaneous, and therefore more noticeable. A recovery of 2 or 3 degrees is readily observed.

But entire exclusion of one eye from vision is not neeessary to reveal latent squint. Placing before one eye a piece of dark blue or purple glass will so change the 
color of an ordinary lamp-flame as to overcome the tendency to binocular fusion. The eye will deviate, and a false image having the color given by the glass will be seen. The direction of the false image and the distance of its separation from the true image will indicate the kind and degree of the squint.

The most valuable test for latent squint is the Maddox rod. A piece of glass rod placed before one eye, acting as a very strong eylinder, produces such a distortion of the images formed by light passing through it, that all tendeney to fuse them with the images of the other eye is overcome. On looking at a point of light, as a small flame at a distance of 4 to 6 meters, this appears as a long streak, perpendicular to. the direction of the rod. If the balance of the ocular museles is perfect, this streak appears to pass directly through the point of light as seen by the other eye, as in Fig. $83, A$. But in latent squint the

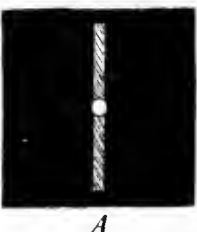

$A$

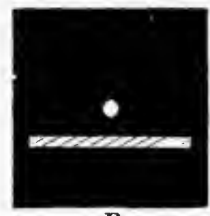

$B$

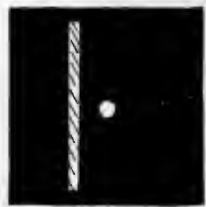

C

FIG. 83.-Positions of streak of light seen with the Maddox rod test: $A$, orthophoria ; $B$, hyperphoria ; $C$, exophoria or esophoria, according as the rod is held before the right or the left eye.

streak appears displaced in the direction opposite that of the deviation. Thus if there be a right hyperopia, the rod placed before the right eye will show the streak below the point of right, as in Fig. $83, B$. To test this vertical balance the rod is placed vertically, eausing a horizontal streak. To test the lateral balance it is placed horizontally, causing a rertical streak, which in esophoria or exophoria appears to pass to the right or left of the light, as in Fig. 83, $C$. To test the balance at the near-working distance, a point of light is not readily used and a white spot, 1.5 to $2 \mathrm{~mm}$. square, on a black card, 
is substituted. The ordinary Maddox rod gives with such a spot so feeble a streak that it is better to employ a piece ent from the side of a large rod, or a cylindrical lens of 20 . or 30 . D. refracting power.

The Graefè Test consists in placing with its base direetly up before one eye, a prism strong enough (8 or 10 degrees) not to be "overeome" by the turning of one visual axis lower than the other: this eauses vertical diplopia. On looking at a black dot on a white eard, two inages of the dot are seen. If the lateral balance of the museles be perfeet, one image is directly below the other; if there be latent lateral squint, the lower image will be displacerl laterally. Graefè proposed this test to deteet insufficiency of convergence. It is less useful for testing the vertical balance.

The Maddox double prism consists of two prisms ground on one piece of glass, base to base. It is placed before one eye so that the line joining the two prisms passes horizontally across the pupil. On looking, at a black dot on a white eard, the eye behind the prisn sees one inage displaced upward and another downward; while with the other eye the dot appears in its true position. If the muscular balance is perfect, the three images are seen in line, the true image being just midway between the false images. Any lateral displacement of the images indicates tendeney to lateral deviation; any vertical displacement a tendency to vertical deviation.

To measure the extent of a latent squint prisms are used. The prism that will rectify the displacement of the false image indicates the amount of deviation present. Such a prism being placed before the eye, no movement of deviation or recovery oceurs on covering or uncovering. With the dark glass, such a prism causes the true and false images to come together; with the Maddox rod it causes the streak to pass through the image of the light; with the Graefè test it brings the one dot direetly below the other; with the double prism the true and false images come in line and are equidistant.

The prisms furnished in the trial case are sufficient for 
the above tests. But speeial instruments lave been devised to facilitate such measurements by combining with the Maddox rod or the Graef'è test some form of rotary prism.

The Stevens phorometer is such an instrument, based on the Graefè test, and fitted for the very alceurate placing of the prisms. The little instrument devised by the author and illustrated in Fig. 84 combines the rotary

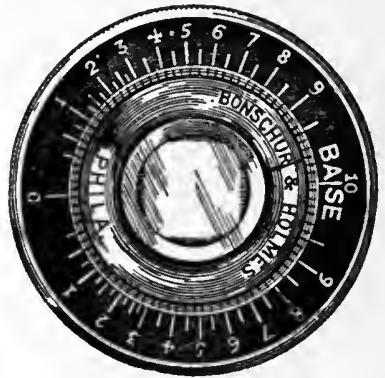

FIG. 84.-Phorometer eombining Maddox rod and rotary prism.

prism with the Madklox rod. It measures slight deviations with great accuracy; and 川р to 10 centrads. Higher deviations must he partly corrected by a 10 or 20 centrads prism before the other eye, and then the remaining deviation ean be measured by this instrument.

Rotary deviation is rentered evident by use of a test giving a linear image. 'Thus with the prism base up or the double prism, a horizontal line is substituted for the dot. If there is no rotary deviation of the eye, such as has been spoken of when considering paralytic squint, the true and the false images of the line remain parallel. If there is rotary deviation, the inage belonging to the deviating eye will appear to be rotated in the opposite direction. The lines of light given by two Maddox rods, placed one before each eye, may also be used in the same way; and the angle over which they must be rotated, to make the two lines appear parallel, gives the amount of rotary deviation. 
To discriminate between an insufficiency and a heterophoria, the latent squint must be studied in different parts of the field of fixation. Usually it will suffiee to note the deviation with the eyes directed forward ; turned strongly to the right (or faee to the left), eyes turned to the left (or tace to the right); the eyes turned up (or head thrown forward), turned down (head thrown backward); and with the eyes turned to the ordinary position for reading or other work.

In deciding on the proper course to be pursued with reference to a case of latent squint, it is also important to ascertain the amount of abduction, adduction, and sursumduction (see p. 192).

This is most conveniently done with a rotary prism by which any prismatic effect fiom 0 to 30 centrads may be obtained. The form suggested by the author (see Fig.

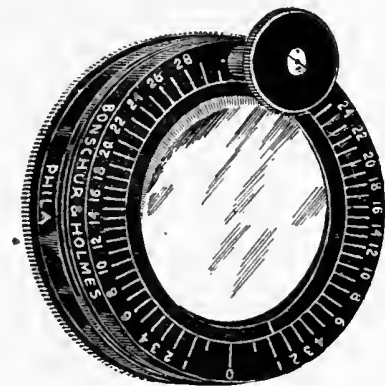

FIG. 85.-Rotary variable prism.

85), measures even the smallest degrees of deviation with great aecuracy.

Treatment. - Where the latent squint is of moderate amount and the. power of "overeoming" prisms with the base in the direction of the deviation good, or where there coexists a considerable error of refraction or other probable cause for the symptoms, the tendeney to squint may be disregarded, at least until other factors in the case have been looked after. In all eases where a notable 
error of refraction exists, its correction should take precedence of any operative treatment for the muscular fanlts.

In many cases heterophoria is an important indication regarding the wearing of correcting lenses. Thus with a moderate or low hyperopia the existence of two or three centrads of esophoria emphasizes the need for the coustant wearing of correcting lenses.

If the latent squint is considerable ( 2 centrads or up)ward of vertical deviation, 4 to $8 \mathrm{Cr}$. of divergence or convergence), prisms should be tried. Prisms for this purpose do not strictly "correct" a deviation, they allow it withont strain or inconvenience. Thus for exophoria we use prisms with their bases toward the nose. These allow the eye to turn ont somewhat while still preserving binocular vision. In general, the strength of the prisms used in this way"should be such as to "allow" half of the deviation; but sometimes nearly the whole deviation may be "allowed" with advantage.

If lenses are worn, the prismatic effect may be attained with great accuracy, and with least expense, by decentering the lenses. When an eye looks through any part of a lens, except its optical center, the effect is that of a prism with its base at the thickest part of the lens. Thus decentering a convex lens "in," or a concave lens "out," gives the effect of a prism with its base toward the nose. Decentering a convex lens "up," or a concave lens "down," gives the cffect of a prism with its base up. The prismatic effect increases as the optical center of the lens is departed from. Thus by removing the optical center a certain distance from the point where the visual line will pierce the lens, any desired prismatic effect can be obtained up to the limits of the strength of the lens and the size of the glasses.

The greater the effect to be produced the greater must be the decentering; and the stronger the lens the less it needs to be decentered. For all practical purposes the number of millimeters of decentering required in any given case may be found by the following rule; multiply the required centrads of deviation by ten, and divide by 
the strength of the lens in diopters. Thus to find the decentering of a 4 . D. lens necessary to produee 2 centrads of prismatic effect $2 \times 10 \div 4=5 \mathrm{~mm}$.

Systematic exercise of the ocular muscles by an entirely different use of prisms is sometimes of great value. For this purpose the prism is turned so as to increase temporarily the work of the apparently weak museles, in the hope of thus securing a better development and stronger action of them. Thus for right hyperphoria the eyes may be fixed on a distant object, and a rotary prism be placed before the right eye with its base up, making necessary an increased exertion of the muscles that turn the right eye down or the left eye up. The prism being turned so as to inerease its effeet, the patient is told to keep the object looked at single as long as possible. When doubling oceurs, the prism is removed or turned back, and the eyes permitted to rest a minute; then the exercise is repeated. For latent convergent squint, the eyes may be made to fix a near-point, while strong prisms are placed before them with the bases toward the nose; then the point of fixation is withdrawn from the eyes until it appears double, when the eyes are allowed to rest. For insufficiency of convergence, prisms with base toward the nose may be used. The fixing of a point held at some distance from the eyes, which is then gradually brought eloser and closer until it is seen double in spite of a strong effort, is also a simple and efficient exereise.

Operations on the ocular museles, for latent squint, are only to be considered after the most eareful study of the ease and the faithful trial of other therapentic measures. They exert a powerful mental effect on the patient, which is sometimes markedly beneficial. They break up for the time vieious habits of using the eye-muscles with unnecessary strain; and they may ehange permanently the state of the ocular balance, but not always with much benefit to the patient. The extent of the permanent meehanieal effect eannot eertainly be known beforehand, or by testing at the time of operation, or immediately afterward. Operation should only be resorted to for 
its mechanical effect when the extent of the latent lateral deviation amounts to 10 centiads (5 degrees) or upward, or the vertial deviation to one half as much; and where the relief by the wearing of prisms has seemed to demonstrate the conncetion of the srmptoms with the latent squint. Tenotomy may be done on the musele which tends to turn the eye too strongly in its direction, or adrancement upon its antagonist. 'The latter operation, if done withont eomplete division of the tendon or great distmbance of neighboring parts, is the less liable to cause untowarl effects.

The extent to which the symptoms associated with latent squint are really due to it is still uncertain. Often the eareful trial of all therapentic measures is called for in such eases. This must include the use of general tonies, asoidanee of eye-strain, worry, overwork, or the habitual use of such nerve-poisons as alcohol, tobaceo, tea, or coffee, partieularly by young persons. Outrloor life and physical exereise are also of great value.

Prognosis. - The permanent relief of the symptoms associated with latent squint is often extremely diffieult. The most brilliant eases of apparent cure of symptoms are liable to return to somewhat their original condition in a few months or vears. Those eases are most likely to be eured in which the use of eorreeting lenses gives relief, or in which it is possible to control favorably the manner of living. A good many are rendered comfortable and kept so by the use of the prisms, or decentered lenses, which "allow" the squint.

\section{SPASTIC SQUINT.}

Deviations of the eyes due to spasm of the oeular museles attend hrsterieal seizures and some forms of braindisease. They may assist in the general diagnosis; but have little localizing value, and require no treatment apart from that of their cause.

\section{NYSTAGMUS.}

Nystagmus is a slight, rapid, to-and-fro movement of 
the eyes, most frequently from side to side (lateral nystagmus); but sometimes up and down or wheel-like (vertical or rotary nystagmus). Usually both eyes exhibit similar movements. They may be increased by efforts to use the eyes (intention mystagmus). It is commonly associated with imperfect vision. It is often congenital, but may arise in connection with disease of the eentral nervons system, especially when that eauses blindness. It often oeeurs in miners who have to work in a poor light, with the eyes directed obliquely upward (miner's' nystagmus).

In most cases no interference with vision is oecasioned by the movements. But in miners' nystagmus, and in some other cases where it comes on in adult life, it oeeasions apparent movement of objeets looked at, and annoying vertigo. When associated with high astigmatism, it may grow less or cease entirely with the wearing of correcting lenses. Recovery from miners' nystagmus often follows change of oceupation. In other cases little improvement can be hoped for.

\section{NODDING SPASM (SPASMUS NUTANS).}

This is a nodding, lateral, or rotary movement of the head, commonly accompanied by nystagmus, with which it is elosely allied. It ustally appears during the first year of life in rachitic patients. It is probably caused by some ocular defeet, or by keeping the child in a dark room in which some bright spot is visible. The bright spot quickly exhausts the portion of the retina exposed to it, and the child changes the position of its eyes to again secure a more vivid impression.

\section{CONGENITAL DEFECT OF ABDUCTION WITH RETRAC- TION OF EYEBALL.}

In rare cases there exists from birth inability to turn the eyes outward, commonly associated with retraction of the eyeball when the cye is turned toward the nose. 'This retraction may vary from 2 to $10 \mathrm{~mm}$. On attempting 
to turn the eye in, there is often some narrowing of the palpebral fissure, the lids being more widely separated when the eye is turned directly forward or the attempt is made to turn it outward. One or both eyes may be affected. The condition is largely due to an organic lefect in the external rectus, which may be replaced by fibrons tissne. Little can be done to renedy such defects, and ill-considered operations only make them worse.

\section{DISEASE OF THE OCULAR MUSCLES.}

Myositis.-Inflammation of the extra-ocular museles produces diplopia, pain in the orbit, exophthalmos, and great impairment of ocular movements. It may be due to syphilis, rheumatism, or to unknown causes.

True hypertrophy, and sclerotic changes with pseudohypertrophy of these muscles, have been reported. Rheumatism of their tendons of insertion is occasionally noticed. It oecurs in connection with acute articular rheumatism, renders painful all ocular movements, may be easily mistaken for episeleritis, and yields promptly to anti-rhemmatic remedies. 


\section{CHA P TER IX.}

\section{DISEASES OF THE CONJUNCTIVA.}

Hyperemia (Dry Catarrh).-The appearance of hyperemia of the conjunctiva has already been deseribed (p. 60). It is conmonly attended with itching, smarting, and burning, or the sense of a foreign body in the eye, feeling worse after use of the eyes or exposure to heat. Chronic hyperemia is indistinguishable from mild vernal eonjunetivitis.

Causes.-These are, for aente hyperemia, local irritants, as dust or irritating vapors, excessive exposure to the sun or strong winds, excessive use of the eyes, or their prolonged use when tired, indulgenee in aleoholic beverages, gout, a general febrile condition, eommencing inflammation of the conjunctiva; and acute eatarrh of the mucous membranes in general, especially of the nasal mucous membrane. For ehronie hyperemia one should always search for a persistent, or frequently reeurring, cause. The most common of such canses are: eye-strain from habitual overwork or the presence of ametropia; chronic hyperemia of the nasal and related mucous membranes, including catarrh of the lacrimal passages; repeated attacks of acute hyperemia; prolonged exposure to excessive heat; and chronic alcoholism.

Treatment.--Acute hyperemia tends strongly to spontaneous recovery, and requires only removal of the cause, rest for the eyes, and sone soothing eollyrium, such as a solution of boric acid with or without borax. Chronic hyperemia requires, first, the removal of the cause, and if this prove insufficient, some of the milder forms of treatment for ehronic catarhal conjunetivitis. 'The removal of the eanse, however, may include relief from eye-strain, or long and careful general treatment, as to overeome a general catarihal tendency.

Acute Catarrha1 Conjunctivitis (Simple Ophthalmia, Catarh of Conjunctiva, Mucopurulent Conjunctivitis). -When to hyperemia are added swelling of the conjune- 
tiva and conjumetival discharge, the case beemes one of conjunctivitis.

Causes.-The canses include all those of conjunetival hyperemia. 'The instillation of atropin or other mydriatic causes or aggravates conjunetivitis in a fow persons who have sueh an idiosynerasy. There ean be no douht that certain pathogenic bacteria are the essential factors in the causation of many eases of acute conjunctivitis. Among the most important of these are the staphylococei, the streptococei, the peumococeus of Fränkel, and the so-called xerosis bacillus. These are found in cases which must still be classed tugether by their elinical characteristics. The other organisms eausing distinet clinical types of disease are mentioned in the deseriptions of those types of eonjunetivitis.

Symptoms.-The discharge of acute catarrh of the conjumetiva is at first seanty and may be only apparent by the adhesion of the lids in the morning, after it has dried upon their margins throughout the night. It may amount to but a slight increase of the normal secretion, which is washed away by the usual or inereased secretion of the tears. As the case progresses the amount of discharge increases; and its character may vary to the abundant flow of purulent conjunctivitis. Small masses of the discharge may be noticed lying at the junction of the lower liel and eyeball, or may be found in the lower enl-de-sac of the conjunetiva, upon everting the lid.

The appearance of the lids varies with the degree of hyperemia, the changes in the epithelium, and the anount of exutation in the deeper tissues. The hyperemia gives increased redness, which may appear only in the larger number or larger size of the visible vessels. Thickening of the epithelial layer masks the increase of redness and gives the appearance of a gray film upon the surface of the conjunctiva. Exulation into the deeper tissues, by separating the vessels and by pressure upon them reducing their ealiber, tends to dininish the redness, sometimes to even less thin the normal.

The pain of acute conjunctivitis is usually most marked 
early in the eourse of the disease, is strictly local, and may vary from a slight discomfort to severe buming pain. 'To some extent it is proportioned to the severity of the inflammation, but it also depends somewhat on the eondition of the nervons system. It resembles that of simple hyperemia, and is deseribed in many ways, but nsually as more or less of an itching, smarting, scratching, or burning charaeter. It may be spoken of as aching, though probably true aching when present is eomnected with considerable swelling of the neighboring parts, or involvement of the deeper tissines of the eyeball. In the early stages there is often the exact sensation of a foreign body in the eye.

Exudation in conjunetivitis occurs within the tissues, causing swelling, or upon their surface as discharge. It is generally accompanied by loss of transparency, so that the deeper details normally visible throngh the conjunetiva are hidden. It involves largely the loose tissnes lying beneath the membrane, and if severe, affects the whole thickness of the licls. On the eyeball the tissues affected are thickest posteriorly where the membrane is reflected upon the licls; hence, if the swelling be slight or moderate in amount, it is most noticeable in this region. If, however, the amount of serous exudate be great, the pressure posteriorly tends to force it forward, so that it raises up the conjunctiva to its attachment around the cornea; and the cornea appears surrounded by a perpendicular or overhanging wall of translucent tissue. This condition is called chemosis.

Careful examination of the affeeted tissue will often show that it is the seat of numerous minute hemorrhages. The swelling of the conjunctiva, however great, never endangers the integrity of that membrane. But ehemosis is supposed by pressure to interfere with the zone of vessels upon which the nutrition of the cornea depends; and the sulcus formed by it at the corneal margin eertainly favors the retention of the discharges, and, in that way, the infection of the cornea.

Discharge from the conjunctiva consists of inereased normal seeretion and cast-off epithelium, with a variable 
proportion of pus and micro-organisms. If the proportion of pus be small, the masses found floating in the tears will be gray or whitish in color and rather stringy in appearance. As the proportion increases, the discharge becomes more purulent in character, and sometimes is decidedly so, even in cases that would be classed as catarrhal conjunctivitis. At all times the apparent amount of discharge and its consistence depend largely on the extent to which it is diluted by the lacrimal secretion. In the earlier stages the increased flow of tears is liable to carry away all other discharges unnoticed. Later, the secretion of tears is less copious, and the amount of mucous or purulent matter appears relatively greater.

Diagnosis.- The hyperemia of conjunctivitis is to be distinguished from that of keratitis, iritis, or glaucoma, etc. (see p. 61). From other forms of acute conjunctivitis the eatarrhal often cannot be differentiated at the outset, except that the symptoms are generally less violent than in purulent or diphtheritic conjunctivitis. The differentiation from more chronic forms must also wait until these have time to develop their special characteristics. The bacteriological examination and identification of the organisms present will in some cases be the only way of deciding whether or not the case belongs in this class, or one of the specific forms of conjunctivitis. The special clinical characters of the other forms of conjunctivitis discussed in connection with them furnish a basis for their differential diagnosis from this variety.

Treatment.-After the removal of the cause, so far as it is removable, the treatment consists largely in rest and eleanliness. 'The rest of the eyes should be supplemented by general rest, if the inflammation be severe; and should always inclucle sufficient sleep. Cleanliness is to be secured by frequent bathing of the eye, with the free instillation of a solution of boric acid and borax or sodium chlorid, at intervals of from one to four hours, according to the amount of discharge. Weak solutions of mercuric chlorid, mereuric iodid, or oxycyanid may be used for the same purpose. But in eatarrhal conjunetivitis care should always be taken to avoid solutions strong enough to act 
as irritants, their cleansing power being far more important than their specific antiseptic influence.

Solutions of argyrol, 4 to 10 per cent., may be used at short intervals. In the more severe cases, applications of silver nitrate or protargol solution may hasten recovery. The use of laxatives and appropriate remedies for any coincident departure from general health may be needed.

Prognosis.-Most cases of acute conjunctivitis recover completely in a few days. But when due to staphylococci, the disease may persist longer. Lacrimal and nasal disease must also be excluded before promising prompt recovery.

Influenza bacillus conjunctivitis occurs usually in children in connection with influenza epidemies. The discharge is abundant but watery.

Exanthematous Conjunctivitis.-The early stage of measles, small-pox, scarlet fever, and some of the other exanthemata is frequently marked by conjunctival hyperemia and catarrh, to which the above name has been given. It is characterized rather by hyperemia and swclling without much discharge, although with measles and scarlet fever the conjunctival secretion may even become purulent, and in small-pox well-marked examples of the eruption may be found, on the bulbar conjunctiva, especially near the corneal margin. Usually the conjunctival tronble quickly subsides, bnt it may require treatment even after the constitutional disease has run its conrse.

Acute contagious conjunctivitis is a specific disease caused by infection, the active agent being a small bacillus first studied by Weeks, and which nay be found in the conjunctival discharges.

Symptoms and Course.- It begins two or three days after infection, with glueing together of the lids and the appearance of dry yellowish masses on their margins or about the inner canthus, especially in the morning. Hyperemia and discharge rapidly increase for two or three days, and the discharge often becomes purulent. The deeper fine vessels of the eyeball are much injected, giving it a pink appearance. Hence the popular name of "pink-eye." 'There is also usually some involvement of the upper air-passages and adjoining sinuses, causing 
slight coryza. The common course of the disease is to complete recovery in a few days, but it may become subacute and continne for several weeks. It appears to spread by direct contact, extending to the different members of a family, or through a school or barracks. It may eause marginal ulceration or haziness of the cornea.

Diagnosis.-From catarrhal conjunetivitis it can be distinguished by the peculiar yellow secretion adherent to the lashes, the occurrence of other cases in the same honse, either before or afterward; and by the identification of the Weeks' bacillus with the microseope. It is a small bacillus resembling that of monse septicemia. It stains readily with methylene blue, and loses its color by the Gram method. It is found within the cells and also free in the discharge. It is diffieult to obtain in pure culture, being generally mixed with a club-shaped nonpathogenic bacillus.

A form of acute contagious conjunctivitis which many olservers lave been unable to distinguish from the above seems to be caused by the pmemococeus (Fraenkel); an ovoid or lanceolate encapsulated coceus often found in pairs, hence ealled the micrococeus lanceolatus (Talamon), or the diplococens preumonice (Weichselbanm). It exists in the normal saliva of many persons.

Treatment.-This will generally be similar to that of acute catarrhal conjunctivitis. Cold applications may be nsed the first two or three days. 'The more severe cases should be treated by applications to the everted lids of a 2 per cent. solution of silver nitrate, repeated every day or two, until the discharge and swelling are markedly diminished.

Diplobacillus conjunctivitis is characterized by compuratively slight discharge, often only noticed by the glueing together of the lashes after sleep. There is moderate irritation and smarting, chiefly in the evening. Many of the cases run a subacute or chronic course, extending over many weeks or montlss. The invasion is generally insidions, but the attack is sometimes acute; and the more severe cases may be taken for commencing trachoma. 
The palpebral eonjunctiva and corners of the eye are red. The discharge is gray, stringy in character, and accumulates at the canthi. The disease is caused by a diplobacillus first deseribed by Morax and Axenfeld.

The treatment is the instillation of a solution of zine sulphate, $\frac{1}{2}$ to 2 per cent., two or three times daily. Gifford used zine ehlorid, $\frac{1}{5}$ of 1 per cent., and Alt a 2 per cent. solution of protargol. Treatment should be sontinued at longer intervals for several days or weeks after apparent recovery, to prevent relapse.

Ophthalmia nodosa is an inflammation of the conjunctiva, sometimes extending to the deeper tissues of the eye, due to the presence of caterpillar hairs. The conjunctivitis tends to relapse again and again, and where each hair is embedded, a rounded gray swelling is formed. Excision of the offending particle, which may be extremely minute, is the proper treatment.

Brief Recurring Episcleritis.-Under the name Episcleritis Periodica Fugax, Fuchs described a form of conjunetival and episcleral hyperemia, attended with pain, but without discharge; lasting hut a few days, but recurring at intervals of a week to several montlis. In some cases it lasts for many years. It seems to depend on some obseure condition of the general system; and is little benefited by treatment.

Purulent Conjunctivitis. (Purulent Ophthalmia, Acute Blennorrhea, Gonorrheal Ophthalmia, Ophthalmia Neonatorum..-This affection is characterized by great swelling of the conjunctiva and lids, and abundant discharge, at first serous and later purulent.

Cause.-In most eases this is the implantation upon the conjunctiva of the gonococcus, by contact with fingers or clothing carrying the infective material; or by similar contact in the birth-canal during labor. Disease elinieally similar may be produced by other pyogenic organisms.

Symptoms and Course.- Within one or two days after infection the eye presents the symptoms of acute catarrhal conjunctivitis, rapidly inereasing in severity, with excessive swelling of the lids and free discharge. This dis- 
charge is at first clear and watery, then it contains shreds and flakes of mucus and may be discolored by blood. Gradually it becomes more purulent, until it has the appearance of typical creamy, or slightly greenish, pus. The first indication of the gravity of the attack is found in the severity of the symptoms and the rapidity of their progress. 'The lids, in the early stage are tense, often smooth and shiny. The swelling of the eonjunctiva gives rise to chemosis, and interferes considerably with the eversion of the lids. When the diseharge becomes purulent, the lids generally beeome softer, and the swelling diminishes. In a few days the palpebral conjunetiva shows hypertrophy of the papillæ. Its surface becomes velvety in appearance, and later may be obseured and covered to a depth of two or three mm., with the pale, or dark-red

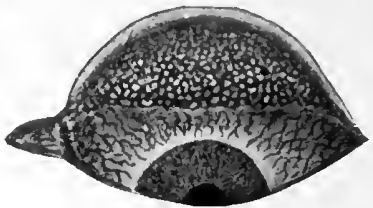

F16. 86.-Papillary granulations of the late stage of purulent conjunctivitis, shown on the everted upper lid, with severe hyperemia of the bulbar conjunctiva.

granular masses. 'These are illustrated in Fig. 86. The discharge, under treatment rapidly, or without treatment more slowly, diminishes; but several weeks are usually required to restore the conjunctiva to an approximately normal condition.

A common complication and the great danger of the disease is involvement of the cornea. This has been thought to depend chiefly upon the pressure of the swollen lids, or the ehemotic conjunctiva; but it may oecur from direct infection by the virulent discharge that bathes it, espeeially where this lies in contact with the cornea, in the erease formed by the overlapping of the swollen conjunctiva. When this oceurs a small ulcer forms near the eorneal margin, which rapidly 
extends, both in area and in depth; or a considerable part of the cornea-usually at the center-rapidly bccomes opaque and breaks down, leaving a large extending ulcer. Such an ulcer is liable to cause perforation and the serious or fatal results described under suppurating ulcer of the cornea (Chapter X). In debilitated subjects, or under inefficient treatment, the hypertrophy of the conjunctiva above described is liable to be excessive and to continue, with moderate discharge, for many weeks.

Varieties.-Gonorrheal ophthalmia the disease is called when it is clearly due to infection with the virus of gonorrhea, or the gonococcus is found in the discharge. Cases of this character include the most serious and dangerous cases of purulent ophthalmia.

Ophthalmia neonatorum is the name given to purulent conjunctivitis in the new-born. Infection usually occurs during birtl, although some children are born with the inflammation already developed, probably having been infected after early rupture of the membranes in a slow labor. A few cases also become infected subsequent to labor, from lack of proper cleanliness. A majority of cases, including all in which the inflammation is most violent, show the presence of the gonococcus in the discharge. Cases of ophthalmia immediately after birth do occur that clearly have a different origin and character.

Diagnosis.-Purulent conjunctivitis is to be first suspected from the violence of the symptoms of conjunctival inflammation; the extent and rapid progress of the swelling; and the free watery and flaky discharge. Conjunctivitis coming on within four or five days after birth should at once be regarded as probably purulent. In adults the history of an antecedent urethral or vaginal discharge, or exposure to contagion, can usually be obtained. Later the profuse secretion of the thick pus is very characteristic, and still later the existence of large, soft, dark-red granulations, covering the inner surface of the lids, is suggestive of the naturc of the case. Microscopic examination of the discharges as described (p. 67), stained with methylene blue, and also tried by the Gram 
metlıod, may be necessary to decide the nature of doubtful eases. Preparations so made may also be valuable in regard to the medico-legal aspects of the case.

Treatment.- The most inportant point is the cleansing of the eye of all discharges as frequently as this becomes necessary. In the carliest stage the free watery discharge may so far accomplish self-cleansing that other measures are of more practical importance. In healthy adults, where the swelling is great, the application of cold by pledgets of lint laid on a block of ice and thence transferred to the lid, and changed cvery one or two minutes, is often employed. When the swelling begins. to diminish, or the discharge to become markedly purulent, cold is of less value. It must also promptly be discontinued when haziness of the cornea shows that its nutrition is being interfered with; and is not to be resorted to for weak patients. Cold is diffieult to apply effieiently in the purnlent conjunctivitis of infancy, and is not so beneficial.

When seen very early the comrse of the discase may sometimes be modified by a single free application of a strong solution of silver nitrate; but during the period of watery discharge and great tension of the lids, such an application is not to be repeated.

As the discase passes into the stage of free secretion of pus, the thorongh and frequent cleansing of the eye becomes of the highest importance. All discharge escaping from the palpebral fissure should be promptly removed with absorbent cotton, which will take it up without unneecssary wiping of the lids. As often as every hour at the height of the disease, or even more frequently if the discharge is very profuse, the eonjunctival sac should be thoroughly waslied out, and all shreds elinging to its surface be renioved with absorbent cotton. For such washing the solution may be of boric acid, or very weak solutions of trikresol, potassinu permanganate, merenric ehlorid or cyanid, or formaldehyde. The important points are that it shall be used freely and effieiently, and shall not be so strong as to act the part of a local irritant. In any case 
the water is the more important ingredient of the solution; and the object to be aimed at is the complete mechanical removal of discharges, rather than their destruction or nentralization in situ by the chemical antiseptic. For such washing, various irrigators in the form of hollow lid elevators, or speenla, perforated for the eseape of the solution, have been devised; but no instrument will be efficient without careful thoroughness in its use; and the rubber-bulb pipette will do as well. It should have a perfectly smooth nozzle, and as large a bulb, up to one or two ounces, as is obtainable. The point of the tube is to be inserted between the lids near the outer commissure, and the solution forced into the eye. Care must be taken to provide for the subsequent disinfection of the tube when allowed to come in contaet with the lids, as by allowing it to stand in a stronger antiseptic solution in the intervals. As the discharge becomes less, the intervals between the washings may be lengthened. But it must be insisted that the frequent gentle but thorough cleansing of the eye is of more importance in this disease than all other remedial measures taken together.

As the secretion hecomes purulent applications of 2 to 4 per cent. solutions of silver nitrate, or 20 to 40 per cent. solutions of protargol to the conjunctival surface of the everted lids are indicated. Such applications may be repeated daily, occasionally even oftener, or at longer intervals. The rule must earefully be observed not to repeat the application of the nitrate until the red and rather raw appearance of the lid, which may be noticed for some hours after an application, has given place to the usual suceulent appearance characteristic of the disease. The applieations of such solutions are to be continued at lengthened intervals until the cure of the case is nearly eomplete, or the condition has changed into one of ehronic eonjunctivitis. In addition a 2 per cent. solution of protargol may be instilled every two or three hours.

Where the swelling of the lids is very great, preventing 
their free eversion and complete cleansing, and causing considerable pressure upon the eycball, canthotomy should be practiced; or in infants, the upper lid may be divided by a vertical incision (see Chap. XIX).

For debilitated patients the application of heat, either by cloths wrung from water of a temperature of $130^{\circ} \mathrm{F}$. or upward, or by the hot-water coil, or the Japanese hotbox, must replace the application of cold that might be resorted to in the more robust. When involvenent of the cornca is noted, such applications of heat must replace cold in all cases. To be effective the application of cold must be continuous; but high degrees of heat may be used for short periods, five to twenty minutes, with intervals of three to four hours during which the eye is kept moderately warm. Especial treatment directed toward the corneal complications will be referred to in Chapter X, on Diseases of the Cornea.

The general treatment may include rest in bed until the swelling and discharge are beginning to subside. Internally it is well to commence with a free laxative or decided eathartic, and subsequently to give quinin and tincture of the ehlorid of iron, the latter in full doses. If the patient be debilitated, other tonies and stimulants may be indicated to keep up the nutrition of the cornea. Pain, if severe, may be met with small doses of morphin or acetanilid.

Prophylaxis.-Scarcely secondary in importance to the treatment of this disease are certain precautions for its prevention. In adults, usually but one eye is affected in the beginning, and the greatest care should be taken to avoid the conveyance of the virus to the second eye. To more certainly prevent this, when the first eye seems likely to be lost, it is advisable to close the second eye with an impervious dressing. Linen may be placed upon the lids, over this a compress of absorbent cotton, and on this some protective, the whole to be retained by collodion painted all around the margin of the dressing. If it be important for the patient to be able to sec, this dressing may be replaced by a large wateh-glass made fast at its 
margin by strips of adhesive plaster. This is called Buller's shicld, from the name of its proposer. Knapp uses a piece of mica, and leaves the temporal margin free for circulation of air. Through it the patient can have the use of the sound eye, and the surgeon ean watch for any indications of disease, while the chances of infection are reduced to a minimum.

At birth it commonly happens that both eyes are infeeted during the passage of the head through the vagina, but even after this has oceurred the outbreak of the disease may be prevented. 'To accomplish this the child's eyes should be immediately eleansed, and a 2 per cent. solution of silver nitrate freely instilled. If this preeantion, known as the Credé method, be adopted, the disease will generally be prevented. So grave a calamity is bliudness from purulent conjunetivitis that the use of this precaution has been urged at the birth of every child. Such a general application is not desirable, since it might do harm in unsuitable cases; but it should be borne in mind and resorted to whenever there is a probability that the mother is infected with gonorrhea.

The importance of this matter may be appreciated when it is remembered that a large proportion of all eauses of blindness operate only in adult life or old age, while this entails blindness from infancy. Even when there seems no chance of infection, the appearance of redness or discharge in an infant's eyes should at onee command the attention of those in eharge of it.

Prognosis.- In few diseases does prognosis depend so much upon treatment. Effieient treatment, begun early enough, will save the eye in almost all cases of ophthalmia neonatorum, and in a large proportion of the violent eases of gonorrheal ophthalmia in adults. If, however, the patient's general nutrition and resisting power are much below the standard, a purulent eonjunetivitis of very moderate severity may eause general opacity or sloughing of the cornea. In such cases this is liable to oceur late. In otherwise healthy subjects, if the cornea remain elear until the diseharge has begun deeidedly to 
diminish, there is a very strong probability that it will escape damage. If the conjunctiva alone is involved, recovery is complete.

Croupous Conjunctivitis (Plastic Conjunctivitis, Croupous Ophthalmia). - In certain cases commencing as violent catarrhal or purulent conjunctivitis, the plastic material thrown out upon the surface of the lids, instead of being earried off' in flakes by watery discharge, remains adherent as a gray rather soft layer that can be removed by rubbing or with the forceps, leaving the lid-surface red and bleeding at certain places. A deposit of this kind may oceur in severe eatarrhal, acute contagious or mild purulent conjunctivitis. After some days, the membrane deposited separates spontaneously, leaving the surface of the conjunctiva much the same as in the later stages of severe catarrhal inflammation.

The prognosis is rather favorable, deposit is usually confined to the surface of the lids, and the cornea rarely becomes involved. The diagnosis between this condition: and diphtheria of the conjunctiva will be considered under the latter heading.

The treatment should include the cleansing and general measures appropriate for a mild case of purulent conjunctivitis. But cold is to be avoided, and hot applications used instead. The membranous deposit should be left undisturbed, and applications of silver nitrate should not be tried until the false membrane has disappeared.

\section{Diphtheria of the Conjunctiva (Diphtheritic Con-} junctivitis.) - When on everting the lids in a case of commencing conjunetivitis, one finds parts of their inner surface pale gray, infiltrated with rigid material that strongly resists the manipulation of turning the lids, and the subconjunetival tissue all infiltrated, diphtheria of the conjunctiva must be suspected, although it is a rare disease.

Symptoms and Course.-In sich a case the lids are tense, greatly swollen, and are very much more rigid than they would be from the same amount of swelling in comection with purulent conjunctivitis. It may be quite 
impossible to evert them. The paler areas of the conjunctiva mark the greatest infiltration and shutting off of blood-supply. While the surface of the conjunctiva may be covered with a false membrane similar to that which forms on the tonsils, this may be quite absent; the fibrinous exudate being situated within the tissues.

As the ease progresses, the whole lid may become the seat of the rigid infiltration, which may extend to the ocular conjunctiva. The eye is painful, the lids hot and red. For several days the rigid infiltration continues, then it begins to soften, and the affected tissue is very apt to slough. The discharge is at first watery, later becoming turbid with fibrin and effused blood, and purulent or mucopurulent in the stage of softening. The local process is accompanied by fever and general depression, such as mark the course of diphtheria elsewhere.

The cornea is apt to become affected early, and to break down rapidly and be partially or totally destroyed. The slonghing of the lids is liable to cause adhesions between them and the eyeball (symblepharon).

Cases occur in whieh the firm infiltration of the lids is entirely absent, the symptoms being in the main those of catarrhal conjunetivitis. But the cornea rapidly breaks down, and the microscope shows the presence of the Klebs-Lïffler bacillus.

Diagnosis.-The recognition of typical diphtheria of the eonjunctiva should not be difficult. The rigidity of the lids in excess of that ordinarily noticed, with the same amount of swelling, and the gray patehes of strangulated tissue, which may rm together and include the whole surface of the conjunctiva up to the corneal margin, are unlike anything seen in purulent or catarrhal eonjunctivitis. As compared with eroupous eonjunctivitis, the condition is entirely distinct. In croupons conjunctivitis the membrane is situated upon the surface, somewhat like the membrane of diphtheria in the pharynx, while in diphtheria of the conjunctiva there may be no membrane upon the surface, or it is less noticeable than the rigidity of the deeper tissnes. In general the 
diagnosis is to be established by finding of the KlebsLöffler bacillus; but it should be remembered that the so-called xerosis bacillus, which may very generally be obtained from the normal eonjunetiva (and which probably has no conneetion with xerosis) resembles so closely the true diphtheria baeillus that they cannot be certainly distinguished exeept by enlture experiments and their effeets on the lower animals.

Treatment.-Diphtheria of the conjunetiva is to be recognized as essentially the same disease as diphtheria of the pharynx or larynx, and is to receive the same general treatment. It is of the lighest importance that it should be promptly recognized, and treated by full injections of the diphtheria antitoxin, repeated at intervals of not more than sixteen hours (Standish). The results of this line of treatment applied early have been almost universally satisfatetory, and its importanee oversladows that of all local remedies. Locally cold may be applied, if swelling of the lids is great, the patehes of gray, rigid infiltration small and few, and the cornea not infeeted. If, however, mueh of the tissue is being strangulated by excessive fibrinous infiltration, or the general condition of the patient is one of depression, or the cornea shows signs of infiltration, eold is to be avoided, and hot applieations made as described for purnlent conjunetivitis. In any ease, the cold should be limited to the first day of the attack; and subsequently, heat continuously applied to favor the softening of the lids with the least possible sloughing of tissue. Careful cleansing of the eonjunetiva is important. After the proeess of softening, a solution of silver nitrate may be applied, at first very cautiously, to the inner surface of the lids. If only one eye is involved, the other should be carefully protected from infection, as in purulent eonjunetivitis. During the attack, and subsequently, sueh general remedies as tincture of the chlorid of iron, free stimulation with alcohol, and the use of strychnia, will be indicated.

Prognosis.-The chanee of saving an eye affected with the disease depends largely on the prompt resort to 
the use of the antitoxin. Without it a very large proportion of eyes have been destroyed by the sloughing of the cornea. Under its use, nearly all reported cases have terminated in recovery.

Chronic Membranous Conjunctivitis.-Rare cases occur, chiefly among children, in which with some swelling and slight conjunctival discharge, there are found, on everting the licks, extensive patches of grayish or whitish, tough, firmly adherent membrane, the removal of which leaves a raw blceding surface. There may be no great interference with the use of the eye; which, except for the swelling of the lid, would look normal. This condition may continue for montlis, or even years, without material change. The removal of the membranc is promptly followed by its renewal. Sometimes but one eye is involved; but both are liable to become affected. In connection with this condition, there arise acute exacerbations, in which the cornea may slongh and the eye be lost. The connection of this condition with acute diphtheria is uncertain. Repeated examinations have sometimes failed to discover the Klels-Löffler bacilli; and in other cases they were only discovered during acute exacerbations. No treatment has been found to cut short the disease or greatly influence its course.

Chronic Catarrhal Conjunctivitis. - Repeated attacks of acute catarrhal conjunctivitis, or the persistent action of influences that tend to cause acute conjunctival inflammation, as eye-strain, habitual exposure to irritant dust or vapors, or artificial heat, chronic disease of the lacrimal passages with regurgitation of mucopurulent discharge into the conjunctiva, are among its common causes.

Symptoms and Varieties.-Chronic catarrhal conjunctivitis affects chicfly the palpebral portions of the conjunctiva, extending in bad cases or acute exacerbations to the ocular portion. These exacerbations arise from whatever increases the hyperemia of the parts. The surface may be slightly reddened and roughened, by the enlargement of the papillæ, constituting the so-called 
"gramulated lids," which are something very different from granular conjunctivitis. The discharge eonsists of only a few shreds of mucopurulent matter, which may collect at the canthus; or, during the closure of the lids at night it may, by drying on the lashes, glue them together so that some force is required to open the eyes in the morning. The eyeball may be perfectly normal in appearance or may present only a few dilated veins. A common form of disease affects old people who live in bad hygienie surroundings. There is little or no discharge, and the entire surface of the lids remains smooth. The epithelial layer is apparently thickened, so that the conjunctival surface of the lid presents the appearance of purplish-red covered with a gray film. This form of the disease is attended with a great deal of smarting and burning, on account of which the patient usually seeks relief, and is willing to undergo prolonged treatment.

Diagnosis.--The diagnosis of chronic catarrhal inflammation of the conjunctiva is to be made from the history of the case, the appearances above described and the absence of symptoms eharacterizing other forms of chronic conjunctival disease, which will be referred to in connection with those diseases.

Treatment consists of: First, removal of the cause, if this be possible; as the relief of the eye-strain by glasses, change of occupation or residence when the disease is due to habitual exposure to some irritant; or removal of lacrimal obstruction. If there is considerable thickening of the lids, or discharge, they may occasionally be bathed for two or three minutes with very hot water. The local applications should include some rather strong astringent, as a solution of silver nitrate $\frac{1}{2}$ to 1 per cent., a solution of tamnin in glycerin, or crystal of alum, applied to the surface of the everted lid. Where such applications cannot be made at intervals of two or three days, a solution of zinc sulphate $\frac{1}{4}$ to $\frac{1}{2}$ per cent. may be given to be dropped into the eye once or twice daily. In a very mild ease boric acid solution may answer best. For decidedly chronic cases, either alone or in connection 
with the astringents mentioned, an ointment of yellow oxid of merenry should be used once daily.

Prognosis.-This disease can last indefinitely; and often the cure will depend entirely upon the removal of the cause. If, however, the condition has lasted for years, some of its effects are likely to persist in spite of any treatment. The chronic eonjunetivitis of old people, attended by smarting, is commonly not completely curable; but is eapable of alleviation, which is usually highly appreciated.

Parinaud's conjunctivitis is a rare disease characterized by a severe onset, great swelling of the lids, polypoid granulations of the conjunctiva, involvement of the neighboring lymphatic glands, and ultimate recovery. It affects commonly but one eye, attacks children and adults, and the onset is attended with slight rigors and severe general depression. The disturbance and swelling of the pre-auricular, sub-maxillary, and cervieal lymphatic glands of the affected side are marked; and sometimes these go on to suppuration. If the granulations are not very numerous, they may be cut off and their bases cauterized. Other treatment seems to have but little effect, but the case goes slowly on to recovery.

Vernal Conjunctivitis (Spring Catarh, Frïhjahr Catarrh). - This is a rather rare disease, affecting children and young persons, recurring year after year, during the summer. The more marked eases begin in the spring and last until cool weather in autumn. After some years the attacks become less severe, and finally may cease altogether.

Symptoms and Course.-The inner surface of the lid presents a general redness, with enlargement of the papilla. In typical eases there is the appearanee of the blueish white film, like a thin layer of milk, spread over the conjunctival surface. Both eyes are affected, though sometimes one more than the other. In a considerable portion of the cases the ocular conjunctiva appears normal. In typieal eases, however, it presents lyperemia, and at the corneal margin a plicated thickening and in- 
creased redness, which may be pigmented. There is considerable smarting pain and inereased lacrimation during the leight of the attack.

In the palpebral form, the epithelial layer may be greatly thickened, and large flattened masses appear on the tarsal portion of the upper lid, especially toward its posterior margin. Bad eases remain troublesome throughout the year, becoming aggravated in the warm season.

Treatment.-No plan of medicinal treatment, either general or local, can be relied on to ent short the disease. The discomfort ean often be diminished by cutting off the larger masses of thickened epithelium, or local application of yellow oxid of mereury ointment, solutions of tamin or sodium hyposulphite, 5 to 10 per cent. The

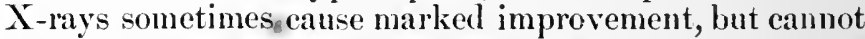
be relied on to cure the disease. Where possible, the patient should spend the summer in a cooler elimate, as at the monntains or seashore. Any excess of clothing should be aroided and diet carefully attended to.

Prognosis.-The prognosis as to ultimate recovery without permanent damage is good, but the duration of the attack camnot be foretold, and there is a liability to recurrence of the trouble year after year.

Follicular conjunctivitis is a form of subacute or chronic conjunctivitis in which pale, translucent follicles, or masses are found in the folds of the conjunctiva where it passes from the globe onto the lid. 'The appearance of the follicles is very noticeable in comparison with the hyperemia present. 'The condition is essentially a catarrhal conjunctivitis, and amenable to the same treatment. But the presence of the enlarged follieles justifies its separate classification to emplasize its difference from trachoma.

Trachoma (Granular Conjunctivitis, True Granular Lids, Chronic Blennorhea, Chronic Ophthalmia, Egyptian Ophthalmia) is a specific inflammatory disease of the conjunctiva, arising from infection, and rumning an extremely chronic eourse. Its bacterial canse is still mnecrtain, but the contagion exists in the secretions. It arises under 
bad hygienic conditions, and where people are crowded together, as in the steerage-passage across the ocean, in barracks, schools, and orphan asylums. From such centers of contagion it extends in communities that present favorable conditions for it by reason of overcrowding or lack of cleanliness. Race exerts an important influence, it being common among the Italians, Irish, and people of Northern Europe, and very rare among American negroes. Climate, and probably the amount and character of the dust in the atmosphere, have some influence upon it. But it is not, as some have supposed, only found at low altitudes.

Symptoms and Course.-Many cases arise insidiously, so that the patient does not recognize that there is anything the matter until the ease is well developed. In a majority, however, the first effect of the specific virus is an inflammation that cannot be distinguished from acute catarrhal, or purulent conjunctivitis. Such inflammation, however, declares its character by running a slower course, with gradual thickening of the conjunctiva and deeper tissues, moderate mucopurulent discharge, and the progressive development of the characteristic granulations. These granulations vary in size, from the smallest perceptible to three or four $\mathrm{mm}$. in diameter. They are more or less deeply embedded, but mostly protrude somewhat. Their appearance is illustrated in Fig. 87.

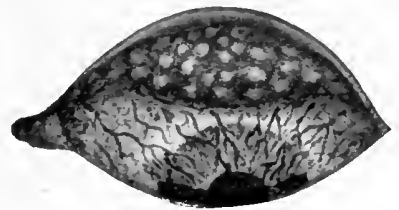

Fia. 87.-Trachoma, showing the traehoma-granules on the everted upper lid, with pannus extending on the upper part of the cornea to below the mar. gin of the pupil.

They have the gray color and translucency of sago grains, when partly soaked in water. They are largest where the conjunctiva passes from the eyeball to the lids. 
The entire surface of the lids, particularly of the upper, may be studded with them; but they are never massed together and mutually compressed, like the papillary granulations seen after purulent conjunctivitis (see Fig. 86). They are much larger than the papillæ of ehronic conjunetivitis, and their presence in other parts than the retrotarsal folds distinguishes them from the enlarged follicles of follicular eatarrh.

As the entire surface of the lids becomes seriously involved and considerably roughened, corneal complica-. tions are apt to arise, endangering the sight. These are described under the headings of pannus, corneal ulcers, and opaeities (Chapter $\mathrm{X}$ ).

The full development of typical granulations and corneal complications usually requires several weeks or months. When this stage has been reached the ease may remain without essential change for years. In a majority of cases the trachoma granules, which consist of masses of leukoeytes, undergo partial organization into connective tissue. The contraction of this tissue may stop the formation of granules, but always learls to deformity of the lids. Ultimately all appearance of the granules may vanish and the entire surfice of the lids become smooth, presenting the appearance of chronic eatarrhal conjunetivitis, and only the sequels of the disease, lid-deformity, conjunctival contraction, and corneal irregularity, may remain. These will remain, however, thronghout life.

The above description refers to a typical case of trachoma. Each feature included in it may at some time be lacking. In some cases that appear, from association, to be due to trachoma virus, the granules never develop, the case running the course of a chronic catarrhal conjunetivitis with considerable discharge, and perhaps with involvement of the cornea. In a considerable portion of eases, the disease, although characterized by well-developed trachoma granules, seems to give little or no discomfort a large part of the time, the patient only noticing its existence during the exacerbations of acute inflammation, which oeeur at intervals. Oceasionally these cases 
go on to an enormous, almost horny thickening of the lids, before seeking treatment. In a few patients without efficient treatment, and in a large proportion under such treatment, the disease runs its course in a few months without involving the eornea, and leaves but very slight contraction of the conjunctiva, or deformity of the lids. In other cases the inflammation is intense, the discharge excessive, the cornea becomes involved early, and only prompt and vigorous treatment can prevent complete blindness. In some cases the trachoma granules, although present, are deeply embedded beneath the thickened opaque eonjunctiva, or in the masses of fibrous tissue that have developed in the lid, so that they are not seen.

Diagnosis.-The presence of the typical trachoma granules already deseribed scattered over the surface of the lids is sufficient to establish the diagnosis. If they are confined to the retrotarsal fold, the case may be merely one of follicular catarrh. Involvement of the cornea with a history of eatarrhal eonjunctivitis, and marked cicatrieial contration, is also charaeteristic. In the early stage marked objective changes. in the conjunctiva with little discomfort point toward trachoma. Sometimes the termination of the case must be known before a diagnosis can be arrived at. The history of opportunity for infection is a valuable indication. But the patient's statement as to the duration of his trouble is often very erroneous.

Treatment.-In the early stage, before the granules have developed sufficiently to render the diagnosis positive, applications of silver nitrate may be resorted to. Whenever the granulations are noticeable, or if they exist hidden under the conjunetiva or in the thickened lid, the progress of recovery will be hastened by mechanieally pressing out the granules. This may be done with the thumb-nails, catching the thickness of the lid, or a fold of its inner surface, between the two nails, and by firm pressure foreing out all that can be so removed from its tissue. It is better done with some form of forceps made for the purpose. Those of Prince have smooth 
fenestrated jaws, with which one or more of the granules are caught, and by a pull of the forceps pressed out. But the writer prefers the roller-foreeps of Knapp, by which the contents of the granules are pressed out, as water is pressed out of clothing by a wringing machine (see Chap. XIX).

In a few cases the mechanical removal of the granular eontents from the lids may be followed by full recovery without further treatment; but in the large majority of cases it only hastens the recovery, which must be brought about by astringent applications; faithfully continued as long as necessary. Removal of the trachoma granules has been effected by free incisions, scraping, or brushing, (grattage and brossage); but these methods are not more efficient than expression, and are more likely to be followed by excessive cicatricial changes.

For eases in which the lids contain little or none of the granular material, the application of astringents is to be relied upon.

These must be thoroughly applied to the whole affeeted surface of the everted lids, any excess being washed away or neutralized. Among such applications, that of the crystal of copper sulphate (bluestone) has been found most beneficial. At the height of an attack it may be applied every day; but usually every seeond or third day is sufficient. Next to it in general usefulness the writer would place the solution of tannin in glycerin. This latter application is more useful when the discharge is slight and the conjunctiva comparatively smooth. Where the thickening is chiefly in the conjunctiva and the discharge considerable, solutions of silver nitrate are most beneficial. A solution of iodin in glycerin or in liquid petrolatum, applied to the everted lids every day or two, has a very decided curative effect. The application of a strong solution of mercuric chlorid has been highly recommended. A solution of 1:500, or even stronger, may be brushed over the conjunetiva, and all excess washed away; but such an application is quite painful. Excision of the affected retrotarsal fold and of the tarsus 
is proper in some cascs. Applications of the X-ray and radium are credited with some cures, but ficil to control the bad cases. The eyes should be kept cleansed of any noticeable discharge by solutions of boric acid or trikresol. In the more chronic cascs, the correction of marked errors of refraction may exert a beneficial influence; and in any case, the avoidance of dust or of a smoke-laden atmosphere will be helpful. An important part of the treatment is that of the alterations produced in the cornea and the lids. These will be considered under their respective headings. But if the palpebral fissure is markedly contracted, interfering considerably with the eversion of the lids for treatment, a canthotomy, or better, a canthoplasty, should be done to increase the efficiency of local applications. If displacement of the lashes is such as to cause them to rub against the cornea or conjunictiva, their restoration to normal position may be a necessary part of the treatment.

Prognosis.-Treatment must usually be continued for months, often for ycars. It is impossible to foretell when it may be safely stopped, and premature suspension will be followed by relapse. In all but the mildest cases, noticeable cicatricial changes in the conjunctiva and lids will remain.

Petrifying Conjunctivitis.-This is a rare chronic disease, characterized by chalk-like deposits which canse white spots in the palpebral conjunctiva, each surrounded by a reddened, swollen zone. Most cases end in recovery, but the eyeball may become involved and the eye lost. It does not seem to be contagious, and the cause is unknown.

Phlyctenular Conjunctivitis (Phlyctenutar Keratoconjunctivitis, Phlyctenular Ophthalmia, Strumous or Scrofulous Ophthalmia, Conjunctivitis Lymphatica).-This affection is excited by many of the causes of eatarrlaal conjunctivitis. It oceurs chiefly in children with an underlying tendency to catarrhal affections of all mucous surfaces, eezematous eruptions, and glandular enlargements.

It is characterized by chronic hyperemia of the pal- 
pebral conjunctiva; and recurrent exacerbations, including the development of phlyctenules on the ocular conjunctiva and cornea and occasionally on the palpebral conjunctiva, with symptoms of acute conjunctivitis.

Symptoms and Course.-The phlyetenular attack usually begins with irritability of the eyes, photophobia, and excessive lacrimation. In one or two days there develop on some portion of the ocular conjunctiva, usually the corneal margin, or upon the cornea itself, vesicular elevations with a red and swollen base. The vesicle, or phlyctenule, quickly becomes an uleer, the contents escaping. The deeper swelling causes the ulcer to appear elevated above the general surface. The redness which is most intense in a limited sector of the conjunctiva, running forward to the phlyctenule (see Fig. 17), continues to increase for two or three days and becomes general. The discharge is slight and is washed away in the excessive How of tears. In a severe attack, a crop of phlyctenules may be scattered all around the margin of the cornea. At the height of the attack, the whole of the conjunctiva may be hyperemic and thickened. In a few days this general redness subsides, but the sectors of enlarged vessels ruming out to the region of the phlyctenules, continue some days longer. These with the swollen tissue of the phlyetenules, gradually return to normal, the whole attack lasting from one to three weeks, mnless prolonged by the formation of a corneal ulcer. The photophobia is often so severe that the child buries its head in a pillow and refuses to use its eyes, even in a darkened room.

Before the termination of the first attack a second may begin, so that the eye is kept continnally red and painful; or there may be an interval in which the eye is apparently normal before the trouble recurs. During the interval the inner surface of the lids will be found hyperemic, the visible vessels being larger and more numerous than normal, and there may be a slight conjunctival discharge causing adhesion of the lids in the morning. In the attack the conjunctiva is always in- 
volved, but the danger of the prolonged inflammation and damatge to the sight lies in the involvement of the cornea (see Chap. X). The conjunetival affection will, in time, if not aggravated by injudicions applications, end in recovery, with restoration of a smooth but sometimes slightly contracted membrane.

Diagnosis.-The diagnosis from acute catarrhal conjunctivitis rests on: the distribution of the hyperemia (see P. 61), the oceurrence of the phlyetenules or the ulcers that succeed them, the excessive photophobia and lacrimation, the history of previous attacks, and the presence of enlarged vessels in normally transparent tissue on the inner surface of the lids. To make a satisfactory examination of a child's eyes, it will often be needful to put it in the position for making applications to the conjunctiva, and sometimes to use a lid elevator. The habitual tight closure of the lids frequently gives rise to a macerated condition of the skin near the outer eanthus, with the formation of fissures or rhagades radiating from the outer canthus.

Treatment.-Every case of phlyetenular conjunctivitis requires the careful consideration of the general nutrition, and of local influences outside of the eye and its immediate appendages. A proportion of cases will recover without other treatment if placed on proper diet. This should consist largely of milk and well-cooked farinaceous foods. The strict prohibition of tea or coffee, and fried foods is very important; and the restriction of sweetmeats, cakes, and candy, which should be taken only at the close of a meal and with plenty of water. Care of the diet may be supplemented by the administration of remedies addressed to the alimentary canal, as small doses of calomel, followed by some other laxative, and the digestants where indicated.

Next in importance is the careful treatment of the nasal passages. These will often present a chronie thickening and hyperemia of the mucous membrane, which, although often but another expression of the general disorder, especially hinders the return of the conjunctiva to 
normal, and should receive appropriate local treatment, including cleansing, alterative applications, as iodin, compound tincture of benzoin, ete., and spraying with liquid petrolatum.

Where the patient presents distinet evidence of glandular involvement and anemia, general tonies, especially syrup of iodid of iron, or hydriodic acid, with quinin, shonld be given. Iroeal treatment to the eye is not less important. Of greatest benefit are applications of the ointment of yellow oxid of mercury, commencing with a weak preparation, and increasing its strength until the application causes some little smarting. The ointment is to be applied onee daily, usually at bed-time, by drawing down the lower lid and placing witl: $n$ it a piece the size of a grain of rice or slightly larg $r$. The eye is then closed and the closed lids are rubbed over the globe, until the drug has been diffused to every part of the conjunetiva; and the portion escaping between the lids is rubbed well into their margins.

If the inflammation of the conjunctiva is severe, applications of a solution of tannin in glycerin should be made every two or three days to the everted lids. The use of the mercuric oxid must be continued during the intervals between the attacks, and oceasionlly for weeks or months after the eyes seem free from inflammation. In the more severe ehronic cases it is well, also, to continue the application of glycerin and tanmin. Where the photophobia is severe, the fissures in the skin of the lids near the outer canthus greatly aggravate the trouble. These should be tonched either with tamin in glycerin, or with 1 or 2 per cent. solution of silver nitrate. The making of applications to the lids in these cases is often somewhat difficult; and the means for assuring efficiency in applications to the eyes of children, mentioned in Chapter XVIII, must be resorted to.

Prognosis.-The individual attack of phlyetenular disease is ustally recovered from within two or three weeks; but subsequent attacks are extremely probable. 
Permanent damage always depends on the lesions of the cornea.

Pterygium.-Pterygium is an extension of conjunctival and subeonjunctival tissue upon the cornea, triangular in shape, with the apex toward the center of the cornea, and the base at the eorneal margin, usually toward the nasal side. Its appearance and usual situation are shown in Fig. 88.

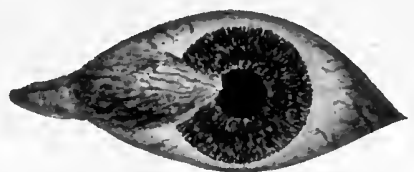

Fig. 88.-Pterygium extending over the margin of the pupil.

Symptoms and Course.-Pterygium sometimes follows corneal ulcers. It also follows traumatism, and probably arises from the presence of minute foreign bodies, and ehronic irritations without previous loss of eorneal tissue. In some way it seems to be largely influenced by elimatic or local conditions, being much more common in some places than in others. It is slowly progressive, often for a long time; but finally it becomes stationary usually before it has encroached much upon the area of the pupil. The eonjunctiva covering it is generally quite vasenlar and supported by a thick mass of subeonjunctival tissue, and this vascularity and thiekening extend upon the selera to the region of the caruncle.

It is probable that the thick developing mass of connective tissue underneath it is a factor in the drawing forward of the conjunctiva upon the cornea. The vascularity and prominence of the pterygimm vary from time to time, being greatest during the period of growth and often mueh diminished at later stages when the growth seems to undergo partial atrophy. It is loosely comnected with the cornea, which, after its removal, may be found normal except for the alsence of the epithelium and a slight disturbance and haziness of 
its superfical layers; the portion overlying the selera is, however, pretty firmly connected with it. It may occur in early adult life, but is more common after middle age.

Pterygium is not painful, and so long as it does not approach the region of the pupil, is only unpleasant because of its appearance. If it eneroaches upon the pupil, sight is impaired; and often before the growth reaches the pinpillary margin, an area of astigmatism which alvances before it, may impair vision, partienlarly when the pupil is somewhat dilated. When very extensive it mav cause limitation of the movements of the eyeball and diplopia in the peripheral portions of the field of fixation.

Diagnosis.-Ptergyium is to be distinguished from superficial vascular leratitis by its appearance of lying upon the cornea, having a margin distinctly elevated above the corneal surface. It differs from dermoid of the corncal margin in its greater vascularity, in the distribution of its vessels, and in its triangular shape as contrasted with the rounded or ovoid form of the dermoid. From pingnecula it differs in extending on the cornea, which pinguecula never does (see Fig. 89).

Treatment.-If small and not progressive, removal is not to be urged. During periods of exeessive hyperemia, the treatment may be that of a mild subacute conjunctivitis. If progressive, and partieularly if already approaching the pupillary margin, it should be removed. This may be done by excision or transplantation. Ligation, formally practiced, is not to be advised. The advantage of transplantation is that, should the pterygium again develop, requiring a second operation, the parts are left in a more favorable condition for it. After excisions, the loss of substance makes a second operation more difficult, and more liable to cause impairment of the ocular movements. For a very large pterygium, the most effective method is to excise it and by an epithclial skingraft, or, better, a graft from the mueous membrane of the lip, to eover the denuded portion of the sclera. The aftertreatment includes regular eleansing of the eonjunctiva 
and the removal of the sutures, usnally on the second or third day. There is at first some swelling, but this rapidly subsides. Small pterygia may be cheeked by eleetrolysis, or the apex of the growth may be destroyed by the galvanic or actual cautery.

Prognosis.-In a large proportion of eases pterygim, if left to itself, never interferes seriously with the vision, and operation is only of benefit in that it removes an unsightly deformity. The rate of development or its ultimate size cannot be surely predicted. 'The seemity from reenrrence depends much on the eompleteness of the removal of the mass of connective tissue overlying the selera.

Pinguecula is a yellowish elevation of the conjunetiva to the nasal side of the cornea, eaused by an aceumulation of connective tissue and fat. It is shown in Fig. 89. When slightly inflamed, it may become prominent,

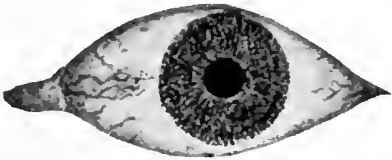

FIG. 89.-Pinguecula with large conjunctival vessels to the nasal side of the cornea.

and cause disfigurement. It may develop into pterygium, but usually it requires no treatment.

Pemphigus, in very rare cases, affects the conjunctiva, isolated spots become affected, quickly lose their epithelimm, and undergo slurinking; then other portions of the membrane undergo the same changes until the conjunetival sae is obliterated, the sight lost, and the lids bomnd down elusely to the globe. The disease occurs in eachectic patients, who suffer from pemphigus affecting the skin. Hygienic measures and internal remedies, especially arsenic, are chiefly to be relied on. Loeally, soothing collyria may be used, and if the disease is once thoroughly checked, skin-grafting into the eonjunctival sae may be resorted to. . 
Xerosis, or essential shrinking of the eonjunetiva, has been reported as occurring independently of pemphigus, and oecasionally as the final stage of that disease. The comea participates in the process, becomes dry and opaque, and sight is lost.

\section{Tuberculosis and Lupus of the Conjunctiva.-} Tubereular lisease of the eonjunetiva is mire, yet oceasionally cases ocenr. The course of the affeetion is very ehronie, and its general characters resemble those of trachoma; but it lacks the eharaeteristie trachoma-granules, is less liable to involve the cornea, and is more regular in its course. The palpebral conjunctiva is chiefly affected, and the lids appear swollen and firm to toneh. The infiltration as seen from the conjunctival surface, while nodnlar, is red or yellowish-gray, and does not resemble the sago-grains of trachoma. The surface often becomes nlecrated, whieh is not the case with trachoma; and the lymphatic glands in front of the ear are apt to be affected early.

Tubercle bacilli may be found in the seeretion, but they are few in number and may escape detection. Inoculation of the diseased tissue into the anterior chamber of the rabbit is a nore reliable test. In most eases there is evidence of tuberenlar disease in other parts of the body.

Treatment.-Locally, soothing applieations and mild antiseptics may be used, while the general treatment of tuberenlosis, including diet, reginen, and climatie influences, shonld be carefully earried ont. Speeific treatment by injections of tubereulin may be resorted to. If, in spite of these measures, the conjunetival lesions remain mnimproved, the affected tissne may be exeised or canterized with earbolie aeid, and dressed with iodoform.

Syphilis of the conjunctiva may oceur at any stage of the discase. The primary sore oceurs most often near the immer canthus, or in the lower enl-de-sac. It presents an ulcer with a hard hase and glandular involvement, lasts several weeks, and is eomparatively painless. In connection with skin-ernptions there may be a elnonie catarrhal conjumetivitis not influenced by local treatment 
or the removal of ordinary causes; but curable by antisyphilitic treatment. Gumma is very rare; but chronic nlcer with great infiltration sometimes occurs in late syphilis, and may be mistaken for cancer.

Amyloid degeneration of the conjunetiva is a rare condition, characterized by the deposits of amyloid material in the conjunctiva and lids. It is usually associated with trachoma, but may occur independently. 'The lids are thickened and rigid, the cxudate being yellow in color and occurring in larger masses than the trachomagranules, being continuous bencath the whole surface. There is usually a history of previous disease, and absence of the discharge and symptoms of acute inflammation, which mark the progress of trachoma.

Symblepharon.-If in any way the conjunctiva is destroyed on both the eyeball and the inner surface of the lids, especially if such destruetion involves the retrotarsal fold, the resulting cicatrix is liable to bind the lid to the eyeball (see Fig. 90). 'This most frequently occurs

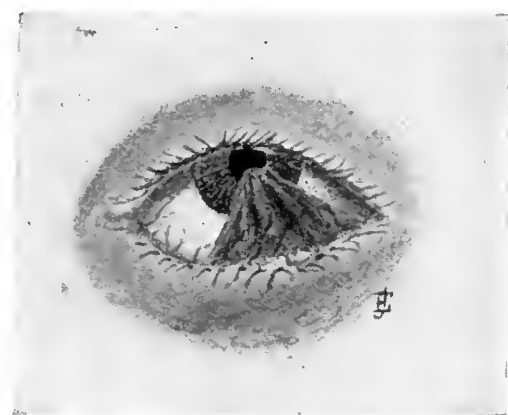

Fig. 90.-Symblepharon.

after burning of the conjunctiva with hot metal, lime, or other caustics, the lower part of the conjunctiva being usually affected. Sometimes the adhesion extends onto the cornea, and may even cover the whole of it, preventing useful vision. Even when this does not oeeur, the limitation of the movement of the eyeball may causc annoying 
diplopia. The conneetion between the eyeball and the lids is brought out most strongly by drawing the lid away from the globe, when it is rotated away from the adhesion. Such adhesions continue to contraet and become more annoying, often for many months, and the prognosis with referenee to them should be guarded.

Treatment.-Much ingenuity has been expended to prevent the formation of such adhesions between the lids and eyeball, by: repeatedly breaking them up, or continuously wearing some form of metal shield. But little ultimate benefit has resulted from such measures. Where the connecting bridge of the conjunctiva is entirely isolated, so that a probe ean be passed beneath it (anterior symblepharom), the division of the bridge gives complete relief. If the fold extends to the conjumetival enl-de-sac (posterior symblepharon), but is comparatively narrow, it may be possible to make a permanent opening behind it, by wearing for six weeks or longer a piece of lead wire passed through its base; or it may be divided near its base, and the conjunetiva from opposite sides brought together, making an isolated bridge of the adhesion, which can subsequently be divided. In a majority of eases requiring operation such methods are inapplicable, and the best result is to be obtained by freely dissecting the joining fold away from the eyeball, allowing what there is of it to go as epithelial covering for the lid, and covering the denuded area of the globe by mucous- or skin-grafts. The mere division of a symblepharon gives only temporary benefit.

Edema has been referred to in eonneetion with conjunctival inflammation. It may, however, oecur apart from this, in cases of paralysis of the ocular muscles, as an effeet of certain drugs, particularly potassium iodicl and quinia, or as a variety of so-called angioneurotic edema. Emphysema of the subconjunetival tissue may oceur from injury in the nose.

Ecchymosis.- Small hemorrhages into the conjunetiva and deeper tissues mark the eourse of all severe conjunetival inflammation, and especially that of acute 
contagious conjunctivitis. More extensive extravasations of blood oceur by the rupture of blood-vessels during coughing, vomiting, etc. in purpuric conditions, from general vascular degeneration sometimes preceding henıorrhage into the brain or other vital organ, and even without any discoverable eause. Such extravasations require no treatment, undergoing complete absorption, without eausing unpleasant symptoms other than the disfigurement.

Tumors.-Benign tumors occasionally occur in the conjunctiva. Clear cysts form especially in the lower eul-de-sac. Angiomas involve the lids, and are considered in that connection. Dermoids usually involve the corneal margin. Fibromas occur as snall polypoid growths, and osteoma has been met with. Papillomas grow in masses with a strueture and surface resembling cauliflower. They start usually from near the immer canthus, but may extend so as to hide the cornea. They recur unless very completely removed. Lipoma is seen on the outer portion of the eyeball. Cysticercus occurs rarely. On the West Coast of Africa the "eye-worm," filaria, is acquired. It may be seen at times rapidly moving under the conjunctiva. These tumors and parasites are to be treated by removal.

Epitheliona may start from the conjunetival margin of the cornea; in this situation it is sometimes pigmented. Sarcoma arises from exposed portions of the conjunetiva and is usually pigmented. Such tumors of the conjunctiva usually devolop very slowly. Their early removal without saerifieing the eyeball may be tried, but if there be doubt as to the completeness of such removal, extirpation of the eye, with the growth, is necessary.

Concretions in the Conjunctiva.-On everting the lids one may often detect one or nore yellowish masses, the size of a pin-liead, lying in the conjunctiva. These are accumulations, in small divisions of the Meibomian glands, or in the other glands of the mueous membrane. They are at first of cheesy consistence, and may remain a long tine without making any disturbance, 
although patients not rarely diseover them, and aseribe to their presence symptoms due to other causes. They may, however, undergo ealeareous ehanges; and, by thimning of the membrane over them, come to aet very mueh as foreign bodies in the conjunctival sac, causing irritation, redness and discomfort. If this oecurs, each offending mass should be removed. It is readily turned out of its bed with the point of a needle.

Burns of the conjunctiva may occur, from hot steam, ashes, powder, other explosives, or drops of molten metal. Similar injuries may be caused by contact with some caustic, such as strong mineral acids and alkalies, and especially lime. Whether the injury be by heat or a ehemical caustic, the affected tissue will be found rather pale and opaque, and edema of the adjoining tissues quickly develops. The danger of such injuries lies in the involvement of the cornea and in the liability of their causing symblepharon. The resulting inflammation, unless very severe, is usually limited to the immediate seat of the injury, which is the eonjunctiva of the eyeball, exeept when molten metal or caustic has run into the lower eul-de-sae, involving also the palpebral portion of the membrane. A like distribution of the redness and swelling characterizes the resulting conjunctivitis.

Oceasionally a sharp attack of conjunctivitis is caused by sunburn. 'The hyperemia is most severe in the portion of the conjunctiva exposed to the sun's rays; but there may be general swelling of the membrane, and aeute burning and smarting.

Treatment.-As promptly as possible any foreign particle remaining at the seat of injury should be removed, and a ehemieal caustic thoroughly neutralizer. The stronger acids may be removed and neutralized by thoronghly washing with a solution of borax, and the alkalies by washing with milk or sweet oil. 'The action of lime may be cheeked by dropping sweet oil or a solution of eane sugar into the eye. Particles of lime become firmly united to the esehars they cause, but their removal should be accomplished. After this the eye may be treated with 
borax and boric acid solution, to thoroughly cleanse it, and a drop of liquid petrolatum instilled to protect the exposed nerve-endings. Eschars should not be disturbed any more than is necessary for removing foreign particles, or neutralizing the eaustic eausing them.

Other injuries and foreign bodies are considered in Chapter XVII.

Discoloration of the ocular conjunctiva by pigment deposits is common in the colored race; and occasionally occurs in the white. A more general and uniform brownish discoloration is eaused by long continued applications of silver nitrate. In Addison's disease and in various forms of anemia, the conjunctiva is transparent, and the sclera seen through it, pearly white. This is to a considerable extent normal in young children, the conjunetiva and subconjunctival tissue becoming thickened, more vascular and yellower with age.

Diseases of the Caruncle.-Inflammation of the earuncle occurs with conjunctivitis. It is marked by redness and swelling. It is particularly noticeable in eonjunctivitis from eye-strain, when the other evidences of conjunetivitis may be slight and easily overlooked. Occasionally the caruncle is the seat of abscess. Chronic non-inflammatory enlargement is called eneanthis. Occasionally numerous short hairs spring from the caruncle. They may be so directed as to canse redness and irritation of other parts.

\section{CHAPTER X.}

\section{DISEASES OF THE CORNEA AND SCLERA.}

\section{General Conditions Regarding the Cornea.-} The cornea is composed chiefly of a tissue closely allied to white conmective tissue, is normally devoid of bloodvessels, and is covered with a layer of conjunctival epithelium. With the latter point may be associated its liability to involvement in conjunctival disease. Its lack 18 
of ressels canses the location of hypermia connected with morbid processes affecting it, to be in the zone immediately surronnding it, where ramify the vessels from which its nutriment is drawn. This separation of the tissue from its base of supplies canses its particular liability to undergo ulceration and to slough. Corneal inflammations are liable to rnn the chronic course that inflammations do in white fibrons tissnes in other parts of the body. Its transparency depends upon a delicate balance of nutritive processes, likely to be disturbed by any departure from the normal; and rarely entirely regained when any considerable portion of its tissue is replaced by the new-formed connective tissue of a scar. Many of the inflammations in it are characterized by loss of substance giving rise to comeal nlcers. Where this does not oceur, or after the replacement of tissne lost, the prominent symptom is the opacity.

Finally the corncal tissue is compelled to sustain the ontward pressure of the intra-ocular fluids, and when softened by disease it gives way before this pressmre, eausing changes of shape and permanent disturbances of its nutrition. And whencerer corneal inflammation lasts for any considerable time there is a tendency to extension of the blood-vessels upon and into the corneal tissue. These vessels continne to develop until the inflammation has passed its height, and the process of repair is well started; then they diminish in size and number, and may entirely disappear.

The special conditions affecting the cornea cause peculiarities in the symptomatology and therapentics of corneal inflammations that must be strongly emphasized, lest they be overlooked or neglected. That the absence of ressels in the cornea causes the redness of keratitis to appear as a pericorneal zone, has long been recognized; but attention has only recently been drawn to the significance of the corresponding ring exudate; so-called ringabscess of the coinea. An acute, severe injury to the cornea, whether by infected wound or the toxins of virulent bateria otherwise introdncerl, canses an abundant immigration of lencocytes. These, pressing toward the corneal 
eenter, leave the corneal margin comparatively clear, while necrosis or irreparable damage to the central portion of the cornea checks or arrests their progress, massing them in a ring of exndate. 'This ring may be incomplete in some particular direction, or other influenees may ehange its shape, so that the front of the cell exudate may appear as an irregular or a straight line; or as two lines meeting at an angle.
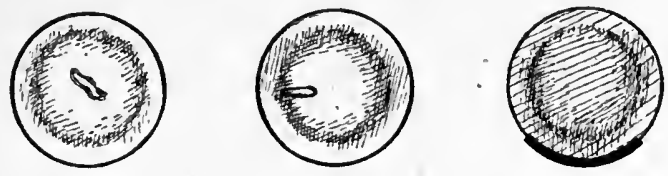

FIG. 90 a.-Ring abscess of the cornea.

The temperature of the cornea, at least while the eye is open, is decidedly lower than the general body temperature. 'To this lower temperature, unfavorable to the development of many of the pathogenic bacteria, especially the gonococcus, may be aseribed a part of the immunity of the cornea from infection. 'The alvantage of such immmity is wholly lost when the eye is kept closed under a warm bandage. Indeed, it is probably only maintained by iced applications to the closed lids so long as the lids are not materially thickened by exudate. It is best preserved when the eye is kept open most of the time, exposed to comparatively cool atmosphere. This therapentic advantage is given up whenever we use a bandage or fix a dressing upon the eye.

The mechanical cleansing of the cornea by the margin of the lipper lid during the act of winking is wonderfully complete. Upon the smooth cornea with normal nictitation, it is almost impossible for germs to find lodgment in injurious amounts. Conjunctival swelling at the limbus, or any abrasion of the corneal surface, permits bacterial colonies to gain a foothold. Hence, avoidance of the slightest mechanical injury to the corneal margin; or its exposure by incision, redueing ehemosis, are therapentic indications of great practical importance. The cleansing influence of normal nictitation is also lost by the use of fixed dressings. 
CORNEAL ULCERS.

Simple U1cer of the Cornea (Non-suppurating Ulcer, Ulcerous Keratitis). - This condition consists essentially in loss of a portion of the corneal epithelium, and of the true corneal tissue beneatl. It may arise from traumatism, either external or that due to a rongh or deformed lid; or from a local inflammatory process, attended with disintegration of tissue, as in phlyetenular keratitis, or herpes of the cornea ; or as a complication in acute conjunctivitis.

Symptoms and Course.-The loss of corneal substance is to be detected by the irregularity or break that it causes in the reflection from the cornea of a window or lamp-flame when this is reflected from the part involved. It is commonly attended with pain of a burning, smarting or aching character, dread of exposure to light and air, and excessive lacrimation.

An ulcer may properly be elassed as simple when not surrounded by markedly infiltrated and disintegrated tissue, when it does not tend to materially extend after its first formation, and is not complicated by perforation or other accident. In its carliest stage its surface lacks the polish of the normal cornea. But as soon as the process of repair is fairly started the bottom of the uleer appears glazed over, giving as bright a reflection as does the cornea around it, although its surface may be quite noticeably depressed.

During the process of repair, the excavation fills up until the surface of the nleer becomes continuous with that of the surrounding cornea. This is accomplished by the formation of new tissue beneath the epithelial layer, which new tissue is at first not perfectly transparent, but rather gray in color; so that the opacity attending such an ulcer tends to increase throughont the period of healing, and is most noticeable several days, or sometimes weeks, after pain and other evidences of inflammation have disappeared.

The existence of an ulcer is quickly followed by 
hyperemia of the nutritive vessels of the eornea, causing a red or pink pericorneal zone. If the uleer be situated near the center of the cornea this zone will be almost equally pronounced all around the corneal margin. If the ulcer be close to the corrieal margin, the portion of the pericorneal zone adjoining it will be chiefly, or alone reddened; and as the ulcer heals, the redness will disappear last in this loeality. Pain is usually considerable, and in some forms, especially where there is a broad shallow excavation as by an infant's finger nail, or in the ulcers that occur with chronic conjunctivitis in old people, pain may be very severe. It is generally accompanied by photophobia and excessive lacrimation.

Diagnosis.-The careful inspection of the reflex from every part of the corneal surface will usually reveal the loss of substance. If there is difficulty about discovering it in this way, a drop of a solution of fluoresein will stain the cornea green over the whole ulcerated surface revealing exactly its extent. It is sometimes diffienlt to distinguish an old opacity of the cornea from one due to recent infiltration. On this account the inspection should be made by daylight, or white artificial light, to recognize the true color of the opacity.

Treatment.-If a corneal uleer be due to traumatism, any foreign particles remaining in it shonld be removed. The tendency to recover is strong, and, beyond cleansing, little active treatment is required. Still every uleer, however simple it may appear, is in danger of becoming complicated by infection, and of extending so as to cause perforation of the cornea, and, therefore, should be closely watched. To guard against infection, the eye should be eleansed with an unirritating solntion, such as one of boric acid or sodinm chlorid, and kept closed between the times of making applications to it, by a very light dressing.

A mydriatic, such as atropin or duboisin, should be instilled two or three times a day if there is deeided redness and irritation. Pain if not eompletely relieved by the mydriatic, may be met by applications of heat, either 
bathing with hot water, or the more eontinued applieation of dry heat. Often the proper treatment of the condition, either constitutional or local, which eauses the ulcer, will be more important than the tratment of the ulcer itself. Rest and a tonie treatment are usually indicated.

Suppurating U1cer (Perforating Uleer, Infecting or Sloughing Ulcer, Ring Ulcer, Creeping Ulcer, or Serpiginous Ulcer).-In this seetion are considered lesions of varied eharaeter and due to many distinet canses, but all charaeterized by a tendeney of the ulcer to extend by the disintegration of neighboring tissue. The direction in which sneh extension oceurs depends somewhat on the cause of the lesion and has given rise to elassifieations into varieties according to the form assumed. But while these different varieties vary somewltat in their elinical aspeets, in their essential dangers and treatment, they are largely similar. For one who has large elinieal experienee and fair aequaintance with the subject, each of the terms at the heal of this seetion may serve to present a distinct clinieal pieture. But for the student or practitioner of moderate experience in dealing with comeal. ulcers, the essential facts will be best grasperl by a general description of those features which all varieties have in common, with brief reference to speeifie differences.

Symptoms, Varieties, and Course.-Suppurating uleer may start from an injury, from an apparently simple uleer, from the opening of a comeal abscess, or from the sloughing of injured or severely infiltrated tissue. It presents the symptoms of simple nlcer, but often of greater severity and more rapid development. The floor of the uleer (when wiped dry) is devoid of luster, and is infiltrated. 'The tissue at the margins is also clouded or opaque with infiltration. The infiltration may be gray or distinetly yellow, the latter color indicating a stronger tendeney to pus formation and rapid breaking down of tissue.

The direetion in which the infiltration is most marked 
is that toward which the ulcer is most likely to extend. If unchecked, the infiltration and disintegration of tissue may rapidly involve large parts of the cornea (sloughing ulcer), may extend to deeper layers of the cornea, leading to perforition (perforating uleer); may extend along the corneal margin until it forms a complete girdle around the cornca (ring ulcer). It may extend rapidly by an opaque yellow margin, first in one direction, then in a slightly different direction, or even in an opposite direction, by a breaking down of the corneal tissue on one side of it, usually with some undermining of the surface, but without much tendency to penetrate the deeper layers and perforate the cornea (serpent, or creeping ulcer). So long as the ulcer has an opaque, sharply excavated, or undermined nargin, and the adjoining tissue remains devoid of vessels, the process is extending. When the tissue adjoining the ulcer is found clear, or has become distinctly vascular, the extension of the dilcer is checked. When the floor of the ulcer (after wiping it with absorbent cotton) is found smooth and reflecting like the surface of the cormea, the process of repair is fairly begun.

Perforation is the great danger of the corneal ulcer, being followed by the most disastrous effects. No corneal ulcer can be regarded as free from this danger so long as it is extending or is opposed by inadequate power of repair. The thickness of the normal cornea is usually about 1 millimeter, but a cornea previously diseased, or even a normal cornea, may be much thinner than this, so that perforation may occur when not expected. On the other hand, some forms of corneal ulcer have swollen margins, so that with a depth as great as the normal thickness of the cornea, no perforation may ocenr.

The deepest layers of the cornea, and particularly the membrane of Descemet, usually resist the process of disintegration longer than the more superficial portions, so that after the ulcer has reached them its further progress may be checked. When, however, the floor of the ulcer is wide, the thin layer of tissue forming it is unable to 
resist the intra-ocular tension, and may be found bulging into the uleer, concealing its real depth, until the thimned tissue gives way. In a few eases the disintegration extends quickly to the deeper layers of the cornea, and the whole thickness of the membrane separates in a single slongh. After the eornea has been perforated the uleer may eontinue to extend until the cornea has been destroyed. In other cases the process of repair now gains the advantage over the process of disintegration, and no further extension of the disease oceurs.

With perforation the contents of the anterior chamber escape, and the iris and lens are pushed forward against the cornea. If the perforation be

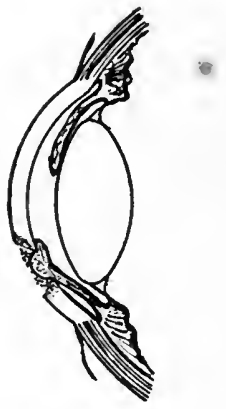

Fig. 91.-Perforating uleer of the cornea with incarceration of the iris and commencing repair. in front of it, the iris commonly becomes adherent to the margin, and the aqueous humor, acenmulating behind it, pushes it forward into the opening. This condition is shown in Fig. 91. In this situation its surface quickly becomes coated with plastic exudate, which indergoes organization, and the mass of new tissue, with the altered iris, forms the sear-tissue that replaces the part destroyed in the formation of the nleer. (See Corneal Opacities.)

With the escape of the eontents of the anterior chamber the pupil strongly contraets, so that the iris is drawn in front of the perforation unless it be very small and quite central. In that case the lens may be pushed forward and close the opening. Even when the perforation is in front of the iris, the lens-surface may come in contaet with the cornea. It then beeomes the seat of plastic exudate, and the epithelium of the eapsnle undergoes proliferation, at least, in yomng patients. 'The exudate closing the opening in the cornea, allows the reacmmulation of the aqueous humor, which pushes the lens back. from the 
corneal opening, putting the exudate connecting the lens and cornea upon the stretch, and breaking it and re-establishing the anterior chamber. The drag upon the lenscapsule in this process, with the influence of the exudate remaining upon it, tends to establish a small opaeityanterior polar cataract (see Chap. XIV).

Causes.-To the causes sufficient to produce simple ulcer of the cornea, are always added for the production of suppurating ulcer, local infection and insufficient resisting power on the part of the tissue. 'The infective agent is usually one of the pyogenic organisms, which may be derived from the discharge of a purulent conjunctivitis, or the regurgitation from a chronically inflamed lacrimal sac. Or it may be the pneumococcus which Holden has connected with serpent ulcer, tending to extend between the corneal layers; or the diplobacillus, or the diphtheria bacillus, or one of these with the pus cocci.

The deficient resisting power may be caused by pressure of severe chemosis, or greatly swollen lids upon the pericorneal vessels that furnish the nutritive supply of the cornea. It may be due to impaired innervation, as in paralysis of the fifth nerve, or with herpes zoster. Or it may be due to some specific poison acting upon the tissue through the general circulation, as in small-pox, where the cornea is liable to become involved; or to an impaired or debased nutritive supply from general disorders of the circulation, or wasting disease. It may follow unnatural exposurc of the cornea, and inability of the lids and tears to keep it properly cleansed, as by cicatricial destruction of the lids, paralysis of the orbicularis muscle, or pushing forward of the eyeball in exophthalmic goiter, or orbital tumor.

Diagnosis.-Besides the points mentioned as to the diagnosis of simple ulcer, in every case of corneal suppuration it must be carefully determined which of the above conditions share in cansing the lesion; and at each visit the surgcon must try to ascertain by carcful examination whether the infiltration that precedes loss of sub- 
stance is still extending. The exact organisms of infection ean only be determined by careful microscopic and enlture examinations of the scrapings obtained from the surface of the uleer.

Treatment.- In the carlier stages the important thing is to check the progress of the uleer. 'This will be effected by combating the causes, and by disinfection of the ulcer itself. 'Thus, in a case of purulent conjunctivitis, the treatment of the conjunctivitis must be pushed energetically. Where the infection comes from regurgitation from the lacrimal sae, the sac must have thorough antiseptic treatment. In so far as the breaking down of the comeal tissue is due to general impairment of nutrition, tonics and stimulants must be resorted to. If the ulcer is of trammatic origin, it should be thoroughly freed from any retained foreign particles.

In carrying out these measures, however, care must be taken not to do injury to the cornea itself. 'Thus, in making applications of silver nitrate to the conjunctiva in a gonorrheal ophthalmia, eare must be taken not to allow the solution to come in contact with the cornca. For the same reason the use of cold is contraindieated, and hot applications that will quicken corneal nutrition are to be favored.

The early treatment of the ulcer itself is to disinfect it, and to prevent reinfection. Many uleers do better under a light protective bandage that keeps the eye closed and excludes foreign matter. Particles of dust lodging on the normal cornea are promptly wiped away by the margin of the lid and carried off in the tears. But when there is loss of substance, the lid-margin eannot remove from the interior of the ulcer the particles which may lodge upon it, and which, therefore, remain to increase irritation and renew infection. The chief means of disinfection is the mechanical removal of disintegrating tissue by curetting, and the destruction of it by the actual cantery. For ulcers that are spreading at all rapidly, the infiltration extending beyond them into neighboring tissues, causties, like silver nitrate, or strong solutions of 
mereurie chlorid, have not sufficient penetrating power to be efficient.

The most generally applicable treatment is thorongh curetting or scraping. This may be done with a spud for the removal of foreign bodies or other blunt instrument. (See Chapter XIX.)

This operation not only removes most of the infected and infective material, but it also quickens the flow of lymph in the direction of the uleer, tending still further to limit infection. It must be rejeated as often as the area of infiltration is found to be extending; sometimes within twelve hours, usually within a day, if repetition be required at all.

Where the case can be carefully watched and the uleer efficiently scraped as often as is necessary, this mode of treatment is usually efficient. When, however, the ulcer is deep, the pressure necessary in euretting may cause the rupture of the thinned cornea; and where the patient cannot be frequently examined, or where his control over the eye is so poor that euretting eannot be thorough, the actual eautery is distinetly superior.

For the cauterization of an uleer, the corneal eautery, a probe, or a steel knitting-needle may be heated to white heat in an alcohol flame; or the galvano-cantery may be employed to touch and destroy all the infiltrated tissue (see Chap. $\mathrm{XIX}$ ). The eye niay then remain elosed for several hours, unless conjunctival discharge needs to be removed. The slough left by the cantery will in many cases prevent the very early recognition of extension of the disease. But if the application has been sufficiently thorough, subsequent extension will generally not oceur. The application of the cautery is not in itself very painful, if eare is taken not to hold the heated metal close to the eye, but to touch the affected area and then withdraw it ; and its application is usually followed by considerable relicf from pain lue to the ulcer.

The removal of softened tissue by a forcible jet of water or some antiseptic solution, called hydraulic curetting, las been highly recommended. 
Where other means fail to arrest the progress of the uleer, a powerful influence in that direetion is brought into play by paracentesis of the anterior chamber. This, by relaxing the tissue of the cornca, causes a considerable increase in the stream of lymph passing into that membrane from its nutrient vessels, and allows the free eseape of this fluid externally, tending strongly to increase the resisting power of the corneal tissue against the attack of pyogenic organisms. The anterior chamber may be opened by a broad needle or the point of a cataract-knife, inserted near its lorrer margin, and then twisted in the wound, sufficiently to allow the contents to drain away. Or it may be opened by what is called the Sacmisch incision, which must extend through the cornea across the ulcer from the sound tissue on one side to the sound tissue on the otherr side.

Opening the anterior chamber may also be indicated to relieve the tension of the cornea when the floor of a deep ulcer seems to be on the point of bursting. The operative incision is likely to heal without adhesions of the iris, which would almost ecrtainly occur should the ulcer be allowed to perforate. It may be necessary to reopen the incision on successive days with a probe to secure the full benefit of this measure. After opening the anterior chamber, as after perforation by the corneal ulcer, the extension of the disease is generally checked and recovery begins.

As a loeal application Chandler and Risley have recently recommended a 10 per cent. ointment of cassareep, both to relieve pain and favorably influence the course of the disease. $H$. Derby has claimed the same benefits from the use of holocain. A one per cent. solution of formaldehyd is sometimes beneficial ; but it causes pain which eocain will not prevent. Atropin, and sometimes eserin, are of value in relieving pain and improving the circulation.

In the way of general treatment, rest in bed is often of great importance. Abundance of nutritious food is usually indicated, and in a few cases alcoholic stimulants 
prove of value. These must, however, be used with great caution and their effeet-watched, for alcohol lessens the resisting power of the eorneal tissue to the action of pyogenic bacteria. A remedy which seems to increase the corneal resistance is tincture of the chlorid of iron, given in rather large doses. Quinin is also valuable in tonic doses, one or two grains three times a day. Pain may be relieved by morphin, acetanilid or hot applications. The local or systemic use of antipneumococcic or streptococcic serums has been eredited with good effeets, but serum treatment cannot be relied on.

When the extension of the ulcer has been checked and healing commenced, the local treatment should consist in atropin, and cleanliness and rest of the parts, with the continuance of such treatment of the conjunctiva as may be neeessary.

When perforation has oceurred with prolapse of the iris, if the ulcer be small and the cornea in favorable condition, it may be well to excise promptly the protruding iris, usually under general anesthesia. The prolapse may first be seized with the forceps, and somewhat dragged, first in one direction and then in another, until it is probable that the adhesions between the cornea and the iris are broken up. Then while the iris is still on the stretch the prolapse is to be cut away, as elose to the margin of the uleer as possible, either with the scissors or by transfixing it with a cataract-knife and shaving it off close to the cornea. If the operation has been suceessful, the cut edges of the iris will be at once retracted into the anterior elamber and away from the margin of the corneal perforation. If the neighboring cornea be much infiltrated, or if the prolapse be very large, or of more' than one day's standing, it is better to leave it alone. If later the cicatrix shows a decided tendency to excessive bulging, healing may be hastened and made more satisfactory by excision of the prolapse (as deseribed in Chap. XIX) at a later period. The treatment of the results of corneal ulcerations will be considered under opacities of the cornea. 
Special Forms of Corneal U1cer.-In old people with impaired nutrition, a form of simple uleer, usually situated near the margin of the eornea, associated with conjunetivitis, and often chronic or subacute, causes great pain withont marked hyperemia of the eye or other evidences of inflammation. It shows little tendency to extend, and little tendeney to heal spontaneonsly; but under the proper treatment, the instillation of a weak solution of eserin and bathing the eye twice daily, or oftener, with very hot water, and in some cases with the use of a protective dressing, relief from pain, and healing are promptly secured.

Malarial ulcer is common in patients who have suffered from malarial disease. It is marked by slight tendeney to extension, much pain, and complete resistance to local treatment unless accompanied by the internal use of yumin with or without iron and arsenic. The uleer is branching in form ; and the part of the comea on which it is situated is often quite insensitive to touch. The infiltration is moderate, and gray in color ; and the pericorneal redness commonly severe.

Herpetic ulcer, deseribed by Horner, oceurs with herpes of the lids and other parts of the face, in connection with febrile diseases, especially of the air-passages, as pharynigitis, bronehitis, pnemononia, ete. It begins with small vesicles on the cornea, severe pain, photophobia and lacrimation. The vesieles are very small, but may rum together and form linear uleers of considerable size. Healing depends on the general nutrition of the patient, but is usually prompt. The treatment is that for simple corneal ulcer.

Dendritic or mycotic ulcer is named from its branching form, or from its supposed dependence upon a speeial miero-organism. It is attended with marked photophobia, lacrimation, and the hyperemia of keratitis. It should be treated by thorough scraping, or by touching each part of it lightly with the gal rano-cautery.

Bullous keratitis oecurs when the nutrition of the eye has been damaged by previous disease, especially in con- 
nection with chronic iridocyelitis or glaucoma. It also occurs after traumatisms eausing extensive abrasions. Blebs either small or large form on the surface of the cornea, with pain, hyperemia, and other symptoms of infiltration. 'The blebs rupture leaving abrasions or deeper ulcers. They tend to reenr again and again. The treatment consists in atropin and hot applications locally, with avoidance of irritants, and a general tonic treatment including quinin and iron. And in case of traumatic origin, careful protection of the eye during healing. It may be necessary to ennelcate the eye if blind, on account of the repetition of the attacks.

Filamentous keratitis designates a group of cases in which from a corneal ulcer or wound-surface minute threads of tissue or fibrin are found hanging.

Keratomalacia is an cxtensive softening and slonghing of the cornea, occurring in patients very poorly nourished, as after acute or chronic wasting disease, and especially in infants. The treatment must be addressed to the general condition, and the eye guarded from irritants.

Neuropathic or neuroparalytic keratitis oceurs after disease of the ophthalmic branch of the fifth nerve, or its nuclei. The affection scems to be partly trophic and partly trammatic in character. Ulceration often occurs, bint is not extensive if the ulcer be guarded from infection. Some opacity of the cornea usually accompanies it. This form of ulcer is to be recognized particnlarly by testing the sensibility of the cornea, or finding other evidence of disease of the nerve. It is to be treated by closure of the eye under a protective bandage, the instillation of atropin, or a weak solution of eserin, cleanliness, and careful avoidance of irritants. Treatment mnst usually be continued for several wecks or longer, until the resisting power of the cornea becomes re-established. After destruction of the Gasserian ganglion, this disease may be prevented by keeping the eye closed and carefully protected for several weeks.

Herpes zoster, occurring in the distribution of the ophthahnic branch of the fifth nerve, and partieularly if 
vesicles oceur on the side of the nose, is liable to be aceompanied or followed by the involvement of the cornea. In some cases a vesicle forms on the cornea, leading to ulceration and subsequent opacity. In other eases the corneal changes resemble those of neuropathic keratitis. The deeper structures of the eye may be involved and the sight entirely lost. In most cases sight is permanently damaged by resulting opacity. The neuralgic pain which attends the disease may last long after the local disease has run its course.

Phlyctenular Keratitis (Scrofulous Ophthalmia, Strumous Ophthalmia, Lymphatic Keratitis, Fascicular Keratitis, Vascular Keratitis).--This disease is essentially the same as phlyctenular conjunctivitis (see p. 261), phlyetenules occurring on the cornea instead of at the limbus, or upon other portions of the conjunctiva. The conjunctiva is more or less involved in all cases, but the disease only becomes obstinate, severely painful, and dangerous to sight, when the cornea is affected. The causes are those of phlyetenular conjunctivitis.

Symptoms and Course.-The first perceptible lesion of the cornea is an elevation of the epithelium at some point by an aceumulation of a serous fluid beneath it. This is the corneal phlyctenule. Michell has reeently found that it is essentially a lesion of reaction against micro-organisms, especially the staphylococeus. The epithelium covering it quickly gives way, the fluid escapes, and a small approximately circular uleer is left. This occurrence is attended with pain, photophobia and excessive lacrimation; and there is hyperemia of the ocular conjunctiva and of some portions, or all, of the pericorneal vessels. The photophobia is generally even more marked than with phlyctenular conjunctivitis. Often two or three or more phlyetenules occur together, or they may follow each other in quick succession. Usually the ulcer formed heals rapidly, leaving a slight nebula and some irregularity of the corneal surface. But in more severe cases, or after repeated attacks, the healing is slow, superficial vessels extend from the limbus to the seat of 
the uleer, and continuing from uleer to uleer may form a leash stretching to the center of the cornea, or beyond it. The disease shows a strong tendency to relapse, and with suceessive attacks, the restoration of the eye to normal during the intervals becomes less complete; until it remains continuously hyperemic, with a clonded and vascular cornea.

Treatment.-The general lines of treatment indicated for phlyctenular conjunctivitis, must be followed with more care and constancy when the cornea becomes inrolved; and in addition special measures must be adopted for the keratitis. The irritability of the eyes, and dread of exposure to the light and air, cause the child to bury its eyes in a handkerehief or a pillow, to avoid all exposure of them. This is partienlarly unfortunate, since it tends strongly to aggravate and continue the disease. Indeed, if in any case free exposure of the eyes to light and air can be maintained, the cure of the eyes, except as to removal of opacities and irregular astigmatism, is not usually difficult. The excessive irritability is best met by instillation of a mydriatic, preferably atropin. A powerful aid in this is the regular application of the solution of tamnin in glycerin to the inner surface of the lids, once every two or three days, and the diffusion of ointment of the yellow oxid of mercury, in the conjunctival sac every night. In addition, dark glasses should be worn to protect the eyes from the light, and to prevent the constant application of a handkerehief to them, while permitting the air to circulate about them.

The small fissures which form in the skin of the lids near the outer canthus, should be touched from time to time with a solution of silver nitrate, and the skin earefully dried and protected with some petroleum preparation. Where photophobia is very great the sudden plunging of the face in ice-cold water has been practiced with advantage; but this is rarely necessary.

During the stage of uleeration, the treatment of simple uleer of the cornea must be followed, and care taken to guard against infection. If the ulcer becomes chronic 
and vessels extend out to it from the corneal margin, it shonld be scraperl or lightly tonched with the actnal eantery. For the treatment of resulting opacities, see Opacities of the Cornea.

Prognosis. - Phlyetenular keratitis rarely causes absolute blindness; but when neglected, it is responsible for many cases of life-long impairment of vision. Promptly. treated, such impairment can almost always be prevented.

Abscess of the Cornea, Hypopyon and Onyx.When the process of suppuration at first affeets a limited portion of the deeper tissne of the eornea, abscess results.

It may follow trammatism, or be secondary to suppuration in other parts of the eye. Its symptoms are, in the main, those of suppurating ulcer of the cornea, which it tends to become by the breaking down of the more superfieial layers of the cornea. It is usually attended with. severe pericorneal hyperemia and great pain. In some cases the corjunctiva becomes ehemotic and the lids edematous. The symptoms increase in severity with the extension of the abscess until it opens, usually upon the corneal surface; after which it runs the comse of a suppurating ulcer. It must be distinguished from a plastic deposit or a eieatrix in the cornea ehiefly by its color and the history of the case.

Hypopyon is the acemmulation of pus in the anterior clamber. It may depend upon abscess or suppurating nleer of the cornea; or upon suppurative disease of

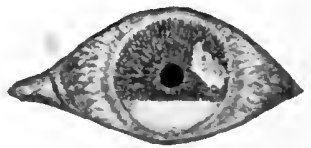

FIG. 92.-Corneal ulcer on the upper temporal quadrant, with hypopyon ocelpying the lower one-third of the auterior chamber.

the iris or deeper portions of the eye. It is illustrated in Fig. 92. A considerable amount of pus may pass throngl the anterior chamber without any visible acenmulation. Only when the amomnt poured into 
the aqueous humor is too great to escape promptly, or when the eomsistence of the material is such as to prevent its escape, does hyopyon develop. Because some pus is always passing from the chamber, and the hypopyon represents only a certain residue or excess, it may vary greatly in amonnt, being at one time barely perceptible, and a few hours later filling a large portion of the chamber. It appears as a yellowish mass behind the cornea, with a curved lower liorder corresponding to that of the anterior chamber and a horizontal upper margin. Often it is promptly displaced and its upper margin changed by a change in the position of the eye. But if it contains a considerable proportion of plastic material its form may alter quite slowly.

Onyx is an aceumulation of pus in the cornea between the layers of the true comeal tissue. It occurs at the lower portion of the cornea, by gravitation of pus from a suppurating ulcer or abscess. It is bounded above by an approximately horizontal line, and is less likely than hypopyon to change shape or position with movement of the eyes.

Treatment.-Like other purulent accumulations, the above should be treated by free evacuation and drainage. When lypopyon is slight, if there be no other indications for opening the anterior chamber, it may be left undisturbed. With onyx, if at all considerable in amount, it is better to incise the cornea deeply enough to allow the escape of the accumulation. The corneal tissue may not at first be appreciably involved; but to allow it to soak in the purulent accumnlation, might convert it into an alscess. Corneal abscess should always be promptly and freely opened. It never undergoes complete resolution; and usmally it continues to extend until it secures a free exit. Usually either a crucial ineision should be made, or the tissue of the eornea superficial to the abseess entirely cut away, and the abscess-cavity thoroughly scraped. Even if it is subsequently to be cauterized, it may be better to first freely open it. After it has been opened, it should be treated as any other suppurating uleer. 


\section{NON=ULCERATIVE KERATITIS.}

Interstitial Keratitis (Parenchymatous, Syphilitic, Strumous, or Diffuse Keratitis).-In many cases inflammation of the cormea shows no tendency to cause loss of substance, or suppuration; but goes on to the deposit of new material causing opacity, with often the extension of blood-ressels into the cornea. All such cases properly belong under the head of Interstitial Keratitis. No sharp line of distinction separates these from other forms of keratitis. In superficial vascular keratitis, the vessels and the exudation may often be seen to invade the true corneal tissue. The invasion is even more common and more marked in pannus. And corneal ulcerations occasionally occur in the course of typical interstitial keratitis.

Causes.-Under interstitial keratitis are included cases due to many causes. Keratitis attending herpes zoster, or fifth-herve paralysis may be largely of this character. Arlt named as its most important variety lymphatic or scrofulous keratitis. But Hutchinson's description of interstitial keratitis due to hereditary syphilis, is so definite and fits so many cases, that it is best taken as the type of the disease, with which other varieties may be compared. Even when clearly associated with hereditary syphilis, the attack may be excited by acute illness, rheumatism, eye-strain, exposure to local irritants, or other whealthy influences; and relapses and recurrences are commonly so caused. Interstitial keratitis may arise late in the course of acquired syphilis.

Symptoms and Course.-The disease begins with irritability of the eyes, photophobia, pericomeal redness, and interference with vision; which, at first very slight, increase from day to day until they become intense. As the symptoms increase in severity, from some part of the corneal margin, most frequently above or below, a broad mass of finc looped vessels begin to encroach on the cornca. These are surrounded by opacity, and give the affected region a peculiar yellowish-red or salmon color. Examination with a magnifier demonstrates that the 
opacity and vessels are in the depth of the cornea. At the same time, the changes beneath it render the corneal surface quite irregular.

The opacity of the cornea may inerease until the iris and pupil are quite hidden, and the patient praetieally blind. Sometimes before this, and often after the cornea has cleared up again, the iris may be seen to be bound down by posterior synechiæ of greater or less extent. In a few cases, deposits in the anterior chamber also eause extensive anterior synechix, without there having been any perforation of the cornea. Sometimes one eye is affected before the other, or more severely affeeted than the other; but usually both are involved. The cornea may resemble ground glass, or the deposits in certain parts may be completely opaque. Sometimes they are so dense and yellow as to look like corneal abscess; and if attended by deeided swelling, may properly be regarded as gumma of the cornea.

After a time, which varies from a few weeks to many months, the corneal opaeity begins to grow less dense. This is first noticed near the margin of the cornea, the center remaining clouded longest. But at length the eentral cloud gets thinner, and the corneal vessels diminish in size and grow less numerous. Some of the vessels, however, often remain and may be discovered with a magnifier years afterward, or throughout life. Usually the cornea becomes comparatively elear again, but almost always shows some haziness by oblique illumination, and causes marked irregular astigmatism with eorresponding permanent impairment of vision. In many eases, even when carefully treated throughout, the iris is left bound down by synechir. Often, too, the ophthalmoseope shows that the inflammation has involved other parts of the uveal traet; and patehes of ehoriodal atrophy, and pigment changes remain as permanent records of the attack. Interstitial keratitis occurs ehiefly between the ages of five years and twenty. Its duration is fiom a few weeks to two or three years; and slow clearing of the cornea may continue even longer. 
Varieties.-When not due to inherited syphilis, the disease is apt to run a less uniform conrse, and periods of improvement may alternate with exacerbations. The cornea is often less vascular, the ressels do not run in such characteristic loops, and the opacity is less likely to be evenly distributed. When due to scrofula, there is more apt to be ulceration.

In a few cases, a clond of opacity is limited to a certain part of the cornea, usually the center, and but few if any corneal ressels develop (circumseribed infiltrution of the cornea).

Occasionally, in connection with a focus of scleritis situated near the corncal margin, a somewhat triangular opacity will extend into the cornca, which to some extent becomes permanent, and appears as an extension of the sclera. This process may be repeated at various parts of the corneal margin. It is called sclerosing keratitis. In rare cases in old people, there sometimes occurs a yellowish exudation at the margin of the cornea, with symptoms of inflammation which later subsidc. The vessels of the limbus cxtend in over it, the opacity becomes gray, and closely resembles an areus senilis, except that no clear tissue separates it from the corneal margin. 'This is called keratitis marginalis.

Diagnosis.-Interstitial keratitis is recognized by the general distribution of the opacity in the cornea, its depth, and the form and situation of the vessels. The vessels are arranged in fine approximately parallel loops, which start from the deeper portions of the corneal margin. This is illustrated in Fig. 93, in which $A$ represents the vessels in interstitial keratitis, $B$ those of phlyetenular keratitis, and $C$ those of pannus. In these latter forms of vascular keratitis, the ressels start from conjunctival vessels and increase in number and diminish in size by branching off from main trunks.

The pericorneal redness is usually ummistakable at the height of the attack, althongh there may be, in addition, some conjunctival hyperemia. At an early stage the diagnosis will be greatly aided by other evi- 
denees of inherited syphilis, especially the sunken bridge of the nose, scars abont the angles of the month, and the Hutchinsom teeth. The characteristic deformities of the teeth consist in the notehing of the central incisors, and the peg shape and deficient develop-

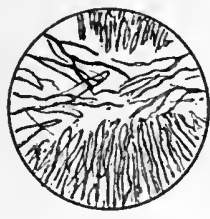

A

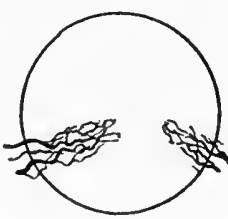

$B$

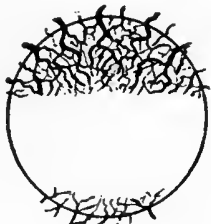

$C$

Fig. 93.--Vascular keratitis. Distribution of corneal vessels in the various forms. $A$, Interstitial ; $B$, Phlyctenular or fascicular; $C$, Panuus

ment of the lateral incisors. These are shown in Fig. 94.

These deformities are only exhibited by the permanent teeth. The milk teeth are generally poor, decaying often down to the gums before they are replaced. Any marked deformity of the permanent ineisors, especially if they are small so that they do not fill the jaw, but stand separately with gum showing between, may be due to inherited syphilis. But as Harrison Allen pointed out, considerable disturbances in the development of the

\section{Doot}

FIG, 91,-Hutelinson teeth.

teeth are also eansed by the exanthemata of childhood, oecurring when the crown of the tooth is developing. Some deformity of the teeth is present in half the cases of interstitial keratitis. The listory of still-births, or repeated miscarriages before the birth of the patient, also points strongly to inherited syphilis. 
After the keratitis has run its course, the existence of synechix, or patches of choroidal atrophy and pigmentchanges, indicate the nature of the disease that has left the cornea defective. The same evidences may raise a strong probability of intra-uterine interstitial keratitis, causing eongenital opacity of the cornea.

Impaired hearing due to lesions of the interual ear often coming on, or growing worse at the time of the keratitis, also indicates syphilis.

Treatment.- The loeal treatment should include the regular instillation of a solution of atropin, so long as there continues any pericorneal redness; and afterward until the eyes cease to be unduly irritable. The strength of the solution and the frequency of the instillations should be suffieient to keep the pupil well dilated; or if this cannot be accomplished, as much atropin must be instilled as can be used without causing serious general symptoms of mydriatie intoxication. Atropin is to be preferred to other strong mydriaties because its action is more persistent, and it is less likely to cause general symptoms.

The action of the atropin may be aided, and pain diminished by bathing the eyes, for three to five minutes before each instillation of the drug, with very hot water. If the hyperemia is very great, a decided beneficial influence is exerted by abstracting an ounce or more of blood from the temple with the artificial leech. This should be done in the evening when it will have most influence in procuring sleep. Dark glasses should be worn to lessen the photophobia. Subeonjunetival injeetions of mereuric chlorid have been tried, but are of doubtful value. All other local treatment should be avoided during the earlier stages. Astringent and irritant applications are harmful. When the hyperemia is almost gone, the ointment of yellow oxid of mercury may be used to hasten the clearing 11 ' of the opacity; and other measures for the same purpose will be indicated later (see p. 304).

The constitutional treatment is very important. This should include a general tonie regimen, and for a case 
caused by syphilis a long-continued course of mercury in moderate doses. The child should have plenty of sleep; a carefully regulated nutritious diet, avoiding tea, coffee, and sweets; regular cold bathing; and out-of-door life, away from dust and smoke, if possible. Syrup of iodid of iron, syrup of hydriodic acid, or tincture of the chlorid of iron may be given. Cod-liver oil is sometimes very valuable. The mercurial course may begin with calonel, until the bowels are decidedly acted upon, and then be changed to inunctions with a drachm of mercurial ointment once daily. If the month becomes at all affected, the mercury should be suspended, and potassium iodid in moderate doses (5 grains) given until the mouth is well. Then the mercury may be given in smaller dose. After the inflammation has passed its height, the mercurial may be given in small doses internally with potassium iodid.

Prognosis.-Interstitial keratitis may last from a few weeks to five years. Very few cases recover under two months, and the majority are fairly over it within a year. But no one can tell at the outset how long the particular case will continue. It is safe in the beginning to predict that the sight will get worse; and at the height of the disease, one can surely promise that it will greatly improve in the end. Very few, if any cases recover normal vision; but the final opacity of the cornea may be scarcely distinguishable. Recurrences of the disease are rare; but they may occur years later, and generally leave the patient with poorer vision than he had after the first attack.

Punctate keratitis is a term that has been applied to the small points of deposit which occupy a triangular space on the posterior surface of the cornea in cyclitis and iridocyclitis. But in typical cases it is uncertain if the condition of the cornea has any connection with their formation, or does more than furnish them a restingplace. In some cases of interstitial keratitis, the opacity, especially at a late stage of the disease, consists chicfly 
of points grouped in the lower portion of the cornea, keratitis punctata syphiliticu, or profunde.

A forn of inflammation closcly allied to corneal herpes, but with little tendency to the formation of ulcers has been termed keratitis punctata supcrficialis. It begins with symptoms of acute catarrhal conjunctivitis. But several day's later, minute gray dots are found seattered irregularly over the corneal surface, being least numerous near the margin.

Striate keratitis occurs after injuries to the cornea. It is characterized by lines of rather faint gray opacity, that appear within the first two days after the injury. It is most frequently seen after cataract extraction, when the lines are found perpendicular to the direetion of the comeal incision. It is not of serious significance, being unattended 'with other evidences of corneal inflammation, and ultimately disappearing in all cases, often within a week. It probably depends on dilatation of lymph-spaces from general disturbanee of the cornea, as in the delivery of a full-sized hard cataract.

Pannus (trachomatous keratitis, superficial vascular keratitis) is primarily a discase of the conjunetiva covering the cornea. But since the decper layers of the cornea become involved, and it is attended with all the symptoms of keratitis, it is well to consider it here.

Causes and Varieties.-The vaseular opacity sometimes left by prolonged phlyetenular keratitis has been ealled pannus. But the application of the term is now usually restricted to the eondition arising in trachoma. If the layer of hazy vascular tissue be thin it is pannus temuis; if it be thick and fleshy, pammes crassus.

Symptoms and Course.-Pannus does not arise in the course of trachoma, mitil that disease is well established, causing marked roughening of the inner surfice of the lids. It oecurs ehiefly in cases in which, on aceount of swelling of the lids, or for other reasons, the eyes are not kept fully open. It may develop rapidly with intense hyperemia, causing severe photophobia and practical blindiness, in a few weeks. The patient may 
date the eommencement of his eye trouble from the beginning of the pannms, not counting the trachoma which may have existed a long time previously. It consists in great thickening, vaseularity, and haziness of the superficial layers, of those parts of the cornea which are most eontinuously in contact with the lids. 'The part always affected is the upper part of the cornea, sometimes as far down as the center. In some eases a small area at the lower margin is also involved. The usual distribution of the pannus is shown in Fig. 87. Sometimes it is complieated with deep uleeration of the cornea.

Abrasions of the surface are frequent. In most eases if the lids are comparatively enred, rendered smooth and free from active disease, the pannus disappears, or is redueed to a slight haziness, with a few inconspienous vessels. If, however, the lids have been much deformed by the disease, and especially if they press upon the cornea with permanent narrowing of the palpebral fissure, the panums may remain after the trachoma has ceased to be active.

Diagnosis.-The portion of the cornea affected, and the eondition of the lids will distingnish pannus from pterygium. The horizontal boundary quite separates it from other vaseular opacities of the cornea; and a close inspection of the vessels shows their characteristic formation. This, with other forms of corneal vascularity is illustraterl diagrammatically in Fig. 93.

Treatment.- In a large proportion of eases of pamnus, the only treatment required is that of the trachoma. As the lids improve, the pannus improves equally, often becoming mimportant long before the treatment of the trachoma ean be safely suspended. 'This is especially the case when the trachoma is efficiently treated from a period shortly after the development of the pannus. The effect on the pannus of a thorough rolling of the lids is sometimes very prompt and remarkable. But in ehronic eases special measures must sometimes be resorted to. Photophobia and pain are nsually much lessened by instillations of atropin, or one of the other mydriatics. But 
it must be borne in mind that in a few persons these drugs aggravate any form of eonjunctivitis ; and trachoma is no exception.

If there be marked shrinking of the palpebral aperture, and pressure of the lids upon the globe, eanthoplasty should be done. It inereases the efficiency of applications for the trachoma, and greatly lessens the traumatism to which the cornea is continuously subjected.

Formerly inoculation of the eye with gonorrheal pus was a recognized remedy for pannus. It was often effective in thimning the pannus, and the danger of corneal perforation was much less than in the normal eye, on account of the vascularity of the cornea. But it has of late years been replaced by the use of jequirity, which produces much the same effect with less risk. It is applied either as an infusion, lightly brushed on the inner surface of the upper lid, or as an impalpable power dusted on the same part (see Chap. XVIII). It produces a sharp purulent, or crompous eonjunctivitis, which runs its course in a few days, leaving the lids and pannus decidedly better.

Where severe pannus remains after the condition of the lids scems no longer to furnish a sufficient cause for it, the vascular surface may be curetted away, the ressels may be closed as they pass on the cornea by burning a line with the galvano-cautery, or peritomy may be done (see Chap. XIX).

Persistent opacity that is almost non-vascular may require other treatment given for the removal of corneal opacities.

Prognosis.-Severe pannus is never followed by perfeet recovery, but there may be restoration of good vision. The ultimate condition of the cornea will depend largely on that of the lids.

\section{CORNEAL OPACITIES:}

Causes and Varieties.-The plyysiological opacity which may be brought out as a diffused haziness in the 
normal cornea, and resolved under a strong magnifier into separate dots and masses, nust not be confused with opacities due to disease. Areus senilis is usually seen in the aged, but sometimes in early life. It is a gray are scparated from the upper and lower margins by a narrow strip of clear cornea. It tends, with time, to become denser, and to extend in a complete circle (see Fig. 95). It is no contraindication to corneal operations, nor does it indicate fatty degeneration in other organs.

A faint haziness of the cornea left by preceding inflammation is a nebula, a spot of more decided gray opacity a macula, and a dense cicatricial opacity, usually whitc in color, a leukoma. The density of an opacity left by an ulcer depends largely on its depth. Usually a perforating ulcer causes leukoma, and if the perforation has been at all large, some part of the iris is apt to remain connected with the scar, making it an adherent leukoma. Such an opacity will often present a few rather large vessels which arise from, or inoseulate with, those of the iris (sec Fig. 96).

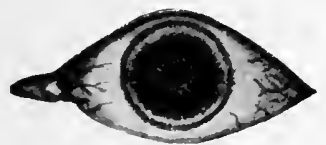

FIG. 95.

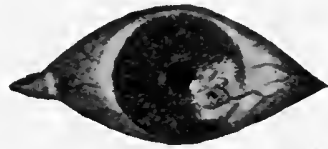

FIG, 96.

FIG. 95.-Arcus senilis.

FIG. 96.--Adherent leukoma, point of included pigment near its center, large vessel extending on it from the conjunctiva, and pupil distorted by traction on the iris.

Congenital opacity of the cornea occurs in the form of minute scattered dots, probably due to intra-uterine keratitis. Another form is that of a dense leukoma occupying the center of the cornea, and sometimes extending almost to the corncal margin. It is due to arrest of the clearing of the cornea, which is all opaque at an early stage of development. Sometimes these opacities greatly diminish after birth. Another variety of central opacity of the cornea, sometimes liereditary, has been known to develop after birth. 
Band-like opacity of the cornea occurs in two forms. A very few old people, witl cyes otherwisc apparently healthy, present a gray film eovering the pupil, and occupying most of the corneal surface habitually exposed when the lids are opened, the corneal nargin remaining elear. The opacity lies close to the surface, but the surface itself remains snooth. Its appearance is illustrated in Fig. 97.

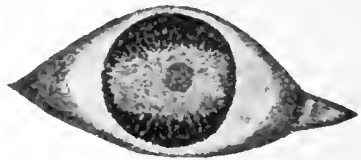

FIG. 97.--Band-like opacity of the cornea.

It is attended by no symptoms of irritation, but greatly impairs the vision. Uncler cocain, the cpithelinm and underlying film, which consists partly of lime salts, may be scraped away, and the resulting abrasion treated with solutions of boric acid and atropin. Band-like opacity is also frequently seen in blind eyes which are undergoing degenerative changes.

Family degeneration of the cornea causing opacity, begins and is most dense near the center of the cornea, while the extreme periphery remains comparatively clear. The opacity may begin with dots " nothlar opacity," or with interlacing lines or strcaks, "grill-like" or " latticeform " opacity. Later the whole mass of tissue becomes opaque. It usually begins about puberty ; but sometimes later in life. It is always bilateral and nltimately canses practical blindness. So treatment except iridectomy, in cases favorable for it, has proven beneficial.

Opacity following the prolonged application of a lead-lotion to an abracled or ulcerated cornea, is of a dense white color and situated just below the cormeal surface. It is usually said to be due to a preeipitation of some insoluble lead compound. Recently, however, some films of the kind have been examined, in which no trace of lead was found. Such opacities may be removed by seraping. Sometimes they are thrown off spontaneously. 
Gray opacity of the cornea oceurs also from iridochoroiditis, from contact of exudates with the posterior surface of the cornea, and in glaneoma, and from burns and other injuries.

Opacity of the cornea from staining with blood-pigment oecurs in some cases of extensive hemorrhage into the anterior chamber. The cornea beeomes of a smoky reddish-brown color, the clond of discoloration being always most dense at the center. The margin of the eornea remains comparatively elear throughont, and in the end the whole membrane usually elears up.

Pigmentation of the cornea occurs after elironic inflammation with increased tension; points of previously gray opacity becoming altered to black or brown pigmentspeeks which may be permanent.

Symptoms. - Corneal opacity impairs vision, not only by preventing properly focussed light from entering the eye, but also, when strongly illuminated, by throwing into the eye a large amount of diffused light, which "drowns out" the impression of such focussed light as may reach the retina. Any decided opacity of the comea is a personal disfigurement, to eseape which patients frequently seek the assistance of the surgeon.

Treatment.-Recent ol:aities following eorneal inflammations contimue to diminish spontaneously for months or even years. Such diminution is partly by alteration of new tissue into closer correspondence with the normal tissue of the comea, and partly by removal of exurdates. Certain mereurial preparations, especially the ointment of the yellow oxid, and calomel dusted upon the surface of the comea, have a reputation for hastening the latter process. "It should be remembered that calomel should not be dusted in the eyes when potassium iodid is taken internally; for the iodid being largely excreted through the tears, an intensely irritant componind is formed which eanses a violent conjunctivitis.

When the process of resorption eomes to a standstill, it ean often be rendered active again by varions decided irritants. Thus massage with powdered boric acid, or 
other substances, through the closed lid, or direct massage of the cornea may have the desired effect. Direct massage of the cornea may be made with a corneal spatula, or the back of a lens-spoon, using considerable pressure over the spots of opacity, but not enough to provoke severe or prolonged irritation. The massage should be repeated at intervals of three days to two weeks.

Galvanic electricity may be used upon some chronic opacities with decided benefit. The cathode applied to the cornea should terminate in a metal cup which aceurately fits it, in which may be placed a drop of mercury. The broad anode of sponge is applied to the cheek. From $\frac{1}{4}$ to $1 \frac{1}{2}$ milliamperes of current are to be applied, for from one to three minutes. The application is made under cocain ; and there should be little if any subsequent irritation. It may be repeated every two or three days.

In adherent leukoma, the greatest diminution in the opacity will be brought about by dividing the adhesions of the iris to the cornea. An operation accomplishing this often causes enlargement of the pupil, and the admission of a greater amount of diffuse light, by which vision is made worse rather than better. To diminish the light adnitted through the hazy part of the cornea, tattooing has been advocated (Wecker). To secure a pupil removed from the corneal opacity, optical iridectomy may be resorted to. If the patient is practically blind before, he may be greatly benefited by optical iridectomy; but if he previously possessed moderate vision, the operation is apt to be disappointing. 'Transplantation of the cornea fiom one of the lower animals is only applicable to the very rare cases of dense permanent central opacity, in which there has been no perforation of the cornea; and in these it has been of little practieal value. When the eye is entirely blind, tattooing of the cornca or enucleation or evisceration of the eye may be done for cosmetic reasons.

Prognosis.-Decided opacity of the cornea, especially if it extend deeply, rarely or never clears up entirely. The greatest improvement is seen in early childhood, 
especially after interstitial keratitis. When dense opacity has to a great extent cleared up in early life, it may partly return, with the degenerative ehanges of old age. Even eyes that have become free from noticeable corneal opacity, generally retain enough irregular astigmatism to greatly impair vision,

\section{PROTRUSIONS OF THE CORNEA.}

\section{Anterior Staphyloma (Corneal Staphyloma).-} Causes.-After a large perforation of the cornea, and extensive prolapse of the iris, the portion of iris remaining embedled in the sear-tissue which replaces the cornea, drags the other parts of the iris in elose contact with the corneal margin, and effectually eloses the chief outlet for intra-ocular fluid (see Chap. XV). The sear also, being relatively less resistant than the normal sclera, often gives way before the intra-ocular tension and bulges. Prolapse of the iris always bulges when it oceupies a perforation; but later the deposit of new tissue, and its cieatricial eontraction, usually flattens it down. At this stage the intra-ocular fluid still finds sufficient avennes of escape. Later still, when the same cicatricial contraction has drawn the whole iris into eloser contact with the cornea, and has consolidated the tissue, rendering it comparatively impervious to intra-ocular fluids, the pressure within the eye rises to such an extent as to cause the secondary distention designated staphyloma. Or the distention may remain throughout, while the scar-tissue thickens ㄴ) and the prolapse, withont material change of shape, becomes a staphyloma. When the whole eornea becomes involved in the process, the ease is said to be one of total staphyloma, when part of the cornea remains comparatively unaltered it is patial staphylome.

symptoms.-Decided anterior staphyloma eauses so much protrusion, that its presence and movements may be reeognized through the elosed lids; and if very large it renders eomplete closure of the lids impossible. The most prominent portion of the staphylona protruding con- 
tinuously between the lids becomes red and irritated, or dry and skin-like in appearance. The staphyloma is always opaque; but if very recent it may be so thin that the dark pigment-layer lining it shows through, giv-

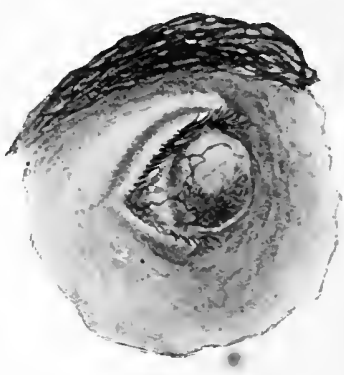

Fig. 98. - Total anterior staphyloma. ing it a grayish-purple color, the resemblance of which to that of a ripe grape gave the name to this condition. Usually this color is gradually lost, the most of the scar becoming rather white, with some few vessels in it; and perhaps one or more masses of black pigment from the incarcerated iris. The margin of the staphyloma (what was the margin of the cornea) may remain partly transparent; and through this the iris is apt to give a blne-gray color. The appearance of corneal staphyloma is illustrated in Fig. 98 .

The rubbing of the lids by the protruding mass may cause symptoms of irritation; or the simple stretching or pinching of nerves in the scar-mass may cause pain. The protrusion may remain stationary for months or years; but it is always liable to give way before the intra-ocular pressure and become more distended. The pressure is especially effective at the re-entering angle, where the staphyloma joins the normal outline of the eyeball. Partial staphyloma, therefore, tends to become total ; and total to increase, so that a staphyloma once covered by the lids comes to protrude between them. If allowed to go on, the process ends in rupture of the weakest part of the staphyloma, and escape of a large amount of aqueous humor. After this, the staphyloma partly collapses, the rent closes, and the distention again occurs. 'This may be repeated, but ultimately the rupture is apt to set up a general inflammation of the nveal tract, which ends in shrinking of the eychall. Sometimes a corneal staphyloma leads to general distention of the eyeball. 
The opacity of total staphyloma always causes blindness. Even if some part of the cornea remains clear in partial staphyloma, it is usually so distorted as to allow very imperfect vision. If the staphyloma be progressive all useful sight may be lost. Eyes, so blinded, retain good perception of light often for many years, especially in children, where the distensibility of the sclera long saves the retina from loss of function through pressure. A child with double staphyloma will often find great enjoyment in holding its spread fingers between its eyes and the light, and moving them from side to side to get the effect of the alternate light and shadow.

Diagnosis.-Corneal staphyloma will be easily distinguished from the other kinds of opacity of the cornea by the marked departure from the normal outline of the eyeball. From new growths affecting the front of the eyeball it may be known by the comparative absence of vascularity, the whiteness of the center, in contrast with the bluegray margin, and the history of antecedent inflammation and long continuance withont much change of appearance. Then, too, in staphyloma the sclera is evidently continuous with the tunior; not overlaid or burst through as in the case of a new growth.

The diagnosis between total and partial staphyloma must be made on account of the difference in prognosis and treatment. The chief difficulty lies in the deceptive appearance of clear cornea with the iris behind it, presented by the margin of a total staphyloma. Unless an appreciable depth of anterior chamber can be made out between the periphery of the cornea and the iris, the staphyloma must be regarded as total.

Treatment.-Partial staphyloma, without tendency to increase, is sometimes best let alone. Even if the vision of the affected eye might be improved by iridectomy, this will probably be no help to. the patient if he has good sight in the other eye, unless the iridectomy will extend his field of vision. Otherwise, the imperfect retinal images gained by the iridectomy are likely only to interfere with his use of the more perfect retinal images 
formed in the other eye. If, however, the other eye is blind, or both are seriously impaired, there is every reason to give the best sight possible by doing iridectomy where it will allow light to enter the eye through a pupil placed behind the clearest and most regular part of the cornea. If the staphyloma has long been stationary, and is not very extensive, the iridectomy may be solely for optical effect, and as small as it can readily be made in the required situation. If the staphyloma is at all progressive, or is very large or quite recent, it will be better to make a large iridectomy, and to earry it well to the ciliary margin of the iris to sceure its utmost influence in keeping down intra-ocular tension, and preventing extension of the staphyloma.

For total staphyloma, nothing ean be done that promises restoration of sight. The indications are simply for the prevention, or diminution of disfigurement or discomfort. These indieations may also justify similar operations in partial staphyloma. Tattooing may be done to improve the appearance of the eycball; or, if distention is going on, incision or excision may be practiced (see Chap. XIX). For a thin staphyloma that will collapse when punctured an incision may be enough. For a thicker, unyielding staphyloma, exeision of a portion, usually the greater portion, will be better. Where, in spite of this operation, the tendeney to distention continues, especially if there is with it a tendeney to distention of the sclera, evisceration or enucleation of the eye must be resorted to.

Prognosis.-In total staphyloma, restoration of any useful vision is quite impossible. Even light-perception is likely to be ultimately lost by prolonged pressure on the retina; and degeneration of the eyeball, or the effeets of rupture, may necessitate its removal. In partial staphyloma, even a very small piece of clear cornea may allow restoration from complete blindness to useful vision; and patients who are thus blind appreciate even slight improvement. But it must be remembered that an eye with even a small corneal staphyloma is seriously 
damaged, and especially vulnerable to various injurious influences.

Keratectasia (Ectosia of the cornea) is a giving way of the cornea, due to lessening of its relative resisting power, by disease which also causes comeal opacity, without there having been a previous perforation of the cornea, or inclusion of the iris in a scar. If small and recent, puneture of the comea, especially with the galvanocautery, may be tried. If extensive and old, tattooing or enucleation may be indicated.

Conical Cornea (Keratoconus.)-Disturbances of nutrition that attract attention to the cyes in no other way, may so weaken the cornea that it will give before the intra-ocular pressure. The point of greatest weakness, which is usually a little below the center of the cornea, is forced forward, and beeomes sharply curved. While around it, the eornea assumes a rather conical form. Fig. 99 shows the general outline of the cornea in a seetion

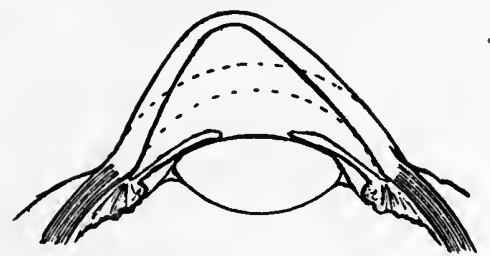

FIG. 99.-Diagram of conical cornea. The dotted lines show the normal curve of the cornea.

through the apex of the eone. Conieal eornea arises usually before the age of twenty, sometimes after an attack of exhausting disease, sometimes under the strain of seliool-work. If the protrusion is moderate, the cormea remains clear, or only shows a slight opacity on oblique illumination. If the protrusion is extreme (it sometimes amounts to a half-inch or more), the opacity is nore noticeable. 'The protrusion usually occurs in both eyes, and eontinues to increase for a time, and then becomes stationary. But it may again change in later life. 
Its most important effect is its influence on the refraction of the eye. The apex of the cone, from its increased curvature and displacement forward, is rendered very highly myopic; while the sides of the cone, by their flattening, balance the forward displacement so that toward the edge of the pupil the eye will be but slightly myopic, or even hyperopic. This eauses high aberration (see p. 186), and the appearance of the light and shadow in the pupil long recognized as characteristic of conical cornea, which is shown in Fig. 100. The error of refrac-

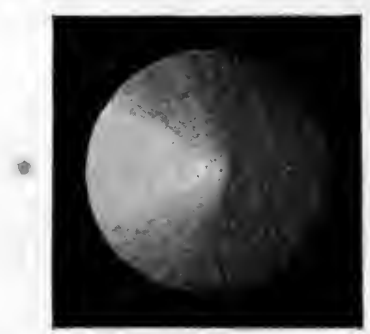

FIG. 100,-The skiascopic appearance in the high aberration of conical cornea.

tion always makes vision imperfect, and only rarely ean it be corrected by lenses so as to give vision approaching the normal standard. The lenses giving best vision are usually strong concave sphericals, combined with very strong cylindricals. If the conicity is of high degree, and increasing, it is proper to attempt to elieck it by operation. This may be the excision of a small lensshaped piece from the apex of the cone, or by touching and perforating the apex with the galvanocautery.

Keratoglobus. - When, instead of giving way at one part, the cornea distends uniformly before the intraocular pressure, this condition results. Besides being pushed forward, the cornea is enlarged laterally, so that it may be 12 or $15 \mathrm{~mm}$. in diameter, instead of the normal size of 10 to $11 \mathrm{~mm}$. The eye looks prominent, the anterior chamber is very deep, the iris looks flat, the pupil is small. Usually the refraction is quite myopic. 
Both eyes are commonly affected. The condition may attract no special attention, being regarded simply as a personal peculiarity. It develops in early life. Correction of the error of refraction is the only treatment required. Keratoglobus is also a symptom of buphthalmos (see Chap. XV).

Tumors originating in the cornea are extremely rare, although it may be involved in growths starting in the eonjunctiva, or penetrating it from the interior of the eye. Dermoid tumor of the junction of the cornea and conjunctiva is not so rare. It is congenital, but may grow after birth. It occurs most frequently at the temporal side, lying partly on the eornea and partly on the conjunctiva. It has the eolor and appearance of a piece of skin, and often presents numerous small hairs, which may cause irritation of the lids. Removal of the tumor may be indicated for cosmetic reasons. It is done under cocain by simply dissecting it off from the cornea and sclera; and drawing the conjunctiva as much as possible over the denuded surface.

Burns of the cornea, either by heat or causties, by eausing eoagulation and opacity of the superficial layers, appcar serious, even when slight. They may eause deep slonghing, or, in conneetion with burn of the conjunctiva, a subsequent symblepharon. Those by lime are frequent and serious. They must be treated by thorough cleansing and a protective dressing (see p. 272).

Wounds and foreign bodies in the eornea are eonsidered in Chapter XVII.

\section{DISEASES OF THE SCLERA.}

Scleritis (Selerotitis, Episcleritis).-Inflammation of the sclera oceurs from the causes of inflammation in white fibrous tissue in other parts of the body, exposure, gout, rheumatism, syphilis, scrofilla, "disturbed menstruation," and more obscure errors of nutrition. Two forms are recognized, a superficial (episcleritis) and a deep inflammation. The former leaves the eye uninjured; but the latter 
may extend to the deeper coats of the eye, and by intraocular lesions injure the sight.

Symptoms.-The liyperemia and swelling are commonly limited to one or more round patches, of a dusky- or purple-red, due to deep hyperemia, over which pass enlarged conjunetival vessels. The affected spot is deeidedly prominent from the swelling, and may be tender to touch. The accompanying pain varies greatly, being in some catses trifling, in others very constant and severe. The swelling and discoloration usually subside slowly after many weeks, often leaving a spot of bluish discoloration, which may be slightly depressed, or which may become distended, causing a staphyloma. A marked characteristic of the disease is its tendency to reeur again and again, and in spite of all treatment.

Diagnosis.-From phlyctenular conjunetivitis it is distinguished by the more dusky or purple color of the hyperemia, and its depth, and chronic course; and in some cases by the absence of pain and pliotophobia, also by the age of the patient. The cases of scleritis most resembling phlyctenular disease oceur in adults or elderly people. From iritis and keratitis, it is distinguished by absence of changes in the iris or cornea, except when complicated by sclerosing keratitis. The deep eases are to be distinguished from the superficial by the wide extent of the hyperemia.

Treatment.- I ocally lathing the eye with very hot water, and instillations of atropin are generally of benefit. Massage, gentle during the acnte hyperemia, and more vigorons at a later stage, is also of value. Touching the affected part from time to time with the actual cautery has been useful iu some eases. The general treatment is important. Syphilis, gont, rhenmatism, or intestinal anto-intoxication should receive careful attention. Diet, habits, and manner of living nust be regulated if possible; and change of climate, or residence at some spa may be worth trying, in ricw of the liability in cases of deep inflammation to scleral staplyyloma or intra-ocular lesions that may destroy the sight. 
Staphyloma of the Sclera (Partial Scleral Ectasia). - Weakening of the seleral coat by injury, deep seleritis, gumma of the ciliary body, or in connection with choroiditis, may cause the distention of the weakened part before the intra-ocular pressure. Or abnormal increase of intra-ocular tension may do the same thing with the normal selera. The lesion is named according to location, a eiliary, equatorial, or posterior staphyloma, or ectasia. The bulging is readily perceived anteriorly; and by focal illumination, the thinness of the selera may be demonstrated. Posterior staphyloma is recognized and studied with the ophthalmoseope (see p. 162). Nothing except removal of eauses ean be done in the way of treatment, since the disturbance of nutrition that allows such distention makes operative interference dangerous or useless, unless sight has been lost. Then enucleation or some substitute may be neeessary.

Buphthalmos is a general dilatation of the selera, which begins in ehildhood, and usually progresses until vision is entirely lost. (See Chap. XV.)

Injuries of the selera are considered in Chapter XVII.

\section{CHAPTER XI.}

DISEASES OF THE IRIS, CILIARY BODY, AND CHOROID; SYMPATHETIC OPHTHALMIA.

The iris, eiliary body and ehoroid, eonstitute together the uveal tract, the vascular, or nutritive coat of the eye. The elose anatomical and physiological relations of its different parts demand that their diseases should be considered together, not only in the text-book, but equally in the ordinary elinical work of diagnosis and treatment. Their vital importance to the non-vascular transparent tissues, the vitreous, erystalline and aqueous, which depend on the uveal traet for their nutritive supply, is also to be bom in mind in connection with loss of transpareney or other disease in those tissnes. 


\section{UVEITIS.}

Inflammation of any part of the uveal tract might properly be termed a ureitis. The important practical point is that when inflamnation seriously attacks one part of the uveal tract, other parts do not entirely escape. It is generally understood that tenderness of the eyeball, observed in connection with iritis, is due to involvement of the eiliary body. Inflammation of the ciliary body without involvement of other portions of the tract is known to be rare, and relapsing inflammation of the choroid is liable to become complicated by irido-cyelitis. While it is convenient to deseribe and elassify iritis, eyclitis and ehoroiditis as separate diseases, one must remember in clinieal work that each is a form of uveitis and that othar forms of nveitis are very likely to aeeompany it.

Another fact of the greatest clinical importance is that baek of every case of uveitis is some general disease or diathetie state, like syphilis, rheumatism, intestinal autointoxication, etc., and that success in dealing with the ocnlar lesions will depend ehiefly upon the recognition and mastery of the general condition from which it springs. So true is this, and so important is it, that the absence of the more eommon eonstitutional eauses for uveitis should only stimulate the seareh for the rarer condition which may be responsible for this particular case. If there be no evidence of syphilis or rheumatism, one should immediately consider the possibilities of diabetes, chronic uephritis or ehlorosis; and auto-intoxication of unusual character remains as a possible explanation when other general conditions are exchuded. Even in eases of tramatic uveitis the outeome depends more frequently upon the general condition of the patient than upon the extent of the wound, or the bacteria which have invaded it.

\section{IRITIS AND CYCLITIS.}

Iritis.-Causes.-Of all eases of iritis one-half are caused by syphilis, one-fourth by rheumatism, including a group of allied conditions of nutrition; and most of the remainder by gout, traumatism, preceding febrile dis- 
eases, certain cachexias, gonorrhea, diabetes, and new growths in the iris, with a frequency diminishing in somewhat the order named. Eye-strain is also a cause of some importance. The conjunction of two or more of these causes increases the liability to iritis, although in many cases a conjunction of causes is not perceptible.

Symptoms and Course.-A typical case of iritis begins with discomfort in the eye, which usually increases to a distinet ache referred to the brow immediately above the eye. With this there is often increased secretion of tears, and the eye becomes reddened. The hyperemia may to some extent involve the conjunctival vessels, especially if the eye is kept covered or bandaged; but its constant characteristic is the marked pericorneal zone (see p. 61), illustrated in Figs. 18 and 101. 'This zone, com-

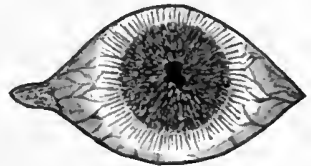

FIG. 101.-Iritis with contracted, irregular pupil and pericorneal zone.

mencing as light pink, becomes more pronounced as the severity of the attack increases, and its color deepens toward a brick-red or a dark purplish hue. When the pericorneal zone is well marked there is generally discoloration of the iris (see p. 71), loss of luster and indistinctness of its surface, and contraction of the pupil, with irregular dilatation in the dark-room.

As the case goes on, the pain becomes more severe, being worse at night, and preventing sleep. It is referred to the eyebrow, nose, or the whole front of the head, is of an aching character, usually severe; and only in rare cases slight or absent. It continues until the height of the disease is passed, and may be felt as an occasional discomfort after the inflammation has ceased. The eye may also be tender on pressure, although this is associated chiefly with cyclitis.

The pericomeal redness continues usually until after the 
pain has become inconstant or has passed away. In the latter stages it varies greatly with the exposure of the eye to irritant influences; and after the eye seems free from redness, a little manipulation of it, or exposure to air or strong light, or even simply directing attention to it by inspection, may cause the appearance of marked hyperemia in a few minutes. Such an eye is said to be irritable; and the condition of undue irritability may continue for one or two weeks after the cessation of constant hyperemia. The blurring and alteration of appearance of the irissurface increase with the severity of the inflammation. They are due to changes in the structure of the iris itself, partieularly its anterior epithelial layer ; and also to haziness and discoloration of the aqueons humor by exudation.

The contraction and fixity of the pupil become more marked, unless overeome by a mydriatic; and its form becomes irregular. These changes of form are dne to lyperemia of the iris, exudate into the iris-tissue, and adhesion of the iris to the lens-eapsule. They are illustrated in Figs. 101, 102, and 103; and are always most

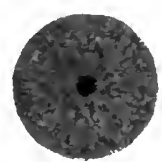

A

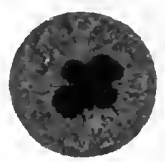

$B$

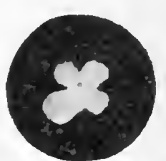

C

FIg. 102--1ritis. A, with pupil contracted; $B$, with pupil dilated, showing adhesions of the iris to the lens-capsule; $C$, with pupl dilated, as scen with the ophthalmoscope.

noticeable when the pupil is most under the inflnence of a mydriatic. They should be studied by oblique illumination and with the ophthalmoscope.

Adhesions between the lens-eapsule and the iris usually form first at isolated points of the margin of the pupil; but they may extend along the whole pupillary margin, or to a large part of the posterior surface of the iris. At the points of adhesion the iris is prevented from retracting when subjeeted to the influence of a mydriatic, and these 
points appear projecting into the dilated pupil, as in Fig. 102. In contrast with the above, hyperemia or exudation in a limited portion of the iris causes a rounded projection into the pupil, as shown in Fig. 103.

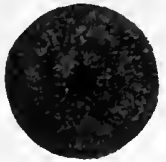

$A$

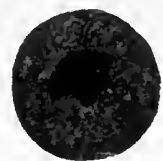

$B$

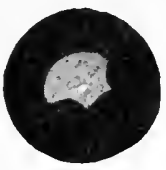

$c$

FIG. 103.-Iritis, pupil distorted by local swellings of the iris. $A$, pupil contraeted; $B$, pupil dilated; $C$, as seen with the ophthalmoseope.

The adhesions of the iris to the lens-capsule, posterior synechice, are at first very weak and easily broken. Hence the early use of a mydriatic may cause sufficient pull upon them to break them, a portion of the exudate remaining as an opaque brown spot upon the lens-capsule. A number of such spots often mark what lias been the margin of the pupil before dilatation. Later, when they have become partly organized, the same pull may stretch the synechia; the iris retracting, but still retaining a connection with the lens-capsule by a thread of adhesion. But the exudate tends to undergo organization into firm connective tissue. When this has occurred, the retractile force of the iris, even under the strongest mydriatic, is unable to sever or stretch the synechia, and the iris

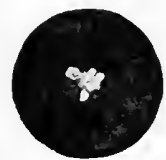

$A$

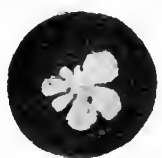

$B$

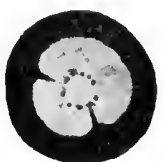

$C$

Fig. 104.-Pupil distorted by iritic adhesions. $A$, on first use of mydriatic; $B$, adhesions stretehed and one broken off; $C$, all the adhesions broken loose but two, leaving a ring of dots of exudate on the lens-capsule.

remains permanently bound down. The effects of these different conditions on the appearance of the pupil, when subjected to a mydriatic, are shown in Fig. 104.

In a large number of cases, even if the exudate causes 
no posterior synechia, it appears as a precipitate on the posterior surfice of the comea, the so-called keratitis punctata, to be referred to under cyclitis (page 324).

Although not a characteristic symptom, impairment of vision almost always occurs in iritis. It is most constantly due to clouding of the dioptric media, either the cornea or the vitreous may be affected, and the aqueous is almost always altered. Synechie are also likely to cause more or less opacity of adjoining portions of the erystalline lens. In some cases the iritis is followed by a myopia which may last for several weeks or months. The dilatation of the pupil by a mydriatic adds to the impairment of vision. 'The tension of the eyeball is generally not markedly altered in acute iritis; but it may become so in acute or recurrent attacks, when certain conditions diseussed in Chapter XV arise.

The subsidence of iritis is shown by diminution of the pain and hyperemia, and better dilatation of such parts of the pupil as are not bound down firmly by the synechia, such dilatation depending on lessened hyperemia, or the removal of the exudate from the tissue of the iris, or both. A renewal of the inflammation is indicated by symptoms similar to those of the original attack. Relapses are quite liable to occur, especially if the causative condition has not been entirely remedied.

Varieties.-The form of iritis described above is called simple or plastic iritis. It is closely allied with parenchymatous iritis, in which the exudation being chiefly within the tissue of the iris causes marked swelling. Purulent ivitis is usually associated with similar disease of other parts of the weal tract. It occurs with acute infectious diseases, meningitis, pneumonia, or pyemia. It may cause hypopyon. When in plastic iritis the exudate is so abundant that it coagulates, forming a grayish mass in the anterior chamber, which may be mistaken for a dislocated lens, the case is said to be one of spongy, or fibrinous, iritis. Quict or insidions iritis, occurs chiefly in anemic, poorly-nourished women approaching middle life. It is attended with no pain, and the hyperemia is 
so slight as sometimes to pass unnoticed. The patient comes for impairment of sight, and the iris is found firmly bound down to the lens-capsule. This form has been designated uveitis, on the supposition that only the posterior or uveal layer of the iris is inflamed. The serous iritis of older authors is here described as cyclitis. Iritis is also divided into varieties according to its causation.

Syphilitic iritis occurs as one of the secondary lesions of that disease, mostly within the first year after the infection. In the majority of cases both eyes are affected. It always becomes plastic, although at first it may appear scrons, and it is often also parcnchymatous, being marked by the formation of small papules or condylomata near the margin of the pupil. A rather similar form appears in hereditary syphilis during the first year of life. An iridocyclitis often accompanies interstitial keratitis, or it may occur alone as a tertiary lesion of acquired or inherited syphilis. More or less iritis attends the formation of gumma in the iris (see page 330). Syphilitic iritis properly treated is not especially liable to recur.

Rheumatic iritis may accompany an outbreak of aeute articular rheumatism, may alternate with attacks of subacute rheumatism, or may occur after special exposure as the only manifestation of the diathesis. It is attended with severe pain and hyperemia, often affects but one eye, and is especially liable to recur. It is marked by the early formation of synechiae, which, however, are narrow and casily torn asunder or stretched under the influence of a mydriatic.

Gouty iritis, arthritie ophthalmia, resembles rheumatic ilitis, but is usually less violent. Iritis sometimes accompanies chronic interstitial nephritis. Auto-intoxication of some kind should be considered as a cause of iritis.

Gonorrheal iritis may occur with acnte gonorrheal rheumatism, as a violent plastic iritis ending in recovery, with comparative freedom from sequels. Or it may occur at a later stage as a less violent iritis with a strong tendency to relapse. Diabetic iritis is marked by extensive exudate, which is usnally fibrinous but may be 
purulent, and which generally clears up very well under treatment. The possibility of diabetes should be borne in mind in all eases of iritis of obscure causation. Ophthalmia nodosa may involve the iris with the formation of nodules in its tissue (see page 243).

Traumatic iritis may arise from direct injury or the lodgement of a foreign body in the iris; or it may follow bruise withont any pereeptible lesion within the eyeball. New growths involving the iris generally give rise to inflammation. Glancoma of the inflammatory type is constantly attended by iritic inflammation. Inflammations of the comea, as well as those of the ciliary body and choroid, are liable to involve the iris.

Diagnosis.- The diagnosis of iritis rests on visible changes in the iris. A careful examination of the eye by oblique illumination and with the ophthalmoscope, and the careful testing of mobility of the iris and pupil are essential. It is to be distinguished fiom cyclitis by the absence in the latter of changes in the iris itself, although the other symptoms of iritis are present. Keratitis is distinguished from iritis by discovering ehanges in the cornea, such as haziness, localized opacity or ulceration, without alteration in the iris, except such change of color, and blurring of detail as the corneal haze would cause. When keratitis occurs in an eye presenting alterations of the iris due to a preceding iritis, or iritis attacks an eye having corneal opacities or irregularities, the differential diagnosis may be impossible.

In conjunctivitis the redness is conjumetival (Fig. 16) or phlyetenular (Fig. 17), not pericorneal (Fig. 18); the pain is smarting, burning or the feeling of a foreign body, not aching; and is confined to the eye, not referred to the brow, nose or cheek as in iritis; the iris is unaltered in appearance or reaction; and the vision is generally unaffected. The differential diagnosis from glancoma is extremely important. It is discussed in comnection with that affection (Chapter XV).

When iritis follows tramutism, one must make sure that it does not mask more serions lesions. And as it 
attends new growths in the iris and in deeper parts of the eye, the recognition of the iritis must not prevent the search for such more serious eauses. The diagnosis of the different varieties of iritis rests on points mentioned in.deseribing them.

Treatment.-The treatment of iritis includes: the removal or treatment of its cause, the subjection of the iris to the inflnenee of a strong mydriatic, the relief of pain, antiphlogistic measures, and the improvement of the general health and nutrition.

General Treatment.-Mereury is of special value in plastic iritis. The author prefers to begin with calomel in doses of $\frac{1}{8}$ to $\frac{1}{2}$ grain, three or four times a day, continued until they produce a decided effect on the bowels, or other evidence of the general action of the drug. After this the mercury may be continued in a different form (see Chapter XVIII), for syphilis, or discontinued in the non-syphilitic. Where rheumatism is the cause, salycilates should be given freely. The patient should keep dry and warm, and the Turkish bath, or exposure of the surface to superheated air may be benefieial. The diet should be regulated to the exelusion of whatever is imperfeetly digested. A gouty iritis requires regulated diet, excluding all aleoholie drinks, acid fruits, and all articles known to have produeed previous gouty attacks, and much meat. Alkalies and alkaline waters may be given freely, with colchicum, or piperazin. For iritis in the diabetic, the regulation of the diet beeomes of chief importance. Gonorrheal iritis should be treated much like that due to rhemmatism, with the addition of careful attention to any urethral discharge. Malarial iritis requires quinin in large doses, and sometimes arsenic.

Many who suffer from iritis are distinetly anemic and poorly nourished, or even cachectic. Such patients should have tincture of ehlorid of iron in full doses, and tonic doses of the cinchona alkaloids. In its later stages plastic iritis is often benefited by the internal use of morlerate doses of potassium iodid. If the iritis be violent, the patient will do best to remain in bed. In 
any case he should aroid fatigue or exposure. Sudden or great ehanges of light must be avoided, but confinement in darkness is not advantageous. Intestinal auto-intoxication requires attention to diet, and exereise.

Local Treatment.- The eye should be brought quickly and completely under the influence of one of the stronger mydriaties. Atropin is probably best, because of the slower recovery from it, and its slighter tendency to cause constitutional symptoms. Its action may be greatly assisted and hastened by the simultaneous instillation of cocain (see Chapter XVIII). Since it is of great importance to secure dilatation of the pupil, and the danger of mydriatic intoxication limits the amount of the drug that can be used at one time, it is often well, even when both eyes are affected, to make the chief mydriatic attack on one eye one day, and the other the next. The cocain is to be used in such a mydriatic attack. If a good dilatation of the pupil be not secured at first, it may be well to repeat the mydriatic attack a few days later, when the use of mercury may have weakened the adhesions, or may have reduced the hyperemia or exudation in the iris. After the best dilatation of the pupil has been obtained, it is to be kept up by the use of so much of the mydriatic as may be neeessary. This may require at first the use of the strong solution four to six times a day. Later, a weaker solution may be used, and one to three instillations may suffice. The use of the mydriatic should usually be continued until the eye is entirely free from redness, or irritability. A few cases of iritis, usually complicated with severe cyclitis; do better if the mydriatic is discontinued early, as after two or three days.

Next in importance is the local application of heat. Cold may be of benefit in traumatic cases during the first twenty-four hours after the injury, but otherwise it does little good in iritis. Hot applieations are better. These may be by bathing the eye and surrounding parts with water as hot as can be borne, immediately before the instillation of the mydriatic, or when the eye becomes especially painful; or the continuous use of dry heat by 
the hot-water coil or some form of electrical heater. Heat lessens hyperemia and pain. Dionin may also be used as an analgesic by placing the powder in the eonjunctiva once or twice in the twenty-four hours.

Local bleeding from the temple, either by the natural or the artificial leech, also controls pain ; and is often the starting point for progressive improvement. It is of use chiefly in the more acute cases attended with acute pain. It may be repeated on successive days, or even more frequently, if the pain recurs (sce Chapter XVIII). In general, the eye should not be bandaged, unless this is needful to protect it against severe cold.

If the relief of pain be not effected by the local treatment, it may be best to give analgesies, like opium, or acetanilid, a little before bed-time to secure as much sleep as possible; for loss of sleep may seriously hinder resolution. For the sequels of iritis see page 326.

Prognosis.-When an iritis is seen early, the patient should be warned of the serious nature of the attack, the danger of permanent damage by iritic adhesion, that the eye is likely to become more inflamed and painful before it begins to get better, and that several weeks or months may be required for complete recovery. The results of an attack depend largely on treatment; but also upon constitutional conditions that cannot be exactly appreciated. While partial restoration to normal generally occurs, complete restoration is exceptional. Recurrence and relapse are most common in the insidions iritis of the eachectic, especially of anemic women. They are also common in rheumatic and gouty iritis. They are rare after well-treated syphilitic iritis. Although the recovery of the iris may be complete, concomitant lesions, as of the cornea, ciliary body and the choroid, may cause permanent damage. An attack of even simple iritis may lead to such changes or sequels as will totally destroy the usefulness of the cyc. Yet sometimes an eye, blind as the result of iritis, niay be restored to great usefulness by proper operative treatment. In few diseases is an early positive 
definite statement as to the ultimate result more rash and wortliless.

Cyclitis (Serous Iritis, Iridocyclitis, Keratitis Punctata).-Most eases of iritis show some extension of inflammation to the ciliary body ; and in but few eases of cyelitis does the iris entirely escape. Yet some points regarding cyclitis should be considered separately.

Symptoms, Causes and Varieties.-The severe pain and pericorneal hyperemia resemble those of iritis, and the vision is impaired, equally or to a greater extent, on account of opacities in the vitreous. In severe acute cyclitis the eiliary region becomes very tender to tonch. The eauses are the same as those of iritis, but traumatism, eye-strain and syphilis are relatively more important. The recognized varieties are about like those of iritis. In plastic eyelitis there is exudate into the eiliary body and the vitreous, with great danger of subsequent eicatrieial changres. Purulent eyclitis is associated with purulent choroiditis (see page 343 ).

The most eharacteristie symptom is the deposit of exudate on the posterior surface of the eornea, usually called keratitis punctata. The deposit eonsists of eells, fibrinons material, and miero-organisms. It is distributed usually in isolated dots arranged in a triangle, with its base at the lower margin of the cornea, and its apex upward. This is shown in Fig. 105. The dots are larger and eloser together in the lower part of this space; and if there is a large amount of exudate they coalesce, forming

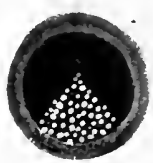

A

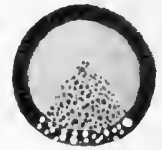

$B$

FIG. 105.-Deposits on posterior surfuce of the cornea, so-ealled keratitis punctata: $A$, as seen by oblique illumination (the spots are never white, but gray or even dark brown); and $B$, as seen with the ophthalmoseope.

irregular masses. At first the cornea on which they are deposited is unaltered. But if they remain long in con- 
tact with it, each spot gives rise to opacity in the posterior layer of the cornea itself, which may remain permanently. Deposits of similar material sometimes occur on the anterior surface of the iris and lens-capsule.

The pupil in cyclitis may be somewhat sluggish, but is not contracted unless some iritis or hyperemia of the iris is present. The periphery of the iris may be retracted, increasing the depth of the anterior chamber, especially late in plastic cyclitis.

The tension of the eyeball is apt to be slightly increased in the early stages of the cyclitis, and much elevated if secondary glaucona supervenes. In chronic eyclitis without glaucoma the tension is often much lowered.

Diagnosis.-Cyclitis may be recognized by the same symptoms as iritis, with the spots of exudate on the posterior surface of the cornea, and the tenderness of the ciliary region. Without these latter the case may be regarded as one of iritis without cyclitis. On the other hand, if in spite of the other synptoms the iris presents no visible alteration, the case must be classed as cyclitis withont iritis. Probably the myopia often observed after iritis depends rather on the changes in the ciliary body. In some cases of iritis, neither marked changes in the iris, nor the formation of synechi occur for several days, the case at first appearing like cyclitis. But in such cases it will be found that mydriatics show less power to dilate the pupil than in the normal eye, on account of hyperenia already existing in the iris. Syphilitic iritis often shows this peculiarity. Cyclitis is liable to be confused with keratitis, and conjunctivitis, and most of what has been said of the differentiation of these affections from iritis will apply here. It must also be distinguished from glancoma (see Chapter XV).

Treatment.-This is the same as the treatment of iritis, except in respect to the use of mydriatics. Most cases of cyclitis complicated with iritis do well under a mydriatic. Some cases of simple cyclitis are equally benefited by mydriatics. But a few eases of cyclitis do badly under a mydriatic. Hence mydriatics must be 
used cantiously, and sometimes disearded altogether. On this account the briefer mydriaties, duboisn, lyoseyamin and scopolamin, are decidedly preferable to atropin, and even homatropin may be preferred for tentative use in simple eyclitis.

Prognosis.-Cyelitis is more dangerous than simple iritis, and the prospect of serious permanent injury to the eye increases with the severity and duration of the attack, especially with the amount of ciliary tenderness and hyperemia, and the extent of exudation into the vitreous as shown by its opacity.

\section{SEQUELS OF IRITIS AND CYCLITIS.}

The gravity of iritis is due chiefly to the permanent lesions eaused by it which rise into prominence as the inflammation of the iris subsides.

Myopia following iritis is observed as soon as the media become sufficiently clear, after the subsidenee of the inflammation. It continues to diminish, and after several weeks or montlus it passes away, the refraction becoming about the same as it had been previous to the attack. It may recur with recurrences of the iritis. It is mostly noticed in eyes previously but slightly myopic or hyperopic. In eyes highly hyperopie the hyperopia is commonly temporarily diminished. These elanges of refraction should be met by prolonged use of a mydriatic, and by the adaptation and proper changes of lenses.

Posterior Synechiæ. - A few adhesions of the iris to the lens-eapsule may be attended with no serions consequenees, particularly if they are slender, and streteh sufficiently to allow pretty free movement of the iris ; and are placed outside the limits of the contraeted pupil, as they are apt to be when the pupil has been kept under the influence of a mylriatic during the height of the iritis. Such bands tend to become more yielding and thinner with time, and may cease entirely to interfere with the movements of the iris.

If, however, a broad unyielding adhesion is loeated near the center of the lens-capsule, as it will be if a mydriatic 
has not been used, it interferes with the entrance of light through the pupil, and exerts a continuous traction on both the lens-capsule and the iris. The drag on the capsule affects the curvature of the adjoining portions of the lens-surface, causing irregular astigmatism; and disturbs the nutrition of the part, so that a limited opacity of the lens results, interfering still farther with the light entering the pupil. The drag on the iris tends to cause renewed attacks of iritis. These are usually less acute than the primary attack. But since the iris is bound down to start with, whatever exudation occurs, tends to extend its adhesion and cripple it still farther. In this way the condition of the iris tends from bad to worse, until one or the other of the graver conditions that are liable to fellow iritis is brought about.

Various operations for freeing the iris have been devised and practiced with good results. In the best of these, the iris is freed from its adhesions, either with a blunt hook, or by seizing and pulling it with delieate forceps, corelysis, care being taken to avoid rupture of the lenscapsule. But operations for posterior synechia are not often undertaken unless the indications are urgent, and the adhesions broad and firm; in which case iridectomy is the better procedure. Usually such an operation sliould be done only when the eye has bcen for some time quite free from hyperemia. But indications may arise so urgent as to justify operation on an acutely inflamed iris.

Occlusion of the Pupil.-In rare cases of plastic iritis, free deposit of fibrinous cxudate from the aqueous covers the lens-capsule over the whole area of the pupil, forming a gray membrane; and partial occlusion is more common. This membrane remains, permanently occluding the pupil and greatly interfering with vision. Even a gray fringe at one side of the pupil may interfere greatly with vision. Occlusion is to be treated by making an artificial pupil by iridectomy, when the eye has become free from signs of irritation.

Exclusion of the Pupil (Anmelar Posterior Synechice).-When the whole pupillary margin of the iris 
is bound down to the anterior capsule of the lens, not only do the effects of broad adhesions oceur, but the escaje of fluid from the posterior to the

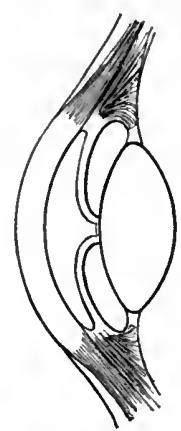

FIG. 106.-Ballooning of the iris (after Nettleship). anterior chamber is interrupted (see Chapter XV), and other grave conditions arise. The fluid behind it pushes the iris forward, eausing it to bulge, as in Fig. 106. This is spoken of as ballooning of the ivis (iris bombé). The iris rises up on either side of the pupil, usually not equally all round, but in swellings separated by depressions where it is bound down by adhesions. In the midst of these elevations of the iris the pupil appears depressed and is spoken of as crater-like pupil. With the absence of its normal novements, and under the pressure to which it is subjected, the iris generally undergoes atrophy. Its forward displacement at the periphery is liable to bring it in eontact with the cornea, closing the angle of the anterior chamber and eausing a seconclary glancoma. (See Chapter XV.)

Such an eye, if left to itself, is almost certain to undergo degenerative changes that will render it hopelessly blind. Iridectony shonld be done upon it as soon as possible, and repeated, if necessary to establish a free permanent communication between the anterior and posterior chamber. Iridectomy should be done even though the exeluded pupil be perfectly clear, and the vision still good.

Total posterior synechia is the condition in which not only the margin of the pupil, but the whole central posterior surface of the iris, is firmly adherent to the lenscapsule. It may follow a single severe attack of plastic iritis untreated with a mydriatic, but commonly it follows repeated relapses, especially of insidious iritis. It may cause the whole anterior chanber to be shallow. But there are no local bulgings like those of "iris bombé," and the pupil presents no crater-like depres- 
sion. Rather the iris around the pupil appears thin and flattened.

In most cases, accompanying changes in the deeper parts of the eye have cansed diminished intra-ocular tension, and hopeless blindness. When, however, good perception of light remains, some vision may be preserved; or farther degenerative changes in the eyes may be prevented by iridectomy. 'This, however, must be accompanied by removal of the crystalline lens, although it may still be clear. In total synechia, it is commonly impossible to remove any considerable piece of the iris and make a free opening into the posterior chamber, which is obliterated except at its periphery, without also removing the adherent lens-capsule; and any injury to the capsule causes such opacity and swelling of the lens, unless it be promptly removed, as would make the operation very harmful, rather than beneficial. Extraction of the lens must be done to render suceessful the operation of iridectomy.

Atrophy and Degeneration of the Iris.-Protracted or repeated attacks of iritis, numerous and firm synechire, exclusion of the pupil and total synechia, are likely to be succeded by degenerative changes in the iris. The surface loses its normal inequalities and luster, becomes comparatively uniform and dull, and of a grayish color. The iris is thinned, its proper tissue atrophied. With these, corresponding ehanges occur in other portions of the uveal tract; and such an appearance of the iris is a most unfavorable sign as to the condition of the deeper parts of the eye.

Sometimes without general degenerative changes, atrophy of a particular part of the iris may occur. Thus after exclusion of the pupil in early childhood, complete atrophy of certain parts leaves gaps in the iristissue, rescmbling congenital polycoria. Thinning of the iris by absorption, until the red fundus-reflex can be readily seen through it, may occur after the disappearance of local deposits in the iris, especially after gumma; or it may occur after bruising or stretehing of the iris, as in 
cataract extraction; or in elderly people without any history of previous disease or injury.

\section{NEW GROWTHS IN THE IRIS AND CILIARY BODY.}

Gumma of the Iris and Ciliary Body.-In iritis occurring as a secondary symptom of syphilis there are often (some writers say always) small tenmporary papules, grantules, or condylomata, sitinated near the pupil, which break down, sometimes giving rise to visible debris in the anterior chamber. In the tertiary stage gummata in the form of large rounded masses, like those shown in Fig. 107, appear in the iris, with severe iritis. These undergo absorption under treatment for syphilis, leaving distinet sears in the iris. Gumma arising in the ciliary body is attended with eyclitis, and may canse marked displacement of the iris, or staphyloma of the eiliary region and corneal astigmatism. It should receive the same treatment as gumma elsewhere, except that mereury is relatively more important than potassium iodid.

Tuberculosis of the iris occurs before the age of twenty. It begins as isolated nodules in the iris-tissue, each surrounded by minute vessels. The iris is swollen and inflamed throughont. The general appearanee is illustrated by Fig. 108. The individual deposits may

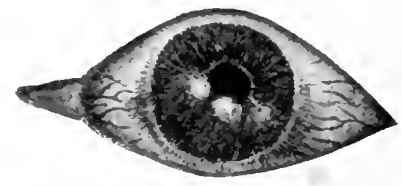

FIG. 107.-Gumma of the iris, the new growths seen as rounded prominences of ligbter color, below the pupil.

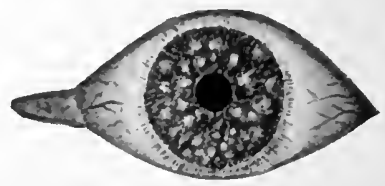

FIG. 108.-Tuberculosis of the iris, the tubercles showing as small light prominences. Some pericorneal hyperemia.

continue to grow until several millimeters in diameter; or they may undergo alsorption, and be followed by a fresh crop. Oceasionally but a single growth appears (granuloma of the iris), which may increase in size and 
destroy the eye. In rare eases the growths finally disappear leaving the rye with good sight and the patient free from tubereular lesions. Mostly the eye is destroyed, and the patient succumbs to general tubereulosis. The treatment is the general treatment for tuberculosis and iritis.

Sarcoma of the Iris or Ciliary Body.-Bareoma in the iris starts as a single brown mass which at first grows very slowly, If not mueh pigmented, vessels may be traced upon it. Frequent hemorrhage may oeeur. If it starts behind the iris, it becomes adherent to it; and, carrying it away from its ciliary attachment, causes an iridodialysis. It is most common in early adult life, but may oecur at any period. After a period of slow growth which may last for years, sareoma causes inflammation and increased tension of the eyeball, breaks through the sclero-corneal coat, and terminates in a rapidly growing tumor and death. In a few cases the growth has been removed with the segment of the iris from which it springs, and has not reeurred. More frequently the whole eyeball must be exeised, or if it has penetrated the selera the whole contents of the orbit should be removed, as for sareoma of the ehoroid.

Carcinoma of the iris or ciliary body is very rare.

Benign Tumors. - A congenital projection of the uveal layer of the iris forward through the pupil, such as

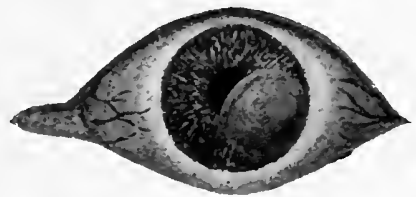
FIG. 109.-Cyst of the iris occupying the lower outer part of the anterior

is normal in the eye of the horse, is called ectropion of the uvea. It appears as one or more chocolate-brown nodules on the pupillary margin.

Minute benign pigmented growths, melanomata, some- 
times oceur in the iris. Cyst of the $i r$ is is a gray round translueent tumor having much the appearance represented in Fig. 109. It consists of a thin transparent wall, containing a serous fluid. An epidermoid pearl or pearlcyst of the iris is a small white slowly-growing mass of. epithelial or atheromatous material. Both eysts and epidermoids disturb and injure adjoining tissues by pressure, and if undisturbed may cause glateoma. They commonly start from some injury, especially the implantation upon the iris of a cilium, or a piece of epithelium from the skin or conjunctiva. They should be excised. A few cases of vascular tumor of the iris are recorded.

\section{MOTOR DISORDERS OF THE IRIS AND CILIARY MUSCLE.}

The normal reactions of the pupil and their alterations by disease have already been described (page 72), and are further referred to in Chapter XX. Persistent dilatation of the pupil from whatever cause, is called mydriasis. The most frequent cause of mydriasis is the use of a mydriatic. It may be placed in the patient's eye without his knowledge, as by a contaminated dropper ; or he may use it and deny it. The amount required to produce mydriasis is so minute that it may be splashed into the eye, eausing unilateral mydriasis; or taken in medicine or food quite unconseiously, when it will cause equal dilatation of both pupils.

Persistent contraction of the pupil is called myosis. It may also be caused by drugs, especially eserin (physostigmin) or pilocarpin locally, and opium interially. Various conditions of the iris, espccially moderate hyperemia, also cause it. Exaggeration of the normal alternating contraction and dilatation of the pupil on passing from a dim to a bright light is hippus. 'Tremulousness of the iris, when the iris loses the support of the erystalline lens, is called iridodonesis.

Cycloplegia, paralysis, or paresis of accommodation, paralysis, or paresis of the eiliary musele, is to be sharply distinguished from presbyopia, although their symptoms 
are in some respeets precisely alike. The former is loss of power in the muscle, an inability to influence the still flexible lens, a true paralysis or paresis. The latter arises from increased resistance of the lens, limiting the effect produced upon it by the normal ciliary muscle. Presbyopia comes on imperceptibly, and rarely or never diminishes. Paralysis of aceommodation may be entirely sudden ; even when most gradual it changes notably from montl to month; and it may end in partial or eomplete recovery. One or both eyes may be affected.

Causes and Varieties.-The most frequent cause is the influence of a cycloplegic drug, which, at the same time, produces dilatation of the pupil. Diphtheritic paralysis of the accommodation comes on at the third to the sixth week from the onset of the disease, and lasts from a few dlays to six months. It is commonly not attended with dilatation of the pupil. It is sometimes complete, but more frequently partial. Similar weakness of aceommodation may follow epidemic influenza, "grip," and other acute diseases. Paralysis of the ciliary muscle may also attend degenerative changes in the brain and spinal cord. It may be caused by nasal disease.

Spasm of the ciliary muscle, or spasm of accommodation, has been already alluded to (pages 129 and 149). It also is produced by drugs, eserin (physostigmin) and pilocarpin, and by disease of the central nervous system. The treatment is the use of a mydriatic, and the removal of the cause, if possible.

\section{SYMPATHETIC OPHTHALMIA.}

When, after injury, an eye is permanently damaged by plastic inflammation of the uveal tract, the fellow eye is liable to suffer from what is called sympathetic disease. Cases apparently similar occur in which the first eye is diseased without trammatism; but these may be instances of bilateral idiopathic diseasc, one eye being affected before the other. Sympathetic involvement of the second eye has been recognized for two hundred years. 
Donders pointed out that there were two separate diseases, one marked by great liability to eomplete destruction of sight, and but slightly influenced by treatment, sympathetic inflammation; the other eausing great temporary interference with vision, but promptly cured by removal of the injured eye, sympathetic irritation. Obscure sympathetic amblyopia may also oceur. The wounded one is called the exciting eye; the other the sympathizing eye.

Sympathetic Inflammation (Sympathetic Ophthalmitis, Cyclitis or Iridocyclitis, Uveitis Maligna, Migratory Ophthalmia).--Sympathetic ophthalmitis is a general inflammation of one eye, following injury to the other eye, and charaeterized by an insidious invasion, severe inflammation of the uveal tract, a chronic course, with strong tendeney to repeated relapses and exacerbations, and ending often in complete blindness.

Symptoms and Course.-Sympathetic disease rarely or never begins until two or three weeks after the injury of the exeiting eye. It most frequently occurs at from six to ten weeks; and after two years from the primary injury it is extremely rare. The first symptom may be inability to sustain an effort of accommodation in the sympathizing eye. This is usually followed by hyperemia of the whole eye, at first slight, but gradually inereasing. In a few eases, there has been early optic neuritis, and neuroretinitis. In other cases, the first lyperemia is mainly conjunetival. In all eases, however, there soon appear discoloration of the iris, pericorncal redness, pain, photophobia, specks of exudate on the posterior surface of the eornea (keratitis punetata), plastic exudation binding the iris to the anterior capsule; and elouding of the vitreous humor. These symptoms increase in severity until vision is greatly impaired. Under treatment, or possibly without it, they may then greatly improve. But usually there is a relapse, the plastic exudation increases, the vitreous becomes more elouded, and vision still further reduced.

If the case is going on to partial or eomplete recovery, the relapse will be less severe than the original attack; 
and probably after one or two relapses there will be continued improvement. If the case passes toward an unfavorable termination, each relapse leaves the eye more damaged ; and relapses continue to occur at intervals of a few weeks to many months, until all vision is lost, and the eyeball shrunken and soft. Commonly, diminished tension may be noticed within a few days after the commencement of the inflammation of the uveal tract. The pain at first is rather slight, and the iris may be firmly bound down before it is realized that the inflammation is at all serious. Subsequently the pain and dread of use of the eyes, or of exposure to light, become more marked.

Opacity of the vitreous usually interferes with the study of the ophthalmoscopic changes, but alterations of the choroid are the rule, while much inflammation of the optic nerve and retina are believed to be exceptional. Occasionally, there is severe inflammation of the cornea and conjunctiva, the latter without any great amount of discharge. Cases have been reported as of sympathetic origin, where the inflammation was confined to the cornea and conjunctiva. But it is doubtful if these should be regarded as instances of sympathetic disease.

Causes and Pathology.-The only well understood element in the causation of this disease is the injury to the exciting eye. This injury may possibly, in some cases, be a simple plastic inflammation of the uveal tract of that eye. But in the great majority of cases it is a plastic inflammation following perforation of the coats, occasionally following perforation by ulceration, as in intra-ocular tumor, usually following perforation by traumatism. When to traumatism is added the lodgement of a foreign body inside of the vitreous chamber, the risk of sympathetic inflammation is greatly increased. The removal of such a foreign body, after plastic inflammation has been set up, does not remove all chance of sympathetic disease, but does diminish the probability of its occurrence. Penetrating wounds of the ciliary region have been noticed to be especially likely to cause this 
disease. Wounds penetrating through the cornea, anterior chamber and iris are decidedly less likely to cause it. It more frequently occurs in children and young persons than in later life.

How the disease of the exeiting eye sets up the disease in the other is not known. But the speeulations regarding it are of interest for their bearings on general pathology. The optic nerves conneeted by the ehiasm, and the lymph-channels immediately around them, have been regarded as the path by which an infection "migrated" from the one eye to the other. But there is little mieroseopieal or experimental evidence to support this. Experiments made to confirm it have nearly all failed to produce any inflammation of the seeond eye. And where such inflammation was produced, it was probably part of a general infection rather than a genuine sympathetic ophthalmitis. It has been supposed that the ciliary nerves were the channels through which the exciting eye injuriously affeeted the sympathizing eye; but here too, positive evidence is lacking. Sometimes changes have been found in these nerves, sometimes they have not; and if the influenee of the nerves be one of perverted function, marked histologie changes in them should not be expeeted. It has been suggested that some morbid material from the exciting eye may enter the blood and set up inflammation in the uveal traet of the sympathizing eye, although doing no harm in other parts of the body. This might be a eytotoxin developed from cells of the uveal tract (Brown Pusey); although such an oecurrence seems at variance with the law that no organism develops toxins destruetive to its own cells.

Finally, it is suggested that through the ciliary nerves the injured eye is capable of unfavorably influencing its fellow, so that the influences tending to excite inflammation therein, which would otherwise be suecessfully resisted, are able by aid of this morbid predisposition, to overcome the resistance of the tissues; and that a sympathetic inflammation is set up by the injurious substances from the exciting eye, or the ordinary causes of inflan- 
mation acting in the presence of this constant unfavorable influence exerted by the injured eye.

Diagnosis.-When one eye has been lost or seriously impaired, any inflammation in the second eye should excite suspicion. The careful examination of the pre'viously blind eye will then indicate if it be liable to cause sympathetic disease. If it be blind with diminished tension, adherent and degenerated iris, and opacity preventing any view of the fundus, especially with any history of injury, it must be regarded with grave suspicion. In the supposed sympathizing eye the presence of the signs of iridocyclitis point to sympathetic inflammation. Without these the diagnosis cannot be certainly made.

Even though the disease be sympathetic, one must still distinguish between inflammation and irritation. Sympathetic inflammation comes on usually within a few weeks or a few months after injury. Or if it arises later, it mostly follows a renewal of the inflammation in the exciting eye. Irritation usually occurs ycars after the exciting eye has been injured, and has long been free from inflammation, and its tissues have undergone degeneration, especially if it be the seat of calcareous changes, or ossification of the choroid.

Sympathetic irritation may be attended with great irritability of the sympathizing eye, increased lacrimation, fear of light and complete inability to use the eye. But on examination it will be found that the pupil reacts freely to light, and that the iris is of normal appearance; and on removal of the cause of irritation, complete recovery occurs within a few hours or days. The earliest symptoms of sympathetic inflammation may, however, closely resemble those of sympathetic irritation. In both cases it may be difficult to use the accommodation.

Treatment.-The fact that the exciting eye has already been greatly damaged or destroyed, and that after the actual involvement of the sympathizing eye the most efficient treatment may fail to save it, makes prophylactic treatment of the highest importance. 'This consists in 
the removal of what is liable to become an "exciting eye." On this account the eyeball should be removed:

A. If blind from injury and the seat of iridocyclitis. (1). When known or supposed to contain a foreign body which cannot be extracted. (2). When the injury has oceurred in the ciliary region. (3). If the injury be recent (within two years) and the patient cannot remain within easy reach of competent professional advice, even though the eye does not contain a foreign body, and the womnd was not in the ciliary region.

B. If not blind, but with greatly impaired vision and the seat of iridocyclitis. (1). If known to contain a foreign body that cannot otherwise be removed. (2). If the wound be in the ciliary region, and the inflammatory process be active with diminished intra-ocular tension.

C. If the eye has been so severely injured that all chance of further useful vision is destroyed, even though inflammation has not yet set in, it should be removed if the patient cannot remain under competent observation.

The operations of enucleation of the eyeball and its substitutes are described in Chapter XIX. Their value in preventing sympathetic ophthalmitis may be considered here. It cannot be claimed that evisceration, with or without the insertion of an artificial vitreous, has been practiced long enough or widely enough to prove that it is equal in value to enucleation; but it has been suffieiently pratised to show that it has value in this direction. If infection travelling through the optic nerve, or by the lymph-channels adjoining it, be a factor in producing sympathetic ophthalmitis, evisceration must always be inferior to enucleation as a prophylactic measure, for infection already lodged in the sclera or adjoining lymph-spaces would be undisturbed by eviseeration, but would be thoronghly removed by enucleation. Besides the removal of the injured eye, the only measures of prophylaxis are those of general hygiene, and care in the use of the eyes.

When sympathetic inflammation has already begm, we must first consider the value of the exciting eye. In a few cases this retains useful vision; and, singularly 
enough, may still continue with useful vision, although the sympathizing eye may be entirely lost. In such cases the exciting eye will be in the end the only seeing eye and must therefore be retained. But if the sight of the exciting eye be already lost, or if it is the seat of active inflammation that is likely to destroy its sight, it shonld be removed at the earliest possible moment. Years ago the opposite advice of a few authorities left the surgeon in uncertainty as to what he should do. But the experience of the profession has now demonstrated that the chance of recovery of the sympathizing eye, is much better if the exciting eye be promptly removed.

The adaptation of an artificial eye to replace the globe removed is discussed in Chapter XIX.

The patient should be confined to a darkened room, spending must of the time in bed, but allowed to move about sufficiently to avoid bed-weariness. The eye must have complete rest and should be kept fully under the influence of atropin, unless iritic adhesions have already beeone so extensive and firm that the drug can cause but little or no retraction of the iris. Leeches, or the artificial leech, may with advantage be applied to the temple daily for a few days during the height of the attack. Bathing the eye for a few minutes in very hot water may be practised every few hours.

The general treatment should inelude the use of mercury ; up to, but not beyond, the point of constitutional impression. This may be given in laxative doses of ealomel, and inunctions, until some effect is produced; and then its action sustained by the internal use of the protiodid or bichlorid. In addition, tincture of the chlorid of iron in large doses has appeared beneficial ; and small doses of quinin are usually indicated. Equal in importance with such specific medication is care to improve in every way the general health and nutrition of the patient. If pain prevents sleep, small doses of morphin or acetanilid may be given each evening.

After the inflammation has subsided, it is sometimes necessary to do iridectomy or some allied operation, to 
make a clear passage where the pupil has been closed by the attacks of inflammation. Such operations are difficult on account of the inelastic brittle condition of the iris, and are very liable to be followed by a renewal of inflammation. They are best postponed until many months, or even years, after all symptoms of inflammation have subsided.

Prognosis.-The majority of cases of sympathetic ophthalmitis end in blindness. Probably half of those energetically and intelligently treated from early in the disease, do not escape this fate; and it is certain in all neglected cases. Even when the disease seems to yield promptly to treatment, the prognosis must be carefully guarded. The special tendency to relapse must be insisted on ; and where the eye has been already considerably damaged the danger of relapse and further impairment will not be over for two years. When, however, the relapses become less and less severe, and the eye on the whole is improving, the ontlook is encouraging; and if the recovery from the earlicr attack is complete, and has lasted for one year, the cye may be regarded as eured.

It is to be borne in mind that even after the removal of an injured eye the danger of sympathetic inflammation continues for at least three or four weeks. In numerous eases it has appeared two or three weeks after the removal of the exciting eye; and has run a characteristic course, though generally such attacks have been mild and amenable to treatment.

Sympathetic Irritation (Sympathetic Neurosis).This condition, long confused with sympathetic inflammation, is one in which the sympathizing eye may be rendered entirely useless, temporarily, or so long as the exciting eye is retained; yet on removal of the exciting eye, recovery is complete within a few hours or days.

Symptoms and Course.-Sometimes during the first few days after injury to the eye, and before it is time for sympathetic inflammation to develop, the other eye may appear disturbed, very sensitive to light and irritable 
when used. But this primary disturbance quickly subsides and many months or years elapse before true sympathetic irritation is likely to be developed. It begins with difficulty or pain in using the eyes for near work. If the accommodation be not actually diminished in amount, the eiliary musele is quickly tired; and blurring of near-vision, or pain, oceurs after the eyes have been used but a short time. Soon photophobia and exeessive lacrimation develop; then general hyperemia of the conjunctiva and selera. These symptoms may yield to rest of the eyes, or improve spontaneously. I Later they recur, grow worse, and become more constant. Examination of the eye becomes difficult, but the pupil dilates fully, and by using cocain, the media and fundus of the eye ean be seen to be normal. In sympathetic amblyopia, the impairment of vision is more gradual and eonstant, and the photophobia, lacrimation, and hyperemia, slight or entirely absent.

The diagnosis has been discussed in connection with that of Sympathetic Inflammation (page 337). It may also be needful to distinguish these eonditions from hysteria, malingering (where damages are involved), and the dread of blindness, which sometimes greatly disturbs patients who have lost an eye by injury.

Treatment and Prognosis.-The removal of the exciting eye is the only treatment and the whole treatment. Perfeet cure ean be promised from it. If this is not removed, the disability of the sympathizing eye will remain, partial or complete, under any other treatment. For the relief of sympathetic irritation eviseeration is equally as effective as enucleation. Even optico-ciliary neurotomy will give at least temporary relief.

\section{DISEASES OF THE CHOROID.}

Purulent Choroiditis (Suppurative Choroiditis or Irido-choroiditis, Panophthalmitis). - Purulent inflammation of the choroid is rarely or never confined to that membrane. Not only does the whole uveal traet participate in the process, but the retina and vitreons are involved and usually the whole eyeball, and sometimes adjoining structures suffer with it. 
Causes.-Direct infections by perforating wound of the eyeball, septic operations, especially cataract extraction or needling, or suppurating ulcer of the cornea, are the common eauses of choroidal suppuration. It may also arise from suppuration or thrombosis in the orbit. From these causes it attacks only the one eye. It also oecurs, generally affecting both eyes, from metastasis or embolism, in erysipelas, puerperal sepsis, septie endoearditis and other forms of pyemia, scarlet fever, cerebrospinal meningitis, influenza, and other acute specific diseases.

Symptoms and Course.-The attack is usually very severe. The exceptions to this occur late in the course of exhausting febrile disease, and with cerebrospinal meningitis in young ehildren. There is severe pain in the eye and head, intense hyperemia of the whole eye and its appendages; swelling of the conjunctiva with chemosis; sudden swelling of the lids; and sometimes such swelling of the orbital tissues as to cause marked protrusion of the eycball. There is great tenderness. There may be a distinct rigor ; and rapid elevation of the bodily temperature, with the general symptoms of pyrexia, including delirium.

The vitreous and often the anterior media quickly become so hazy that nothing ean be seen through them, and hypopyon may form. In most eases the sclerocorneal coat is perforated so as to permit the free escape of pus before any marked anelioration of symptoms oceurs. The pain then diminishes, the eyeball becomes soft, shrinks, and phthisis bulbi results; the eye, after many weeks, or even months, beconing quiet, and free fron hyperemia or pain.

Where the disease arises in eonnection with the specific fevers, it is apt to run a less violent course. Great pain and swelling may be absent. The vitreous becomes opaque, and appears yellow by focal illumination. Hypopyon may be noticed; but there occurs no perforation of of the sclero-corneal coat. The tension of the eyeball, at first rather elevated, falls below the normal, the hyperemia and tenderness slowly disappear, and after many weeks, 
the eye is found soft, with more or less opacity of the vitreous, and discoloration and degeneration of the iris. The purulent accumulation in the vitreous is often designated pseudo-glioma. Its differentiation from glioma of the retina is important. It is given in connection with that affection.

In a few cases, usually in young children, after cerebrospinal meningitis (the author has also seen it after typhoid fever), some sight remains in the eye, and slowly improves with the diminution of the vitreous opacity, which continues for many months, or even years afterward.

Diagnosis.-Purulent choroditis is only liable to be overlooked when it supervenes upon severe inflammation of the eye, as suppuration of the cornea or the orbit, or in erysipelas of the lids; or when, in connection with exhausting general disease, the onset is insidious and the patient so ill as not to call attention to the loss of sight. It is liable to be mistaken for orbital cellulitis, in which, however, the dioptric media remain clear; or confused with acute glaucoma, which can be known by the dilated pupil, the absence of history of any cause for choroidal suppuration, and the lighter swelling of the conjunctiva and neighboring parts.

Treatment.-This is to be directed mostly to relieving pain and shortening the course of the disease. If the patient will consent to it, these indications will be most promptly and effectively met by at oncc enucleating the eyeball. Enucleation during panophthalmitis has been credited with causing meningitis and death. Numerous cases have been reported in which death by meningitis followed the enucleation of suppurating eyeballs. But in some of these cases it is evident that the meningitis lad begun before the enucleation, and in others it is probable that it would have occurred without enucleation, as it has done sometimes when enucleation was not practiced. The author believes that the patient's risk of meningitis is not increased by enucleation if the operation is a surgically clcan one, sufficient blecding is allowed, and perfectly free drainage of the orbital tissues is secured. The former 
practice of at once stopping the bleeding that follows enucleation, by packing the orbit, and keeping it for hours under firm pressure, was far more likely to have eaused meningitis than the enueleation.

If the patient refuses enueleation, or his general condition prevents it, the eye may be poulticed; and at the end of two or three days freely ineised through the eornea, to allow the escape of the erystalline lens and the purulent aecumulations behind it. Pain may be lessened by free leeehing from the temple; and opimm and acetanilid given internally. A free laxative may be given, and afterwards the tincture of chlorid of iron, and quinin, with such other treatment as the patient's general condition demands.

The few cases in which any vision is retained should be treated without poulticing or ineisions, eommonly with prolonged rest of the eyes under a mydriatic. Espeeial attention should be given to everything ealculated to build up the general health.

Prognosis.-Severe panophthalmitis always ends in blindness, generally with shrinking of the eyeball. But an eye thus lost is not likely to excite sympathetic inflammation. In pseudo-glioma there is no chanee of restoring sight. In the few cases that retain some vision, slow improvement may continue for one or two years, and very useful although not perfect sight may be ultimately obtained.

Plastic Inflammation and Atrophy of the Choroid.-Under this head are included all non-purulent inflummations of the choroid. Although to some of these conditions the term plastie inflammation may appear not to be strictly applicable, they all show a strong tendeney to produce permanent visible alterations of strueture through the organization of exudates. Sueh alterations eommonly include both the formation of eieatricial eonnective tissue, and the atrophy to a greater or lesser extent of normal elioroidal struetures. Hence the neessity of considering them as two parts of a single proeess.

Causes.-The choroid is liable to be involved in all 
kinds of inflammation of the iris and ciliary body, so that all causes for those inflammations are causes of choroiditis. Plastic choroiditis and atrophy also arise without iritis or cyclitis, from eye-strain, especially in progressive myopia ; from syphilis ; from obscure disorders of general nutrition attended with anemia, in connection with menstrual derangements; and from traumatism. It has been supposed that choroidal atrophy occurred without inflammation from mere stretching of the ehoroid in high myopia; but this is not certain.

Symptoms and Course.-The eharacteristic symptoms of plastic inflammation of the choroid can only be studied with the ophthalmoscope. The acute stages attended with hyperemia may present flashes of light that oceur at short intervals when the patient is in comparative darkness. The retina in contact with the affected area may suffer, so as to cause impaired vision, and a sense of a cloud before the sight (positive scotoma). But if the affected area is away from the macula, this impairment of vision will readily passed unnoticed. Accompanying opacities of the vitreous or lens may also impair vision. Sometimes great atrophy of the choroid occurs without much impairment of vision; and the choroidal changes may be far advanced before any opacity can be seen in the vitreous or lens. The process may be entirely painless, or there may be a dull aching referred to the eyes and frontal region. In the absence of iritis and cyclitis, the eye externally presents a normal appearance; or in exceptional cases there is a slight hyperemia of the deep seleral vessels. With the ophthalmoscope we camnot direetly recognize general hyperemia of the choroid; but it is attended with heightened color of the optic disk, the capillary vesscls of which spring from the same source as the choroidal vessels, and not from the central retinal vessels. The early stage of choroiditis causes a lighter yellowish color of the fundus, with blurring of the choroidal details if these are visible. This blurring if general may cause a more uniform scarlet color; if confined to certain portions it causes blotches of the lighter, yellower red. A slight 
choroidal inflammation is apt to canse absorption of the layer of pigment-cells that overlie it, the retinal pigmentlayer. If this layer be generally absorbed, the choroidal vessels are visible, as in Fig. 118, and the upper and lower part of Fig. 110. If the retinal pigment-layer be thinned or lacking in scattered areas, it gives the fundus a "patchy" appearance.

Acute plastic choroiditis may give rise to well-marked localized swellings over which the retinal vessels may be scen to pass, or the affected area may be partly or wholly hidden by a diffuse haziness of the vitreous in front of it. After a few days or a few weeks, the swelling disappears and the choroid in the affected area becomes thinned. This may leave the larger choroidal vessels, which lie in its decper layery uncovered, and abnormally prominent, or it may include these so that the affected area shows the white sclera.

The earliest stages of ehoroilitis show no pigmentchanges, but as the ease progresses toward atrophy these always occur. The margin of the affected area always shows specks and blotehes of dark-brown or black pigment-masses; and similar deposits oceur within the atrophic area. Such deposits may be noticeable within two weeks of the onset of acute choroiditis; but they may continue to increase and alter for many nonths. Finally they seem to reach a permanent condition, and remain with atrophy throughout life, a visible recort of previons disease. Their appearance is illustrated in Fig. 110. Opacities in the vitreous and crystalline lens may also remain as evidence of a previous choroiditis.

Varieties.-Mryopic choroiditis has already been deseribed in connection with myopia (page 160). Dissemimated choroiditis is characterized by distribution of the choroidal changes in seattered areas, the intermediate fundus being comparatively normal as in Fig. 110. One or two such areas, the remainter of the choroid being healthy, constitute a localized choroiditis. A single area oeeurring at the macula is called a central choroiditis. In this position the scotoma it causes is sure 
to attract attention; and even comparatively slight changes will be noticed on that account. A form of central choroiditis occurring in old people, called therefore senile choroiditis, may be a cause of poor vision and disappointment after cataract extraction. In anterior choroiditis the lesions are confined to the anterior portion

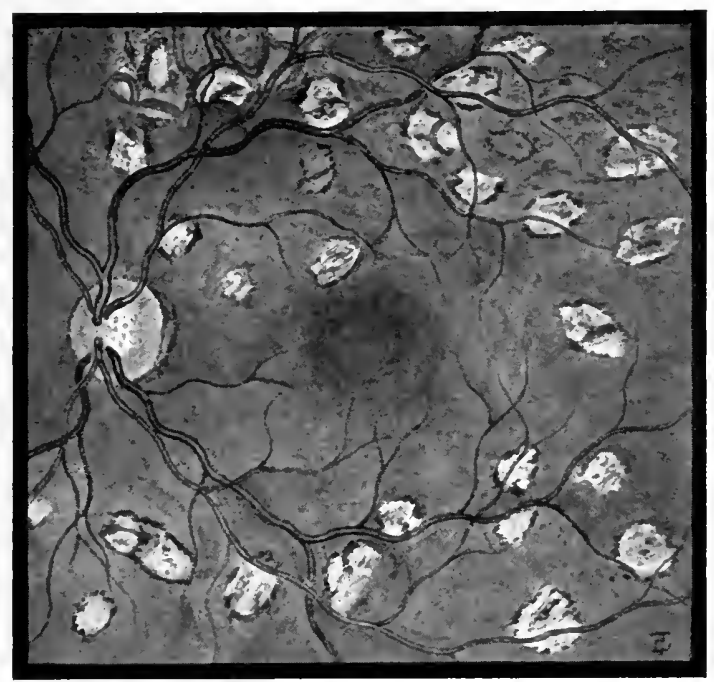

FIG. 110.-Disseminated choroiditis. Patches of choroidal atrophy seattered over the fundus. The macula has escaped damage. A partial atrophy near the left upper corner exposes the choroidal vessels.

of the choroid. Sometimes they are so far forward as to be out of sight with the ophthalmoscope; and their existence can only be guessed from the presence of opacities in the anterior portion of the vitreous.

Diffuse choroiditis invades one or a few large areas of the fundus. The exudate is usually extensive, and slowly gives place to atrophy. Marked pigment-clianges may be noted while yet the yellowish color of the exudate forms the background for the pigment-markings.

Diagnosis.-Choroidal inflammation and atrophy must 
be distinguished from retinitis, by the fact that the retinal vessels are not altered in size or outline, and are not hidden or partially obseured in eertain parts of their eourse. This will also distinguish ehoroidal atrophy from other retinal eonditions as opaque nerve-sheaths, fatty degeneration, ete. It must, however, be remembered in eonnection with choroiditis that diffuse haziness of the vitreous may so veil the retinal vessels as to simulate retinitis; and that not rarely both retina and ehoroid are involved in the same inflammation (see page 101). Atrophy of the choroid must also be distinguished from coloboma. This is most diffienlt as between the rounded partial colobomas that oceur in the macula and elsewhere, and isolated patehes of ehoroidal atrophy. The black pigment-deposits in the choroid may be confused with opacities in the vitreous or lens. Compare Figs. 63 and 110 with Figs. 115, 116,117, and 118. Patehes of anomalous pigmentation may readily be taken for patches of ehoroiditis. (Sce page 99.)

Treatment.-For choroiditis the eyes should, as far as possible, be put at rest, usually under the full influence of a mydriatic. They should constantly wear correeting glasses. In acute cases the patient may be kept for a few days in a darkened room, with little active exertion; and loeal bleeding from the temple may be practieed on suecessive days. Exposure to excessive light and sudden changes of light must be avoided, dark glasses which are large enongh, and fit so as to protect the eyes thoroughly, should be worn out of doors. The eyes must also be guarded from radiant heat as from a stove, open fire, or lighted lamp.

Alteratives, especially mereury and potassium iodid are commonly given for a considerable time. If syphilis is probable, the former should be used freely by inunetion, until its constitutional effeets begin to manifest themselves. Subeonjunctival injections of mereuric chlorid have been advocated as of marked value. Any other probable cause or underlying dyserasia should receive appropriate treatment. But often none can be discovered. 
It is then of the highest importance in all cases to improve the general condition of the patient. On this account confinement to a dark room should be resorted to only in the acute cases, and with them limited to a very few days. In chronic eases, the patient should live as much as possible in the open air, and often a change of oecupation or residence will be of benefit.

Prognosis.-Choroiditis is always a very serious disease. Sight lost through it is never perfectly restored; and so long as it is active, or recurs involving new areas, every effort should be made to limit its ravages. Localized choroiditis dne to eye-strain is most amenable to treatment; and next to this, choroiditis due to syphilis ; these being the varieties whose etiology is best understood.

Choroidal hemorrhage is rare as compared with retinal hemorrhage. If deep and diffused, it may merely cause a deeper red of the affected portion of the fundus; if more superficial, it cannot be distinguished from hemorrhage in the deep layers of the retina, except that it has not the very dark red color sometimes presented by retinal hemorrhage. From hemorrhage into the nervefiber layer of the retina, it is distinguished by its rounded ontlines as contrasted with the "flame shape" of the retinal hemorrhage. The choroidal vessels are the most frequent source of hemorrhage into the vitreous. The treatment is merely that of the associated conditions.

Detachment of the choroid from the sclera is sometimes found in dissecting degenerated eyeballs, but is very rarely seen with the ophthalmoscope. So seen, it cannot be distinguished from detachment of the retina, unless the choroidal vessels are visible, in which case it resembles sarcoma of the choroid.

Colloid masses may form in the choroid in elderly people, causing rounded whitish spots, which may be massed together at the macula, or seattered over the fundus. They do not necessarily impair vision.

Ossification of the Choroid.-In eyes long blind and degenerated, calcareous change is often found in the 
choroid; and sometimes the choroid is replaced by true osseous tissue. If the ossification he sufficiently extensive, it may be detected by pressure upon the globe through the elosed lids. It may become an indieation for removal of the eye, by eausing sympathetic irritation.

Shrinking of the eyeball is apt to follow extensive plastic disease of the uveal tract. With the contraction and organization of the exudate, which forms a mass behind the lens, the retina is detached from the choroid, and drawn with the shrunken vitreons into a chord, stretehing from the optie nerve to the posterior pole of the lens. The lens is often shrunken and pushed forwarl, the anterior ehamber appears shallow, and the cornea smaller than normal. The eyeball is softened, so that the pressure of the four recti museles canses it to assume a somewhat quadrate form. This condition comes on slowly, sometimes after repeated attacks of inflammation, sometimes after a single severe attack. When suppuration of the uveal tract goes on to perforation of the seleroeorneal eoat the shrinking is more irregular, much more rapid, and the resulting stump smaller, with less resemblance to a normal eye. Fuchs calls the former eondition atrophy of the eyeball, the latter phthisis bulbi. Other writers use these terms interehangeably. The former eondition is attended with greater danger of sympathetic inflammation, and therefore is an indication for enucleation. The latter may permit of the wearing of an artificial eye over the stump. Either, after many years, may eause sympathetic irritation.

\section{TUMORS OF THE CHOROID.}

Sarcoma of the ehoroid oceurs about once in 3000 eases of eye-disease, mostly about middle age. It starts usually as a rounded lobulated tumor in the fundus of the eye, distinguished from detachment of the retina by the vessels which may be seen lying bencath the retina. Its appearance is illustrated in Fig. 111.

The growth eauses blindness of the overlying retina, 
and a corresponding defect in the field of vision. But if it does not involve the region of the macula, it may grow a long time without attracting the patient's attention, and without any alteration of the external appearance of the eye, or other symptoms. Hence this is called the latent stage of the disease. It often lasts for years.

Iater the eye begins to show evidences of deep inflammation, and the tension of the globe is increased. This is called the inflammatory or glaucomatous stage. The an-

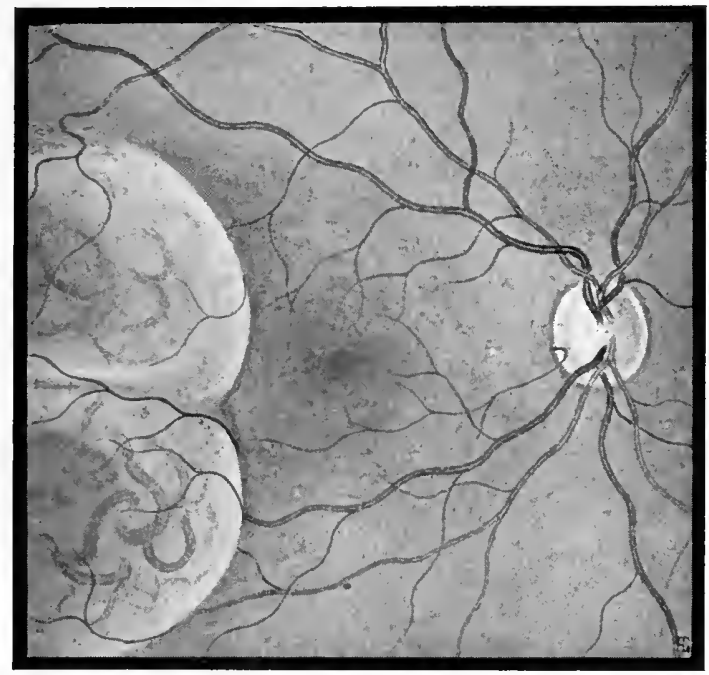

F1G. 111.-Sareoma of the choroid in the right eye, starting to the temporal side of the macula; first stage. 'lhe rombled masses of the growth are seen on the left, eontaining vessels that look like choroidal vessels, and with the finer retinal vessels ruming over them.

terior chamber is shallow, the eye painful; and it may be very difficult to make the diagnosis between this condition and ordinary glaucona. After a time, varying from a few weeks to many months, the growth penetrates the selera, the tension of the eyeball falls, and the pain abates. If the perforation be far enough forward, the tumor-mass is at once seen springing from it, but if out 
of sight, the case may still remain obscure. In this third stage its growth is rapid and soon eauses the appearance of a large tumor in the orbit. The fourth or final stage begins with the involvement of other portions of the body by metastasis. The case ends in death from rapid exhaustion or the overwhelming of some vital organ.

Diagnosis.-Sareoma of the choroid is distinguished from glioma of the retina by the age of the patient. Sareoma is extremely rare in childhold; glioma occurs only before the age of twelve years. From simple detachment of the retina it is distinguished by its reddish yellow color, the seeing of vessels beneath the retina, the absence in most eases of movement of the retina, floating on a serous fluid, and by transillumination (p. 77). The latter is of value chiefly for tumors anterior to the equator of the eyeball. Ophthalmoseopic examination, using direct sunlight, may reveal the tumor through the detached retina. The distinction from primary glauenma is given in comnection with that disease (Chapter $\mathrm{XV}$ ). When the tumor has perforated the selera, its character may be recognized by the microseope ; or, usually, by. its abundant pigmentation.

Treatment.-This is the earliest possible removal of the eyeball; or if the sclera is already perforated, the removal of the whole eontents of the orbit. When the growth eannot wholly be removed, the treatment with the mixed toxins of erysipelas and bacillus prodigiosis (Coley's method) offers a small ehance of eure. If the growth of the tumor eannot be checked, it should be kept well cleansed and disinfeeterl.

Prognosis.-The spindle-eell variety of sarcoma may be permanently eured by complete removal. Round-cell sareoma returns; often very promptly, sometimes not for several years. The life of the patient may not be materially prolonged by the removal of a round-cell sareoma; but the course of the disease may often be rendered less painful, and a respite secured, even though the recurring growth may seem to progress more rapidly.

Tuberculosis of the choroid is rare. It causes 
rounded yellowish spots, which grow rapidly without pigment-ehanges, but rarely reach the size of the optie disk. These require no treatment. Sometimes it forms a single large mass resembling sarcoma, for which the eye should be enucleated.

Carcinoma and adenoma oceur, the former as a rare tumor usually secondary to carcinoma of the breast.

\section{ANOMALIES OF THE IRIS AND CHOROID.}

Anomalies of the Iris.-The iris is never of uniform color throughout, nor are the markings preeisely alike in the two eyes. When the differences of color are very striking the eondition is termed heterochromia. The small dark masses at the edges of the pupil, called ectropion of the uvea have been already alluded to (see page $331)$.

The fibrovascular membrane which occupies the pupil in early fetal life, is sometimes. incompletely removed, leaving one or more threads of opaque tissue which extend into or aeross the pupil, ealled persistent pupillary membrane. Such threads are distinguished from posterior synechias due to iritis by the faet that they are attached not to the pupillary margin of the iris, but distinetly to its anterior surface. If numerons, they may conneet with a mass lying in the pupil, and attached to the anterior

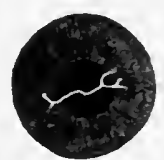

FIG. 112.-Persistent pupillary membrane, usually gray or the color of the iris.

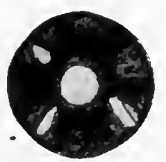

FIG. 113.-Polycoria seen by ophthalmoseopic illumination.

surface of the lens. The more eommon appearance is shown in Fig. 112.

Anomalies of the Pupil.--Displacement of the pupil from its position near the ecnter of the iris is called corectopia. Multiple pupil is ealled polycoria. Only 
one of such pupils is supplied with a distinct sphineter, except in the case where the normal pupil is divided into two by a persistent pupillary membrane. Sometimes the pupil is extended in a certain direction, usually downward, by a deficiency of the iris-substance. This is called coloboma of the iris. The anomaly may amomnt to only a slight notch in the margin of the iris, may extend partly across the iris, or may include its whole width, the pupil reaching behind the margin of the cornea. It may vary in width and shape. A common form is shown in Fig.

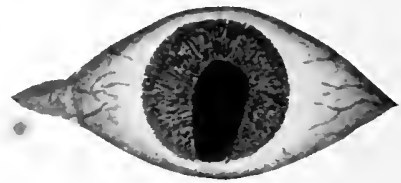

Frg. 1]4.-Congenital coloboma of the iris, pupil extending downward, below the lower margin of the eornea.

114 , as seen by oblique illumination. It may accompany coloboma of the lens as shown in Fig. 133, which represents its appearance as seen with the ophthalmoscope. Its form is more rounded than that of the coloboma usually left by iridectomy (see Fig. 165). In rare eases the piupil extends the whole width of the cornea, no iris being visible. This is called aniridia or irideremia. With the ophthalmoseope a dark line shows the margin of the lens against the general red ground of the fundusreflex.

Coloboma of the choroid oceurs in two forms. In one the defieiency of the choroid, allowing the white sclera to be seen throngh it, extends backward from the ciliary region (usually from below) toward the optic disk, sometimes not extending to it, sometimes including it. This form is frequently accompanied by coloboma of the iris and lens. It is illnstrated in Fig. 115. The other form consists of a rounded, area, sometimes situated at the maenla, sometimes in other parts of the fundus. The coloboma is often crossed by retinal vessels, sometimes 
also by large choroidal vessels. Its margins always show pigment-masses, and some pignientation may be scattered over its surface. It may be divided, as in Fig. 115, by a

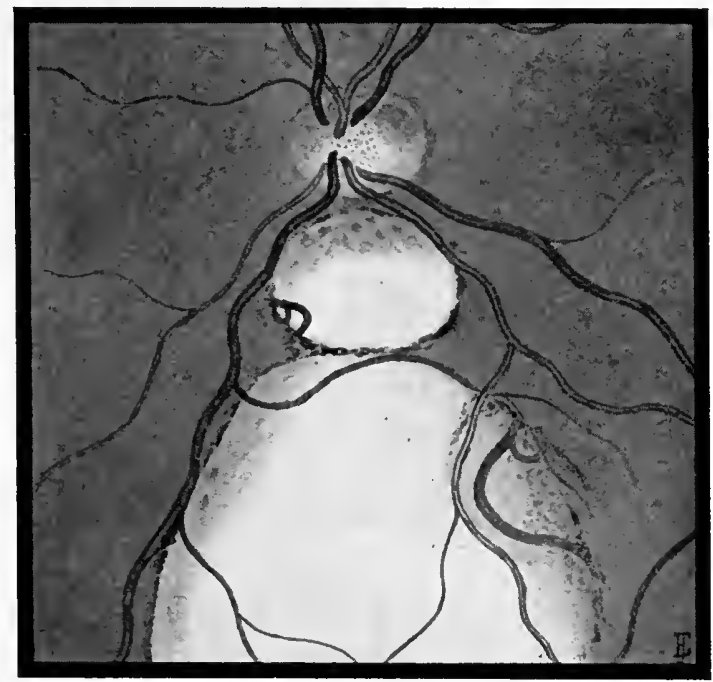

FIG. 115.-Coloboma of the choroid of the left eye. Below the optic disk is seen a small oval coloboma, and below it a larger one that stretches forward probably to the ciliary body. Retinal vessels cross it, and a choroidal vessel runs out into it.

narrow strip of normal or nearly normal fundus. It may be of about the same level as the adjoining fundus, or considerably depressed in portions or throughout. It is distinguished from choroidal atrophy, albuminuric retinitis, and opaque nerve-fibres, chiefly by its regular rounded form, and from the last two by the pigmentation of its margin (compare Fig. 115, with Figs. 110, 117, and 125).

Albinism.-The absence of pigment from the uveal tract accompanies the yellowish-white hair, eyclorows and lashes, and the absence of pigment in the skin, that characterize the albino. The iris usially appears a dull leaden-blue or gray, the pupil may show a red reflex even by ordinary illumination. With the ophthalmoscope the 
pink fundus-reflex may be obtained through the iris. The whole fundus appears yellowish-white, with the optic disk very pink by contrast. The ehoroidal and retinal vessels are seen with equal distinctness, and apparently intermingled. The condition is liable to be hereditary or to affect brothers and sisters. It is in most cases attended with very marked errors of refraetion, especially high astigmatism and hyperopia. The eyes are habitually partly closed, to lessen the amount of light entering them, and to diminish the effeets of imperfeet focussing. Such eyes require the eareful correction of refractive errors, and guarding from sudden changes of illumination.

Minor Anomalies of Pigmentation.-The choroid presents all gracles of pigmentation, from complete absence in the albino, to the dark saturation which gives the negro fundus a dark brown, rather than red appcaranee. Occasionally isolated black or brown points or patehes of pigment are seen as congenital anomalies, often but a single one, sometimes several scattered through the fundus. Sometimes one or more large irregular patches of the sort, resembling the common representations of sun-spots, may be found in the macula. Such anomalous pigment-deposits are distinguished from those of atrophy by the absence of thimning or other defeet of the choroid. They cause no impairment of vision. 


\section{CHA P'TER XII.}

\section{DISE $A$ SES' OF THE RETINA.}

General Considerations. - The retina is an off-shoot of the central nervons system. This, and the physical conditions under which it is placed, influence the eharacter of its diseases and give them especial interest. Disturbances of its function are capable of minute localization and exact study, and the greater part of the retina is absolutely open to inspection, under magnification most uscful for the connection of symptoms with pathologic alterations. These facts give its diseases immense importance in the study of general pathology. For the gaining of definite conceptions of pathologic processes, ophthalmoscopy offers advantages in many ways superior to those afforded by the microscope or the post-mortem room.

The neurons of the retina, like those of the brain, have their function disturbed or depressed below the level of consciousness by pressure. Yet they are capable of regaining function, if the pressure be not too severe or prolonged. Their function is similarly depressed by impaired circulation; and if the impairment continue long enough, degenerative organic changes follow. The retinal neurons are also sensitive to toxic influences exhibiting varying degrees of susceptibility, and illustrating most minutely and significantly the essential phenomena of poisoning.

It should be borne in mind that the optic nerve is but a commissure connecting the retina with various other parts of the central nervous system. The diseases classed as belonging to the optic nerve, and the amblyopias, are largely retinal diseases; so that this and the suceeding chapter must be considered together.

Symptoms of Retinal Disease.-The diagnosis of diseases of the retina rests upon studies of functional impairment by tests of vision, visual field, and color vision ; and the nse of the ophthalmoscope. Most of them are named as forms of retinitis, but some so named might more properly' be spoken of as degenerations. 
Impairment of Vision.-Retinal disease, not manifest in any other way, will cause impaiment of vision. There may be ibnormal after-images, or deficient power of recovery from the changes produced by exposure to light, which may lead to impairment of vision in strong light, day-blindness; or its undue impairment in diminished light, night-blindness. The latter is apt to occur endemieally when nutrition is impaired, especially by lack of food, or confinement. The retina, otherwise normal, may so suffer from prolonged exposure to excessive light as to have its sensitiveness greatly impaired, even for comparatively strong illumination, snou-blindness. This occurs from exposine in high momintains and in polar regions. It is distinct from retinitis due to exeessive light (see page 371 ).

Hyperesthesia of the retina shows itself by discomfort in the presence of strong light, and attempts to avoid it; but without the tendency to close the lids, and press upon them, which is shown in the photophobia of conjunetivitis or keratitis.

Metamorphopsia, due to displacement of the percipient elements of the retina by exudation, is usually noticed when retinitis involves the region of the macula. Fine parallel lines, when their images fall on the atfected area, appear crowded together from separation of the retinal clements, or spread apart by crowding together of these elements; or a straight line appears to have an angle at the point looked at; or one portion of the line appears displaced as regards the other portion. These appearances are most noticeable when the line is turned in some special direetion.

Hyperemia of the retina is recognized ehiefly in the enlargement of the larger retinal vessels. These vary markedly in ealiber in normal eyes, so that only extreme departures from the usual standard ean be classified as abnormal, unless the eye in question has been recently examined ophthalmoscopically. Tortmosity of the vessels is a more definite evidence of increase in their fullness; but even very marked tortuosity may oceur as a eongenital anomaly in perfeetly healthy eyes, and may be 
limited to a single retinal vessel (see also page 92 ). Undue redness of the optie disk is apt to oceur with retinal hyperemia.

Anemia of the retina of a moderate degree is even harder to recognize with certainty than is hyperemia. It is shown by narrowing of the vessels, and straightening of their eourse. Acute anemia of the retina with extreme eontraction of the retinal arteries, the veins being broad and dark with pallor of the optic disk, and sudden blindness is called ischemia of the retina. It occurs after excessive hemorrhage, as metrorrhagia, and in acute disease, as erysipelas, and cholera. In quinin-blindness both arteries and veins are contraeted. Both hyperemia and anemia of the retina are frequently judged present or absent merely by the hyperemia or anemia of the optic disk; but it must be remembered that the circulation of the optic disk is even more intimately connected with the circulation of the choroid than with that of the retina.

Alterations of the Vessels.-General anemia shows itself in the retina by quite other signs than those of retinal anemia. The retinal veins beeome broad and pale with a wide light streak. Changes in the blood, as in diabetes, may alter the color of the retinal vessels so that it becomes difficult to distinguish arteries from veins or either from the general color of the fundus. Patehes of fatty degeneration causing a glistening white appearance may be found in the walls of the vessels, particularly in connection with albuminuric retinitis. The affeeted portion of the vessel appear's as a white band, and beyond it the vessel may assume the normal appearance, or whole vessels may be thus altered to white streaks. This appearance is quite different from that of the faint gray lines seen on either side of the vessel where it erosses another vessel or other dark background upon the optic disk; and which may also be seen to extend beyond the disk, in eyes that have been the seat of retinal inflammation, or in vascular disease.

Iregularities of caliber are noticerl in the retinal vessels, 
unassociated with marked retinal disease, or great disturbances of the general circulation. They may also be seen after neuroretinitis and as an early sympton of renal vascular disease, or of grave disturbances of the cerebral eirenlation or of cerebral hemorrhage. Pulsation of the vessels is elsewhere discussed. (See page 86 and Chapter XV.)

Retinal hemorrhage appears as one or more dark red spots, which slowly disappear with the decoloration of the clot, and may be succeeded by white spots of fatty degeneration. Hemorrhage is most frequently situated in the nerve-fibre layer, where the effused blood pushes its way between the bundles of nerve-fibres; giving the patch a striated appearance, especially noticed at the margins, in the directions the nerve-fibres run. Hemorrhages of this shape and appearance are called flameshaped. They are illustrated in Plate I, 2, and Figs. 116 and 117. Hemorrhage into the deeper layers of the retina does not present this appearance, but has a rounded edge in all directions, and the retinal vessels may sometimes be seen to cross in front of it, although almost invisible against such a background.

A large pateh of hemorrhage hiding the retinal vessels, and having a rounded ontline, especially liable to cover the macula, and often slowly shifting position from day to day under the influence of gravity, is called a subhyaloid hemorrhage because it is located not in the retina but on its surface. Such a hemorrhage may undergo complete absorption, with full restoration of acuteness of vision. This rarely or never happens when the hemorrhage occurs in the retina.

Retinal Opacity from Exudate.-The transparency of the retina is markedly impaired by the presence of exudate, even by simple edema. If the swelling be great, the normal red of the fundus may be entirely replaced in the affeeted area by a gray or bluish eolor, closely resembling the appearance of detached retina. Above and below the optic disk where the nerve-fibre layer is thickest, the distribution of the exudate between the nervefibre bundles gives the retina a striated appearance, some- 
what like that of partial opaque nerve-fibers. In other parts of the retina the areas of swelling and opacity have rounded outlines, which may be quite distinct, or the patch may shade imperceptibly into nornal fundus. The appearances produced by retinal exudates are most pronounced in those regions where the retina is thickest, about the optic disk and macula, and are scarcely discernible at the anterior peripheral parts of the retina. The haze of retinal swelling usually covers and conceals portions of the retinal vessels; but where the vessel lies entirely upon the surface of the retina the gray background of the swollen retina causes it by contrast to stand out with unusual distinctness. This is illustrated in Fig. 116.

Fatty degeneration may take place in the connectivetissue elements of the retina, or in exudates into the retina, and especially the remains of hemorrhages. It causes spots that may have a dirty yellow or reddish hue, but which in most typical cases are pure glistening white. These may be arranged in characteristic figures, as in albuminuric retinitis and in circinate retinitis.

- Pigment-changes.-The layer of hexagonal pigmentcells lying next to the layer of the rods and cones belongs, embryologically, to the retina. It is properly called the retinal pigment-layer. Loss of its pigment renders visible the vessels and intravascular spaces of the choroid; and is usually associated with choroidal disease, as in myopia. (See Fig. 63.) This pigment is always scanty at the periphery of the retina, and often becomes absorbed as a senile change. In certain diseases pigment is deposited in the more superficial layers of the retina and especially along the vessels, covering portions of them as with a blanket, and to that extent concealing the vessels. (See Fig. 118.) These pigment-deposits are associated with chronic disease, or may mark the site of former hemorrhages.

Atrophy of the retina occurs as a sequel to diseases of the retina or optic nerve, or both; especially from embolism or thrombosis of the central vessels of the 
retina, or atrophy of the optic nerve. It is indicated by great diminution in the size of the retinal vessels, and sometimes by absence of the retinal pigment.

\section{RETINITIS.}

Simple retinitis (edema of the retina, serous retinitis) is characterized by more or less opacity of the retina, which may be limited to a few small spots, or may involve a large part of the retina in the region of the posterior pole. It may affeet one or both eyes. The vessels are usually somewhat broad and tortuous, some of their curves being veiled by the hazy retina. Vision is impaired over the portion of the field corresponding to the affected retina.

Etiology and Diagnosis.-This disease may be cansed by eye-strain, or by unrecognized constitutional conditions. Other forms of retinitis often begin by simulating this one, and only acquire their special characters later. The diagnosis is made by excluding the canses of the special forms of retinitis. But it is sometimes difficult to distinguish the haziness due to retinal swelling, from that due to vitreous opacity, or the blurring eansed by astigmatism (see page 176); and marked edlema may be mistaken for detachment of the retina.

Treatment.-Simple retinitis requires rest of the eyes in a moderate and constant light; often with correction of errors of refraction, sometimes with the continued use of a mydriatic. A mild purgative may be given, and followed by the use of iodids in small doses. The general health should be attended to. Under such treatment recovery is nsually complete, if the case be truly one of simple retinitis. A few cases with dense masses of exndate may have corresponding permanent scotomas.

Purulent Retinitis (Metastatic or Embolic Retinitis). -Clinically this disease cannot be distinguished from purulent elioroiditis (see page 341 ), except that it more frequently runs the chronic conrse that results in pseudoglioma. It is distinguished by the microscope after the 
eye has been enucleated. It is caused by wounds, partienlarly by foreign bodies penetrating the cornea and lodging in the vitreous, without injury to the choroid; and by metastasis in the course of pucrperal fever, pyemia, etc.

Sometimes, in connection with septic disease, small white spots and hemorrhages appear seattered in the retina, without other inflammatory symptoms, or much impairment of vision. This eondition is ealled septic retinitis.

Leukemic Retinitis or Neuroretinitis.-Profound leukemia, and pernicious anemia, are apt to be attended by a form of retinitis in which there is great and general

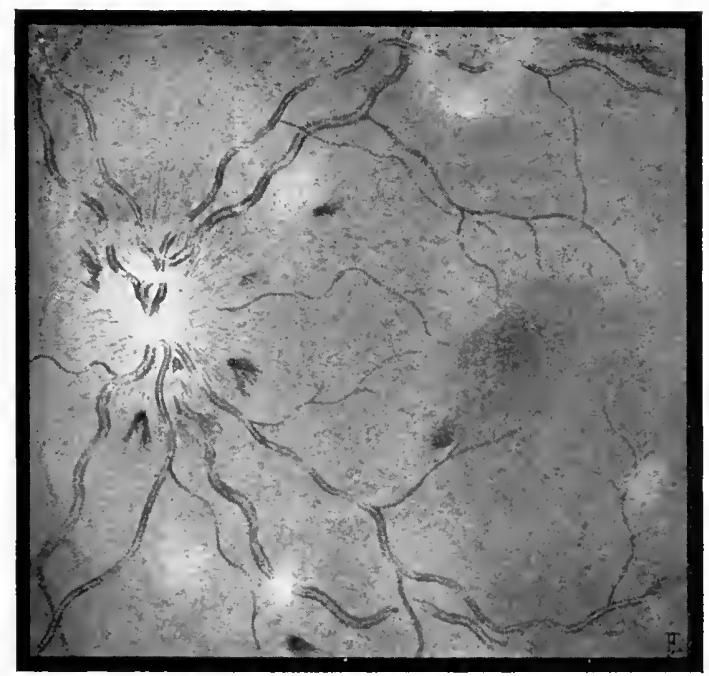

FIG. 116.-Leukemic retinitis of left eye. The optie disk is entircly hidden by swelling, and ill-defined light patches of exudate hide parts of the retinal vessels. The macula is slightly affected. Several "flame-shaped" hemorrhages are show by darker patches.

swelling and opacity of the retina, often extending upon the optic disk. There is enlargement of the retinal veins, sometimes enormous, and, in the later stages, 
numerous flame-shaped hemorrhages. The appearances are represented in Fig. 116. If the case be sufficiently chronic some of the patches of more dense exudate may show evidence of fatty degeneration. The general color of the fundus is light and often strikingly yellow; and the vessels are broad and pale, with visible sheaths. Both eyes are affected, although often to different degrees.

Etiology and Diagnosis.-The essential cause is the leukemia, or pernicious anemia; and its recognition with that of the retinal changes, establishes the diagnosis. Much the same retinal ehanges have been seen in cases of profound anemia from other causes, and in connection with hemophilia. Malarial disease of the retina may present much the same appearances.

Treatment and Prognosis.-The treatment is that of simple retinitis, with the treatment of the leukemia. The retinal lesions commonly appear late, and do not often improve muel, eontinuing to grow worse until the fatal termination of the general disease. Usually they do not eause blindness. Inprovement in the general condition may lead to great improvement in the retinal swelling, with improved vision.

Hemorrhagic Retinitis (Apoplexy of the Retina).Sometimes with a history of rather rapid impairment of vision, usually in one eye or to a greater extent in one eye than the other, a patient presents numerous flameshaped hemorrhages scattered throughout the fundus, with some swelling and opacity of the retina. One eye may remain unaffeeted, but usually both become involved, although sometimes not the second until months or years after the first. If the ease be watehed, fresh hemorrhages are detected from time to time; and white or yellowish spots, or areas of pigment disturbance, follow. The optic disk may be red and swollen. The retinal veins are dilated, but the arteries may be rather small.

Etiology and Diagnosis.-The clisease is most frequently seen in elderly persons, althongh some retinitis may accompany reeurring hemorrhages in young men. In all cases it is probable that the vessels of the retina 
are diseased; and the extra-ocular vessels, too, are generally abnormal. In some of the cases there is a thrombosis of the central vein of the retina. But in general the canses are not clear. The recognition of such a condition as Bright's disease would of itself remove the case into another class. Some hemorrliage is likely to occur in most forms of retinitis.

Treatment and Prognosis.-Rest of the eyes, protection from strong light by dark glasses, and the local abstraction of blood from the temple, are recommended. Subconjunctival bloodletting has been tried by Cross. The avoidance of excitement and the correction of any abnormality in the circulatory or digestive systems, are of equal importance. But in spite of treatment, hemorrhages recur, and sight is permanently damaged, even in young patients. In the larger number of elderly patients the eye is rendered practically blind. There is considerable danger of a subsequent rise of tension, causing a particularly intractable form of glaucoma ; and the probability of death within a few months or years, especially from cerebral hemorrhage, is relatively great.

Albuminuric Retinitis (Renal-vascular Retinitis, Retinitis of Bright's Disease). - This disease is chiefly encountered among elderly people, who come secking relief for impaired vision. The onset of the symptom is often sudden, corresponding with the occurrence of hemorrhage or swelling in the region of the macula. The ophthalmoscope shows spots or patches of hemorrhage or fatty degeneration scattered throughout the retina; or grouped in certain portions, especially about the macula. The retinal vessels are irregular in caliber, especially the veins, parts of which may be dilated and tortuous. Sometimes the retina over an extensive area about the optic disk and macula is greatly swollen, and of a dirty reddish or yellowish color, or even glistening white. Usually the optic disk is reddened and its margin obscured by swelling.

Examination shows diminished climination of urine, and the presence in it of albumin and casts, although 
albumin may at times be absent, and the casts not numerous. Close questioning will generally reveal some chronic impairment of health, especially nausea and headache; and almost invariably the arteries throughout the borly show undue rigidity, and the pulse is tense though often small.

Etiology and Diagnosis.-In addition to the canses of simple inflammation of the retina this form of retinitis

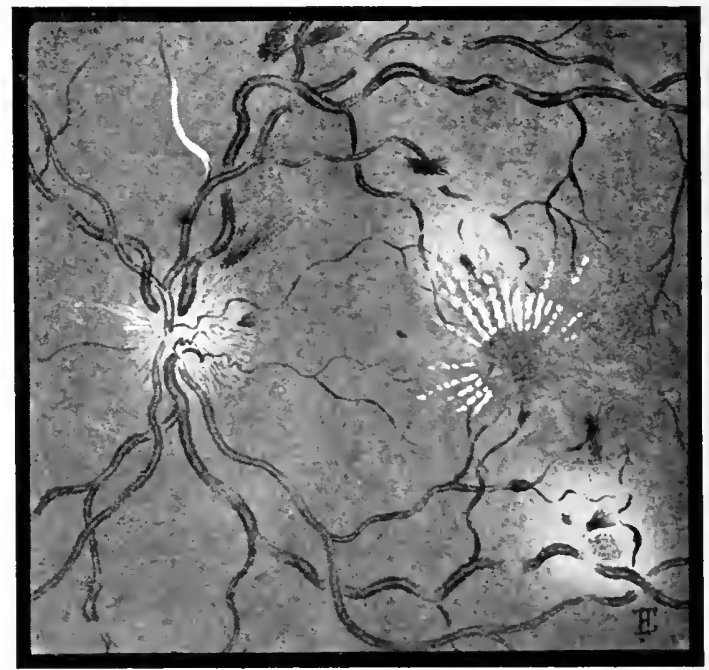

FIG. 117.-Albuminurie neuroretinitis of left eye. The disk is hidden by a moderate viscular swelling. The maeula shows the stellate grouving of white dots and streaks, and above and below are indefinite patches of retinal exudate. A braneh of the superior temporal artery directly above the disk has turned white, and there are numerous flame-shaped hemorrhages. The retinal veins are irregularly dilated.

clearly depends on the general degenerative changes of grave renal-vascular disease. It may occur in acute Bright's lisease, after scarlatina, in lead poisoning, or with the albuminuria of pregnaney. But the largest. number of cases occur in chronic interstitial nephritis, at a time when increased arterial tension can no longer keep up the normal excretion by the kidneys, when the ves- 
sels have already undergone serious degenerative changes, and the evidenees of grave disease are beginning to appear elsewhere. In the presence of these general disturbances any evidence of retinitis, or even the mere presence of isolated hemorrhages may class the ease as one of albuminuric retinitis.

The ophthalmoseopic appearances are, however, so typical that an almost certain diagnosis may be based on these alone. They are illustrated in Plate I, 2, and in Fig. 117. Fatty degeneration causes dots and larger areas of snowy whiteness. In typieal eases these are arranged in lines radiating from the center of the maeula, sometimes in all directions, sometimes only in a limited sector of the region. In other parts of the fundus the dots are seattered irregularly, and are eommonly less numerous. Usually a few small scattered hemorrhages are found, although they may be absent at a single examination. Sometimes the henorrhages are large and very numerous.

The appearances in the macula are sometimes imitated in optic neuritis from brain disease. But in those cases there is always great swelling of the disk. Albuminurie retinitis may also be attenderl with neuritis. But it may present the maeular ehanges without material changes in the optic disk; and when the disk is muel affected the retinal lesions are generally more extensive than are found in eonnection with neuritis from other causes. Alterations in ealiber are most pronouneed in eertain vessels, while others appear almost or quite normal.

Albuminurie retinitis, although not an early symptom of renal-vaseular disease, may be the first that reveals the nature of the case. In all eases presenting suspicious changes in the retina the eondition of the kidneys, lieart, and general circulation, should be carefully studied.

Treatment.-As in other forms of retinitis the eye shonld have rest. Reading must be suspended or greatly limited. Errors of refraction or failure of aecommodation should be earefully met by proper lenses, to be worn whenever the eyes are used. Beyond this the treatment is that of the general condition; regulated diet, woolen 
clothing, removal to a dry mild climate, and careful avoidance of worry, or mental strain. Internally strychnin in moderate doses is sometimes markedly beneficial. Preparations of iron are valuable in many cases, but may do serions harm in those showing a strong tendency to develop fresh hemorrhages.

Prognosis.-Occurring immediately after scarlatina, with acute Bright's disease, during pregnancy, or with lead poisoning, albuminuric retinitis may end in reeovery, often, however, not complete. Where it occurs with chronic renal-vascular disease, if the eyes have been mueh strained as by hard use, insufficient help from glasses, ete., complete rest of them may be followed by marked improvement of vision. But in most cases, if the eyes are used, repeated attacks of swelling and hemorrhage occur, leaving vision more and more impaired. There is a tendency sometimes to go on to atrophy of the retina and the optic nerve; but most patients retain quite useful vision until death. As a sign of the general disease and the approaching fatal termination of the case, albuminuric retinitis is of great significance. (See Chapter XX.)

Gouty retinitis occurs in elderly persons subject to other manifestations of gout. It causes progressive impairment of vision, affects both eyes, is marked by yellowish-white patches of exudation in the region of the macula and disk, hemorrhages which oceur ehiefly in the earlier stages, thickening and opacity of parts of the walls of the vessels, marked narrowing of parts of the arteries, and dilatation of parts of the retinal veins. The vessels throughont the body give evidence of marked sclerosis. The urine is of rather high specifie gravity. It contains a large amount of uric acid, rarely albumin, and no casts. The treatment is that of the gouty diathesis with rest for the eyes, and avoidance of excitement. Blindness does not usually oeenr, but there is little or no recovery of sight once lost; and a large proportion of the patients die of cerebral hemorrhage.

Diabetic retinitis occurs in the course of saccharine diabetes. It is eharacterized by the appearance in 
the retina of small ivory-white dots; most numerous about the macula and toward the disk, but not arranged in any stellate or regular figure. In a few eases large white plaques have been seen, toward the periphery of the fundus. The optic nerve is not affected. Rarely spots of pigmentation are seattered through the fundus. Minnte points, or larger spots of hemorrhage are usually seen; and sometimes typical hemorrhagic retinitis is encountered in diabetes. The treatment is that of diabetes; and the chance of improvement depends on the chance of improving the patient's general condition.

Syphilitic retinitis and chorioretinitis occur as secondary lesions; sometimes rather early, but usually one year or more after infeetion. They may run their course without perceptible involvement of the ehoroid; but in the larger number of cases there are distinct spots of choroidal infiltration, and later permanent atrophic and pigment-changes. Not rarely the lesions of the posterior portions of the eye accompany iritis. There is always some opacity of the posterior part of the vitreous, dustlike in character, gradually inereasing and gradually passing away. (See Chapter XIV.) In the choroidal cases the fundus is decidedly speckled. Retinal opacity is most marked in a zone around the optic disk, or may be localized especially in the macnla. The optic disk is red, hazy, and sometimes quite obseured, ultimately it may present a yellowish-white appearance of partial atrophy. The vessels are usually but little altered, but may be narrowed in the later stages. Retinal hemorrhage is rare. In a few cases, however, numerous hemorrhages of rather large size are distributed thronghout the fundus. Sometimes the inflammation is localized at the macula, and shows an especial tendency to relapse.

Central acuteness of vision is lowered in all eases, and seotomas of varions forms are apt to occur. There is night-blindness, excessive impairment of sight when the illumination is slightly diminished ; and a persistent dazzling or shimmering of light that is very amnoying. Metamorphopsia oceurs and is likely to be permanent. 
Diagnosis.-The dust-like opacity of the posterior vitreous, the spots of gray or white, but not brilliant white opacity of the retina, the speckled ehoroid, the red hazy disk, the slight changes in the vessels, and the chronic conrse of the disease constitute a eharacteristic pieture. The nature of the retinitis will be confirmed by a history of syphilis or of other characteristie syphilitic lesions, and the absenee of other eommon causes of retinitis. But this form of retinitis is one of the most characteristic single lesions of syphilis, and, without other evidence of its nature, should be regarded as syphilitic.

Treatment and Prognosis.-Retinitis of this character should be met by the prompt, effeetive, and prolonged administration of merenry. Inunetions should be given at first. Subsequently, some other mode of administration may be resorted to, but as much should be given as possible without produeing constitutional effects. The eyes should be kept at rest, during the acute stage a mydriatie may be used, and they should be protected from excessive light or sudden changes of illumination. At a late stage potassium iodid may prove useful. Under treatment vision generally improves and the disease is permanently checked; but vision is very rarely restored to normal, and in most cases permanent retinal lesions are revealed with the ophthalmoscope.

Punctate retinitis (retinitis punctata albescens) is characterized by a great number of white or yellowishwhite points scattered throughout the fundus, without pigment-changes. Vision is usually somewhat impaired. It is not progressive, and in most recorded cases has probably existed some time before it was discovered.

Striate retinitis is characterized by light yellowish or gray lines or streaks just hack of the retinal vessels, some straight as though drawn upon, others curved or with branching ends. The streaks have not the direction of the vessels or of other known structures. The disease appears in early life. The streaks may mark a previous detachment of the retina. Vision in the affected eye is generally greatly impaired, but not entirely lost. 
Proliferating Retinitis.-Attacks of retinitis attended with extensive hemorrhages sometimes result in the formation of dense bluish-white or gray masses of connective tissue, which extend from the retina into the vitreous, hiding completely certain parts of the fundus. To this condition, which is seen more often as a sequel than as an active pathological process, the above name is applied.

Circinate retinitis is characterized by brilliant white spots arranged in the form of a wreath near the macula or disk. They lie behind the retinal vessels, may remain unchanged for years; and are often accompanied, and perhaps always preceded, by retinal hemorrhages. The condition occurs mostly after middle life, and may affect one or both eyes. Vision is always impaired, usually growing worse gradually.

Retinitis from excessive light occurs from keeping the gaze fixed on the sur without sufficient protection, usually while watching an eclipse or looking for sun spots. The ophthalmoscope shows little or no alteration of the affected part of the retina, which may not be larger than the fovea. There is a small central scotoma, persistent, annoying, dazzling, and sometimes metamorphopsia. The injury may be prevented by use of smoked glass so dark that objects cannot be seen through it by ordinary illumination, and through which the sun causes no persistent, annoying after-image. When the injury has oceurred, rest for the eyes and avoidance of sudden changes of illumination will be beneficial. If vision is not reduced below one-third, recovery of normal vision may be expected in from one to six months, although careful testing may still show the presence of a minute relative or absolute seotoma.

Exposure to excessive light may be an exciting canse of chorioretinitis, with ophthalmoscopic changes and seotoma. Such a condition has followed exposure to a stroke of lightning. Exposure without proper protection to a powerful electric arc light, canses, besides the effects of excessive light on the retina, violent smarting pain in 
the conjunetiva, with swelling and infammation, probably due to something beside the light. The conjumetival symptoms subside in a few days. The repair of the retinal tissue sometimes requires much longer, and may not be complete.

Pigmentary Degeneration (Retinitis Pigmentosa).This is usually congenital. From early childhood nightblindness is noticed, the patient being practically blind in a feeble light, although no defect may be noticed in good daylight. The field of vision is restrieted, usually con-

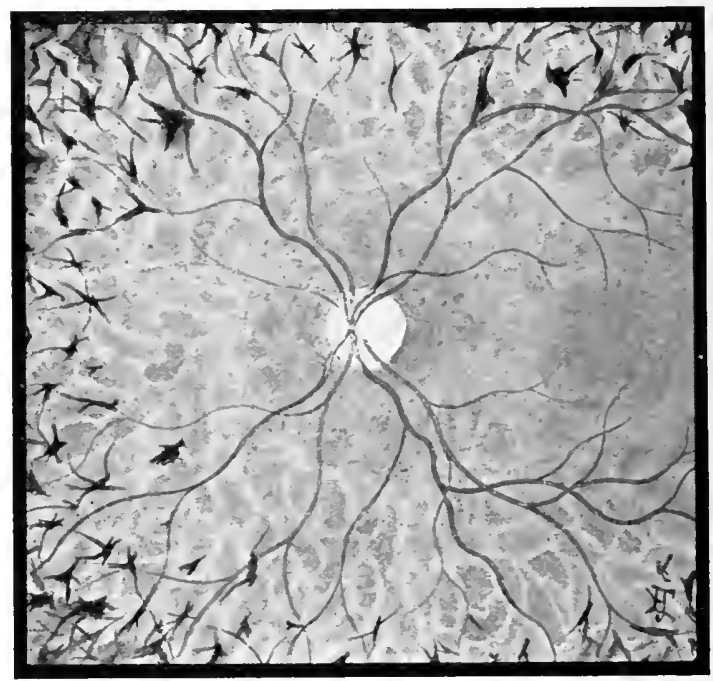

FIG. 118.-Pigmentary degeneration of the retina. The disk is white, the retinal vessels are narrowed. The retimal pigment is atrophied, revealing the choroidal ressels. The charaeteristic pigment-patehes are seen in the periphery.

centrically, at first only when in a feeble light. These symptoms are slowly progressive, the patient becoming helpless after sumset; and the field of vision greatly narrowed, althongh full acuteness of central vision may be possessed in a good light.

The characteristic ophthalmoscopic changes include. loss of the nomal pigment from the retinal pigment- 
layer, and accumulations of pigment forming dark-brown or black masses of a stellate or branching shape, compared to that of bone-corpuscles. 'These masses often lie along blood-vessels, around which they seem wrapped like a blanket. They are first seen, and most numerous, in the extreme periphery of the fundus, and gradually invade the posterior or central portion, but rarely extend to the immediate neighborhood of the maeula and optic disk. They are shown in Fig. 118. As the case progresses the retinal vessels become greatly narrowed, and the optic nerve atrophic. Both eyes are affected. Eyes presenting this form of retinal degeneration are often highly ametropic.

Etiology, Varieties, and Diagnosis.-Congenital cases can often be traced to consanguinity of parents, heredity, or inherited syphilis. Five to ten per cent. of congenital deaf-mutes suffer from this disease. A form of the disease is seen as a tertiary manifestation of acquired syphilis. It appears much later, often not until middle age ; and is attended by choroidal atrophies and pigmentaccumulations. Cases may be found presenting ophthalmoseopic appearances grading from those of typical chorioretinitis to those of typical pigmentary degeneration. In a few cases, the symptoms of which otherwise are those of this disease, the pigment-accumulations in the retina are entirely lacking. In typical cases the narrowed field, night-bliudness, slow progress, and ophthalmoscopic symptoms are characteristic. In the atypical eases careful consideration of all symptoms must determine where the case belongs.

Treatment and Prognosis.-The treatment consists of careful and very moderate use of the eyes under the best conditions, including the constant wearing of correcting glasses, and protection from excessive light and sudden variations of illumination. The internal use of strychnin in moderate doses, the instillation of a weak solution of eserin, and the applying of the galvanic current to the eyeball have been recommended as beneficial. But no treatment eures the disease, and it is doubtful if anything more than general hygienie measures delays its somewhat 
irregular progress. The majority of patients become hopelessly blind by the age of sixty years. The form due to acquired syphilis is more amenable to treatment; and, while running a comparatively rapid course, is not so sure to go on to complete blindness.

Amaurotic Family Idiocy (Infantile Cerebral Degeneration, Symmetrical Changes at the Macula, Tay's Choroiditis). - This disease attracts attention during infancy or early childhood, by inability to see, or general progressive museular weakness, without evidence of localized lesions of the nervous system. Ophthalmoscopic examination shows a rounded gray or white area oceupying the center of each retina, with usually a dark-red or brownish-red spot, eorresponding to the center of the macula, somewhat like the appearance in embolism of the central artery of the retina. In a few months the optic nerve atrophies, the patient becomes entirely blind, and the muscular weakness increases, until the disease torminates in death. Autopsies show degeneration of the large nerve-cells of the retina and the pyramidal cells of of the cerebral cortex. Several children of the same parents may be affected; and the reported cases have been of Jewish parentage.

Angioid streaks in the retina are brown streaks of pigment, often with lighter borders, forming an irregular network like a system of anastomosing vessels, but not related to either retinal or choroidal vessels. They may follow retinal hemorrhage or detachment.

Retina1 Macular Atrophy (Hole in the Macula).This may result from injury to the eye, from senile change, or other serious disturbance of nutrition. A dark oval spot, half the size of the optic disk, seen at the macula, seems depressed below the general surface of the retina.

Spasm of the retinal arteries sometimes ocenrs, eausing temporary blindness. Usually it lasts but a few sceonds, but it may recur. If more permanent, it leads to thrombosis, and permanent vascular obstruction.

Obstruction of the retinal vessels causes blindness, usually sudden. It may be due to endarteritis, thrombosis, embolism, or combinations of these condi- 
tions. Thrombosis usually oceurs, whatever the primary cause of obstruction. It is often impossible to determine the primary condition; although primary venous thrombosis is credited with causing more extensive retinal hemorrhage. When the circulation of the whole retina is obstructed, blindness is complete and usually permanent. When a limited part of the retina is involved, a corresponding part of the visual field is lost. If the macula be supplied by vessels that escape entirely, as cilio-retinal vessels, central vision may remain unimpared, while the field is greatly narrowed. After permanent obstruction the retina degenerates and atrophies.

Diagnosis.-Retinal obstruction is recognized with the ophthalmoscope. The branches of the artery do not at first seem much altered in appearance, except as they are concealed by retinal opacity. The veins are in some portions greatly narrowed, and at other points of full width or broadened by flattening. Sometimes the slow return of blood in bead-like or longer masses, may be seen in one or more branches of the retinal veins.

The central portion of the retina becomes quite hazy within a few hours after the accident, giving that part of the fundus a bluish-gray or white hue, except just at the fovea where is seen in almost all eases a dark red spot. The exudation and opacity may be more dense along the vessels. Where the vessels dip into it they are partially or wholly lost to view, and on this account may seem to be narrowed or interrupted. Toward the periphery of the fundus the gray opacity thins ont until the color of the fundus appears quite normal. Retinal hemorrhages may occur, especially in the region of the macula.

The nsual appearance of the fundus is shown in Fig. 119. After a few days the retinal haze begins to disappear, but retinal degeneration keeps the central part of the furdus white, with its distinct central red spot, sometimes for several weeks. At a later stage there remains only a complete atrophy of the optic nerve, with extreme narrowing or obliteration of retinal vessels.

Treatment and Prognosis.-In a few cases the embolus has, spontaneously, become broken up or displaced, 
and the retinal circulation partly or wholly restored. In a few cases the same result nay be brought about by active massage of the eveball, or by temporary dilatation of the artery by inhalations of nitrite of amyl. Both of these measures should be tried, and repeated two or three times a day luring the first ten days or two weeks after the occurrence of embolism. If they fail to influence the

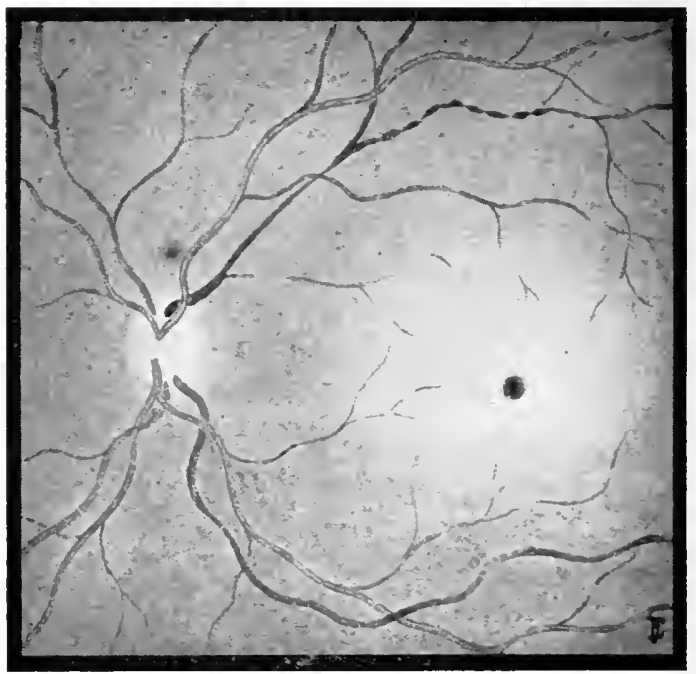

Fic. 119.-Embolism of the eentral artery of the retina on the third day. The arterjes are little altered in aplearamee; the veins are irregular from partial collapse. The superior temporal veiu slows the bead-like appearance. The center of the fundus is gray with edema, except the center of the macula, which appears as a dark round spot.

olsstruetion, there is sometimes a partial re-establishment of the eirculation throngh shrinking of the embolus or relaxation of the arterial walls, with return of vision in some part of the field. But generally the blindness is permanent. With complete blindness, after the first two or three weeks the cuse must be regarded as liopeless.

Thrombosis of the retinal artery probably arises in connection with degenerative changes in the arterial 
walls, or spasm of the musenlar eoat. The symptoms resemble those of embolism, except that the onset of blindness may not be quite so sudden, or may be attended with temporary blindness of the other eye, giddiness, faintness, or other evidence of disturbance of cerebral eirculation. Attacks of temporary blindness through brief arterial spasm may have preceded the thrombosis.

Thrombosis of the Retinal Veins.-The symptoms of this condition resemble somewhat those of embolism of the retinal artery. The veins are enlarged and tortuous, although the arteries may be narrowed. Hemorrhages are numerous, especially about the optic disk, which may be extremely red. Loss of vision is less sudden than in embolism, and there is more likely to oceur a return of the circulation, at least in some of the vessels, and a partial restoration of sight. The patient should be kept quiet, and on a restricted diet, unless this is contraindicated by his general condition. Saline laxatives may be given, or venesection resorted to.

Detachment of the Retina (Co-arctation of the Retina, Amotio Retine).- Separation of the retina from the choroid by serous fluid had been before noticed by oblique illumination, and in dissecting enueleated eyes. But the use of the ophthalmoscope has shown it to be a not rare condition.

Symptoms and Course.-The detached portion of the retina becomes blind, although in rare eases it may retain light-perception for some time. It may also suddenly cut off vision, by falling in front of a part still normal. Usually the patient complains of sudden impairment of vision, whieh on investigation is found to affect only a portion of the field. There may for a time be sufficient power of vision retained in the detached retina to allow a noticeable metamorphopsia, or to cause annoying vertigo from displacement, and movement of the percipient elements. Any part, but more commonly the anterior portion, may be the starting-point of detachment. But by the gravitation of subretinal fluid the lower part of the retina usually becomes affeeted. Ultimately the whole 
retina is drawn away from the choroid, retaining only its attachments at the optic disk and its anterior margin, having somewhat the shape of a straight trumpet with the shrunken vitreous lying within it. Both eyes may be affected, but in the majority of cases one escapes. After the detachment has become complete, the lens often becomes opaque, and other degenerative changes oceur. The tension of an eye with detached retina is likely to be below normal.

With the ophthalmoscope the retina appears as a somewhat opaque, gray nembrane, floating in rounded folds; upon which may be traced branches of the retinal vessels, apparently very small because displaced forward so much within the focus of the lens through which they are seen. Where the retina is viewed obliquely its opacity is most evident. Through parts that are nearly perpendicular to the surgeon's line of sight the red reflex of the choroid may be seen. Where the retina is but slightly and recently separated from the choroid, no opacity may be perceived; and the detachment may be revealed only by the displacement of the retinal vessels. Sometimes distinct tears are found in the retina, through which the choroid may be seen. Portions of the retina which are just becoming detached may exhibit a peculiar fine mottled reflex, which may be compared to the reflexes from "pebbled" leather. "The more striking appearances of detachment of the retina are shown in Fig. 120.

Causes.-Detachment of the retina occurs more frequently in men than women, and the liability to it increases with age. It may be caused by bruise or by perforating wounds of the eyeball either at once, or subsequently by eicatricial changes. Highly myopic eyes are chiefly liable to it, and choroidal disease, hemorrhage, or an intra-ocular growth may cause it. It may appear after a special effort, as conghing, vomiting, or heavy lifting.

Diagnosis.-Sudden impairment of vision in one eye affecting chiefly or solely a portion of the visual field, should always suggest this affection. With the ophthal- 
moseope its situation and extent can usually be studied. If, on aceount of opacity in the cormea, lens, or vitreous, this is not possible, eareful mapping of the field of vision must be relied on.

When detachment is recognized, it is necessary to determine if the separation is caused by fluid (simple detachment) or by a new growth, as sarcoma of the choroid. This will be done by noting the presence of large vessels or a distinct mass beneath the retina, the

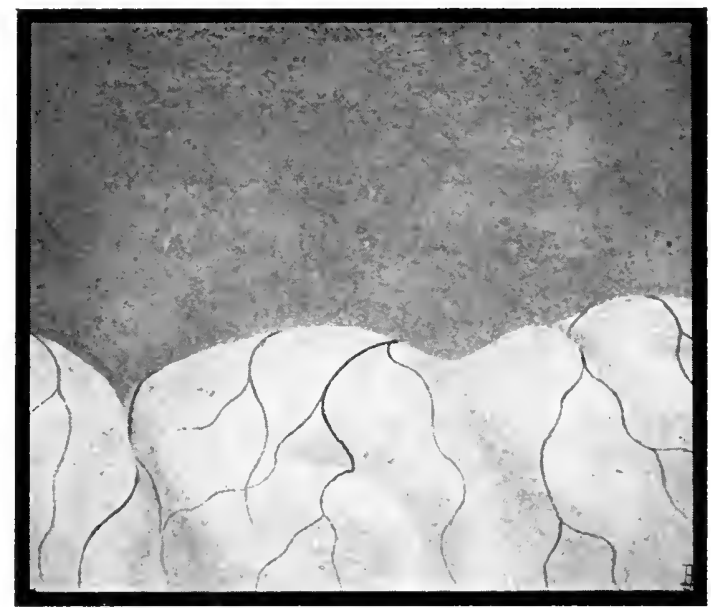

Fig. 120,-Detachment of the retina, seen with a strong eonvex lens which focusses for the detached portion below, and leaves the normal fundus above quite ont of foeus. Note the rounded folds which float on liquid, and the very small retinal vessels upon them.

absence of any wavy motion of the retina, and the normal or increased tension of the globe in case of new. growth ; or the absence of any tumor visible through the retina, the wavy movement and alteration in the form of the folds eaused in it by movements of the eye, and the normal or diminished tension in the eyeball in simple detachment. A new growth eoncealed beneath detached retina which floats upon fluid surromding the growth may be revealed by strong illumination, as direet sunlight. 
It is sometimes diffieult to distinguish between a small detachment, and a limited swelling and opacity of the retina in retinitis. Unless there be distinct folding or floating of the affected area, it should usually be regarded as swelling rather than detachment, even though the pushing forward of the retina amounts to 4 . or 5 . D.

Treatment.- This should include rest in bed, with absolute rest of the eyes, best under a pressure-bandage. Pilocarpin sweats have sometimes proved of benefit; as have potassium iodid, or salycilic acid in moderate doses. The injection of tincture of iodin or similar substanees into the eye is not to be recommended. In many cases the withdrawal of the subretinal fluid by an incision in the selera, has produced great temporary improvement; but generally there has been a subsequent return of the detachment. Recently Stillson has reported more permanent relief by making, by the galvanocantery, one or two round holes in the selera beneath the detachment.

Prognosis.-Spontaneons reattachment of the retina occurs in rare cases. Treatment fails to eure in most eases. The chance of recovery, or of the detachment remaining partial, is better for trammatic than for spontaneous detachment. Most eases of detachment with high myopia or choroiditis, become total.

Subretinal cysticercus is seen oceasionally in Europe, but no ease is reported in America. One case of subretinal echinococcus has also been recorded.

Glioma of the retina (or gliosarcoma) is a malignant growth that oceurs in early ehildhood. It may be present at birth, or appear during infancy. It affeets one or both eyes, and tends to a fatal termination through extension to the brain, or by exhaustion.

Symptoms and Course.-Attention is first attracted by a shining yellowish-white reflex from back of the pupil ; and the eye is found to be blind. Beer ealled it "amaurotic eat's-eye." The tumor grows rapidly and may fill the globe in a few months. As it grows, increase of ocular tension oceurs, and symptoms of inflammation arise. The eye becomes red, painful, and tender. Usually 
it passes throngh the same stages as sareoma of the choroid (see page 350); but the first and second stages do not usually last so long as the corresponding stages of sarcoma. The method of extension is through the optic nerve to the brain, and by metastasis to other organs. In a few cases the inflammatory synuptoms include a severe iridocyclitis, which may end in diminished intra-ocular tension and partial shrinking of the eyeball. This has the effect of completely masking the original disease, causing a variety called cryptoglioma.

Diagnosis.-Glioma is distinguished from pseudoglioma by growth of the tumor, by its rounded lobules, by the presence of minute vessels upon it (although this has been simulated by pseudo-glioma), by the absence of any history, or cause of purulent choroiditis, or retinitis, and by normal, and later increased tension, instead of the lowered tension common in psendo-glioma.

Treatment.-The affected eye should be removed at the earliest possible moment, with as much of the optic nerve as can be taken with it. If there is any probability that the growth has already extended beyond the eyeball, the orbital contents should also be removed; and it may be wise to remove and cauterize portions of the walls of the orbit.

Prognosis.-Removal while the growth fills but a small part of the vitreous is likely to effect a permanent eure. Removal while the growth is still eonfined within the globe offers a fair chance, one in three, of cure. Removal after the orbital tissues are involved is likely to be followed by reeurrence. Operation is useless when the tumor has extended beyond the orbit; and without removal, early death is certain.

Anomalies of the Retina.-The most striking of these, opaque or medullated nerve-fibers, has been sufficiently described (page 91); the characteristic appearance is shown in Fig. 121. Accumulations of pigment have also been mentioned (page 99). The arrangement and distribution of the retinal vessels varies greatly. Some of the more common forms are shown in Plates I and II 
and Figs. 72, 84, 87, 90, and other illustrations of the fundus.

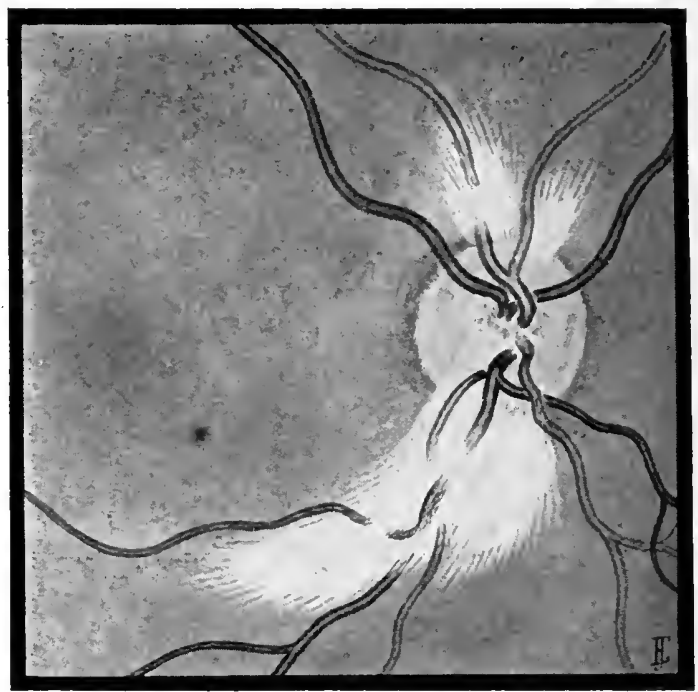

Fif. 121.-Medullated or opaque nerve-fibers in the retina of the right eye. Some parts of the retinal vessels are hidden. The striations take the normal course of the nerve-fibers.

Anomalies of the macular region are especially liable to mislead the ophthalmoscopist. The usual appearances have been deseribed (page 88). Not rarely, one encounters small white, or yellowish white dots which may suggest albuminuric or diabetic retinitis ; or inflammation of the center of the ehoroid. Yet on eareful investigation, absence of any impairment of function proves that these appearances are anomalous, rather than pathologic. Very extensive alterations in the retinal pigment, areas of thinning, and black blotelies, are usually aceompanied with some impairment of vision. Yet this may be trifling, compared with what might be expeeted from the ophthalmoseopic appearances discovered.

Anomalies of the retinal vessels are most common. Some of these are illustrated in the accompanying 
figures. (A) shows an unusual parallelism between arteries and veins, with a large pigment deposit of the class that seems to have no pathologic significance. $(B)$ shows the other eye of the same patient which exhibited neither of
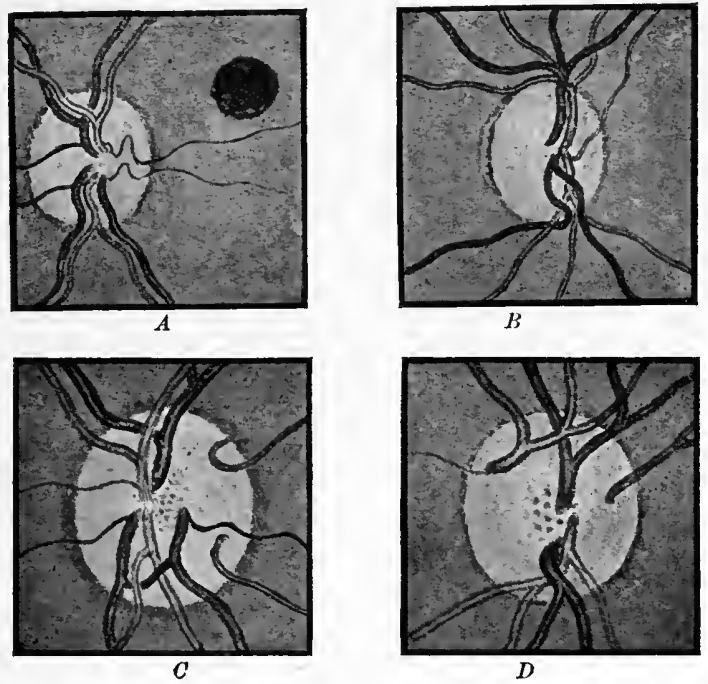

Fig. 121 a.- $A, B, C, D$.

these peeuliarities, but the lower temporal rein is looped around the artery. In $(C)$ are shown two large eilioretinal vessels and an anastomotie braneh conneeting the lower veins. In $(D)$ the upper retina is supplied by a very large cilio-retinal artery.

\section{CH A P T E R X I I .}

DISEASES OF THE OPTIC NERVE, VISUAL TRACT AND CENTERS. AMBLYOPIAS.

Hyperemia of the Optic Nerve-head (Hyperemia or Congestion of the Papilla or Optic Disk).-This is shown by general redness of the optic disk, and increase 
in the number of the smallest visible vessels (see page 93 ). The redness may be so great that there remains no contrast between the disk and the surrounding fundus. If there be a distinct physiological enp, the bottom of this is usually not reddened, but appears by contrast unusually white and noticeable. But the normal hue of the optic disk varies greatly, so that unless one has the other eye normal, or a previous observation to make comparison with, it is only in marked cases that he can say positively that the nerve-head is hyperemic. Hyperemia is caused by strain of the eyes, whether from ametropia, prolonged use, or unfavorable conditions of eyc-work; by exposure to strong light or heat, by injury, or in inflammation of the anterior segment of the eye (as a foreign body in the cornea), or conjunetivitis, and by the causes of hyperemia and inflammation of the retina, or ehoroid.

Anemia of the optic disk, or papilla, is as diffienlt to estimate as hyperemia. It causes the disk to appear pale, comparatively uniform in color and devoid of small vessels. It is a most important synutom of optic atrophy, and may be produced by general anemia or by loeal obstruction to the blood-supply. The surgeon who seés large numbers of hyperemie disks is liable to think the normal disk anemic by contrast.

\section{INFLAMMATIONS OF THE OPTIC NERVE.}

Neuroretinitis (Papilloretinitis).-Inflammation of the optic nerve always involves the adjoining retina. The swelling extends beyond the borders of the nerve, and if there is opacity it hides the margin of the choroidal opening. Still, if this is all, the ease is spoken of as one of optic neuritis. Retinitis extending to the margin of the disk veils and may quite hide the choroidal margin; and if not attended by any swelling of the disk, it is properly called retinitis.

The optic nerve and the retina forming one continuous structure, with the elosest anatomic and physiologic dependences and relations, morbid processes affecting the 
one, frequently extend to the other, and often the two are almost equally involved. Any such extension, beyond the limits above indicated, constitutes the ease one of neuroretinitis. Neuroretinitis oceurs in connection with renal-vaseular disease, leukemia, gout, syphilis, lead poisoning, and sympathetic ophthalmitis; and severe neuritis arising in the course of brain disease very often extends so largely to the retina, as to warrant including it under this head.

Optic Neuritis (Intra-ocular Optic Neuritis ; Papillitis, Choked Disk).-O Optic neuritis is of great importance on account of the-evidence it gives of extra-ocular disease, and its liability to end in optic atrophy. It may cause no symptoms apart from the appearances revealed by the ophthalmoseope. Vision may be unaffected by even violent neuritis, and impairment of vision, when present, may generally be regarded as due to a supervening optie atrophy, rather than to the neuritis.

Symptoms and Course.-The essential symptoms of optic neuritis are increased vascularity, swelling and opacity of the nerve-head extending beyond the margin of the disk. With the swelling always occurs haziness of the nerve-head, so that the margin of the choroidal opening, and the deeper details of the nerve-head, such as the lamina cribrosa, and the deeper parts of the vessels are blurred or hidden.

Swelling of the nerve-head is illustrated in Fig. 30. It pushes forward the vessels which lie upon the disk so that their refraction as measured with the ophthalmoseope heeomes more hyperopic. The extent of the swelling is estimated by comparing the refraction of the most hyperopic of the vessels, with the refraction of the nearest part of the neighboring retina, that appears unaffected.

Usually this is done in diopters of refraction, as a swelling of $7 \mathrm{D}$. The actual depth in millimetres of such a swelling may be found from the table on page 134 .

When the swelling is slight, the disk red, resembling in color the general fundus, and the physiological cup obliterated, there may be little beyond the convergenee 
of the retinal vessels to indicate the position of the nerveentrance. As the swelling inereases, however, it becomes distinetly more gray, and lighter than the usual color of the fundus, on account of the separation of the minute vessels by exudate.

When the swelling is slight, the larger retinal vessels may be little altered in appearance, or slightly and uniformly enlarged. As the swelling becomes greater its pressure upon them causes obstruction of the bloodcolumns, so that the retinal arteries are narrowed, while the veins appear broad, dark, tortuous, and often irregular in caliber. Something of this appearance is illustrated

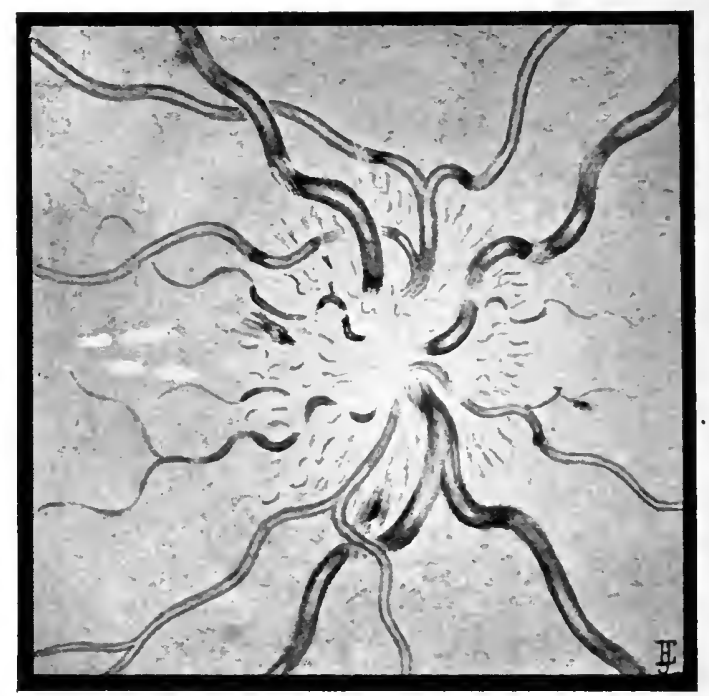

Fig. 122.-Optic neuritis in a case of tubercular meningitis, right eye. Optic disk hidden by gray striated swelling; retinal veins very large and tortuous.

in Fig. 122 and in Plate II, 8. These changes in the vessels, with sharp limitation of the swelling to the immediate vicinity of the nerve-entranee, have caused severe optie neuritis to be called choked disk. 
In the majority of eases of marked neuritis, retinal hemorrhages oceur. Most frequently they are on or near the swollen nerve-head, but sometimes in other parts of the fundus. About the papilla they are very notably striated, by extension, between the bundles of nervefibers. In this situation it is often not easy to distinguish between a small hemorrhage and a lilated blood-vessel. In severe neuritis there are often small isolated patehes of exudate in other parts of the retina, partieularly in the direetion of the macula. Extensive lesions of the kind would place the ease in the eategory of neuroretinitis.

Perfect vision may continue for weeks or months in spite of typieal optic neuritis, with great swelling. In many eases the impairment of vision is so slight as to escape the patient's notice. But when the secondary atrophic changes begin, vision may be lost very rapidly. The two eyes may present very similar ophthalmoscopic appearances, and yet one be practically blind while the other retains almost full vision; and the difference between the two may be merely that in the first eye the process is a few days further advanced than in the seeond. Usually, however, central vision is somewhat affeeted. The patient eomplains of a mist before the eyes, or of persistent after-images, and eolor-pereeption may be impaired. Careful testing often shows an appreciable enlargement of the physiological blind spot. The concentric or irregular contraetion of the field of vision for form and color is that described under optic atrophy.

The course of optie neuritis may be aeute or ehronie. When dependent "pon acute brain disease, rheumatism, or suppression of menstruation, it may reach its height in a very few days. In slowly growing brain-tumor, the swelling may gradually increase for many months or for years. In either ease it tends to pass over into a stage of atrophy. Although in some of the acute cases normal vision may be preserved, some atrophy of the choroidal margin, with permanent opacity of the disk and in the vessel-walls, almost always remains. 
Of the stage of subsidence, failure of vision may be the first sign. Usually the swollen papilla becomes paler, and the visible vessels fewer, although some may still be noticeably dilated, and meshes of new-formed ressels, like those seen after hemorrhage in the vitreons, may appear. Fresh hemorrhages cease to appear, the swelling

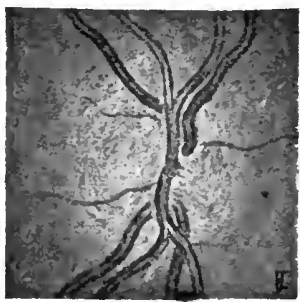

FIG. 123.

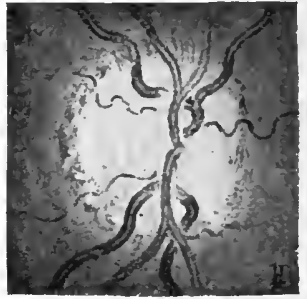

FIG. 124.

FIGs. 123, 124.-Optic neuritis from brain tumor, right eye. Fig.123 shows an early stage, the disk obscured by swelling. FIG. 124 shows the last stage passing into optic atrophy.

decreases, the hyperopia of the most prominent vessels gradually diminishes. The vessels themselves, especially the veins, get smaller, the swelling grows paler, the outlines of the optic disk begin to show through it, and the ease passes over into one of consecutive atrophy (see Plate II, 9, and Fig. 124).

Diagnosis.-At the height of a serere case, optie neuritis is unmistakable. In the earlier stages it must be distinguished from normal prominence of the optic disk; and the slight cases due to eye-strain must be separated from those due to more serious conditions. At one time the normal optic nerve-head was supposed to usually projeet into the eye, and hence it was called the optic papilla. In some eyes this is actually the normal condition. In many eyes the most prominent vessels are hyperopic 1 or 2 D. as they pass off the disk. Such prominence must be considered normal, aren though the disk be quite red, if there be no opacity to veil the disk-margin.

In eases of eye-strain, however, it not rarely happens that with this prominenee and redness of the disk, there is 
also some "filling in" of the physiological cup, and sufficient opacity to obsenre the disk-margin, especially above and below. Such a case may be regarded as one of optic neuritis. But if the eye-strain be present, it may be ascribed to that cause, unless symptoms of organic disease likely to eause optic neuritis be also noticeable. In the latter case the diagnosis ean only be made by watching the eye for some days. If the swelling and opacity. increase,.even though slowly, and the retinal veins become decidedly dilated and tortuous, serious organic disease in the brain or elsewhere is indicated. The character of the optic neuritis gives little information of the nature of its cause.

Etiology and Pathology.-The largest number of cases of well-marked optic neuritis arise in connection with organic disease of the brain and its membranes. It oceurs at some time in 90 per cent. of the cases of brain-tumor. Next in frequency comes meningitis, then abscess, softening, thrombosis of the sinuses, hydrocephalus, and rarely cerebral hemorrhage. The other known eanses are syphilis, rheumatism, renal-vascular disease, lead-poisoning, suppression of menstruation; or inflammation in the orbit, or in the sphenoidal or ethmoidal sinuses. It may be associated with the dropping. of watery fluid from the nostril, and has been provoked by surgical treatment of the nasal passages.

Optic neuritis may be caused by extension of inflammation from contiguous parts; and certain poisons capable of similarly affecting other nerves can cause optic neuritis. But its connection with intracranial disease is not so clear. The chief hypotheses account for its causation by intracranial pressure acting through the ophthalmic vein, or acting through the lymph-channèls surrounding the nerve, and especially at the point where the central vein of the retina energes from the optic nerve. Direct extension of the inflammation from within the cranial cavity has been assumed as the explanation, although microseopical evidence of such a process throughout the nerve-trunk has often been lacking. The trans- 
mission through the lymph-channels of chemical substanees capable of exciting iuflammation, or of morbid influences through vasomotor or trophic nerves, have also been supposed to be the active ageneies in causing optic neuritis; but of the relative value and correctness of these various lypotheses, we eamnot at present judge.

Treatment.-The essential point is the removal of the cause of the neuritis. Where the eause is local, radical loeal measures should be resorted to. Removal of an intraeranial growth, or even relief of intracranial pressure withont excision of a growth, is commonly followed by prompt improvement. Syphilis should be combated by the energetic administration of mereury and of potassium iodid. Non-syphilitic optic neuritis is to be met by large and inereasing doses of potassium iodid, maintained near the limit of the individual tolerance. The eyes should be allowed to rest, and should be protected from excessive light or sudden changes of illumination. Tapping the sheath of the optic nerve just baek of the eyeball, reaching it from the temporal side, has been tried with doubtful benefit.

Prognosis.-The prognosis in optic neuritis depends upon its cause. When it arises from incurable cerebral disease, it passes on into optic atroply and blindness. When it arises in connection with acute curable disease, complete reeovery with full vision is possible. The prospeet is not good for regaining sight already lost, except in those cases of monoeular neuritis, arising from rheumatism, cold, or local disease in the orbit or neighboring bones or earities. Rapid loss of sight in chronic neuritis is unfavorable. Narrowing of the visual field is more significant of progressive loss of sight than is impaiment of central vision withonit contraction of the field.

Optic neuritis gives little indieation regarding the issue of the discase causing it, although a severe chronic neuritis points to the continuanee and probable progress of its cause. In many cases of cerebral disease it appears as a late symptom. But sometimes it appears early, and very slowly progresses and passes on to atrophy. 
Retrobulbar Optic Neuritis (Orbital Optic Neuritis).-There occur rare cases of rapid impairment of vision in one eye, with pain in and about the orbit, soreness on moving the eye, and tenderness when the eyeball is pressed back into the orbit. With the ophthalmoscope the nerve-head, at this time, appears normal or but slightly swollen and hazy. But after several weeks or months if sight is permanently damaged, the signs of optic atrophy may appear. The impairment of vision generally affects only one part of the visual field, or affects some parts more than others.

Usually the disease runs an acute course ending with partial or complete recovery of vision. It is not especially significant of cerebral or general diseases. It has the same causes as peripheral neuritis affecting other nerves : as extension of local inflammation, cold, rheumatism, syphilis, alcoholic and other poisons, and acute infectious diseases. It may also attend chronic degenerative disease of the central nervous system.

The treatment is the removal or treatment of the cause, with local blood-letting at an early stage. Later potassium iodid may be given, and still later strychnin. The prognosis should always be guarded, but recovery may occur even after several months.

A chronic retrobulbar neuritis is generally regarded as the lesion in toxic amblyopia. The disease is considered under the later name (see page 397 ).

\section{ATROPHY OF THE OPTIC NERVE.}

Optic nerve atrophy (Optic Atrophy or Degeneration of the Optic Nerve) is characterized by impairment of vision, contraction of the field of vision, pallor and shrinking of the nerve-head as seen with the ophthalmoscope, and in some cases marked diminution in the size of the retinal vessels.

Symptoms.-The failure of vision may be rapid when the atrophy supervenes upon optic neuritis; but in other cases is usually slow, somretimes continuing progressive 
for years. The patient may complain of a eloud or mist before him. The progress is sometimes rather rapid, at others the eondition may seem stationary. There may be days when the patient believes his sight improving. The carliest positive symptom is marked contraction of the field of vision, first for colors and then for form. The contraction of the color-fields may go on to complete obliteration, usually in the order of their size, so that the patient becomes blind first for green, then red, and later for blue.

The appearance of the nerve-head is that of anemia.

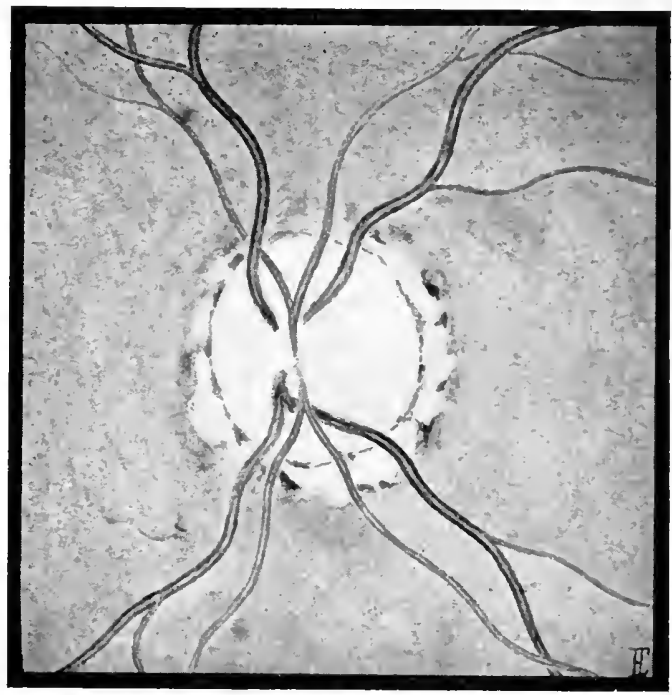

F1f. 125.-Optic atroply conscentive to neuritis, left eye. The disk is deal-white, slightly depressed, and surrounderl ly a rint of at rophied and disturbed eloroid. The retinal vessels are somewhit irregularly narrowed.

The swelling caused by optie neuritis loses its red, becoming paler and gray, or the pink of the normal disk gives place to a white or gray eolor; and small visible vessels become fewer. The mirgin of the disk, at first hidden in retinitis or neuritis, slowly becomes more distinct, 
losing even the slight blurring above and below, which is caused by the passage of the thick layer of normal nervefibers across it. The shrinking of the nerve does not usually cause diminution in the choroidal opening; and a scleral ring may appear within it, around the shrunken nerve-head. The shrinking is most manifest in the depression of the nerve-head, deseribed on page 97 , in which depression the normal exeavation usually disappears (see Fig. 31). The diminution of the retinal vessels, may at first only affect the arteries (after neuritis); or may be a very gradual shrinkage of both arteries and veins. It may be absent, the retinal vessels appearing quite normal. (Compare Fig. 125 and Plate II, 9 with plates and figures representing the normal disk.)

Causes.-Optic atrophy is caused by optie neuritis, and therefore by most of the causes of neuritis. It follows certain forms of retinal diseases, especially syphilitic ehorioretinitis, pigmentary degeneration, embolism and thrombosis. It may also be caused, apart fronı neuritis, by syphilis, venereal and other exeesses, impaired nutrition in old age, acute infections diseases, ehronic poisoning, malaria, or diabetes. Laceration of, or direet pressure on the optic chiasm or optic tract by broken bone, hemorrhage, or new growths, may eause it. A very important class of eases arise in conneetion with spinal sclerosis and general paralysis of the insane. [See Plate II, Fig. 10.] The optic atrophy may be the earliest lesion, appearing years before the impairment of locomotion. In rare cases optic atrophy is hereditary, appearing in early life, usually soon after puberty, in several of the males of suecessive generations. It is probable that disturbances of circulation due to high altitude are sometimes a factor in causation. Some eases must still be called idiopathic.

Varieties. - Atrophy oceurring without antecedent disease of the optic nerve or retina, as from impaired nutrition, or with spinal sclerosis, is called primary atrophy. It is marked by increased distinctness of the details of the optic disk, as the margins and lamina crib- 
rosa, while the adjoining portions of the choroid appear unaltered. The eolor of the nerve-head is usually gray. The retinal vessels long remain of normal size, or are but slightly diminished. The narrowing of the visual field is usually regularly concentric. Primary atrophy is commonly bilateral.

Secondary optic atrophy is a term often restricted to cases not following neuritis, as those oceurring from pressure upon the optie tracts. The eolor of the disks is white, or rather gray, as in primary atrophy, and the disk-margins distinet. The visual field is liable to show seotomas, or irregular interruptions, the exact eharacter of which depend on the special cause of the atrophy.

Consecutive atrophy (neuritic, post-neuritic, or postpapillitic, retinitic, or choroiditic atrophy) is atrophy following optic neuritis, or retinal, or choroidal diseases, as a later stage in a continuous process. In post-neuritic atrophy the disk-margins may at first be quite hidden, and the nerve-head swollen, but of a pale gray color. Slowly the swelling passes into excavation, the diskmargins become more distinct, and the color a more dead white. The retinal veins are at first large, but gradually shrink until they bear nearly the normal proportion to the shrunken arteries. The nerve-head is opaque, the lamina is hidden. The choroid about the nerve-entrance is more or less atrophie, with speeks and blotehes of pigmentaccumulation. Often the area of disturbed and partly atrophied choroid forms an irregular ring around the disk. The walls of the retinal vessels are somewhat thickened and opaque. Gray or white streaks extend on either side of the principal vessels beyond the margin of the optic disk. The field of vision is narrowed, the boundary being often marked by irregular re-entering angles.

Retinitie or choroiditie atrophy may start with slight haziness of the disk, which remains opaque, but not hidden by an opaque swelling; its color is yellowish. The retinal vessels beeome contracted, sometimes extremely narrow. The ehoroid about the disk shows no greater alteration than in other parts of the fundus. The form 
of the field is often affected by the distribution of the retinal lesions.

Simple atrophy is primary atrophy, or secondary atrophy, presenting similar appearanees. White atrophy and gray atrophy are so ealled on account of the eolor of the disk. This depends partly on other faetors, but tends to white when there is a marked increase of the interstitial connective tissue of the nervehead, and to gray when there is atrophy of the nervefibers without inercase of connective tissue.

Diagnosis.-The difficulties of deeiding whether an optie disk is abnormally pale have already been diseussed on pages 96 and 384. While the ophthalmoseopic appearances of advanced atrophy are usulilly quite striking, it is always prudent to earefully ascertain the acnteness of vision and the extent of the visual fields before making a diagnosis. Care must be taken to exelude other conditions, as errors of refraction or opacities of the media, that would impair central vision; or detachment of the retina that might be the real cause of a limitation of the field of vision. Very striking appearances of atrophy may exist with full acuteness of vision, or a normal field.

Treatment.-In the early stages the vigorous treatment of the eause is most important. Later the use of strychnin in ascending and full doses, either by the mouth or hypodermically should be tried, and persisted in for some months. Nitroglycerin may prove of value; and inhalations of nitrite of amyl repeated every day or two have seemed to benefit. Strict attention to the general health comes next in importance, and change of residence, especially change of altitude, may be tried, if practicable. The whole list of "alteratives" have been given without showing marked influence, the iodids offering most hope of benefit. Galvanism has been advocated ; but its effieacy is doubtful.

Prognosis.-In primary atrophy this is extremely grave. The atrophy usually goes on slowly to complete blindness. The prognosis is altogether bad when secondary atrophy succeeds a lesion that has already caused 
blindness. In consecutive atrophy when the neuritis has been due to a continuous progressive cause, brain-tumor, little is to be hoped. In other eases of secondary and eonseentive atrophy the prospeet is better; but generally the most that can be hoped for is to retard or eheck the deterioration of vision. In some eases of atrophy following acute disease, and with the toxic amblyopias, positive improvement of vision or eomplete restoration are to be hoped for. The optic disk may be very pale and eontimue so, and yet great improvement of vision may be brought about. The vision in the periphery of the field gives the most valuable prognostic indication. If the field is progressively narrowing, even though central vision may be unaltered, the outlook is gloomy. If the field of vision is not narrowed, even though eentral vision is greatly impaired, one may hope for improvement.

\section{OTHER ORGANIC CHANGES IN THE OPTIC NERVE.}

Hyaline bodies in the nerve-head (Druscn) are small, translucent, rounded, multiple masses, partly or wholly hiding the nerve-head. They are rare and are found mostly in eyes that have suffered serious damage from disease of the optie nerve, retina, or choroid; but they have been noted in eyes otherwise apparently normal.

Tumors of the optic nerve are rare. They are generally benign myxomas or fibromas. They develop behind the eyeball, usually begin in childhood, with impairment of vision that may not be noticed until, without pain, the eye begins to protrude, being pushed direetly forward or a little downward. The ocular movements remain remarkably good for so much protrusion. The growth of the tumor is very slow. With the ophthalmoseope, some eases show optie neuritis, sometimes with great swelling and obstruction of the retinal vessels. This may give place to atrophy, with great narrowing of the vessels.

The growth should be excised as soon as reeognized. 
Sometimes this can be done without removal of the eye ; but in most eases the eye, which is always blind, has been enueleated with the tumor. There is little tendency to recurrence.

Coloboma of the optic nerve or its sheath has already been sufficiently described (page 98).

\section{TOXIC AMBLYOPIAS.}

Many drugs are capable of causing impairment of vision ; bnt with only a few are the effects so frequent, so characteristic, and so directly connected with lesions of the retina and optic nerve as to merit consideration here. Two very distinet types of toxic amblyopia are easily recognized, the one most frequently associated with the prolonged use of tobacco, the other best understood as arising from excessive doses of quinin.

Tobacco Amblyopia (Amblyopia ex abusa, Central Scotoma, Retrobulbar Neuritis).-This form of amblyopia occurs once in from 500 to 1000 eases of eye-disease. It is unknown in childhood, very rare among young men, and among women. The best recognized lesion is a degeneration of certain parts of the optic nerve, the papillomacular bundle, including the fibers coming from the macula entering at the disk, at the lower outer part of the nerve, and becoming central in the nerve-trunk about the optic foramen. It is possible, however, that the changes in the optic nerve are secondary to changes in the retina.

Symptoms.-Attention is first attraeted by impaired vision, there being a mistiness at the center of the field that obscures the object looked at. This is more troublesome in a bright light, varies a good deal from time to time, and may increase so fast as to interfere with ordinary eve-work in a very few days. Usually both eyes are similarly affected. In rare cases, but one may suffer. Careful testing always reveals a central colorscotoma for green and red, sometimes very small, but in other cases extending from around the fixation-point 
toward and sometimes including the blind-spot. Sometimes all colors are confused within the central scotoma, or the whole field for green or red may be swallowed up, rendering the patient quite color-blind. In bad and chronic cases the scotoma may become absolute, lightperception being lost in the center of the field. In a few cases there is some narrowing of the periphery of the visual field; but this must be regarded as rather accidental, and not a usual symptom of the disease.

The ophthalmoscope gives no certain evidence as to the presence of the disease in the early stages. The disk sometimes appears slightly hazy and a dirty red, but this is not marked or characteristic. Late, in bad cases, the atrophy of the affected nerve-fibers, with proliferation of comnective tissue, eauses the outer, or lower outer, quadrant of the disk to become pale gray or even greenish.

The course of the disease is essentially chronic. The disturbance of vision often continues to get worse for weeks or montlss, the patient being beguiled by the days of improvement to hope for recovery, or secking relief at the optician's by changes of glasses. Finally, the condition becomes stationary, or, under proper treatment, vision slowly improves or returns to normal.

Causes.-Tobacco may cause this disease in whatever way it gains entrance to the system, though the larger number of cases are due to smoking. The amount required varies greatly with different persons; amblyopia sometimes begins after the amount used has been greatly diminished from what was habitual when the patient was younger. The manner of using, as smoking before meals, the kind of tobacco, and racial predisposition, all influence the liability to the disease. Besides the prolonged exposure to tobacco and the influence of age, causes of impaired general nutrition help produce the disease. It often arises after a severe nervons shock, or special mental depression or emotional strain, and may accompany impaired digestion, "tobaceo heart," impaired power of concentrating the mind, or sleeplessness.

Diagnosis.-The history of variable fogging of central 
vision, not improved by glasses, and the central scotoma for red and green are characteristic. It only remains to find if the cause be the use of tobacco or of some other toxic agent, or whether it is hereditary atrophy or chronic retrobulbar neuritis from cold, or attending spinal sclerosis. In the latter cases there is more general involvement of the field of vision than in tobacco anblyopia, especially contraction of the periphery, which may be quite irregular.

Treatment.- The first point is the complete avoidance of tobacco in every form, and of all other substances, especially alcohol, liable to cause the same lesions. Next every means should be employed to restore the general health of the patient, as sleep, good food, and relief from strain. If the case is seen while the impairment of vision is increasing, potassium iodid should be given in moderate doses for two or three weeks. But the special remedy is strychnin, in increasing doses, until marked improvenient begins or the limit of tolerance is reached. Then the dose arrived at should be continued until recovery is complete, or, with intermissions of a week or two, for many months. Inhalation of nitrite of amyl will often cause marked temporary improvement in vision; and the internal use of nitroglyecrin may improve it more permanently.

Prognosis.-If the case is seen within the first few weeks, and the patient will abstain entirely from the use of tobacco and alcoliol, complete recovery can generally be brought about, and may occur without other treatment: Great reduction in the consunption of these two narcotics may be followed by practical recovery, but this is much less certain. Persistence in their use is pretty sure to lead to great impairment of vision or practical blindness, although complete blindness (through optic atrophy) is rare. Even after complete recovery, the lower outer quadrant of the disk may continue very pale. The disease sometimes recurs if the use of tobacco is resumed.

Alcohol amblyopia (amblyopia ex abusa) is essen- 
tially the same disease as tobacco amblyopia. In a very large proportion of eases it is the joint action of the two poisons that canses the disease, but either alone is capable of causing it. The influence of alcohol may be sometimes traced, in the oceurrence of the amblyopia at an earlier age, in a greater tendency to permanent lesions, and in liability to run into complete atrophy.

Methy1 alcohol (wood-alcohol) drunk to intoxication sometimes eauses blindness. Recovery may oceur, or there may be temporary improvement of vision, followed after several days by progressive loss of sight and optic atrophy. The treatment has included piloearpin sweats and large doses of potassium iodid. Strychnin nay be used in the later stages.

Iodoform amblyopia occurs in a few cases after the prolonged use of iodoform dressings to large raw surfaces from wounds or burns, or the internal administration of large doses of the drug. Its onset is accompanied by other symptoms of iodoform poisoning, fever, a rapid, soft pulse, diarrhoea, headache, delirium, disturbed sensations, or stupor. In the best reported cases the visual disturbance was in the main similar to that of acute tobacco amblyopia. The diagnosis would be based on the presence of these symptoms with a history of the use of iodoform. The treatment is the same as for tobacco amblyopia, beginning with the removal of the toxic influence; and the prognosis is equally farorable.

Bisulphid of carbon amblyopia occurs among workmen who inhale the vapor of this substance as used in the process of vulcanizing rubber. The general symptoms of the poisoning are, at first, vertigo, irritability, and excitement, and later, dejection, loss of memory, cutaneons anesthesia, and muscular weakness and atrophy. The amblyopia is very similar to that produeed by tobaceo. It is to be treated in the same way, the important point being the avoidance of the continued inhalation of the fumes of the poison.

Nitrobenzol, used in making certain explosives and perfumes, causes amblyopia among those who work ex- 
posed to its fumes and dust. The general symptoms include headache, muscular weakness, cyanosis, and mental disturbance. The disturbance of vision closely resembles that of tobacco amblyopia, except that there is also contraction at the periphery of the field of vision. The pupils are dilated, and with the opththalmoscope the eye-ground and vessels appear strikingly darker than normal, and the retinal veins large and tortuous. The treatment resembles that for tobacco amblyopia, and the prognosis is good if the patient can escape further exposure.

Quinin Amblyopia (Quinin Blindness).-Quinin, and in larger doses the other cinchona alkaloids, have the power of causing a characteristic, temporary or permanent disturbance of the visual apparatus. Twelve or fifteen grains of the drug in divided doses has produced marked temporary amblyopia; but the causative dose has usually been very large, often several drams.

Symptoms and Course.-General symptoms of quinin poisoning, as deafness, ringing in the ears, fulness of the head, headache, and unsteadiness of gait, and sometimes visual hallucinations, precede the amblyopia, which may be deferred for days. When it comes, the onset is often very sudden, and in bad cases the blindness becomes absolute. This absence of light-perception may last from a few hours to several weeks. The pupils are widely dilated. The ophthalmoscope shows great diminution of the retinal vessels, extreme anemia of the disk, and sometimes a slight general opacity of the retina, with a red-spot in the macula resembling embolism of the retinal artery.

After a time vision for form returns. So soon as it can be investigated, the visual field is found greatly contracted and color-blind. Gradually vision improves and color-perception returns, usually to a narrowed field. The optic disks remain white, the retinal vessels greatly contracted. Cases have been reported as quinin blindness with a central scotoma, and without contraction of the visual field. Their true nature is doubtful. 
Diagnosis.-Quinin blindness might be taken for retinal embolism or thrombosis; but these attack but one eyc, while quinin amblyopia affects both.

Treatment.-The administration of quinin must be stopped, and bromids or hydrobromic acid may be given internally. Inhalations of nitrite of amyl should be tried cautiously during the first few days. Strychnin is to be given hypodermically or in ascending doses by the mouth.

Prognosis.-All recorded cases have recovered some sight, although in one it was only ability to count fingers. But after complete blindness even of very short duration there will remain some permanent impairment, especially contraction of the visual fields; and patients who have once suffered in this way are liable to relapse after comparatively small doses of the drug.

Salicylic acid and sodium salicylate in large doses sometimes cause amblyopia quite like that produced by quiniu. It should be similarly treated.

Acetanilid can also cause temporary blindness with retinal anemia, which should be treated with nitrite of anyl and strychnin.

The use of a strong alcoholie preparation of Jamaica ginger as an intoxicant has been quickly followed by blindness, which was to a great extent permanent.

Filix mas sometimes causes amblyopia, but its effects have not been well studied.

\section{CONGENITAL, HYSTERICAL, AND SIMULATED AMBLY. OPIAS.}

Amblyopia, or weakness of sight, may properly be restricted to eases in which there is no discoverable canse for the impaiment of vision; and amaurosis to cases of blindness with equal absence of ascertainable lesions. We have used the tem toxic amblyopias in connection with the effects of eertain poisons, because the essential lesions by which they may ultimately be elassified are not yet established. $\dot{A}$ few other conditions still remain that are classified as amblyopias. 
Congenita1 amblyopia of one eye, or chiefly affecting one eye, is often a factor in the production of squint. Less frequently it exists without any fault of the ocular movements. It may affect the whole field of vision or take the form of seotoma. It may be regarded as an arrest of development, which might occur after birth, since probably vision is then only imperfectly developed.

Amblyopia from imperfect focussing of the light upon the retina may be regarded as similar to congenital amblyopia, except that until quite late in life vision is still capable of marked improvement. It is best studied in cases of high astigmatism, in which the giving of the most aceurate correcting lens will at first leave vision quite imperfect. But with the wearing of the correcting lens vision improves, at first rapidly, then more slowly, until after many weeks or months it may in young persons rise to normal.

Congenita1 color-blindness may also be regarded as a special form of congenital amblyopia, although it shows no tendency to association with other congenital anomalies affecting vision. It has been sufficiently discussed (page 49). It should always be excluded before regarding impaired color-perception as a symptom of disease.

Hemianopsia, sector defects, and scotomas with transient amblyopia are sufficiently considered in relation to diagnosis in Chapter II, and in Chapter XX. In so far as they are not due to lesions of the eye or optic nerve, they are really symptoms of brain disease.

Hysterical amblyopia and simulated amblyopia, although probably not the same thing, are to be detected by the same tests; and may here be considered together. The first step in every case is by a thorough objective examination, including the use of the ophthalmoscope, skiascopy, oblique illumination, and careful observation of the eye movements, to exclude all errors of refraction or ocular diseases, or to recognize their share in the symptoms.

Tests.-When amblyopia of but one eye is alleged, the 
best tests are those which exclude the "seeing" eye without the knowledge of the patient. This may be done (Harlan's test) by placing a pair of trial frames upon the patient, with the correcting lens before the "blind" eye, and before the "seeing" eye a strong concave or convex spherical lens. Or (the author's test) two strong cylindrical lenses may be placed before the "seeing" eye, which when turned a certain way will give the optical effect of its correcting lens. The patient having been convinced that he can see through these lenses, one of them is turned without his knowing it so that he can see nothing through them, and what he reads is known to be seen with the "blind" eye. These tests enable one to ascertain exactly the vision of the "blind" eye.

As another test the patient may be made to look with the stereoscope, at a picture, or at a word, part of which is seen by one eye and part by the other. Recognizing the whole word or describing both parts of the picture, proves vision with both eyes. Again, the patient may be induced to read colored letters through colored glasses, the glass before the "seeing" eye being of the color complementary to that of the letters, and rendering them invisible to it. With any of these tests one may by covering the alleged blind eye interrupt vision, and demonstrate to the patient or to a third party that it was the "blind" eye that saw.

The holding of a 5 centrad prism before one eye, with the base up or down, produces such a vertical displacement of the retinal images that the patient cannot "overcome" it by turning the eye to a corresponding extent; and, if both eyes see, causes a vertical diplopia. By holding the prism before the "seeing" eye, the patient will usually say that it makes a lamp-flame look double, not knowing that this proves vision in the other eye also.

The above tests may be defeated by the patient elosing the "blind" eye and so recognizing that the other is excluded from seeing, or that, with the prism one image disappears. 
A test that is harder to demonstrate to others, and which does not give the exact acuteness of vision of the blind eye, but which nothing but violence preventing its application can defeat, is the objective test with prisms. If a prism of 6 or 8 centrads is placed before one eye with its base to the temple, the eye with sufficient vision involuntarily turns slightly toward the nose, to restore the correspondence of the retina to the images formed upon it. No effort of the patient's will can prevent this movement.

When blindness of both eyes is claimed, the last test is still applicable. The corresponding movement, as the prism is placed or withdrawn, shows with certainty the existence of vision sufficient to perceive diplopia, probably equal to at least one-twentieth of the normal standard. The reaction of the eyes to this test in the different possible eases are: If both eyes see, the eye before which the prism is placed moves, the other remains fixed, or makes a very slight tremulous movement; if one eye sees, and the other is blind, the prism before the sceing eye causes both to move equally, while before the blind eye it causes neither to move; if both eyes are blind, the placing and withdrawing of the prism eause no motion.

When it is elaimed that both eyes are weak, but not blind, the vision should be tested with various test-types at different distances, care being taken that the foeussing shall be equally good at all distances, so that the acuteness of vision shonld really be the same. The patient who reads the 40 -meter type at 4 meters, can read the 2 -meter type at 20 centimeters. 'The patient with vision really imperfect will do this. But with hysterical or simulated amblyopia, tests at different distances will show great discrepancies. The patient's vision is really at least as good as the best vision arlmitted for any distance. The above tests are gencrally more practical and more conclusive and exact than the older method of placing the patient thoroughly under the influence of ether and noting the evidences of vision during the period of recovery.

Hysterical amblyopia may also be marked by hemianop- 
sia or other limitations of the field of vision, especially a variable concentrie narrowing; or there may be colorblindness or reversal of the order of the color-fields.

Developmental Alexia (Congenital Word Blindness). -Although not a disease of the eye, nor strietly speaking, a defeet of sight, the clinical reeognition of it is almost invariably by ophthalmologists. It consists in an inability to remember or associate the symbols of language, with the spoken sounds or their meanings. The child may be bright, and mentally well-developed in every other way, but quite unable to read or even to reeognize the letters of the alphabet after years of effort to learn. In some cases, numbers and music are read normally, drawing and needle-work present no especial diffieulties, yet reading of even short, simple words may be impossible. In most cases the deficiency is finally overcome, the power to read developing at a later period than usual.

Diagnosis.-Good vision may be proved by ability to reeognize figures or dots, or generally some letters that are known, even when these are small as conld be recognized by the normal eye; while other letters are not known or only recalled by tracing them with the hand, or words are recognized by going through the lip motions that would be used in spelling them.

Treatment.-Children thus afflicted should not be tanght in classes with normal children. The visual memory should be developed by copying the letters, cutting them out of paper, ete., following on the printed page the reading of another person aloud, or writing from dictation.

Prognosis.-In the great majority of eases, the defeet may be eompletely overeome hy proper treatment. 


\section{CHA P TER XIV.}

DISEASES OF THE ANTERIOR CHAMBER, CRYSTALLINE LENS, AND VITREOUS HUMOR.

\section{THE ANTERIOR CHAMBER.}

THE anterior chamber is a lymph-space of varying size, liable to alteration of the character and amount of fluid passing through it, to infection, and to obstruction.

Depth.-It is most shallow in carly infancy from the undeveloped condition of the eye, and in old age from the increased size of the crystalline lens. It is deep in aphakia and very deep in keratoglobus, both from prominence of the cornea and from flattening of the iris.

It is often rather deep in myopia. It may also be deep in plastic inflammation causing shriuking of the vitreous and retraction of the lens. It appears deeper when there is any opacity in the cornea.

The anterior chamber is found shallow in glaucoma, in cataract during the stage of the swelling of the lens, during parenchymatous infiammation of the iris, or from bellying forward of the iris after exclusion of the pupil. After injury of the eye it may be shallow from traumatic cataract, and is quite obliterated so long as a perforating wound permits the free escape of the aqueous humor. In degenerated shrunken eyes it may be very shallow. The anterior chamber is of unequal depth in different symmetrical parts, from dislocation or partial absorption of the lens, unequal swelling of the iris, or partial synechia.

Alterations of the aqueous humor occur in all cases of inflammation of the ciliary body and iris. Turbidity of the aqneous is then a cause of impaired vision, and may be made out by careful oblique illumination. In some cases a gelatinous exudate occupies a large part of the chamber (spongy ivitis). Hypopyon has been described (p. 290) in connection with comeal suppuration, one of its causes. The anterior chamber may contain erystals of cholesterin. 
Hyphemia, or blood in the anterior chamber, appears of a dark-red color, usually as a distinct mass in the lower part of the chamber. It may come from the conjunctival limbus, during operation, or from the iris or deeper parts of the uveal treat from either injury or disease. The mere presence of blood in the anterior chamber is not of serious importance. It is grave only as a symptom of the cause of the hemorrhage, or of the impaired nutrition of the eye. When the general nutrition of the eye is perfect, as in cases of simple injury, the hyphemia may be removed very rapidly, a mass occupying the greater part of the chamber disappearing in a few hours. But in certain diseased conditions, as in ehronic glaucoma, a small amount of blood may remain without perceptible diminution for weeks.

Infection of the anterior chamber gives rise to iritis or keratitis. Obstruction is considered in connection with glaucoma, which it causes. Cysts and other tumors of the iris grow into the anterior cliamber ; and it may also contain a foreign body, cysticercus, or filaria.

\section{DISEASES OF THE CRYSTALLINE LENS.}

Cataract.-The most constant and obvious symptom of disease of the erystalline lens is opacity, so that nearly all such diseases come under the term cataract. Cataract has been recognized to include any opacity of the crystalline lens or its capsule. But the term has gained popular eurreney almost wholly in connection with those eases in which an extensive opacity prevents or impairs vision. Hence its use in addressing the laity should be restricted to that meaning, or accompanied by an explanation of its more inclusive definition.

Alterations of the Lens by Age.-Changes of consistence are deseribed in connection with accommodation and presbyopia, pages 124 and 144 . Changes of size are taken up in connection with glaucoma (Chapter X V); here changes of transparency are alone referred to. The crystalline lens is never perfeetly transparent. In childhood 
by illuminating the dilated pupil very obliquely from one side, and looking at it very obliquely from the other side, one may see a faint gray reflex from the anterior surface of the lens, the most striking portion having the form of a star, the branches of which correspond with the lenssectors. With increasing age this reflex beeomes more dense, until in many elderly persons the appearance of the pupil by ordinary illumination is quite that of gray opacity of the lens, although the lens and the patient's acuteness of vision may be quite normal. But in addition to this general loss of transparency, age is attended with a great liability to distinct localized opacities of the crystalline lens. The writer noted such opacities in 77 out of 100 patients upward of 75 years of age. Yet such opacities are not sufficiently constant to be regarded as a neeessary or entirely normal senile change.

Senile Cataract (Hard Cataract).-The usual association of age with common forms of eataraet justifies the term "senile eataract," while the increasing rigidity and size of the nueleus which also accompanies age, gives oceasion for the term "hard cataract," in contradistinction to "soft cataraet," or opacity occurring in a lens which has no hard nucleus.

Symptoms and Course.-The only symptom noticed by the patient is impairment of vision. 'This comes on gradually, sometimes so gradually that in one eye useful vision may be entirely lost before any impairment is noticed. In other cases after a few weeks or months of rapid loss of vision, it may remain unchanged or even notably improve. The whole field of vision is equally affected, there is no narrowing at the periphery of the field, and eolor-perception remains relatively good. When the opacity is not distributed equally throughout the lens, the acuteness of vision may vary, being in one case better in a feeble light, and in another case better in a strong light. The impairment of vision in some eases never goes so far as to prevent the counting of the fingers held a few inches before the eye; but in others, the patient may find it difficult to recognize the direction in 
which the hand is moved before the eye, or the direetion in which a lighted candle is held before it. Light-perecption always remains.

The impariment of vision may at first be due to changes in the refraction of the lens, rather than opacity. This may be an inereased refraction at the nucleus, causing mropia with the pupil eontraeted, or negative aberration when the pupil is dilated. This myopia may enable the patient to read without the convex lenses on which he has long been dependent, and hence is called second sight. But it causes a corresponding diminution of distant vision, and often there is enongh opacity of the lens attending it to diminish near vision also. In other eyes the refraetive ehange prodnees irregular astigmatism, which eauses sectors of light and shadow that resemble cortical opacities of the lens, and which appear when the light is thrown into the cye from the ophthalmoseope mirror, held at some little distance as in skiascopy. This disturbanee of refiaction often eauses marked monocular polyopia, especially when the pupil is dilated. 'The patient sees at night several moons overlapping each other, or sees a point of light, like a distant electrie light, broken into several separate irregular lights, differing from each other in the direction of their rays.

Objectively, cataract is to be studied with oblique illumi-

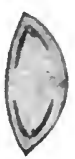

A

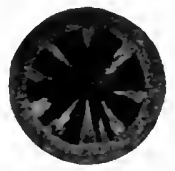

$B$

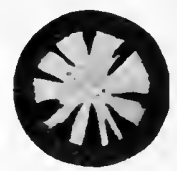

$C$

Fu. 126.-Cortieal cataract. A, section of lens showing position of opacities. $B$, appearauce of dilated pupil by oblique illumination. $C$, appearance with the oplithalmoscope.

nation and the ophthalmoscope. By the former the opacity appears as a lighter mass against a dark baek-gromnd, with the latter the opacity appears black against the red fundus-reflex. (See Figs. 126-128.) The opacity may 
appear as a diffuse cloud, or as sharply limited masses surrounded by clear lens-substance. 'These masses have
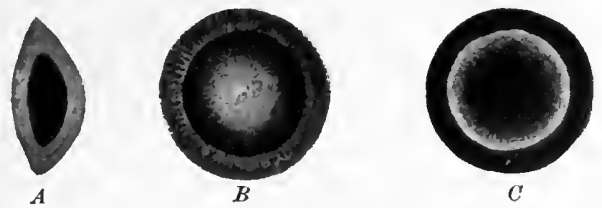

FIG. 127.-Nuclear cataract. $A$, section of lens. $B$, appearance of dilated pupil by oblique illumination. $C$, appearance with the ophthalmoscope.

most frequently the form of pyramids, spicules, or striæ, broadest toward the ciliary region, and with their aipices pointing toward the center of the pupil.

Eyes in which cataract is developing, generally show evidences of eye-strain, as pain after use, redness of the optic disk, or conjunctival hyperemia. In some eases the eye-strain must be regarded as a cause of the cataract, in others it is an effect of the increasing difficulty of vision. Patients suffering with cataract find a bright light annoying, beeause of the diffusion caused by its shining on the lens opacity.

The stages through which eataraet usually passes when the patient lives long enough are:

Incipient cataract, while the opacity is still partial, and portions of the pupil still remain elear enough to give useful vision.

Swollen cataract, when the opacity has become more general but is still not eomplete. The lens at this stage is markedly swollen by imbibition of fluid, and pushes forward the iris, making the anterior chamber shallow.

Mature cataract, when the whole lens has grown opaque, and has returned to abont its normal volume.

Hypermature cataract, when the lens is shrmken, hard, sometimes partly ealeareous, and often its eapsule, thick, tough, and thrown into ridges or folds. In a very few cases, a senile cataract has undergone spontineous absorption, or has become rlislocated out of the line of vision, with a restoration of sight. 
Varieties.-The above different stages are spoken of as varieties. In addition, we may reeognize in the earlier stages varieties based on the location of the opacity, thus :

Nuclear cataract is opacity of the lens-nucleus, generally appearing as a diffuse clouding, most dense behind the center of the pupil. It is illustrated in Fig. 127.

Cortical cataract is the term applied to cases presenting opacities in the lens-cortex. At first there are isolated needles or spicules of opacity, situated in either the anterior or the posterior cortex or in both. They are usually larger and more numerous in the lower nasal quadrant of the lens than in any other portion. Their distribution and appearance are illustrated in Fig. 126. Cortical is the most common form of senile cataract. In the early stages, a case may be purely cortical or entirely nuclear; but, in most cases of nuclear cataract, some opacities may be found in the cortex, and always the cortex becomes somewhat opaque before maturity.

Choroidal cataract is the term applied to cases in which choroidal disease is followed by a very slowly developing, diffuse nuclear opacity, of a decidedly brown color. The nucleus is very brown and hard, and the opacity often remains so incomplete that some vision is retained for many years. This form occurs in myopic eyes.

Black cataract those rare cases are called in which the lens is a very dark brown; so that by oblique illumination the pupil looks black, and almost normal in appearance, even when the cataract is mature.

Morgagnian cataract is characterized by a hard nucleus surrounded by the fluid remains of the degenerated cortex. The movable nuclens may be taken for a dislocated lens, especially as the fluid in the lens-capsule is sometimes comparatively clear and there may be trembling of the iris.

Complicated cataract is cataract in an eye that has been the seat of other serions disease, as iritis, iridocyclitis, or detachment of the retina. Its extraction is often rendered more difficult by extensive synechias; and the 
prognosis is modified by the permanent damage the eye may have suffered, apart from the lens-opacity.

Traumatic cataract includes all cases due to injury. Some of these, developing slowly, present quite the char.acters of senile cataract. The injuries of the lens are discussed in Chapter XVII.

Diagnosis.- Partial opacity of the crystalline lens is best recognized with the ophthalmoscope, using a strong convex lens belind the mirror, which should be held about the focal distance of this lens from the eye. If the opacity be cortical, it may be concealed by the iris, unless one looks obliquely so as to see behind the iris. In nuclear eataract, the whole pupil may appear obscured, until by looking obliquely the periphery of the lens is found clear. To make a complete examination of the lens, it is often necessary to dilate the pupil with cocain. The ophthalmoscopic examination should never be omitted in a case of suspected cataract; for only thus can one avoid the terrible blunder of allowing a patient to go hopelessly blind with glaucoma or optic atrophy, while waiting for a supposed cataract to ripen.

When it is ascertained that cataract is present, the character and completeness of the opacity should be studied by oblique illumination, especially with the binocular magnifier. The maturity of the cataract is estimated by determining the depth of the opacity behind the margin of the pupil; usually by the breadth of the shadow which the iris throws upon it when the light falls very obliquely across the eye. If the whole cortex of the lens is opaque, the opacity coming up to the level of the pupil, the shadow is very narrow. If between the edge of the iris and the opacity, upon which the shadow is thrown, there remains clear lens-substance, the shadow is broad. The two conditions are illustrated in Fig. 128.

Another indication as to the maturity of cataract is found in the peculiar mother-of-pearl luster of the surface of the lens under oblique illumination, which is seen when the superficial cortex begins to be affected but has not become fully opaque. Complete opacity is shown by 
a comparatively uniform white or gray appearance of the whole pupil.

When the question of an operation comes to be deeided, care must be taken to exclude, as fir as possible, other lesions, such as optic atrophy or detachment of the retina, which would render operation useless. This is done by testing the field of vision, and the ability to tell

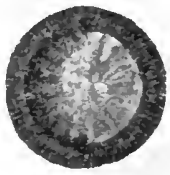

$A$

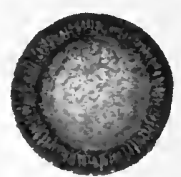

B

F1G. 128.-Senile cataract. $A$, partial, $B$, mature, as scen by oblique illumination, the source of light being on the left. A shows the broader shadow.

the direction of a light, (light-projection) by holding a candle, or the ophthalmoscopic mirror in different directions before the eve; and by testing the quantitative lightperception by turning a light-flame up and down, or by holding the candle-flame or the ophthalmoscopic mirror at different distances.

Causes and Pathology.-Beyond a general connection of eataract with certain factors, as age, diabetes, or disease of the uveal tract, but little is known of the cause of lens-opacity. Exposure to heat may cause it. This is most striking in the case of glass-blowers. Heredity is a recognized factor. Exhausting disease will hasten the development of cataract. So will any extensive disturbance of assimilation. Cataract has followed epidemies of ergotism; and experimentally eataract has been produced in the lower animals by feeding with naphthalin.

Diabetic cataract is clearly dependent upon diabetes. It usually presents a diffuse clouding of the lens, which may grow worse, or better, with the general condition of the patient. The comnection of eataract with chronic Bright's disease is meertain. Chronic dyspepsia seems to predispose to it; and tetany has been observed to be followed by it. 
Traumatic cataraet becomes opaque by the imbibition of aqueous humor, which separates the lens-fibers and destroys the refractive uniformity of the lens. At first, in ordinary senile cataract, spaces form between the lensfibers, especially at the junetion of the nucleus and cortex, and at the periphery of the lens. Later, the lensfibers themselves become irregular and disintegrated.

Treatment.-The management of immature or incipient cataract is a matter of more general interest than the extraction of mature cataract, and is of equal practical importanee. The first point is to remove eye-strain. Even if this has not been a primary eause of the lensopacity, it arises as vision becomes impaired, and influences the eye unfavorably. If the eye is still capable of useful vision, its ametropia, including often astigmatism due to lens-changes, should be carefully eorreeted; and the glasses may require frequent elanges. The patient must be strongly urged not to use the eyes too long or under unfavorable conditions. The impending danger of eataract should be mentioned, if necessary, to enforce eareful use of the eyes. Exposure to excess of light, or heat from fire or lamp, must be avoided. If mueh diseomfort is eaused by exposure to bright light, dark glasses should be worn, eare being taken to see that they do not eause eye-strain by irregular refraction. If the opacity is nuelear, improvement of vision may be secured by keeping the pupil partly dilated with weak atropin solution, instilled every second or third day. If the opacity is chiefly in the peripheral cortex and the center of the lens is clear, the annoying diffusion of light can be reduced by keeping the pupil contracted with a solution of piloearpin, $1: 500$, instilled every norning, or twiee daily. The general health of a patient, and especially the digestive function, should receive careful attention. The free drinking of water seems to retard, or sometimes completely cheek the advance of senile eataraet.

If the patient lives, and the opacity increases, the time comes when the removal of the opaque lens must be considered. If but one eye is serionsly affected, the eatarnet 
should not be removed until it is fully mature; then it should be extracted, before it passes into a state of hypermaturity. Maturity is shown by complete opacity of the cortex, disappearance of the mother-of-pearl reflex from its surface, and reduction of the swelling, as shown by increase in the depth of the anterior chamber to the normal. In this condition, the cataract is most easily extracted.

Ripening Operations.-When, however, both eyes are affected, as soon as the better eye becomes incapable of useful vision, so that the patient is compelled to give up all ordinary occupations, measures should be adopted for the early removal of the lens. Sometimes ripening may be hastened by massage of the lens. Indirect massage is done by tapping the anterior chamber, drawing off the aqueous so that the lens falls against the cornea, and then stroking the cornea with a corneal spatula, within the area of the pupil previously dilated with coeain. Or iridectomy may be done, and similar stroking of the cornea over the area of the pupil and the coloboma in the iris. Direct massage is done either with or without iridectomy, by introducing a spatula into the anterior chamber and stroking the anterior capsule of the lens. The author prefers the operation first mentioned. After it, if the lens has a firm nucleus, the anterior cortex rapidly becomes hazy and within two to six weeks entirely opaque.

Even without any such preliminary operation a cataract may be removed before maturity. The special difficulties of such removal are that portions of the cortex, still clear, remain adherent to the lens-capsule, and later become opaque, preventing good vision until they have become absorbed, or are removed by an operation for secondary eataract; and that the swollen lens may require a slightly longer corneal incision. But after fifty years of age the bulk of the lens can be removed as nucleus; the cortex left, if not in the anterior chamber, will cause no irritation; and the waiting even for a secondary operation or the absorption of the remaining cortex is not so irksome after the principal operation is safely past. In the hands 
of skilful operators the risks of extraction are not materially increased by immaturity of the cataract.

Mature or complete cataract is to be treated by extraction. The operations and the preliminary and after treatment are described in Chapter XIX. The writer prefers, for most cases, extraction without ividectomy, as being a simpler operation and leaving the patient with slightly better vision and less dependent on his glasses. But when the iris is very rigid or is bound down by posterior synechiæ, or there is a strong probability of prolapse of the iris, because the patient is restless and unruly, or the eyes prominent, extraction with iridectomy is better. Before doing extraction, care should be taken to have the patient in the best physical condition that he is capable of, and to make sure there is no chronic conjunctivitis, or nucopurulent accumulation in the lacrimal passages that will be liable to infect the corneal wound.

Glasses.-After cataract extraction, a secondary operation may be necessary (see Secondary Cataract), and the patient is compelled to wear glasses. If the ametropia has been low before the cataract, removal of the lens will leave hyperopia of 10 to $12 \mathrm{D}$.; and cataract extraction commonly leaves astignatism against the rule, which is at first very high, but ultimately diminishes to less than $3 \mathrm{D}$. The changes in refraction may continue for some months, and until they are complete, permanent glasses cannot be fitted. For near work convex $3 \mathrm{D}$. spherical must be added to the distance-glasses. Patients often complain of the distortion produced by their strong glasses, to which on account of their agc they become but incompletely accustomed, and only after a long time.

When both eyes are the scat of cataract, the sccond should be operated on when its cataract becomes mature. Both eyes should not be risked by operation at the same time. But if both cataracts are ripe, and the cye first operated on does well, the second operation may be done within a few days.

Prognosis.-Of persons over fifty years of age who show distinct opacity of the crystalline lens, probably not 
more than one in ten ever requires operation. The early appearance of such opacity, and its rapid and continuous inerease, point toward a probable need of extraction ; yet such eases may at any time ecase to be progressive. Nuelear opacity is apt to be slowly progressive, the choroidal form rarely reaching complete maturity. Opacitics recently formed, or progressive, are more apt to be indefinite or hazy. Those that have ceased to change, are sharply ontlined in elear lens-substanee. But regarding the progress of eataract there is always great uneertainty, and a definite prognosis ean never be given.

Cataract extraction brings improved vision in over 90 per cent. of the eases ( 97 per eent. of the author's eases of simple extraetion); but eataraet oceurs in eyes not otherwise entirely healthy, so that full vision is only attained exeeptionally, even with the strong convex lenses they require. The means of exeluding eases not likely to be benefited are given under diagnosis. If light-projeetion and quantitative perception are defective, removal of the cataract, however successful, will not improve vision, except in a few eases in which the opacity is extremely dense. The extraction of a hypermature cataraet is liable to be followed by inflammation of the ureal tract, and a poor visual result.

After eataract extraction, vision generally becomes impaired through thiekening of the eapsule, (secondary cataract), mnless the operation for this condition has been done shortly after the extraction. In about 1 per cent. of cataract extractions, glaweoma follows, especially after operations for secondary cataract. Patients that have suffered from eataraet are quite as liable as others of their age to choroidal discase, optic atroplyy, and detached retina.

Juvenile or Soft Cataract.-Cataract occurring in young persons is usually devoid of a firm nucleus, such nueleus as existed in the lens having been broken down by the degenerative process. It presents the appearance of senile cataract, except that the pupil is apt to appear more white and uniform in eolor. A perfectly uniform milky 
appearance indicates a fluid cataract. Soft cataract is commonly traceable to a distinct cause. A few cases are congenital; some are due to traumatism ; some are probably due to convulsions, at least the association of soft cataract with previous general convulsions is common; diabetes causes some cases; a few seem due to carly senile changes in the lens.

Treatment.-Soft eataract does not usually require extraction. If largely fluid, an incision 5 to $8 \mathrm{~mm}$. long in the cornea, with a similar shorter incision in the anterior capsule, will allow it to be pressed out, or drawn out through a suction currette. If more consistent, it may be opened by discission and allowed to undergo absorption, the process being hastened from time to time by repeating the needling; any part remaining unabsorbed may afterwards be extracted. No fixed age can be set, up to which needle operations to produce absorption are proper, and after which extraction must be done; but generally before twenty absorption can be relied on, and after thirty it is rarely sufficient. In doubtful cases we may begin by a needle operation that makes but a small opening in the anterior capsule, being prepared to follow it, if necessary by extraction.

Partial Cataract.-All lens-opacities are at some time partial ; but in some cases a fixed and characteristic portion of the lens is involved, and there is no tendency to extension of the opacity to other parts, for many years, or throughout life. Such opacities often affect both eyes. Cataracts of this lind are named by the characteristic form or situation of the opacity.

Anterior polar cataract (anterior capsular cataract or pyramidal cataract) occurs at the anterior pole of the lens, involving the capsule, and is usually somewhat pyramidal in shape. It may be congenital, possibly the remains of pupillary membrane; or it may be aequired in early childhood through perforation of the cornea. (Sec page 280.) Anterior polar cataract is usually but a small speck upon or beneath the surface of the lens, which does 
not suffieiently olstruet the pupil to require treatment. Its appearance and location are illustrated in Fig. 129.

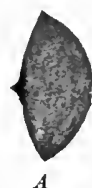

A

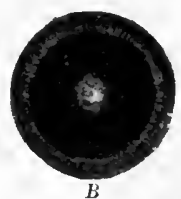

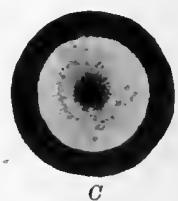

C

Fig. 129.-Anterior polar or pyramidal cataract. $A$, seetion showing projecting opacity on anterior surface of lens. $B$, pupil by oblique illumination. $C$, pupil by ophthalmoscopic illumination.

Posterior polar cataract may be congenital, arising from ineomplete clearing of the point at which, during fetal life, the hyaloid artery reaches the posterior capsule of the lens. This form eonsists of a small rounded opacity situated to the nasal side of the posterior pole of the lens, and only discovered with the ophthalmoseope, with which it appears as a small black dot against the red fundus-reflex. Another form is a larger mass of opacity, often of a radiating figure, which developes in connection with high myopia, ehoroidal disease, or ehronic retinal disease; and which may progress to complete eataract. This form interferes sonie with vision. It is illustrated in Fig. 130.

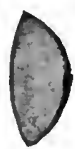

$\boldsymbol{A}$

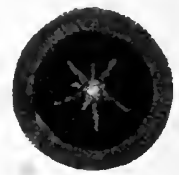

$B$

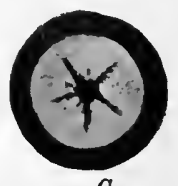

C

FIG. 130.-Posterior polar cataract. $A$, section showing opacity just within the posterior capsule. $B$, appearance of dilated pupil by oblique, and $C$, by ophthalmoscopic, illumination.

Lamellar Cataract (Zomular or Perinuclear Cataract).- In this form there is opaeity of a layer surrounding the nueleus, the nueleus within and the cortex outside this layer remaining elear. This distribution of the opaeity, and the appearances it causes are illustrated in Fig. 131. 
In rare eases there are two such complete concentric zones of opacity, separated by clear lens-substance. More frequently, the periphery of the lens presents commencing opacity of a seeond layer; such partial opacities are called "riders." The appearances of lamellar cataract resemble those of nuclear cataract in that both present a cirele of opacity at the center of the pupil, surrounded by elear

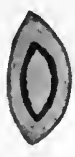

$A$

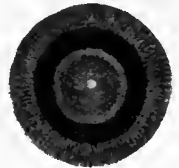

$B$

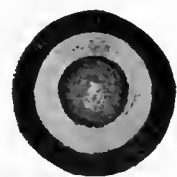

C

Fig. 131.-Lamellar cataract. $A$, section of lens. $B$, pupil dilated seen by oblique, and $C$, by oph thalmoseopic, illumination.

lens-substance. But they differ in that in lamellar cataract the opacity is most dense at the margin of the eircle, while in nuclear cataract it is most dense at the center.

This form of eataract is congenital, or arises in early childhood. It is often associated with a history of convulsions, dental defects, or other congenital deficiencies of the eyes.

Fusiform cataract is a spindle-shaped opacity extending from the anterior to the posterior pole of the lens. This is also called coraliform cataract. Specks of opacity may be found in varions parts of the lens remaining unchanged thronghout life. Such a speck at the center of a nucleus would be ealled central cataract.

Diagnosis.-Partial cataract is most certainly detected by eareful search with the ophthalmoseope. The exact location of the opaeity is to be determined by the methods described in Chapter IV (see page 81). A small partial cataract might be mistaken for a foreign body in the lens.

Treatment.-Partial cataract is serions in so far as it obstructs the pupil. Often the complete dilatation of the pupil produces great improvement of vision. In a few of thesc cases an optical iridectomy enabling the patient to 
see past the obstruction will be beneficial ; but usually if the impairment of vision justifies operative interference, it is best to remove the lens, by extraction in adults, or discission in children. The loss of accommodation by removal of the lens is of less importance in these cases, because with decided lens-opacity, the accommodation is usually found greatly diminished. Then, too, a lens with partial opacity is especially liable to complete cataract at a later period. Even opacity confined to the capsule, or lying on the normal capsule, as the exudate in ocelusion of the pupil, cannot be removed without removal of the whole lens.

Secondary Cataract (Cupsular Cataract or Aftercataract).-The common operations for removal of cataract leave a part or the whole of the lens-eapsule in the eye. Operations for getting rid of the capsule with the lens have been devised; but their difficulty and risk are not compensated by their arlvantages. Usually the capsule includes the remains of the cortex adherent to it. The transparency of the capsule is disturbed by the extraction of the lens, and the adherent cortex at first swells and becomes opaque; but after this the capsule clears up and the cortex is absorbed, and the vision improves to a maximum a few weeks or months after the extraction. Then there oceurs a slow process of thiekening of the capsule, which causes vision to deteriorate, until, eommonly within two years, it has fallen a good deal below the maximum attained shortly after operation. In other eases, as after the extraction of an umripe eataract, the cortex left behind canses an opacity that cutirely obstructs the pupil, and would require many weeks or months for its absorption. Or after the extraction of a hypermature or complicated cataract the capsule is so decidedly opaque as to seriously impair the vision. Again, after diseission of soft cataract there often remains a comparatively thin, but tough opaque mass, which tends to persist indefinitely without further absorption and to beeome ealcarcous. These are all included under the heading of secondary cataraet. 
Diagnosis. - With the ophthalmoseope, if the obstruction of the pupil is partial, black lines or masses are seen, which are found to be in the plane of the pupil; and the details of the fundus are found to be indistinet. The ophthalmoseopic appearances of secondary eataract are shown in Fig. 132. By oblique illumination these opacities

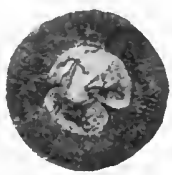

FIg. 132.-Secondary cataract. Appearance of the pupil by ophthalmoscopic illumination. Two iritic ahcsions. The capsule clearer in upper part of the pupil.

appear gray or brown. When the obstruction is complete, the pupil is seen to be ocenpied by a gray or white mass rescmbling a mature cataract; but this is distinguished from primary or lenticular cataract by the great depth of the anterior chamber, and tremulousness of the iris, showing that the bulk of the lens has been removed; and by history of the previous cataract operation of some sort. It is to be distinguished from opaeity in the anterior vitreous by the general condition of the eyeball. In simple sceondary eatarat the tension is usually normal or not mueh diminished, and the light-projection and quantitative pereeption are good. But vitreous opacity, such as might simulate secondary eataract, is often attended with decided lowering of the intra-ocular tension, and the loss of light-projection or perception.

Treatment.-Secondary eataract is to be met by making a suffieient opening through it, or by extracting it from the eye. The former operation is resorted to for comparatively thin membranes that can be readily ent or torn through, and which are likely to retract and leave a clear opening after division. The removal of the opacity is indicated when it is comparatively thick and rigid, and especially when it oceupies a small area just behind the contracted pupil. 'The operations for these 
purposes are described in Chapter XIX. They are not without danger. They may cause infeetion of the eye, and general inflammation of the uveal tract.

Dislocation of the lens (luxation of the lens, ectopia lentis) oceurs sometimes as a congenital anomaly. The lens is displaced usually upward, but sometimes in other dircetions. The displacenent is commonly symmetrical in the two eyes, but may be confined to one. 'The edge of the lens may be seen in the pupil, appearing with the ophthalmoseope as a lark line on the red background, distinguishable from anything else by its even eurve. Its appearance is illustrated in Fig. 133. Vision is commonly

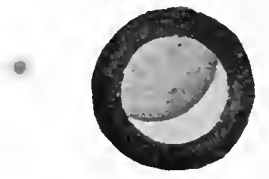

F1G. 133.-Congenital dislocation of the lens upward and to the nasal side in the left eye. Curved lens-margin seen crossing the dilated pupil.

impaired on account of imperfect focussing, either through the edge of the lens where the eye is myopic, or ontside the lens where it is hyperopic. Rarely the two sets of rays cause monocular diplopia. The iris is pushed forward on the side toward the lens. In some cases the lens scems -fixed in its anomalous position, but often it is movable. In a few cases, the patient has been able to swing the lenses into position behind the pupil, or allow them to drop away by changing the position of his head and eyes.

The discolated lens may remain perfectly clear, although it generally appears a faint gray by oblique illumination. If entirely loosened from its normal connections, it gradually beeomes opaque.

Oceasionally spontaneous dislocation of the lens oecurs through relaxation or atrophy of its suspensory ligament. Often it only amounts to a partial disloeation, the lens falling back at one part, making the depth of the anterior chamber unequal in different portions and at different 
times. In other cases the dislocation is complete, the lens falling quite away from the puipil, and lying usually in the lower part of the vitreous chamber. Such a freely movable lens is liable to become displaced through the pupil into the anterior chamber.

When dislocated into the anterior chamber, the clear lens may be recognized by the eurved line of brilliant reflex from its edge. If opaque, it of course hides the central portion of the iris, and is distinguished from opacity of the cormea by its distinct edge and greater depth when viewed binocularly. It may be elosely simulated by the exudate in spongy iritis. A dislocated lens if at all movable is a constant souree of danger in the eye. It is liable to cause disorganization and opacity of the vitreous, to set up ehronic inflammation of the uveal tract, or to bring on glaneoma.

Treatment.-Except in cases where the lens is firmly fixed in its abnormal position, and does not interfere with vision, a dislocated lens should be removed-by diseission and absorption in young eyes, or by extraction in later life. Sonctimes a dislocated lens ean be extracted like an ordinary cataract, sometimes it requires the use of a lens-spoon, and sometimes a two-pronged fork called a bident, or a straight needle, has been thrust behind it to hold it forward to the pupil, in position for extraction.

Sometimes a lens dislocated into the anterior chamber can be returned behind the iris (where it is less likely to cause immediate harm) by dilating the pupil fully with homatropin, and manipulating the eyeball. After it las thus been returned, it may be kept behind the pupil by the instillation of eserin (physostigmin) solution once or twice a day.

In a few cases of traumatic subluxation the lens seems to be restored to its normal position and support under long rest of the eye, with the use of mydriatics. Yet mydriaties must be used eautiously when the lens is dislocated, on aceount of the possibility of their increasing the liability to glaucoma.

Coloboma of the lens is a congenital anomaly in 
which the lens appears notched, usually at its lower margin. It is rare, and mostly associated with eoloboma

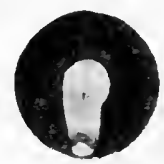

Fig. 134-Congenital coloboma of the lens seen through coloboma of the iris downward.

of the iris and choroid, as in the case illustrated in Fig. 134.

Lenticonus is a rare irregular protrusion of one of the lens-surfaces, usually the posterior, causing irregularity of refraetion a little like that of conical cornea. It may be studied by skiascopy ; and by shifting the point of view, the irregular refraetion is seen to depend on the lens rather than the eornea.

Aphakia, or eomplete absenee of the lens, may oecur as a congenital anomaly. But most of the eases supposed to be of this class are really eases in which a very small lens is disloeated so as to be invisible.

Injuries of the lens are considered in Chapter XVII.

\section{DISEASES OF THE VITREOUS.}

Vitreous Opacities.-Impairment of transparency is the most eonstant symptom of disease of the vitreous body. It is a symptom, too, that is prominent in many cases of diseases of the ehoroid, eiliary body and retina, for it is upon the vessels of these parts that the nonvaseular vitreous depends for its nutritive supply.

Symptoms and Varieties.-Vitreous opaeities vary from the slightest exaggeration of the normal specks that ean be pereeived subjeetively in the healthy cye (see page 42) to great masses that render the eye practically blind. Opacities of much importance are to be reeognized by the ophthalmoscope, although some too small to be visible do eause annoying shadows, especially when the retina is hyperesthetie from eye-strain. 
Perfectly diffuse haziness of the vitreous sometimes occurs in connection with acute hyalitis, retinitis, cyclitis, or choroiditis. Visible opacities have the forms of fine dust, larger flakes, shreds or bands, and large membranous masses. They are illustrated in Fig. 135. The dust-like opacity is eommonly due to syphilitie ehorioretinitis or

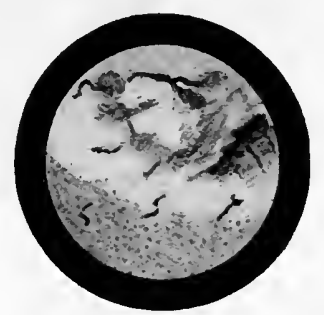

FiG. 135.-Opacities of the vitreous, dust-like at lower part of pupil, with threads and membranous masses above.

cyclitis. The fakes and shreds are formed in chronic choroidal disease, or progressive myopia ; the large floating membranous masses are usually the remains of hemorrhages into the vitreous. Extensive organized menbranes fixed in position by firm attachment to the retina are supposed to have developed as a result of chronic retinal disease, and are spoken of as retinitis proliferans.

Inpairment of vision from retinal opaeities varies with their density and situation. Often the patient can by certain movements of the eyes or head throw an obstructing opacity out of the line of vision, and so, for an instant, see much more elearly. In other eases the vision grows better when the eyes are for some time kept steady, and the floating masses allowed to settle down.

Diagnosis.-Subjectively the shadows of vitreous opacities may be confused with scotomas due to retinal or choroidal disease, with after-images of bright lights, or with the photopsias of disturbance of the visual centers. With the ophthalmoscope the opacities may be mistaken for pigment-masses in the choroid, or opaeities in the lens or cornea. The eharacteristic of the vitreous opacities is 
their peenliar tremulons movement and gradual settling to a position of rest after any movement of the eyes. Their ustal shapes differ, too, quite deeidedly from those of ehoroidal pigment-patehes or lens-opacities, and their depth in the eye as measured by their refraction (sce page 134) or parallax (see page 82) indicates their eharaeter.

Treatment.- 'This must be ehiefly the treatment of the eause of the opacity, or the disease with which it is assoeiated. When no other ocular lesion is discoverable, any abnormality of the general health should be attended to. Alteratives, espeeially mereuric ehlorid and potassium iodid, in moderate doses long eontinued, may be quite beneficial. Pilocarpin sweats, abstraetion of blood from the temple, and local applications of moderate galvanic or high frequeneyveurrents have been reported benefieial. Large membranous opacities that are chronic may be divided with a narrow knife, causing improved vision and shrinkage of the opacity. In all cases, choroidal disease is probably present and requires treatment. Nasal disease is also a probable eause of vitreous opacities.

Prognosis.-The smallest vitreous opacities, those that canse the muscee volitantes are apt to occasion the greatest alarm. Generally the patient may be assured that they are not a sign of danger. But the prognosis as to restoration of the transparency of the vitreous is at best doubtful. Syphilitie opaeities and those following hemorrhages sometimes elear up remarkably, even after many months; those attending ehronic ehoroidal disease and high myopia generally remain, althongh they may become less annoying.

Fluid Vitreous (Synchisis). - Undue fluidity of the vitreous is only reeognized by the unduly free movement of opaeities in it. It very generally oceurs with extensive vitreous opacities. It is of practical importanee by indicating degenerative ehanges in the eye, and by eomplieating operations for eataraet or glaneoma.

Sparkling synchisis (synchisis scintillans) is the name given when there are sonttered throngh the fluid vitreous small erystals of cholesterin, tyrosin and phosphates, 
which are seen with the ophthalmoscope to glitter and flash as they move, after any movement of the eye. 'This condition is usually found in degenerated eyes, but is not incompatible with perfect vision. It is not affected by treatment.

Hyalitis. - Inflammation of the vitreous arises from inflammation of the retina, ciliary body or choroid, or by infection through a penetrating wound, or foreign body. It is marked by diffiuse opacity, the accumulation of pus-cells in varions portions, and the symptoms of the disease with which it is associated. It tends to run a chronic course. A few eases partly clear up ; but usually the vitreous comes to present the yellowish mass, called psendo-glioma (see page 343 ), sight being lost and the tension of the globe permanently diminished. Rare cases of traumatic hyalitis make complete recoveries.

Treatment.-Hyalitis is to be regarded as rather a symptom of the discase causing it, to which the treatment is to be directed. It is good surgery to remove a sightless eye containing a collection of pus in the vitreous, even though there be no ehance that it conceals a foreign body, or question of its being glioma of the retina.

Hemorrhage into the vitreous comes from the uveal tract or retina, and is due to traumatism, vascular disease, or possibly alteration in the blood itself. Cases of obscure etiology occur in early adult life. It causes dark masses, which may appear red on the margins. $V$ ision may be redueed by it to bare light-perception, or objects seen through it may appear red. The clot is slowly absorbed, and there may be restoration of good vision, but generally some opacity remains.

Treatment.-At the time of the hemorrhage, rest, with the head high, eold to the eye, the taking of blood from the temple, and cardiac depressants, may be employed. Subsequently careful attention to the general health, with pilocarpin sweats, and small doses of potassium iollid, may be resorted to. Remaining membranons opacities may be cut through after they become non- 
valscular, and all tendeney to inflammation or recurrence of hemorghage appear's to have passed away.

Blood-vessels in the vitreous are sometimes formed after the ocenrence of repeated liemorrhages. They arise from the retinal vessels, pass forward into the vitreous in the form of net-work of small vaseular loops, more or less enveloped in opacity, and after a few montlis or longer may shrink and entirely disappear. A mass of such vessels is illustrated in Fig. 136.

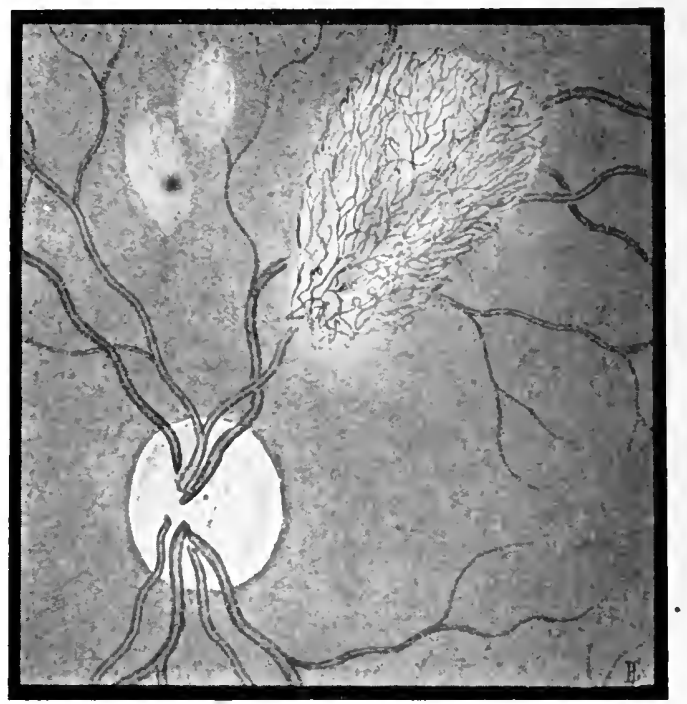

Fig. 136.-New-formed vessels in the vitreous, hiding part of the upper temporal vessels in the left eye. These vessels, being in advance of the fundus, eould not be seen distincily at the same time as the fundus, as represented in the picture.

Detachment of the vitreous alone is not elinically recognized; hut it attends detachment of the retina, and shrinking of the exulate after erelitis.

Parasites in the Vitreous.-Filaria, liydatids, and crsticereus lave been found in this situation. In Nortl Germany eysticereus is not reery rare. It appears while alive as a round bluish-white cyst; from which extends 
the white neek, with the head moving slowly back and forth independent of the movements of the eye. After its death it may become so corered with lymph as to be unrecognizable with the ophthalmoseope. If the parasite is not removed, the eye is liable to beeome blind and shrunken.

Persistent Hyaloid Artery.-In early fetal life a branch from one of the retinal arteries passes forward from the optic disk to the posterior pole of the lens, where it breaks up into many minute branches. This vessel is ealled the hyaloid artery. Usually it atrophies before birth, but in a few eases, some traees of it remain throughout life, and in a very few it eontinues to carry blood. The most common triee of it is a speek on the posterior eapsnle of the lens; next in frequency are tags of gray tissue on the optie disk, and sometimes a wavy, gray connective-tissue ehord marks its eourse through the vitreous.

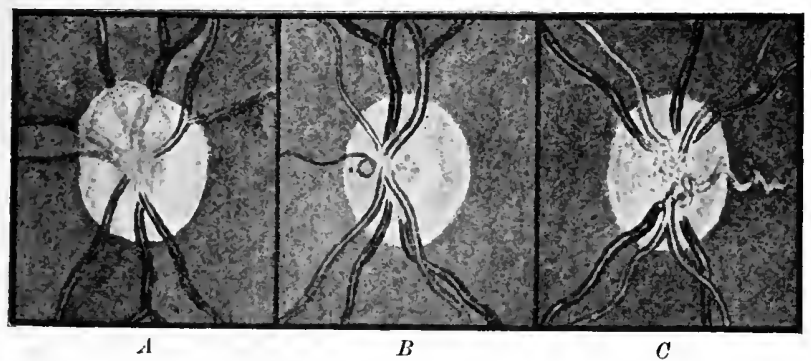

FIG, $136 a .-A, B, C$, persistent hyaloid remains.

The more common types of peristent remains of the hyaloid artery, as they appear in the fundus, are shown in the aceompanying Fignres, $A, B, C$. (A) represents the membranous form, partially concealing the vessels on the disk. In the case represented, it had a definite outline. Often it shows a number of irregular tags, or a gradual 
transition into normal vitreons tissne. (B) shows a cyst-like formation upon, or attached to one of the vessels of the optic disk. The nature of such bodies may seem puzzling, but they are congenital, and probably associated with retrograde changes in the hyaloid vessels. (C) shows the rarer form which more closely resembles a vessel, and in which may be minute vessels arrying blood.

Persistent hyaloid remains must be distingnished from products of intra-ocular inflammation, as the exudate of retinitis near the maenla, vitreous opacities of inflammatory origin, or proliferating retinitis (see page 371 ). They may also be mistaken for foreign bodies in the vitreous, or for intra-oenlar eysticerens.

\section{CHA PTER X V.}

\section{DISORDERS OF TENSION OF THE EYEBALL.}

Normal Intra-ocular Currents and Pressure.The preservation of the shape of the eyeball, the curvature of the eornea, and the normal relation of the dioptric surfaces to the retina depend on the intra-ocular tension. The sclerocomeal coat is a closed sac fitted to resist internal pressure. Its contents, pressing outward at every point, keep it distended, against the external pressure of the lids, extra-ocular museles, and orbital tissues. This normal intra-ocular tension equals the pressure of a column of merenry 25 to $30 \mathrm{~mm}$. (1-1.2 inches) in height. It varies somewhat within the limits of health, and may vary in disease from nothing to the equivalent of $200 \mathrm{~mm}$. ( 8 inches) of mercury or more.

The cornea, crystalline, and vitreous humor are non- 
vascular, and are nourished by fluid from the capillaries of other tissues. The supply of this fluid must be kept up eontinuously, or the nutrition of these parts of the eye would suffer. 'This fluid, constantly poured into the eye, must as constantly eseape from it, or undue distention of the eyeball and increased intra-ocular tension result. Inereased inflow must be balaneed by a free passage through the channels of escape. This suggests the existence of a mechanism co-ordinating inflow and outflow. But of the portion of the nervous system for the regulation of intraocular tension we know little.

The inflow of fluid comes through the cornea from the vessels of the pericorneal zone, from the choroid, and particularly from the vessels of the eiliary processes. From the latter sources the fluid passes through the vitreous body around the erystalline lens, forward through the pupil. The prineipal escape of fluid from the eye oceurs at the angle of the anterior chamber, where the cornea is devoid of epithelium, and large lymph-spaces connect the anterior ehamber with the canal of Schlemm,

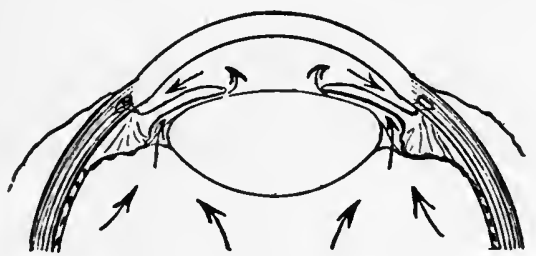

Fic. 137.-Path of intra-ocular fluids.

a large drainage-chamnel within the sclera. The path of the intra-ocular fluid is illustrated in Fig. 137.

Diminished intra-oenlar tension may arise from diminished inflow or increased outflow; or increased tension from increased inflow or diminished outflow. Of these possible eonditions most is known abont diminished inflow, causing lowered tension; and diminished outflow, eausing increased tension. 
Intra-ocular tension is tested by placing the tips of two fingers, usually the two fore-fingers, either on the upper lid above the eartilage when the lids are lightly closed and the eye rolled down, or upon the sclera below the cornea when the eye is rolled up. Making pressure with one finger while the other steadies the cycball, the amount of pressure required to dimple or press in the surface of the eye is a measure of the intra-ocular tension.

Care must be observed that a rigid selera is not mistaken for inereased tension. The best guide as to change of tension is comparison of the resistance of the eye under examination with that of a normal eye,-either the patient's other eye if normal, the surgeon's eye, or that of some third person. Allowance must be made for individual peculiarities and inereasing rigidity of the selera with inereasing age.

By this method very exact knowledge of the changes of intra-ocular tension eannot be attained, and the common plan of indieating such ehanges is probably as exact as conld be practieally useful. This plan, singested by Bowman, is:

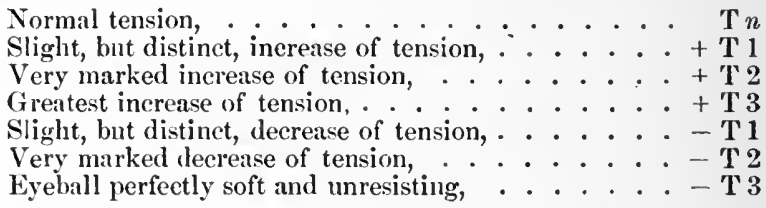

Sometimes $+\mathrm{T}$ ? and $-\mathrm{T}$ ? are used to indicate a doubtful inerease or decrease.

\section{GLAUCOMA.}

Glancoma is increased intra-ocular-tension, with the catses and results of such increase. The word originally, in the ancient Greek, referred only to the reflex of light in the pupil, including, among other conditions, cataract. But as other conclitions have been classed under other titles it has gradually come to inelude only the 
disease causing blindness with increased tension of the eyeball.

Primary glaucoma includes all cases of increased intra-ocular tension not preceded by injury or other marked disease of the eyeball. It includes glancoma with exacerbations, and simple glaucoma. Secondary glaucoma includes several forms of diverse origin, but with the common tendency to blindness with high tension.

Glaucoma with exacerbations (inflammatory glaucoma, acute and chronic) is marked by a sudden appearance or sudden increase of its symptoms, which subsequently remit or intermit, but again recur. The recurring exacerbations gradually become more severe, each time leaving the eye damaged to a greater extent, and finally they end in complete blindness, with great pain.

Symptoms and Course.-Early loss of the power of accommodation, increasing hyperopia and the appearance or increase of astigmatism against the rule, are thought to indicate the probability of glaucoma (incipient glaucoma). Frequent changes in the amount or direction of the astigmatism, or inability to use the eyes to a normal extent without obvious reason for it, have the same significance. But these symptoms cannot be regarded as surely symptoms of glaucoma, since they all occur in eyes that never show any tendency to increased tension.

The first positive symptom to attract attention is usually disturbance of vision. The vision in one or both eyes is temporarily blurred, or a ring or halo is noticed around the lamp-flame at night. This halo is 10 degrees or 12 degrees in diameter and exhibits the colors of the rainbow, with the violet inward, the red outward. Like the dimness of vision, it is at first entirely intermittent, is seen when the patient is tired or indisposed, and after a good night's rest, disappears. At the periods of impaired vision, the pupil is somewhat dilated, although at other times still of normal size. Close examination will show that the anterior chamber is shallow, especially toward its periphery. 
The obscurations of vision recur, become greater, last longer, are attended with more marked dilatation of the pupil, and subsequently with pain. They also become marked by redness of the pericorneal zone, and distinct attacks of acute inflammation, attended with general cloudiness of the cornea, and consequent alteration of the appearance of the iris, and blurring of the ophthalmoscopic image. Examination will now show that the field of vision is becoming impaired, and probably the acuteness of vision at the fovea will remain below normal between the attacks. With the progressive impairment of central vision and the narrowing of the visual field the halo symptom becomes less noticeable or disappears al together.

If the ease be not efficiently treated, the exacerbations become more frequent and severe, the remissions less complete. The permanent alteration of the field and of central vision become greater, until blindness, constant pain and continuous inflammation are established (absolute glaucoma). After a variable period of pain and inflammation these may subside, leaving a sightless but painless eyeball; or the intra-ocular tension may cause staphyloma and rupture, with partial escape of the contents of the globe, suceeded sometimes by panophthalmitis.

If not checked by treatment, the course of the disease is always to complete and irremediable blindness. In rare cases this results from the first outbreak noticed, or through one violent outbreak preceded by only a few insignificant exacerbations (glaucoma fulminans). In rare cases, after one or two exacerbations, the eye remains free from them for some time, or the excerbations oceur at long intervals and increase but little in severity.

Corneal Anesthesia.-At first, during the exacerbations, and later eontinuously, the eornea becomes comparatively insensitive to touch; and we have an exquisitively painful eye showing less reaction when lightly touched on the cornea than the normal fellow eye. 
Pain always attends glancoma with exacerbations, and usually in the later stiges is extremely severe. The writer has known a patient to lose fifty pounds weight in six weeks, throngh the suffering from glaneoma. The pain is not relieved by drugs or by any form of local treatment, exeept such as diminishes the intra-ocular tension.

The impairment of the field of vision begins commonly in the periphery, is usually greater on the nasal side, and is apt to be permanent. Fig. 138 shows a common form

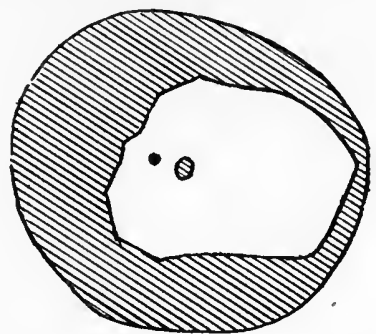

FIG. 138. - Field of vision in glaucoma.

of limitation; but the form may vary greatly. In some eases the outline of the field becomes very irregular, often seotomas may be found. Central vision is sonictimes lost while some eceentrie vision is still retained, but ultimately all pereeption of light is lost.

The ophthalmoscopic symptoms inelude the appearances produced by pressure. The most striking is cupping of the optic nerve (see Plate II, 6, and Fig. 32, p. 97). The increased tension also eanses collapse of the arteries in the interval between the pulse-waves, giving rise to arterial pulsation. This may be seen either at the margin of the eup, or where the vessels appear on its floor. Pulsation of the veins in this situation is normal in many eyes. Arterial pulsation is one of the first symptoms of inereased intra-oenlar tension. But it is often diffieult to deteet, and may be temporarily abolished by previons pressure 
on the eyelall, as in testing intra-ocular tension. The formation of a enlancoma-cup refuires time. During the early exacerbations, no sign of it will be detected. When formed, however, it is permanent, and is usually the most positive sign of glancoma to be found between the exacerhations. In chronic glaneoma the optic disk is usually surrounded by a comparatively miform ring or halo of

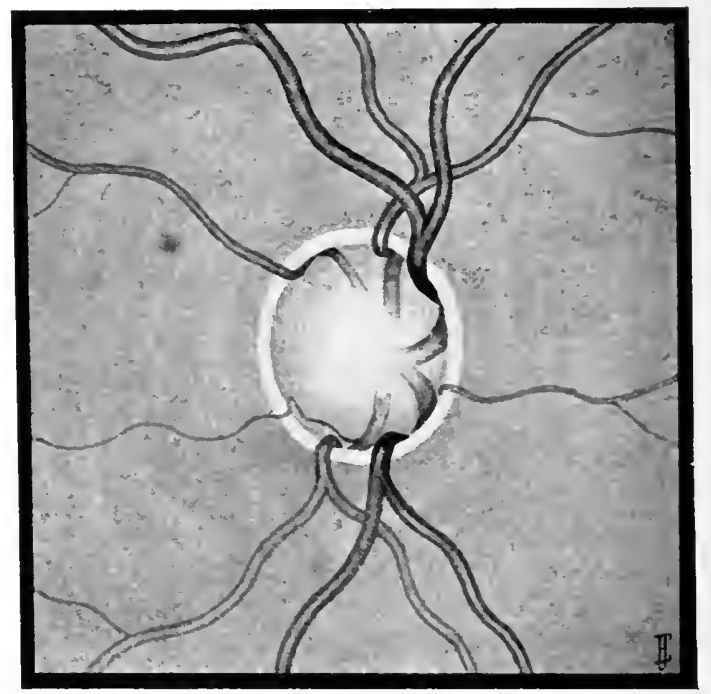

FIG. 139.-Fundus in chronic glaucoma. Disk deeply cupped to its extreme margin, and surrounded by a white ring or "halo" of choroidal atrophy. Vessels disappear on sides of the glaucoma-cup.

clioroidal atrophy. The ophthalmoscopic symptoms of glancomat are illustrated in Fig. 139.

Causes and Pathology.-On the average, ont of ten eases of glaucoma six oceur in women and four in men. Jews are particularly liable to it. Negroes suffer from it but rarely. The liability is hereditary in certain families; and it increases with age up to seventy, and after that declines. It is rare before the age of forty. Still, sev- 
eral eases have been reported occurring before the age of twenty. An exacerbation may be excited by grief, mental shoek, worry, exhanstion, and especially by dilatation of the pupil with a mydriatic.

Examination of eyes removed for absolute glaucoma, the clinical history of the disease, and the influences of treatment, all indicate that a very important factor in eausing increased tension in the eyeball, is blocking of the outflow from the anterior chamber. Eyes blind with this disease show the periphery of the iris permanently adherent to the posterior surface of the cornea, the lymphchannels being entirely closed. This condition is illustrated in Fig. 141, in contrast with the normal condition

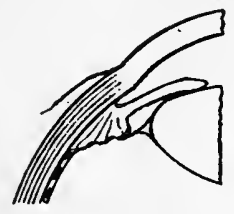

FIG. 140.

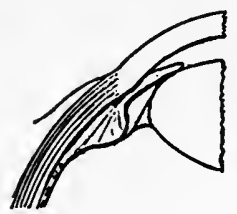

FIG. 141.

Angle of the anterior chamber: Fig. 140, in the normal eye; Fig. 141, in a glaucomatous eye.

shown in Fig. 140. The action of mydriaties also illustrates the infuence of blocking the angle of the anterior chamber. The dilatation of the pupil eauses thickening of the periphery of the iris, thus closing for the time the outflow channels. Cocain, while dilating the pupil, so contracts the blood-vessels as to prevent thickening of the iris periphery; and it does not show the same tendency to produce an outbreak.

The conditions which bring about secondary glaucoma also aet the same way. Dislocation or swelling of the lens pushes the periphery of the iris forward. Ocelusion of the pupil, eausing iris bombé, does the same thing. Eserin (physostigmin) by contracting the pupil, thins the periphery of the iris and draws it away from the cornea, thus reopening the ontflow chamels.

Priestley Smith has shown that the predisposing influence 
of age is also thus explained: The crystalline lens, like other epithelial structures, continues to grow throughout life, at least until sixty or seventy years of age, when it may begin to degencrate and shrink; the enlarged lens pressing on the ciliary processes, and through them pushing forward the periphery of the iris, predisposes to the blocking of the angle of the anterior chamber. He also points out that eyes having a comparatively small cornca, and therefore less space between the lens and the ciliary processes are more liable to glaucoma. Glancoma may be associated with rheumatism, gout, vascular disease, and disturbances of circulation. Eye-strain has been regarded as a factor.

Diagnosis.-Glancoma is characterized by increased intra-ocular tension; but a slight increase cannot be recognized with certainty; and even in glaucoma of long standing, the tension may much of the time be normal. The history of repeated attacks or relapses is very suggestive, and cupping of the disk, with impairment of the field of vision is quite characteristic. Dilatation of the pupil, shallowness of the anterior chamber, and dilatation of the scleral veins, are also important symptoms.

When the premonitory symptoms of glaucoma are present, but a positive diagnosis cannot be made, the instillation of homatropin or euphthalmin will probably cause arterial pulsation and other signs of increased tension, if glancoma is really imminent. This is a proper diagnostic procedure, provided its character is explained to the patient, and his assent obtained to the prompt treatment of the disease, if thus rendered manifest.

Glaucomatous attacks are sometimes mistaken for neuralgia, the severe pain being referred to the brow and cheek rather than to the eye. Such an error can always be avoided by examining the tension of the eye, the field of vision, the size of the pupil, and the appearance of the optic disk.

The haziness of the cornea with pericorneal redness may cause it to be confused with keratitis; but with these symptoms the tension is always raised, and the pupil 
somewhat dilated in glaueoma, while in keratitis the tension would be normal and the pupil rather eontracted. Sometimes glaueoma has been mistaken for erysipelas. It lacks the tense red skin; and erysipelas does not present the changes of the eyeball that mark glaueoma. It should be remembered that acute glaueoma sometimes follows or conplicates facial erysipelas.

Iritis resembles an exacerbation of glancoma in pain, photophobia, impaired visiou, and pericorneal redness; but in iritis the pupil is contracted instead of dilated, and often bound down by posterior synechiæ. Cyclitis still more elosely resembles glaucoma, for, in eyclitis, the pupil may be widely dilated by a mydriatic, and slight increase of tension may oceur. The existence of deposits on the posterior surface of the cornea, or the age and history of the patient, or the integrity of the field of vision, may decide the diagnosis. In doubtful eases it will be better to avoid a mydriatic until observation of the ease has settled the diagnosis. The inflammatory exacerbations of glaueoma are generally aceompanied by markedly high tension. Other points as to the diagnosis are considered with simple glaneoma.

Treatment.- The ehief remedy for glaueoma is a large iridectomy (see Chapter XIX). This is curative in the sense that in most eases of glaucoma with exacerbations the increase of tension is permanently relieved, and further pain and inflammatory attacks prevented. But the eye is not restored to its original condition; henee, the earlier the iridectomy is done, the better the result.

Sclerotomy (Chapter XIX) and radial incision of the ciliary body are also done to relieve glancoma. They should not be depended upon for eyes in which there is a reasonable chance of saving useful vision by iridectomy. Stretehing the nasal branch of the ophthalmie division of the fifth nerve has been practised on theoretieal grounds, but is of doubtful value. Jonnesco and Abadic have recently urged and practiced excision of the cervical sympathetic. In operating on one eye, it is generally well to instil a myotic in the other, since the excitement and 
shock of operation sometimes provoke an outbreak in the second eye.

In commencing or suspected glaucoma the careful correction of errors of refraction nay be beneficial. After iridectomy there usually remains an increased astigmatism against the rule, which must be corrected to give the best vision.

In the earlier stages, while the pupil can still be contracted by them, the instillation of the myotics, eserin, (physostigmin,) and pilocarpin have a marked influence in relieving and preventing exacerbations. This influence is enhanced by combination with cocain, whieh tends to lower the intra-ocular tension as well as contract the iris. In a few cases the use of these drugs has been followed by no return of increased tension. But they should be regarded only as palliative. In most cases the myotic when used for a time gradually loses its beneficial influence until it becomes quite powerless; and meanwhile great and irremediable damage may be done to the eye. Mydriatics (except as indicated on page 440) are to be carefully avoided in primary glaucoma.

Care should be taken to avoid indigestion, worry, overwork, loss of sleep, and congestion of the head from stooping, which may precipitate an attack. The use of natural mineral waters and other means of increasing elimination are beneficial. Sometimes an attack can be relieved by a hot bath, morphin internally, sleep, or a moderate catharsis. Gentle massage of the eyeball through the closed lids tends to reduce the tension. When sight is gone and pain continues, enucleation of the eye is the only thing certain to give relief.

Prognosis.-Glaucoma left to itself causes blindness, and usually great pain; and when well-marked exacerbations have occurred, there is little prospect of farther usefulness of the eye except through operative treatment. In a few cases moderate attacks of glaucoma occur at intervals for several years before much permanent impairment of vision or other damage results.

Early iridectony, while the pupil is still mobile, the 
fields of vision not much contracted, and the cupping of the disk slight, commonly cures glaucoma, preserves what sight remains, and may restore what has been lost within a few days. In a few cases the repetition of iridectomy cures when the first operation has failed to do so. Iridectomy done late in the disease is less sure to check it. When the field of vision is encroached upon to near the point of fixation, iridectony may be followed by loss of central vision. Or the operation may cause temporary blindness by blood left in the anterior chamber, or hemorrhage from the choroid. In a few cases, operation is followed in a few hours or days by a violent return of high tension, great pain and inflanimation, (malignant glaucoma), for which the eye has to be enucleated. Glaucoma usially attacks both eyes, but occasionally the second eye altogether escapes.

Simple glaucoma (chronic primary glaucoma) is a disease in many respects essentially distinct from glathcoma with exacerbations. The increase of tension is at first slight, and very gradual. The anterior chamber is not especially shallow, the pupil is not dilated, there are no inflammatory exacerbations. The field of vision may be greatly contracted before central vision is notably impaired. There is no clouding, and no marked anesthesia of the cornea until late in the disease.

Causes and Pathology.-These are probably essentially different from those of other forms of glaucoma. There is little evidence of obstruction of the angle of the anterior chamber, although there may be closure of the lymph-channels that connect it with the canal of Schlemm, by connective-tissue hyperplasia. In some cases, high tension cannot be demonstrated until after the disk has become deeply cupped, or the eye quite blind. In a few eases, otherwise like glaucoma, no positive inerease of tension can be detected at any time. Yet these cases differ from simple optic atrophy in having a distinct glancoma-cup. It is this form of glaucoma that is probably most closely connected with gout, rheumatism, general angioselerosis, and chronic nerve-exhaustion. 
Diagnosis.-The patient is over fifty years of age, and both eyes are usually affected, though often one considerably earlier or more than the other. The glancoma-cup and narrowing of the field of vision are always present, and tension is usually increased. Upon these symptoms and the absence of others the diagnosis must rest. This is the form of glaucoma most likely to be mistaken for cataract.

Prognosis and Treatment.-Simple glancoma runs a chronic course, usually lasting several years before blindness is complete; and often it is not attended by severe pain. It is also less curable by iridectomy than glaucoma with exacerbations, and sometimes does badly after that operation. One cannot, therefore, urge it as in other forms of glancoma. Still, iridectomy done early offers the best prospect of permanent arrest of the process.

If the patient declines to have an iridectomy done, the regular instillation of eserin (physostigmin) seems, sometimes, to delay the loss of vision. The internal use of alteratives and strychnin may be of benefit. Excision of the superior ganglia of the cervical sympathetic is a justifiable but uncertain experiment.

Secondary glaucoma includes all cases in which increased intra-ocular tension arises in consequence of other serious lesions of the eye.

Hemorrhagic Glaucoma.-In a few cases, after numerous retinal hemorrhages, glancoma supervenes. Often several months elapse between the appearance of the first hemorrhage and the rise of intra-ocular tension. After the glancoma sets in, the course and symptoms are essentially those of an acute glancoma with exacerbations. The prognosis is very bad. Vision is impaired to start with. Iridectomy usually fails to check the course of the disease, and eserin is commonly ineffective. A large proportion of cases are only relieved of pain by enucleation. The second eye mostly escapes, but often the patient dies in a few years of cerebral hemorrhage or other vascular disease. Still, iridectomy may save the eyc, and, if the patient so desires, should be tried as a forlorn hope. 
Post-iritic Glaucoma.-The effect of annular synechia, exclusion of the pupil, in damming back the fluid which should normally pass forward through the pupil, causing ballooning of the iris, and thus, obstruction of the anterior chamber, has already been explained (page 328). In other (ases, iritic inflammation seems to extend to the angle of the anterior chamber, and by cicatricial contraction to cause its closure. Eyes that have suffered from chronic syphilitic inflammation of the uveal tract are liable thus to devolop glaucoma.

For exclusion of the pupil, a moderate iridectomy done early and so sitmated as to give the best optical effect, may prevent further mischief. For cases in which glaucoma follows iritis without exclusion of the pupil, the regular glaucoma iridectomy should be done, great care being taken to remove a large part of the ciliary border of the iris. In post-iritic glaucoma, mydriatics may sometimes be used without danger, and with advantage. When the iris is extensively bound to the lens-capsule by adhesions, there is little danger of mydriatics' doing serious harm in the glaucomatous eye.

Glaucoma with Intra-ocular Growths.-Sarcoma of the choroid and glioma of the retina, at a certain stage of their growth, canse increased tension with the general symptoms of acute glaucoma with exacerbations. The pain and obvious inflammation of this stage, with loss of sight, which rapidly becomes complete, and the prospect of no other relief, often induce the patient to submit to the only efficient treatment, the removal of the eye.

Glaucoma Following Traumatism.-Injuries causing dislocation or much swelling of the crystalline lens are generally followed by glaucoma; even where no disturbance of the lens has been noticed, glaucoma has sometimes followed. Dislocation of the lens into the anterior clamber is usually followed by a prompt rise of intra-ocular pressure. Swelling of the lens, always accompanied by opacity, or complete luxation, or decided loosening of the lens from its normal attachments, should be met by its prompt removal. Slighter displacements 
may be treated by rest with instillation of physostigmin, or a mydriatic, or by a glancoma iridectomy.

Glaucoma from adherent leukoma arises when the lenkoma tends to extend and to drag the iris into eloser contact with the cornea, and become a staphyloma. The tension does not usually get very high, because the staphyloma yiclds before it. The treatment is that given for anterior staphyloma.

Buphthalmos (hydrophthalmos, glaucoma of childhood) depends on a congenital failure of the angle of the anterior ehamber to open as it does in the course of normal development. This causes inereased tension, which, in the developing eye, leads to gradual distention of all its coats. The appearance thus caused is illustrated in Fig. 142. The globe appears large and prominent, the eornea

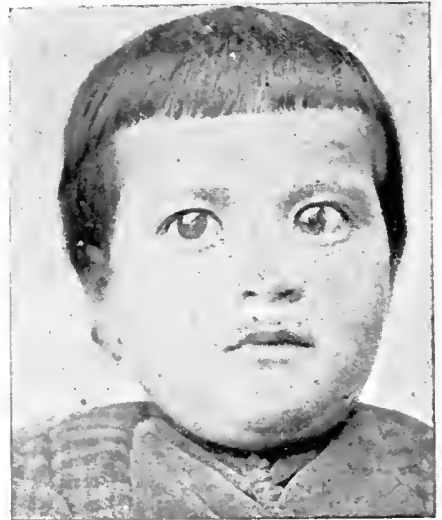

Fig. 142.-Buphthalmos. (From a patient of Dr. Walter B. Johnson.)

enlarged (keratoglobus, see page 310 ), and the selera bluish on account of its thinning. The lens remains small and becomes loosely attached. The optic disk becomes deeply cupped and sight gralually deteriorates. The refraction is usually myopic, although great flattening of the cornea, and laek of development of the lens may make it emmetropie or even hyperopic. A few cases of myopia, 
starting in early childhood, and continuing slowly progressive, but without the above ehanges in the anterior segment of the eyeball, are probably of similar character. Iridectomy or sclerotomy offers some chance of checking the disease.

\section{DIMINISHED TENSION OF THE EYEBALL.}

A perforating wound of the eyeball allowing the free escape of the aqueous, or of the fluid of the vitreous humor, at once brings the intra-ocular tension down to zero where it remains until the wound has become sufficiently closed to prevent further outflow. Then, with the process of healing, the intra-ocular pressure slowly rises with the resisting power of the scar until it reaches normal. Corneal fistula will continue the low tension indefinitely; and cystoid cicatrix, due to inclusion of the iris in the corneal or scleral wound and its imperfeet elosure, with drainage of intra-ocular fluid beneath the conjunctiva, may also keep down the tension. A marked fall of tension may be produced in the normal eye by external pressure, as from a tight bandage.

Some cases of injury to the eye or neighboring parts. present prolonged reduction of intra-ocular tension; sometimes lasting for weeks, without any abnormal opening for the escape of fluid. This may be due to a nervous mechanism for regulating intra-ocular tension, set in action by injury or disease within the cye. Iridocyelitis is apt to be attended with lowered tension of the globe; and when the disease terminates unfavorably the softening is permanent. Cocain causes a marked decrease of intra-ocular tension, possibly by mere contraction of intra-ocular blood-vessels, possibly by influence on a regulating mechanism. Lowered tension is usually an unfavorable sign, yet there may be restoration to normal; and even the prolonged low tension does not render impossible the restoration of useful vision.

Ophthalmomalacia is a rare condition, characterized by pain, deep injection, photophobia, and diminished ten- 
sion of the cye, coming on withont known cause, and after several hours or days ending in recovery. Such an attack may recur. It should be net by rest and protection of the eyes, the use of a weak solution of physostigmin, and for severe pain, hot applications. Tonies, and attention to general hygiene are indicated.

\section{CHAPTER XVI.}

DISEASES OF THE LIDS, LACRIMAL APPARATUS, ORBIT, AND ORBITAL WALLS.

Anomalies of the Lids.-Cryptophthalmos is the name given to that rare condition in which the imperfectly developed eyeball is covered by ordinary skin, the special structures of the lids and the conjunctiva being absent. Ablepharia is a partial or total absence of the lids which leaves the rudimentary eyeball and conjunctival sac exposed. Coloboma of the lid (eleft lid) is a triangular defect, commonly of the upper lid, which is suggestive of hare-lip. It may be associated with dermoids of the limbus, or small bits of separate cartilage, epitarsus; or through it the skin may be a continuous covering of the eycball. Other deformities, such as symblepharon or distichiasis, may be congenital.

\section{INFLAMMATION OF THE LIDS.}

Blepharitis is a term applicable to any inflammation of the lid. Most of these are considered under diseases of the conjunctiva, of the skin, of the lashes, ete. Here are given a few not readily classified.

Blastomycosis is a chronic purulent inflammation due to a fungus, the spores of which gain entrance to the tissues through injury. The surface involved is covered with erusts, under whieh are minute abscesses, from which a sero-purulent discharge may be squeezed out. It gradually extends by a soft elevated edge. It canses great deformity of the lids. The treatment includes use 
of the X-ray locally, and the internal administration of potassium iodid in large doses.

Margina1 Blepharitis (Blepharo-adenitis, Blepharitis Ciliaris, Ophthalmia Tarsi, Tinea Tarsi, ete.).-Redness of the lid-margins, with swelling, involvement of the sebaceous glands with excessive secretion, scaliness of the lid-margins, sometimes with erusts covering excoriations or distinet ulcers, and disease of the hair-follicles with alteration of the lashes, is a common clinical picture. The condition is essentially chronic. Sometimes there is only recurring redness and swelling with slight scaliness, more often the condition is constantly present, growing from time to time better, and again worse. It may last for years, causing entire loss of the lashes, and permanent thickening and rounding of the lid-border, with slight eversion and inflammation of the exposed conjunctiva (lippitudo.)

The disease begins in childhood, usually in the serofulous and poorly cared for. It is closely associated with a slight chronic conjunctival irritation or inflammation, and may depend on nasal disease. Eye-strain is a common cause. The condition gets worse from use of the eyes, or exposure to wind or dust.

Treatment.-Errors of refraction should be carefully corrected. Conjunctivitis, or lacrimal or nasal disease must have appropriate treatment; and the general health and hygienic surroundings must be looked after. I Locally the scabs and the scales should be softened by prolonged soaking in weak soap)-suds, or solntion of sodium bicarbonate, and thoroughly removed. All lashes that are loose or which show inflamed follicles should be removed. Excoriations and ulcers may be touched with silver nitrate either the solid stick or a 10 per cent. solntion. A weak ointment of yellow oxid of mereury should be well rubbed into the lid-margin, or an ointment containing milk of sulphur, or resorein, may be used; or the scaly lid-margin may be rubbed daily with a cotton swab dipped in 1 per cent. solution of formaldehyd. 'The latter will cause intense irritation if it comes in contact with the 
conjunctiva. The cleansing and anointing of the lidmargins should be repeated at bed-time, and the treatment of the conjunetivitis kept up, often for many weeks.

Stye (hordeolum) is a snall furuncle situated near the lid-margin, and often pointing around one of the lashes. It begins with a small red and painful swelling at the edge of the lid, and goes on to suppuration in about three to six days. At its height it sometimes causes a general swelling of the lids that may partly conceal the original lesion; but which quickly disappears when the stye opens. Two or more styes may oceur at the same time, and there is very apt to be a succession of them. They are caused by a predisposing condition of general health, with eyestrain, and local infection of glands or hair-follicles from conjunctivitis, exposure to dust, ete.

Treatment.-The individual stye may sometimes be aborted by local applications of cold. Generally its course is liastened and rendered more favorable by bathing with very hot water. It should be opened when suppuration has occurred by an incision made with a-cataractknife parallel to the lid-margin. To prevent farther reeurrences, eye-strain should be removed by proper glasses and regulation of eye-work. Conjunctivitis or other local disease should be properly treated. Internally a laxative should be given with tonics, especially iron. Potassium bitartrate taken internally seems to deserve its popular reputation as a preventive of styes.

Abscess may oceur in any part of the lids. It is commonly due to injury or orbital disease. It should be opened early, and the eavity cleansed with hydrogen dioxid.

Tarsitis, inflammation of the cartilage of the lid, is usually due to syphilis and yields to antisyphilitic treatment. It is marked by thickening and tenderness of the cartilage over which the skin moves freely. It may also be associated with marginal blepharatis, or with trachoma, when the treatment appropriate for those affections is indicated. 


\section{DISEASES OF THE SKIN OF THE LIDS.}

The skin of the lids is subject to most of the skin diseases, as erythema, herpes, and the exanthematous eruptions. 'These, with leprosy and certain rare hypertrophies of the skin, need not be discussed here. With regard to others, it is necessary to mention only the peculiarities they present when occurring in this situation.

Eczema is caused by keeping the eye bandaged, by overflow of tears in conjunctival or corneal disease with excessive lacrimation; or it may occur quite apart from ocular disease. It may be treated by careful cleansing with warm water and a non-irritating soap, or borax solution, and then dusting with a mixture of equal parts of oxid of zinc, lycopodium and starch in impalpable powder; or if the surface be quite dry, zinc ointment may be applied daily, taking care to remove the old thoroughly before a fresh application. In chronic cases other recognized treatment for eczema may be required.

Fissures of the external canthus (rhagades) arise under the conditions which cause eczema ; especially if there is tight closure of the lids, and wrinkling of the skin near the canthus on account of photophobia. On stretching the folds apart, one or more elongated raw surfaces appear. The condition aggravates a tendency to blepharospasm. The raw surfaces should be touched with silver nitrate, either in stick or strong solution. In an obstinate case it nay be worth while to do canthotomy.

Toxic dermatitis (Rhus Poisoning, Dermatitis Venenata, and Drug Eruptions).-The poison oak, and poison ivy are capable of causing a violent inflammation of the skin, in certain susceptible persons, even without actual contact. They are most virulent in the spring and early summer. The lesions are not confined to the lids, but the swelling there may be so great as to completely close them. There is intense itching and burning, and the skin may be dotted with sinall papules or vesicles. The treatment inclucles careful protection of the surface, with soothing lotions. 
A few patients in whom the mydriaties cause conjunctivitis may also suffer from violent dermatitis, with heat, great redness and swelling, especially of the lids. The condition quickly improves on withdrawal of the drug. In toxic dermatitis, the important point is to recognize the canse, usually through the history of the case.

Erysipelas usually attacks the lids by extension from other parts of the face. It causes great swelling, the surface being red and tense. It is distinguished from other diseases of the lids, by the general symptoms of illness. When attended by deep suppuration it may cause orbital abscess, or blindness through optic neuritis, or atrophy from pressure, or thrombosis of the retinal vessels, or glancoma. The treatment is that of erysipelas elsewhere; with hot fomentations, and early free incisions if there be orbital cellulitis.

Herpes zoster (zona, shingles) in the region of the ophthalmic branch of the fifth nerve is of special importance because of the strong tendency to involve the cornea and iris, especially when vesicles form on the side of the nose. It is sometimes raistaken for erysipelas, but should be easily recognized by the distribution of the eruption limited to that of the nerve, and always limited sharply at the median line. The eharacteristic neuralgic and burning pain may begin before the eruption, and may last for months afterward. Motor nerves of the region may also suffer. The eruption begins with groups of bright red spots on which vesicles form in a day or two, which later dry up. They may leave permanent sears, which, years later, by their distribution, furnish sufficient basis for a positive diagnosis.

The vesicles should be dusted with an emollient powder, and carefully protected from rupture. Opium or acetanilid may be given internally to relieve pain, and tonies, rest, and hygienic measures employed to build up the general health.

Molluscum (molluscum contagiosum or epitheliale) is a rounded dingy white or red tumor, originating in a sebaceons gland, sometimes as large as a pea, with a dark 
central opening, from whieh white cheesy contents ean be squeczed out. These tumors may oceur in great numbers all over the body. The disease occurs in marked endemies and is probably eontagious. The treatment consists in exeising each individual tumor.

Warts and horn-like growths of epithelium ocenr in the lids; the latter sometimes attaining the length of half an inch or more. They should be exeised.

Xanthelasma (xanthoma, vitiligoidea) appears on the skin of the lids after middle life, as slightly elevated, flat, yellowish patehes, eompared to the appearanee of washleather, symmetrieally placed on the two sides of the face, and slowly inereasing in area until they may eover the greater part of the lids. The affected skin ean be excised to avoid the disfigurement, but the pateh may reeur. It is harmful in no other way.

Milium is a minute, white, rounded elevation of the surface due to a sebaeeous eyst. Its removal (for cosmetie reasons only) may be effeeted by digging out the eyst with a needle, or puneturing it and touehing it with a eaustic; or by eleetrolysis.

Spontaneous gangrene of the skin of the lids is a rare disease. It may reeur, and may prove fatal.

Syphilis.-The primary sore may oceur upon the lids, infeetion being earried there by the tongue or fingers. It occurs as a rounded ulcer with an extremely hard base, running a slow eourse with very little pain for the extent of the lesion, with swelling and induration of the preauricular glands. The uleer should be kept elean, and as soon as the diagnosis is confirmed, anti-syphilitie treatment must be instituted.

The various eruptions of seeondary and hereditary syphilis may appear on the lids. Occasionally an uleer due to the breaking down of a gumma is met with after other manifestations of the disease have passed away. It is liable to be mistaken for lupus or rodent ulcer. Whenever sueh an origin for the sore is possible, anti-syphilitie treatment should be thoroughly tried. The influenee of 
syphilis in causing tarsitis has been noted. It may also catuse falling of the eyebrows or lashes.

\section{DISEASE OF THE LASHES AND EYEBROWS.}

The hairs here as elsewhere, may become decolorized or whitened(canities, poliosis), or fall spontaneously (alopecia). More frequently the lashes are rendered unhealthy, distorted or destroyed by inflammation of the lid involving their roots.

Pediculosis (Phthiriasis Cilionum).-The pediculus pubis or crab louse is sometimes found on the eyelashes. The nits or ova appear as numerous pear-shaped yellowish bodies $1 \mathrm{~mm}$. or less in length, each glued fast to a hair. The adult louses is 1 or $2 \mathrm{~mm}$. long, flat, oval, gray in color, and lying close to the skin is much more difficult to see. They are quickly killerl by eareful eleansing of the part, and rubbing in the ointment of oxid of mercury 1 to 60 or stronger.

Trichiasis ; Distichiasis.-Displacement of the eyelashes becomes of practical importance when it is such that they come in contact with the cornea or conjunctiva, and so become a source of irritation. Distichiasis is strietly the condition in which an extra row of lashes on the inner lid-margin, turn toward the eye while all the other lashes are normally directed. Trichiasis is a condition in which the lashes are wrongly direeted against the eye, but there is no inversion of the lid-margin. Practically the two have the same significance, and in most cases trichiasis is essentially a commencing entropion.

Symptoms.-In young children the lashes of the lower lid are sometimes turned in against the eyeball. Apart from this it is more often the lashes of the upper lid that are misplaced. The rubbing of the hair against the cornea or conjunctiva causes redness, lacrimation, burning and the fceling of a foreign body in the eye; or it may cause opacity or vascularity of the cornea, or conjunctivitis with purulent discharge. 'The efforts to get 
relief by forcible closure of the eyes, nay make matters worse by turning in additional cilia. After removal of the offending hairs the eye is better until they grow again, when the symptoms are renewed.

Diagnosis. - Ingrowing laairs should be thought of in any case of chronic or lecurring conjunctival irritation, and a careful search made for them. Often they are small, and of a light color, and very difficult to see. They are best discovered by oblique illumination, and with the binocular magnifier.

Treatment.-If few, the patient may prefer to simply have the displaced lashes pulled out, as often as they get long enough to make trouble, or they may be permanently removed by electrolysis. When the number of displaced lashes is large, some such operation as is recommended for entropion should be done.

\section{DISTORTIONS, DISPLACEMENTS, AND ADHESIONS OF THE LIDS.}

Entropion, inversion of the lid-margin, may be produced by spasmodic contraction of the orbicularis muscle, spasmodic entropion. This is favored by redundancy of the skin in childhood, or swelling of the lids after injury, or operation about the eye; by relaxation of the skin in old age, or by loss of support of the lids by the eyeball as from phthisis bulbi, atrophy of the orbital fat, or enucleation. It may be brought about by any cause of ocular irritation; it often arises while an eye is bandaged; and, once started, tends to increase the irritation and so to perpetuate itself.

Entropion is also associated with cicatricial changes in the lids, and with shrinking: of the conjunctiva from chronic disease, especially trachoma. This is called organic or cicatricial entropion. It is usually increased by orbicular spasm. To recognize the presence and extent of an entropion the eyes should be carefully inspected without touching them. Even a light touch on the lids may be sufficient to draw the lashes away from the eyeball. 
Treatment.-Spasmodic entropion may be relicved by removal of the exciting cause; or by keeping the lashes everted for a time by a strip of plaster, or by painting the earefully dried skin with collodion, coat after coat; or by keeping a fold of skin pinched up with forceps. If the above measures fail, some operation must be performed. In children eanthotomy may be practiced. In other cases, one of the operations described in Chapter XIX may be resorted to for the upper lid. For the lower lid, caustic potash may be applied along a line parallel with the lid-margin, and $4 \mathrm{~mm}$. from it to produce eversion by the eschar it causes.

Ectropion.-Eversion of the lid so that the conjunctival surface is exposed, may result from swelling of the conjunctiva (acute ectropion). The effect is increased by exophthalmos, spasm of the orbicularis muscle, and obstruction of the conjunctival veins, so that when restored the lid promptly turns out again, weakness or paralysis of the orbicularis musele allows the lower lid to fall away from the eycball and the conjunctiva to become exposed (paralytic ectropion).

Organic ectropion, or dragging away of the lid-margin from its normal position by eicatricial contraction, oceurs after burns, abscesses, slonghing, or wounds of the lids and neighboring parts. The exposed conjunctiva becomes congested or hypertrophied; and the secretions, with the tears, no longer passing through the everted punctum, dry upon the exposed conjunctiva and the neighboring skin, and tend to aggravate the trouble.

Treatment.-The removal of the eause may be sufficient in acute cetropion, or incision, or excision of a part of the everted conjunetiva may be needed. Paralytic ectropion often requires no treatment, or the lacrimal passages may require attention. Or it may, as does organic ectropion, require an operation which must be specially planned to meet the needs of the case (see Chapter XIX).

Iagophthalmos (Pulsy of the Orbicularis). - Inability to close the eyes is present in severe organic ectropion; or may be due to congenital defect, exophthalmos, staphy- 
loma, or paralysis of the seventh (facial) nerve. It may be associated with oculomotor palsy when other parts of the facial nerve escape. The puncta not being properly applied to the eyeball, epiphora results. Strong effort to close the eye causes no wrinkling in the affected lids, but eauses the eye to roll upward. The turning up of the cornea usually secures it sufficient protection in lagophthalmos to prevent its destruction, but it may suffer from exposure.

Blepharospasm.-Annoying twitehing of the lids, often so slight as to be unnoticed except by the patient, is a symptom that may arise from the instillation of physostigmin, conjunctival irritation, eye-strain, or lack of nerve tone, as from loss of sleep. It is of less importance than the patient often thinks it, and is eommonly relieved by removal of the cause; but in some patients is apt to recur.

Spasmodic contraction of the lids, usually with those of other muscles of the face or movements of the head, are seen in chorea. Excessive winking is seen as a kind of habit-chorea. It is mostly, at least in the beginning, associated with eye-strain, or local irritation. Spasmodic closure of the lids follows the entrance of an irritant into the eye, or attends corneal disease, or fissure of the skin near the outer canthus. In rare cases, it is a reflex of irritation in the nose or about the teeth. Such cases are commonly cured by removal of the cause.

The most scrions cases are those of tonic spasm without discoverable local cause. The elosure of the lids may last but a few minutes, or for hours, or even weeks; and has sometimes been suceeeded by temporary blindness. Section of the nerve may afford relief.

Ptosis, or inability to raise the upper lid, may be hysterical or due to paralysis of the levator muscle, swelling or hypertrophy of the lid or neighboring parts, offering a mechanieal obstacle, or to habitual closure of one eye to avoid blurred vision, or to congenital defeet.

Paralytic ptosis is usually associated with other evidences of paralysis of the oculomotor nerve, and is due 
to syphilis, rheumatism, pressure of the nerve by hemorrhage or a new growth, or to disease of the central nervous system. The completeness of the paralysis may be judged by noting if on looking up there be any retraction of the skin where it passes from the lid to the upper margin of the orbit where normally such retraction occurs. The treatment must at first depend on the cause. But if after many months no power is recovered in the paralysed muscle, the tronble may be somewhat remedied by operation (see Chapter XIX), unless the uncovering of the eye will cause diplopia fron other third nerve palsies.

Congenital ptosis is often hereditary and assoeiated with other congenital defeets. In a few cases where the lid cannot be raised alone, it can be raised in association with movements of the lower jaw. Congenital ptosis may be due to hypertrophy of the lids. It usually allows the patient an imperfeet use of his eyes. It can only be remedied by operation, or mechanical support for the lid.

Epicanthus is a fold of skin stretching from the brow to the side of the nose, and eovering more or less completely the imner canthus. It is congenital ; often associated with ptosis, and minor degrees of it are frequently seen in early ehildhood. Usually with development of the nasal bones the deformity disappears. It may be lessened by removing from the bridge of the nose a piece of skin shaped like a section of a convex lens, and then bringing together the two sides.

Blepharophimosis, or narrowing of the palpebral fissure, may be congenital, or due to adhesion of the lids at the onter canthus after uleeration, or to cicatricial contraction of the lids and conjunctiva from trachoma. It interferes with eversion of the lids for local applications; and greatly increases the injurious influenee of rough eicatricial lids upon the cornea. On these accounts it is often best to remedy it by canthoplasty (see Chapter XIX).

Anchyloblepharon, or union of the upper and lower lids at a point between their extremities, may be congenital, in which ease it may be relieved by simple division. But more frequently it is dne to burns or similar injuries, and 
is associated with symblepharon (see page 269); and is to be treated by such operations as the symblepharon may require.

\section{SWELLINGS AND TUMORS OF THE EYELIDS.}

Edema.-The loose subcutaneous tissue and redundant skin of the lids permit of the rapid aceumulation of serous fluid in large quantities, and its equally rapid disappearance. A small stye or slight injury will sometimes be followed by enormons swelling; and severe intra-ocular disease or injury may eanse similar swelling. Renal disease, heart disease, malaria, arsenical poisoning ete., cause marked edema of the lids, which is increased while lying down and diminished when in the erect position. It may be caused by acute indigestion. In some persons it is a chronic or recurring condition of obscure origin, which gives annoyance for years. It may arise from syphilis.

Emphysema of the lids and orbit arises as part of a more general emphysema, or through the entrance of air from the air-cavities of the head into the subcutaneous cellular tissue, commonly through fractures of the bones containing these cavities. The air is forced into the tissues throngh sneezing, and blowing the nose; and gives rise to a soft elastic crackling swelling that may increase with alarming rapidity, but subsides when the forcing of the air into the tissues is stopped.

Chalazion (tarsal cyst) is a small firm rounded tumor of the lid, closely attached to the cartilage, and over which the skin moves freely. It develops slowly, often without inflammation, and withont attracting the patient's attention until it has attained some size. Two or more may be present at the same time. It is most frequent in early adult life. Often mild inflammatory symptoms are present in the later stages. It grows for several months, becoming the size of a pea or larger. It arises from a meibomian gland, and consists largely of granulationtissue surrounded by a nembranous wall. It is not a retention-cyst, but its contents may molergo softening so 
that it becomes an encysted abscess. It is annoying on account of its appearance, and the sense of weight or stiffness it causes in the lid.

The conjunctiva opposite the growth shows a spot of lighter yellow, or gray color ; and, if undisturbed, after many months the ehalazion may open through this spot, discharge its fluid contents into the conjunctival sac, and slowly contract. After it opens, the granulation-tissue is apt to fill the cavity and may protrude on the conjunctival surface. A small chalazion may disappear spontaneously without opening, or at an early stage its contents may be pressed out.

Treatment.-This is operation by incision or excision, (see Chapter XIX), and, if either be present, the removal of eye-strain or chronic conjunctivitis to prevent a recurrence.

Lipoma.-Aceumulation of fatty tissue in the lids is rare. It may occupy the whole or a limited portion. If it be unsightly or interfere with the lid-movements, it may be excised. Fibroma, a firm tumor, often present at birth and enlarging years later, occurs in the lids. Neuroma and cysticercus of the lid have been reported. Dermoid, lymphoid, and other tumors of the orbit frequently involve the lids.

Angioma (nevus, vascular tumor) of the lid may vary from the superficial capillarity which makes a "mother's mark" to a eollection of large vascular sinuses having a definite wall (cavernous angioma), or masses of large dilated vessels (telangiectasis), which may extend deeply in the orbit, or be associated with abnormalities, or the retinal or choroidal vessels. Such growths appear at or shortly after birth, and often tend to increase in size, at least for a time. A few spontaneonsly disappear.

Diagnosis.-A vascular tumor can be recognized by its variability in size. When the child cries, or is held head down, the tumor noticeably enlarges. By firm pressure it may be reduced, or caused to disappear. If not thus reducible, it is commonly connected with an artery of some size, and exhibits deciled pulsation. 
Treatment.-For a superficial nevus cauterizing with nitric acid, or sodium ethylate, may be resorted to. The caustic is applied with a glass rod. The eschar must be left undisturbed until it separates spontaneously, the caustic being applied repeatedly if needed. Vaccination of the nevus has affected its removal. A larger or deeper angioma, if diminishing, should be let alone; and if stationary, should be attacked with great caution. But if clearly increasing, it should be promptly excised, or ligated by multiple ligatures, or subjected to electrolysis. Excision is on the whole most satisfactory ; but the surgeon should always start prepared for a serious operation. Electrolysis may be afterward resorted to for small portions that escape excision.

Sarcoma.-Primary sarcoma may occur in the lids. If not pigmented, it somewhat resembles chalazion, for which it has been mistaken. It should be promptly and completely excised; and even then may recur.

I upus (tuberculosis of the skin) occurring on the face may involve the eyelids, and may extend thence to the conjunctiva. It must be borne in mind in connection with the diagnosis of syphilis and epithelioma.

Epithelioma (rodent ulcer, Jacob's ulcer) begins most frequently on the margin of the lower lid, as a flat thickening of the skin most prominent and hard at the margins. It begins usually after middle life, and may remain with no change except a slight extension of its surface for many years. Then the center ulcerates, and becomes covered with a brownish crust. After this the ulceration keeps pace with the deposit, slowly extending until it may destroy a large portion of the face without involving the lymphatic glands, or giving rise to secondary deposits.

Diagnosis.-In a typical case the appearance is characteristic, but local irritants or attempts at treatment may disguise it; and syphilitic ulceration might be mistaken for it. The syphilitic ulcer develops more rapidly, and has softer, punched-out edges. Where there is the slightest doubt, energetic antisyphilitic treatment should be 
tried. Lupus starts in early life, usually on some other part of the face, extends by the formation of isolated nodules which later coalesce, has softer and less definite edges, is attended with more redness and inflammation of neighboring parts, lacks the characteristic ulcer of epithelioma, and runs even a slower course. Epithelioma of the lids sometimes assumes the form seen elsewhere, forming a thick mass that breaks down at the center and extends with comparative rapidity.

Treatment.-Large masses should be excised if practicable, or the thickness of the growth reduced by euretting. Remaining masses, small tumors, recurrences, and all inoperable growths shonld receive treatment by the $\mathrm{X}$-ray. The tube used should have a spark-gap of 1 to 2 inches. It should be brought as close as possible to the tumor, and the eye and healthy parts shielded from the ray. Many cases can thus be permanently cured, and nearly all can be retarded in their course.

Burns of the lids, if small, heal quickly and cause no trouble, but if extensive they cause permanent deformity of the lids, through cicatricial contraction. They should be treated by exclusion of air, either by a dressing of carbolized oil and lime-water, or by lint soaked in a solution of borax or sodium bicarbonate. After two or three days the surfaces should be cleansed once daily and dusted with iodoform. Extensive granulating surfaces should be covered with skin-grafts.

Other injuries of the lids are considered in Chapter XVII.

\section{DISEASES OF THE LACRIMAL PASSAGES.}

Epiphora (Stillicidium Lacrimarum, Watery Eyc).The tears secreted to keep moist the surface of the cornea, and remove irritants from the eonjunctival sac, pass normally through lacrimal passages into the nose. Failure of the lacrimal drainage-system to remove the tears fast enough causes then to accumulate in the eye, and run over the edge of the lid. 
The amount of lacrimal secretion varies greatly in health, in response to nerve-impulses sent to the gland. It can be enormously inereased, as by emotion, exposure of the eye to wind, dust, or irritating vapors, or disease, particularly inflammation of the cornea or iris. The drainagesystem, parts of which are little more than tubes of capillary size, failing to dispose of the increased secretion, overflow results-exeessive lacrimation (reflex epiphorc). Epiphora of this kind may result from irritation of the lacrimal passages themselves, or even of the nose. It may also arise from retinal impressions, as a briglit flash of light, or from the effect of moderate light upon an over-sensitive retina.

Every case of epiphora should be earefully considered, with reference to its possible origin in one of these sourees of reflex aetion. Even where there is obvious organie disease of the lacrimal passages, this in itself raises a presumption of accompanying reflex epiphora, and the share this has in the symptoms should be earefully considered.

Treatment.-To remove an excessive reflex as to light or the rush of air in riding a bieyele, the eye must be accustomed to the stimulus, and any excessive irritability of the nervous system redueed as far as possible. The treatment of epiphora due to obstruetion of the laerimal passages will be considered in eonneetion with the various diseases which cause it.

Closure (Atresia) of the Punctum.-Closure of the punetum may be eongenital, or may arise from the eversion, and non-use of the punctum, or from disease or injury to the parts. It may affeet one or more of the puneta. If the eanalieulis is normal, the punetum may be opened, and dilated with a fine-pointed probe. An ordinary pin with a good point is well adapted to the purpose. The proper position for the punetum having been determined, this point should, with a slight rotary motion, be thrust into it, until it is well dilated. The dilatation may need to be repeated a few times to make it permanent. Closure of the punetum with elosure of 
the canaliculus must be treated as for the latter condition.

Displacement of the Punctum.-The normal punctum is directed toward the eyeball where it reaches and draws in by its eapillary action the thinnest film of tears. When the punetum is located on the edge of the lid instead of on the inner margin, or when the lid is somewhat everted, the tears before reaching it must accumulate to an abnormal extent, and perhaps flow over the lid-margin. This is a common cause of epiphora. Misplacement of the punctum in the lid may be congenital. Eversion may be due to any cause of eetropion or lagophthalmos, to slight thiekening and rounding of the lid-margin in blepharitis, or to swelling in conjunctivitis, contraction of the skin of the lid near the punetum, or senile relaxation of the lower lid. It may be quite sufficient to eause serious epiphora, althongh there is no displacement of the lid noticed on casual inspection.

Treatment.-If the canse of the eversion of the punctum ean be removed, as by eure of eonjunetivitis, blepharitis, or facial paralysis, or restoration of the lid-border to normal position in ectropion, this may cure the eversion. If this cannot be done, it is cnstomary to slit the eanalieulis. (See Chapter XIX.)

Obstruction of the canaliculus may oceur through stricture, inflammatory swelling of its lining membrane, pressure from without, by polypi, or from a forëign body, as an eyelash, or a "tear stone" (dacryolith) within it. The latter is a mass, consisting largely of calcium phosphate, formed by the presence of a leptothrix, a filamentons form of bacteria. Or the eanalienlus may be absent as a congenital anomaly, or destroyed by tramuatism.

Treatment.-Inflammatory swelling may be reduced by appropriate treatment to the adjoining conjunctiva and the lining membrane of the laerimal sae, which are always involved. Strieture may be dilated by passing successively larger probes from 1 to 4 or 6 (see Chapter XIX); although a permanent cure usually requires 
slitting of the canaliculis, which is also necessary when foreign bodies must be extracted.

Obstruction of the Nasal Duct.-This is commonly due to partial or complete closure, through nasal disease, of the duet where it enters the nose, to inflammatory swelling of its lining membrane, to fibrous stricture usually situated at the upper end, or to disease of the bony walls surrounding it. It always causes epiphora, with swelling of the lacrimal sac and regurgitation of its contents into the conjunctival sac under pressure.

If the obstruction continues any length of time, it is attended with inflammation of the lining membrane of the sac, which is usually catarrhal but often becomes purulent. The regurgitation of the contents of the sac extends the inflammation to the conjunctiva, setting up and keeping up a chronic conjunctivitis, often called lacrimal conjunctivitis.

Diagnosis.-The swelling of the sac is seen as an ovoid swelling (lacrimal tumor, mucocele), situated at the side of the nose and extending more below the canthus than above. This tumor varies in size from time to time, and may entirely disappear under firm pressure which forces ont the contents of the sac. The situation of the swelling, and its diminution with the regurgitation of its contents into the conjunctiva, are very characteristic. In some cases a portion of the contents may, under pressure, be foreed into the nose. An important point is to try whether, by means of the lacrimal syringe, fluid ean still be forced through the obstructed duct into the nose.

Treatment is directed toward re-establishing a sufficient passage from the lacrimal sac into the nose. In some cases treatment of the nose, as the removal of constricting bands or scars, or hypertrophy of the lower turbinals behind which the duct opens, will be sufficient. In other cases, cure of an inflammation of the mucous membrane of the sac and duct may reopen the latter by reduction of the swelling. For this purpose the passages should be regularly syringed out with a solution of protargol or argyrol, and the patient instructed to fre- 
quently empty the sae by pressure upon it. Any abnormality of the pmeta or eanalieuli which would interfere with the flow of fluid through the duet must be correeted, for the health of the laerimal passages cannot be seeured without the free flow of tears through them. The above measures will often give permanent relief, if the obstruetion is still incomplete or intermittent.

For the more serious eases it is necessary to slit a eanaliculis, preferably the upper, unless the lower is displaeed or obstrueted, and to probe the duct (see Chapter XIX). The passage having thus been opened the lumen must be maintained, either by the repeated passing of the probe, or by the eontinuous wearing of a style until the tendeney to re-contraetion of the strieture has been fully overcome. The probes used should be as large as ean readily be passed, $3 \mathrm{~mm}$. in diameter or even larger. But the re-establishment of the lacrimal passages by probing is a very serious undertaking, to be reserved for skilled hands and for exeeptional eases. Often the process can be hastened by eutting the strieture (Chapter XIX), followed by the insertion of a style of about $3 \mathrm{~mm}$. diameter.

Sometimes absorption is hastened by conneeting the probe, while in situ, with the negative pole of a galvanic battery, and passing through it a eurrent of about 2 milliamperes for 2 to 5 minutes. Disease of the bony walls of the lacrimal canal may require removal of diseased bone. In sueh cases, when the tissues are greatly altered by lacrimal abscesses, or when the treatment by probing cannot be carried out for a sufficient length of time, it is best to exeise or completely obliterate the laerimal sae (see page 542).

Prognosis.-Laerimal obstruetion so $\bullet$ serious as to require operative treatment is not followed by restoration of the passages to normal. 'The slit canaliculis never takes the tears from the eye quite as nicely as the normal passage ; and permanent maintainance of a eapillary passage eamot be hoped for. Relative eure is obtained by establishing an abnormally large and patulous eanal, more likely than the normal canal to reeeive irritants both from 
the conjunctiva and from the nose. Through such a canal, air and nasal discharges, may be blown into the eye, in blowing the nose. Relief may be obtained from the more serious effects of lacrimal obstruction; but only by painful and tedious measures.

Iacrimal Abscess.-Allusion has been made to the chronic inflammation of the lacrimal passages that attends obstruction. If this eontinues there is great liability to more aente inflammation of the sae, acute dacryocystitis, with infection of the surrounding eellular tissue, and the formation of an abseess. The tumor caused by distension of the sae becomes enlarged, red, and painful, tending to extend rather downward; and if let alone softens and breaks, establishing a false vent for the contents of the sac, a lacrimal fistula.

Treatment.-The eanaliculus should be slit so as to make quite a free opening into the sac, and if near the point of breaking, the absecss may also be opened externally. Both sac and abseess cavity are then to be thoroughly cleansed with hydrogen dioxid solution; and after a day or two when the extreme soreness of the parts has somewhat abated, the passage should be re-established into the nose. Only the removal of the obstruction or the complete destruction of the sac will secure the closure of a lacrimal fistula or the permanent healing of the parts.

\section{DISEASES OF THE LACRIMAL GLAND.}

Inflammation (dacryo-adenitis) is rare, and commonly secondary. It has been associated with mumps, syphilis, gonorrhea, rhenmatism, and septic absorption. Usually it is chronic, giving rise to redness and swelling of the upper lid, and a firm tumor which may be felt on palpation at the upper and outer margin of the orbit, with injection of the adjoining conjunctiva. Aeute inflammation may go on rapidly to suppuration, with enormous swelling of the lids.

Chronic inflammation should be treated, by attention to any general disease, with mercury and iodids internally, 
and cautious massage of the part with mereuric oxid ointment. Acute inflammation requires hot applications and early incision. If a fistulous opening be found in the skin of the lid, it may be transferred to the conjunctival surface, by a ligature passed into and around it, tied on the conjunctival surface and tightened until it euts through.

Hypertrophy, or enlargement of the gland, may be congenital or may follow syphilis. It is sometimes so great as to displace the eyeball and cause great deformity. Prolonged antisyphilitic treatment should be tried, but if it fails, extirpation may be necessary.

Dislocation of the lacrimal gland causes it to be seen and felt in the lid below the orbital margin. It may be spontaneous or traumatic. In children it sometimes follows a fall on the face, with or without a wound of the brow. The gland should not be hastily exeised.

Cyst of the lacrimal gland (dacryops) is due to-obstruction of one or more of its ducts. It appears as a bluish translueent tumor, beneath the conjunctiva of the upper lid, sometimes varies in size, the obstruetion being ineomplete, and is notably increased by anything that provokes the secretion of tears. It may be incised, and the incision repeatedly opened until its edges have healed. Or a suture may be passed through its walls and allowed to eut itself out.

Tumors of the laerimal gland are rare. Chalky concretions sometimes form in it; and adenoma, sareoma, myxoma, epithelioma, osteochondroma, lymphoma, and lydatid cyst of the gland have been met with.

\section{DISEASE OF THE ORBIT AND ORBITAL WALLS.}

Orbita1 Cellulitis (Abscess or Phlegmon of the Orbit). - Symptoms.- Inflammation of the cellular tissue of the orbit begins with deep orbital pain, headache, limitation of ocular movements, protrusion of the eye, swelling and dusky redness of the lids and conjunctiva. Retinal hemorrhage, and neuroretinitis to be followed by optic 
atrophy, may attend inflammation behind the globe ; and sloughing of the eornea may occur when there is great swelling at the front of the orbit. Panophthalmitis may occur. In the more violent cases, a general chill occurs at the outset, followed by fever, and marked evidence of general illness.

Course and Varieties.-It may develop in facial erysipelas, in which case both orbits are mostly involved, may follow excessive exposure to cold or acute fevers, especially typhoid and scarlatina, may arise by metastasis in pyemia, or from local injury, panophthalmitis, periostitis of the orbit or similar disease of the neighboring parts.

Diagnosis.-Orbital cellulitis must be distinguished from pauophthalmitis by the absence of opacity of the dioptric media, or other evidence of suppuration within the globe ; from purulent conjunctivitis in which there is more conjunctival discharge and no exophthalmos or limitation of ocular movements; and from thrombosis of the cavernous sinus, which is marked by great swelling in the orbit, with pain and obstruction of the circulation, but which may be distinguished by the presence of cerebral symptoms, palsies of certian ocnlar muscles, before general immobility of the eyeball occurs, and by the pre-eminence of the venous element in the hyperemia. But the diagnosis might be complicated by the supervention of the orbital inflammation on either of the other conditions mentioned.

Treatment.-The cellulitis should be carefully attended to, especially if it is a local suppuration, or periostitis. The patient should be put to bed, and full doses of tincture of chlorid of iron, with moderate doses of quinin and such other general treatment as may be indicated. Blood should be taken from the temple freely in the early stage. Hot fomentations should be applied at short intervals. As soon as there is evidence of any puscollection, it should be given frce vent. But earlier than this, if the swelling is very great, deep incisions should be made near the orbital margins. If practicable, these 
should be marle from the conjunctiva, being preceded, if necessary, by canthotomy. But if necessary they should be made through the lids, avoiding the position of the oblique muscles. In facial erysipelas, additional incisions may be required in the lids. If panophthalmitis supervenes, an ineision should be made through the cornea that will let out all the contents of the globe ; or the eyeball may be enucleated.

The incisions should be washed out with hot antiseptie solutions, and the fomentations continned until the swelling begins to subside.

Prognosis.-Orbital cellulitis endangers the sight through ocular inflammation and optie atrophy; and it endangers life through thrombosis or extension into the cranium, especially when due to erysipelas.

Inflammation of the oculo-orbital fascia (lenonitis) may be caused by gout, rheumatism, influenza, inflammations of the eyeball, or injury, especially operation on the ocular muscles. It is indicated by swelling of the lids, particularly the upper, pain on the movement of the eye, and conjunctival edema which may be limited to a small portion of the membrane. If not caused by injury of the orbital tissue it is not attended by suppuration, but it gives rise to extensive fibrous adhesions of the globe, which hinder enucleation of the eye if this becomes necessary.

It should be treated by rest of the eyes, and dry heat or occasional hot fomentations. Internally iodids, salycilates, potassium acetate, or colchicum may be given, with saline laxitives, and anodynes, if necessary. For suppurative cases, free drainage for pus, and frequent hot irrigations or fomentations, are to be employed.

Periostitis, Caries and Necrosis. - Acute general periostitis of the orbit causes the symptoms of orbital cellulitis due to it. Chronic periostitis gives rise to thickening of the periostem, which, if not deeply situated, may be felt as a hard inmovable swelling,- - fibrous thickening, or a soft fluctuating mass-abscess. There is deep-seated pain in the orbit, and may be tenderness to 
pressure. There may or may not be exophthalmos or other displacement of the eyeball. The disease is usually due to syphilis, tuberculosis, disease of the neighboring cavities, or traumatism, the latter often acting as an exciting cause. If suppuration occurs, the abscess slowly makes its way to the surface, the skin becomes reddened, and upon the opening of the abscess a sinus is discovered with bare carious bone at the bottom. In rare cases a considerable fragment of bone may be present. The fistula thus established tends to become chronic. If the opening is near the orbital margin, the skin becomes firmly adherent to the bone, causing deformity of the lids. If the sinus opens into the conjunctiva, its origin is probably quite deep in the orbit.

Diagnosis.-Chronic periostitis starting deep in the orbit may cause no distinetive symptoms until it extends well forward. Near the orbital margin the swelling it causes might be confused with gumma of the orbit, a mistake usually not serious, since syphilis is the most frequent cause of periostitis. Where a sinus exists, care should be taken to make sure that it is not caused by a foreign body, lodged in the orbit unknown to the patient, at the time of an injury to which the pcriostitis is ascribed. Careful scarch must also be made for a cause of the disease in the neighboring sinuses connected with the nose.

Treatment.-Periostitis without suppuration should be treated with mercury and large doses of potassium iodid, or cod-liver oil, iodid of iron, etc., or alteratives and general tonics. Any abscess should be freely opened as carly as possible; and a drainage-tube introduced or the cavity packed with iodoform ganze, and after that washed out at regular intervals, with hydrogen dioxid or other antiseptic. Dilute hydrochloric acid may be injected in the hope of removing carious bone and stimulating granulations. Curetting the carions surface, or attempts to remove necrosed bone should be deferred until the surgeon has learned pretty accurately the limits of the disease, and until a free external opening is established.

Enophthalmos.-Sinking of the eyeball in the orbit, 
eausing it to appear smaller than its fellow, occurs from emaciation, traumatism, paralysis of the sympathetic, and possibly other nerve-lesions.

Exophthalmic goiter (Graves' or Basedow's disease) is not essentially a disease of the eyes, but its ocular symptoms and complications are of such importance that it very often is brought to the notice of the ophthalmic surgeon.

Symptoms.-Along with increased rapidity and irritability of the heart's action and variable enlargement of the thyroid, there occurs exophthalmos, which may reach such high degree that it is impossible for the cornea to be covered by the lids, and the exposed portion of the cornea may become vascular, or may ulcerate or slough, destroying the eye. The protrusion of the eye (proptosis), however, often appears greater than it really is, on account of the retraction of the lids. These are habitually separated more widely than nomal (Dalrymple's sign). They are incompletely closed in winking, and the interval between the attempts at winking is irregular, being sometimes much prolonged (Stellwag's sign). On looking downward, the upper lid, instead of normally following the motion of the globe, remains more or less elevated (von Graefe's sign). Usually these symptoms are bilateral, although the exophthalmos may be greater on one side than on the other. But they may affect but one eye.

Treatment.-The general tonic treatment and regulated life which should be carried out need not here be dwelt upon. The eyes should be studied as a possible souree of nerve-strain, and treated accordingly. If the exophthalmos becomes excessive, it may be best for the cosmetic effeet, or to prevent corneal disease, to try to narrow the palpebral fissure by tarsorrhaphy; yet even this may be ineffective. If sloughing of the cornea occurs, enucleation may be necessary.

Pulsating Exophthalmos.-Under this title are included cases presenting several distinct pathological conditions, which are best considered together, because the symptoms they present are so nearly indentical that in 
practice it may be quite impossible to decide which condition is present.

Symptoms.-There is exophthalmos, the eye being displaced forward (and usually a little downward) sometimes so far that the lids cannot be closed over it. Pulsation of the orbital contents is sometimes visible, and always perceptible to touch. A decided bruit is present, very annoying to the patient, and heard distinctly by the surgeon over the orbit and the neighboring regions of the skull. The eyeball by firm pressure may be restored toward its normal position, but again protrudes when the pressure is removed. These symptoms are relieved largely or completely by pressure on the carotids. Vision is often but moderately impaired; but some cases show optic neuritis, and there may be enormous dilatation of the veins, both of the retina and orbit: The movements of the eye are limited, the orbital muscles may be quite paralyzed, and the pupil widely dilated. The bruit is heard by the patient as a blowing, puffing, buzzing, singing, whistling, roaring or hammering noise, and is often accompanied by vertigo. The lids and conjunctiva are often swollen, and show venous congestion, and the cornea may become hazy, or ulcerated from exposure. The whole area supplied by the ophthalmic branch of the fifth nerve may be anesthetic. A distinct soft pulsating tumor may sometimes be felt below the brow.

Causes and Pathology.- This condition has been ascribed to aneurism of the ophthalmic artery, but this lesion has been found in very few cases. The symptoms do not occur with unruptured aneurism of the internal carotid. The most frequent lesion is a laceration of the carotid artery within the cavernous sinus. This may be due to traumatism causing fracture of the base of the skull, in which cases the symptoms develop rapidly within a few weeks after the injury. It also occurs spontaneously, usually in elderly women, the symptoms developing quite suddenly after a feeling of something having broken within the head. In a few cases, a vas- 
cular tumor has been discovered in the orbit; and in some autopsies no significant lesions have been found.

Diagnosis.-The condition may be closely simulated for a time by a highly vaseular malignant new-growth in the orbit. But the absence of traumatism, and the gradual development of symptoms, with the attendant cachexia, should distinguish the malignant disease. In trying to fix the cause of the particular ease, the feeling of something giving way, and sudden onset, or the history of injury with other symptoms of fracture of the base of the skull, characterize the arterio-venous aneurism of the carotid and cavernous sinus. In aneurism of the ophthalmic artery or vascular growths in the orbit the development of symptoms will be more gradual.

Treatment and Prognosis.-The course of this disease usually extends over several months or years. A few cases recover spontaneously, more die of rupture of the arterio-venous aneurism. Compression of the carotid may lead to cure, and should be tried if practicable. It is more likely to cure the idiopathic cases, and can sometimes be kept up by the patient himself. If it fail, ligation of the carotid is the most promising measure and should be tried. A vascular tumor may be treated by excision or electrolysis.

Angiomata of the orbit usually extend into the lids (see page 460 ).

Dermoid cysts of the orbit are congenital, but develop slowly. They appear most frequently at the inner or outer upper margin of the orbit. They are smooth, rounded, elastic, not closely connected with the skin, but usually with firm connection with deeper structures. They may be quite small and superficial, or may have prolongations to the depths of the orbit, or even beyond. Some idea of the size of the cyst may be obtained from its behavior under pressure. If superficial, it shows little change of size; if deep, the visible portion retreats under pressure, and the eyeball and other contents of the orbit are pushed forward. Dermoids require removal on account of their unsightly appearance. If not very deep, 
they should be excised, care being taken to dissect out the whole sac, to avoid recurrence. Very good results lave been obtained by opening the sac, emptying it, and placing in it a few crystals of silver nitrate, or injecting tincture of iodin.

Other Cysts.-Encephalocele is congenital, and appears at the inner angle of the orbit. It pulsates, and is reducible by pressure through passage of the fluid into the cranium. It should be let alone. The child dies of accompanying cerebral lesions, or of meningitis from inflammation starting in the sac.

Another congenital eyst is that always associated with extreme microphthalmus or anophthalmus, and developed from what should have furnished the interior structure of the eye. This distends the lower lid and may ocenpy the whole orbit. In addition there have been found in the orbit exudation-cysts following hemorrhage, hydatids and cysticercus.

Orbital tumors, if at all extensive, cause protrusion of the eye, which, if not too rapid, is accompanied by compensatory hypertroplyy of the lids, particularly the upper. Such a tumor is usually fixed, although the movement of the loose tissues over it often gives a deceptive sense of movement of the tumor. They may reach a very large size, and greatly displace the eyeball, without causing complete blindness. Often the character of the growth can only be recognized by microscopical examination. The question of a syphilitic origin should always be considered, and doubtful cases submitted to the test of careful anti-syphilitic treatment. Tumors of the optic nerve are discussed on page 390.

Sarcoma of the several varieties occurs in the orbit. It may start from the walls of the orlit, or from any of its contents, or may invade the orbit from neighboring cavities. The recognized treatment is early extirpation, althongh the growth is liable to recur. Gencrally the whole of the orbital contents should be removed, and if the growth be large, it will be well on the following day to cauterize the orbital walls with chlorid of zinc paste. 
The method of Coley of injecting mixed toxins is also worthy of trial and further development.

Fibroma and fibrosarcoma also occur in the orbit: Carcinoma invades the orbit seeondarily. Lymphoid growths (lymphoma) occur in and about the orbit in eases of leukemia. Chloroma, a growth of a light green color, is also closely eonnected with leukemia though often classed as a sarcoma.

Osteoma (ivory exostosis) is a hard, rounded, firmlyfixed, slowly-growing tumor, that appears usually at the upper inner angle of the orbit, somewhat back from the margin. It causes no pain in the early part of its course, and little disturbance of vision. The growth commonly starts from the ethmoid or frontal sinus, and may extend toward the brain as well as toward the orbit. It is commonly attaehed by a comparatively narrow pedicle. Early removal is the best treatment, though this is attended with some risk if the growth has extended toward the brain.

Hyperostosis.-Excessive and irregular development of bones of the skull may eause distortion, displacement and great asymmetry of the orbits.

Imperfect development of the orbit may, but does not always, occur after early enueleation of the eye.

\section{DISEASE OF ADJOINING SINUSES.}

Allusion has been made to the share of diseases of the nose or its aecessory sinuses in causing optic neuritis, narrowing of the field, or loss of vision, impairment of accommodation, vitreous opacities, disease of the conjunetiva, cornea, or uveal tratet; and a more general summary of the subject will be found on page 582. It is here necessary to consider the direet extension of sinus diseases into the orbit, and the symptoms and complications which they cause.

Disease of the maxillary antrum, more eommon than was formerly recognized, may arise from disease of the upper teeth, coryza, or in conineetion with influenza 
or other infectious discases. The pain it causes must not be ascribed to glaucoma, iritis, or eye-strain. It may be attended by edema of the lids, conjunctival swelling, or retiual hyperemia. Antral abscess extending into the orbit causes all the symptoms of orbital inflammation, with displacement of the eyeball upward, paresis of the inferior rectus or inferior oblique, and the appearance of a tumor in the lower part of the orbit. The recognition of the cause of the orbital disease may depend on recognition, by transillumination, of filling of the antrum, or by clinical history of previous antral disease. Malignant growths, starting in the antrum, may cause much the same train of symptoms. Treatment of the antral disease is the primary indication.

Disease of the Frontal Sinus.-Temporary closure of the passage between the frontal sinus and the anterior cells of the ethmoid is followed by a sense of fulness in the frontal region, or frontal headache, which may become extremely severe, and tenderness over the pulley of the superior oblique. Recurring attacks of headache from this cause may be wrongly ascribed to eye-strain. Where the closure is due to swelling of the mucous membrane, it may be cut short by passing a probe into the sinus, or by the application of adrenalin solution to the upper part of the nose. Chronic or permanent closure of the exit from the frontal sinus is followed by the accumulation of mucus, causing mucocele ; or pus and abseess or empyema of the sinus. The aceumulation causes a loss of the red glow over the sinus usually obtained by transillumination with a small electric lamp placed beneath the brow. It is eustomary to compare the appearances obtained on the two sides; but frequently the disease affects both sides, or one side of the sinus may be very small or absent. An X-ray examination may be a valuable supplement to the transillumination test. The pain or headache is usually continuous, but subject to severe exacerbations and made worse by stooping or straining. There is commonly some tenderness over the sinus. Abnormal discharge into the nose is usually absent. Often the dis- 
ease is unrecognized until distension of the sinus causes bulging downward of the roof of the orbit, or a fistulous opening through the bone leads to orbital inflammation and abscesses.

Displacement of the eyeball is apt to be downward and outward, but swelling in the orbit may also eanse forward displacement, Even at this stage, the passage of a probe through the fistulous opening into the sinus may be necessary to differentiate the condition from orbital periostitis. Where the disease has not extended into the orbit, intra-nasal treatment nay be sufficient. But where the orbit has been invaded, it becomes neeessary to produce obliteration of the frontal sinus by one of the operations deseribed in works on the diseases of the nose.

Ethmoidal Disease.-Mucocele and empyema of the ethmoidal eells are quite liable to cause destruetion of the orbital plate; and tumor, or suppurative inflammation within the orbit. The displacenent of the eyeball is commonly outward and forward. The condition may resemble severe lacrimal disease. The probing of a fistula may be necessary to establish a diagnosis. It is probable that, without any such extension into the orbit, ethmoidal disease is associated with some cases of disease of the uveal tract and vitreous opacity.

When the ethmoidal disease has not broken through the orbital wall, free drainage through the nose and appropriate intranasal treatment may effeet a eure. When, however, an abseess or fistula in the orbit communicates with the ethmoidal cells, a free opening should be made through the orbital tissues and the ethmoidal eells into the nose, a drainage tube inserted, and the eavities kept thoroughly eleansed.

Sphenoidal disease is not known to extend into the orbit exeept through the ethmoid. It may, however, canse thrombosis of the orbital vessels, as well as optie neuritis and optie atrophy, through the close relation of the sinus to the eavernotis sinus, orbital veins, and optic nerve. 


\section{CHAP'TER XVII.}

\section{MECHANICAL INJURIES OF THE EYE AND ITS APPENDAGES.}

\section{CONTUSIONS.}

The lids with their loose cellular tissue permit free extravasation, and free diffusion of the blood which is extravasated.

Hence bruise of the lids is likely to be followed by very noticeable ecchymosis and much swelling. The swelling comes and goes rapidly. The discoloration takes one or more weeks to disappear. The lids also become discolored from hemorrhage attending injuries to the bones of the orbit, or the base of the skull. With such injuries, the discoloration appears many hours or days after the injury, and then not at the point of impact but at the part of the lids just within the margin of the orbit.

In bruise of the lids extravasation is checked by the immediate application of pressurc. The traditional beefsteak, with its astringent albuminous juices, offers an excellent method. Equally efficacious is the prompt application of cold, as by an ice-compress. The benefit of cold ceases with the period of extravasation. After that, pressure, and later occasional hot fomentations, and massage, are indicated.

Heavy contusions about the head are liable to cause fracture of the bones of the orbit, with important effects on the eye and its appendages. Fracture of bones enclosing air spaces connected with the respiratory tract may admit air to the cellular tissue, causing emphysema (see page 459). Blows on the brow or the frontal and malar eminences are transmitted to the sphenoid, where their force may cause fracture involving the optic foramen, and immediate blindness, from laccration or compression of the optic nerve. At first the ophthalmoscopic appearances may be normal, but in a few wecks white atrophy of the optic nerve appears; and from the first the pupil responds 
imperfeetly or not at all to light thrown into the affected eye.

Paralysis of other cranial nerves may follow fractures of the base of the skull, either at once from laceration or hemorrhage, or gradually after several days from pressure by exudate or callus. The abducens is by far the most frequently affected, the paralysis being often bilateral.

Dislocation of the eyeball may be produced by certain contusions, as by the horn of a cow. The globe has thus been pushed out so that the lids fell behind it, or has been thrust into the nasal eavity or maxillary antrum. Fracture of the walls of the orbit thrusting them outward, or atrophy of orbital tissue following injury, have caused enophthalmos (see page 471). Fracture of the walls of the orbit, thrusting them in, emphysema, hemorrhage, inflammatory exudate, or the palsies of the ocular muscles cause exophthalmos. Traumatic pulsating exophthalmos is elsewhere described (page 472). Traumatic dislocation of the lacrimal gland into the lid has occurred.

Rupture of the eyeball is cansed by blows like that of the fist. It is commonly located a little back of the upper inner part of the corneal margin, and parallel with it. Often the erystalline lens, and sometimes also the iris, is dislocated through the rupture, beneath the conjunctiva. The line of rupture appears somewhat irregular, and dark with incarcerated uveal pigment. The lens is at first yellowish, becoming whiter and shrunken with the lapse of time. The iris if not torn from its attachment falls back from the cornea, especially in the direction of the rupture, where it may be folded under so as to be entirely concealed. The softness of the eyeball immediately after injury will reveal the existence of a rupture, if located so far back that it cannot be seen.

After recent rupture, the prolapsed lens or iris should be removed from beneath the conjunctiva, and the edges of the rupture drawn together with fine sutures. Usually the injuries to the interior of the eye are so great as to make the eye useless; but a few cases recover with useful sight by the aid of lenses. 
Contusion of the eyeball not powerful enough to cause rupture of the sclera oceurs from a blow with a small stone, a marble, the cork of a champagne bottle, or the knot on the end of a whip-lash. It may cause conjunctival ecchymosis, rarely a small superficial slough and ulcer of the cornea, and often serious damage to structures within the sclerocorneal coat.

Rupture of the iris from contusion of the eyeball is not rare. It may occur at the ciliary border, iridodialysis, causing a false pupil behind the margin of the cornea, and a flattening of the side of the normal pupil toward it, as shown in Fig. 143. Radiating ruptures of the iris also oceur. They may appear either as nicks in the margin of the pupil, rupture of the sphincter, or fissures in the substance of the iris. These are shown in Fig. 144. Such
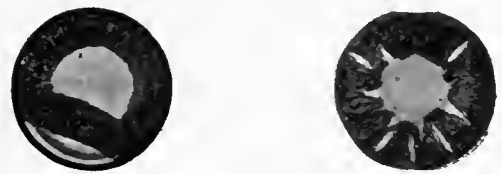

FIG. 143.-Iridodialysis, tearing of iris from its ciliary attachment, making a false pupil, through which is seen the lens-margin, and causing flattening of the true pupil. Oplithalmoseopic illumination.

Fig. 144.-Multiple ruptures of the iris. Tears in the sphineter, and separation of the radiating iris-fibers.

lesions are attended with hemorrhage into the anterior chamber, hyphemia (page 408) which may for a time conceal them or may call attention to a rupture so small as otherwise to be overlooked. Such hemorrhage is eommonly entirely absorbed in two or three days, but it may recur.

Paralysis of the iris-sphincter (traumatic iridoplegia) without rupture may occur from stretching. The pupil is found partly dilated and sluggish. It usually regains its power in a few days or weeks. Permanent dilatation is more apt to depend on slight rupture.

Traumatic cycloplegia, paralysis of accommodation from injury to the ciliary body, may also occur, causing imperfect vision from inability to focus near objects. 
A temporary astigmatism may arise from injury to the same part.

There may also be hemorrhage into the vitreous, eausing complete loss of sight until it is removed by absorption.

The treatment for such injuries by contusion, is at first complete rest of the eye, under a mydriatie, with the application of eold if there are signs of violent reaction. After all symptoms of inflammation have subsided, it may be well to try the effect of a myotic if the pupil remains dilated. When iridodialysis causes diplopia or annoying diffusion, an incision may be made in the extreme periphery of the cornea opposite the center of the separation, and the edge of the iris drawn into it and incareerated or fastened with a stitch; or the detached portion of the iris may be removed by iridectomy. Such injuries to the iris often permanently impair vision.

Injuries of the lens by contusion of the globe include traumatic cataract and dislocation of the lens. The former is eaused by rupture of the lens-capsule and differs little from that eaused by penetrating wounds. Dislocation of the lens (see page 424 ) may be into the anterior ehamber (Fig. 145). More commonly it is backward,

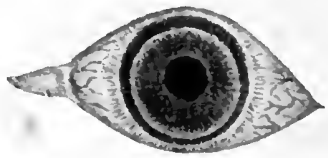

FIG. 145.-Dislocation of the elear lens into the anterior chamber. Iris and pupil seen through the lens. Pericorneal hyperemia.

and still more frequently it is only partial, the lens tilting back at some part of the eireumference, causing myopia and astigmatism by its inereased curvature and oblique position. 'These results may be permanent or there may be eonsiderable reeovery. Such injuries should he treated by the early application of cold to diminish reaction, rest, and usually the placing of the eye mnder a mydriatic. 
Later a myotic may be benefieial, and the measures indicated on page 425 become appropriate.

Traumatic Edema of the Retina (Commotio Retince).-Bruise of the eyeball is sometimes followed by temporary impairment of sight without any external evidence of injury. But the ophthalmoscope shows in the first few hours a diffuse gray haziness or more dense opacity of the retina at the posterior pole of the eye, probably due to edema. This haziness soon begins to

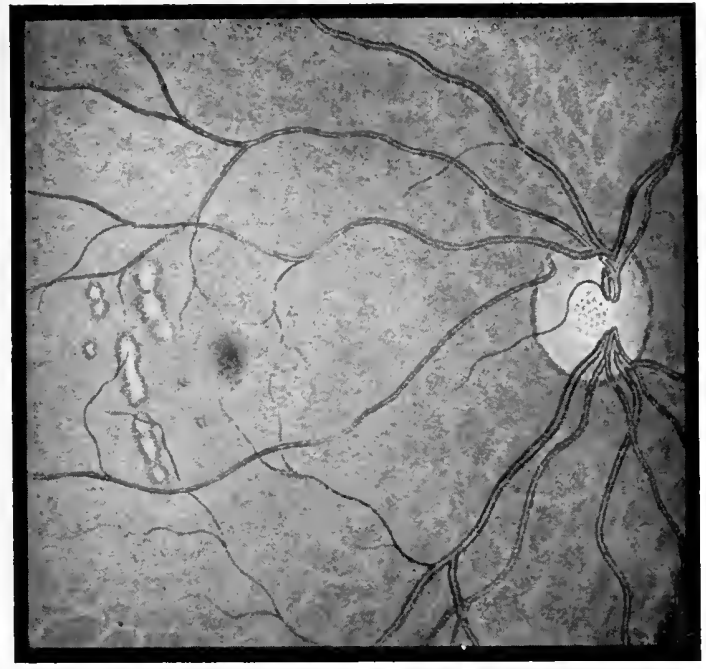

Fig. 146.-Traumatie edema of retina and ehoroid, four hours after eontusion of the right eye. The dark spot is the center of the maeula.

diminish and passes off entirely in from two to four days. It is often associated with slight lesions of the choroid, which remain visible longer. $\Lambda$ fter disappearance of the retinal opaeity, the vision is soon restored to normal. Rest of the eyes, with guarding against exeessive light is all the treatment required.

Injuries of the Choroid. - With the changes of the retina above described, there often occur small patches of light, yellowish, swollen choroid, which may be 
arranged in something of an are or creseent coneentrie with the optic disk. These, if not attended with hemorrhage, fade gradually away after a few days, the fundus beeoming quite normal in appearance. But if the injury has been more severe, the patehes may run together forming one or more light crescents, or these may for a time be eoncealed by hemorrhage into the vitreous. A few weeks later, when the hemorrhage has been absorbed, the

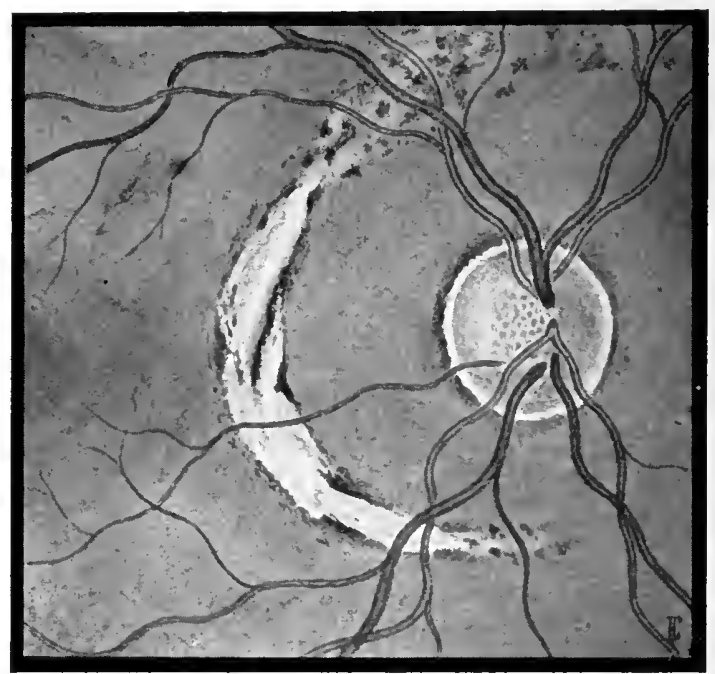

FIG. 147.-Rupture of the choroid, right eye, from contusion by a small stone. The "rupture" lies between the disk and the macula.

creseent is found to be a choroidal atrophy with massing of pigment along its borders. Often there are also ineomplete choroidal atrophies in other parts of the fundus. This is the appearance known as mupture of the choroid and illustrated in Fig. 147. The retinal vessels are scen to cross the atrophic area uninjured. The lesion is probably an atrophy following injury and partial rupture of the tissue of the choroid. Its striking curved form, 
usually roughly concentric with the optic disk, may be due to a sharp bending of the coats of the eye occurring along this line, when the globe is forced back against the support given by the optic nerve. In severe. injuries, effused blood may pass behind the choroid detaching it from the selera.

Treatment is similar to that of other contusion-lesions within the globe-rest under a mydriatic. After the slight lesions, recovery may be complete. But "rupture" is usually attended with marked permanent impairment of vision.

In rare eases optic neutritis or atrophy may be due to force transmitted to the nerve from bruise of the eyeball or other contents of the orbit.

\section{WOUNDS WITHOUT LODGEMENT OF FOREIGN BODIES.}

Although it is convenient to consider apart wounds complicated by the lodgement of a foreign body, it is best to regard every ease of traumatism as possibly complicated in this way, until investigation reveals the contrary. The question of probable infeetion must also be eonsidered in every ease, and the effort made to render the wound aseptic. In doing this it must be remembered that hemorrhage is a guard against sepsis, and should not be checked too promptly, nor should effused blood be too industrionsly diluted and washed away by watery solutions.

Wounds of the lids, on account of the vascularity of the parts, unite early. But beeause of the looseness of the tissues involved, the lips of the wound are very liable to be displaced; and if they unite thus, a permanent deformity is caused. On this aceount it is extremely important that the parts should be at once brought into proper apposition, and permanently fixed by a sufficient number of well-placed sutures. Any delay about doing this is especially harmful, inereasing the amount of seartissue, where for cosmetic reasons, as. well as the future flexibility and usefulness of the part, it is especially 
important to reduce the scar-tissue to a minimum. When there is absolute loss of tissue, it is better to replace this by drawing in neighboring tissue by some plastic operation than to trust to its replacement by granulation-tissue.

The resulting deformity is least when the wound lies parallel to the fibers of the orbicularis muscle. It is likely to be greatest and most difficult to prevent when the wound extends through the free edge of the lid. In some of these cases a fine straight needle and harelipsuture may give the best result. Care should be taken to secure cleanliness of the surfaces brought together, and inflammatory swelling must be kept down by the continous application of cold. The stitches should be carefully placed, including the depth of the tissues. They may be inspected each day, and any that show evidences of stitch-hole abscesses, removed early. But some must remain until the swelling subsides and union is likely to be firm. If the stitches are withdrawn carly, the parts must be supported and protected by properly placed strips of adhesive plaster. The same dressings are to be employed as after operations on the lids (see Chapter XIX).

Wounds in certain regions require special care. Thus the division of a canaliculus generally makes it necessary to slit both portions to prevent ohstruction to the flow of tears. A wound of the upper lid may divide the tendon of the elevator muscle, in which case the divided ends must be searched for, and united to prevent permanent ptosis. Deformity of the lids cansed by old scars can sometimes be lessened by prolonged massage; but may require some of the most delicate and difficult of plastic operations. Swelling of the lids shonld never prevent careful search for accompanying lesions of the eyeball.

Penetrating wounds of the orbit are usually deep in comparison with their extent on the surface. They are, therefore, especially liable to hide foreign bodies, difficult to thoronghly cleanse, and uncertain as to the structures involvel. They may even be entirely concealed, or easily overlooked on accomt of the swelling of 
superfieial struetures. Injury of the optic nerve will cause instant blindness. Injury to a musele causes impairment of function that may only be discovered later. Hemorrhage, or empliysema produces exophthalmos, which, from the latter canse, is reducible by pressure.

In the treatment of such wounds, the removal of any foreign body, cold to keep down swelling, asepsis, and drainage are the inportant points. Shortly after injury, the wound should be washed ont with warm boric aeid or salt solution. Later, hydrogen dioxid should be employed. If there is tendency to the formation of a sinus, a drainage-tube should be introduced, or the wound packed with iodoform gauze.

Wounds of the conjunctiva only usually require eleansing, the replacing of any flap in normal position, and elosing of the eye for one or two days until union ein oceur. Very extensive division and separation of the menbrane may require sutures. They shonld be fine and removed by the third or fourth day.

Wounds of the Cornea.-Even slight abrasions of the cornea, such as are often made by the finger-nail of an infant, may cause extreme pain, with photophobia and inability to use the eyes. The cornea is particularly liable to infection; so that all corneal wounds should be closely watched until the surface is again covered with epithelium. Even after this, an erosion may reeur without evident eause. Corncal injuries are particularly dangerous in the presence of lacrimal obstruction.

On account of the rigidity of the cornea, there is very little tendeney to displacement of the parts; so that even extensive irregular wounds very rarely require suture. Deep wounds always leave some permanent impairment of transparency, although this may be slight, and if not in front of the pupil, of no importance. When the wound extends into the anterior chamber, the eseape of aqueous humor causes the loss of the normal tension of the globe, and aholition of the anterior chamber. Wounds of the cornea involving deeper structures are ehiefly of importance in that connection. 
The treatment must include careful cleansing, repeated daily, the instillation of a mydriatic, protection of the eye by a light dressing, to prevent the entrance of particles of dust which tend to lodge in the wound; and if this is of some length and extends through the cornea, complete rest of the eyes, and even rest in bed, until union has occurred. Cold applications should be used with eantion.

Wounds of the sclera, if they do not perforate it, require simply eleansing, and heal quiekly. If they extend through the whole thickness, they eanse diminished tension of the eyeball, and danger of infection of the vitreous. All struetures prolapsing into the wound should be excised. The wound must be earefully eleansed, and if extensive, closed with one or more fine sutures. Cold may be used for the first day or two, to keep down reaction; and the eye should be kept at rest under a mydriatic until repair is well started. Very extensive wounds of the selera may still allow recovery of the eye, even with useful vision. When, however, from the general disorganization of the eye, or the commencement of iridoeyclitis, it beeomes eertain that only a sightless and disorganized globe can remain, it will greatly shorten the period of disability, as well as remove the danger of sympathetic ophthalmitis, to promptly enucleate the injured organ.

Wounds into the ciliary body are regarded as especially dangerous. The prolapse of the eiliary body into the wound is likely to interfere with drainage, and consequent swelling of the lens may increase the obstruetion, and infeetion is especially liable to occur. Especial eare must, therefore, be taken to remove all prolapsed or injured tissue, even though this neeessitates enlarging the original wound.

Wounds Involving the Iris. - That a penetrating wound involves the iris may be suspected from the presence of blood in the anterior chamber; or recognized by distortion of the pupil, or the existence of a second opening in the iris. Prolapse of the iris into a corneal wound 
appears as a rounded dark brown tumor, at the site of the wound, while the pupil is found distorted, and the iristissue dragged in the direction of the prolapse. The protruding iris is at first readily distensible by the escaping aqueous, and may appear to include more of the iris than it really does, and may vary in size from day to day. It soon becomes covered with a layer of gray translucent lymph, and then slowly flattens down to an adherent lencoma, unless it be quite extensive or the surrounding cornea softens, in which case more iris may be drawn in, and anterior staphyloma develop.

Treatment.-Simple incision of the iris, or clean removal of a part of it, is generally not followed by exeessive reaction, or prolonged healing. When, however, the iris prolapses into a corneal or scleral wound the case is more serious. In a few cases of prolapse into small eorneal wounds, the iris may be pushed back into position and the prolapse not recur. Cases of prolapse near the periphery may be left to flatten down without further trouble. But in all cases of large prolapse near the center of the cornea, or of probable infection of the protruding iris, that are seen within the first day or two, the protruding portion should be cut off, and the stump freed as far as possible from its adhesions to the cornea. From about the third to the tenth day it may be best not to excise a prolapse of the iris, because of inereased risk of general infection of the eye. After the tenth day the excision of the prolapse should be done if it seems to be extending. Prolapse of the iris greatly retards the complete healing of the wound, a large prolapse taking six or eight weeks to flatten down.

Wounds of the iris are to be treated with rest and mydriatics until the eye is free from redness and irritability. At first cold may be used to lessen the reaction, if it does not injuriously influence the cornea. The eye should be kept elosed with a light dressing (see Chapter XIX) until the corneal wound is well united, or the prolapse is flattening down.

Wounds of the lens eause swelling and opacity 
which generilly goes on to traumatic cataract, and in young persons may be followed by complete absorption of the lens. The opacity may be noticed with the ophthalmoseope, or by oblique illumination, immediately after the injury. It begins at the wound, and extends with a rapidity proportioned to the size of the opening in the lens-capsule. If this is large the whole lens may become hazy in a few hours. (See Fig. 148.) If the progress is

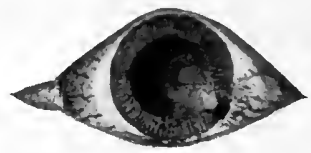

FIG. 148.-Traumatic cataract, commencing, after wound of lens, with small prolapse of iris.

slower the opacity may assume a somewhat stellate form, closely resembling posterior polar cataract. (See Fig. 130.) When the wound in the capsule is quite small it may entirely close, and the opacity disappear, or remain permanently confined to the immediate seat of injury. Sometimes the haziness of the lens beeomes general immediately after the injury, then in a few weeks clears up to a great extent, but several months later the lens slowly becomes entirely opaque.

When the opening in the capsule is large, the swelling of the lens pushes out fragments of the cortex or even the whole nuclens. These lie in the angle of the anterior chamber until dissolved and absorbed. They usually cause pericorneal redness, pain, photophobia, and may even oceasion iridocyclitis and loss of the eye.

Treatment.-The eye shonld immediately be placed under atropin, with rest and protection from excess of light. If the wound is minute, this gives the best ehance of healing without eausing general opacity ; and the complete inaction of the ciliary musele must be thus maintained-for many weeks. If the swelling of the lens is great, and the eye shows signs of irritation, the lens, or at least the nucleus and greater part of the cortex, should 
be extracted. If the patient is young and the lens-changes cause no serious disturbance, they may be allowed to proceed without interference until absorption is complete; or if it cease, one or more needle-operations may be done to renew the process until the pupil is clear. If the wound is through the ciliary region it will be best to enlarge it and remove the lens with other injured tissues without delay. After removal of the crystalline, a correcting lens will be required for distant vision; but usually it will be impracticable to employ the eye along with the other if it has good vision.

Wounds involving the vitreous are of importance chiefly on account of their liability to infection, which will be considered in connection with the lodgement of foreign bodies.

\section{FOREIGN BODIES IN THE EYE AND ORBIT.}

The possible lodgement of a foreign body should be considered in connection with every penetrating wound of the eye or its related structures. Their removal is necessary to recovery, and their presence is liable to be quite overlooked. They are searched for in the same general way as foreign bodies imbedded in other parts of the body.

For pieces of metal and glass, that are not too minute, the Röntgen or x-rays afford very valuable assistance. The importance of locating a foreign body exactly has led to the taking of radiographs, from different directions; and the use of a metal indicator (method of Sweet) placed at a known position in front of the eye, with the radiograph of which that of the foreign body can be accurately compared. To get the best results, a current of high tension must be used allowing a short exposure; and the patient should be placed in a comfortable attitude, (best lying down), to lessen the blurring due to slight changes of position. The sensitive plate is bound to the temple next the injured eye, and the tube placed on the opposite side of the head and rather in front. To locate foreign 
bodies in the orbit, bits of lead may be fastened to the skin at known points on the orbital margin to give points for comparison.

Lids and Orbit.- The swelling of the lids after injury readily conceals any foreign body lodged in a wound made in or through them; hence in every ease, the depth of the wound should be carefully examined, enlarging it if necessary to admit the little finger for the purpose. Very large foreign bodies have been extracted from the orbit, or from the maxillary antrum, nose, or brain-cavity, into which they had passed through the orbit, when the history of the case, or the previous examinations by other surgeons, had given no indication of their presence. When found a foreign body must be removed. Especial care should be taken to secure very free drainage, if there is any suspieion of penetration of the eranial cavity.

Powder-grains are liable to be lodged by accidental explosions in the lids, conjunctiva, cornea, or selera. The potassium nitrate and sulphur of the grain are quickly removed, causing a temporary inflammation; while the fine particles of charcoal become gradually diffused through the neighboring tissues, causing a permanent bluish stain. Removal of the grains should be effected as quickly as possible. The more superficial may be removed by thorough scrubbing. The deeper grains should be touched with the galyano-cautery, or with nitric acid, causing a slough in which the particles of carbon are imbedded. These procedures may be carried out. under local infiltration-anesthesia if the grains are few, but if the grains are numerous, they require anesthesia by chloroform.

Foreign Bodies in the Conjunctiva.-These have direct access only to the part of the conjunctiva exposed between the lids on either side of the cornea ; but they are liable to be carried by the rubbing of the lids on the eyeball into other portions of the conjunctival sac. Most fiequently small particles will be foind to rest on the surface of the upper lid, about the middle of the upper border 
of the tarsal cartilage, as illustrated in Fig. 149. But they may become lodged in other portions, especially in the retrotarsal folds; and if retained many hours, they

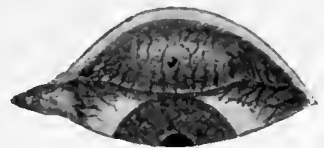

Frg. 149.-Foreign body lodged on conjunctiva of upper lid. Lid everted to show the usual point of lodgement.

become imbedded in the swelling caused by their presence, and even large masses may remain concealed for months. The heads of grass, and grain, and hairs of caterpillars are likely to become imbedded in the swelling of granulations they cause, and thus remain undetected. (See Ophthahmia Nodosa, page 243.)

Foreign bodies are to be searched for ; first by careful inspection of the exposed portion of the ocular conjunctiva; then by the eversion of the upper lid (see page 58); then by retraction of the lower lid with the eyeball turned strongly upward; and then the lifting of the upper lid from the globe, while it is turned strongly downward. Points of inflammation and swelling of the membrane are to be very carefully exposed. When found the foreign body is to be promptly removed. Usually it can be wiped away with a pledget of cotton, otherwise it may be seized by fine forceps. Particles of quicklime, or of metal that has entered in a molten state, may require snipping loose with the scissors.

Foreign bodies in the cornea cause much pain and discomfort when they project sufficiently to scratch the upper lid with every. act of winking. But if entirely imbedded, they may be unnoticed until after onc or more days' attention is drawn to the eye on account of the resulting inflammation. Then there are found perieorneal redness, photophobia, excessive lacrimation, a contracted pupil, and often reddening of the optic disk. If left alone, suppuration goes on around the foreign body, with 
all the dangers of a suppurating ulcer of the cornea, until the foreign body is loosened and wiped away by the lids

In rare cases, suppuration does not occur, but the corneal epithelium proliferates around it until the foreign body is imbedded in white epithelial masses, which lie in a depression of the corneal surface. It may thus be retained for weeks, months, or even years. The resulting lesion is a white or gray spot, which may or may not have vessels running to it from the limbus. It is illustrated in Fig. 150. Particles of powdered chareoal, the residue of a powder-grain, and a few other aseptic substances, may

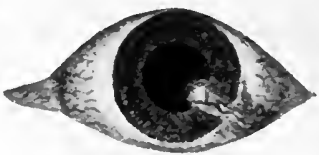
FIG. 150.-Appearances caused by foreign body retained six weeks in the
cornea.

remain in the cornea indefinitely withont causing irritation. - Other substances act as irritants of a specific character, as the fragments of oyster shells, which cause "oyster-shuckers' keratitis."

Diagnosis.-Haziness of the cornea, or greater congestion of the nearest portion of the pericorneal zone, may point out the location of a foreign body ; or this may be revealed by irregularity of the corneal surface, which can be detected by placing the cornea so that the surgeon can see in it the reflection of a large window, and wiping away the tears and mucus with a swab of absorbent cotton; or by a drop of fluorescin solution, which will color any point where the corneal epithelium has been lost.

But a foreign body may be deeply imbedded, and may produce the most scrious effects, although so sinall as to be scarcely visible to the unaided eyc. The cornea must therefore be searched with the ophthalmoscope, using the strongest convex lens with which it is furnished, to 
discover anything lodged in front of the pupil, and with a good magnifier under oblique illumination.

Foreign bodies in the eornea must be distinguished from small opacities in the deeper media (see page 81 ), exudates in the cornea, or even specks of pigmentation on the iris.

Treatment.-The foreign body should be at once removed (see Chapter XIX) with the damaged and softened tissue around it. 'This includes the removal of the ring of brown staining which quickly forms around any foreign body containing iron, and which if left will separate subsequently after prolonging the irritation (see also page 499). Any remaining uleer is to be treated as directed on pages 277 and 282 .

Foreign bodies in the sclera may be quite concealed by the swelling of the conjunctiva. If left there, they may remain for many years without eausing irritation, or may ultimately be thrown off.

Anterior Chamber and Iris.-A wound through the cornea or limbus, with the diminished ocular tension, reveals that the wounding substance has penetrated the globe. Usually it goes deeper, but sometimes it stops in the anterior chamber or iris, and a careful search should be made for it there. Hemorrhage into the anterior chamber may eonceal it for a time; but usually eareful seareh by oblique illumination will diselose it, for the most minute foreign bodies have net sufficient foree to pass through the cornea.

Treatment.-If imbedded in the iris, the foreign body may sometimes be picked out with the magnet (if steel), or with fine forceps introduced through an ineision in the nearest part of the periphery of the cornea, But usually it is much safer, as well as easier, to do an iridectomy, removing the injured portion of the iris with the foreign body in it. When the foregn body lies loose in the anterior chamber, it should be extracted through an incision in the lower part of the limbus. The subsequent treatment is, cold to reduce reaction, rest, the use of a strong mydriatic, and other treatment for iritis. All 
foreign bodies in the anterior ehamber are dangerous; even an eyelash or bit of epithelium carried in through a perforating wound of the cornea, becomes the starting point of a cyst (see page 332).

Lens. - In the lens a foreign body neeessarily causes eataract, which will soon conceal it. It is therefore important in all eases of foreign body in the eye to earefully examine the lens with the ophthalmoseope, and oblique illumination and a good magnifier, as soon after the injury as possible. If the opaeity has already gone so far as to make the presence of the foreign body uncertain, the Röntgen rays, or the subsequent presence or absence of inflammation of the uveal tract, must be relied on for a diagnosis.

A foreign body in the lens does not usually cause infeetion of the eye, or severe inflammatory symptoms, unless there is great swelling and rapid disintegration of the lens. With the foreign body in the lens it is therefore advisable to wait until the traumatic cataract has matured, or so far advanced as to make its removal neeessary, and then the lens should be extracted through a rather large incision, with an upward iridectomy, if this is neeessary to give the swollen lens free exit. The foreign body will nearly always be extruded with the lenssubstance; if it is not it must be removed with a magnet, scoop or forceps.

Vitreous, Retina, and Choroid.-A foreign body entering the vitreous and remaining in it, or penetrating the eoats of the back of the eye, usually causes infection, and loss of the eye through purulent or ehronic plastic inflammation; and, so long as it remains, it constitutes an espeeial menaee to the other eye, through sympathetie ophthalmitis. 'The foreign body may be small, the sight at first unimpaired, less pain may be felt than from a slight abrasion of the cornea, and yet the eye may be doomed to immediate destruetion.

If the foreign body be small the reaetion may be slight, severe inflammation not setting in until the consequenees of infection extend from the wound to other structures, 
but the ultimate loss of the eye is none the less certain. If the foreign body be large, its entrance eauses so much hemorrhage and general disturbance that sight is at once lost, and the patient may show decided symptoms of shock. Great edema of the conjunctiva and lids may quickly occur, so that in a few hours the eye shows clear evidence of severe injury, and before these symptoms subside the suppurative or chronic plastic inflammation is fairly started. Some foreign bodies, as metallic copper and its alloys, cause inflammation by their chemical properties even when aseptic.

Diagnosis. - After injury, the eye should be thoroughly examined at the earliest possible moment. It may then be easy to determine the presence or location of a foreign body which a few hours later would be quite concealed by increased opacity of the lens or diffusion of hemorrhage. The pupil should be dilated and a careful ophthalmoscopic examination madc of every part of the interior of the eye. Metallic particles are generally detected by their glitter. Air-bubbles in the vitreous which appear as spheres with a dark ontline, although they tend to rise to the upper part, may indicate the direction taken by the foreign body; or its track may be marked by shreds of blood-clot. A localized hemorrhage may be found to conceal it; or a wound of exit may be discovered.

If the foreign body cannot be seen, careful inquiry must be made as to the probable nature of the body by which the wound was inflicted, its size, and the direction of impact. If it be a piece broken as from the edge of a chisel, the size and shape can be ascertained by inspection of the tool. If a fragment is believed to have struck the eye, and not to have entered, only the finding of the fragment can be regarded as proving this. Patients are likely to assert positively that nothing has remained in the eye, because the familiar sensation of a foreign body on the surface is lacking, or because they hope that the injury is not so serious. Sometimes there is even a clear, but incorrect, history of the wounding body having 
dropped out after injury. If, with a corneal wound, there is also penetration of the iris or lens, it may be confidently assumed that the wounding body has passed in ; and we may presume it has remained, unless it be something like a piece of wire, which has been pulled out afterward. The discovery of loealized hemorrhages in the fundus quite unconnected with the wound of entrance is a strong indication of the presence of a foreign body.

When nothing can be seen with the ophthalmoscope, the field of vision should be taken with a candle in the dark-room; and a marked scotoma, or other defect in the visual field may indicate the location of the foreign body. Instantaneous blindness, produced by a small foreign body, as a bird-shot, indieates that the optie nerve has been struck either at the disk or behind the eyeball. Ecchymosis of the lids appearing some time after the injury, and most intense near the margin of the orbit, or ecchymosis of the conjunetiva, appearing similarly in the retrotarsal fold, is evidence of orbital hemorrliage, which, if not from the wound of entrance, proves that the foreign body has not lodged in the eyeball, but has passed on into the orbit. If a foreign body, as a birdshot, has entered the eye through the posterior.segment, the softening of the globe, and hemorrhage in the vitreous announce the accident.

The Röntgen rays should be appealed to in all doubtful cases. But some foreign bodies cast no appreciable shadow from them; and even metallic partieles if smaller than $1 \mathrm{~mm}$. in two dimensions, are likely to give no evidence of their presence.

Treatment and Prognosis.-The earliest possible removal of the foreign body is the first thing to be considered in the mass of eases. It should usually be done at any eost, even to the removal of the eye. Particles of iron may often be removed by the magnet (see Chapter $\mathrm{XIX}$ ). The certainty of the removal is proportionate to the strength of the magnet and the size of the bit of steel. Other foreign bodies, not influenced by the magnet, must be removed, if possible, by foreeps or a seoop. For 
this purpose it is the surgeon's duty to open the eyeball whenever the location of the foreign body can be known with strong probability.

The second point is to remove all badly damaged and probably infected tissue. On this account, the wound of entrance should be enlarged, or the new incision made free; and all tissue in which the foreign body is entangled should be removed with it. After this, the treatment is to be that appropriate to wounds of the parts, careful cleansing, cold to subdue reaction, rest of the eye, and rest in bed until reaction begins to subside.

A few foreign bodies pass through the vitreous into the retina, choroid, or sclera, without causing infection or serious inflanmation. These have usually entered through the cornea, and iris, or lens, or have passed through the lids. They are usually very small. When such a foreign body is firmly imbedded and has remained quite innocuous for several days or weeks, it is proper to let it be and await developments. But such cases are so rare, that the possibility of a benign course ought not to influence the treatment of recent cases.

Even after the successful extraction of a foreign body the safety of the eye is not assured. In the majority of cases, useful vision will be lost, and the injured eye may have to be sacrificed for the safety of the other. Even when the eye seems to do well for a time, it may become the seat of a slow uveitis that after weeks or months will destroy it. The prospect of a useful eye is best after early removal of a small foreign body which has entered through the iris and lens, and when the tissue in which it lics has keen removed with it. 


\section{CHAPTER XVIII.}

\section{REMEDIES AND THEIR APPLICATIONS.}

\section{ROENTGEN RAYS.}

Roentgen Rays.-Beside the harm the $\mathrm{X}$-rays do to other parts of the body, experiment has shown they ean do great damage to the eye. They should be applied by one who has a fair knowledge of their effects and experience in their application under skilled supervision. But, if used with caution, experience shows that the $\mathrm{X}$-ray may be effectively employed for diseases of the eye without any necessary risk of serious unfavorable effects. Care must be exereised to avoid (a) too long exposures; (b) too many exposures before the patient's suseeptibility has been thoroughly tested (several weeks); $(c)$ unnecessary exposure of healthy parts. To meet the last requirement, a shielded tube, a mask rendered impervious by tinfoil or lead paint, or a plate of glass or metal with an opening just large enough to expose the part to be treated, niay be employed.

\section{REST.}

Rest of the eyes may be made absolute by the use of a cycloplegie and the complete exclusion of light; or by darkness alone, if the accommodation has been lost by age. Commonly only relative rest is required. Under the ordinary bandage light reaches the retina and stimulates it to functional activity. Yet, with both eyes bandaged there is very little incitement to exertion of the oenlar museles, and under cycloplegies there is rest from the effort of aceommodation.

Suspension of the customary oeenpation may be all the rest required in a given case. Even the looking at distant objects is a valuable rest for those habitually engaged at close looking. Directions to rest the eyes should 
specify how they are to be rested. Rest, by use of lenses and prisms, is discussed in Chapters VII and VIII.

Exclusion of the light is indicated in active inflammations of the retina and photophobias of retinal origin.

Absolute darkness is rarely advisable, and only for short periods, on account of the general depression it eauses. The chief benefits of exelusion of light are gained by moderate illumination and avoidance of eontrast, by sudden increase of illumination, or looking at bright lights with a dark background. Smoked glasses should be worn only during exposure to the brightest light, or when the eyes are first exposed to bright light, being removed when the eyes become accustomed to it. Amber yellow glass is beneficial by exeluding most chemical rays.

General rest, through its powerful influence on the circulation and the nervous system, is an important means of combating acute inflammation. Rest in bed is the most complete rest for those who find it not irksome, and it includes rest from many stimuli that act on the nervous system when the patient is up. It is most important, in the early stages of an inflammation, or to restore an exhausted patient to a general condition favorable to healing. When it becomes decidedly irksome, it is generally no longer helpful, but may have an effeet quite the opposite of that songht. Even when the object of so-called rest is simply to prevent displacement of parts, as of the flap after eataract extraction, or a graft after a plastic operation, it may, if too rigidly enforced, defeat the purpose, by causing a nervous irritability in which the patient will not be able to avoid the slight movements that are harmful.

\section{MASSAGE.}

Massage of the eyelids, often combined with the use of boric acid powder or ointment, is sometimes a valuable aid in chronic conjunctivitis and trachoma. The required movements are those of stroking or friction of the lid upon the globe, with some kneading between the forefingers or the thumb and finger. The stroking should 
be from the lid-margins. The manipulations for increasing the efficieney of conjunctival applications are given on page 505 .

For episcleritis, pannus, and glaneoma, pressure is to be made upon the eyeball through the elosed lids. The direction of the movements should be radial, from over the center of the cornea toward the equator of the eyeball ; and circular, around the center of the cornea as a center.

To reduce infiltrations, lessen the effects of cieatricial contractions, and put the parts in the best condition for plastic operations, pinching up of the skin of the lids, and kneading or rolling it between the thumb and finger, is an important procedure.

For corneal opacities massage consists in stroking the corneal surface in a radial or circular direetion with the baek of a lens-spoon, spatula, or special instrument made for the purpose, after the eye lias been bronght under the influence of a local anesthetic. Massage of the lens is considered under cataract operations.

Massage for glaucoma is performed by placing the points of two or three fingers and the thimb so as to press through the lids upon the anterior portion of the selera; and by alternating the pressure and shifting their position causing the dimpling of the different parts of the eyeball.

\section{APPLICATIONS OF HEAT AND COLD.}

Dry heat is applied to relieve pain by covering the eye with hot dry cloths, frequently changed, or something hot wrapped in flannel. The electric heater, in which a proper current is passed throngh a flat coil of light wire, is eonvenient; but a coil of tubing throngh which hot water cireulates will serve. Hot air may he obtained by foreing air throngh a heated tube. Diy air may have a temperature of $100^{\circ}$ to $150^{\circ} \mathrm{C}$. A mixture of air and steam may be used at a temperature of $40^{\circ}$ to $50^{\circ} \mathrm{C}$. Superheated air, seeured by passing air throngh a platinum tube coiled in the flame of a Paquelin burner, can be used to eanterize the cornea. 
Hot fomentations are used to relieve pain, seeure resolution, or hasten and facilitate suppuration. They are applied by placing a eloth wrung out of very hot water upon the eye, and changing it for another equally hot, whenever it beeomes comfortably cooled. Generally they are continued but a few minutes at a time, such periods being repeated if needful several times a day. The temperature that the region of the eye will endure with ultimate comfort and benefit is often surprisingly high, especially when it has had a few minutes to become gradually accustomed to the heat.

Hot Water as a Caustic. - In some cases of ulceration of the cornea, an excellent influence is exerted by dropping upon the uleer one or two drops of water as near the boiling temperature as possible. To do this, the eye is prepared for the application. Then the one or two drops of water are held in the pipette over a lampflame until just at the boiling point, and then dropped on the ulcer as quickly as possible. The prolonged use of very hot applieations in eaneer will sometimes destroy the morbid tissue. A sponge wet from minute to minute with boric acid solution, as hot as can be borne, is held to the part twenty minutes of every two or three hours.

Hot Water as a Styptic.-The best agent to eheck bleeding after enucleation of the eyeball, or removal of a tumor, is hot water. It may be applied by wringing it out of sponges as hot as ean be borne, so as to fall in a stream on the bleeding area; or it may be better applied from a large pipette, such as is used for washing the conjunctiva. It seems to exert no deleterious influenee on the eonjunetiva or wound-surface, even when so hot that the neighboring skin must be carefully guarded from the overflow, for fear of its being burnt and blistered.

Poultices must be used with eaution about the eye, sinee they may aggravate eonjunetival and corneal inflammations, or favor disastrous intra-ocular suppuration. Sometimes as for a stye or other lid-inflammation, the suppurating point may be covered by a poultice so ad- 
justed as to leave free a large part of the lids and the fissure between them.

Cold is used upon the eye to prevent or lessen the reaction after injury, and to combat acute inflammation in its early stages. It is contraindicated when there is risk of sloughing of the cornea, or when its application causes serious discomfort. To do good the application of cold must be continuous. A common method is to place by the patient's head a block of ice upon which are laid three or four pieces of surgical lint, or small cloths. One of these is laid upon the closed lids for a minute or two, until it becomes a little warm, when it is replaced by another piece and laid back on the ice to cool again. Cold may also be applied by pounded ice in a small, light, rubber bag, or by ice-water run through a coil of lead or rubber tubing.

\section{THE MAKING OF APPLICATIONS TO THE CONJUNCTIVA.}

Conjunctiva1 Instillations.--Solutions are dropped in the conjunctival sac, either that they may be absorbed through the cornea and thus reach and influence the interior of the eye, or for their direct action on the conjunctiva itself.

To affect the interior of the eye it is important that the solution should reach the cornea undiluted. The best effect is obtained by having the patient look downward, fixing the gaze on some point on the floor and staring fixedly at it with the other eye. The upper lid of the eye in which the solution is to be placed is then gently raised by slight traction on the skin of the lid with one finger of the left hand, and retained thus by pressure of the skin against the upper margin of the orbit. If the patient's head rests against a firm support where he cannot draw back from this pressure, it is easy thus to control the movements of the lid. The patient's head should be tilted back so far that when the upper lid is drawn up the lashes will be out of the way.

With the ordinary rubber-bulb pipette or medicine 
dropper, the required drop or drops are then deposited on the upper margin of the cornea. They should not be allowed to fall any considerable distance, on account of the increased shock from the force with which they will strike the eye. On the other hand, the dropper should not touch the patient for fear of infection. An instillation will be more agreeable if the solution is brought to blood heat, or a little warmer, before applying it. After the application, the lid is to be held open until the patient so far regains control over his eyes that he can again hold them open without assistance.

To Affect the Conjunctiva.-If the drops are intended not for corneal absortion but to influence the conjunctiva, the patient may be allowed to roll the eyes up, the lower lid being drawn down by the finger pressed against the margin of the orbit, forming a eup in which drops may be placed. Such an application can be made most effectively when the patient is lying down. The lower lid being still drawn from the globe, the eye should be rolled in various directions until the solution is diffused throughout the conjunctival sac. As soon as the lids are allowed to close tightly, much of the solution will be expelled.

When it is desired to prevent fluids placed in the conjunctiva from passing with the tears into the nose, as to prevent the constitutional effects of a mydriatic through its absorption from the mucous membrane of the nose and throat, gentle traction should be made on the lids - near the inner canthus, in such a way as to turn the puncta away from the eye, and a pledget of absorbent cotton held in contact with the puncta. Simple pressure upon the canaliculi, through often recommended, unless so strong as to be very unpleasant, is probably of little avail for this purpose.

The eye-douche may also be used to make applications to the conjunctival sac. The solution is placed in it, and the eye applied to it and opened. On throwing the head back the solution enters the conjunctival sac.

Washing Out the Conjunctiva.-The water or solution used should be at blood-heat or warmer. The 
patient's head should be thrown far back. The patient or an assistant should hold a mass of absorbent cotton to the cheek so as to catch the overflow of fluid. The pipette should have rather a large opening, and a bulb holding one or two fluid ounces. The upper lid should be drawn away from the eyeball by the lashes, and the solution driven into the conjunctival sae with something of a spurt. This is repeated with the stream directed toward the middle and each end of the upper lid, along the lower lid, and into the canthus. The escaping fluid is then to be wiped away, and the process repeated as often as necessary.

\section{Applications of Astringent and Caustic Solu-} tions.- When the solution to be applied to the conjunctiva is so irritant that it would be unsafe to freely instil it, it is applied by means of a mop made by twisting a little absorbent cotton around the end of a tooth-pick, or match-stick. This is dipped into the solution, and any excess is pressed ont against the side of the bottle. The lid is everted, as for examination (see page 57). The eye is turned strongly down while the applieation is made to the upper lid, and up for the lower lid. The application having been thus made to the exposed portion of the lid-surface, the lid is to be turned in, and with the eye still turned downward, the upper lid is pushed back as far as possible under the brow ; and a similar manipulation practiced for the lower lid. This makes the part of the lid reached by the mop a carrier of the remedy into the retrotarsal fold which eannot be so reached. The strength of an application ean be regulated largely by the dryness or saturation of the mop.

Solid applications to the conjunctiva are made after similar exposure of the membrane by eversion of the lids. The surface applied to the conjunetiva must be smooth, and not applied with unnecessary foree. To get a strong effect, the application must be made slowly to give the solid time to dissolve. Where a slight effect is songht, the surface may be dried or partly dried and touched lightly. 
Medicated gelatin disks are applied by dipping in water to soften their edges, and then with a camel'shair brush laying the disk on the scleral conjunetiva near the upper outer margin of the cornea. The eye is then to be closed for several minutes.

Applications to the conjunctiva in children, who are liable to resist, or by a sudden movement of the head to endanger the eye, should be made thus: The child is seated on the lap of the assistant or parent with its back to the surgeon, who spreads a towel or oil-eloth apron upon his knees, and then takes the child's head between them. The assistant controls the ehild's hands and legs; and the surgeon can hold the head perfectly secure and steady between his knees, while having both hands free for use in making the application.

Subconjunctival injections are made with the hypodermie syringe, throngh a fine needle. After the use of a local anesthetie, the conjunetiva is seized with fixation-forceps, just back from the corneal margin. The point of the needle is thrust fairly into the loose subeonjunctival tissue, and the required number of drops, usually 2 to 6 , gently expelled. The patient's head should be firmly supported. Some of the solutions used eause severe pain. The needle is quiekly withdrawn, and the lid pressed for a minute or so against the point of puncture to retain the fluid, and diffuse it throughout the adjoining loose tissue.

\section{ANTISEPTIC AND CLEANSING SOLUTIONS.}

Heat, the most generally reliable of antiseptic agencies, may be applied to solutions liable to be contaminated, by repeatedly bringing them to the boiling-point, or by boiling for five minutes whenever used in the eye.

Water is the most important ingredient of all antiseptic solutions. The thorough washing away of infectious materials, and of what may serve as a nidus for pathogenic bacteria, is far more important than the cliemical action of any solution that can be safely used in the conjunctival sae; for it is of prime importance that such 
solutions, which must be used freely to be effective, shall not be in any way injurious.

Hydrogen dioxid (peroxid of hydrogen) as furnished in 3 per cent. solution (Aqua Hydrogenii Dioxidi, U.S. P.) is the best agent to cleanse freely opened abscesseavities or sinuses, the liberation of oxygen wherever it comes in contact with pus foreing out the contents of small pockets and folds. It is also a powerful styptic.

Potassium permanganate is used in disinfecting the skin or conjunctival sac, and as a eleaning wash in purulent conjunctivitis. In the strength of $1: 2000$ it may be used freely, but strong solutions are quite irritant.

Formaldehyd in saturated 40 per cent. solution in water, called formalin, is a powerful antiseptic, but very irritant. Dilutions from $1: 20$ to $1: 200$ may be used to cauterize corneal uleers. Solutions of $1: 500$ to $1: 2000$ are effective in cleaning abseess-cavities and sinuses, and for disinfeeting the skin of the lids and the eyelashes prior to operation.

Formalin,

Distilled Water,

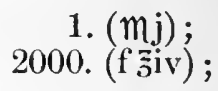

may be used to cleanse the conjunctiva in purulent conjunctivitis, although even this causes considerable smarting. A solution of 1:4000 is preferable for cleansing the conjunetiva prior to operation. Formaldehyd is the best chemical disinfectant for surgical instruments. (See Chapter XIX.)

Trikresol is one of the least irritating of reliable germieides. The following solution may be marle the menstruum for collyria, and will prevent their contamination by bacterial growths:

$$
\begin{aligned}
& \text { Trikresol, } \\
& \text { Distilled water, }
\end{aligned}
$$$$
\begin{aligned}
& \text { 1. }(\mathrm{mj}) \text {; } \\
& \text { 1000. (f } \check{\text { zij }}) \text {. }
\end{aligned}
$$

Or a solution of double that strength may be used to rinse the pipettes and to keep them in. 
Mercuric chlorid (bichlorid of mercury, eorrosive sublimate) may be used in washing out abscess-cavities and sinuses, and for cleansing the skin of the lids. The proper strength is
Mercuric chlorid (corrosive),
Distilled water,
1. (gr. j); 1000. ( $\mathrm{f} \tilde{\mathrm{s}} \mathrm{ij})$.

For use as a wash in the conjunctiva it should have a strength of not over 1:5000, and is best replaced by less irritant solutions. In the strength of $1: 500$ it is applied to the inner surface of the lids for trachoma.

Mercuric iodid (biniodid of mercury) is used as an antiseptic wash, in what is called Panas solution:
Mercuric iodid,
Absolute alcohol,
Distilled water,
1. (gr. $\left.\frac{1}{7}\right)$;
400. (f $3 \mathbf{j})$;
to make 20,000 . (f $\tilde{3}$ vi).

Mercuric cyanid is similarly employed in the strength
Mereuric cyanid,
Distilled water,

$$
\begin{aligned}
& \text { 1. }(\operatorname{gr} \cdot \mathrm{j}) ; \\
& 5000 .(\mathrm{f} z \mathrm{z})
\end{aligned}
$$

\section{CONJUNCTIVAL APPLICATIONS.}

Silver nitrate is used in the Créde method for destroying the virus of ophthalmia neonatorum, by dropping into the eyes of the new-born child a few drops of the following solution
Silver nitrate,
Distilled water,
2. (gr. x);
100. (f $\tilde{j} \mathrm{j})$.

A solution of the same strength, or two or three times this strength, is applied to the lids once every one or two days in purulent ophthalmia, during the period of profuse purulent discharge. After the application of one of these solutions the excess is often neutralized by a solution of sodium chlorid. But it is better to have no excess. The severity of the application is readily modified and con- 
trolled by the saturation of the cotton applicator. Numerous solutions of slightly different strengths are therefore unnecessary. One solution, weaker than the above, is useful for catarrhal eonjunctivitis, as the following:
Silver nitrate,
Distilled water,
1. (gr. ij);
250. (f $\mathrm{zj})$.

Organic salts of silver, recently introduced as substitutes for the nitrate, are less irritant ; but their therapentic value is not yet so well established. The principal one is protargol a combination of silver with a proteid base. It is stable and freely soluble.
Protargol,
Distilled water,
1. $($ gr. $x)$;
50. $(\mathrm{f} \tilde{\mathrm{s}} \mathrm{j})$;

may be used as a collyrium in conjunctivitis, or to cleanse the lacrimal sac in dacryocystitis. A 20 per cent. solution is used as an application to the everted lids in purulent eonjunctivitis.

Argyrol is the least irritant of the silver salts, its use commonly cansing no discomfort whatever. It may be employed in solutions of from 2 to 40 per cent. The solution should be fresh. It is said not to be reliable after two weeks.

Pyoktanin is a name applied to both the aniline dyes methyl violet (blue pyoktanin) and auramin (yellow pyoktanin). They are chiefly useful in ehronie inflammation of the lacrimal passages. The following may be used as a collyrium or to cleanse the passages:
Methyl violet,
Distilled water,
1. $($ gr. j) ;
1000. (f $\tilde{z} \mathrm{ij})$.

Boric acid solution is used slightly weaker than a saturated solution.

Boric acid,

Distilled water,

$$
\begin{aligned}
& \text { 1. (gr. xij) ; } \\
& \text { 40. (f } \vec{\jmath} \mathrm{j}) \text {. }
\end{aligned}
$$

It must be made sterile by boiling. When preseribed as 
a collyrium, rose-water or eamplior-water may be used. It is often preseribed in eombination with borax, thus :
Sodium biborate,
Boric acid,
Rose-water,
1. (gr. vj);
2. (gr. xij) ;
80. ( $\mathrm{f} \tilde{\mathrm{z}} \mathrm{j})$.

Sodium chlorid solution is used to cleanse the eye, wash out the anterior chamber, and to float epithelial grafts for plastic operations. It is
Common salt,
Distilled water,
1. (gr. iij) ;
160. (f $3 \mathrm{j})$.

\section{DUSTING POWDERS.}

Iodoform, for use in the eye, should be in impalpable powder. It is dusted in as a dressing for wounds or after operations.

Boric acid, aristo1, and acetanilid may be similarly used. They are free from the disagreeable odor of iodoform, but it is not certain that either is as beneficial as iodoform.

\section{CAUSTICS, ASTRINGENTS, AND IRRITANTS.}

Arsenic, for the destruction of malignant growths, may be used:
Arsenous acid,
Creasote,
1. (gr. j) ;
60.(f $3 \mathrm{j})$.

This must not be used on a large surfaee. It requires three or four days to do its work, and is quite painful; it is to be followed by poulticing until the slough separates.

Zinc chlorid is used for the same purpose as the above.

Zine chlorid and wheat flour, equal parts, are mixed with a little water to form a thiek paste. It may be spread on the walls of the orbit, when all oozing has stopped, after removal of the orbital contents for a malignant growtl.

Copper sulphate is used in erystal. The erystal 
may be cut or ground into the more convenient form of a pencil. It should be rinsed and wiped off after using, and care taken to see that it always presents a smooth surface. If allowed to remain damp, it quickly roughens.

Lapus divinus is composed of copper sulphate, potassium nitrate, and alum, each equal parts, fused together with 2 per eent. of their united weight of camphor.

Mitigated silver nitrate stick is made by fusing
Silver nitrate,
1 part.
Potassium nitrate,
2 parts.

Alum crystal, preferably reduced to the more convenient form of a stick, is an efficient astringent, to be applied to the everted lids for ehronic eonjunctivitis. It is much less irritant than the substances mentioned above.

Solutions of
Alum,
Distilled water,
1. $(\mathrm{gr} . \mathrm{xx})$;
25. (f $\mathrm{jj})$;

are also useful in the same cases of chronic conjunetivitis.

Tannin dissolved in glycerin is a most valuable loeal application for phyletenular conjunetivitis, and the late stages of trachona.
Taunin,
Glycerin,
1. $(3 \mathbf{j})$;
8. $(\mathrm{f} \tilde{\text { sj }})$,

is the proportion commonly used. Half this strength will sometimes be equally effective; and the official glycerite (U.S. P.) of twice the strength may be employed.

Zinc sulphate, the active ingredient of many popular collyria, has been found especially valuable in diplococcus eonjunctivitis. It may be used in
Zine sulphate,
Distilled water,
1. (gr. j) ;
200. (f ziij).

Two or three drops may be instilled once or twice a day. Solutions either stronger or weaker than this may be employed. 
Zinc chlorid is recommended by Gifford for diplococeus conjunctivitis in the strength
Zinc chlorid,
Distilled water,
1. (gr. j);
500. (f $\mathrm{sj})$;

to be used like the zine sulphate solution.

Boroglycerid (glyceritum, boroglycerini, U.S.P.) is used in trachoma and chronic catarrhal conjunctivitis, usually of full strength, but it may be diluted with an equal quantity of glycerin.

Iodin dissolved in glycerin or petrolatum is to be applied on cotton to the everted lids for trachoma.
Iodin,
Glyeerin,
1. (gr. vj) ;
75. $(\mathrm{f} \overline{z j})$.

Jequirity, the bean of the abrus precatorius, is used to excite acute inflammation in trachoma, either by dusting on the everted lids an extremely fine powder, or by painting them with a 2 per cent. infusion.

\section{OINTMENTS.}

Yellow oxid of mercury is an impalpable powder prepared by precipitation. Chemically, it is mereuric oxid, the same as the red oxid, which is unsuitable for application within the eye because of its crystalline character. The official ointment (U.S. P.) is too strong (10 per cent.), but may be used properly diluted.

$$
\begin{array}{ll}
\text { Yellow oxid of mercury, } & \text { 1. (gr. j); } \\
\text { Petrolatum (soft), } & 60 .(\text {.j) } ;
\end{array}
$$

is a good strength to begin with. But it may do best if only half this strength, or of considerably greater strength. The preparation is liable to alter by prolonged exposure to light.

Boric acid ointment is of value, with massage of the lids, for trachoma. It may be made:

Boric acid,

Lanolin (Adeps Lame Hydrosus,

1. (gr. vj);

$$
\text { U.S. P.) 10. (3j). }
$$


Iodoform ointment may be used instead of the powder :
Precipitated iodoform,
Petrolatum, soft,
1. $($ gr. vj) ;
10. $(3 \mathrm{j})$.

Zinc ointment is an excellent protective; but for use about the lids the official ointment (U. S. P.) of 1 to 5 may with advantage be diluted with once or twice its weight of lanolin.

\section{ANESTHETICS.}

General anesthesia is now required in ophthalmic surgery mainly for entcleation of the ey eball, removal of orbital tumors, for important operations on inflamed eyes, as iridectomy for glaucoma, or extensive use of the cautery. Ether is the safer anesthetic, except for brief operations, where somnofor'm will produce sufficient anesthesia without requiring to be repeated. Where the cautery is used, chloroform must be employed, because it is not. inflammable.

Local anesthesia sufficient for most operations on the eye is produced by the instillation of cocain or holocain. For foreign bodies in the eornea, pterygium and similar operations involving only superficial struetures, the anesthesia thus produced is perfect. For operations on the ocular muscles only the pull on the tendon is necessarily painful. Chalazion operations, and others involving the lids, are not rendered painless by such instillations. Cataract operations, and iridectomies on eyes free from inflammation, usually canse little discomfort. For these latter operations coeain should be first instilled about fifteen minutes before commencing the operation, and the application repeated once or twice at intervals of five minutes. For more superficial operations the time after the first instillation need not be more than five minutes; operation should be completed in about twenty minutes after the last application, since by that time anesthesia is diminished. Cocain causes drying of the cornea and softening of the eyeball. Holocain is free from the above disadvantages, and it produces anesthesia 
more quickly, but its influence is more brief. Cocain constricts the vessels and lessens hemorrhage, holocain does not.

Cocain may be used in solutions of from 2 to 10 per cent., the stronger for operations on the lids, or upon inflamed eyes, on which it produces comparatively little effect. A good solution for general use is

Cocain hydrochlorate, Distilled water,

5. (gr. iij);

100. (f $\mathbf{3 j}$ ).

It should be fresh or freshly sterilized with heat.

Holocain is used in

Holocain,

Distilled water,
1. (gr. j) ;

100. (m. 100).

It is decidedly antiseptic, such a solution inhibiting and destroying the pus-organisms coming in contact with it.

Eucain is a local anesthetic which causes too much irritation when applied to the conjunctiva, to be generally used in ophthalmic surgery.

Stovain is used in 2 to 4 per cent. solutions, which are not damaged by boiling. It does not produce anemia of the part, but may cause disturbance of the corneal epithelium.

Alypin is used in 2 to 5 per cent. solution, which is not impaired by boiling ten minutes.' It produces superficial hyperemia of the parts, and may cause corneal transudation if used freely.

Infiltration anesthesia is produced by injecting into the part a weak saline solution, as one of sodium chlorid 1 ; cocaine hydrochlorate 1 ; and distilled water 500. A drop or two is injected into the skin, causing a small wheal. The needle is then withdrawn, and reinserted in the edge of the wheal, which is already anesthetic. A drop or two more is injected here, and thus the area of anesthesia extended until sufficiently large. For decper anesthesia, deeper injections are made through this area. 
In the thin vascular tissue of the lids, the injections must be made quickly to seeure satisfactory anesthesia.

\section{MYDRIATICS.}

Cocain hydrochlorate is the best mydriatic for producing brief dilatation of the pupil in the dark room. It gives wide dilatation in the dark room while not destroying the reaction to light, or materially lessening the power of accommodation; so that it causes the patient little annoyance. It produces wider dilatation of the senile pupil than the other mydriaties, and with much less risk of eausing glaucoma. A drop of the ordinary anesthetic solution may be used from 40 to 50 minutes before it is required to have the pupil dilated. Its influence passes off in twelve hours.

Euphthalmin hydrochlorate in 5 per cent. solution dilates the pupil almost as much as cocain, and produces rather more weakening of the accommodation. The dilatation it causes is maintained in strong sunlight, and recovery from its effects requires about twenty-four hours. It is the best brief dilator of the pupil for examination in a strong light.

Homatropin makes a good dilator of the pupil; the effect of which passes off in about one day if used in the following solution :
Homatropin hydrobromate,
Distilled water,
1. (gr. j) ;
500. $(\mathbf{f} 3 \mathbf{j})$.

Cocain and homatropin make a most satisfactory mydriatic in this combination:

Cocain lyydrochlorate,

Homat. lyydrobromate,

Distilled water,
4. (gr. j);
1. (gr. $\left.\frac{1}{4}\right)$;
1000. (f ziv).

Atropin is better where it is desired to keep the pupil continuously dilated, as for nuclear cataract.
Atropin sulphate,
Distilled water,
1. $\left(\operatorname{gr} . \frac{1}{4}\right)$;
2000. (f $3 \mathrm{j})$. 
A single drop instilled once every two or three days will answer the purpose. (Sec also Cycloplegics.)

\section{CYCLOPLEGICS.}

Homatropin is the best cycloplegic for diagnostic purposes. The solution used is :

Homatropin hydrobromate,

Distilled water,
1. (gr. iij);

40. (f $3 \mathrm{ij})$.

A drop of this solution is instilled in the eye every five minutes until four to six have been thus applied. The maximum effect is produced in one hour. Recovery begins an hour or two later, and is usually complete in forty-eight hours. The instillations should be carefully made by the surgeon, or a trained assistant. So used, homatropin is a reliable cycloplegic not likely to cause constitutional symptoms.

Atropin sulphate exerts the most prolonged control over the ciliary muscle. It is therefore fitted for use when the accommodation is to be kept continuously in abeyance, and the éye given a period of mydriatic rest. It is especially indieated when the instillations are to be made by unskilled persons, who may fail to make some of them effective. The strength used for this purpose is :
Atropin,
Distilled water,
1. (gr. iv);
120. (f $3 j)$.

One drop of this is instilled three times a day.

Duboisin, hyoscyamin, and scopolamin salts are used for practically the same purposes as atropin. They resemble each other very closely in their action, and have the special advantage over atropin of a shorter period of recovery. Weight for weight they have more than twice the physiological effect of atropin. The usual solutions are :

Hyoscyamin hydrobromate,

Distilled water,

1. (gr. j) ; 300. $(\mathrm{f} 3 \mathrm{v})$; 
Or
Duboisin sulphate,
Distilled water,
1. (gr. j);
240. (f ziv).

The above are used as the cyeloplegic atropin solutions, one drop in the eye three times a day.
Scopolamin hydrobromate, Distilled water,
1. (gr. ss); 1000. (f $\tilde{j}$ ) ;

is used like the homatropin solution, two or three drops being instilled, a drop at a time with intervals of five or ten minutes. Hyoscyamin and duboisin may be used similarly. If carefully applied, complete paralysis of accommodation is thus produced, with less risk of constitutional symptoms than with stronger solutions, and recovery occurs in from four to seven days.

Stronger solutions are required to break up adhesions of the iris to the lens-capsule, and to maintain dilatation of the pupil in iritis as:

Atropin sulphate,

Distilled water,

Or
1. (gr. j) ;

60. (f $3 \mathrm{j})$.

1. (gr. j);
120. (f, $3 \mathrm{ij})$.

One of these is to be instilled every five minutes until the pupil is dilated, or until symptoms of mydriatic intoxication begin to appear. Eversion of the puncta will hinder the appearance of the toxic symptoms, and two or three instillations of a 5 per cent. solution of eccain will increase the mydriatic effect.

Gelatin Disks.-Homatropin is used, associated with cocain, in gelatin disks. Used in this way it produces more effect than the same amount of homatropin used alone. Each disk contains usually onc-fifticth of a grain of each drug. 'Two disks are placed in the eye, fifteen to thirty minutes apart and allowed slowly to dissolve.

Other mydriaties and the myotics are also applied in the same way. But the gelatin disks are not generally to 
be preferred to solutions. The disks or lamellæ commonly used contain :

Homatropin hydrobromate, $\frac{1}{500}$ or $\frac{1}{50}$ gr. ;

Atropin sulphate,

Cocain hydrochlorate,

Physostigmin sulphate,

Pilocarpin nitrate, $\frac{1}{500}, \frac{1}{500}$, or $\frac{1}{2} \frac{1}{00} \mathrm{gr}$. ; $\frac{1}{200}$ or $\frac{1}{50} \mathrm{gr}$; $\frac{1}{1000}$ or $\frac{1}{250}$ gr.; $\frac{1}{500} \mathrm{gr}$.

A single disk may be used instead of a drop of one of the solutions previously mentioned.

\section{MYOTICS.}

Physostigmin or eserin (sulphate or salicylate) is a powerful myotic capable of neutralizing the mydriatic influence of five times its weight of homatropin. In young persons it can cause very painful cramp of the ciliary muscle, and sphincter of the pupil, and on that account must be used with caution. For instillation in corneal disease, or to contract the pupil after simple extraction of cataract it may be used in solution of

$$
\begin{aligned}
& \text { Physostigmin salicylate, } \\
& \text { Distilled water, }
\end{aligned}
$$

To contract the pupil in glaucoma, instillations of this solution may be first tried; and then if necessary stronger solutions may be employed up to 1:120 (gr. iv to $\mathrm{f}$ 亏j). The weakest solution that will produce moderate contraction of the pupil is the one to be chosen. As an ocular tonic, still weaker solutions are recommended as
Physostigmin,
Distilled water,
1. $\left(\right.$ gr. $\left.\frac{1}{20}\right)$;
$10,000$. ( $\mathrm{f} 3 \mathrm{j})$.

Pilocarpin hydrochlorate is a weak myotic, being able to neutralize only one-fourth its weight of homatropin. It is used in the proportion of
Pilocarpin hydrochlorate,
Distilled water,
1. $($ gr. j) ;
500. (f $3 \mathrm{j} \mathrm{j})$.

It may be instilled three times a day or less frequently to contract the pupil in cortical cataract, or as a local tonic. 


\section{MISCELLANEOUS SOLUTIONS.}

Extract of suprarenal body is replaced by preparations of its active principle, as adrenalin chlorid, etc. Adreualin may be used in solutions of $1: 1000$ or weaker. Intraocular liemorrhage and acute glancoma have been aseribed to it.

Dionin may be used once in twenty-four hours or longer, in powder placed in the conjunctival sac, or in solutions of 0.5 to 10 per cent. in distilled water. It eauses burning, followed by hyperemia and chenosis.

Fluorescin solution is used to detect the location and extent of corneal ulcers. It contains

$\begin{array}{lr}\text { Fluorescin, } & 1 . \\ \text { Sodium biearbonate, } & 2 . \\ \text { Distilled water, } & 100 .\end{array}$

A drop of this, plaeed in the conjunctival sac, quickly stains green all tissue exposed by the loss of epithelium.

\section{DRUGS USED FOR THEIR SYSTEMIC INFLUENCE.}

Mercury most quickly produces its specific effects when given by inmetion. Mlercurial ointment (unguentum hydraigyri, 50 per cent. of metallic mercury) should be rubbed into the thinner parts of the skin, to the amount of 2 to 4 grammes (3ss to j), once or twice daily. For exactness, it may be preseribed with each dose separately wrapped in waxed paper. The rubbing should be with the slightest friction, and is best done with a glass rod. It should be continued until the ointment has largely disappeared, at least fiftcen minutes. If the friction causes irritation, the inunction should not be repeated upon the same part for two or three days.

Calomel is the best form in which to give mereury when it is desirable to obtain a purgative, as well as a specific, effect. It is given in doses of 1 centigramme (gr. $\left.\frac{1}{6}\right)$ every two to six hours.

The administration of moreury should be promptly suspended on the appearance of evidence of its action 
about the mouth. After these symptoms have subsided, one of the following slower methods may be resorted to :

The yellow iodid (green iodid) is best given in pill, in doses of $\frac{1}{3}$ to 2 grains, three times a day, often combined with opium.

Corrosive sublimate (mercuric chlorid) may be given in solutions of potassium iodid (which it converts into the red iodid of mercury), in doses of $\frac{1}{60}$ to $\frac{1}{12}$ of a grain, three times a day.

Mercury may also be given hypodermically, or by deep intramuscular, or intravenous injections, onee every two or three davs. These are to be resorted to when other methods of administration fail to eheck the disease, or provoke serious mereurial symptoms.

Potassium iodid, to be effective in the lesions of tertiary syphilis, or in optic neuritis, must be given in large doses. The rule is to eommenee with a dose of 10 or 15 grains, given three or four times a day, and to rapidly inerease the close until the desired effeet is produced, or the physiologic action of the drug is manifest. This is conveniently managed by giving the patient the drug in concentrated solution,
Potassium iodid,
Distilled water,
1. $(\tilde{3} \mathrm{j})$
2. (f $3 \mathrm{ij})$;

begimning with twenty or thirty drops, and adding two drops to the dose each day, or at each dose, according to the urgency of the ease. When the eoryza, gastrie disturbance, eruption, or persistent taste of the drug is noticed, its administration may be suspended for a day or two, and then resumed in slightly diminished dose.

Strychnin, when given for toxic amblyopia or optic atrophy, is most effective administered in ascending doses, or those approaching the physiologieal limit. It is most safely given in solution, or in carefully prepared grannles. Commeneing with a dose of $\frac{1}{24}$ of a grain, this may, from time to time, be increased to $\frac{1}{20}, \frac{1}{16}, \frac{1}{12}, \frac{1}{10}$, and sometimes to $\frac{1}{8}, \frac{1}{6}$, or even $\frac{1}{5}$ of a grain, three times a day. The patient must be kept on his guard against an exees- 
sive dose; and each time a new solution is preseribed the dose should be at first slightly diminished. When stiffness of the neek or jaws is noticed, or ordinary movements produce unpleasant jerking within an hour or two after the taking of the medicine, the dose should be slightly diminished.

Hypodermically, the dose is about the same as by the mouth, but it is administered only once a day. It is gradually increased from day to day until the limit of tolerance is reached.

Pilocarpin, given to producc sweating, in detachment of the retina, choroiditis, and vitreous opacity, is best administered hypodermically. From 2 to 10 minims of the following solution are injected :

Pilocarpin hydrochlorate (or nitrate), 1. (gr. ij);

Distilled water, 30 . (f $3 \mathrm{j})$.

The patient is then kept warmly covered up in bed for three or four hours. This may be repeated daily. 


\section{CH A P T E R X IX.}

\section{COMMON OPHTHALMIC OPERATIONS.}

\section{GENERAL CONSIDERATIONS.}

Preparation of the Patient.-For office operations the eye should be thoroughly cleansed with boric acid solution, the lids, lashes, and adjoining parts of the face having been previously serubbed with soap and water. If there be lacrimal or other septic disease it should generally be treated first. But in emergency-operations, as removing a foreign body, or iridectomy for prolapse of the iris, we may have to be content with thoroughly washing out the lacrimal passages before cleansing the eye. A weak solution of mercuric chlorid, 1:5000, may be used for this purpose, but thoroughness in the washing is to be mainly relied on.

House patients should be accustomed to their surroundings, spending one day in the hospital before the operation, sliould have the bowels freely opened, a general bath, and the conjunctiva cleansed repeatedly with boricacid solution. The lids and neighboring parts and, especially the lid-margins and lashes, should be thoronghly cleansed with soap and water. Any conjunctivitis should be treated until the eye is free from discharge or undue redness, before undertaking a eataract or plastic operation. In cases of lacrimal disease that cannot otherwise be cured, it may be best, as a preliminary measure to obliterate the lacrimal sac. When there is lacrimal disease, and no time to treat it, as in acute glaueoma, the sae may be thoroughly washed out and the puncta temporarily obliterated by tonching them with the actual or galvanic cautery. They can be reopened after the healing of the corneal wound. Operations that can be delayed should not be donc during acute bronchitis, or temporary depression of the general health from any cause. But extreme age, or feeble health is rarely a positive bar to success in ophthalmic operations. 
Preparation of the Surgeon.-Septie eases should not be seen for several hour's before operating. The hands of the operator and his assistants should be thoroughly scrubbed with soap and hot water, the nails, ete., carefully eleaned, and the scrubbing repeated. They must then be kept from touching surfaces that have not been rendered similarly aseptic.

If the operation is one not frequently done, the operator should go carefully over every step of it in mental review, or previously practice it on the eyes of lower animals. He should see that every instrument and applianee is in place, earefully try the light that is to be used, and adjust seat or position so that every necessary movement may be made with the greatest ease and freedom, and without danger of jostling. When operating without an aceustomed assistant, it is best to have all instruments within the surgeon's reach and to make the temporary assistant's duties as few and definite as possible.

Preparation of the Instruments, etc.-After use, and before it has liad time to dry, every instrument should be earefully cleaned with hot soap and water, special attention being given to all joints, and to rough instruments to insure that they retain no mass or elot of infective matter. This should be attended to by the surgeon himself, or a specially trained nurse or assistant. The instruments should be kept in a tight case, with powdered paraform, which gives off constantly formaldelyyd vapor. Instruments used for eases of suppuration and trachoma should be kept separate from those used for aseptic operations. Before using, the instruments should be again washed, and the jointed and rough instruments boiled for two minutes. Knives and other cutting instruments are to be dipped in boiling water. The instruments may remain in boiled water, or can be loosely wrapped in sterile absorbent cotton until wanted.

Another method is, after eleansing, to place instruments that cannot be boiled in a solution of formaldehyd 5 to 20 per cent. to which has been added 3 per cent. of borax. In this they remain continuously until required for use. 
They are then rinsed in a boric acid solution and wiped with cotton to remove any deposit, and are ready for use.

Position and Illumination.-For operating on the eye the patient's head should be about as high as the lower part of the surgeon's chest, firmly supported, and with the faee directed upward. This position may for minor operations be attained in a chair, the head resting on a head rest, or against the surgeon's chest. But for important operations it is best seeured upon a table, the height of which must be adjusted according as the surgeon prefers to sit or stand while operating. In operating upon a bed, the patient must be so that the head of the bedstead will not interfere, as across the bed or with his head toward the foot of the bed. The head must be supported on a firm hair pillow under which a board may be plaeed to give additional steadiness.

Generally the light should come from the side of the eye operated on. The best light is the brightest that can be obtained short of direct sunlight, coming from rather a small space, and in such direction that the surgeon shall not be baffled by annoying reflections from the cornea. The conditions to be met are essentially those of a good oblique illumination. An eleetric lamp furnished with shade and condenser is the most manageable source. But with the patient brought close to a window that opens to clear sky, an excellent illumination can be arranged by diffuse daylight. The patient should be brought into position, and the light carefully tested and adjusted before beginning the operation.

\section{Retraction of the Lids and Fixation of the Eye-} bal1.--The patient should steadily fix his gaze upon the proper designated spot; and by so doing he will lessen the discomfort of operations done without general anesthesia. For many operations retraction of the lids and fixation are best accomplished with the operator's left hand. Standing behind the patient, the fore-finger retracts the skin of the upper lid, and fixes it by pressure against the upper margin of the orbit; while the middle-finger similarly fixes the lower lid against the lower orbital 
margin. This secures retraction of the lids without pressure on the globe, and the traction on the conjunctiva tends to steady the globe. To fix the globe more firmly, pressure must be made with the fingers above and below the cornea.

When the left hand will be otherwise employed, the lids must be retracted by a stop-speculum, which is

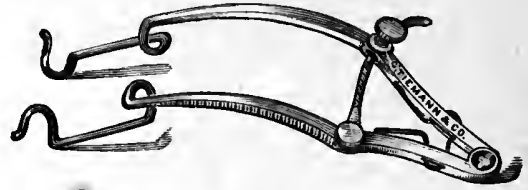

Fig. 151.-Stop-speculum.

slipped between them and then opened as widely as it can be without causing pain. The best form is shown in Fig. 151. Or the lids may be retracted by an assistant using for the upper lid a retractor such as is shown in Fig. 152. To protect the eyeball during operations on the lids the lid-spatula shown in Fig. 156 is employed.

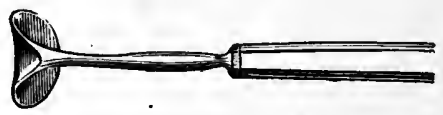

FIG. 152.-Lid-retractor.

When pressure on the globe must be avoided fixationforceps (Fig. 153) must be used. For use on the conjunctiva their jaws should be serrated rather than toothed,

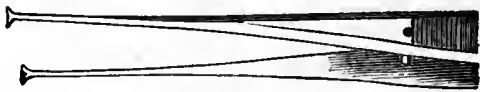

FIg. 153.-Fixation-forceps for seizing the conjunctiva.

and they are to be applied as close to the limbus as possible where the conjunctiva is most firmly connected with the sclera. They should make no pressure on the globe. 
For siezing upon the firm deeper tissues, fine-toothed foreeps are made (Fig. 154).

Sponging for eye operations is best done with masses of absorbent cotton moistened with boric acid solution,

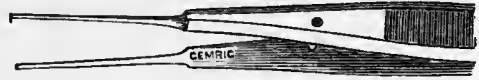

Fig. 154.-Fixation-forceps for holding deeper firm tissues.

and then squeezed dry as possible. These may be wrapped on sticks six or eight inches long, before moistening, to enable the assistant to keep his hands out of the way. Blood may also be washed away with solutions of boric acid or common salt.

\section{DRESSINGS.}

Simple Dressing.-To give the eye rest, protect it from slight temperature changes, exclude mechanical, chemical and bacterial irritants, and provide for the absorption of the slight discharge that escapes between the lids with the least discomfort, without pressure and without undue local heat, are the indieations to be met by the dressings after an ophthalmic operation.

The author most frequently employs the following: A few layers of gauze, large enough to cover the orbit, are laid upon the elosed lids, and on these a sufficient mass of absorbent cotton. This is retained by one or more strips of adhesive plaster, one inch wide, extending from the center of the forehead to the cheek, with perhaps one strip from the temple to the opposite side of the nose.

If the other eye is to be elosed a similar dressing is to be placed over it. If it is desired to have a moist dressing, the gauze may be covered with surgical lint dipped in boric acid or other solution, and a layer of oiled silk or rubber protective added over the cotton. When it is important that the lashes should not stick to the dressing, it may be smeared with soft petrolatum, or boric acid ointment. 
Pressure-bandage.-When required, pressure is made by means of a bandage. A large wad of absorbent cotton is earefully adjusted to properly distribute the pressure; then a roller of elastic flannel, 2 inches wide and 5 yards long, is started upon the oceiput, earried under the mastoid and ear on the side of the affected eye, up over the eye, high on the temporal region of the side of the head, and down to the point of starting. The bandage will be most firm if every alternate turn is earried above the ear on the affected side and low on the opposite side of the head. It should be pinned at the points of intersection. The bandage will not retain its position well unless it does make some pressure. It is therefore unsuitable for use after many operations.

To seeure simple elosure of the lids, isinglass plaster is used. A strip of the plaster $\frac{1}{2}$ inch wide is placed on the palpebral fissure, and one or more strips at right angles to this, extending from just under the brow down to the eheek. This dressing, when dry, is likely to eause some diseomfort. Only the thinnest and most flexible plaster answers the purpose properly.

Ring Dressing. - After plastic operations, especially after skin-grafting, it is best to make a ring of absorbent cotton, large enough to include the whole field of operation, and thiek enough to support the dressing without its coming in contact with the new-formed surface.

The Liebreich bandage was originally a light knitted bandage secured by tapes; . but the name has come to be applied to varions forms of thin bandage fastened by tapes. It may be single (for one eye) or donble (for both eyes). It is convenient, when the dressing must be removed frequently to instil drops or to eleanse the eye.

Mask Protector.-To protect the eye from injury by accidental strokes during sleep, as after cataract extraction, a woven wire mask, or aluminum protector, is sometimes used.

Eye-shades should be light, and allow sufficient air to enter around them to keep the covered eye cool and 
dry. A nice one is made of aluminum covered with silk. Buller's shield, to exelude infection while permitting the use of the eye, is deseribed on page 249.

\section{HEMOSTASIS.}

In ophthalmic operations and for wounds about the eye, it is rarely needful to ligate bleeding vessels. Pressure soon controls bleeding; so does hot water (see page 503). Solutions of cocain greatly diminish the bleeding when that drug is used as a loeal anesthetic. This action adds greatly to the value of eocain for operations for pterygium, squint, ete., where bleeding nay cause embarrassment. Hydrogen dioxid quiekly ehecks bleeding, but as the froth it makes would equally embarrass the operator, it generally eannot be used until the close of the operation. Extract of suprarenal body applied before proeeeding to an operation will greatly diminish the bleeding.

\section{ABSTRACTION OF BLOOD.}

The loose tissue of the lids is so liable to excessive swelling after a leech-bite, that lecehes are usually applied to the temple, which may be prieked until blood appears to induce them to bite. Each American leech will draw abont one fluid-dram of blood, the European leeeh four times as much.

The artificial leceh consists of a circular knife made to eut with a rotary movement; and a glass eylinder that can be exhausted of air by a screw-piston. From one to four ounces of blood may be taken from the temple with advantage. In severe ocular inflammations this may give more relief from pain than any other measure.

\section{OPERATIONS UPON THE LIDS.}

The removal of displaced lashes is commonly effected with forceps such as are shown in Fig. 155. The tips should elose upon one another with perfect aceuracy. To see the fine white lashes which are most frequently at fault, oblique illumination should be employed. 
The binocular magnifier mounted on a head-band is also of great assistance (sec page 69).

For the permanent destruction of the lashes, electro-
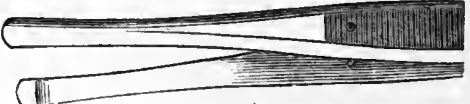

Fig. 155.-Epilation-forceps.

lysis is to be practiced by thrusting a fine needle, conneeted with the negative pole of the battery, as aceurately as possible to the root of the hair (the positive pole being

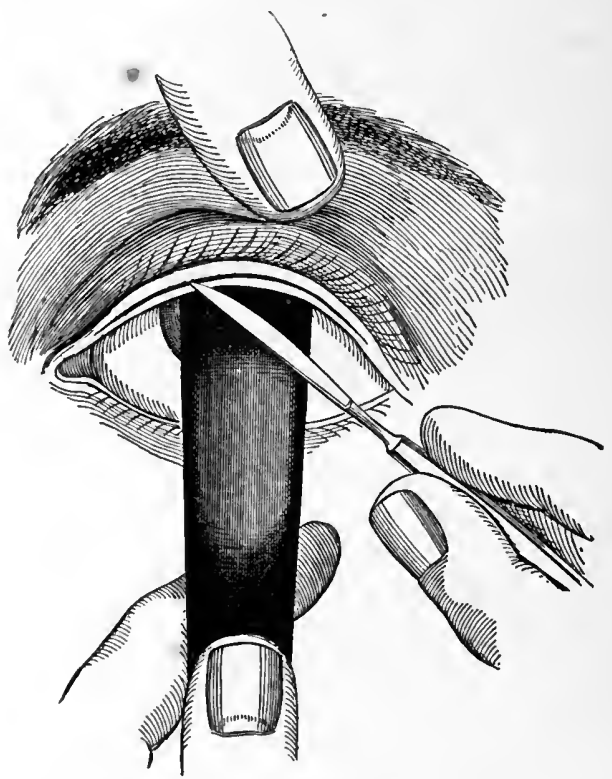

FIG. 156.-Making the intermarginal incision (Hotz).

held in the hand), and allowing a current of 2 or 4 milliamperes to pass through it for five to twenty seconds. Minute bubbles of gats escape, and the hair should be found loose in its follicle. 
When the lid has become greatly distorted by cicatricial changes, as after trachoma, so that restoration of the lid-margin to good position is impossible, the best result may be obtained by excision of the hair-bulbs, "scalping." The "intermarginal incision" (see Fig. 156) is made just back of the hair-bulbs, and another incision parallel to it, and 2 or $3 \mathrm{~mm}$. above it, on the surface of the lid. The strip of tissue between, including the hair-bulbs, is removed, and the skin and conjunctiva brought together by fine sutures. The tract is dusted with iodoform and the eye covered with a light dressing.

Operations for entropion and distichiasis, bearing the names of their originators and modifiers, are sufficiently numerous. And several of them possess particular advantages for certain cases. The most generally applicable for entropion of the upper lid is the following: The upper lid is put upon the stretch, and an incision is made parallel to the lid-margin, and so far below the upper border of the cartilage that when drawn up to it the lid-border will be pulled upon sufficiently to evert all the lashes. The tissue covering the cartilage, including the fibers of the orbicularis muscle, is then carefully removed. The skin attached to the lid-margin is then drawn up and fastened to the upper margin of the cartilage by three sutures, which are afterward carried through the other lip of the wound, which is thus closed. Iodoform is dusted on the line of incision and the whole covered with a light dressing. After four or five days the sutures are removed and all dressings omitted.

If such a readjustment would cause much tension on the skin of the lid-margin, it is well to begin by making the "intermarginal incision" behind all the lashes; and when this is made to gape, by tightening the sutures that close the incision at the upper border of the cartilage, to transplant into it a sufficient strip of mucous membrane from the lower lip, which may be held in place by sutures passed through it at either end. Frequently the intermarginal incision and mucous graft alone will be sufficient.

Entropion of the lower lid due to redundant skin is 
relieved by excision of an appropriate piece of skin and the bringing it together with sutures, or by producing cicatricial contraction of the skin with caustic potash (see page 456).

Canthotomy is done to extend temporarily the palpebral fissure, to prevent irritating pressure and secure more complete eversion of the lids in conjunctivitis, or for the relief of fissure of the skin at the outer canthus. One blade of a pair of strong blunt-pointed scissors is introduced into the conjunctival sae at the outer canthus,

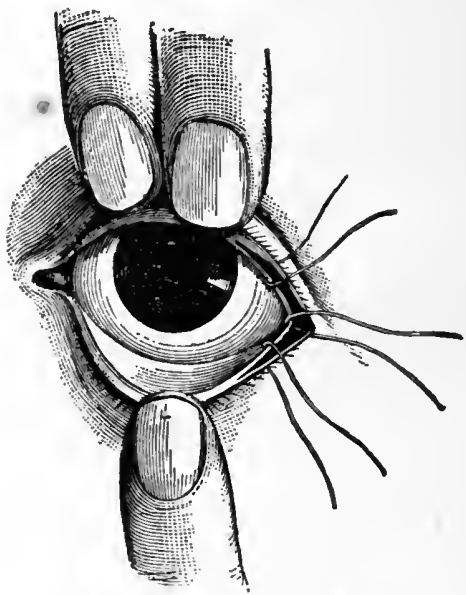

FIG. 157.-Canthoplasty (Meyer).

the other blade being placed on the skin near the margin of the orbit. The inner blade must be made to press exactly into the canthus, so as not to cut either lid; and while the lids are stretcher apart with the thumb and finger, the tissnes are divided at a single stroke. The incision may also be made with a scalpel or bistoury.

Canthoplasty is done to permanently extend the palpebral fissure. After the incision for canthotomy above described, the conjunctiva and skin are brought together, so as to cover the raw surfaces and prevent their remion. 
Three sutures are required. One is placed at the termination of the incision, the extreme angle between the lids, where it is most important to secure accurate junction of the skin and eonjunctiva, and one on either side of this on the upper and lower lids. The sutures should take a good hold on the conjunctiva, emerge near the conjunctival edge of the raw surfice, re-enter near the skin-margin, and take a good hold on the skin without much of the deeper tissures. The eut with the stitches introduced is shown in Fig. 157. It is sometimes well to undermine the skin somewhat to make it elosely meet the conjunctiva. Iodoform may be dusted upon the wound and a light dressing applied to cover it.

The effeet of a eanthoplasty may be increased by division of the tarsal ligament. This is put upon the stretch by pulling the upper lid toward the nose, and then divided by fine-pointed seissors, the points being introduced between the skin and conjumetiva directly upward.

Division of the upper lid is practised to relieve pressure and facilitate the treatment of purulent ophthalmia, or to facilitate plastic operations in the upper conjunctival sae, and prevent subsequent displacement. With blunt strong scissors the lid is divided vertically near its center, and each flap is turned up and stitehed to the brow by a suture passing through its angle. After the purpose of the operation has been served, the edges of the lid are freshened and carefully brought together with fine sutures.

Union of the lids (tarsorrhaphy) may be done at the outer eanthus to shorten the palpebral fissure, for passive ectropion of the lower lid, or lagophthahmos. For this purpose the lids are drawn together as desired and the point for the new canthus marked on each. From this point outward, a narrow strip of tissue, eontaining the bulbs of the lashes, is removed from each lid. This strip may include more of the skin-surface of the upper lid and more of the conjunctival surface of the lower. The two lids are then brought accurately together by sutures, 
which must inchude the thickness of the lid and be left in place until mion is firm.

To protect the cornea in exophthalmic goitre, the central portion of the lids may be united. In this case the lashes are left, in the hope that union need be only temporary, The freshened surface includes not less than half of the inner edge of the lids; and the stitches must be deep and well drawn up to secure a sufficiently firm union, to be of any value.

To secure immobility of the parts for a few days, as after a wound or plastic operation on the lids, the lidmargins may be stitched together without freshening their edges, care being taken to avoid the rubbing of the stitches against the cornea.

Ectropion Operations.-Ectropion, due to thickening of the conjunctiva, usually affects the lower lid. It may be treated by removal of the conjunctival and subconjunctival tissue by a $\mathrm{V}$-shaped incision and bringing the edges together by sutures. If the deformity be too great for that, the incision may include the whole thickness of the lid and should be brought together with

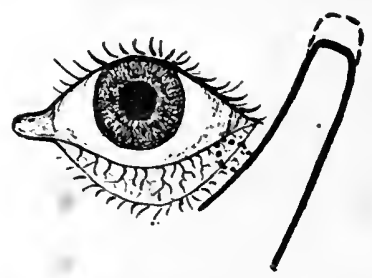

FIG. 158.-Argyll Robertson's strap-operation for ectropion of the lower lid.

a fine hare-lip pin and sutures. A safer operation, if applicable, is the removal of a triangular piece at the outer end of the lid with the formation of a strap running up on the temple, as illustrated in Fig. 158. The strap is first ent as indicated ly the heavy line, then the triangle inchuled by the dotted lines is excised and the lid drawn up in place by the strap and the piece of skin 
covered by the strap (see broken line) is removed. The parts are then brought together with sutures. Eetropion, through the dragging of scar-tissue, requires some form of plastic operation.

Plastic Operations on the Lids.-The replacement of tissue to remedy distortion of the lids caused by loss of tissue gives scope to the widest experience and the most ingenious adaptation of means to ends. It should be undertaken only after eareful study of many different plans of procedure, since any of these may give hints of especial value in the particular case. It is here only possible to indicate a few general principles. A successful result can only be attained by permanently relieving the lids of all abnormal tension. They have no support that enables them to resist even a slight continuous traction. Skin to replace the lids must be extremely thin and flexible, or the operation substitutes one deformity for another. On this account, skin from the immediate vicinity of the lids, or from the temple, is better than from other parts. Cicatricial skin, if its vitality is good, is also well suited for the purpose (Hotz). The desirable skin may be brought in by sliding flaps. The full thickness of the skin may be transplanted without pedicle from distant parts, as the inner surface of the arm, but there is a liability of subsequent shrinkage of the flap. The most generally applicable method is that of trans planting large epitheilal skin-grafts, proposed by Thiersch. This should be used to cover all raw surfaces in the vicinity of the lids which may cause subsequent deformity.

Epithelial Grafts (Thiersch Grafts).-The surface to be covered should be free from granulations, and aseptic. The skin from which the graft is taken, commonly the inner surface of the arm, is carefully cleansed without the use of any strong antiseptic. 'The skin is put upon the stretch and a shaving removed with a sharp razor. The razor-blade must be flooded with salt-solution, to float the graft and prevent it from being broken. A graft slightly larger than the surface to be covered is 
most desirable. It is floated from the razor into position, and trimmed to the exaet size of the raw surface with scissors. The field of operation is then to be protected by a ring dressing (page 528), kept warm and moist with a layer of proteetive, and left undisturbed for two or three days.

Ptosis Operations. - Where ptosis is due to hypertroplyy of the skin or other tissues of the lid, the tissue obstrueting lid-movements is to be exeised. If the contractile power of the elevator of the lid is laeking, exeision of a strip of the orbieularis musele, or of the muscle with the skin over it, or even including a part of the tarsal cartilage, may be of benefit. But if the loss of

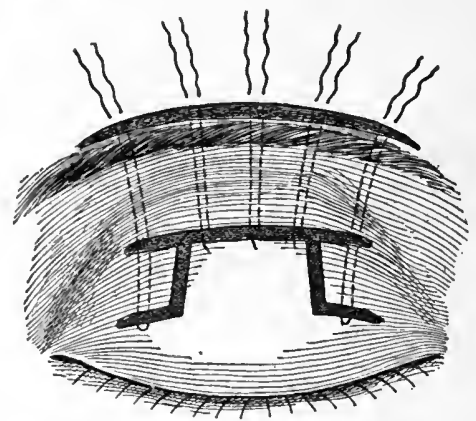

FIG. 159.-Panas' operation for ptosis (Hotz).

power in the elevator be complete, such excisions do little good. The eonnection of the lid with the frontalis musele, so that by its action the lid can be elevated, is then to be aimed at. This may be effeeted by a wire or light gold chain passed from the tarsus up under the brow, or by Panas' operation, in which a tongue of skin from the lid is drawn up under the bridge of tissne formed by undermining the brow (see Fig. 159). Motais' operation unites a central slip of the tendon of the superior rectus to the tarsal eartilages, enabling the lid to follow aceurately the movements of the eyeball. 
Chalazion is excised by making an incision through the skin over it, parallel to the lid-margin, and carefully dissecting it out. The operation is facilitated by the use of a lid-clamp, to prevent hemorrhage. The incision is closed with a fine suture. This operation is rather tedions and quite painful.

Incision with scraping and cauterization is a shorter operation and mostly preferable. 'The lid is everted with the lid-clamp or with the fingers. The discolored spot on the eonjunctival surface is made prominent, and freely excised in a direction perpendicular to the lid-border. The contents are then scraped out with a curette, and the interior of the cavity touched with a point of copper sulphate. The cavity fills with blood, which may require two or three weeks for its entire removal.

\section{OPERATIONS ON THE CONJUNCTIVA.}

Pterygium.-Small pterygia may be destroyed by the galvanic cautery; or by electrolysis, by passing a 3 milliampere current for one minute through a fine platinum needle thrust under the growth, parallel to the corneal margin, and repeating once or twice with the positions of the needle $2 \mathrm{~mm}$. apart.

Excision begins by dissecting up the pterygium, and upon the thoroughness with which this is done depends chiefly the success of the operation. The pterygium being grasped with forceps about the corneal margin is cut loose from the cornea with a Beer's knife, eare being taken to go deep enough to leave only normal corneal tissue, especially at the apex. Prince introduces a strabismus-hook beneath the pterygium, and with it tears loose the corneal portion. After this part is loosened it must be seized with forceps and the scleral portion dissected up, the same care being used to remove all the tissue down to the sclera. When the growth has been dissected up, incisions are made at the upper and lower margins, coming together near the caruncle. The conjunctiva may then be brought together with one or more sutures, 
but should not be made to cover the selera entirely up to the eorneal margin.

Transplentation.-With the scissors, the conjunetiva is loosened up below the pterygium after it has been disseeted back from the cornea, and a thread with a needle on each end is passed through the apex of the growth. Both needles are then carried downward beneath the conjunctiva until opposite the retrotarsal fold, where they are made to emerge into the conjunctival sac 6 or $8 \mathrm{~mm}$. apart. The thread, being drawn upon the pterygium, is dragged down beneath the eonjunetiva, and fastened there by the tying of the thread. This method, suggested by MeReynolds, is superior to transplanting the pterygium into an open slit in the conjunetiva, or doubling underneath upon itself toward the inner canthus. The transplanted growth slowly atrophies. A large pterygium may be excised, and the exposed sclera eovered by a graft of mucous membrane from the lower lip.

Symblepharon operations usually aim at covering with epithelium the surface exposed when the eyeball is dissected free from its adbesions to the lid. This may be done by grafts of skin or mueous membrane, or, in some cases, by sliding-flaps of conjunctiva, or by turning in a skin-flap. The epithelial grafts may be spread upon an artificial eye, which when inserted will retain them in proper position until firmly adherent.

Epithelial grafts of mucous membrane may be obtained from the conjunctiva of the rabbit, lut will commonly be taken from the under lip of the patient. The surface having been prepared for its reception, the lip is grasped by fencstrated foreeps, which put a portion of its mueous surface on the streteh and turn it out so that an cpithelial flap can be cut with a razor, as in epithelial skin-grafting. This flap is similarly floated into position, pressed into place by noistened cotton swabs, and allowed to dry for a few minutes before the lids are elosed. Both eyes are elosed for the first day or two, and after that the operated eye is elosed for three or four days. Such flaps come to resemble the conjunctiva in appearance, 
while skin-flaps always remain white, and on the eyeball are somewhat disfiguring.

Trachoma operations are designed to expel the peculiar infiltrate that characterizes the disease. They should be thorough, and done under general anesthesia. Knapp's roller-operation is preferred. 'The upper lid is everted (see page 58), and the fold thus formed is grasped with fixation-foreeps, and turned out so as to expose the retrotarsal fold. One blade of the roller-forceps (Fig. 160) is then thrust into the fold, the other is applied to the everted surface of the lid, the two are pressed firmly together, and as they are pulled away, press out the gray gelatinous exudate. The rollers are then ap-

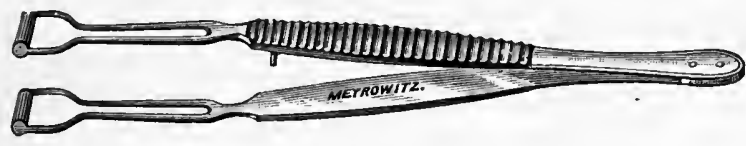

FiG. 160.-Knapp's roller-forceps for trachoma.

plied to a slightly different portion, and the movement repeated, until the conjunctiva is free from granules and the lid-tissues very soft and flexible.

To clear the parts near the lid-margins and commissures, one roller is placed in the conjunetiva, and the other upon the skin-surface. Thus every part of the fold of transition, and even the periphery of the ocular conjunetiva, can be brought within the grasp of the forceps. Care should be taken not to include and disturb the ocular conjunctiva more than is necessary, and to see that the rollers turn freely, so as not to drag and tear the conjunctiva. After the rolling is finished, the parts are to be eleansed with boric acid solution. 'The operation is followed by swelling and discoloration of the lids, which may be kept down by the use of ice for a few hours. Relief is marked within the first two or three days, but additional treatment must be used to eomplete the cure.

Peritomy may be done for pannus when it continues after the lids have been rendered comparatively smooth. 
It consists in the removal of a strip of conjunetiva and subconjunetival tissue around the eireumference of the cornea. The strip removed should be 4 or $5 \mathrm{~mm}$. wide, an incision being made that distance from the corneal margin, and the tissue thoroughly scraped away down to the selera. Usually the tissue is removed all around the cornea, but sometimes the removal may be confined to a part of the limbus a little greater than that through which vessels enter the corneal tissue.

\section{OPERATIONS ON THE LACRIMAL PASSAGES.}

Syringing of the passages is done either through the normal canalieulus, after slight dilatation of the punctum, or throngh the slit canaliculus. The tube to be introduced through the punctum should be about the thickness of a No. 2 Bowman's probe having an outside diameter of little over $\frac{1}{2}$ millimeter, and may be curved to 90 degrees. The tube to be used after slitting the canaliculus should be rather conieal, about $1.5 \mathrm{~mm}$. in diameter at the tip, and enlarging rapidly from this so as to fill the opening into the sae whatever its size. The ordinary hypodermic syringe, or a dental syringe, ean be used, but it is better to have one the barrel of which holds two fluid-drams. It must not leak either at tube or piston, for in some cases the obstruction may be overcome by the use of moderate persistent force; and it is safe to use thus what force ean be applied without eausing serious pain. For solutions of silver nitrate a gold tube or a. glass syringe may be employed.

Slitting the canaliculus is done for misplacement of the punctum and as a preliminary to treatment of obstruction of the nasal duct. It is done with a knife having a probe-point, which is made to enter the punetum, and being pushed along the canaliculus, this point guides the knife as it cuts its way into the lacrimal sae. A finger on the lid keeps it tense against the edge of the knife. Great care should be taken to evert the lid in the region of the canalieulus, and to turn the edge of 
the knife toward the eyeball so that the cut shall be made into the conjunctiva, and not in the lid-margin. If probes are to be passed, care must be also taken to make a large opening into the sac by pressing with the point of the knife as it is withdrawn. narrow entrance to the sac hinders the passage of the probe, causes pain and the risk of making a false passage.

\section{Probing the Nasal Duct.} -Lacrimal probes are made of silver, or the larger ones of aluminum. Bowman's are numbered from 1 to 8 , Theobald's, from 1 to 16 . No. 1 is $.25 \mathrm{~mm}$. in diameter, No. 16 is $4 \mathrm{~mm}$. in diameter. The smallest are chiefly useful in probing the canaliculi. Those of chief value for the nasal duct are Nos. 6 to 13. The probe should be given a curve approximating that shown in Fig. 161, and the ends should be bluntly conical.

The canaliculus having been slit, the patient's head is firmly supported, the lid is put upon the stretch, and the point of the probe carried in the direction of the slit canaliculus until it is arrested at the inner wall of the lacrimal sac by the resistance of the nasal bone. The probe is then turned so that the lower end points downward, a very lit-

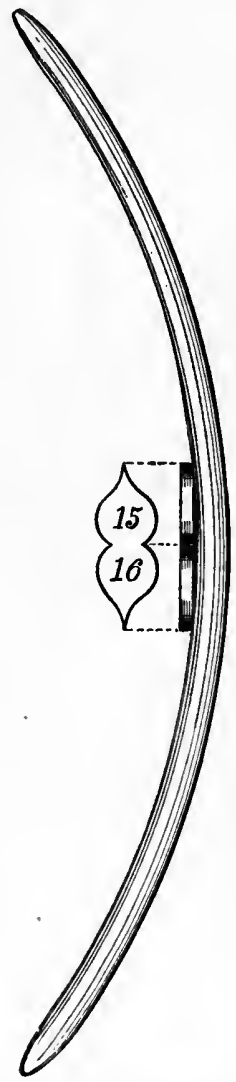

FrG. 161.-Theobald's lacrimal probe. tle forward, and slightly from the median line. Thrusting it in this direction, with a slight rotary motion, to disengage the point and find most exactly the direction of 
the eanal, the chief resistance is encountered at the upper end of the nasal duet. The point being earried throngh by firm, steady pressure, there is still eneountered a less resistance from the grasp) of the stricture on the sides of the probe, until the point comes in contact with the floor of the nose, or sometimes a bony obstruction at the exit of the duet.

The operation causes pain, which is only moderated by previously injecting the passages with cocain solution. In children and nervous persons it will be better to use a general anesthetie. It is best to begin with about a No. 6 probe, and in general to pass the largest that can be passed without exeessive force. The probe should remain in position twenty to forty minutes. It should be introdueed every second day; and when the largest probe, usually No. 11 to No. 13, has been used, the intervals may be lengthened.

Cutting a I,acrimal Stricture.-After the passage of a No. 6 probe, the Thomas stricturotome (Fig. 162)

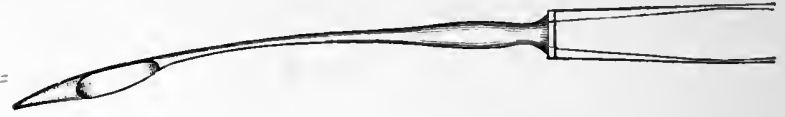

FIG. 162.-Thomas stricturotome.

is introdueed in the same manner as a lacrimal probe; as it is withdrawn the cutting edge is pressed firmly against the stricture, ineising it. When the stricture has thus been divided, the instrument may be pushed down, with the blade turned in another direetion, the shank being flexible to allow of this tuming, and a second cut made.

Extirpation of the Lacrimal Sac.-An incision $20 \mathrm{~mm}$. long is made parallel to the nose, half-way between the inner eanthus and the side of the nose, with its middle point slightly lower than the eanthus. This is carried down until the laerimal sae is recognized by its pale or bluish color. The incision is spread by retractors. The sac is dissected out, going down into the 
lacrimal eanal as far as possible, and the duct cut off. The wound is then elosed by sutures. Any mucous membrane remaining should be removed by curetting. An easier method, but followed by slower liealing, is to incise the sac, which may then be packed with cotton saturated with monochloracetic acid ; or', solid silver nitrate may be placed in it to destroy its lining membrane.

\section{OPERATIONS ON THE EYE=MUSCLES.}

Tenotomy is done to lessen the influenee of the tenotomized muscle on the position of the eyeball, as upon the internal rectus for convergent squint. With fixationforceps the conjunetiva and subconjunctival tissue are raised in a fold parallel with the corneal margin, over the insertion of the tendon to be divided, $5 \mathrm{~mm}$. back from the cornea for the internal reetus, $7 \mathrm{~mm}$. for the external. This fold is then divided horizontally by snips of the

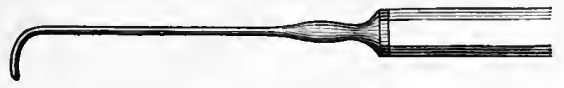

Fig. 163.-Strabismus-hook.

scissors eutting down to the sclera. A strabismus-hook (Fig. 163) is then introduced, with its point pressed firmly against the sclera below and behind the insertion of the tendon, and passed upward until it includes the upper

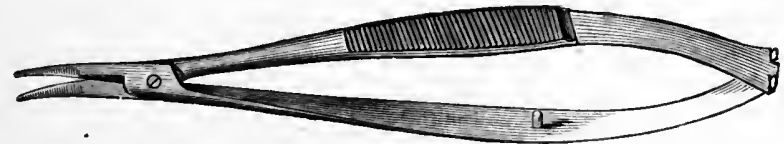

FIG. 161--Strabismus-scissors.

margin of the tendon. It is then drawn upon sufficiently to put the tendon slightly on the stretch. Blunt-pointed strabismus-scissors (Fig. 164) are then passed with one blade in contact with the hook, and the other beneath the 
conjunctiva, but in front of the tendon; and by successive snips the included part of the tendon is divided. The hook is then turned with the point down, so as to make sure to include the lower part of the tendon, and this is fully divided. Sometimes side slips of tissue connecting the tendon with the selera must also be fished up with the hook and severed. When all limiting fibers have thus been divided, the hook can be readily drawn forward to the corneal margin.

Partial tenotomy differs from complete in leaving a thin strand of tissue standing at each margin of the tendon, which can be stretched with the hook to the desired state of relaxation.

Extended tenotomy may be practiced for excessive convergent squint with marked limitation of outward movements. After completing the tenotomy of the internus, the strabismus hook is slipped beneath the tendon of the superior rectus, the nasal one-half or two-thirds of whieh is divided. In a similar manner the nasal portion of the inferior rectus is divided.

After tenotomy the eye should be cleansed and closed for a few hours, then left without any dressing. The effect of a complete tenotomy is usually 10 to 15 degrees; by extended tenotomy, double that effect may be produced.

Advancement of one of the ocular muscles is done to increase its influence upon the position of the eyeball. Thus, in divergent squint, the internal reetus musele should be advanced to turn the eye in. When a great rotation of the eye is desired, advancement of one muscle is combined with tenotomy of its antagonist. The effect may also be increased by including in the sutures the eapsule of Tenon and overlying tissue.

To advance the tendon alone, an incision $10 \mathrm{~mm}$. long is made parallel to the line of insertion of the tendon and midway between that line and the corneal margin. The conjunctiva is then undermined to the corneal margin and back as far as the suture is to be introduced, and the tendon is isolated that far back. A ligature of black silk, with a fine needle at each end, is fixed to the globe, by 
passing one of the needles beneath the superficial layers of the sclera parallel to the corneal margin, and quite close to it, so that the ligature ineludes 2 or $3 \mathrm{~mm}$. width of firm seleral tissue. 'The tendon is then raised on a strabismushook. One needle is carried under the lower edge of the tendon and made to pierce it from beneath, sufficiently far back from its insertion; the other needle is similarly passed the same distance back beneath the upper edge, so that the two ends of the ligature shall include between them about the middle third of the tendon. The two loops are now drawn safely out of the way, and the tendon divided at its insertion. If the end of the tendon included by the ligature is over 3 or $4 \mathrm{~mm}$. in length, the excess should be cut off. The eye is then drawn into proper position and the stitch tied. The eye is kept closed for a few hours, and then regularly cleansed. The stitch is removed in eight or ten days.

Lateral displacement with tenotomy of the superior rectus is done in paresis of the superior oblique. A suture is introduced through the tendon and into the selera to the temporal side, before the tendon is divided. When this is tightened; the tendon is drawn out and back from its original insertion.

\section{OPERATIONS ON THE CORNEA.}

Removal of Foreign Bodies.-A local anesthetic should be used and the patient convineed by touching of the eye that the operation will not hurt. $\mathrm{He}$ is then direeted to keep both eyes open and fixed in a certain direction, to bring the eye into favorable position. The spud shown in Fig. 165 is then plaeed alongside the foreign body and pushed steadily between it and the corneal tissue until the foreign body is loosened and displaced, and can be wiped away. Sudden dabbing and miscellaneous scraping while the patient is rolling the eye about are to be avoided. Small foreign bodies require the use of a magnifier (see page 69), and in any case the corneal injury should be examined with a magnifying lens to see that no partieles of foreigu substance remain. Any 
softened or probably infected tissue adjacent should also be scraped away.

Curetting of the cornea is practised for infected corneal ulcers. After instilling a local anesthetic, all softened tissue in the ulcer is scraped away with a corneal spud or spatula. The tissue adjoining the ulcer is also

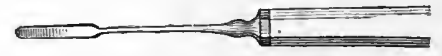

FIG. 165.-Spud for removing foreign bodies from the cornea.

scraped from the sound tissue toward the center of the ulcer, to press out whatever infected exudate may be present in it. This scraping should be repeated so often as the slightest extension of corneal infiltration can be detected.

Paracentesis, tapping of the cornea, is resorted to for hypopyon, or to relieve intra-oenlar pressure, as when a corneal ulcer is liable to perforate, or a swollen lens is causing trouble. It is done under local anesthesia through the lower margin of the cornea. A paracentesisneedle (Fig. 166), with a thick shoulder to prevent it from entering too deeply, a broad needle, or the point of a Graefe knife may be used. The incision is made parallel to the corneal margin. Care must be taken not

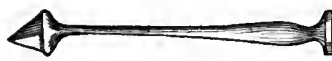

Fig. 166.-Paracentesis-needle.

to wound the iris or lens. The incision may be reopened by introducing a probe once daily so long as is necessary.

Incision Through Corneal U1cer (Sacmisch Operation).-When an infected or sloughing ulcer of the cornea is extending and likely to perforate, this operation is done to prevent prolapse of the iris, drain the involved tissue, and to check the extension of the infection. A Graefe knife is entered in the sound tissue on one side of the uleer with its back toward the iris, earried through the anterior chamber behind the ulcer, the point brought 
out through the sound tissue on the other side, and the knife made to cut its way out. This makes an incision through the whole thickness of the cornea, across the whole width of the ulcer, which may subsequently be kept open by probing.

The actual cautery is applied to the cornea to destroy powder grains, to eheck the progress of an infected ulcer, or to alter a chronic ulcerative process. A platinum needle or a fragment of a steel knitting-needle the size of a No. 6 lacrimal probe may be employed. The eye being placed under local anesthesia, the needle, grasped in an ordinary needle-holder, is held in the flame of an alcohol lamp until its end is white hot, and then is quickly tonched to the point to be cauterized. This may be repeated several times until the necessary extent of tissue has been eauterized. The operation is attended with little pain, unless the hot needle is held too long close to the eye. Cauterization should be thorough, destroying all infected tissue, the extent of which may be previously made more evident by use of fluorescin.

The galvano-cautery may be used for the same purpose as the above, or to open a corneal abscess or the anterior chamber, or for conical cornea. On account of its greater manageability and rapidity of action it is preferable where many powder-grains are to be destroyed. The small platinum tip is attaehed to a handle in which the circuit can be readily made and broken. The conductors should be light, and so supported as not to drag on the handle or interfere with the steadiness and accuracy of the operator's touch with the cautery point. The tip should be used at a white heat so as to do its work in the shortest possible time, before neighboring tissues can be injured by heat. The necessary current may be obtained by an adapter from the incandescent-light current, from a storage battery, or from three or four good canterycells. The circuit is made as the cautery tip is bronght near the point to which it is to be applied, and broken the instant the application ceases. It is better to make a number of short applications than to attempt to burn 
much tissue at a single contact. For conical cornea the anterior chamber should be penetrated.

Tattooing the cornea is employed to overcome the unsightly appearance of a corneal leucoma. The eye should previously be free from irritation, and the tissue to be colored must be but slightly vascular. India ink is rubbed in distilled water to a thick paste, spread on the part of the cornea to be colored; and picked in, either with a small flat needle like the Bowman needles, or with a bundle of fine cambric needles in a special handle, or bound together so that when held obliquely their points will all penetrate the cornea equally. The punetures should be as oblique as possible to the corneal surface. The operation may require to be repeated until the center is colored black like the pupil, and the other parts gray to represent the iris. The color may slowly diminish by diffusion, and requires renewal to keep a black center. If the operation is aseptic, but slight irritation follows.

Fuchs removes a circle of the anterior corneal surface, tattoos tlie underlying tissue, and replaces the circle as a temporary covering.

Excision of anterior staphyloma (abscission or keratectomy) may be resorted to, when nothing can be hoped from iridectomy. With a Graefe or Beer's knife the staphyloma is transfixed from side to side, the point of entrance and exit lying fairly behind the staphyloma. The edge of the knife being directed toward the upper or lower margin, it is made to cut out, separating one-half the base of the staphyloma; the other half is then severed with slightly curved scissors. Any pieces of thick hard tissue in the margins of the wound, or tags of loose langing tissue, should be trimmed away. The two sides of the wound may be brought together with three or more fine sutures, the eye dusted with iodoform, cleansed twice a day and kept elosed under a dressing until the sutures are removed in from five to ten days. 


\section{OPERATIONS ON THE SCLERA.}

Anterior sclerotomy is done for glancoma. A narrow Graefe knife entered $1 \mathrm{~mm}$. behind the upper outer part of the sclerocorneal junction is bronght ont at a corresponding point of the nasal margin of the cornea. By a slow sawing movement the knife is made to pass between the iris and cornea, making a scleral incision until the bridge of uncut tissue is reduced to about $3 \mathrm{~mm}$, when the knife is withdrawn. If the iris prolapses into either side of the wound, as shown by the pupil becoming oval, it must be drawn out and cut off.

Posterior sclerotomy is done for glancoma, detachment of the retina, or for the extraction of a foreign body or a cysticercus. The point of elcetion is near the equator of the eyeball above or below the external rectus. But it may be needful to place the incision under the greatest detachment of the retina, or most convenient to a foreign body. The incision is made radially in the direction of a great circle passing through the anterior and posterior poles of the eye, with a narrow knife or broad needle. By slightly displacing the conjunctiva before inserting the knife, the scleral opening is made subconjunctival. The knife may be turned in the wound before withdrawing it, or a spatula may be substituted for it, to allow the escape of the contents from the interior of the globe. Unless the incision is very extensive, it requires no suture.

\section{OPERATIONS ON THE IRIS.}

Iridectomy.-Removal of a picce of the iris is an operation that presents important variations according to the purpose for which it is done. It is done as a preliminary to the extraction of cataract, when the pupil is excessively small, or its margin bound down with arlhesions, or there are special risks for a cataract-extraction. Experience has shown that the risks are slightly less when the iridectomy is done as a preliminary operation than when it is done at the time of extraction.

The eye is placed under local anesthesia, the lids re- 
tracted with a speculum, and the globe steadied with the fixation-forceps. The point of a bent keratome (Fig. 167) is entered at the upper margin of the cornea and pushed steadily forward, with the plane of the blade parallel to the plane of the iris, until the corneal incision is sufficiently long, 6 to $8 \mathrm{~mm}$. Then the knife is withdrawn

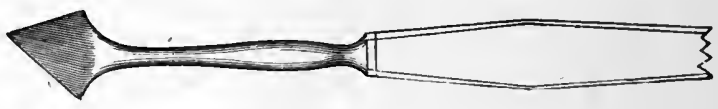

Fig. 167.-Bent keratome.

without touching the iris or lens, or scraping the cornea with the point. The iris-forceps (Fig. 168) are introduced into the corneal incision, opened slightly, made to seize the iris near its pupillary margin, and withdrawn, dragging this part of the iris with them. The part of the iris drawn out is then cut off with one snip of the scissors. The iris-stump is usually promptly retracted. If caught in the angles of the wound, it must be carefully freed and returned within the anterior chamber, either by making the wound gape by pressure on the selera, or by stroking with a spatula from the angles toward the center of the woumd. Blood remaining within the anterior chamber need cause no alarm, it will be quickly absorbed. The

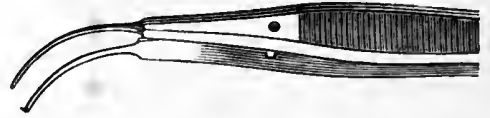

FIG. 168.-Curved iris-forceps.

eye is then to be closed with a light bandage for a day or two until the corneal incision has closed. A mydriatic should be used until the eye is free from redness.

The anesthesia of the iris produced by cocain or holocain is often imperfect. It may be improved by placing a drop of the anesthetic solution upon the corneal incision 
before attacking the iris. But the patient should be warned that the eut may hurt a little, so that he may make a special effort to avoid any sudden movement. The symmetry of the iridectomy depends on seizing the iris opposite the middle of the corneai incision, and holding it opposite the center while being eut. The size of the iridectomy will depend on the amount of iris drawn into the scissors; but when the iris returns to its position it will generally appear larger than might have been expected. When the iris-margin is firmly bound down to

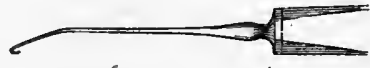

FIG. 169.-Blunt iris-hook.

the lens-capsule it is more readily freed and brought out by the blunt iris-hook (Fig. 169) than with the forceps.

Optical iridectomy is required when the natural pupil is obstructed by opacity of the cornea, partial cataract or deposit on the lens-capsule. If the eye already possesses some vision, and especially if the other eye has good vision, the result of the operation is apt to be disappointing. The refraction of light is always irregular at the periphery of the cornea and lens, and a portion of the cornea that looks clear with iris behind it may be found quite hazy when seen against an artificial pupil. But if the patient was previously entirely blind, the restoration of sone sight is very highly appreciated.

An optical iridectomy must be located so as to give the best vision, where the media are clearest, and where it will not be covered by the margin of the lid. The best effect will be obtained by making the opening in the iris as sinall as possible, thus reducing the diffusion of light due to imperfect focussing. If the iris is universally adherent to the lens-eapsule, it will only be possible to get a clear artificial pupil by extracting the lens.

Iridectomy for glaucoma is best done through a scleral incision made about $1 \mathrm{~mm}$. outside the margin of the cornea. At least one-fifth of the iris should be 
removed, entirely up to the ciliary margin. If the eye is inflamed this should be done under general anesthesia. On account of the shallowness of the anterior chamber and the length of incision required, the corneal incision is made with a narrow knife, used as in cataract-extraction, to make a puncture and counter-puncture and then to divide the intervening bridge of tissue. The iris being drawn well out, one blade of the iris-scissors is introduced through the pupil behind the iris, and, the iris being dragged towards one side of the corneal incision, a radial ent is made in the iris at the other side. The iris is then torn loose from its eiliary insertion, and at the other angle of the corneal incision a second radial cut eompletes the iridectomy.

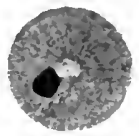

A

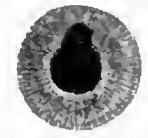

B

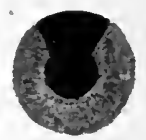

C

FiG. 170.-Various forms of iridectomy : $A$, Optical iridectomy for occlusion of the pupil. $B$, Small iridectomy preliminary to extraction of the leus. $C$, Iridectomy for glaucoma.

The typical colobomas obtained in the different forms of irideetomy are shown in Fig. 170.

Iridotomy is incision of the stretched iris-fibers, to make an artificial pupil when the natural pupil has been closed by inflammation, following an operation or injury which has removed the erystalline lens. It may be a simple cut made with a narrow knife perpendicular to the iris-fibers, or two euts forming a V made with Wecker's forceps-seissors, introduced through a corneal incision and the sharp blade thrust through the iris. A similar operation including both iris and lens-capsule is called iridocystectomy.

Corelysis, or breaking loose of iritic adhesions, may be done with a carefully rounded blunt hook introdnced throngh a small corneal incision and passed behind the margin of the pupil. Great care should be taken not to injure the lens-capsule. 
Iridencleisis is dragging the iris into a small corneal incision and leaving it fast there, to give a small and favorably situated pupil, in cases of corneal opacity. In iridodesis (iridesis) the small prolapse of the iris obtained for the same purpose is tied with a delicate silk thread.

\section{OPERATIONS UPON THE LENS AND ITS CAPSULE.}

The cataract-knife is usually the broad knife of Beer (Fig. 171), Sichel and Richter, or the narrow knife of

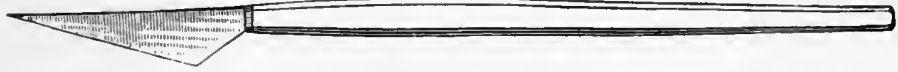

FIG. 171.-Beer's cataract-knife.

Gracfe (Fig. 172). The author prefers the knife shown in Fig. $173,3.5$ or $4 \mathrm{~mm}$. wide at its widest part.

Simple Extraction.-The lids, conjunetiva, and lid-

FIG. 172.-Gracfe's cataract-knife.

margins having been very thoroughly eleansed, local anesthesia is produced by not more than three instillations of cocain, or holocain solution, at intervals of five minutes.

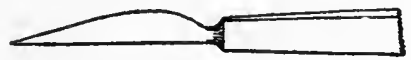

FIG. 173.-The author's cataract-knife.

The patient lies on a bed or table. The operator stands or sits at lis head; or, if not ambidextrous, at the patient's left side for his left eye. The lids being held by a speeulum, the eye is fixed by grasping with foreeps the tissue at the lower nasal margin of the cornea. The patient is also strongly urged to assist fixation by keeping his other eye steadily directed rather downward throughout the operation. The cataract-knife is en- 
tered just in the margin of the clear cornea and 1 or 2 $\mathrm{mm}$. above the temporal end of the horizontal diameter, starting at the position shown by the solid lines in Fig. 174 , with its cutting edge upwards and its plane parallel to the plane of the iris. The knife is then thrust horizontally forward, the point emerging through the counterpuncture symmetrically placed at the nasal side of the cornea. The knife is pushed on until it reaches the position indicated by the broken lines, and is then withdrawn with an upward pressure sufficient. to divide the remaining bridge of tissue.

The eye is allowed to rest an instant, before proceeding to open the capsule. The knife is cleansed with boric acid solution, and its back introduced in the corneal incision until it is almost in the position shown by the broken lines, (Fig. 174). It is then withdrawn until its point lies in

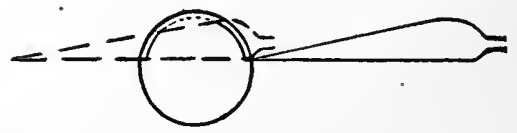

F1G, 174.-Cataract-incision. The solid lines show position of knife commencing the incision. The broken line shows the position of greatest forward thrust. The remaining bridge of tissue, shown by the dotted curve, is to be divided as the knife is withdrawn.

the upper temporal margin of the pupil where it is made to enter the lens-capsule. The knife is now thrust forward so that its cutting edge makes an incision in the capsule at the upper part of the pupil, and the edge comes in contact with the upper nasal margin of the pupil. The knife is then withdrawn, and the eye released from the fixationforceps.

Most operators open the capsule with a special instrument, the cystotome, shown in Fig. 175. 'The point is introduced sidewise, then turned toward the capsule, and made to open it by one or more scratches.

The delivery of the lens is accomplished by placing the back of the lens-spoon against the lower margin of the cornea, and pressing direetly backward. This tilts the lower margin of the lens backward, and canses the 
upper margin to be pushed forward, where it dilates the pupil and enters the corneal wound. Slight counterpressure may be made on the selera just above the cornea with a spatula, which may also be made to retract the center of the upper lip of the corneal incision, if necessary to facilitate escape of the lens. The pressure is steadily continued, so graduated as to keep the lens

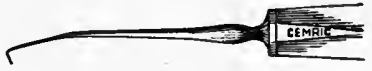

FIG. 175.- Cystotome.

advancing; but giving time for the sphineter of the pupil to stretch, and the lens to change shape under pressure. The pressure must not be intermitted until the widest part of the lens-nueleus has emerged from the corneal wound. Then the pressure may be slightly but not entirely relaxed while an assistant removes the lens-nucleus; and the surgeon carefully inspects the pupil. If it is believed that some cortex remains in the lens-eapsule, the pressure is renewed and the lens-spoon is slid up after the cortical masses; or the lower lid-margin is substituted for the lens-spoon until the fragments of cortex are pressed out.

The iris is then to be returned to its normal position by making the corneal incision gape by slight manipulation of the globe, or by lightly stroking the iris ont of the angles of the corneal incision. When the pupil beeomes cireular and eentral, the eye is to be cleansed with boric aeid solution and dressed.

Errors and Complications.-The knife in the anteterior chamber appears more superficial than it really is, and therefore the point is liable to emerge too far back. If this is diseovered before the eounter-puncture is complete, or while still quite small, it may be rectified by slight withdrawal of the knife and change of its direction. If the iris falls in front of the lnife it may often be gotten off by slightly lifting the entting edge and then thrusting quickly forward. If the knife-edge cannot be 
thus freed, the iris must be cut, and the iridectomy subsequently made regular; or the knife must be withdrawn and the operation postponed.

If the corneal section is too short, it should be lengthened with seissors before attempting to deliver the lens, taking care that the seissors only begin to eut at the end of the incision, and not into one of the lips of the wound. To attempt to deliver the lens through too small a corneal incision is the worst error one is likely to commit. Should the vitreous prolapse, the nucleus of the lens should be quickly delivered with a lens-spoon or wire loop; and the eye cleansed and dressed without much manipulation to expel cortex. When much cortex remains, the best way to extraet it is with a fine stream of borie acid solution, or normal salt solution, from a special syringe or irrigator. Lippineott's is about the best. This should be done if the lens-matter lies in the anterior chamber. But if it is adherent within the capsule it will be safest to leave it to absorption or a secondary operation, having warned the patient that vision will be poor until its removal is complete.

Hemorrhage from the depth of the eye usually destroys it. It is to be checked by at once raising the patient into the sitting posture, with the legs dependent, and applying ice to the eye.

Iris-prolapse.-When the iris does not return to the anterior chamber, or tends to prolapse when pushed back, or the pupil will not remain round and central, the iris should be drawn ont with an iris-hook and an iridectomy done to prevent future prolapse. When the iris prolapses subsequently, if not promptly reduced, it may be eut off, best under a general anesthetic. If the prolapse is let alone and the eye kept under a mydriatic, the healing will be slow (five to eight weeks), but the ultimate result will be quite as good as after iridectomy.

After-treatment.-Both eyes are to be covered with light dressings, which are removed by the evening of the next day, and the edges of the lids carefully eleansed to prevent any irritation that would provoke slight move- 
ments. This cleansing is repeated daily. The fourth or fifth day the unoperated eye is usually left uncovered; the dressing being renewed on the operated eye until the end of a week. When the corneal wound has been entirely closed and the anterior chamber re-established for a day or two, a mydriatic may be instilled.

Delayed union of the corneal wound sometimes occurs, generally attended by deficient hyperemia of the eyeball. Union may promptly follow the discontinuance of the dressing.

Extraction with iridectomy resembles the operation above described, except that an iridectomy, as described on page 549, is done immediately after the corneal section; and the corneal section may be a little shorter. The operation is free from dauger of prolapse of the iris, but incarceration of the iris in the angles of the wound is very liable to occur. It is more liable to be complicated by vitreous prolapse.

Iinear extraction is done for cataracts destitute of large firm muclei. An incision, 6 to $10 \mathrm{~mm}$. long, is made in the clear cornea, with a keratome or a cataractknife. The capsule is opened with the point of the knife and the soft lens-substance squeezed out.

Suction-operation for fluid cataracts: the needle of a syringe or suction-curette is introduced through a small incision in the cornea and capsule, and the lenssubstance sucked out.

Extraction within the capsule is sometimes done. Its superiority is established only for cases in which the the suspensory ligament of the lens has undergone atrophy.

Scoop-extraction is performed by passing the wire loop (Fig. 176), or the lens-spoon behind the lens and coaxing it out, when pressure cannot be made on the globe, as when there is prolapse of the vitreous.

Wenzel's extraction may be done when the iris is universally adherent to the lens. The knife is made to eut cornea, iris and capsule at one thrust ; and after expulsion of the lens, enough iris and capsule are removed to give a clear pupil. 
Discission is done to secure the absorption of soft eataract, or to render transparent lens-substance opaque and facilitate its removal by extraction. It usually requires repetition, in some cases many times, before complete absorption is secured. A knife-needle is the only essential instrument. It may be either straight or curved. Its cutting edge should be 3 or $4 \mathrm{~mm}$. long. It must have a round shank of such thiekness that it will just fill the incision made by the blade. The eye is fixed and the lids held apart with the fingers; or speeulum and fixation-

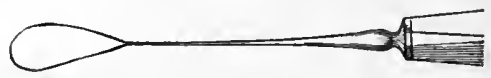

FIG. 176.-Wire loop for extraction of lens.

foreeps can be used. The eye should be under strong oblique illumination; and the binoenlar magnifier (Fig. 21 ), is of great assistance. The pupil is fully dilated with a mydriatic, and a local anesthetic applied.

The knife-needle is introduced half-way between the eenter and the margin of the cornea, and a cut made in the lens-capsule. In a first discission for absorption, there should be a single eut in the eapsule about $3 \mathrm{~mm}$. long, although the knife may be turned and moved in the lens-substance as freely as possible without enlarging the incision. In later operations, when the lens has bcen partly absorbed and the eye has shown itself tolerant of the operation, more free incisions may be made in the capsule.

The needle having been witldrawn, the eye is closed for a few hours with a simple dressing, or absorbent cotton and a Liebreich bandage, and kept under a mydriatie until entirely free from redness or irritability, and until all pieces of lens-substance that may fall into the anterior chamber have been absorbed. Whenever the process of absorption ceases, as it does in two to ten weeks, the operation is to be repeated, the lens being each time more completely broken up. Discission is not devoid of danger. The slight eorneal wound may become the seat of infec- 
tion. Hence, strict precautions must he observed to avoid bruising and to keep it aseptic. If the opening in the capsule be too large, excessive swelling of the lens oceurs, and may eause glaucoma. If pieces of comparatively unaltered lens-substance fall into the anterior chamber, they cause hyperemia of the iris, eiliary body and pericorneal zone. Lens-substance that has been previously disintegrated, by exposure to the aqueous within the capsule, causes less disturbance.

Capsulotomy.-Division of the remaining lens-capsule is necessary, in the majority of cases, to give the best

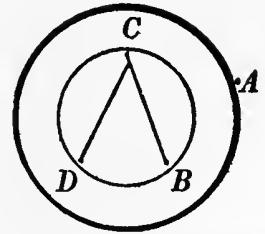

FIG. 177.-Lines for the T-shaped or inverted V-shaped incision of the capsule for secondary cataract.

possible vision after removal of the eataract. The operation differs from discission, as above described, in always aiming at a free division of the membrane which obstruets the pupil. On this account, to give the longest sweep to the eutting edge, to reduce the bruising and twisting of the needle in the cornea, and to get immediate closure of the little wound and guard against infection, the knifeneedle should be introdnced through the limbus, where the eornea is overlapped by vaseular selera and conjunctiva. To seenre gaping of the opening, it is generally necessary to make incisions meeting at an angle. But after the first las been made, the membrane becomes relaxed, so that unless it has been earefully planned, the second incision may be very diffieult to make. A good plan is illustrated in Fig. 177. The needle entering the limbns at $A$ is made to pierce the membrane at $B$, and then to cut it to $C$. It is then slightly withdrawn and made to pierce the membrane at $D$, and to eut ont to $B C$, 
near $C$. When an extensive adhesion exists between the iris and the eapsule, incisions should, if convenient, pass through its base, giving freedom to the iris and securing retraction of the membrane.

If the pupillary membrane be excessively thick and tough, so that a careful sawing cut will not give a good opening, it may be torn from the center by double traction either by two needles introduced at the two margins of the cornea (Bowman's operation), or by two blunt hooks introduced from the two sides and eanght in a central slit (Noyes), or a piece may be removed by an operation similar to iridotomy (page 552). Sometimes the pupil will eontain a thick mass left by imperfect absorption of the leus, which is best extracted through a small corneal incision, by piercing with a sharp hook and twisting it until it is rolled up and freed from its eonnections.

Removal of the lens for high myopia is effected by discission to render the lens opaque and lessen its adhesion to the capsule; and extraction of the mass of lenssubstance, before the swelling of the lens or escape of lens-matter into the anterior chamber, causes serions hyperemia. The free division of the lens at the first operation, advocated by Fukala and others, is attended by unnecessary danger to the eye, and is followed by slow recovery. If hyperemia commences it will be better to extract at once so much as possible of the lens while still clear, rather than wait till it becomes entirely opaque. If the bulk of the lens is removed, the portions remaining can swell and disintegrate without causing much tronble.

\section{OPERATIONS ON THE EYEBALL.}

Magnet-extraction.-Magnets used to extract particles of steel from the eye are of three kinds: Strong permanent magnets may be used to remove small particles of steel from the front of the eye, where the magnet can be brought in contact with them. Portable electro-magnets, like Hirschberg's, have straight and curved points that are 
sterilized and introduced into the eye; where they attract the particle, which may sometimes be heard to strike the point with a elick. They are then drawn out, with the foreign body adhering. Very large fixed electromagnets were proposed by Haab. They are intended to attract the particle and draw it ont of the eye through the wound of entrance; or to draw it around the crystalline lens into the anterior chamber, whence it can be extracted.

For extraction with the portable magnet, the eye and the magnet-tip having been rendered aseptic, the eye may be anesthetized and the wound of entrance, if favorably situated, somewhat enlarged. If, however, the particle has entered through the cornea and lodged in the vitreous, it will be best to extract through a seleral incision made as elose to the location of the foreign body as possible. The tip of one of the most powerfil hand magnets (Sweet, Johnson or Lippineott's) should be introduced just within the incision, and the full eurrent turned on. If this fails to draw the foreign body to it, the tip must be thrust more deeply in the direetion of the foreign body, but as little disturbance of the vitreous, as possible should be aimed at. The "innenpol" magnet is a form of giant magnet in which the coil is made large enough for the patient to place his head within it, and the core to be magnetized is simply a piece of soft iron of the proper shape, which the surgeon holds in his hand, very much as he would a hand magnet.

Enucleation of the Eye.-If the eye be free from inflammation, this operation may be done under local anesthesia, althongh not without some pain. But most eyes requiring enteleation are inflamed and for them a general anesthetic is neeessary. The lids being retracted by the speeulum, the conjunctiva is seized and divided around the corneal margin. The conjunctiva is then pushed back, and with firm pressure the forceps are made to seize the tissue of the insertion of the internal rectus. The strabismus-hook is then passed beneath the tendon, 
and it is divided with the scissors about $3 \mathrm{~mm}$. back from its insertion. The stump so left gives a firm hold for the fixation-forceps. 'The strabismus-hook is now passed downward from the insertion of the internus, breaking up the loose tissue it encounters, until it passes beneath the inferior rectus tendon, which is hooked up and divided at its insertion. The hook is then in the same way passed under the tendons of the external and superior recti museles, which are similarly divided.

The anterior portion of the globe having thus been quite freed from all attachments, the speculum may be removed and the lids retracted by the fingers. The eyeball is then strongly rotated outward, and the tissues pushed back at the nasal side of the globe until with the tip of the finger a thick tense cord of tissue is felt, the optic nerve. The blunt, strong, curved, "enucleation-

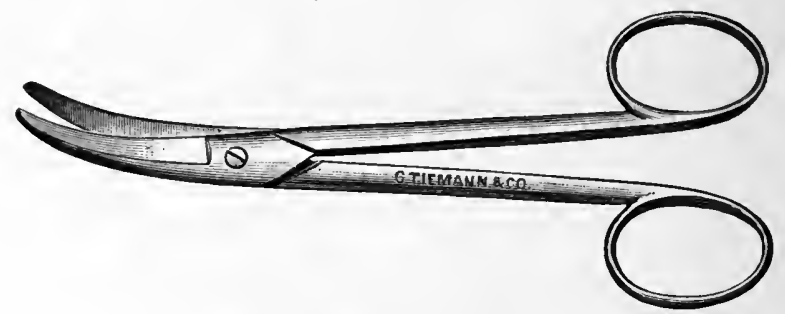

FIG. 178.-Enucleation-scissors.

scissors" (Fig. 178) are now introduced with the points closed, and made to push aside the tissne on either side of the nerve. The nerve is then included between the blades and divided by one strong cut.

The cyeball is now dislocated in front of the lids, and, while turned out, all adherent tissue is divided close to the globe by successive snips. The enucleated eye should be dropped in a 4 per cent. solution of formaldehyd (10 per cent. formalin), to preserve it for subsequent careful examination. 
To secure increased motility for an artificial eye Priestley Snith, before doing enucleation, stitches each of the recti tendons to the overlying conjunctiva, by raising the tissues with fine-toothed fixation-forceps, and passing a suture through the fold.

Complications and Cautions.-The removal of an eye having normal tension and attachments is one of the easiest of important surgieal operations. But if the eye has been the seat of chronic inflammation, it may be firmly bound down in all direetions by new-formed eonnective tissue. It may be impossible to reach the insertions of the recti tendons until a zone of this tissue all around the cornea has been divided by snips with scissors; and the tissue between the tendons may be so dense that in the process of dividing it, the tendons themselves are divided unnoticed. If the globe has been perforated, and is therefore perfectly soft, the selera falls in folds that are liable to be cut with the scissors; and if the eye is shrunken and soft and surrounded with cicatricial tissue, a good deal of care is neeessary to remove it neatly.

In enucleating an inflamed eye there is always a good deal of hemorrhage, which must be eleared away by an assistant during the earlier part of the operation. After the removal of the speculum, when the optie nerve has bcen severed and the adherent tissue is being trimmed away, the lashes or the lid-margins are liable to be snipped by the scissors unless carefully guarded.

When the eye is removed because it contains a malignant growth, as much of the optic nerve as possible should be removed with it. To do this the tissue around the nerve is pushed aside from it, with the closed points of the scissors back nearly to the optic foramen, and the nerve grasped back there by the open blades for division. The error of enucleating the wrong eye has been committed.

After-treatment.-Frce hemorrhage shonld be allowed after this operation, particularly if there has been some extension of inflammation into tissue surrounding the eye. When desirable it is best checked by injecting very hot 
water into the socket. The cavity may then be dusted with iodoform and covered with absorbent cotton. The socket should then be washed out once or twice daily, and dusted with iodoform until after four or five days, when all dressings may be discontinued.

The artificial eye may be fitted as soon as the wound has quite healed, in the second or third week. Its wearing is to be advised, because beside cosmetic reasons it prevents the upper lid from falling over the lower, and being irritated by the lashes. To insert it the upper lid is drawn out and the larger temporal edge of the shell slipped up under it. Then the lower lid being drawn down, the other edge is slipped in and the artificial eye slides into place. It is removed by pulling down the lower licl and slipping a large pin under the lower edge. It should always be removed at night and carefully cleansed. An artificial eye becomes roughened after one or two years of continuous wearing, and then must either be repolished, or replaced by another. In selecting an artificial eye it should be compared with the natural eye in a strong light, where a difference of color, or of size of pupil would be most noticeable. The various forms of glass eye proposed by Snellen seem distinctly superior to the older form of a simple shell for use after enucleation.

Evisceration of the eye may be done instead of enucleation, for pain, as in absolute glancoma ; or to prevent sympathetic discase, although it is not proven that for the latter purpose it is equally efficient with enucleation. It should never be done for malignant disease within the eye. It usually furnishes a better support for an artificial eye than does enucleation; but the reaction and pain following operation are greater, and the healing is more prolonged.

The eye is transfixed just back of the cornea with a Beer's or Graefe cataract-knife, which is made to cut its way out at the upper or lower margin of the cornea. An incision including the whole cornea is completed with strong scissors. The contents of the sclera are then removed, care being taken that no particles of tissue 
remain. The cavity may then be allowed to fill with blood; or the bleeding may be checked, and the scleral surface cauterized with carbolic acid, and the eavity filled with iodoform. The sides of the sclera are brought together by interrupted sutures, or a single gatheringstring suture is run around it.

A layer of surgical lint is laid upon the eye, and iced cloths applied continuously for a day or two to keep down the reaction.

Implantation of an artificial vitreous (Mules' operation) is intended to secure a spherical stump, resembling a shrunken eyeball, for the better support and movement of an artificial eye. After evisceration a hollow sphere of glass, silver or aluminum is inserted in the scleral cavity. All bleeding must first be checked. The sclera is slit vertically above and below to admit the sphere, which must not be too large. The sclera is then brought together in a vertical line by a row of silk, or silkworm-gut sutures, the angles of tissue formed above and below being neatly trimmed down. Then the conjunctiva is brought together over the sclera by a horizontal row of sutures. If the primary closing of the scleral opening is incomplete the sphere will not be retained.

Some operators implant such a globe in the cavity left after enucleation. Bryant has employed a fenestrated globe of aluminum, which fills with granulation-tissue, securing its retention.

A sphere of paraffin, 15 to $20 \mathrm{~mm}$. in diameter, may be used for this purpose. Sutures are placed in the tendons of the recti muscles before these are divided. After bleeding has been checked and the paraffin globe introduced, the opposing recti are sutured together in front of the globe, and the conjunctival opening closed with another set of sutures. This plan is safer and more reliable than the injection of melted paraffin into the cavity. The eye of the rabbit has been implanted in the orbit to furnish support for an artificial eye, but it has 
not been demonstrated to possess advantages over the foreign bodies above mentioned.

Osteoplastic Resection of the Orbital Wall (Kronlein's Operation). - An incision is made convex forward and downward, beginning above the upper outer angle of the orbit, passing down close to the external canthus, and back to the middle of the zygoma; and carried down to the bone. The periosteum is incised along the outer margin of the orbit, and the orbital periosteum separated from the outer bony wall of the orbit and pushed out of the way with the orbital contents. A horizontal section of the bone is made, back from the upper outer angle of the orbit, through the external angular process of the frontal bone and the portion of the orbital wall which separates the orbit from the temporal fossa. From the posterior end of this section another is made, downward and rather backward, to the sphenomaxillary fissure. A third section is made horizontally backward from the lower outer angle of the orbit to the spheno-maxillary fissure. The bony flap thus formed, with the soft parts attached to it, is pushed back from the temple. The orbital periosteum is incised, and, if necessary, the external rectus divided, permitting frec access to the contents of the rear of the orbit.

\section{CHAPTER XX.}

\section{OCULAR SYMPTOMS AND LESIONS CONNECTED WITH GENERAL DISEASES.}

The detailed deseriptions of the symptoms and lesions here mentioned are given in preceding chapters, and must be referred to as mentioned here, if the reader wishes to get a complete elinical picture of the ocular manifestations of any particular disease. 


\section{DISEASES OF THE NERVOUS SYSTEM.}

\section{Organic diseases of the brain and its meninges,} including tumor, meningitis, abscess, aneurysm, traumatism, cerebritis, softening, hemorrhage, embolism, and thrombosis, are all liable to cause optic neuritis (sce page 385$)$. It is therefore of very little value to differentiate these various conditions, but it proves that the symptoms present do arise from organic disease.

Intracranial disease also causes abnormalitics of the pupils (page 72), palsies or spasms of the ocular muscles (page 204), or limitation of the fields of vision (pages 36, 47, 391), which may be either transient (remote symptoms). or permanent, directly due to the lesion. When permanent, they are of the highest value in localizing the disease.

The above symptons in themselves give no positive information as to the nature of the morbid process causing them, as whether a tumor is syphilitic or tubercular. But the close anatomical and physiological relationships between eye and brain make them often suffer from a conmmon cause; and the concomitant eye-lesion may suggest with great probability the nature of the cerebral process. Diseases of the retina and choroid are of greatest importance in this connection.

Optic atrophy attending brain disease, if consecutive (page 391), has the same significance as optic neuritis. But if primary it may point to pressure on the tracts or nerves, in which case it has localizing value; or it may indicate that the trouble is of toxic origin (page 397), or it may belong to a disseminated selerosis. Progressive involvement of one ocular muscle after another, or of different parts of the visual field have great prognostic significance. The former may characterize a form of progressive bulbar paralysis. Nystagmus appears frequently in multiple sclerosis, but it may also appear in any case of prolonged severe impairment of vision. Grave cercbral hemorrhage, embolism or thrombosis is often attended with hemorrhage or vascular disease of the retina of the affected side. 


\section{SYMPTOMS OFTEN EXPLAINED BY OCULAR EXAMINATIONS.}

Coma should always lead to a thorough objective examination of the eves. If uremic, albuminuric retinitis may be found (page 365); if nareotic, extreme equal myosis without other symptoms; if apopletie, myosis and inequality of the pupils may be remarked, with conjugate deviation of the eyes. Organic brain disease may be revealed by optic neuritis; or mydriatic poisoning, by extreme dilatation of the pupils. Convulsions and $d c-$ livium may be referred to their cause, by the same ocular symptoms.

Headache, if persistent or frequently recurring, should always evoke careful investigation of the eyes. Eyestrain is its most common cause (page 53); or it may be due to organic brain disease that will be revealed by optic neuritis or atrophy, or to uremia or other conditions that are attended by characteristic retinitis.

Vertigo, and often nausea, may arise from the causes mentioned for headache. They may also be caused by paresis of one or more ocular muscles, or from strain of these muscles, as in excessive eonvergence from high myopia.

Sclerosis of the Spinal Cord.-In posterior sclerosis (locomotor ataxia, tabes dorsalis), primary gray optic atrophy (page 395), with corresponding visual impairment, occurs in between ten and thirty per eent. of all cases. In a few cases it antedates all other symptoms, sometimes by many years. Sometimes it appears shortly after the lightning pains, gastric crises, or ataxic symptoms; and in these cases the progress of the ataxia is apt to be arrested, and the power of locomotion to remain good for a long time. Occurring in the later stages, the atrophy progresses with the ataxia.

In a similar proportion of cases of sclerosis, paresis or paralysis of one or more ocular muscles occurs. This may also be an early symptom. Such palsies appear suddenly. They may be quite transient, or permanent. The loss of 
light-reflex of the pupil (Argyll-Robertson pupil, page 74), and the less definite condition of myosis are among the most important early symptoms of tabes. The former occurs in three-fourths of all cases, and in very few does the pupil remain normal. Epiphora is a frequent symptom, being sometimes due to relaxation of the lid, sometimes to hypersecretion.

Acute myelitis has been attended with double optic neuritis (page 385). In spinal injuries and caries, hyperemia and anemia of the disk (pages 383 and 384), have been noted, but are not significant. Involvement of the cord or of the nerve-roots in the cervical region may cause myosis and slight ptosis, through paralysis of the cervical sympathetic, or spastic mydriasis, widening of the palpebral fissure, and apparent exophthalmos from an irritative lesion (page 56).

Disease of the trifacial nerve may be accompanied by neuroparalytic keratitis (page 287), or it may cause herpes zoster (page 288). In all cases of neuralgia affecting the ophthalmic division, the possibility of glaucoma should be carefully considered.

Multiple neuritis may include an axial neuritis of the optic nerve causing central scotoma (page 40), or may produce palsies of isolated ocular muscles (page 204).

Epilepsy. - The attack may open with a visual aura, like that of migraine. There may be concentric navrowing of the field of vision, or lowered acuteness of vision after the attacks, and sometimes before them. Narrowing of the retinal arteries has been noted at the beginning of the attack, and marked distention of the retinal veins at the close, or following the seizure. The ocular muscles may participate in the movements, associated movements of the two eyes being especially common. Subconjunctival ecchymoses may be produced, and partial opacity of the lens or complete caturact may arise.

Epileptiform seizures seem, in rare cases, to be due to eye-strain, and to eease when it is relieved.

Tetany has been connected with a form of cataract 
in which the opacity begins before middle life and is long confined to the nucleus.

Migraine. - The attacks of pain are in many cases preceded by scintillating scotoma (page 45), or, in rare cases, this is replaced by a distinct visual hallucination. These visual disturbances do not usually occur with every migrainous attack, but only with an occasional seizure. Sometimes they constitute the whole attack. They may attend the attacks for a time, the migraine having existed before or continuing afterward without any such visual phenomena.

In a large proportion of cases migraine depends upon or is aggravated by eye-strain, and is partially or completely relieved by the careful correction of ametropia (pages 153, 185). Patients who have the visual disturbance are especially likely to think of their attacks as connected with ocular defects. But it is not certain that the connection is closer or more general among these cases than among others. Optic atrophy (page 391) has sometimes been associated with migraine, but more frequently glaucoma has been mistaken for such an association.

Chorea.-The acute chorea of childhood, chorea minor, may be attended with irregular action of the eyemuscles, but is not caused by muscular anomalies. Habitchoreas, habit-spasms, or reflex choreic movements, may be cansed by eye-strain and cured by its relief. Severe eye-strain may also be an important agency in causing the depressed condition of the nervous system, which predisposes to chorea. Retinal embolism (page 374) has occurred in connection with chorea.

Exophthalmic goiter has already been considered (page 472). The ocular symptoms are not essential, but are usually the most striking manifestation of the disease.

Akromegaly.-The hypertrophy may involve the bones of the orbit and the skin of the lids. The ocular movements and reactions of the pupils are often slow or slightly irregular. There may be paralysis of one or more ocular muscles or impairment of central vision, and 
irregular contraction of the visual field (page 41). The most characteristic ocular symptom, though far from constant, is bitemporal contraction of the visual fields, or hemianopsia (page 37), probably from pressure of the enlarged pituitary body upon the optic chiasm. Irregular or unsymmetrical contraction of one or both fields occurs from the same cause ; exophthalnos, double optic neuritis, optic atrophy, nystagmus, and hypersecretion of tears have been reported.

Mind-blindness, inability to receive a mental impression from objects seen; word-blindness, inability to recognize written or printed words ; letter-blindness, inability to name letters, although words are understood; and dyslexia-or an insurmountable difficulty in reading, although the patient possesses perfect sight and can read a few words at a time-are conditions of important significance, liable to be confused with impairment of vision.

Neurasthenia is attended with pain connected with use of the eyes, variable heterophoria, deficient power of abduction, adduction and sursumduction (page 192), twitching of the lids, large but mobile pupils, and persistent after-images. Concentric contraction of the field of vision, hyperemia of the optic disk (page 93), and causes of eyestrain should be carefully looked for.

Myasthenia gravis generally begins with intermittent ptosis (page 457), most noticeable when the patient is tired. Paresis of the orbital muscles is common, and exophthalmos may occur. The symptoms are relieved by rest, but recur: It may be fatal.

Insanity may be attended with visual hallucinations. It presents no ocular symptoms characteristic of the condition in general, or of any particular form of insanity. Ocular symptoms connected with some causative or concomitant condition, like albuminuria, syphilis, or tabes, are common.

Hysteria may present many eyc-symptoms. The more characteristic of these are progressive concentric contraction of the field of vision, like that of neura- 
thenia, contraction of the color-fields or reversal of their normal order, amblyopia or complete blindness of one eye (page 403), squint (page 234), blepharospasm, dilatation or contraction of one pupil (page 76), monocular diplopia withont evident ocular cause (page 46), asthenopia, and complaints of inability to use the eyes or wear glasses. Eye-strain may be a contributory or exciting cause of hysteria.

\section{DISEASES OF THE CIRCULATORY SYSTEM AND KIDNEYS.}

Anemia, if severe, causes characteristic ophthalmic changes. If acute, as from hemorrhage, the patient may become suddenly blind, with ophthalmoscopic changes (page 384), that later may go on to those of optic atrophy (page 391), although at least partial recovery of sight is the rule. Chronic simple anemia presents a pearly-white selerotic, and pallor of the inner surface of the lids. The fundus of the eye appears pale throughout, the retinal arteries are slightly narrowed. The retinal veins are pale but very broad, with a broad light-streak (page 86 ).

Leukemia and pernicious anemia may present the appearance of simple anemia, with even greater pallor of the fundus. In severe cases there exists generally the characteristic retinitis or neuroretinitis with retinal hemorrhages (page 363); lymphoid tumors of the lid and orbit, and chloroma (page 476) are sometimes associated with leukemia.

Diseases of the Heart.-Aortic regurgitation causing a sudden drop in the arterial pressure is liable to cause pulsation of the retinal arteries (page 86). Similar pulsation may be caused by syncope. It may also be noticed in sudden overaction of the heart from excitement, and rarely in exophthalmic goiter. Distention of the right heart and the venous system may eause distention and tortuosity of the retinal veins (page 92). Endocarditis may give rise to embolism of the central retinal artery. General edema dne to heart disease, althongh 
not especially liable to involve the eyelids, may be noticed there upon rising in the morning.

Aneurysm of the aorta or innominate may give rise to embolism of the retinal artery (page 374 ), and to dilatation of the pupil and widening of the palpebral fissure and exophthalmos through irritation of the cervical sympathetic. Aneurysm of the internal carotid may cause palsies of ocular museles (page 204); and if it burst into the cavernous sinus, it causes pulsating exophthalmos (page 472).

Rena1-vascular Disease. - Albuminuric retinitis (page 365) occurs chiefly when after a period of high arterial tension the cireulation begins to fail. The retinal lesions are so directly connected with the vaseular condition, and the retinal vessels are so largely affected in the process, that it would belong more properly with circulatory than with renal disorders. In some cases no albumin may be found in the urine, and no symptoms of kidney disease may be noticed, but chronic advanced angiosclerosis is always present. The kidney disease with which it usually occurs is chronic interstitial nephritis, although albuminuric retinitis may attend the large white kidney, acute nephritis, or the albuminuria of pregnancy.

Retinal hemorrhage (page 360), so marked a feature of albuminuric retinitis, may occur without other retinal changes, and may be followed by hemorrhagic glaueoma (page 444). Detachment of the retina (page 377 ) sometimes occurs, but retinal edema may be taken for a limited detachment. Paralyses of ocular museles oceur in rare eases, and the eye-museles participate in eclampsia.

Uremic amaurosis (page 402) is sudden in its onset, and usually complete, but the pupils continue to react to light. Edema due to renal disease is often most noticeable in the eyelids, but it may exist without affecting the lids.

Albuminuric retinitis, retinal hemorrhage, and palsies of the ocular muscles indicate an early futal termination of the disease. But few patients survive two years after marked retinitis is noticed. 
Diabetes causes cataract which resembles other cataracts in persons of similar age, except for a diffuse clouding of the lens which may vary with the general condition of the patient. Diabeties are sometimes subject to sudden and great changes in the refraction of the eye, closely connected with changes in the amount of sugar in the urine. Diabetic retinitis (page 368), although rare, is a characteristic condition. Retinal hemorrhage (page 360) is common. Central scotoma especially for red and green, due to retrobulbar axial neuritis (page 391), is met with; and optic atrophy may follow. Palsies of the ocular muscles or accommodation may occur, and uveitis (page 314) may be due to diabetes.

\section{DIATHETIC DISEASES.}

Rheumatism. - The characteristics of rheumatic iritis have already been deseribed (page 319). Cyclitis may also occur. A mild cyclitis probably more often than iritis accompanies acute attacks of articular rheumatism. Ocular palsies (page 204) arise from rheumatic disease of the nerve-trunks. But nuany cases loosely classed as rheumatic are, probably, simply neuritis from cold or other non-rheumatic canse. Rheumatic endocarditis is a chief causc of embolism of the central artery of the retina (page. 374). Chronic rheumatic inflammation may affect the sclero-corneal coat of the eye, causing scleritis, episcleritis (page 311), or keratitis. Acnte rhenmatism may involve the fibrous capsule of Tenon or the tendons of the ocular muscles.

Gout.-Gouty inflammation of retina, optic nerve, and choroid (page 368), although clinically distinct from both, is closely allied to diabetic and albuminuric retinitis, and of similar grave prognostic import. Iritis, due to gout (page 319), is insidious and tends to relapses. Scleritis (page 311) and brief periodic episeleritis (page 243) seem to be associated. with gout. Glaucoma, especially simple glaucoma (page 443), occurs in persons of a gonty tendency, and senile cataract has been ascribed to this diathe- 
sis. A recurring hyperemia, or dry catarrh of the conjunctiva, may be due to gout. - Superficial painful ulcer near the corneal margin occurring in old people (page 286) and sclerotising keratitis are also regarded as of gonty origin.

Purpura is often attended with retinal hemorrhage, and hemorrhage may occur in the choroid, conjunctiva, and lids, or in the depth of the orbit where it would cause exophtlalmos. Similar hemorrhage may occur in scurvy, although few cases have been reported.

Scrofula or struma has largely been merged in tuberculosis. But there are certain diseases of the eye distinctly associated with a diathetic condition marked by a pasty, inelastic, rough skin, liable to eczematous eruptions, a tendency to catarrhal inflammations of the mucous membranes, disordered digestion, constipation, foul tongue, and anemia. These diseases are: Marginal blepharitis (page 449), phlyctenular conjunctivitis (page 261), and keratitis, both phlyctenular and interstitial (pages 288 and 292).

\section{CHRONIC INFECTIOUS DISEASES.}

Tuberculosis of the eye is rare. It may involve the iris (page 330), or the choroid (page 352), with distinct characteristic tubercular deposits. It may affect the conjunctiva, causing an intractable inflammation and thickening (page 268), or it may invade the lids, as lupus (page 461). Tubercles in the choroid generally occur in a late stage of general tubercnlosis; but the disease may be primary, or, at least, antedate other manifest lesions. Tubercular disease of the brain causes the same ocular symptoms as other organic brain disease.

Syphilis.-The primary sore may occur on the lids (page 453); or in the conjunctiva (page 268), especially on the caruncle and on the palpebral portion. The sccondary eruption may involve the lids, or cause falling of the lashes and eycbrows; but the important secondary lesions are those of the uveal tract. Iritis (page 319) may be 
the earliest of secondary symptoms, or one of the latest. Cyclitis (page 324) is of much the same significance. They yield well to specific treatment. Syphilitic choroiditis, chorioretinitis (page 369), optic neuritis (page 385), and dust-like opacity of the vitreous (page 427), are more intractable.

Tertiary syphilis of the lids canses tarsitis (page 450), and in both the lids and conjunctiva ulcers with thickened margins that may be mistaken for cancer. A gumma may occur in any part of the eye or its appendages. The more important lesions of the kind affect the iris and the ciliary body (page 330), the walls of the orbit (page 471), and the lacrimal passages (page 466) Chorioretinitis (page 369), retinitis pigmentosa (page 372), optic neuritis and atrophy are important manifestations in this stage. Glaucoma (page 445) may arise in this stage. Palsies of the ocular muscles (page 204) are most often due to tertiary syphilis. Syphilitic disease of the central nervous system, or of other organs of the body, may give rise to the concomitant eye-affections.

Inherited syphilis is the canse of the majority of cases of interstitial keratitis (page 292), and the accompanying iritis, cyclitis, and choroiditis. It oceasions most congenital opacities of the cornea (page 301), and may cause cataract and vitrcous opacities. It may give rise to many of the lesions of tertiary syphilis, and especially to retinitis pigmentosa, and disease of the lacrimal passages. The Hutchinson teeth and their significance are discussed on page 295.

Gonorrhea, by local infection of the conjunctiva, causes the great mass of cases of purulent conjunctivitis in adults (page 243), and of the ophthalmia of the newborn (page 245), with their complieations and sequels of suppuration of the cornea (page 278), corneal leucoma (page 301), and staphyloma (page 305), with permanent blindness. It may also, either with or withont gonorrheal rhemmatism, cause a mild conjunctivitis apparently without infection.

Iritis due to gonorrhca (page 319) may appear early, 
apart from any rhemmatic manifestations, or later with joint involvenent. In the former case it is very acute, with excessive plastic exudation, but yields to treatment and ends in good recovery. In the latter it is less violent, but shows a tendency to relapse, usually in connection with the relapse of the urethral discharge, and the rheumatic symptoms.

Leprosy causes destruction of the lashes and eyebrows, anestletic patches, and nodules in the lids ; and the resulting deformity of the lid may cause disease of the cornea, pannus (page 298). The disease also invades directly the conjunctiva and interior of the eyeball. The limbus is especially the seat of nodules. Iritis and vitreous opacity occur, or the eye may be lost through the corneal anesthesia and neuroparalytic ophthalmia (page 287).

Malaria.-Persons who have suffered from malaria are liable to certain forms of chronic keratitis (page 286), and malarial neuralgias often involve the ophthalmic branch of the trifacial nerve. Optic neuritis (page 385), nsually followed by partial atrophy, attends the tropical malarias. Sudden anemia of the retina may occur and be followed by optic atrophy. Retinal hemorrhages (page 360 ) occur, and effusions into the vitreous (page 429). A transient retinochoroiditis has been described as due to malaria. Sudden amaurosis, apart from the use of quinin, has also been reported.

\section{ACUTE INFECTIOUS DISEASES.}

All these discases may be attended in the acute febrile stage by hyperemia of the conjunctiva (page 60), and photophobia connected with meningeal irritation.

Measles may begin as an acute catarrhal conjunctivitis (page 237). Generally the conjunctiva participates in the irritation of the nucous surfaces, there being conjunctival hyperemia, photophobia, and increased lacrimation. Toward the close of the disease and afterward, there may remain a strong tendency to chronic conjunctivitis, catarrhal (page 253) or phlyctenular (page 261), with a 
tendency to corneal ulceration (page 276). This condition of lowered resisting power may last for many months. Keratomalacia (page 287) has been observed. There may also be a persistent asthenopia without obvious cause, or exeessive annoyance from low degrees of ametropia. Meningitis may cause muscular palsies, optic neuritis, and blindness.

Scarlatina, while less frequently attended with aente eatarrhal eonjunctivitis than measles, is more liable to be followed by serious corneal disease, and lacrimal disease, inflammation of the gland (page 467), or obstruction of the lacrimal passages. It is also liable to be followed by orbital cellulitis (page 468), and the eye-complications of meningitis. But the most important oeular lesions due to scarlet fever are those of albuminuric retinitis (page 365) and associated conditions.

Diphtheria may attack the conjunetiva, causing the elassical diphtheritic conjunctivitis (page 250), or less violent conjumetival disease with destruction of the cornea. More frequent is the diphtheritic paralysis of accommodation (page 333) which eomes on after convalescence from the throat-lesions has begm, and lasts several weeks. Partial or complete palsies of the extra-ocular muscle (page 214) are not rare. They are seen later, sometimes many months after the diphtheritie attack. Convergent squint following diphtheria may be established by excessive efforts during the period of weakened accommodation.

Influenza is followed by a period of nervous depression, during which paresis of accommodation (page 333) and excessive asthenopia or fatigne from use of the eyes are eommon. In a few eases it has been followed by narrowing of the field of vision and optic atrophy (page 391). The writer has seen lens-opacity rapidly inereased by it. It has been followed by orbital cellultitis (page 468). Glatcoma has been ascribed to it.

Smallpox eauses blindness through suppurating corneal ulcer (page 278) which appears near the end of the second week of the disease, never in the early stage. Such ulcers may heal, however, without perforation. 'The 
primary eruption rarely, or never affects the cornea; but it may appear on the conjunctiva and lids, and cause permanent deformity of the lid-margins or the lashes by the sears.

Vaccinia occasionally affects the eyelids, causing great swelling and induration with involvement of the related lymphatic glands. One or more pustules form and run the usual course. The conjunctiva at the height of the disease may present a eroupous deposit (page 250), but the cornea escapes without serious injury. The scars cause deformity of the lid or trichiasis. The disease is generally due to direct inoculation; but cases have been reported in which the lid-lesions followed inoculation elsewhere. Vaccination on the lids has been resorted to purposely for the cure of nevus (page 461).

Chicken-pox may be followed by subaeute catarrhal conjunctivitis or simple corneal ulcer.

Whooping-cough, by the violent straining of the conghing spells, causes hemorrhage which is most frequently loeated under the ocular conjunctiva (page 270), but which may occur in the lids or orbit, or so as to involve the optic nerve, causing blindness by optic atrophy, or may produce palsies through involvement of the motor nerves.

Mumps may cause edema of the lids (page 459) and chemosis through extension of the swelling from the parotid; or the lacrimal glands may be involved (page 457). Exophthalmos, optic neuritis, and consecutive optic atrophy have been reported.

Cerebrospinal meningitis usually affects the eyes. Conjunctivitis occurs in most eases. There may be edema of conjunctiva and lids, and other evidences of venous congestion. Thrombosis of the retinal vein (page 377), and retinal hemorrhages, have been noted. The cornea is often involved late in the disease. Plastic inflammation of the iris and choroid, and purulent choroiditis (page 341) and retinitis (page 362) leading to pseudo-glioma, are very important complications. Optic neuritis, tending to consecutive atrophy (page 391) if the patient survive, is not 
rare. Abnormalities of the pupil (page 72) are common, and palsies of the extra-ocular muscles (page 204) oceur. Purulent inflammation commonly ends in blindness, and plastic inflammation of the uveal tract may do the same. Optie neuritis may be followed by recovery, usually partial. Other conditions commonly end in recovery. A large proportion of cases presenting severe lesions of the eye do not survive the attack.

Erysipelas of the eyclids has already been deseribed (page 452). It is only when affeeting the lids and adjoining parts that it is likely to involve the eye, unless it. causes meningitis. If it extends into the orbit it may cause retinal thrombosis (page 376 ), optic neuritis (page 384 ), or optic ntrophy (page 391). Its tendency to cause glaucoma (page 438) has been frequently noted, but not satisfactorily explained. It may cause inflammation of the lacrimal gland (page 467) or of the lacrimal sac.

Pyemia, septicemia, and puerperal fever are liable to involve the eye, cansing either retinal hemorrhage (page 360) and thrombosis, or purulent inflammation of the choroid (page 341) or retina (page 362), and psendoglioma, or panophthalmitis through septie embolism.

Typhoid fever may be attended with catarrhal conjunctivitis (page 241), and is often sueceeded by decided ucakness of accommodation (page 14). It may be complicated by inflammation of the ureal tract; and in rare cases optic neuritis and subsequent atrophy occur. Typhus may cause conjunetivitis and uveal inflammation. In the typhoid state developing in any acnte disease, the cornea. is liable to suffer from exposure by imperfect closure of the lids, to become dry and hazy, and later to ulcerate.

Relapsing fever is followed after some weeks by ureal inflammation, especially cyclitis (page 324) and choroiditis (page 344 ), attended with ritreous opacity. It may end in recovery, or shrinking of the eye (page 350 ), or panophthalmitis (page 341 ).

Cholera.-In this disease sinking of the eye and contraction of the retinal vessels, with a dark venous color of the arteries, result from the general loss of fluid, and 
the cornea is especially liable to suffer from exposure, leading to keratitis if the patient survives.

Yellow fever begins with marked conjunctival hyperemia (page 237) and lacrimation. Subsequently the general yellow discoloration is added to the redness of the conjunctiva. Subconjunctival hemorrhages (page 270) and retinal hemorrhages (page 360) may oceur.

\section{CONDITIONS OF THE SEXUAL ORGANS.}

Certain of the diseases of the eye show a distinct predilection for one sex rather than the other. Thus, spontaneous retinal hemorrhages occur in young men, and idiopathic optic nenritis is more common in women.

Sexual excesses have seemed to cause optic atrophy in men, quite apart from syphilis or other causes.

Menstruation exerts a marked influence on chronic inflammatory disease, in some women, or upon the recurrence of conjunctivitis or scleritis. Disease of the uveal tract with vitreous opacities is especially influenced by it. Arrest of menstruation may be followed by hemorrhages, either subconjunctival or into the vitreous (page 429 ) or retina (page 360), and much hemorrhages may occur at recurring menstrual epochs. Profuse uterine hemorrhage may cause amaurosis.

Pregnancy may give rise to albuminuric retinitis (page 365), which may be so severe as to justify premature labor to prevent blindness. When the question arises, it is not merely a matter of blindness, since the retinal lesion indicates very grave danger to the patient's life and diminished chances of a living healthy child, cven if born at term. The prognosis for recovery from the retinal lesions, after termination of the pregnancy, is good as compared with other forms of albuminuric retinitis, if serious renal disease does not remain.

Lactation, if too prolonged, and seriously impairing the mother's strength, may canse blindness by anemia of the retina and subsequent optic atrophy. Slight abrasions of the cornea may give rise to a very painful ulceration 
(page 286). The patient may also suffer from asthenopia out of proportion to her ametropia, or the amount of eyework. Ocular disorders ascribed to the menopause are more frequently due to failing accommodation (page 144).

\section{DISEASES OF THE NOSE.}

The intimate relations of the eyes with the nose are illustrated by such common reflexes as the provocation of sneezing by the flashing of a bright light in the eyes, or the free lacrimation produced by any irritation of the nasal mucous membrane.

Acute coryza is commonly attended with conjunctival hyperemia and increased lacrimation, which frequently passes into an acute catarrlal conjunctivitis (page 237) or a blepharitis (page 449).

Catarrhal thinitis of the form compared to eczema of the skin, and frequently coexistent with eczema, is a common cause of relapsing phlyctemular conjunctivitis (page 261) or phlyctenular keratitis (page 268). Its cure nay be essential to prevent further relapses.

Hypertrophic thinitis may, by pressure, close the lower end of the lacrimo-nasal duct, causing lacrimal obstruction (page 465) with all its consequences. Cicatricial contraction after severe acute rhinitis or atroplic rhinitis may do the same thing. Chronic inflamnations within the nose are liable to extend to the lacrimal duct and sac, and produce obstruction by swelling of the lining membrane. Caries and necrosis of the adjoining bones, canse some of the most obstinate and hopeless eases of lacrimal obstruction.

Polypoid growths are probably a cause of optic atrophy. A form of atrophy (page 393) associated with dropping of watery fluid from the nostril, and associated with the presence of polypi, has been reported. The damaging pressure is doubtless exerted in the sphenoidal sinuses. Such growth have also seemed to eause strabismus.

Active treatment of nusal disease, especially by the 
galvano-cautery, has caused temporary amblyopia and even optic neuritis.

Diseases of cavities accessory to the nose (the frontal, maxillary, ethmoid, and sphenoid sinuses) canse caries or necrosis of the orbital walls (page 470), orbital abscess (page 468), orbital exostosis (page 476), exophthalmos (page 465), palsies of ocular muscles (page 204 ), optic neuritis (page 384), and optic atrophy (page 391). Such effects are usually caused by empyema of these cavities, but may be due to mucocele. Such disease nay also cause headaches, which, on account of their location, are likely to be ascribed to eye-strain.

\section{POISONS.}

The effects of drugs upon the eye have been elsewhere set forth, under mydriatics (page 127) or myotics (page 129) and the toxic amblyopias (page 397). Mydriatics may produce decided visual hallucinations. These are also very striking in poisoning by Indian lemp and the mescal button. Myosis (page 76) is one of the effects of poisoning by opium, chloral, and muscarin. Paresis of the ocular muscles and squint with diplopia may be produced by alcohol, gelsemium, and to a less extent by other nareotics. Yellow vision, preceded by brief violet vision, is one of the most striking symptoms of poisoning by santonin. 



\section{BIBLIOGRAPHY.}

In addition to those mentioned in the preface to the first edition, the following publications, all in the English language, will be found most helpful by the student who desires to extend his studies beyond the limits of the present rolume.

\section{GENERAL WORKS.}

Pathology of the Eye. J. Herbert Parsons. Two vols., 1905.

The Eye and Nervous System. Their Diagnostic Relations. By Various Authors. Edited by W. C. Posey and W. G. Spiller, 1906.

The Fundus Oculi, with an Ophthalmoscopic Atlas. W. Adams Frost, 1896.

Text-book of Ophthalmoscopy. Two vols., E. G. Loring, 1891.

Diseases of the Eye. Fifth edition. G. E. deSchweinitz, 1906.

Text Book of Oplithalmology. E. Fuchs. Translated by A. Duane.

Modern Ophthalmology. J. M. Ball, 1904.

The Fye. Its Refraction and Diseases. E. E. Gibbons. Two vols., 1905.

On Becoming Blind. E. Javal. Translated by C. E. Edson, 1905.

\section{ANNUAL AND OCCASIONAL PUBLICATIONS.}

The Ophthalmic Year-book. Edited by Edward Jackson and G. E. deSchweinitz. Since 1904. Including list of all ophthalmic publications.

Practical Medicine Series of Year Books. Diseases of the Eye. Edited by Casey A. Wood. Since 1901.

Progressive Medicine. June volumes since 1899.

American Year Book of Medicine and Surgery. Volume on Surgery. Since 1896.

Transactions of International Ophthalmological Congresses. Tenth, 1904.

Transactions American Ophthalmological Society. Ten vols. since 1865.

Transactions of the Ophthalmological Society of the United Kingdom. Twenty-five volumes since 1881 .

Transactions of the Section on Oplithalmology of the A. M. A. Fifteen volumes since 1891 .

Transactions of the American Academy of Ophthalmology and OtoLaryngology since 1896.

Royal London Ophthalmic Hospital Reports. Sixteen volumes. Issued in parts.

New York Eye and Ear Infirnary Reports. One part each year since 1893. 


\section{MONOGRAPHS AND JOURNAL ARTICLES. Examination of Vision.}

Principle of Test Type Construction. B. A. Randall, "Amer. Jour. of Ophth.," July, 1905.

Determination of Acuteness of Vision and Graduation of Optotypes. John Grcen, "Trans. Amer. Ophth. Soc.," 1905.

Studies in the Light Sense. P. J. Hay, "Arch. of Ophth.," March, 1905.

Bjerrum's Method of Testing Field of Vision. A. H. H. Sinclair, "Trans. Ophth. Soc. of Unitel Kingdon," vol. xxr.

Recent Improvements in Perimetry. F. A. Davis, "Ophth. Record," May. 1906.

Color Vision and Color Blindness. Second Edition. J. E. Jennings.

\section{Extersal Examination of the Eye.}

Atlas of the External Diseases of the Eye. O. Haab. Edited by (i. F. deschweinitz.

Transillunination of the Sclera. H. R. Swanzy, "Ophth. Review," Feb., 1905.

Measurement of Prominence of Eyeball. Edward Jackson, "Amer. Jour. of Med. Sciences," July, 1903.

\section{Opithalmoscopic Examination.}

Atlas and Epitone of Ophthalmoscopy and Ophthalmoscopic Diagnosis.

O. Haab. Edited by G. E. deSchweinitz, 1901.

The Ophthalmoscope and How to Use It. James Thorington, 1906.

Ophthalmoscopic Examination of the Macula. Edward Jackson, "Ophth. Record.," June, 1903.

Blood Tessels of the Optic Disk in Some Lower Animals. E. Nettleship, "Trans. Ophth. Soc. of United Kingdom," vol. xxr.

The Ocular Fundus as Seen by the Mercury Vapor Lamp. M. S. Mayou, "Lancet," Narch, 1903.

\section{General Refraction of tife Eye.}

Anomalies of Accommodation and Refraction of the Eye. F. C. Donders, 1864.

The Refraction and Accommodation of the Ere and Their Anomalies. E. Landolt. Translation by C. M. Culver, 1886.

The Refaction of the Eve. Thirteenth Fdition. G. Hartridge. Refaction and How to Refract. Third Edition. James Thorington. Refraction and Motility of the Eye. W. N. Sonter.

Skiascopy and Its Practical Application. Fourth edition. E. Jackson. Photoscopy (Skiascopy or Retinoscopy). M. D. Stevenson. 


\section{Accommodation and Cychoplegics.}

Further Investigations on Accommodation. K. Grossmann, "Ophth. Review," December, 1904.

Mechanisnı of Accommodation and Astigmic Accommodation. E. Jackson, "Trans. Amer. Acad. of Ophth. and Oto-Iaryngology," 1905.

Apparent Power of Accommodation with Ectopia Lentis. J. W. Charles, "Amer. Jour. of Ophth.," May, 1905.

Strength of the Different Mydriatics and Myotics. E. Jackson, "Trans. Sec. on Ophth., Amer. Med. Assn.," 1895.

\section{Errors of Refraction and Lenses.}

Myopia. Priestley Smith, “Ophth. Review,” December, 1901.

Removal of the Crystalline Lens in High Degrees of Myopia. S. Snell, "Brit. Med. Jour.," Feb. 27, 1904:

Practical and Theoretical Treatise on Astignatism. S. M. Burnett, 1887. Effects of Lid Pressure on the Cornea. G. J. Bull, "Trans. Eighth International Ophthalmic Congress," Edinburgh, 1893.

The Symmetrical Aberration of the Eye. E. Jackson, "Trans. Amer. Ophth. Soc.," 1888.

Anisometropia. A. Duane, "Arch. of Ophth.," Nov., 1901.

Spectacles and Eye-glasses. Their Forms, Mounting and Proper Adjustment. R. J. Phillips.

Biographic Clinics. Three vols. G. M. Gould.

\section{Disorders of Ocular Movements.}

The Muscles of the Eye. Lucien Howe.

Tests and Studies of the Ocular Muscles. Also the Clinical Use of Prisms. E. E. Maddox.

Squint: Its Causes, Pathology and Treatment. Second edition. C. Worth.

Ophthalmic Neuro-Myology. G. C. Savage.

Strabismus or Squint, Latent and Fixed. F. Valk.

Types of Eye Movement. R. Dodge, "Amer. Jour. of Physiol.," Jan., 1903.

Paralysis of Convergence. A. Duane, "Ophthalmology," Oct., 1906.

Deficiency of Adduction and Abduction. Retraction Movement and Contraction of Palpebral Fissure. A. Duane, "Arch. of Ophth.," March, 1905.

Nystagmus. A. Duane, "Arch. of Ophth.," Sept., 1905.

Stereoscopic Exercises with Series of Pictures. A. B. Hale, "Jour. Anier. Med. Assn.," Oct. 10, 1903.

Spasmus Nutans. M. Buchanan, "Ann. of Ophth.," July, 1905.

\section{Diseases of the Coxjuxctiva.}

The Conjunctiva in Health and Disease: N. B. Harman.

Bacteriology of the Conjunctiva. W. B. I. Pollock, "Trans. Ophth. Soc. of Uniterl Kingdom," vol., xxv. 
Bacterial Types of Acute Conjunctivitis. A. Duane, "Trans. Amer. Ophth. Soc.," 1905.

Clinical Importance of the Diplobacillus of Morax and Axenfeld. 11. Gifford, "Ophth. Record," Nov., 1905.

Conjunctivitis Nodosa with Histological Examination. G. E. deSchweinitz and E. A. Shumway, "Trans. Amer. Ophth. Soc.," vol. $\mathrm{x}$.

Fatal Septicemia Due to Ophthalmia Neonatorum. E. W. Stevens, "Ophth. Record," Nov., 1905.

Treatment of Purulent Conjunctivitis. M. Standish, "Trans. Sec. on Ophth., Amer. Med. Assn.," 1904.

Parinaud's Conjunctivitis. C. N. Spratt, "Arch. of Ophth.," MarchMay, 1906.

Vernal Conjunctivitis. W. C. Posey, "Jour. Amer. Med. Assn.," July 25, 1903.

The Ophthalmic History of an English School. Sydney Stephenson, "Arch. of Ophth.," July, 1900.

Pingnecula and Pterygium. A. Alt, "Amer. Jour. of Ophth.," July, 1905.

Pemphigus of the Conjunctiva. W. B. Marple, "New York Eye and Ear Infirmary Rep.," 1900.

Conjunctivit is Petrificans. W. C. Posey, "Ann. of Ophth.," April, 1905.

Tumors of the Conjunctiva. E. A. Shumway, "Jour. Aner. Med. Assn.," Sept. 26, 1903.

\section{Diseases of the Cornea axd Sclera.}

Corneal Epithelium in Repair of Ulcers E. Fnchs, "Trans. Ophth. Soc. of United Kingdom," June 13, 1902.

Quinine for Corneal Ulcers. A. Lawson, "Trans. Ophth. Soc. of United Kingdom," vol. $\mathrm{xxv}$.

Serpent Ulcer of the Cornea caused by the Pneumococens. IH. Giflorl, "Areh. of Ophth.," Mareh, 1898.

Suppmrating Ulecr of the Cornea. C. J. Kipp, "Jour. Amer. Med. Assn.," Aug. 9, 1902.

Chronic Creeping Ulcer of the Cornea. E. Nettleship, "Trans. Ophth. Soc. of United Kingdom," Nov. 8, 1901.

Dendritic Keratitis. J. W. Charles, "Amer. Jour. of Ophth.," April, 1904.

Aspergillus Keratitis. J. M. Ball, “Amer. Med.,” July 6, 1901.

Trophic Keratitis. G. C. Harlan, "Trans. Amer. Ophth. Soc." 1897.

Is Keratitis Ever caused by Rheumatism? I. Connor, "Ophthalmology," July, 1905.

Chancre of the Eye Lid with Interstitial Keratitis. J. T. Carpenter, "Ophth. Record," Dec., 1905.

Corneal Lesions of Acruired Syphilis. S. Stephenson, "Ophthalnoscope," November, 1903.

Family Degeneration of the Cornea. R. W. Doyne and S. Stephenson, "Ophthahmoscope," May, 1905.

Corneal Cysts. F. I. Oatman, "Areh. of Ophth.," May, 1904.

Episcleritis and Scleritis. A. Alt, "Amer. Jour. of "Ophth.," April, 1903. 


\section{Diseases of the Uveal Tract.}

Uveitis. G. E. deSchweinitz, Hiram Woods, Harry Friedenwald, Howard F. Hansell, W. H. Wilder, 'T. A. Woodruff', W. B. Marple. Reprint from "Jour. Amer. Med. Assn.," 1902.

Recurrent Iritis. H. Woods, "'Trans. Amer. Ophth. Soc.," 1905.

Iritis with Bright's Disease. A. Alt, "Amer. Jour. of Ophth.," July, 1905.

Tubercular Iritis Diagnosed and Treated by Tuberculin. W. E. Gamble and E. V. L. Brown, "Jour. Amer. Med. Assn.," Oct. 14, 1905.

Cysts of Posterior Surface of Iris. E. L. Oatman, "Arch. of Ophth.," May, 1905.

Sarcoma of the Ciliary Body and Iris. C. A. Wood and Brown Pusey, "A reh. of Ophth.," July, 1902.

Paralysis and Paresis of the Muscle of Accommodation. G. F. Suker, "Amer. Jour. of Oplith.," July and August, 1903.

Theories of Sympathetic Ophthalmia. H. Gifford, "Arcl. of Ophth.," Nov., 1902.

Sympathetic Inflammation Following Panophthalmitis. W. Zentmayer, "Jour. Amer. Med. Assn." Aug. 19, 1905.

Metastatic Choroiditis. C. S. Bull, "Trans. Amer. Ophth. Soc." 1901.

Meningitis Following Excision of the Eye Ball. C. D. Marshall, "Ophthalmoscope," Dec., 1905.

Central Superficial Choroiditis. T. B. Schneideman, "Amer. Jour. of Ophth.," Jan., 1905.

The Choroidal Arteries a Factor in the Localization of Choroiditis and Retinitis. E. Nettleship, "Royal London Ophth. Hospital Rep.," $\mathrm{xv}, 3,1903$.

Tubercle of the Choroid. G. Carpenter and S. Stephenson, "Ophthalmoscope," August, 1905.

Prognosis of Uveal Sarcoma. C. D. Marshall, "Royal London Ophth. Hospital Rep.," xv, 1.

Metastatic Carcinoma of the Choroid. E. L. Oatman, "Amer. Jour. of Med. Sciences," March, 1903.

\section{Diseases of the Retina.}

Renal Retinitis. E. Nettleship, "Royal. London Ophth. Hospital Rẹp.," xv, 4.

Renal Retinitis in Young Subjects. E. Nettleship, "Royal London Ophth. Hospital Rep.," xvi, 1.

Duration of Life after Appearance of Albuminuric Retinitis. S. Snell, "Lancet," July 15, 1905.

Ophthalmic Changes in Chlorosis, Pernicious Anemia, and Leucocythemia. C. A. Oliver, "Trans. Amer. Ophth. Soc.", 1897.

Pigmentary Degeneration of the Retina. W. L. Pyle, "Trans. Amer. Ophth. Soc.," 1903.

New Formed Vessels in the Retina. S. M. Burnett, "Ophth. Record," Dee., 1899.

Ophthalmoscopic Evidence of General Arterial Disease. Marcus Gunn, “Trans. Ophth. Soc. of United Kingdom," March, 1898. 
Obstruction of the Retinal Circulation. A. H. Thompson, "Ophth. Review," March-April, 1902.

Treatment of Recent Embolism of Retinal Arteries by Digital Massage. II. V. Würdemann, "Trans. Amer. Acad. of Ophth. and OtoLaryngology," 1905.

Cyanosis Retinæ. W. C. Posey, "Jour. Amer. Med. Assn.," Sept., 1905. Treatment of Detachment of the Retina. W. B. Marple, "New York Eye and Ear Infirmary Rep.", 1904.

Pseudoglioma: Cystic Changes in the Retina. G. E. deSchweinitz and E. A. Shumway, "Trans. Amer. Ophth. Soc.," 1901.

\section{Diseases of the Optic Nerve and Tracts.}

Optic Neuritis in Cerebral Tumors. Subsidence after Operation. L. Paton, "Trans. Ophth. Soc. of United Kingdom," xxv.

Retrobulbar Optic Neuritis. E. Nettleship, "Royal London Ophth. Hospital Rep." vol. xv, 1.

Hereditary Retrobulbar Neuritis. H. F. Hansell, "Trans. Amer. Ophth. Soc.," 1900.

Gumma of the Optic Nerve. A. Alt, "Amer. Jour. of Ophth.," July, 1905.

Tumors of the Optic Nerve. W. G. M. Byers, "Studies from the Royal Victoria Hospital," Montreal, Aug., 1901.

Ocular Symptoms of Lesions of the Optic Chiasm. G. E. deSchweinitz and J. T. Carpenter, "Trans. Sec. on Ophth., Amer. Med. Assn.," 1904.

Architecture of the Cerebral Apparatus. W. E. Gamble, "Ann. of Ophth.," April, 1904.

The Mrris and Gale Lectures on the Neurology of Vision. J. H. Parsons.

Binocular and Stereoscopic Vision, Decussation of the Optic Nerve, Ocular Movements, Pupil and Light Reflex. W. Harris, "Brain," xxvii, No. 15, 1904.

\section{Amblyopias.}

Toxic Amblyopias. G. E. deSchweinitz.

Toxic Amblyopias. Casey A. Wood.

Tobacco Amblyopia: Analysis of Urine. G. E. deSchweinitz and D. I. Edsall, "Trans. Amer. Ophth. Soc.," 1903.

Poisoning by Wood Alcohol. C. A. Wood and F. Buller, "Trans. Sec. on Ophth., Amer. Med. Assm.," 1904.

Scintillating Scotoma. Transient Functional Hemianopsia. C. J. Kipp, "Jour. Amer. Med. Assn.," April 22. 1905.

New Tests for Simulated Monocnlar Blindness. Edward Jackson, "Phila. Med. Jour.," A pril, 16, 1898.

Congenital Word Blindness. J. Hinshelwood, "Ophthalmoscope," Oct., 1904. 


\section{Diseases of the Vitreous and Lens.}

Heredity in Various Fornss of Cataract. E. Nettleship, "Royal London Ophth. Hospital Rep.," xvi, 3 and 4.

Association of Cataract with Uncinariasis. A. W. Calhoun, "Ophth. Record," April, 1904.

Regeneration of the Crystalline Lens. R. L. Randolph, "Johns Hopkins Hospital Rep.", vol. ix.

Coralliform Cataract. J. H. Fisher, "Trans. Ophth. Soc. of United Kingdom," $\mathrm{xxv}$.

Extraction of Immature Senile Cataract. A. E. Bulson, Jr., "Jour. Amer. Med. Assn.," Sept. 23, 1905.

Reclination of the Lens. F. T. Rogers, "Jour. Amer. Med. Assn.," April, 22, 1905.

Spontaneous Hemorrhage into the Vitreous. T. B. Schneideman, "Trans. Amer. Acad. of Ophth, and Oto-Laryngology," 1905.

Vascular Growths in the Vitreous. W. B. Marple, "Trans. Amer. Ophth. Soc.," 1901.

Persistent Remains of the Fetal Hyaloid Artery. D. DeBeck, 1890.

\section{Disorders of Tension of Eyeball.}

Pathology and Treatinent of Glancoma. Priestley Smith.

Glaucoma. Its Symptons, Varieties, Pathology and Treatment. A. W. Stirling.

Glaucoma and the Influence of Mydriatics and Myotics. Edward Jackson, "Amer. Jour. Med. Sciences," A pril, 1898.

The Field of Vision in Glaucoma. G. E. deSchweinitz, "Ann. of Ophth.," 1899.

Iridectomy for Simple Glancoma. C. S. Bull, "Trans. Amer. Ophtlı. Soc.," 1902.

Physiology of the Sympathetic in Relation to the Eye. G. E. deSchweinitz, W. H. Wilder, J. M. Ball and J. E. Weeks, 1904.

\section{Diseases of THE LIDS.}

Blastomycosis of Eye Lid. W. H. Wilder, "Jour. Amer. Med. Assn.," Dec., 31, 1904.

Clancre of the Fye Lids. David De Beck.

Pediculi Ciliaris. P. N. K. Schwenk, "Wills Eye Hospital Rep.," 1895.

Ophthalmic Herpes. W. C. Bane, "Jour. Amer. Med. Assn.," Dec., $21,1901$.

Associated Movements of the Eye-lid and Jaw. G. C. Harlan, "Ophthalmoscope," May, 1904.

Emphysema of Lids. T. R. Pooley, "Arch. of Ophth.," Jaul., 1901.

Lymphoid Infiltration of Lids. E. Nettleship, " Royal London Ophth. Hospital Rep.," May, 1902.

Trichiasis and Operations for Trichiasis. W. E. Cant, "Trans. Ophth. Soc. of United Kingdon,", vol. xxiv. 


\section{Lacrimal Disease.}

Chronic Enlargement of Lacrymal and Salivary Glands. Wm. Osler, "Amer. Jour. Med. Sciences," Jan., 1898.

Bilateral Enlargement of the Lacrimal Gilands. W. T. Shoemaker, "Anu. of Ophth.," July, 1904.

Trammatic Dislocation of the Lacrimal Gland with Foreign Body in the Orbit. E. Jackson, "Ophth. Record," August, 1904.

Use and Abuse of the Laerimal Probe. G. F. Suker, "Amer. Jour. of Ophth.," Sept., 1904.

Extirpation of the Lacrimal Sae. A. Knapp, "Arch. of Ophth.," July, 1903.

\section{Diseases of the: Orbit.}

Mrechanism of Enophthalmos. W. T. Shoemaker, "Ann. of Ophth.," July, 1900.

Intermittent Exophthalmos. W. C. Posey, "Jour. Amer. Met. Assn.," Feb. 18, 1905 .

Pulsating Exophthalmos. H. F. Hansell, "Jour. Amer. Med. Assu.," Feb. 18, 1905.

Treatment of Malignant Disease of Orbit by X-Ray. C. S. Bull, "Trans. Amer. Ophth. Soc.," 1905.

Anophthalmos. J. H. Claiborne, "Trans. Amer. Ophth. Soc.," 1901.

\section{Injuries to the Eye and Related Parts.}

Hemorrhage in the Eye Present at Birth. F. B. Coburn, "Arch. of Ophth.," May, 1904.

Late Results of Birth Injury to Cornea. L. Buchaman, "Trans. Ophth. Soc. of United Kinglom," xxy.

Blasting Eye Injuries. J. A. Donovan, "Jour. Amer. Med. Assm.," Aug. 15, 1905.

Foreign Bodies Retained in the Cornea. E. Jackson, "Brit. Med. Jour.," Jan. 8, 1898.

Injuries to the Eye from Particles of Analine Copying Pencil. J. M. Ray, "Ophthalmology," Oct., 1905.

Methol of Loealizing Foreign Bodies in the Orbit. V. H. IInlen, "Jour. Amer. Med. Assn.," A pril 2, 1904.

Methods for Localizing Foreign Bodies in the Eye by Roentgen Rays. J. E. Weeks, "Trans. Amer. Ophth. Soc.," 1905.

Metallic Foreign Bodies within the Eve and Their Removal. G. E. deSchweinitz, "Amer. Jour. of Ophth.," A pril, 1905.

Magnet Extraction. A. Haab, "Jour. Amer. Med. Assn.," Ang. 30, 1902.

Practical Remarks on Magnet Operations. J. Hirsehberg, "Ophthalmoseope," Feb., 1905.

Orbital Traumatisun Causing Monocular Blindness. P. A. Callan, "New York Eye and Ear Infirmary Rep.," 1893.

Blindness and Oevilo-motor Palsies from Injuries not Inrolving the Optic or Oeulo-motor Nerres. A. A. Hubbell, "Trans. Sec. on Ophth., Amer. Med. Assin.," 1904. 
Expert Testimony as it Relates to Ophthalmology. D. T. Vail, "Anier. Jour. of Ophth.," Sept., 1905.

Ocular Injuries, Pensions and Insurance Rates Estimation of Loss of Earning Ability. H. V. Würdemann, "Ophthalmology," Jan., 1905.

\section{Remedies and Their Applications.}

Ocular Therapeutics. A. Darier and S. Stephenson, 1903.

Ophthalmological Therapeuties. Landolt and Gygax.

The Treatment of Diseases of the Eye. V. Hanke. Translated by J. H. Parsons and Geo. Coats.

Ocular Therapeutics. F. W. Mr. Ohlemann. Edited by C. A. Oliver.

Subconjunctival Salt Injections. S. D. Risley, "Jour. Amer. Med. Assn.," August 12, 1905.

Electro-cautery for Corneal Wounds and Ulcers. J. A. Donovan, " Amer. Jour. of Ophth.," Oct., 1903.

Conical Cornea, and Hot Air Cautery. K. Grossmann, "Brit. Med. Jour." Aug. 26, 1905.

Diaphoresis in Ophthalmic Therapeutics. H. Woods, "Jour. Amer. Med. Assn.," Dec., 24, 1904.

Salicylate of Sodium in Large Doses in Inflammatory Eye Diseases. H. Gradle, "Ophth. Record," Feb., 1903.

Infiltration Anesthesia. H. V. Würdemann, "Trans. Sec. on Ophth., Amer: Med. Assn.," 1895.

Storaine: The New Local Anesthetic. S. Stephenson, "Ophthalnoscope," Nov., 1904.

Alypin: A New Local Anesthetic. S. Stephenson, "Ophthalmoscope," Nov., 1905.

Use of Thiosinamin. G. F. Suker, "Jour. Amer. Med. Assn.," Aug. 9, 1902.

Dionin. A. Darier, "Ophthalmoscope," Mareh, 1904.

\section{Operations.}

Atlas and Epitome of Operative Ophthalmology. O. Haab. Edited by G. E. deSchweinitz.

Ophthalmic Operations as Practiced on Animals' Eyes. C. A. Veasey.

Mental Derangement with Eye Operations. C. J. Kipp, "Arch. of Oplith.," July, 1903.

Evolution in Blepharoplasty. A. H. Benson. "Brit. Med. Jour.," Aug. 26, 1905.

Operations for Entropion of Lower Lid. J. M. Ball, "Ann. of Ophth.," Jan., 1905.

Modification of Panas' Operation for Ptosis. F. Allport, "Jour. Amer. Med. Assn.," April 11, 1903.

Operation of Motais. H. D. Bruns, "New Orleans Med. Jour.," June, 1905.

Treatment of Ptosis by Partial Resection of Tarsal Cartilage. E. Gruening, "New York Eye and Ear Infirmary Rep.," 1904. 
Transplantation of Pterygium. J. O. McReynolds, "Ophth. Record," May, 1901.

Technique of Implanting Thiersch Grafts for Symblepharon. F. C. Hotz, "Annals of Ophth.," July, 1905.

Division and Fixation of Flaps for Cicatricial Entropion. F. C. Hotz, "Aner. Jourr. of Ophth.," June, 1903.

Advancement Operations. II. W. Wootton, "Arch. of Ophth.," May, 1901.

Re-adjustment of Superior Rectus for Paresis of Superior Oblique. E. Jackson, "Ophth. Review," March, 1903.

Lateral Displacement of Tendon Insertions for Strabismus. E. Jack-. son, "Jour. Amer. Med. Assn.," Aug. 19, 1905.

Conjunctival Covering of Operative Wounds Opening the Anterior Chamber. E. C. Ellett, "Ophth. Record," April, 1903.

Extraction of Cataract in the Capsule. H. Smith, "Brit. Med. Jour.," Sept., 26, 1903.

Cataract with Small Peripheral Button-hole in Iris. H. B. Chandler, "Arch. of Qphth.," Jan., 1904.

Lens Extraction with Conjunctival Flap. F. M. Wilson and H. S. Miles, "Trans. Amer. Oplith. Soc.," 1902.

Intracapsular Irrigation in Cataract Operations. H. O. Reik, “Ann. of Ophth.," July, 1903.

Reclination of the Lens under Certain Conditions a Justifiable Operation. F. T. Rogers, "Trans. Sec. on Ophth., Amer. Med. Assn.," 1904.

Knife Needle Operation for Secondary Cataract. Edward Jackson, "Arch. of Ophth.," March-May, 1906.

Artificial Eye-balls. H. Snellen, "Ophth. Review," Dec., 1898.

Motility and Position of the Artificial Eye after Enucleation. Priestley Suith, "Ophth. Reriew," Jay, 1899.

Renoval of Eyeball, Conjunctival Sac, and Lid Margins. A. Alt, “Amer. Jour. of Ophth.," March, 1903.

Operation for Providing Cul-de-sacs for the Lodgnient of Artificial Eye. J. E. Weeks, "Trans. Tenth Internat. Congress of Ophth." 


\section{INDEX.}

A Badie, Ch., 441

Abbreviations, 23, 434

Abduction, 193, 231

congenital defect of, with retraction of eyeball, 235

Aberration, 186, 310, 410

Ablepharia, 448

Abrasion of coruen, 299, 487

A bscess of cornea, 278, 290, 291, 547 ring-, 274 of lids, 450

of orbit, 468

Abscission, 548

Absolute hyperopia, 149

scotoma, 39

Accommodation, 124, 132, 149, 152, 341

amplitude of, 126, 146

effect of, 125

spasm of, 149

weakness of, $41,144,164,33$ ?, 341

Acetanilid, 402, 511

Aching, 52, 53, 239

Achromatopsia. See Color-blindness.

Actual cautery, 283, 547

Acuteness of vision, 18, 20, 21, 25, 569

Adaptation to glasses, 190

Adduction, 193, 231

Adenoma, $3 \overline{5} 3$

Adherent leucoma, 70, 301, 304, 446

Adhesion of lids, 66. 238,455

Adjoining cavities, 583

sinuses, diseases of, 476

Adrenal extract, 520, 529

Adrenalin, 520

Advancement, muscular, 214, 222, 234,544

After-treatment of cataract, 556 of enucleation, 583

Age, changes of glasses with, 190 of patient, 18, 21, 26, 146, 221

Air-bubbles in vitreous, 497

Akromegaly, 570
Albinism, 88, 355

Albuminuric retinitis, $91,365,573$, 578,581

Alcohol amblyopia, 399

Alcxia, developmental, 406

Allen, Harrison, 295

Allport, F., 593

Alt, A., 588, 589, 590, 594

Altitudinal hemianopsia, 37

Alum, 512

Alypiu, 515

Amaurosis, 402, 573

Amaurotic family idiocy, 374

Amber yellow glass, 501

Amblyopia, 198, 397, 402

central, 40,397

congenital, 403

ex abusa. 397, 399

ex auopsia, 198

from acetanilid, 402

from alcohol, 399

from carbon bisulphid, 400

from iodoform, 400

from nitrobenzol, 400

from quinin, 401

from tobacco, 397

hysterical, 403

sinulated, 403

sympathetic, 334,341

toxic, 397

uremic, 365 , 573

with squint, 198

A mblyoscope of Worth, 221

Ametropia, 19. 124, 134, 267, 411

Amplitude of accommodation, 1:26. 146

Amyloid degeneration of conjunctiva, 269

Anchyloblepharon, 458

Anemia, 3.99, 363, 383, 572

of optic disk, 96, 3\$4

of retina, $93,359,577$

Anesthesia of cornea, 54, 287, 436

Anesthetics, 514 
Ancurism, 473, 567, 573

Angioid streaks in retina, 374

A ugioma, 271, 460, 474

Angle of anterior chamber, 4:39 of deviation, 111

of vision, 25

Aniline dyes, 67,510

Aniridia, 354

Anisometropia, 188

Anumlar syuechia, 327

Anomalies of choroid, 103

of iris and choroid, 353

of lids, 448

of macular region, $38 \%$

of optic disk, 9s

of pigmentation, 356

of refraction, 124

of retina, 381

of retinal vessels, $38 \%$

Anopthhalmos, 475

Anterior chamber, $40 \%, 425,547$ toreign body in, 495

sclerotomy, $4+1,549$

staphyloma, $30 \overline{5}, 548$

symblepharon, 270

synechia, $71,293,301,304$

Antimetropia, 188

Antipathy to single vision, 220

Antisepties, 507, 523

Antitoxin, diphtheria, 252

Antrum, maxillary, 476

Apex of prism, 106

Aphakia, 407, 41\%. 426

A poplexy, 56\%, 568

Apparent movement, $13 \%$ squint. 199, 219

Application of remedies, 500

Applications to conjunctiva, 504, 509,520

Aqueous humor, 407

Areus senilis, 70,301

Argyll-Robertson pupil, 74, 569

A rgyria, 273

Argyrol, 510

Aristol, 511

Arsenic, 511

Arterial pulsation, 437

Artificial eve, 564

leech, 5:99

Asepsis, 246, 505, 507, 523

Associated movements, 205

Assorted light, 104, 121

Asthenopia, 144, 151, 157, 174, 206. $22 \pi, 435,5 \pi 8,582$

Astigmatic lens, 184

Astigmatism, 46, 167, 169
Astigmatism, changes in, 186 diagnosis, 17.1, 176, 178, 180 irregular, 167

regular, :267, 169

treatment, 181, 188

varieties of, 169,172

Astigmia, 167

Astringeuts, 506, 511

Atresia of punctum, 463

Atrophy of eyeball, 350 of iris, $3: y$

of optie nerve, $98,391,398,567$

of retina, 361

retinal macular, $3 \pi 4$

Atropin, 127, 238, 277, 289, 296, 3\%2, $516,517,518,519$

Auramin, 510

Auto-intoxication as cause of iritis, 319

A vailable aceommodation, 146

Axenfeld, T., 243

Axial hyperopia, 147, 149

myopia, 155, 158

optic neuritis, 391. 397, 574

Axis of eylindrical lens, 168

BACTERIA, 67, 238, 242, 281

Bacteriologic examination, 67,240 , $242,245,252$

Balance of muscles, 20, 24, 192

Ball. J. M., 585, 588, 591, 593

Ballooning of iris, 328

Band of light in pupil, 180 opacity of cornea, 302

Bandages, 528

Bane, IV. C., 591

Base of prism, 106

Basedow's discase, 472, 534, 570

Benson, A. H., 593

Bibliography, 585-594

Bichlorid of mercury, 509

Bieoncave lens, 114

Biconvex lens, 115

Bident. 425

Binasal hemianopsia, 37

Biniodid of mereury, 509

Binocular co-ordination, 198

diplopia, 46, 195. 197, 219, 220

fixation, 40

fusion. 195, 206

magnifier, 68

vision, $33,15 \%, 164,191,198,213$, 220

Bisulphid of earhon, 400

Bitemporal hemianopsia, 37

Bjerrum's test of vision, 35 
Black cataraet, 412

Blackboard fields, 35

Blastony cosis, $44 \mathrm{~s}$

Bleeding, 323, 529

Blenuorrhea, 243, 256

Blepharitis, 448 ciliaris, 449 marginal, 449, 575

Blepharophimosis, 458

Blepharospasm, 56, 457

Blind spot, 33

Blinduess, $32,74,218,249,340,314$, $442,479,498$

Blood in anterior chamber, 408

Blood-vessels in vitreous, 430

Blue glass, $2: 27$

vision, 48

Blurring of sight, 147, 151

Boric acil, 510, 511, 514

Boroglycerid, 513

Bowman, Wm., 434

Brachymetropia, 155

Brain abseess, 387,567

disease, 389,567

tumor, $387,56 \pi$

Brief recurring episcleritis, 243

Bright's disease, 367,573

Brossage, 260

Brown, E. V. L.. 589

Broise of eyeball, 481, 483 of lids, 479

Bruns, H. D., 593

Buchanan, L., 592

Buchanan, M., 592

Bull, C. S., 589, 591, 592

Bull, G. J., 587

Buller, F., 590

Buller's shicld, 249, 529

Bullous keratitis, 286

Bulson, A. E., Jr., 591

Buphthalmos, 446

Burnett, S. M., 587, 589

Burning pain, 49, 239

Burns, 269. 272. 311. 462

Byers, W. G. M., 590

Calmoun, A. W., 590

Callan, P. A., 592

Calomel. 303, 520

Canal of Schlemm, 433. 443

Canaliculus, disease of, 464, 540

Cant, W. E., 591

Canthoplast.y, 261, 531

Canthotomy, 248, 261, 531

Capsule of lens, 77, 422, 553, 554

Capsulotomy, 423, 559
Cureinoma, 331, 353

Card records, 2:

Caries, orbital, 470

spinal, 569

Carotid, rupture of, 473

Carpenter, G., 589

Carpeuter, J. T., 588, 590

Caruncle, diseases of, 273

Case, history, 17

records, 20,2:, 28

Cassareep, 284

Cataphoria, 226

Cataract, $160,407,408,553,569$

anterior polar, 281,419

black, 412

capsular, 422

central, 421

choroidal, 412

complicated, 412, 555

congenital, 419

coraliform, 421

cortical, 412

diabetic, 414

diagnosis of, $413,421,423,444$

extraction, 417, 418, 553

fusiform, 421

glasses, 417

hard, 409

hypermature, 411

incipient, 411,415

juvenile, 418

knives, 553

lamellar, 420

mature, 411, 413. 416

Morgagnian, 412

nuclear, 412,418

operations, 553

partial, 419

perinuclear. 420

ripening operations, 416

secondary, 418, 422

senile, 409

soft, 418

swollen, 411

traumatic, 412, 48\%, 489, 496

treatment of, $415,421,423$

vision after extraction of, 418

zonular, 420

Catarrh of conjunctiva, 237, 253 $255,256,575$

Caterpillar hairs, 243, 493

Cansties, 272, 503, 506, 511

Cantery, 283, 547

Cavernous angioma, 460

sinus, thrombosis of, 469

Cavities adjoining orbit, 476, 583 
Cellulitis, orloital, 313, 5\%8

Centers of vision, $32,37,46$

Centrad, 111

Cent ral cutaract, 4:21

scotomia, 40, 397, 569, 574

Cerebral disease, 374. 389. 567

Cerebrospinal meningitis, $343,5 \pi 9$

Chalazion, 459, 53\%

Chancre, 268, $5 \pi 5$

Chandler, H. B., 594

Cliarles, J. W., 587, 588

Chemosis, 65, 239, 244, 342

Chicken-pox, 579

Children, applications to, 507

Chlorid of merenry, 509 of zine, 513,514

Chloroform, 514

Chloroma, 476

Choked disk, 385

Cholera, 580

Cholesterin ersstals, 83, 408, 429

Chorea, $2: \pi, 5 \%$

Chorioletinitis, 369, 576

Choroid, 87, 99, 341, 567

Choroidal atrophy, 100, 101, 160 , $174,344,34 \tau$

cataract, 412

coloboma, 3.8

crescent, 86

detachment, 349

exudate, 101, 160, 174

hemorrhage, 349

inflammation. See Choroiditis.

injuries, 483, 496

ossification, 349

pigment, 100

riug, 85,100

rupture. 102,484

sarcoma, 350

tuberculosis, 352, 575

vessels, $8 \pi$

Choroiditis, anterior, 317

('entral, 346

dilluse, 347

disseminated, $316,5 \tau 6$

localized, 346

myopic, 160, 346

plastic, 344

purulent, 341,579

senile, 347

Chronic conjunetivitis, 253

glancoma, 435,443

op:aities of cornea, 301

(Cilia, 5.5, 529

Ciliary body, gumma of, 330 sircoma of, 331
Ciliary body, wounds of, 488

muscle, $1: 24,1: 99,332$

Cilioretinal vesscels, 86

Circulation of blood in retina, 43

Cirenlatory disorders, 365, 374, 572

Claiborue, J. H., 592

Cleansing the eye, $246,505,507$

Cleft lid, 448

Closure of punctum, 463

Coats, G., 593

Coburn, F. B., 592

Cocain, 123, 322, 439, 515, 516, 518, 519

Cold applieations, 504

Colloid masses, 349,393

Collyria, 504, 507, 511, 515

Coloboma of choroid, 348,354

of iris. $3 \pi 4,5 \% 2$

of lens, 425

of lid, 448

of optic nerve, 99, 397

Color fields, 47

of fundus, 87

of iris, 71

perception, 47

scotoma, 40, 397

tests, 40

vision, $4 \pi$

Color-blindness, 48, 403

Coma, 568

Consbined extraction, 417

Comitant squint, 200, 203, 214, 223, 225

Commotio retinx, 483

Complementary colors, 49

Complicated cataract, 412. 555

Complications of enucleation, 563

Compound astigmatism, 172, 173

Concave lens, 113, 114, 163, 167 nirror, 137

Concomitant squint, 200, 203, 214 223,225

Concretions in conjunctiva, 271

Confusion colors, 49

Congenital amblyopia, 403

colobomas, 99, 348, 354, 425

color-blindness, 49, 403

opacity of corllea, $296,307,576$

squint, 198

word-blindness, 406

Conical cornea, 187, 309, 547

Conjunctiva, 60, 237

foreign bodies in, 492

wounds of. $48 \pi$

Conjunctival applications, 504, 506, 507,509 
Conjunctival catarrh. See Conjunctivitis.

discliarge, 66, 238, 243, 251, 254, 257

hemorrhage, 239

hyperemia, $60,237,577$

operations, 537

swelling, 65, 239, 244, 251, 342

Conjunctivitis, catarrhal, 237, 253, $255,261,575,577$

contagious, 241,243

croupous, 250

diagnosis of, $60,65,240,242,245$, $251,254,259,263,320$

diphtheritic, 250

diplobacillus, 242

exanthematons, 241

follicular, $2: 56$

granular, 256

lacrimal, 465

lymphatic, 261

membrallous, 253

Parinaud's, 25i

petrifying, 261

phlyctemular, 261, 575

prophylaxis of, 248

purulent, $243,5 \pi 6$

strumous, 261

treatment of, 240, 242, 243, 246, $252,254,256,259,263,504$, 509

verual, 255

Connor, L., 588

Consensual reaction, 74

Contraction of pupil, 75, 316

of visual field, 41, 392, 397

Contusions, 479, 481, 483

Conus, 102, 161

Convergence, 5\%, 193, 205, 218, 226

Convergent squint, 208, 210,222

Convex lens, 113, 115, 167

Convulsions, 568

Copper sulphate, 511

Coraliform cataract, 421

Corectopia, 353

Corelysis, 327, 552

Cornea, applications to, 504, 547

diseases of, 273

fanily degencration of, 302

foreign bodies in, 493,545

ring-abscess of, 274

temperature of, 275

transplantation of, 304

Corneal abrasions, 299

abscess, 278, 290, 291, 547

astigmatism, 172,180
Corveal blood-vessels, $273,288,292$, :294, 295

ectasia, 309

fistula, 447

gumina, 293

infiltration, 294

inflamnation. See Keratitis.

macula, 301

nebula, 301

opacities, $70,2 \tau 4,2 \tau \tau, 296,300$, 302,502

operatious, 545

phlyctenule, 288

pigment, 303

reflex, $70,81,83,88$

repair, 276

section, 284, 546, 553, 556

staphyloma, 305

surface, 17,18

ulcer, 244, 276, 546, 578

wounds, 487

Correcting leuses, 146, 153, 163, 166, $170,185,221,232,348,415$, 417,449

Corresponding points, 194

Corrosive sublimate, 509, 521

Cortical cataract, 412

Coryza, 581

Counting fingers, 29

Cover-test for squint, $199,219,227$

Crater-like pupil, 328

Credé method, 249

Crecping ulcer, 278

Crossed blindness, 32

cylinder, 184

diplopia, 197, 209, 212

Croupous conjunctivitis, 66, 250

Crown glass, 111

Cryptoglioma, 381

Cryptophthalmos, 448

Crystalline lens, 77, 124

aberration of, 187

absorption of, 490

astigmatism of, 172

changes in, 124, 125, 408, 440

diseases of, 408

dislocation of, 424, 439, 443, 480, 482

injuries of, 480, 482, 489, 496

opacity of. See Cataract.

removal of, $165,417,553,560$

Culture-tests, $6 \pi$

Culver, C. M., 586

Cupping of optic disk, 86, 97, 437

Curetting cornea, 283, 300, 546

Curvature hyperopia, 147, 149 
Curvature myopia, 155, 158

Cutting lacrimal stricture, 542

Cyanid of mercury, 509

Cyclitis, 320, 324, 326, 334, 574, 576 Cyclophoria. See Rotary Deviation. Cycloplegia, 127, 332, 481

Cycloplegies, 127, 222

Cylindrical lenses, 167, 183, 185

Cyst, conjunctival, 271

of iris, 332

of lacrimal gland, 468

of lid, 460,475

Cysticercus, 271, 380, 430, 460

Cystoid cicatrix, 447

Cystotome, 554

\section{DACRYOA DENITIS, 467}

Dacryocystitis, 466

Dacryolith, 464 -

Dacryops, 468

Dalrymple's signs, 472

Darjer, A., 593

Dark glasses, 348

room, 349,501

Daturin, 127

Davidson, J. Mackenzie, 500

Davis, F. A., 586

Day-blinduess, 359

De Beck, D., 591

Decentering of lenses, 232

Decussation at eliasm, 32

Degeneration, family, of cornea, 302

of iris, 329

Degree of prisms, 111

of squint. 192

Delirium, 568

Dendritic keratitis, 286

Dennett, W. S.. 111

Depth of anterior chamber, 407

Derby, H., 284

Dermatitis, 451

Dermoids, 266, 271, 311, 460, 474

Detachment of choroid, 349 of retina, $166,352,377,573$ of vitreous, 430

Developmental alexia, 406

Deviating ese, 192, 207, 214

Deviation by prisms, 111 of eye, $192,20 \%, 22 \%$

Diabetes, 315, 359, 368, 574

Diaguosis, 19

Diagrams, 21

Diathetic diseases, 574

Diet, 263, 297, 312

Dilatation of pupil, $75,76,440$
Diminished tension of eyeball, 447

Dionin, 520

Diopter, 117

Dioptric nedia, 105

system of numbering, 117

Dioptries, 104

Diphtheria bacillus, 251, 252, 253, 281

Diphtheritic conjunctivitis, 66,250 , 578

paralysis, $212,214,333,578$

Diplobacillus, 242,281

Diplococcus, 238, 256

Diplopia, 46, 194, 195, 197, 202, 206, $207,214,219,404,424$

Direct massage of lens, 416 method, 131

Discission for cataract, 558

Discoloration of conjunctiva, 273

Disk. See Optic Disk.

Disks, gelatin, 507,508

Dislocation of eyeball, 480 of lacrimal gland, 468 of lens, 424, 439, 445, 480, 482

Dispersion of light, 110

Displacement, lateral, of tendon insertion, 223,545 of punctum, 464

Distention of eyeball, 161, 432, 446

Distichiasis, $454,529,530$

Distortion of images, 45

Divergent rays, 104 squint, $157,209,212,221$

Division of tarsal ligament, 533 of npper lid, 248,533

Dodge, R., 587

Donders, F. C., 586

Donovan, J. A., 592, 593

Double concave lens, 115 convex lens, 114 images, 208 prism, 229

vision. See Diplopia.

Douche, 505

Doyne, R. W., 588

Dragged disk, 162

Dressings, 527

Drug eruptions, 451

Drusen, 349, 393

Duane. A., $585,587,588$

Duboisin, 127, 517, 518

Dusting powders, 511

Dyslexia, 571

Eсchy mosis, conjunctival, 270,498 of lids, 479,498 
Ectopia lentis, 424

Ectropion, 456, 534 organic, 456 paralytic, 456,534 u veæ, 331,353

Eczema, 261, 451

Edema of conjunctiva, 270 of lids, 64, 459, 579 of retiua, 362,573

Edge of prism, 110

Edsall, D. L., 590

Edson, C. E., 585

Educative treatment of squint, 223

Electricity, 213, 304

Electric-light retinitis, $3 \pi 1$

Electrolysis, 267, 530, 537

Electro-magnet, 498

Elevator, lid, 526

Ellett, E. C., 594

Embolism of retiual artery, 570, 574

Emmetropia, 123, 139

Emplysema, 64, 270, 459, 479

Encauthus, 273

Encephalocele, 475

Enophthalmos, 471, 480

Entoptic method, 42, 44

Entropion, organic, 455, 530 spasmodic, 455,530

Euucleation of the eye, 333, 341, 343,561

Epicanthus, 458

Epidermoid pearl of iris, 332

Epilation-forceps, 530

Epilepsy, 227, 569

Epiphora, 462, 569

Episcleritis, 243, 311

Epitarsus, 448

Epithelial grafting, 534, 538

Epithelioma. 271, 461

Equivalent lenses, 116

Erect image, 131, 138

Errors of refraction, 121, 144

Erysipelas, 343, 441, 452, 580

Erythema, 451

Erythropsia, 48

Eseriı, 129, 442, 519

Esophoria, 226

Ether, 514

Ethmoidal disease, 389, 478

Ethylate of sodium, 460

Eucain, 515

Euphthalmiu, 129, 516

Eve, 383

Eversion of lids, 57

Evisceration of the globe, 338, 341, 564
Examination, bacteriologic, 67 entoptic, 42,44

microscopic, 67

of case, 17

of conjunctiva, 60

of eye, 18,568

of lids, 55

ophthalmoscopic, $18,80,81,131$, $142,176,496$

Exanthematous conjunctivitis, 241 eruptious, 451

Excision of anterior staphylona, 308,548

of cervical sympathetic, 441

of chalazion, 460,537

of pterygium, 266, 537

of roots of lashes, 531

Exciting eye, 334

Exclusion of light, 501

of pnpil, 327

Exercises, gymnastic, 213, 223, 233

Exophoria, 226

Exophthalmic goiter, 472, 534, 570

Exophthalmos, 65, 469, 471, 472, 480

Exostosis, 476

Expression for trachoma, 259, 539

Extended tenotomy, 544

External rectus, 208, 210

Extirpation of lacrimal sac, 460 , 542

Extract of suprarenal body, 520, 529

Extraction of cataract, 417, 553, 557 of foreign body, 493, 495, 498, 545. 560

Eyeball, dislocation of, 480

operatious on, 560

promiuence of, 55

rupture of, 480

Eyebrows, 454

Eye-douche, 505

Eye-glasses, 189

Eye-ground, 84

Eyelashes, 55

Eye-shade, 528

Eye-strain, 17, 145, 150, 157, 160, $174,227,253,314,324,388$, $440,449,569,570,572$

Eye-symptoms of general diseases, 566

FACral paralysis, 457

Facultative hyperopia, 149

Failure of accommodation, 147, 151

False image, 197, 207 
False scotoma, 39

Family degeneration of cornea, 302 history, 18

Far-point, 148

Far-sight, 147

Fatty degeneration in retiua, 91, 359

Fibroma, 271, 460, 476

Fibrosarcoma, 476

Field of vision, $23,33,47,373,377$, $391,437,443,498,567,569,571$

- for colors, 47, 392, 397

Filamentous keratitis, 287

Filaria, 2\%1, 430

Filix mas amblyopia, 40:

Finger-tests, 29,36

Fisher, J. H., 591

Fissures of lids, 263, 264, 289, 451

Fistula, lacrimal, 467 of lid, $460^{\circ}$

Five-minute angle, 27

Fixation foj operation, 526 point, 192

Fixing eyc, 192, 207

Flame-shaped licmorrhages, 91, 360

Flashes of light, $4 \overline{5}, 345$

Fliut glass, 111

Fluid vitrcous, 428

Fluoresein, 494, 5:0

Focal distance; 116

illumination, 68

lines and interval, 170, 173

Foens, 113

Focussed light, 104

Fogging, 121

Follienlar conjunctivitis, 256

Fomentations, 503

Forcens, 526. 527, 529, 530, 550

Foreign body, 51. 265, 271

in anterior chamber, 495

in choroid, 496

in conjunctiva, 492

in cornea, 493, 545

in iris, 495

in lens. 496

in lids and orbit, 492

in retina, 496

in sclera, 495

in vitreous, 496,560

sensation of $a, 53,239$

Formaldehyd, 508

Foven, 89

Fracture involving orbit, 479

Friedenwald, H., 589

Frontal sinus, 477

Frost, W. A., 585
Fuclıs, E., 585, 588

Full correction, 153

Fundus, influence of light on color of, 143 reffex, 81,81

Fusiform eutaliact, 421

Fusion binocular', 2:24

training in squint, 221

tubes, 220

Galvanisis, 466

Galvino-culutery, 283, 547

Gamble, W. E., 589, 590

Gangrene of lids, 453

Gelatin disks, 507,518

General anesthesia, 514

discases, $19,157,566$

rest, 501

Gibbons, E. E., 585

Gifford, H., 243, 588,589

Glasses, ehanges with age, 190

smoked, 501

Glaucoma, $407,418,434,569$, 574, 576

absolute, 436

acute, 435

chronic, 435, 443

clip, 98, 437, 443

diagnosis of, 440,444

fulminant, 436

hemorrhagie, 444

incipient, 435

inflammatory, 435

iridectomy, 441, 551

malignant, 443

post-iritic, 445

primary, 435, 443

secondary, 444

simple, 443

treatment of, $441,444,502,551$

with exacerbations, 435

Glioma or gliosarcoma of retina, $352,380,445$

Glycerol of tannin, 512

Goiter, exophthalmic, 534, 570

Golovine, 478

Gonocoecus, 243, 245

Gonorrheal conjunctivitis, 243, 215, 282,576

iritis, 319, 5\%6

Gonld, Geo. If., 587

Golt, $312,368,440,574$

Gowers, W. R., 32

Gradle, H., 593

Graduation of trial frames, 168

Gracfe's kuife, 553

sign, 472 
Graefe's test, 229

Grafts, epithelial, 535, 538

Gram method, 67

Grandelenuent, 356

Grauular conjunctivitis, 256

Granulated lids, 244, 254, 256

Grattage, 260

Graves's disease, 472, 570

Green, John, 586

Grippe, 578

Grossmanu, K., 587, 593

Ground glass, 214

Growth of lens, 440

Gruening, E., 593

Gumma of cornea, 293

of iris and ciliary body, 330

Gunn, Marcus, 589

Gygax, 593

Gymuastic exercises, 213, 223

HAAB, A., 592

Haab, O., 586, 593

Haab's magnet, 561

Hale, A. B., 587

Hallucinations, 583

Halo atrophy, 438 symptom, 435

Hanke, V., 593

Hansell, H. F.. 589, 590, 592

Hard cataract, 409

Harlan, G. C., 588, 591

Harlan's test, 404

Harman, N. B., 587

Harris, W., 590

Hartridge, G.. 586

Hay, P. J., 586

Haziness of retina. 90

Headaehe, 52, 53, 151, 160, 174, 205, 227,567

Heart disease, 572

Heat. 248, 502, 507

Hemianopsia, 34, 36, 42, 74, 403

Hemichromatopsia, 38,48

Hemionia and hemianopia. Hemianopsia.

Hemorrhage, choroidal, 349 eonjunctival, 239

following cataract extraction, 556

in anterior chamber, 408

into vitreous, $429,482,497$

retinal, 90,360

Hemostaties, 503, 520, 529, 556

Hereditary optic atrophy. 393 srphilis, 295, 576

Herpes of cornea, 286, 287, 292
Herpes of lids, 451 zoster, 45:2

Heterochromia, 353

Heterophoria, 204, 225, 226, 231

Hinshelwood, J., 590

Hippus, 73,332

Hirsch berg, J., 592

Hirschberg's magnet, 560

History of (ase, 17, 18

Holden, W. A., 281

Hole in macula, 374

Holnigren test, 49

Holocain, 284, 515

Homatropiu, 127, 128, 516, 517, 519

Homonymous diplopia, 197, 208, 209, 210

hemianopsia, 36

Hordeolum, 450

Horn-like growths, 453

Horopeter, 194

Hot applications, 502, 503, 529

Hotz, F. C., 175, 176, 594

Howe, Lucien, 587

Hubbell, A. A., 592

Hulen, V. H., 592

Hutchinson, Jonathan, 292, 295

Hutchinson's teeth, 295

Hyaline bodjes, 349, 393

Hyalitis, 429

Hyaloid artery, 431

Hydatids, 430

Hydraulic curctting, 283

Hydrogen dioxid, 508, 529

Hydrophthalmos, 446

Hyoseyamin, 127, 517, 518

Hyperemia of conjunctiva, $60,23 \pi$, 261

of glancoma, 63

of iris, 71,315

of optic disk, 93,383

of retina, 92,358

of sclera, 63

pericorneal, $61,315,324$

See Hyperesthesia of the retina, 358

Hypermature cataract, 411

Hypermetropia, 147

Hyperopia, 123, 131, 139, 147, 221

absolute, 149

axial, 147

faenltative, 149

latent, 149

manifest, 149

of curvature, 147

total, 149

Hrperopie astigmatism, 173

Hyperostosis, 476 
Hyperphoria, 226

Hypertrophy of conjunetiva, 244, 245

of lids, $4 \pi 5$

of ocular muscles, 236

Hyplemia, 408

Hypopyon, 290, 407

Hysterieal amblyopia, 403, 5\%1

squint, $234,5 \% 2$

ILLUMINATION, focal, 68,525

of tests, 29

Images, true and fals $3,196,207$

Impairment of vision, 25, 30, 41, $147,151,158,173,318,353$, $391,409,436$

Implantation of artificial vitreons, $56 \overline{5}$

Inch system of numbering lenses, 116

Incipient cataract, 411

glaueoma, $43 \bar{j}$

Ineision, intermarginal, 530

of chalazion, 537

of cornea, $284,341,546,553$

Ineonstant impairment of vision, 41

Index of refraction, 104, 110

Indirect massage of lens, 416 method, 131, 14?

Inequality of pupils, 75

Infantile cerebral degeneration, $\mathbf{3} \mathbf{7}$

Infeetious diseases, 575,577

In ferior oblique, 209,211 rectus, 209,211

Infiltration anesthesia, 515 lymphoid, of lids, 64

Influenza, $5 \pi 8$

baeillus coujunctivitis, 241

Ingrowing lashes, 45.5

Inherited syphilis, 295,576

Injeetious, subeonjunctival, 507

Injuries of ehoroid, 483,496

of ciliary body, 481

of conjunetiva, 487,492

of cornea, 457,493

of eyeball, 480

of iris, 481, 488, 495

of lens, $480,482,489$

of lids, 479,492

of orbit, 479,492

of retina, 583,496

of vitreous, 491,496

Innenpol magnet, 561

Inoculation for pannus, 300

Insanity, 5:1

Inspection of the ese, $17, \pi 1$
Instillations, 504, 515, 520

Instruments, 5:24, 5:26

Insufticieneies, nuseular, 203, 2:5, 231

Intention nystagmus, $2: 34$

Intermarginal incision, 5:30

Interual rectus, 209, 211

Interstitial nepln ritis, iritis in, 319

Intoxication, mydriatic, 128

Intractanial disease, $56 \%$

Intra-ocular currents, $43: 3,439$ tension, 432, 434

tumor's, $350,35 \%, 350,445$

Inverted image, 131, 135, 138, 142

Ioclid of potassium, 303, 521

Iodin, 513

Iodoform, 511, 513

amblyopia, 400

Iridectomy, 304, 30\%, 327, 339, 421, 549,557

for glaucoma, 441, 442, 447, 551

optical, 304, 307, 339, 421, 551

preliminary, 416, 549

with eataract extraction, 41;,55\%

Iridencleisis, 553

Irideremia, 354

Iridochoroiditis, 341

Iridoeyclitis, $324,334,447$

Iridocysteetomy, 552

Iridodesis, 553

Iridodialysis, 481

Iridodonesis, 332, 423

I ridoplegia, 332,481

I ridotomy, 552

Iris, 17, 71,313

bonıbé, 328

erst, 332

diseases of, 313

foreign body iu, 495

gumma of, 320

injuries of, 481,488

prolapse of, $284,480,488,556$

sa rcoma of, 331

trembling of, $: 332,423$

tuberenlosis of, 330

tumors of, 331

Iritis. 313, 314, 441

diabetic, 319

diagnosis of, $61,71,320,325,337$, 440,441

fibrinous, 318

gonorrheal. 319, 321

gont $\mathrm{v}, 319,321$

insidious, 318

malarial, 321

parenchymatons, 318 
Iritis, plastic, 318 purulent, 318 quiet, 318 rheumatic, 314, 319, 321 sequels of, 326 serous, 319,324 spongy, 318 syphilitic, $314,319,3: 1$ tranmatic, 320,489 treatment of, $3: 1,3266,55 \%$

Irregular astigmatism, $16 \tau, 15 \%, 410$ Irrigators, 247

Irritauts, 237, 303. 511

Irritation, sympathetic, 334,337 , 310

Ischemia of the retina, 359

Itching, 52, 239

Ivory exostosis, 476

J.Acksox, E., 585, 586, 58\%, 590, 591, 592,594

Jacob's ulcer, 461

Jamaica ginger amblyopia, 402

Javal, E., 585

Javal and Schiotz ophthalmometer, 178

Jennings, J. E., 586

Jequirity, 300, 513

Johnson, W. B., 446

Jonnesco, T. 441

KERATECTASIA, 309

Keratectomy, 518

Keratitis, $18 \%$

bullons, 286

diagnosis of, $277,281,286,294$, $299,320,440$

diffuse, 292

fascicular, 288

filamentous, 287

interstitial, 292

lymphatic, 288

marginal, 294

neuropathic, 287

oyster-shuckers', 494

parenchymatous, 292

phlyctenular, 288

punctate, $297,318,324$

sclerosing, 294, 312

scrofulons, 288, 292,294

striate, 297

snperficial vaseular, 292,298

trachomatous, 298

traumatic, 494

treatment of, $277,282,286,288$, 291, 296, 299
Keratitis, ulcerous, $276,286,320$ vascular, 288

Keratoconus, 309

Keratoglobus, 310, 407

Keratomalacia, 287

Kidney disease, 572

Kipp, C. J., 588, 590, 593

Klebs-Löftler bacillus, 251, 252, 253, 281

Knnapp, A., 59:

Kilapp, H., 249, 260

Kuapp's roller-operation, 260,539

Kronlein's operation, 566

Kyanopsia, 48

LACRIMAL abscess, 467

conjunctivitis, $253,465,523$

disease, $18,462,523$

fistula, $46 \boldsymbol{\gamma}$

gland, diseases of, 467

obstruction, 465, 466, 523, 540, 542

regurgitation, $253,281,465,523$

tumor, $46 \overline{5}$

Lacrimation, 341, 463, 464, 465, 523

Lactation, 581

Lagoph halmos, 456

Lamina cribrosa, 86,91

Landolt, E., 593

Lanolin, 513

Lapis divinus, 512

Iashes, 56, 261, 454, 529

Latent hyperopia, 149

squint, 204, 225

Lateral displacement, 223,545

nystagmus, 235

Law of sines, 108

Lawson, A., 588

Lead capacity of cornea, 302

Lead-poisoning, 366, 389

Leeches, 529

Length of risual axis, 134

Lens. See Crystalline Lens.

Lenses, 11\%, 164, 167

before eye, 143

oblique, effects of, 189

periscopic, 190

Lens-series, 79. 118

Lenticonus, $4: 26$

Leprosy, 451, 577

Leptotbrix, 464

Letter-hlindness, 571

Leucoma, 70, 301. 405

Leukemia, 363, $5 \%$ ?

Lid-elevator. 526

Lid-margins, 56, 60, 449 
Lids, $56,61,448$ adhesions of, 66 anomalies of, 448 bruise of, 479 coloboma of, 448 diseases of, 448 foreign body in, 492 operatious on, 529

Liebreich bandage, 528

Light difference, 30 iu pupil, 140

intluenee of, on color of fundus, 143

minimum, 30

perception, 30,140

projeetion, 29, 409, 414

reactions to, 73

refraction of, 104

sense, 30

streak on retiual vesscls, 86,359 waves, 104

Lime-burns, 2\%2

Linear extraction, 55i

Lines in astigmatism, 171

Iipoma, 271, 460

Lippitudo, 449

Local anesthesia, 514

Locomotor ataxia, 568

Loring, E. G., 585

Ionpe, corneal, 68

Lupus, 268, 461

Luxation of eyeball, 480 of lens, $424,439,445,480,482$

Lymphatic glands, enlarged, 255, 453

Lxmphoid infiltration of lids, 64

Lymphoma, or lymphoid tumor, 466,476

Macula, hole in, 374

Jutea, $43,88,101$

of cornea, 70,301

Macnlar reflex, 89

region, anomalies of, 382

Maddox, E. E., 587

Maddox rod, 228

Magnet-extraetion, 498, 560

Magnifiers, 68

Malaria, 5\%7

Malarial ulcer, 286

IIalignant glaucoma, 443 myopia, 158

Manifest hyperopia, 149

Marginal keratitis, 294

Marple, W. B., 588, 589, 590, 591

Marshall, C. D., 589
Mask to proteet eye, 528

Massage, 312, 442, 501

of erystalline leus, 416

Mature cataract, 411

Maxillary antrum, 47

Mayou, M. S., 586

MeReynolds, J. O., 538, 591

Measles, 241, 577

Measurement of refraction, 131, 133, 134

of squint, 201,229

Mechanical injuries, 479

Medicated gelatin disks, $50 \% .518$

Medullated nerve-fibers, 91, 381

Meibomian glands, $2 \pi 1$

Molanomata, 331

Meningitis, $343,381,567,579$

Meningocele, 475

Menisens lenses. 115

Menstruation, 581

Mental confusion, 227

Mereurial preparations, 303, 509, 513,520

Meridians of astigmatism, 169

Metamorphopsia, 358, 377

Metastasis, 342, 352, 362

Meter-augle, 193

Methyl aleoliol, 400

violet, 510

Metrie numbers of lenses, 117

Mierophthalmos, 475

Microseopic examinations, 67, 242, 243,245

Migraine, 45, 570

Migratory ophthalmia, 334

Miles, H. S., 594

Milium, 45:3

Mind-blindness, 571

Miners' nystagmns, 234

Mirror, ophthalmoseopic, 130

skiaseopic, 136, 137

Misplaced lashes, 455, 529

puncta, 464

Mitigated silver nitrate, 512

Mixed astigmatism, 173

Molluseum, contagious, 452

Monoenlar blindness, 32

diplopia, 46, 424

neuritis, 389

polyopia. 410

squint, 217

tests, 32,46

Monoscope, 221

Morax, Y., 243, 273

Morgaguian cataract, 412

Motais' operation, 536 
Mounting glasses, 189

Movement, disorders of, 17, 191, 205,332

Movements of eyeball, 57, 159, 191, 200

of lids, 56

Moviug objects, 29, 410

IIucons grafts, 538

Mules' operation, 565

Multiple images, 46, 219, 410, 424 neuritis, 391,569

Iumps, 467,579

IIuscæ volitantes, 42, 160, 428

Muscles, ocular, 1\%, 191 diseases of, 236

hy pertrophy of, 236 operations on, 543 psendoly pertrophy of, 236 rheumatism of, 236

Muscle-stretching, 213

Muscular balance, 20, 24 imbalance, 225

insufficiencies, 225,563

Myasthenia $\mathrm{gravis,} 571$

Mycotic ulcer of cornea, 286

IIydriasis, $76,127,332,440$

Mydriatics, 80, 127, 321, 439, 516 attack, 322

Myelitis, 569

Myopia, 65, 123, 133, 134, 155, 345, $378,407,560$

axial, 155

following iritis, 326

malignant, 158, 446

of curvature, 155

preceding cataract, $\mathbf{4 1 0}$

progressive, 158

temporary, 158

Myopic astigmatism, 173

crescent, 100, 101, 161, 345

Myosis, 76, 129, 316, 332

Iyositis, 236

Iyotics, 129, 442, 519

NArrowing of visual field, 41, 48

Nasal disease, 263, 465, 582

duct, 465, 523, 540

hemianopsia, 37

Nausea, 206, 568

Near-point $126,145,154$

of convergence, $193,201,226$

Near-sight, 155, 162, 410

Nebula, 70,301

Necrosis, orbital, 470

Negative aberration, 186 scotoma, 39
Neonatorum, ophthalmia, 243, 249

Nephritis, interstitial, iritis in, 319

Nerve-head, 85, 94, 391

Nervous disease, 567

Nettleship, E., 586, 588, 589, 590, 591

Neuralgia, 52, 440

Neurastheuia, $5 \pi \mathbf{1}$

Neuritis, 385, 569

Neuroma of lids, 460

Neuropathic or neuroparalytic keratitis, 287, 292

Neuroretinitis, 384

Nevus, 460

Night-bliudness, 358, 369, 373

Nipping of the lids, 159

Nitrate of silver, 509,512

Nitrobenzol amblyopia, 400

Nodding spasm, 235

Normal irregular astigmatism, 188

Nuclear cataract, 412 palsies, 214

Numbering of lenses, 116, 118

of prisms, 111

Nystagmus, 192, 234

OAtMan, E. L., 588, 589

Object lens, 142

Objective tests for malingering, 405

Oblique illumination, 68

lenses, effects of, 189

Obliquely placed lenses, 164

Obstruction, lacrimal, 465

of canaliculus, 464

of nasal duct, 465

of retinal vessels, 374

Occlusien of pupil, 327,439

Occupation of patient, 21

Ocular movements, 191, 192

muscles, diseases of, 236

hypertrophy of, 236

pseudohypertrophy of, 236

rheumatism of, .236

palsies, 205

Oculo motor paralysis, $65,205,214$, 218

Ohlemann, F. W. M., 593

Ointments, 513

Oliver, C. A., 589, 593

Onyx, 290

Opacity of cornea, $70,81,274,277$, 300,502

of crystalline lens, 82

of optic nerve-head, 94

of vitreous, $82,83,335,370$

Opaque nerve-fibers, 91,381 
Operations for cataract, 419, 421, $4: 3,553$

for pterygium, 266, 537

for ripening cataract, 416

for squint, 214, 222, $225,233,470$ 543

for symblepharon, 270,538

on conjunctiva, 537

on cornea, 545

on crystalline lens, 553

on eyeball, 560

on iris, 549

on lacrimal passages, $\mathbf{5 4 0}$

on lids, 529

on inuscles, 470,543

on sclera, 549

ophthalmic, 523, 525

plastic, 535

Ophthalmia, 237, 250

Egyptian, 256

gonorrheal, $243,245,249,282$

neonatorum, $243,245,249$

nodosa, 243,320

phlyctenular, 261

purulent, 243

strumous, 261

sympathetic, 333,488

Ophthalmic migraine, 45

Ophthalmomalacia, 447

Ophthalmometer, 172, 178

Ophthalmoplegia externa, 76,205 interna, 76,332

Ophthalmoscope, $78,130,152,176$

Ophthalmoscopic exanination, 18, $78,80,84,131,143,176,497$ special methods, 143

Optic atroph $5,98,391,398,567$ choroiditic, 393

consecutive, 393

gray, 394,568

hereditary, 393

nenritic, 393

postpapillitic, 393

primary, 393

retinitic, 393

secondary, 393

simple, 394

white, 394

chiasm. 32

disk, $84,93,383,443$

foramen, fracture of, 479

nerve, $84,99,383,397$

atrophy. See Optic atrophy.

head, 384, 397

nenritis, $385,391,567$

papilla, 383
Optical center of leus, 114, 232 iridectomy, 421, 551

Orbit, disease of, $46 \mathrm{~s}$ foreigu body in, 492

Orbital abscess, 470 cellulitis, 343, 468, 470

cysts, 474

fractures, 479

optic neuritis, 391

periostitis, $4 \pi 0$

tumors, 475

wall, osteoplastic resection of, 566

Organie compounds of silver, 510

Orthophoria, 226

Orthoptic exercises, 223

Oscillation of eyeball, $57,192,234$

Osler, Wm., 592

Ossification of choroid, 349

Osteoma, 271, 476

Ostcoplastic resection of orbital wall, 566

Overcoming prisms, 192

PAIN, 51, 54, 233, 287, 315, 3233, 437

Pallor of optic disk, 96

Panas, P., 536

operation of, 536

Pannus, 298, 502

Panophthalmitis, 341, 469

Papilla, optic, 383

Papillæe, enlarged, 244, 253, 258

Papillary granulations, 244, 245

Papillitis, 385

Papilloma, 27I

Papillomacular bundle, 391, 397

Papilloretinitis, 384

Paracentesis of cornea, 284, 546

Paraffin, sphere of, 565

Parallel lines, 183

rays, 104

Paralysis, diphtheritic, 333

of accommodation, 214, 332, 481

of iris, $76,127,332,481$

of ocular muscles, $200,203,204$, 214,479

of orbicularis, 456

Paralytic squint, 200, 203, 204, 214, 479

Parasites in vitreous, 430

Paresis of ocular muscles. 226, 568

Parinaud's conjunctivitis, 255

Parsons, J. H., 58.5, 590, 593

Partial correction, 154

tenotomy, 544

Pathology of sympathetic inflammation, 335 
Pediculosis, 454

Pemphigus of conjunctiva, 267

Perception of light, 30

Perforating corneal ulcer, 245,279

Pericorneal redness, 61, 315, 494

Perimeter, 34, 35, 201

Period of adaptation of glasses, 190

Periostitis, orbital, 470

Periscopic lens, 115, 185, 190

Peritomy, 300, 539

Permanganate of potassium, 510

Pernicious anemia, 363,572

Peroxid of hydrogen, 508, 529

Persistent hyaloid artery, 430 pupillary membrane, 353

Pertussis, 579

Petrifying conjunctivitis, 261

Phillips, R. J., 587

Phlegmon of orbit, 468

Phlyctenular conjunctivitis, 261 hyperemia, 61,262

Phlyctenule, 262, 288

Photometer, 30

Photophobia, 17, 276, 277, 288, 341

Phthiriasis ciliorum, 454

Phthisis bulbi, 350

Physiological cup, 86, 97

Physostigmin, 129, 442, 519

Pigment in conjunctiva, 273 in cornea, 303

Pigmentary degeneration, 372

Pigmentation of fundus, 87, 99, 316, 326,328

of retina, 99, 361

Pilocarpin, 129, 442, 519, 522

Pince-nez, 189

Pingnecula, 266, 267

Pin-hole disk, 31

Pipette, 247

Placido's disk, 71

Plane mirror, 136

Plano-concave lens, 115

Plano-convex lens, 114

Plastic choroiditis, 344

conjunctivitis, 250

iritis, 318

operatious, 535

Pneumococcus, 238, 242, 281

Point of light, 45, 174

of reversal, 135, 138, 181

Poison ivy, and oak, 451

Poisons, 397, 583

Pollock, W. B. J., 587

Polycoria, 353

Polyopia, 410. See also Diplopia.

Polypi, nasal, 582
Pooley, T. R., 591

Posey, W. C., 585, 590, 592, 598

Position for operating, 524

Positive aberration, 186 scotoma, 39, 345

Posterior sclerosis, 393, 568

staphyloma, 162,313

symblepharou, 270

synechia, 71, 76, 293, 316, 326, 328

Potassium iodid, 303, 521 permanganate, 508

Poultices, 503

Powder grains, 492, 494, 547

Powders, 511

Pregnancy, 366, 581

Preliminary iridectomy, 549

Preparation of instruments, 524 of patient, 523

of surgeon, 524

Presbyopia, 144, 154, 164

Pressure-bandage, 528, 529

on the eye, 32

within eyeball, 432

Prince, A. E., 259

Principal focus, 116 meridians, 169

Prism con vergence, 193

diopter, 111

divergence, 193

Prismatic colors, 110

Prisms, numbering of, 110, 111

refraction by, 109, 111

uses of, 192, 203, 205, 213, 220, $224,229,232,404$

Probing lacrimal passages, 466, 541

Progressive myopia, 158, 166

Projection, 194, 197 light, 29

Prolapsc of iris, 284, 480, 488, 556 of lens, 480

of vitreous, 499,556

Prominence of eyeball, 55

Prophylaxis of purulent conjunctivitis, 248

of sympathetic inflammation, 337

Proptosis. Sec Exophthalmos.

Protargol, 247, 510

Protectors, 528

Pseudo-accommodatiol1, 125

Pseudo-glioma, 343, 381, 429

Pseudo-hypertrophy of ocular muscles, 236

Pterygium, 265, 537

Ptosis, 56, 457, 536

congenital, 458 
Ptosis, operations, 536 paralytic, 457

Puerperal fever, 580

Pulsating exophthalmos, 472

Pulsation of retinal vessels, $86,43 \pi$

Punctate keratitis, 297, 318, 324

Punctum, diseases of, 463 proximum, 126, 145 remotum, 148

Pupil, 17, 71, 72, 77, 127, 130

Argyll-Robertson, 74

distortion of, $317,324,327,353$

in cataract, 409,415

reflex from, $81,140,187$

Wernickè, 38,75

Pupillary reactions, 72

Pupillometer, $\gamma^{2}$

Purkinjé, figures of, 43

Purpura, 575

Purulent conjunctival discharge, 66 conjunctivitis, 243,469

Pusey, B., 589

Pus-organisms, 281

Pyemia, 342, 363, 580

Pyle, W. L., 589

Pyoktanin, 510

Quadrant defect, 33

Quantitative perception of light, 29,414

Quinin amblyopia, 401

RABBIT's eye as support for artificial ere, 565

Race, 257, 374, 438

Radiating lines, 175

Radiographs, 492

Randall, B. A., 586

Randolph, R. L., 591

Ray, J. M., 59:

Rays of light, 104

Reactions of iris and pupil, 17, 72

Reading bar, 223

Real focus, 114 movement, 137

Records of cases, 20 of vision, 28 of visual field, 36

Recovery after deviation, 227

Recurrent oculomotor paralysis, 205,215

Red vision, 48

Reduess of conjunctiva, 60 of optic disk, 93

Reduced eye, 122 ocular tension, 447
Reflex epiphora, 463

from cornea, $70,81,83$

from lens, 77

fundus, 81,89

Refracting angle, 110, 111

power of lens, 116

of prisns, 110

Refraction by glass, 106

by cyliudrical lenses, 167

by prisms, 110

by spherical lenses, 113

measurcment of, $131,134,152,162$, 174

of light, 103, 104, $16 \%$

of eye, 123

Refractive index, 105

Regular astigmatism, 167, 169

Regurgitation, lacrimal, 253, 281, 523

Reid's ophthalmometer, 179

Reik, H. O., 594

Relapsing fever, 580

Relative divergence, 218

hemianopsia, 38

scotoma, 39

Remedies and their application, 500

Removal of clear lens for myopia, 165,560

Renal disease, $365,5 \% 3$

Resection, osteoplastic, of orbital wall, 566

Rest of the eyes, 500,501

Retained nerve-sheath. See Opaque nerve-fibers.

Retina, $87,90,92,357,567$

glioma of, 380

injuries of, 483,496

Retinal anemia, 359

anomalies, 381

apoplexy, 364

atrophy, 361

degeneration, 361, 372

detachment, 166, 377, 573

embolism, 365,374

hemorrhage, $90,360,573$

hy peremia, 92,358

hyperesthesia, 358

images, 123, 165. 175, 191

inflammation, 362

ischemian 359

macnlar atrophy, 374

opacity, 360,483

pigment, 99

pigment-changes, 361,372

reflexes, 89,162

thrombosis, 365,376 
Retinal vessels, 43, 86, 92, 359, 393

Retinitis, 348, 362

albuminuric, 365,573

circinate, 371

diabetic, $368,5 \pi 4$

diagnosis of, 362, 361, 366, 370, 373

embolic, 362

from excessive light, $3 \pi 1$

gouty, 368

hemorrhagic, 364

leukemic, 363

malarial, 364

metastatic, 362

pigmentosa, $37 \%$

proliferans, 371,427

punctate, 370

purulent, 362

septic, 363

serous or simple, 362

striate, 370

syphilitic, 369

treatment of, $362,364,365,367$, 370,373

Retinoscopy, 135

Retraction of lids, $56,472,525$

Retrobulbar optic neuritis, 379, 391

Retrotarsal fold, 59

Reversal, point of, 135, 138, 181

Rhagades, 263, 264 289, 451

Rheumatism, 212, 214, 311, 314, 440, $5 \% 4$

of ocular muscles, 236

Rhinitis, 582

Rhus poisoning, 451

Riders, 421

Ring dressing, 528

scotoma, 41

ulcer, 278

Ring-abscess of cornea, 274

Rings around the light, 46

Ripening operations, 416

Risley, S. D., 593

Robertson, Argyll, 534

Rodent ulcer, 461

Rogers. F. C., 591, 591

Roller-forceps operation, 260, 539

Röntgen rays, $492,496,498,500$

Rosy zone, 62, 277, 292, 315, 324, 436

Rotary deviation, 230

nystagmus, 231

variable prism, 231

Rule, astigmatism with or against, 169

Rupture of choroid, 102, 483
Rupture of eyeball, 480

of iris, 481

SAEMISCH incision, 284, 546

Salicylic acid amblyopia, 402

Salt solution, 510

Santonin, 583

Sareoma of choroid, 350, 444

of conjunctiva, $2 \pi 1$

of lids, 461

or orbit, 475

Savage, G. C., 587

Scalping lid, 531

Scarlet fever, $241,365,5 \% 8$

Scars, $17,485,486$

Schiotz aud Javal's ophthalmometer, 178

Schleich's local anesthesia, $\mathbf{5 1 5}$

Schlemm, canal of, 433,443

schneideman, T. B., 589, 591

Sch weigger, C., 236, 431

Schweinitz, Geo. E. de, $585,586,588$, $589,590,591,592,593$

Sehwenk, P. N. K., 591

Sclera, diseases of, 311

thinuing of, 157

wounds of, 488,495

Scleral, crescent, 86

hyperemia, 62

ring, 86

staphyloma, 33, $15 \tau$

Scleritis, 311

Selerosing keratitis, 294, 312

Sclerosis, spinal, 393,568

Selerotomy, 441, 447, 549

Scoop-extraction, 425, 557

Scopolamin, 127, 517, 518

Seotoma, 39, 345, 397, 403

central, 40,397, 569, 574

color, 40, 397

negative, 39

positive, 39,345

ring, 41

temporary, 42,570

Scurvy, 575

Second sight, 410

Secondary cataract, 422

contraction, 206

deviation, 206

Sector-like defect of field, 38, 397

Senile cataract, 409

Sensations, visual, 44

Sense, light, 30

Septicem ra, 342, 363, 580

Sequels of iritis and cyclitis, 326

Serpent ulcer, $278,279,281$ 
Sexual disorders, 581

Shadow-test, 135

Shingles, 452

Shoemaker, W. T., 592

Short sight, 155

Shotted-silk retina, 89

Shrinking of eonjuuctiva, 260, 261, 268

of eyeball, 350

of nerve-head, 391, 393

Shumway, E. A., 588,590

Sight. See Vision.

Silver nitrate, $247,273,509,512$

orgauie salts of, 510

Simple dressing, 527

extraction, 417,553

hyperopic astigmatism, 173

myopic astigmatism, 173

ulcer of cornea, 276

Simulated amblyopia, 403

Sinclair, A. H. H., 586

Sinuses adjoining orbit, 476

Sketches, 21

Skiascopy, 134, 140, 163, 172, 180

Slit, stenopaic, 175, 183

Slitting canaliculns, 540

Sloughing ulcor of cornea, 2\%8, 2\%9

Small-pox, 241, 281, 578

Smarting, 51, 239

Smith, H., 594

Smith, Priestley, 591, 594

Smoked glasses, 501

Snell, S., 587, 589

Snellen, H., 594

Suellen's test-type, 27

Snow-blindness, 358

Sodium chlorid, 511

ethylate, 461

Solid applications to conjunctiva, 506

Solutions, 507, 513, 515, 519 '

Somnoform, 514

Souter, W. N., 586

Spasm, nodding, 235

of ciliary muscle, 149,333

of retinal arteries, 374

Spasmus nutans, 235

Spastic squint, 234

Spatula, eorneal, 550

Spectacles, 189

Speculım, eye, 526

Sphenoidal disease, 389,478

Spherocylindrical lenses, 164

Spiller, W. G., 585

Spinal disease, 393, 568, 569

Sponging, 527
Spratt, C. N., 588
Spring catarrh, 250

Spud, corneal, 545

Squint, 192

alteruating, 218, 2:20

anblyopia with, 198

causes of, 198, 204

comitant, 200, 203, 214, 222

concomitant. See Comitant.

constant, 222

controlled reading in, 224

convergent, 200 , 2222

diagnosis of, 199, 206, 210, 219

divergent, 200,218

fusion training, 221

internittent, 218

measurement of, 201

monolateral, 220

operations, 222, 233,543

paralstie, 200, 203, 204, 214

prognosis, 224

spastic, 234

treatment of, 212, 2:21, 22:3, 231

use of deviating eye, 221

varieties of, 203, 204

vertical, 200,219

Stains for bacteria, 67

Standish, Myles, 588

Staphylococcus, 238, 288

Staphyloma, 162, 305, 313, 548

Stellwag's sign, 472

Stenopaic slit, 175, 183

spectacles, 188

Stereoscope, 224, 404

Stereoscopic effeet, 195

Stephenson, S., 588, 589, 593

Stevens, E. W., 588

Stevenson, M. D., 586

Stevens's phorometer, 230

Stillicidium lacrimarum, 462

Stinging pain, 52

Stirling, A. W., 591

Stovain, 515

Strabismus. See Squint.

Strength of lens, 115, 118

of prism, 110

Streptocoecns, 238

Striate keratitis, 298

Stricture, lacrimal, 465, 542

Struma, 575

Strychnin, 521

Sturm, focal interval of, 170

Stye, 450

Styptics, 503, 520, 529

Subconjunctival injections, 296, 348,507 
Subhyaloid hemorrhage, 90,360

Subjective symptoms, 44

Subluxation of lens, 425

Suction-operation, 419, 557

Suker, G. F., 589, 592, 593

Sulphate of copper, 511 of zinc, 512

Sunburn of conjunctiva, 272

Sunlight, direct, use of, 143

Superior oblique, 209, 210 rectus, 208,210

Supplementary lenses, 120

Suppression of image, 198

Suppurating uleer of coruea, 278, 547

Suprarenal extract, 5:0, 5:9

Surface of cornea, 17

Sursumduction, 192, 231

Sursumvergence, 192

Swauzy, H. R., 586

Sweet, W. M., 491

Swelling of coujunctiva, 239

of lens, 411, 445, 490

of lids, $64,250,259,459$

of optic disk, 95

Swollen cataract, 411, 445, 496

Symblepharon, 269, 538

Sympathetic amblyopia, 334, 341

inflammation, 334, 488

irritation, 334, 337, 340

nerve, excision of cervical, 441

neurosis, 340

ophthalmia, 333,488

Sympathizing eye, 334

Synchisis, 4:28

Synechia, 71, 76, 293, 316, 326, 323

Syphilis, 18, 101, 212, 214, 268, :292, $295,311,324,348,369,377$, $390,445,467,475,575$

Sy rivging, 540

Systemic remedies, 5:20

TABES dorsalis, 568

Tables, 105, 11:, 1.18, 126, 134, 146

Taugent of angle of squint, 201

Tauuin, 51:

Tapping sheath of optic nerve, 390

Tarsal cyst, 459

Tarsitis, 450

Tarsorrhaphy, 533

Tattooing the cornea, 304, 308, 548

Tay's choroiditis, 374

Tear-stone, 464

Telangiectasis, 460

Temperature of cormea, 275

Temporal hemianopsia, 37
Temporary amblyopia, 403

hemianopsia, 38, 42

myopia, 158

scotoma, 42

Tenonitis, 470

Tenotomy, 214, 222, 234, 543

extended, 544

Tension, intra-ocular, 19, 432, 434, 447

Test cards, 28

colors, 49

lenses, 119, 15:, 183

letters, $27,28,30$

objects, 26,34

types, 27,405

Tests of astiguatism, 178, 184

of malingering, 404

of monocular vision, 32

of ocular movements, 57

of ocular teusion, 434

of scotoma, 40

of visual field, 34

of vision, 26,29

Tetany, 569

Theobald, S., 541

Therapeutics, 500

Thiersch grafting, 266, 270, 535

Thomas, C. H., 542

Thompson, A. H., 590

Thonson, Wm., 175, 176

Thorington, J., 586

Thrombosis of caveruous sinus, 469 of retinal vessels, 376

Tinea tarsi, 449

Tobacco amblyopia, 397

Tortuous retinal vessels, 92

Total astignatisnı, 180

hyperopia, 149

synechia, 328

Toxic amblyopias, 397

diagnosis, 398,40 ?

treatment, 399,402

Trachoma, 256, 539 granules, 257

Trachomatous keratitis, 298

Transient amblyopia, 403 hemianopsia, 38,42

Transillumination, 77, 476, 477

Transparency of media, 21

Transplantation of cornea, 304 of epithelial grafts, 535, 538 of pterygium, 266,538

Traumatic eataract, 482,489

eycloplegia, 481

edema of retina, 483

iridoplegia, 481 
Traumatism. See Injuries.

Tremulous iris, 332, 423

'Trial-frames, 168

Trial-set, 119

Trichiasis, 454, 529

Trifacial disease, 569

Trikresol, 508

True image, 196, 207 scotoma, 39

Tubereulosis of ehoroid, 352, 575

of conjunctiva, 268,575

of iris, 330,575

of skin, 461

'Tumors, intra-ocular, 330, 350, 380

of conjunetiva, 271

of iris, 330, 40s

of laerimal gland, 488

of lids, 459

of optic nerve, 396

of orbit, 459

Turbinals, hypertrophy of, 465

Twitehing of lids, 129,457

Typhoid fever, 580

Typhus fever, 580

UlcERs of cornea, 244, 276, 278, 286,546

Unequal pupils, 75

Union of lids, 458, 533

Uremia, 365,573

Use of trial-set, 119

Uveal tract, 313

Uveitis, 314, 334

VACCinia, 461, 579

Vail, D. T., 593

Valk, F., 587

Variable prism, 231 squint, 218

Varicella, 379

Variola, 378

Vaseular disease, 365, 374, 573 tumor, 332, 460

Veasey, C. A., 593

Venous hyperemia, 63

Vernal conjunctivitis, 255

Vertical nystagmus, 235 squint, 208, 209, 219

Vertigo, 227,568

Virtual focus, 114

Vision, 104, 147 aenteness of, $20,21,25,30,387$

Visual angle, 25

centers, $32,37,46,383$

field, $23,33,373,377,391,437$ 443,498

\section{Visual lines, 192 \\ plane, 192, 219 \\ sensations, 44 \\ tract, $\pi 3,383$ \\ zone, 186}

Vitiligoidea, 453

Vitreous, air-bubbles in, 497

blood-vessels in, $4: 9$

detachment of, 429

diseases of, 426

fluid, $4: 28$

foreign body in, 496

lemorrhage into, $429,482,49$ \%

humor, 426

inflammation, 429

membranes in, 427

opacity, 82, 83, 160, 335, 370, $42 \pi$

parasites in, 429

prolapse of, 499,556

wounds of, 491,496

WARTS, 453

Washing eonjunetiva, 505

Watered-silk retina, 89

Watery eye, 46:

Waves of light, 104

Wearing of glasses, 189

Wecker, I. de, 304

Weeks, J. E., 241, 591, 592, 594

Weiss' reflex, 89, 162

Wenzel's extraction, 329,557

Werniekè's reaction of pupil, 75

Whooping-eough, 271,579

Wilder, W. H., 589, 591

Wilson, F. M., 594

Winking, excessive, $45 \pi$ test, 54

Wood, C. A., 585, 589, 590

Wood alcohol, 400

Wood ruff, 'T. A., 589

Woods, Hiram, 589, 593

Wootton, H. W., 594

Word-blindness, 571 congenital, 406

Working distance, 147

Worth, C., 587

Worth's amblyoseope, 221

Wound of ciliary body, 488

of conjunetiva, $48 \%$

of cornea, $48 \tau$

Wounds of eyeball, 342

of iris, 488

of lens, 489

of lids, 485

of orbit, 486 
Wounds of sclera, 488 of vitreous, 491

Würdemann, H. V., 593

Xanthelasma, 453

Xerosis bacillus, 252

of conjunctiva, 268

$\mathrm{X}$-rays, 492, 496

Yellow fever, 581
Yellow oxid of mercury, 264, 513 spot, 43,88

ZeNTMAYeR, W., 589

Zinc chlorid, 511 ointment, 514 sulphate, 512

Zona, 452

Zone, pericorneal, 315, 494

Zoster, ophthalmic, 287, 292, 452 



\section{SAUNDERS' BOOKS}

\section{Nervous and Mental Diseases, Children, Hygiene, Nursing, and Medical Jurisprudence}

\section{W. B. SAUNDERS COMPANY}

925 Walnut Street

9, Henrietta Street
Philadelphia

Covent Garden, London

\section{THE SUPERIORITY OF SAUNDERS' TEXT-BOOKS}

In a recent series of articles entitled

"WHAT ARE THE BEST MEDICAL TEXT-BOOKS?"

a well known medical journal compiled a tabulation of the text-books recommended in those schools which are members of the American Association of Medical Colleges. The text-books were divided into twenty (20) subjects and under each subject was given a list of the various books with the number of times each book is recommended. Saunders' books head ten (10) of the twenty (20) subjects, the largest number headed by any other publishing house being three (3). In other words, Saunders' books lead in as many subjects as the books of all the other publishers combined.

A Complete Catalogue of Our Publications will be Sent upon Request 


\section{Peterson and Haines' Legal Medicine \& Toxicology}

A Text-Book of Legal Medicine and Toxicology. Edited by Frederick Peterson, M. D., Clinical Professor of Psychiatry, Columbia University (College of Physicians and Surgeons), New York; and Walter S. Haines, M. D., Professor of Chemistry, Pharmacy, and Toxicology, Rush Medical College, in affiliation with the University of Chicago. Two imperial octavo volumes of about $75^{\circ}$ pages each, fully illustrated. Per volume: Cloth, $\$ 5.00$ net; Sheep or Half Morocco, $\$ 6.00$ net. Sold by Subscription.

\section{BOTH VOLUMES NOW READY}

The object of the present work is to give to the medical and legal professions a comprehensive survey of forensic medicine and toxicology in moderate compass. An interesting and important chapter is that on "The Destruction and Attempted Destruction of the Human Body by Fire and Chemicals." A chapter not usually found in works on legal medicine is that on "The Medicolegal Relations of the X-Rays." This section will be found of unusual importance. The responsibility of pharmacists in the compounding of prescriptions, in the selling of poisons, in substituting drugs other than those prescribed, etc., furnishes a chapter of the greatest interest. Also included in the work is the enumeration of the laws of the various states relating to the commitment and retention of the insane.

\section{OPINIONS OF THE MEDICAL PRESS}

\section{Medical News, New York}

"It not only fills a need from the standpoint of timeliness, but it also sets a standaxd of what a text-book on Legal Medicine and Toxicology should be."

\section{Columbia Law Review}

"For practitioners in criminal law and for those in medicine who are called upon to give court testimony in any of its various forms . . . it is extremely valuable."

\section{Pennsylvania Medical Journal}

"If the excellence of this volume is equaled by the second, the work will easily take rank as the standing text-book on Legal Medicine and Toxicology." 


\section{Church and Peterson's} Nervous and Mental Diseases

Nervous and Mental Diseases. By Archibald Church, M.D., Professor of Nervous and Mental Diseases and Head of Neurologic Department, Northwestern University Medical School, Chicago; and Frederick Peterson, M. D., Clinical Professor of Neurology and Psychiatry in Columbia University, New York. Octavo, 937 pages, with $34 \mathrm{r}$ illustrations. Cloth, $\$ 5.00$ net; Sheep or Half Morocco, $\$ 6.00$ net.

\section{JUST ISSUED-NEW (5th) EDITION}

This work has met with a most favorable reception from the profession at large. It fills a distinct want in medical literature, and is unique in that it furnishes in one volume practical treatises on the two great subjects of neurology and Psychiatry. In preparing this edition Dr. Church has carefully revised his entire section, placing it in accord with the most recent psychiatric advances. In Dr. Peterson's section-Mental Diseases-the Kræpelin classification of insanity has been added to the chapter on classifications for purposes of reference, and new chapters on Manio-Depressive Insanity and on Dementia Præcox included. A number of the illustrations have been replaced by newer and better ones.

\section{OPINIONS OF THE MEDICAL PRESS}

\section{American Journal of the Medical Sciences}

"This edition has been revised, new illustrations added, and some new matter, and really is two books. . . The descriptions of disease are clear, directions as to treatment definite, and disputed matters and theories are omitted. Altogether it is a most useful text-book."

\section{Journal of Nervous and Mental Diseases}

" The best text-book exposition of this subject of our day for the busy practitioner.... The chapter on idiocy and imbecility is undoubtedly the best that has been given us in any work of recent date upon mental diseases. The photographic illustrations of this part of Dr. Peterson's work leave nothing to be desired."

\section{New York Medical Journal}

"To be clear, brief, and thorough, and at the same time authoritative, are merits that ensure popularity. The medical student and practitioner will find in this volume a ready and reliable resource." 


\section{Frühwald and Westcott's Diseases of Children}

Diseases of Children. A Practical Reference Book for Students and Practitioners. By Professor Dr. Ferdinand Fruhwald, of Vienna. Edited, with additions, by Thompson S. Westcott, M. D., Associate in Diseases of Children, University of Pennsylvania. Octavo volume of 533 pages, containing 176 illustrations.

Cloth, $\$ 4.50$ net.

\section{JUST READY}

This work represents the author's twenty years' experience. Intended as a practical reference work, the individual diseases have been arranged alphabetically. The prophylactic, therapeutic, and dietetic treatments are elaborately discussed.

E. H. Bartley, M. D.

Professor of Pediatrics, Chemistry, and Toxicology, Long Island College Hospital.

"It is a new idea, which ought to become popular because of the alphabetic arrangement. Its title expresses just what it is-a ready reference handbook."

\section{Ruhräh's \\ Diseases of Children}

A Manual of Diseases of Children. By John Ruhrah, M. D., Clinical Professor of Diseases of Children, College of Physicians and Surgeons, Baltimore. I $2 \mathrm{mo}$ of 404 pages, fully illustrated. Flexible leather, $\$ 2.00$ net.

\section{JUST READY}

In writing this manual Dr. Ruhrah's aim was to present a work that would be of the greatest value to students. All the important facts are given concisely and explicitly, the therapeutics of infancy and childhood being outlined very carefully and clearly. There are also directions for dosage and prescribing, and a number of useful prescriptions are included. The feeding of infants is given in detail, and the entire work is amply illustrated with practical illustrations. 


\section{Brower \& Bannister on Insanity}

A Practical Manual of Insanity. For the Student and General Practitioner. By Daniel R. Brower, A. M., M. D., LL. D., Professor of Nervous and Mental Diseases in Rush Medical College, in affiliation with the University of Chicago; and Henry M. Bannister, A. M., M. D., formerly Senior Assistant Physician, Illinois Eastern Hospital for the Insane. Handsome octavo of 426 pages, with a number of full-page inserts. Cloth, $\$ 3.00$ net.

This work, intended for the student and general practitioner, is an intelligible, up-to-date exposition of the leading facts of psychiatry, and will be found of invaluable service, especially to the busy practitioner unable to yield the time for a more exhaustive study.

\section{American Medicine}

"Commends itself for lucid expression in clear-cut English. . . . Treatment is one of the best features of the book, and for this aspect is especially commended."

\section{Bergey's Hygiene}

The Principles of Hygiene: A Practical Manual for Students, Physicians, and Health Officers. By D. H. Bergey, A. M., M. D., Assistant Professor of Bacteriology, University of Pennsylvania. Octavo of $53^{6}$ pages, illust. Cloth, $\$ 3.00$ net.

\section{RECENTLY ISSUED-SECOND - REVISED EDITION}

This book is intended to meet the needs of students of medicine in the acquirement of a knowledge of those principles upon which modern hygienic practices are based, and to aid physicians and health officers in familiarizing themselves with the advances made in hygiene and sanitation in recent years.

\section{Buffalo Medical Journal}

"It will be found of value to the practitioner of medicine and the practical sanitarian; and students of architecture, who need to consider problems of beating, lighting, ventilation, water supply, and sewage disposal, may consult it with profit." 


\section{GET THE BEST

\section{The American Illustrated Medical Dictionary. A new} and complete dictionary of the terms used in Medicine, Surgery, Dentistry, Pharmacy, Chemistry, and kindred branches; with over roo new and elaborate tables and many handsome illustrations. By W. A. Newman Dorland, M. D., Editor of "The American Pocket Mềdical Dictionary." Large octavo, 850 pages, bound in full flexible leather. Price, $\$ 4.50$ net; with thumb index, $\$ 5.00$ net.

Gives a Maximum Amount of Matter in a Minimum Space, and at the Lowest Possible Cost

\section{WITH 2000 NEW TERMS}

The immediate success of this work is due to the special features that distinguish it from other books of its kind. It gives a maximum of matter in a minimum space and at the lowest possible cost. Though it is practically unabridged, yet by the use of thin bible paper and flexible morocco binding it is only $13 / 4$ inches thick. In this new edition the book has been thoroughly revised, and upward of two thousand new terms have been added, thus bringing the book absolutely up to date. The book contains hundreds of terms not to be found in any other dictionary, over 100 original tables, and many handsome illustrations.

\section{PERSONAL OPINIONS}

Howard A. Kelly, M. D.,

Professor of Gynecology, Johns Hopkins University, Baltimore.

"Dr. Dorland's dictionary is admirable. It is so well gotten up and of such convenient size. No errors have been found in my use of it."

Roswell Park, M. D.,

Professor of Principles and Practice of Surgery and of Clinical Surgery, University of Buffalo.

"I must acknowledge my astonishment at seeing how much he has condensed within reiatively small space. I find nothing to criticize, very much to commend, and was interested in finding some of the new words which are not in other recent dictionaries." 


\section{Galbraith's}

\section{Four Epochs of Woman's Life}

Second Revised Edition-Recently Issued

The Four Epochs of Woman's Life: A Study in Hygiene. By Anna M. Galbraith, M. D., Fellow of the New York Academy of Medicine, etc. With an Introductory Note by JoHN $\mathrm{H}$. Musser, M. D., Professor of Clinical Medicine, University of Pennsylvania. I 2 mo volume of 247 pages. Cloth, $\$ 1.5^{\circ}$ net.

In this instructive work are stated, in a modest, pleasing, and conclusive manner, those truths of which every woman should have a thorough knowledge. Written, as it is, for the laity, the subject is discussed in language readily grasped even by those most unfamiliar with medical subjects.

\section{Birmingham Medical Review, England}

"We do not as a rule care for medical hooks written for the instruction of the public. But we must admit that the advice in Dr. Galbraith's work is in the main wise and wholesome."

\section{Pyle's Personal Hygiene}

A Manual of Personal Hygiene: Proper Living upon a Physiologic Basis. By Eminent Specialists. Edited by Walter L. Pyze, A. M., M. D., Assistant Surgeon to Wills Eye Hospital, Philadelphia. Octavo volume of $44 \mathrm{I}$ pages, fully illustrated. Cloth, $\$ 1.50$ net.

\section{NEW (2d) EDITION-RECENTLY ISSUED}

In this new second edition there have been added new chapters on Home Gymnastics and Domestic Hygiene, besides an Appendix of Emergency Procedures.

\section{Boston Medical and Surgical Journal}

"The work has been excellently done, there is no undue repetition, and the writers have succeeded unusually well in presenting facts of practical significance based on sound knowledge." 


\section{Draper's Legal Medicine}

A Text-Book of Legal Medicine. By Frank Winthrop Draper, A. M., M. D., Professor of Legal Medicine in Harvard University, Boston. Handsome octavo of 573 pages, illustrated. Cloth, $\$ 4.00$ net.

\section{RECENTLY ISSUED}

The author of this work has had twenty-six years' experience as Medical Examiner for the city of Boston, his investigations comprising nearly eight thousand deaths under a suspicion of violence.

Hon. Olin Bryan, LL. B.

Professor of Medical Jurisprudence, Baltimore Medical College

" $\mathrm{lt}$ is comprehensive, thorough, and must, of a necessity, prove a splendid acquisition to the libraries of those who are interested in medical jurisprudence."

\section{Jakob and Fisher's}

\section{Nervous System and its Diseases}

Atlas and Epitome of the Nervous System and its Diseases. By Professor Dr. Chr. Jakob, of Erlangen. From the Second Revised German Edition. Edited, with additions, by Edward D. Fisher, M. D., Professor of Diseases of the Nervous System, University and Bellevue Hospital Medical College, New York. With 83 plates and copious text. Cloth, $\$ 3.5 \circ$ net. In Saunders' Hand-Atlas Series.

The matter is divided into Anatomy, Pathology, and Description of Diseases of the Nervous System. The plates illustrate these divisions most completely; especially is this so in regard to pathology. The exact site and character of the lesion are portrayed in such a way that they cannot fail to impress themselves on the memory of the reader.

\section{Philadelphia Medical Journal}

"We know of no one work of anything like equal size which covers this important and complieated field with the clearness and scientific fidelity of this hand-atlas." 


\section{American Text-Book of Diseases of Children}

American Text-Book of Diseases of Children. Edited by Louis Starr, M. D., Consulting Pediatrist to the Maternity Hospital, etc.; assisted by Thомpson S. Westcotт, M. D., Attending Physician to the Dispensary for Diseases of Children, Hospital of the University of Pennsylvania. Handsome octavo, I 244 pages, profusely illustrated. Cloth, $\$ 7.00$ net; Sheep or Half Morocco, $\$ 8.00$ net.

\section{SECOND REVISED EDITION}

To keep up with the'rapid advances in the field of pediatrics, the whole subject-matter embraced in the first edition has been carefully revised, new articles added, some original papers amended, and a number entirely rewritten and brought up to date.

\section{British Medical Journal}

"May be recommended as a thoroughly trustworthy and satisfactory guide to the subject of the diseases of children."

\section{Paul's Fever Nursing}

Nursing in the Acute Infectious Fevers. By George P. PAUL, M.D., Assistant Visiting Physician to the Samaritan Hospital, Troy, N. Y. I 2 mo of 200 pages. Cloth, $\$ 1.00$ net.

\section{JUST ISSUED}

Dr. Paul has written his book especially for the trained nurse, so that all extraneous matter has been studiously avoided. Great stress has been laid upon care and management in each disease, as this relates directly to the duties of the nurse. The work discusses fever in general, then each acute infectious fever separately, and finally those practical procedures necessary to the proper management of the fevers described. 


\section{Friedenwald \& Ruhräh's Dietetics for Nurses}

Dietetics for Nurses. By Julius Friedenwald, M. D., Clinical Professor of Diseases of the Stomach, College of Physicians and Surgeons, Baltimore; and JoHn RuHraH, M. D., Clinical Professor of Diseases of Children, College of Physicians and Surgeons, Baltimore. 12 mo of 363 pages. Cloth, $\$ 1.50$ net.

\section{- JUST ISSUED}

This work has been prepared to meet the needs of the nurse, both in the training school and after graduation. Rectal alimentation and the feeding of operative cases are fully described.

\section{Edinburg Medical Journal.}

"It appears to us to contain all the practical side of dietetics, of handy size and devoid of padding."

\section{Lewis' Anatomy and Physiology for Nurses}

Anatomy and Physiology for Nurses. By LeRoy Lewis M. D., Surgeon to and Lecturer on Anatomy and Physiology for Nurses at the Lewis Hospital, Bay City, Michigan. 1 2 mo of 317 pages, with 146 illustrations. Cloth, \$1.75 net.

\section{JUST ISSUED}

The author has based the plan and scope of the work on the methods he has employed in teaching the subjects, and has made the text unusually simple and clear. The object was so to deal with anatomy and physiology that the student might easily grasp the primary principles, at the same time laying a broad foundation for a wider study. 


\section{De Lee's Obstetrics for Nurses}

Obstetrics for Nurses. By Joseph B. De LeE, M. D., Professor of Obstetrics in the Northwestern University Medical School, Chicago; Lecturer in the Nurses' Training Schools of Mercy, Wesley, Provident, Cook County, and Chicago Lying-In Hospitals. I 2 mo of 460 pages, fully illustrated. Cloth, $\$ 2.50$ net.

\section{JUST ISSUED-NEW(2nd)EDITION}

The illustrations in Dr. De Lee's work are nearly all original, and represent photographs taken from actual scenes. The text is the result of the author's eight years' experience in lecturing to nurses.

\section{J. Clifton Edgar, M. D.,}

Professor of Obstetrics and Clinical Midziffery, Cornell University, New Yorh.

"It is far and away the best that has come to my notice, and I shall take great pleasure in recommending it to my nurses, and students as well."

\section{Davis' Nursing}

Obstetric and Gynecologic Nursing. By EDward P. Davis, A. M., M. D., Professor of Obstetrics, Jefferson Medical College, Phila. I $2 \mathrm{mo}, 400$ pages, illustrated. Buckram, \$1.75 net.

\section{RECENTLY ISSUED-SECOND REVISED EDITION}

\section{The Lancet, London}

"Not only nurses, but even newly qualified medical men, would learn a great deal by a perusal of this book. It is written in a clear and pleasant style, and is a work we can recommend."

\section{Beck's Reference Handbook for Nurses}

A Reference Handbook for Nurses. By Amanda K. Beck, Chicago. $12 \mathrm{mo}$ of 150 pages. Flexible morocco, $\$ 1.25$ net.

\section{RECENTLY ISSUED}

This little book contains information upon every question that comes to a nurse in her daily work, and embraces all the information that she requires to carry out any directions given by the physician.

\section{Boston Medical and Surgical Journal}

"Must be regarded as extremely useful, not only for purses, but for physicians." 


\section{Hofmann and Peterson's Legal Medicine}

Atlas of Legal Medicine. By Dr. E. von Hofmann, of Vienna. Edited by Frederick Peterson, M. D., Clinical Professor of Psychiatry in the College of Physicians and Surgeons, New York. With 120 colored figures on $5^{6}$ plates, and 193 half-tone illustrations. Cloth $\$ 3.50$ net. In Saunders' Hand-Atlas Series.

By reason of the wealth of illustrations and the fidelity of the colored plates, the book supplements all the text-books on the subject. Moreover, it furnishes to every physician, student, and lawyer a veritable treasure-house of information.

\section{The Practitioner, London}

"The illustrations appear to be the best that have ever been published in connection with this department of medicine, and they cannot fail to be useful alike to the medical jurist and to the student of forensic medicine."

\section{Chapman's Medical Jurisprudence}

Medical Jurisprudence, Insanity, and Toxicology. By Henry C. Chapman, M. D., Professor of Institutes of Medicine and Medical Jurisprudence in Jefferson Medical College, Philadelphia. Handsome $\mathbf{r}$ mo of 329 pages, fully illustrated. Cloth, $\$ 1.75$ net.

\section{RECENTLY ISSUED-THIRD REVISED EDITION, ENLARGED}

This third edition has been thoroughly revised and greatly enlarged, so as tc bring it absolutely in accord with the very latest advances in this important branch of medical science.

\section{Medical Record, New York}

"The manual is essentially practical, and is a useful guide for the general practitioner, besides possessing literary merit." 


\section{Golebiewski and Bailey's Accident Diseases}

Atlas and Epitome of Diseases Caused by Accidents. By DR. ED. GolebIEwsKr, of Berlin. Edited, with additions, by Pearce Balley, M. D., Consulting Neurologist to St. Luke's Hospital, New York. With $7 \mathrm{r}$ colored illustrations on 40 plates, I 43 text-illustrations, and 549 pages of text. Cloth, $\$ 4.00$ net. In Saunders' Hand-Atlas Series.

This work contains a full and scientific treatment of the subject of accident injury; the functional disability caused thereby; the medicolegal questions involved, and the amount of indemnity justified in given cases.

\section{The Medical Record, New York}

"This volume is upon an important and only recently systematized subject, which is growing in extent all the time. The pictorial part of the book is very satisfactory."

\section{Stoney's}

\section{Materia Medica for Nurses}

Practical Materia Medica for Nurses, with an Appendix containing Poisons and their Antidotes, with Poison-Emergencies; Mineral Waters; Weights and Measures, etc. By Emily M. A. Stoney, Superintendent of the Training School for Nurses at the Carney Hospital, South Boston, Mass. I 2mo, 300 pages. \$I 50 net.

\section{JUST ISSUED-NEW (3rd) EDITION}

In this work the consideration of the drugs includes their names, their sources and composition, their various preparations, physiologic actions, directions for handling and administering, and the symptoms and treatment of poisoning.

\section{Journal of the American Medical Association}

"So far as we can see, it contains everything that a nurse ought to know in regard to drugs. At a reference-book for nurses it will without question be very useful." 


\section{Stoney's Nursing}

Practical Points in Nursing : for Nurses in Private Practice. By Emily M. A. Stoney, Superintendent of the Training School for Nurses at the Carney Hospital, South Boston, Mass. 466 pages, fully illustrated. Cloth, $\$ 1.75$ net.

\section{THIRD REVISED EDITION-RECENTLY ISSUED}

In this volume the author explains the entire range of private nursing as distinguished from hospital nursing, and the nurse is instructed how best to meet the various emergencies of medical and surgical cases when distant from medical or surgical aid or when thrown on her own resources. An especially valuable feature will be found in the direction how to improvise everything ordinarily needed in the sick-room.

\section{The Lancet, London}

"A very complete exposition of practical nursing in its various branches, including obstetric and gynecologic nursing. The instructions given are full of useful detail."

\section{Stoney's Technic for Nurses}

Bacteriology and Surgical Technic for Nurses. By Emily M. A. Stoney, Superintendent of the Training School, Carney Hospital, South Boston. Revised by FREDERIC R. GRIFFITH, M. D., Surgeon, N. Y. $12 \mathrm{mo}, 278$ pages, illus. $\$ 1.50$ net.

\section{RECENTLY ISSUED-NEW (2d) EDITION}

\section{Spratling on Epilepsy}

Epilepsy and Its Treatment. By William P. Spratling, M. D., Medical Superintendent of the Craig Colony for Epileptics, Sonyea, New York. Octavo of 522 pages, fully illustrated. Cloth, $\$ 4.00$ net. 


\section{Griffith's \\ Care of the Baby}

The Care of the Baby. By J. P. Crozer Griffith, M. D., Clinical Professor of Diseases of Children, University of Pennsylvania. I $2 \mathrm{mo}, 43^{6}$ pages. Illustrated. Cloth, $\$ \mathrm{r} .5^{\circ}$ net.

\section{RECENTLY ISSUED-THIRD EDITION, REVISED}

\section{New York Medical Journal}

"We are confident if this little work could find its way into the hands of every trained nurse and of every mother, infant mortality would be lessened by at least fifty per cent."

\section{Crothers' Morphinism}

Morphinism and Narcomania from Opium, Cocain, Ether, Chloral, Chloroform, and other Narcotic Drugs; also the Etiology, Treatment, and Medicolegal Relations. By T. D. СвотнERS, M. D., Superintendent of Walnut Lodge Hospital, Hartford, Conn. Handsome I 2 mo of $35 \mathrm{I}$ pages. Cloth, $\$ 2.00$ net.

The Lancet, London

"An excellent account of the various causes, symptoms, and stages of morphinism, the discussion being throughout illuminated by an abundance of facts of clinical, psychological, and social interest."

\section{Abbott's Transmissible Diseases}

The Hygiene of Transmissible Diseases: Their Causation, Modes of Dissemination, and Methods of Prevention. By A. C. Aввотт, M. D., Professor of Hygiene and Bacteriology, University of Pennsylvania. Octavo, 35 I pages, with numerous illustrations. Cloth, $\$ 2.50$ net.

\section{SECOND REVISED EDITION}

\section{The Lancet, London}

"We beartily commend the book as a concise and trustworthy guide in the subject with which it deals, and we sincerely congratulate Professor Abbott." 


\section{American Pocket Dictionary 4th Ed.-Recently Issued}

American Pocket Medical Dictiónary. Edited by W. A. Newman Dorland, M. D., Assistant Obstetrician to the Hospital of the University of Pennsylvania. Containing the pronunciation and definition of the principal words used in medicine and kindred sciences, with 64 extensive tables. Handsomely bound in flexible leather, with gold edges, $\$ 1.00$ net; with patent thumb index, $\$ 1.25$ net.

\section{Morrow's Immediate Care of Injured Just Ready}

Immediate Care of the Injured. By Albert S. Morrow, M. D., Attending Surgeon to the New York City Hospital for the Aged and Infirm. Octavo of 350 pages, with 250 illustrations. Cloth, $\$ 2.50$ net.

Dr. Morrow's book on emergency procedures is written in a definite and decisive style, the reader being told just what to do in every emergency. It is a practical book for every day. use, and the large number of excellent illustrations can not but make the treatment to be pursued in any case clear and intelligible. Pbysicians and nurses will find it indispensible.

\section{Starr's Diets for Infants and Children}

Diets gor InFANTS and Children in Health aNd in Disease. By Louis StarR, M. D., Consulting Pediatrist to the Maternity Hospital, Philadelphia. 230 blanks (pocket-book size). Bound in flexible Morocco, \$1.25 net.

\section{Grafstrom's Mechano-Therapy Recently Issued}

A Text-Book of Mechano-Therapy (Massage and Medical Gymnastics). By Axel V. Grafstrom, B.Sc., M.D., Attending Physician to the Gustavus Adolphus Orphanage, Jamestown, New York. I 2mo, 200 pages, illustrated. Cloth, \$1.25 net.

\section{Shaw on Nervous Diseases and Insanity}

\section{Recently Issued-Fourth Edition, Revised}

Essentials of Nervous Diseases ANd Insanity : their Symptoms and Treatment. A Manual for Students and Practitioners. By the late JoHN C. Shaw, M. D., Clinical Professor of Diseases of the Mind and Nervous System, Long Island College Hospital, New York. I $12 \mathrm{mo}$ of 204 pages, illustrated. Cloth, \$1.00 net. In Saunders' Question-Compend Series.

\section{Powell's Diseases of Children 3d Edition, Revised}

Essentials of the Diseases of Children. By William M. Powell, M. D. Revised by Alfred Hand, JR., A. B., M. D., Dispensary Physician and Pathologist to the Children's Hospital, Philadelphia. 12mo volume of 259 pages. Cloth, \$1.00 net. In Saunders' Question-Compend Series. 




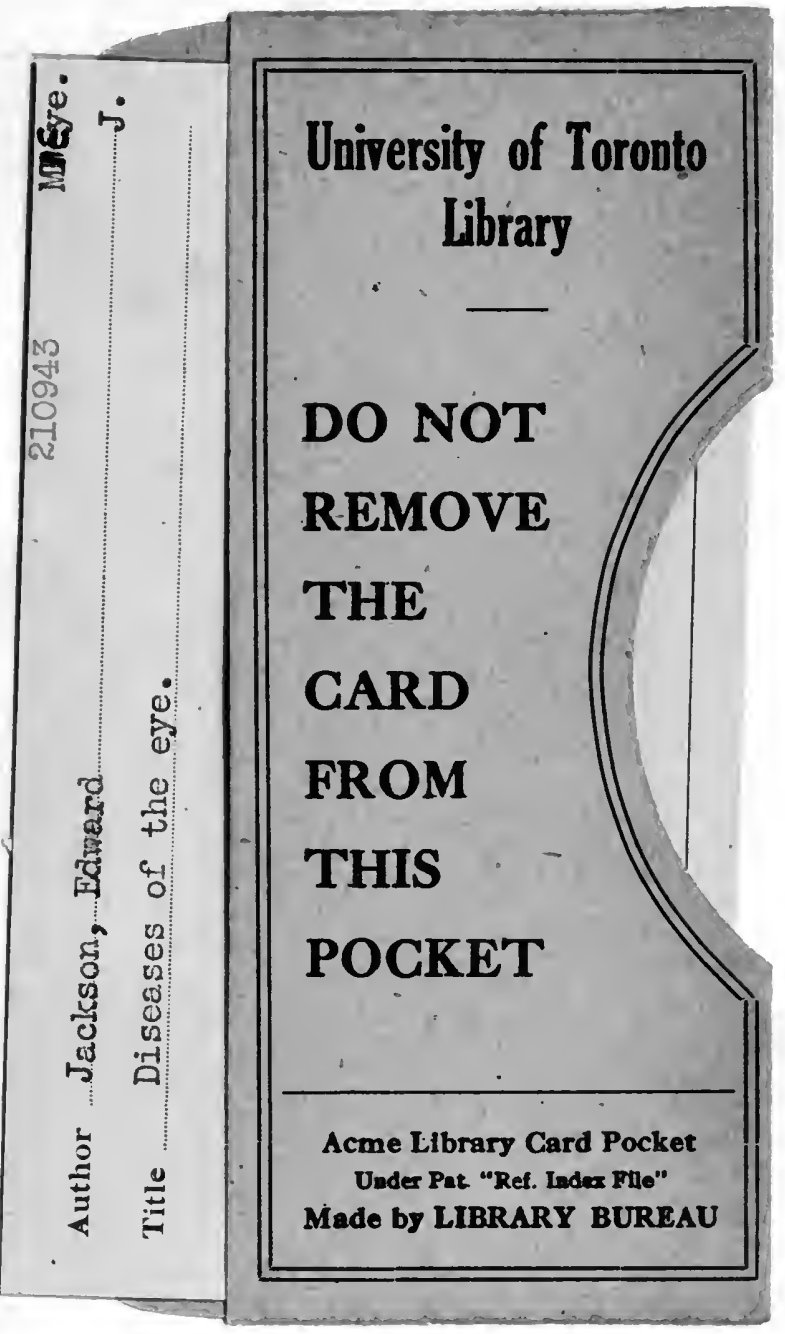


